\title{
Youth in India: Situation and Needs 2006-2007, Tamil Nadu
}

International Institute for Population Sciences (IIPS)

Population Council

Follow this and additional works at: https://knowledgecommons.popcouncil.org/departments_sbsr-pgy

Part of the Demography, Population, and Ecology Commons, Family, Life Course, and Society Commons, and the International Public Health Commons How does access to this work benefit you? Let us know!

\section{Recommended Citation}

International Institute for Population Sciences (IIPS) and Population Council. 2009. "Youth in India: Situation and Needs 2006-2007, Tamil Nadu," report. Mumbai: IIPS. 


\section{Youth in India: \\ Situation and Needs 2006-2007}

स्वास्थ्य एवं परिवार कल्याण मंत्रालय

निर्माण भवन, नई दिल्ली - 110011

GOVERNMENT OF INDIA

MINISTRY OF HEALTH \& FAMILY WELFARE

NIRMAN BHAWAN, NEW DELHI - 110011

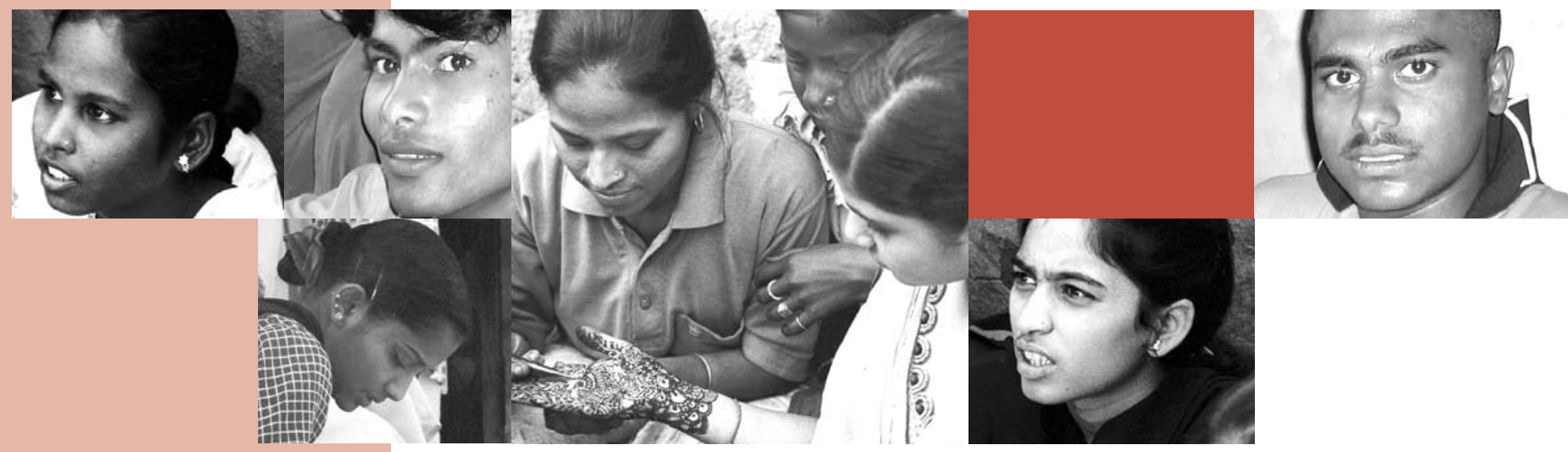

\section{TAMIL NADU}

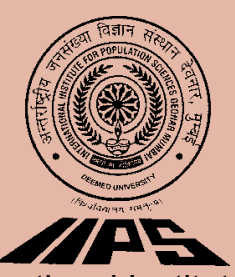

International Institute for Population Sciences

(P) Population Council

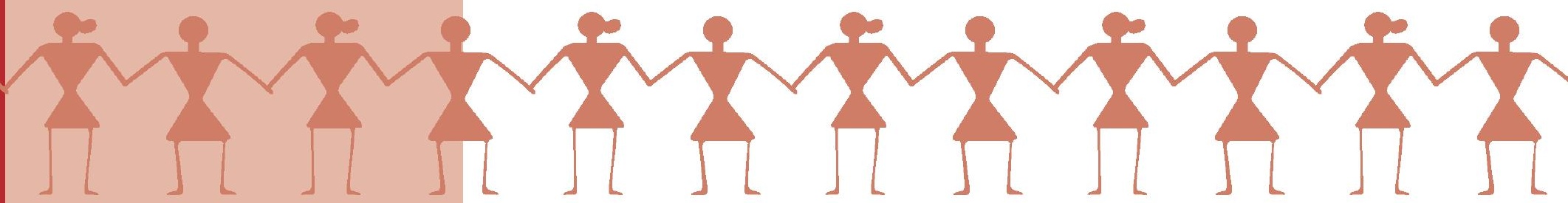


This report is the result of a sub-national study undertaken by the International Institute for Population Sciences, Mumbai and the Population Council, New Delhi, as part of a project to collect information on key transitions experienced by youth in India, including those related to education, work force participation, sexual activity, marriage, health and civic participation; the magnitude and patterns of young people's sexual and reproductive practices before, within and outside of marriage as well as related knowledge, decision-making and attitudes. The project was implemented in six states of India, namely, Andhra Pradesh, Bihar, Jharkhand, Maharashtra, Rajasthan and Tamil Nadu.

\section{For detailed reports please contact:}

\section{International Institute for Population Sciences}

Govandi Station Road, Deonar

Mumbai 400088

India

Phone: 022-42372400/42372518

email: iipsyouth@rediffmail.com

Website: http://www.iipsindia.org

\section{Population Council \\ Zone 5-A, Ground Floor \\ India Habitat Centre \\ Lodi Road \\ New Delhi 110003 \\ Phone: 011-2464 2901/02 \\ email: info-india@popcouncil.org \\ Website: http://www.popcouncil.org/asia/india.html}

The International Institute for Population Sciences (IIPS) is a deemed university under administrative control of Ministry of Health and Family Welfare, Government of India. The Institute engages in teaching and research in population sciences, and has been actively involved in building the capacity of Population Research Centres, and other state and central government offices that address population issues in the country and in the Asia-Pacific region. It has a proven record in conducting national- and sub-national-level studies in reproductive health, including the National Family Health Surveys and District Level Household and Facility Survey under the Reproductive and Child Health programme.

The Population Council is an international, non-profit, non-governmental organisation that seeks to improve the well-being and reproductive health of current and future generations around the world and to help achieve a humane, equitable and sustainable balance between people and resources. The Council conducts biomedical, social science and public health research, and helps build research capacities in developing countries.

Copyright ( 2009 International Institute for Population Sciences, Mumbai and Population Council, New Delhi

Suggested citation: International Institute for Population Sciences (IIPS) and Population Council. 2009. Youth in India: Situation and Needs 2006-2007, Tamil Nadu. Mumbai: IIPS. 


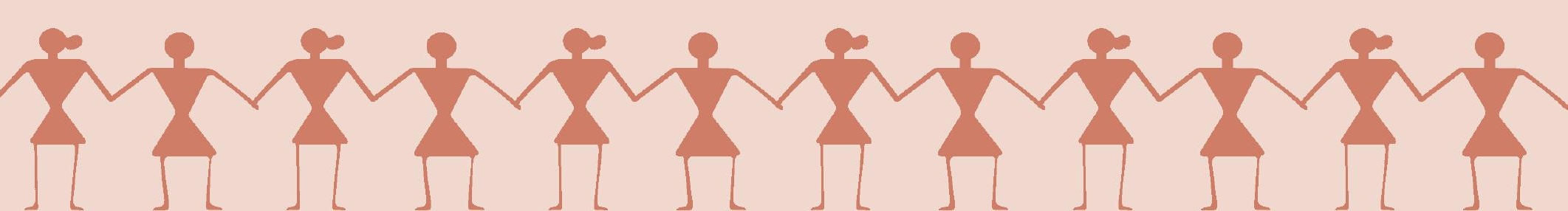




\section{Contents}

Page No.

Tables. viii

Figures xiii

Foreword. xvii

Acknowledgements ...xix

Executive summary xxii

Chapter 1: Introduction ..........................................................................................................

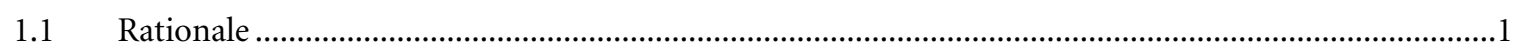

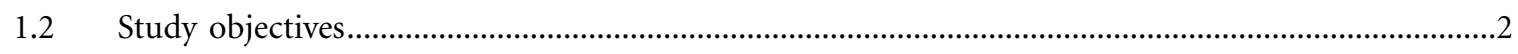

1.3 Tamil Nadu: Overview of demographic and socio-economic features ................................................

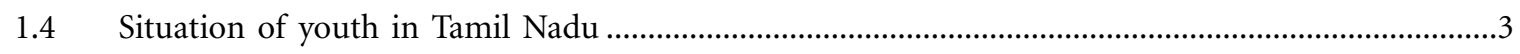

1.5 Youth-related policy and programme environment in Tamil Nadu ...................................................

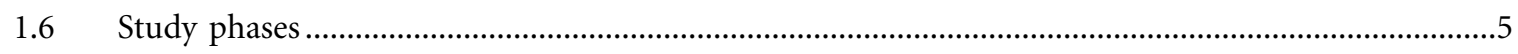

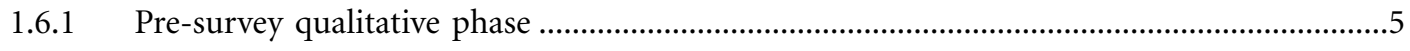

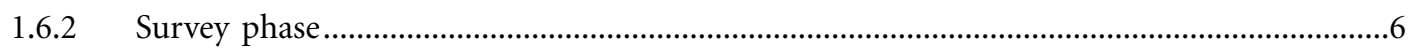

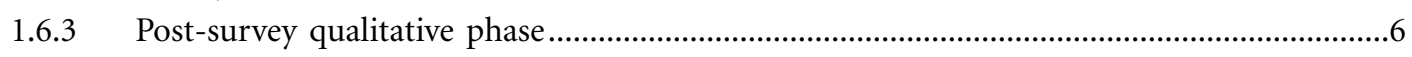

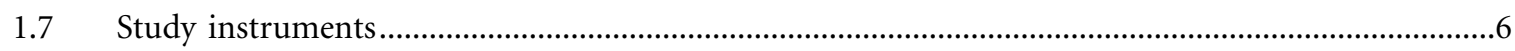

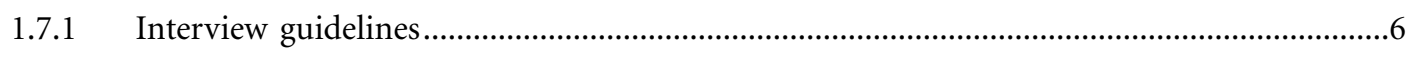

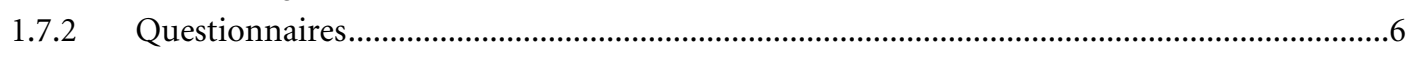

1.8 Study design and sample size estimation for individual interviews .................................................10

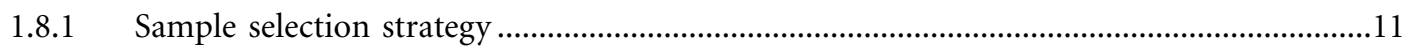

1.8.1.a Selection of households in rural areas ................................................................11

1.8.1.b Selection of households in urban areas .....................................................................

1.8.2 Selection of individual respondents within selected households............................................15

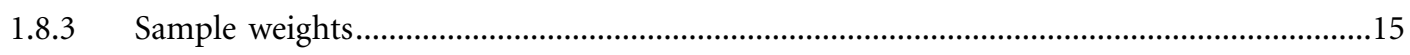

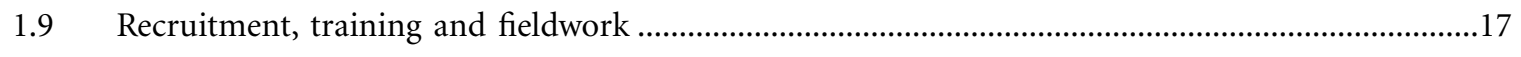

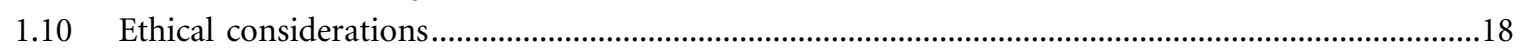

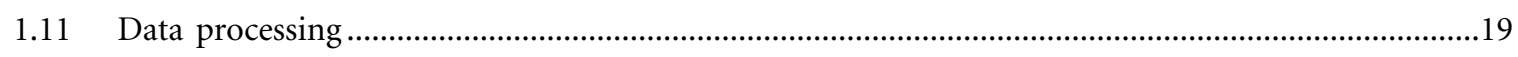

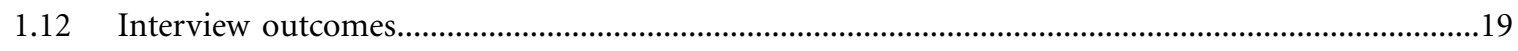

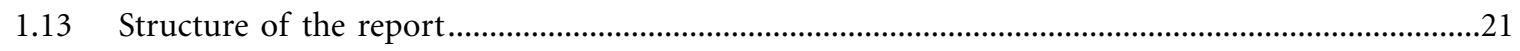


Page No.

Chapter 2: Profile of surveyed communities, households and youth ..................................23

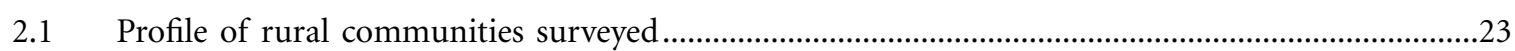

2.2 Profile of the household population: Age-sex distribution ...........................................................26

2.3 Profile of the household population: Marital status .....................................................................28

2.4 Profile of the household population: Educational attainment ......................................................30

2.5 Profile of the household population: Work participation ..............................................................30

2.6 Socio-demographic characteristics of households and heads of households ...................................33

2.7 Profile of the household population: Housing characteristics ........................................................35

2.8 Profile of the household population: Ownership of agricultural land ............................................38

2.9 Profile of the household population: Overall economic status ........................................................38

2.10 Profile of surveyed youth: Background characteristics ..................................................................39

2.11 Profile of surveyed youth: Parental characteristics......................................................................43

Chapter 3: Education ............................................................................................................

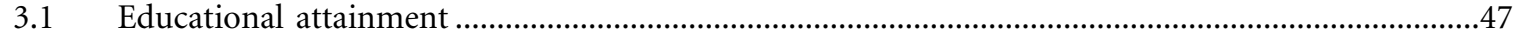

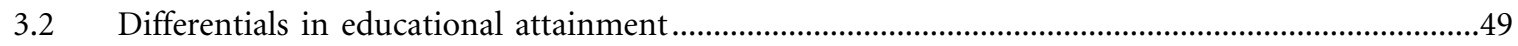

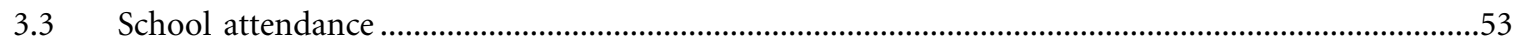

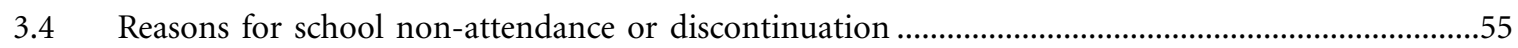

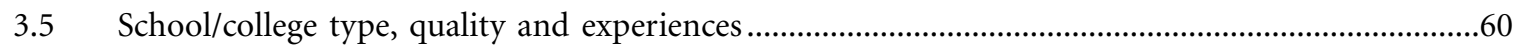

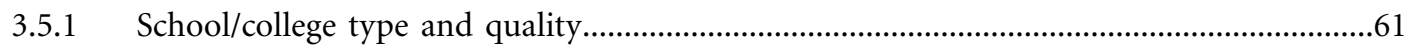

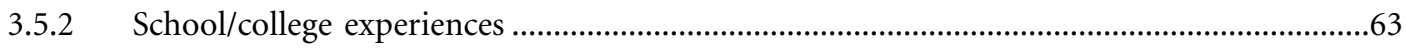

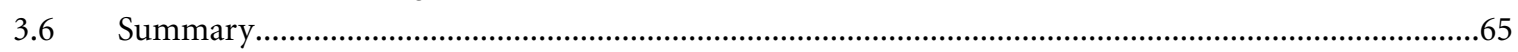

Chapter 4: Economic and non-economic activity...................................................................67

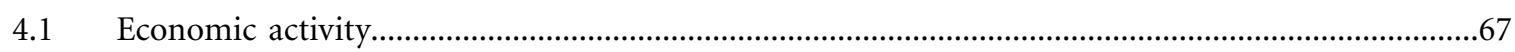

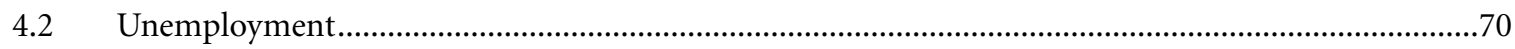

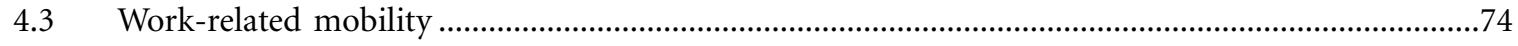

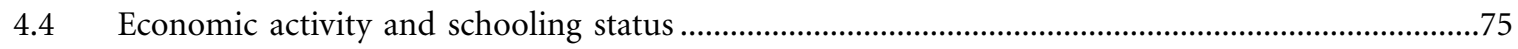

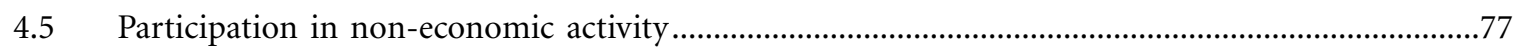

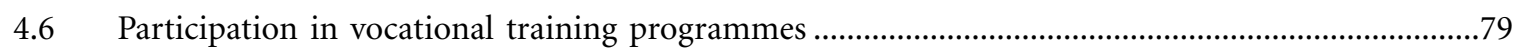

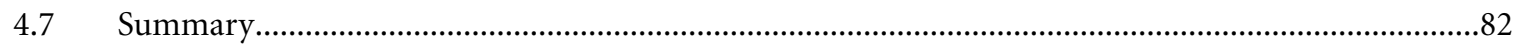

Chapter 5: Media exposure and access to pornographic materials.....................................84

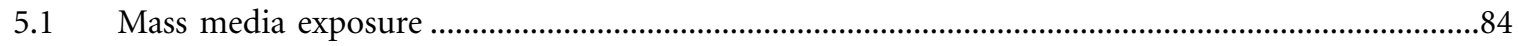

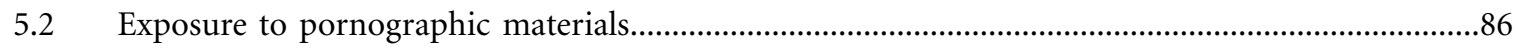

5.3 Youth perceptions about the influence of television and films on youth behaviours .....................89

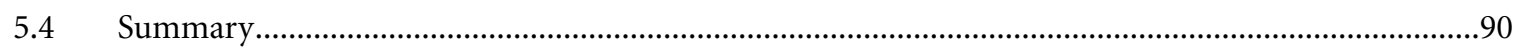




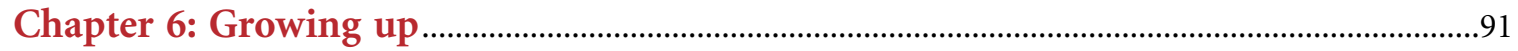

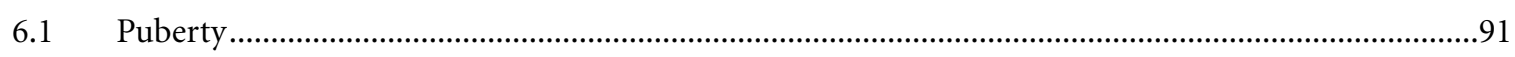

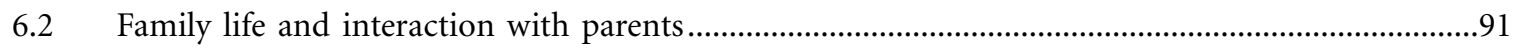

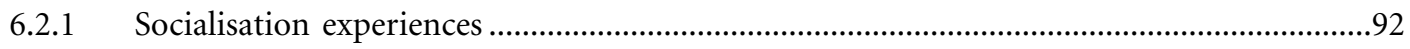

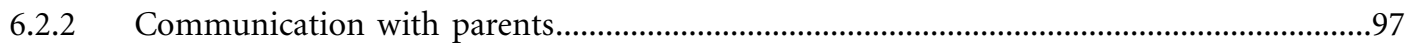

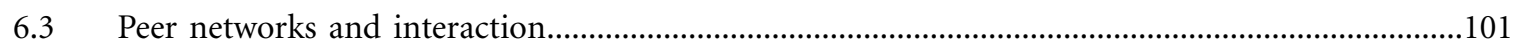

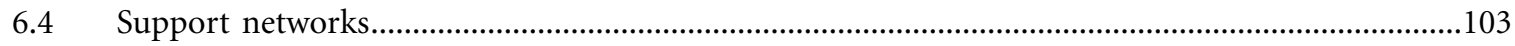

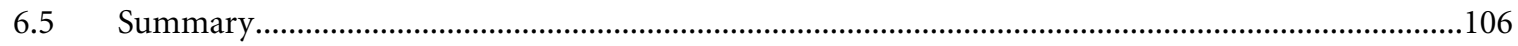

Chapter 7: Agency and gender role attitudes................................................................................108

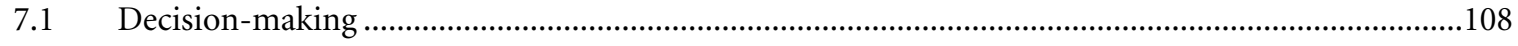

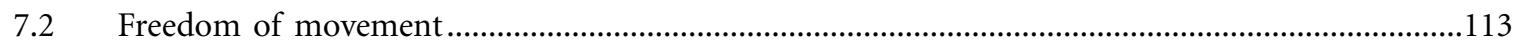

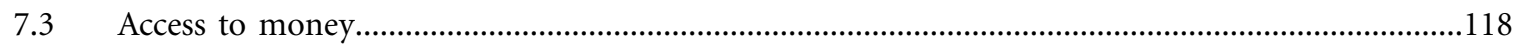

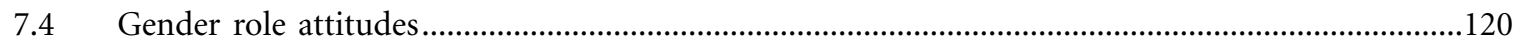

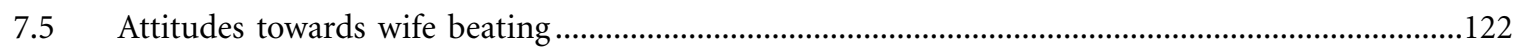

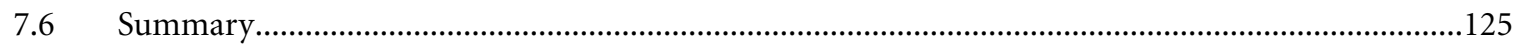

Chapter 8: Awareness of sexual and reproductive health matters........................................127

8.1 Awareness of sex and pregnancy, contraception, STIs and HIV ...............................................127

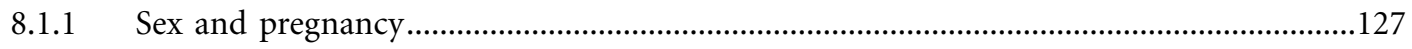

8.1.2 Socio-demographic differentials in awareness of sex- and pregnancy-related matters...130

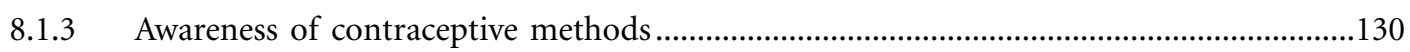

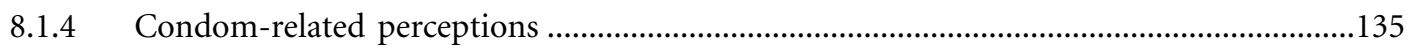

8.1.5 Awareness of contraception prior to marriage ...............................................................136

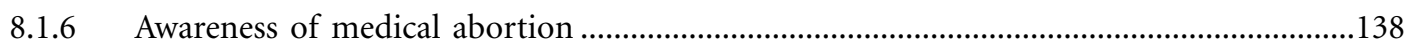

8.1.7 Awareness of sexually transmitted infections (STIs) and HIV/AIDS..............................139

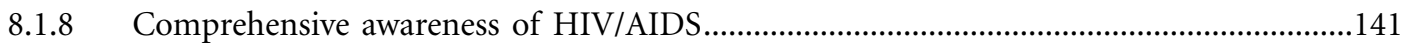

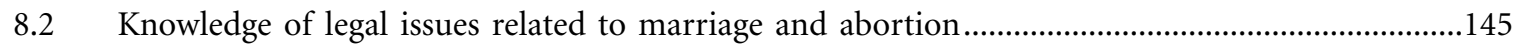

8.2.1 Knowledge of the legal minimum age at marriage........................................................145

8.2.2 Awareness of the conditions under which abortion is legal............................................146

S.3 Sources of information on sex and reproduction .....................................................................148

S.3.1 Sources of information on sexual matters .....................................................................148

C.3.2 Current sources of information on contraception.........................................................148

8.4 Perceptions and experience of family life or sex education.......................................................150

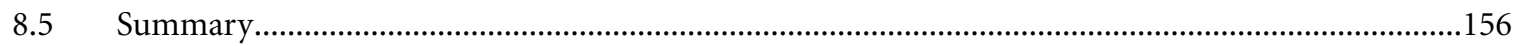


Page No.

\section{Chapter 9: Pre-marital romantic andsexual relationships ...................................................158}

9.1 Development of the questionnaire module on pre-marital romantic and sexual relationships...158

9.2 Attitudes toward pre-marital physical intimacy and sexual relations ...........................................159

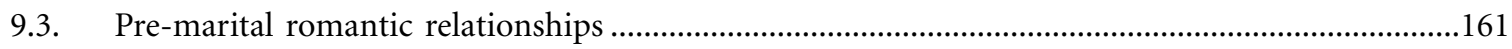

9.3.1 Prevalence of pre-marital romantic relationships .........................................................161

9.3.2 Characteristics of pre-marital romantic relationships ..................................................166

9.3.3 Parental and peer awareness of romantic relationships ..............................................172

9.3.4 Marriage intentions and duration of pre-marital romantic relationships.......................172

9.3.5 Pre-marital physical intimacy and sex with a romantic partner....................................175

9.3.6 Characteristics of sexual experiences within pre-marital romantic relationships............177

9.4 Pre-marital sexual experiences within romantic and other relationships......................................178

9.4.1 Extent of pre-marital sexual experiences ......................................................................178

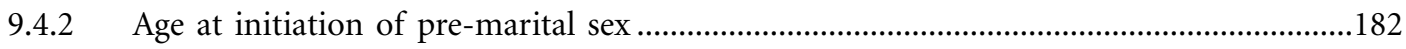

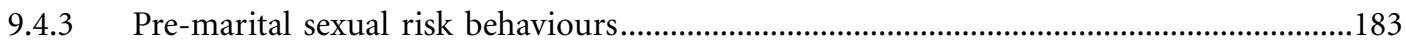

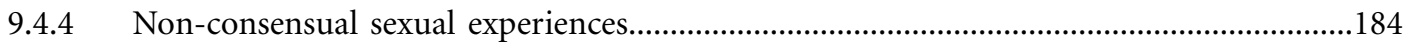

9.5 Triangulation of data on pre-marital sexual experiences among young people............................186

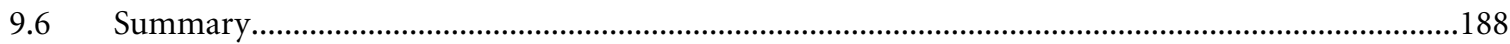

Chapter 10: Transitions to marriageand early married life...................................................190

10.1 Young people's preferences regarding timing and type of marriage...........................................190

10.2 Marriage planning and extent of youth involvement ..................................................................192

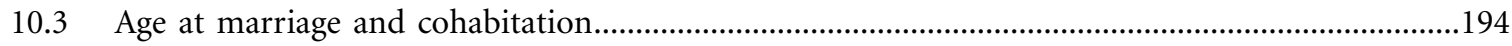

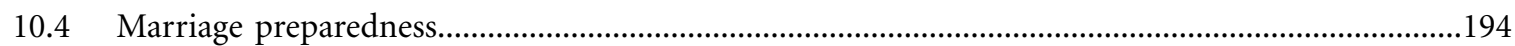

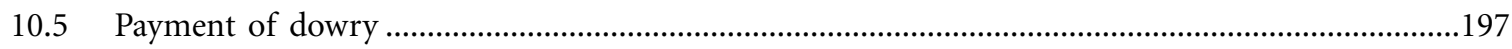

10.6 Early marital experiences: Spousal communication and interaction .........................................197

$10.7 \quad$ Nature of marital sexual experiences............................................................................................199

10.8 Experience of domestic violence within marriage .................................................................200

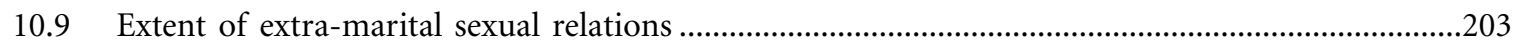

10.10 Contraceptive practice within marriage: Lifetime, current and prior to first pregnancy ..............203

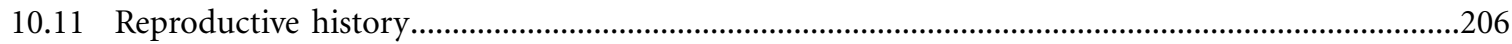

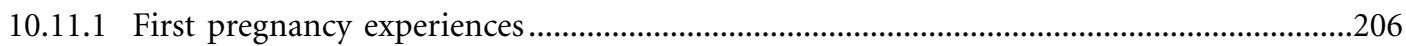

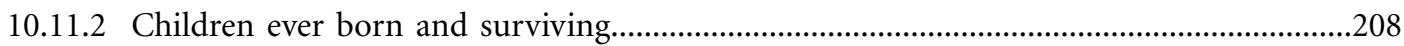

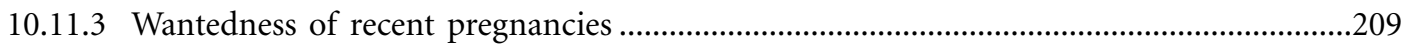

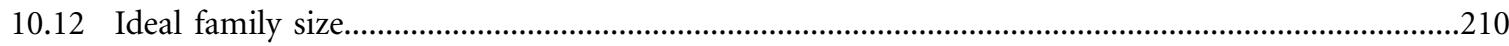

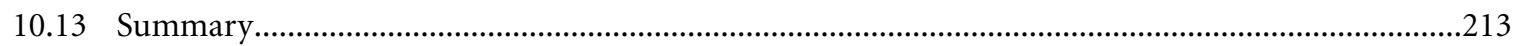


11.1. Substance use

11.2 General and sexual and reproductive health problems ...........................................................216

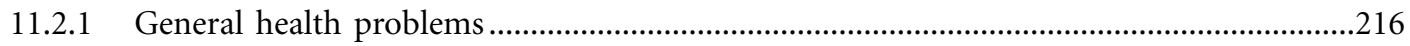

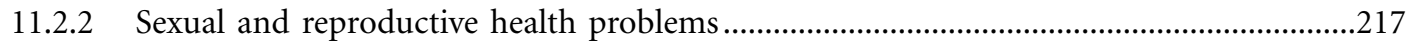

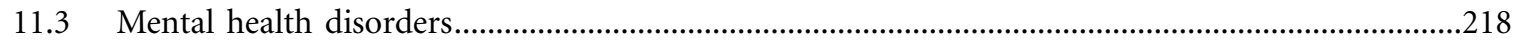

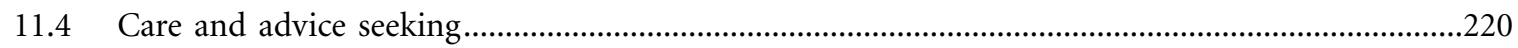

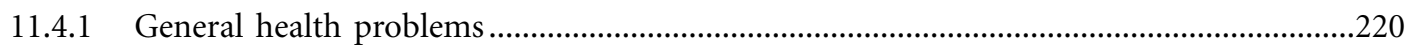

11.4.2 Sexual and reproductive health problems ...................................................................220

11.5 Hesitation to access contraceptive supplies...............................................................................222

11.6 Attitudes towards pre-marital HIV testing and extent of HIV testing........................................222

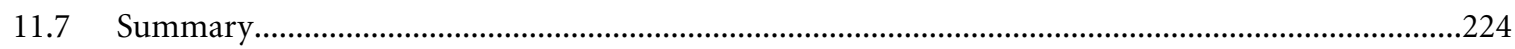

Chapter 12: Participation in civil societyand political life.....................................................225

12.1 Awareness of and participation in government-and NGO-sponsored programmes.....................225

12.2 Participation in community-or panchayat-sponsored programmes..............................................229

12.3 Membership in organised groups ............................................................................................230

12.4 Perceptions about action taken by panchayats in addressing defiance of social norms ...............231

12.5 Voting behaviour and perceptions of political matters .............................................................232

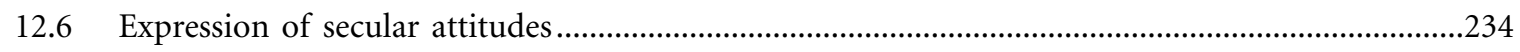

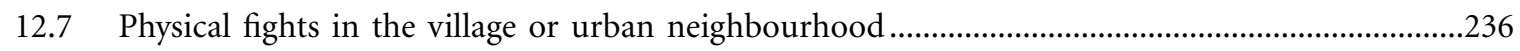

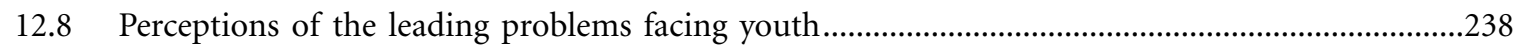

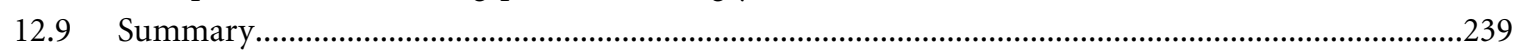

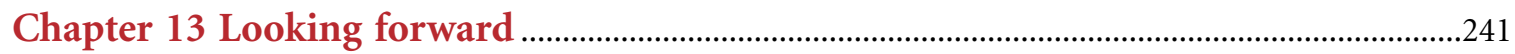

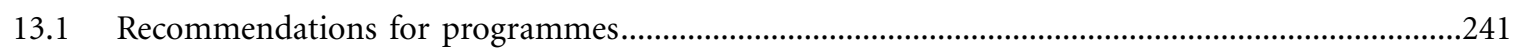

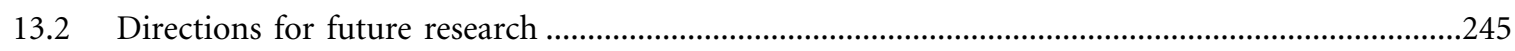

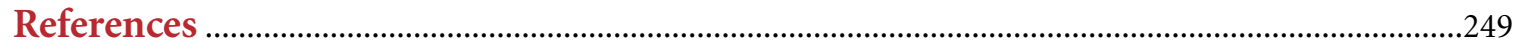

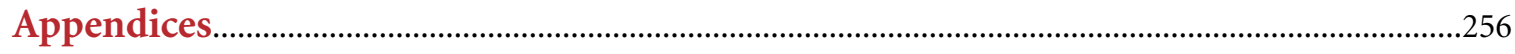

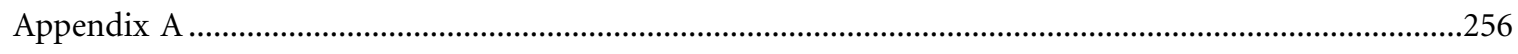

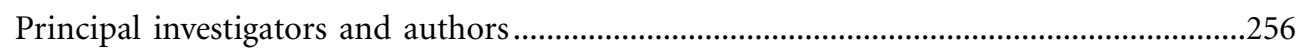

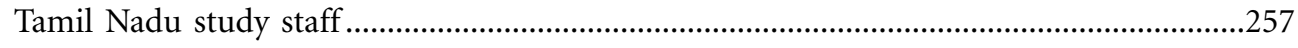

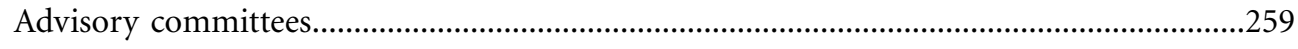

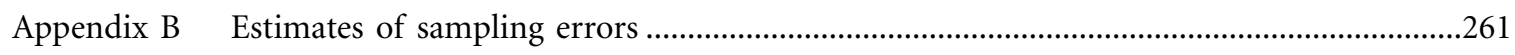

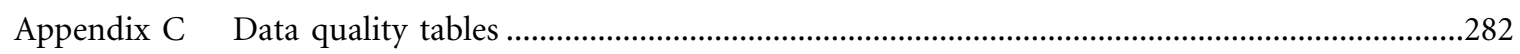




\section{Chapter 1: Introduction}

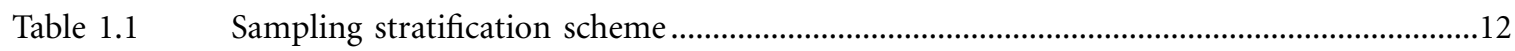

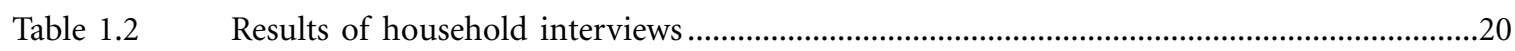

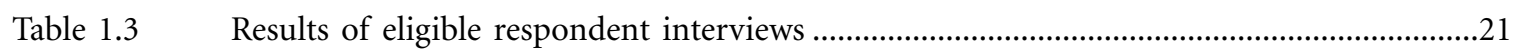

\section{Chapter 2: Profile of surveyed communities, households and youth}

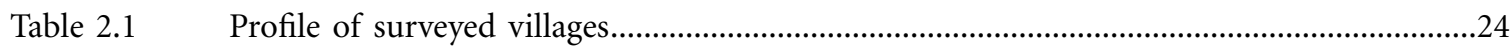

Table 2.2 Proximity of study residents to selected facilities...............................................................25

Table 2.3 Distribution of the surveyed population by age and sex .....................................................26

Table 2.4 Marital status of the surveyed population ………………………........................................29

Table 2.5 Age at marriage of usual residents of households ................................................................30

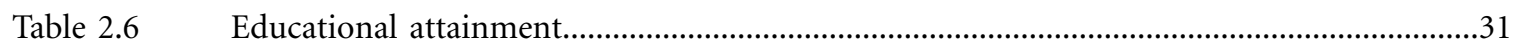

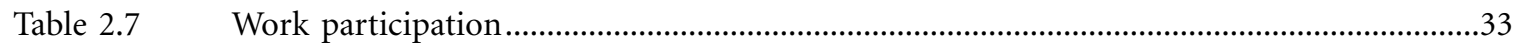

Table 2.8 Socio-demographic characteristics of households and heads of households .......................33

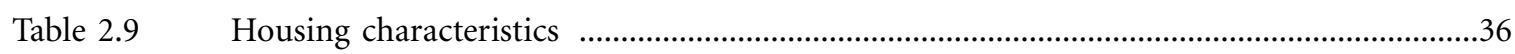

Table 2.10 Household ownership of agricultural land .........................................................................38

Table 2.11 Household assets and wealth status .................................................................................

Table 2.12 Background characteristics of surveyed youth .....................................................................4

Table 2.13 Parental characteristics of surveyed youth ...........................................................................

\section{Chapter 3: Education}

Table 3.1 Educational attainment and current educational status ........................................................48

Table 3.2 Educational attainment of young men by selected background characteristics .................49

Table 3.3 Educational attainment of young women by selected background characteristics..............51

Table 3.4a Reasons for never attending school .......................................................................................56

Table 3.4b Reasons for school discontinuation by level of education ..................................................58

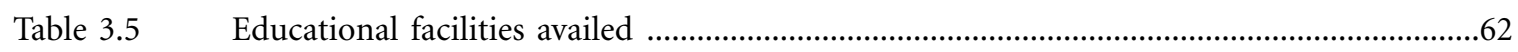

Table $3.6 \quad$ Schooling experiences ………………........................................................................64 


\section{Chapter 4: Economic and non-economic activity}

Page No.

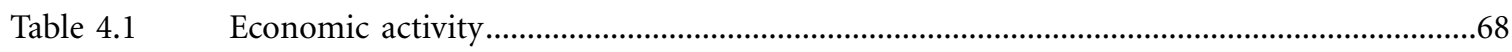

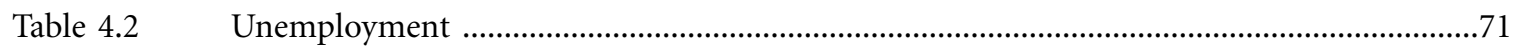

Table 4.3 Unemployment by selected background characteristics..................................................72

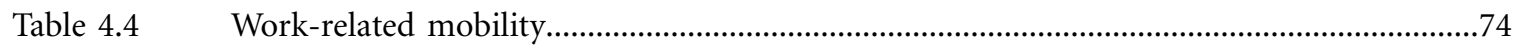

Table $4.5 \quad$ Participation in household chores...................................................................................78

Table 4.6 Participation in vocational training programmes.............................................................80

Table $4.7 \quad$ Willingness of youth to participate in vocational training programmes............................8

\section{Chapter 5: Media exposure and access to pornographic materials}

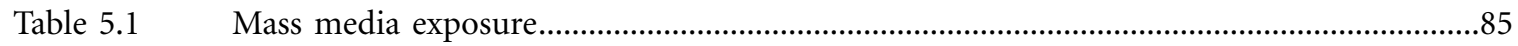

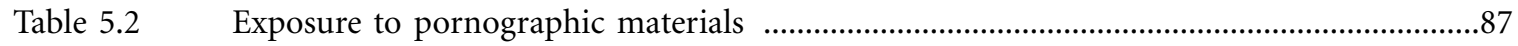

Table 5.3 Perceptions about the influence of television and films on youth behaviours...................89

\section{Chapter 6: Growing up}

Table 6.1a Age at puberty among young women .......................................................................92

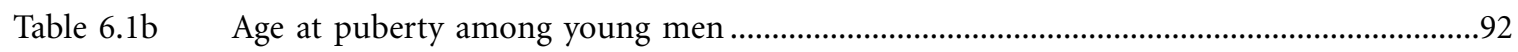

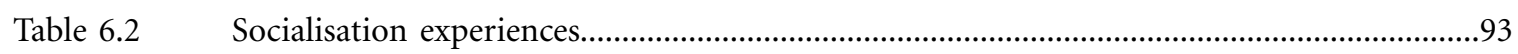

Table 6.3 Perceptions of parental reactions to selected activities ...................................................95

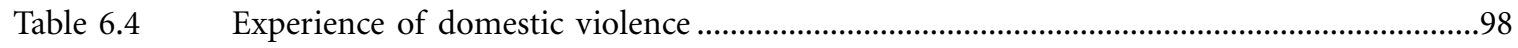

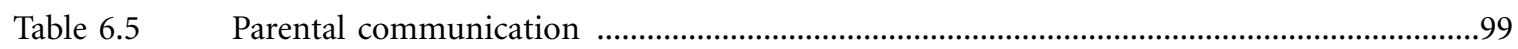

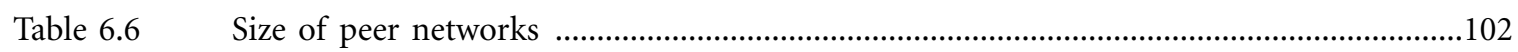

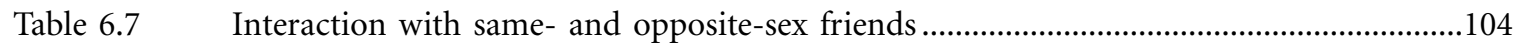

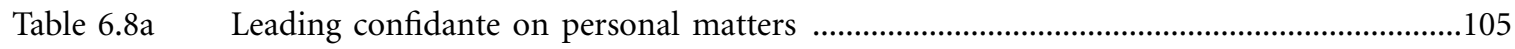

Table $6.8 \mathrm{~b} \quad$ Leading confidante on matters relating to the experience of teasing

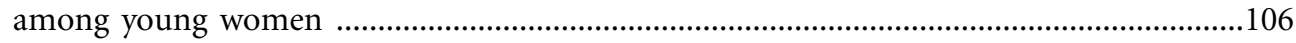

\section{Chapter 7: Agency and gender role attitudes}

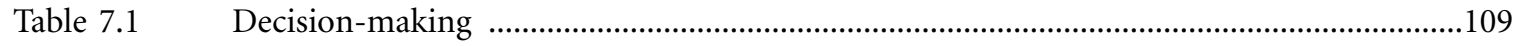

Table 7.2 Decision-making autonomy by selected background characteristics...............................111

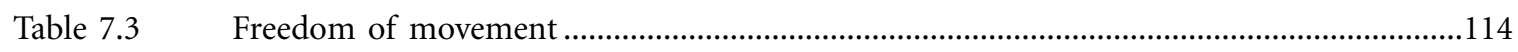

Table 7.4 Freedom of movement by selected background characteristics........................................116

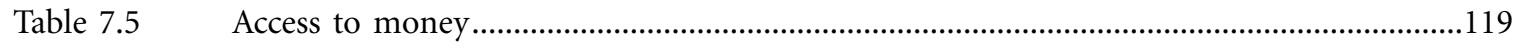

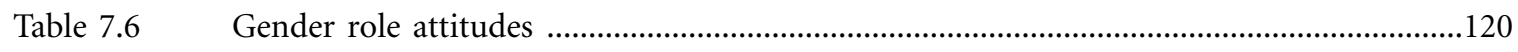

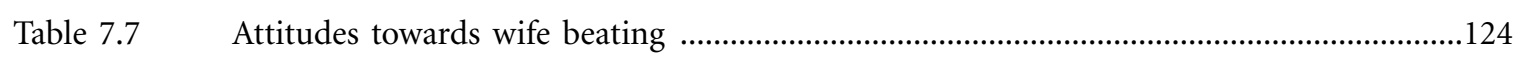




\section{Chapter 8: Awareness of sexual and reproductive health matters}

Table 8.1 Awareness of sex- and pregnancy-related matters.

Table 8.2 Awareness of sex- and pregnancy-related matters by selected background characteristics

Table 8.3 Awareness of contraceptive methods

Table 8.4 Perceptions of selected issues related to condom use....................................................137

Table $8.5 \quad$ Awareness of contraception prior to marriage ................................................................138

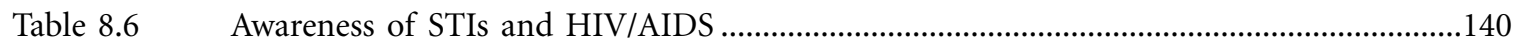

Table 8.7 Comprehensive knowledge of HIV/AIDS by selected background characteristics ...........143

Table $8.8 \quad$ Knowledge of the legal minimum age at marriage $\quad$..........................................................145

Table 8.9 Awareness of the conditions under which abortion is legal ..........................................147

Table $8.10 \quad$ Sources of information on sexual matters before marriage................................................149

Table 8.11 Current sources of information on contraception ........................................................151

Table 8.12 Perceptions about family life or sex education..............................................................152

Table $8.13 \quad$ Experiences of family life or sex education ....................................................................155

\section{Chapter 9: Pre-marital romantic andsexual relationships}

Table 9.1 Attitudes toward pre-marital physical intimacy and sexual relations ..............................160

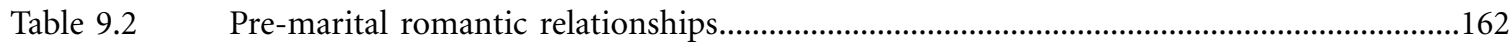

Table 9.3 Prevalence of pre-marital romantic relationships by selected

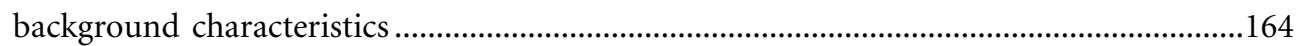

Table 9.4 Characteristics of pre-marital romantic relationships and partners.................................167

Table 9.5 Meeting places with pre-marital romantic partners.........................................................171

Table 9.6 Peer and parental awareness of first pre-marital romantic relationship..........................173

Table 9.7 Marriage intentions and duration of pre-marital romantic relationships ........................174

Table 9.8 Physical intimacy and sexual experiences in pre-marital romantic relationships.............176

Table 9.9 Characteristics of sexual experiences within pre-marital romantic relationships .............177

Table 9.10 Overall pre-marital sexual experiences .......................................................................179

Table 9.11 Overall pre-marital sexual experiences by selected background characteristics................181

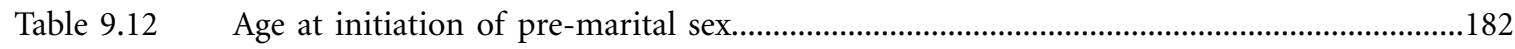

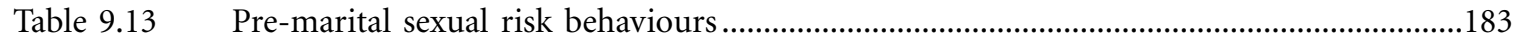

Table 9.14 Pre-marital non-consensual sexual experiences ...............................................................185

Table 9.15 Levels of pre-marital romantic and sexual experiences by different reporting methods. 


\section{Chapter 10: Transitions to marriageand early married life}

Table 10.1 Preferences regarding timing and type of marriage......................................................191

Table 10.2 Initiation of discussion on marriage and extent of youth involvement ............................193

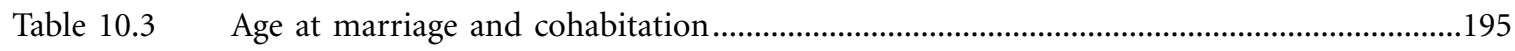

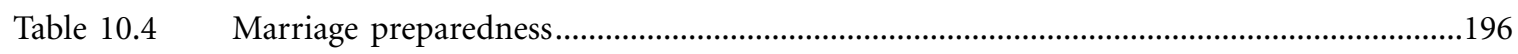

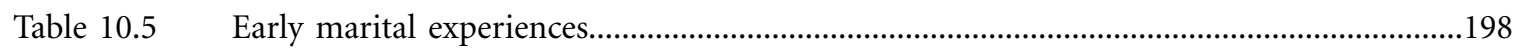

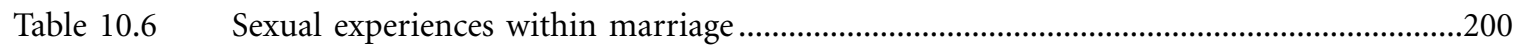

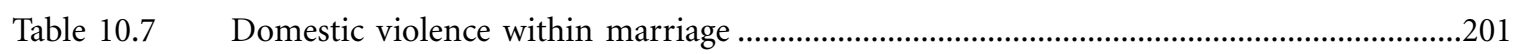

Table $10.8 \quad$ Extent of extra-marital sexual experiences.....................................................................203

Table $10.9 \quad$ Contraceptive use within marriage …..........................................................................204

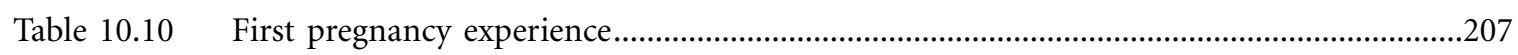

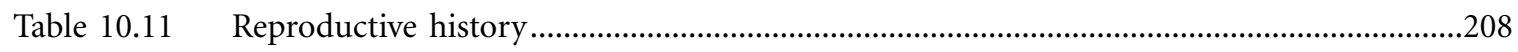

Table 10.12 Children ever born and surviving by selected background characteristics .....................209

Table 10.13 Wantedness of most recent pregnancy ..............................................................................210

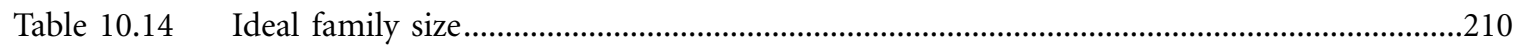

Table 10.15a Married young men's preferences for sons and daughters by selected

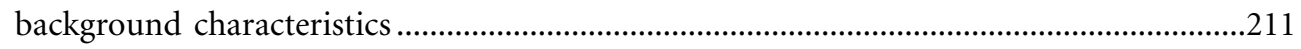

Table 10.15b Married young women's preferences for sons and daughters by selected

background characteristics .........................................................................................212

\section{Chapter 11: Health and health seeking behaviour}

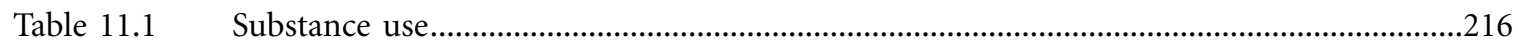

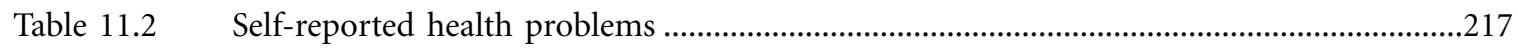

Table 11.3 Reported symptoms or behaviours suggestive of mental health disorders.......................219

Table 11.4 Care and advice seeking for reported health problems .....................................................221

Table $11.5 \quad$ Hesitation to access contraceptive supplies ..................................................................223

Table 11.6 Attitudes towards pre-marital HIV testing and extent of HIV testing .............................223

\section{Chapter 12: Participation in civil societyand political life}

Table 12.1 Awareness of and participation in government-and NGO-sponsored programmes ........226

Table 12.2 Participation in community-led programmes..................................................................229

Table 12.3 Membership in organised groups..............................................................................230

Table 12.4 Perceptions about actions taken by the panchayat in case of defiance of social norms..232

Table 12.5 Voting behaviour of eligible youth and perceptions about political matters....................233

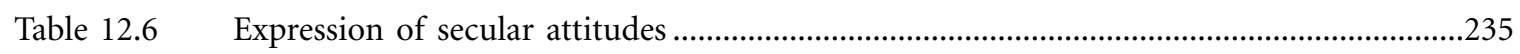

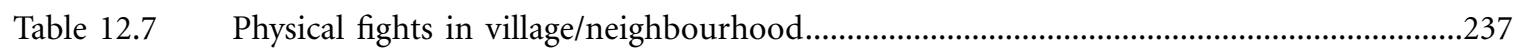

Table $12.8 \quad$ Perceptions about the leading problem facing youth .......................................................238 
Page No.

\section{Appendix B: Estimates of sampling errors}

Table B.1 List of selected variables for sampling errors, Tamil Nadu, 2006......................................263

Table B.2 Sampling errors, Tamil Nadu, 2006 ...................................................................................265

\section{Appendix C: Data quality tables}

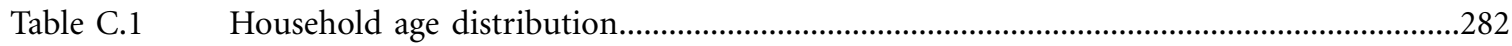

Table C.2 Single-year age distribution of eligible, selected and interviewed young men ..................283

Table C.3 Single-year age distribution of eligible, selected and interviewed young women ............284

Table C.4 Completeness of reporting ....................................................................................................285 
Figure 3.1 Percentage of youth who were in school at ages 12 and 15, according to residence, Tamil Nadu, 2006

Figure 3.2a Cumulative percentage of youth who had completed each year of education (Classes 1 to 17), Tamil Nadu (combined), 2006.

Figure 3.2b Cumulative percentage of youth who had completed each year of education (Classes 1 to 17), Tamil Nadu (urban), 2006

Figure 3.2c Cumulative percentage of youth who had completed each year of education (Classes 1 to 17), Tamil Nadu (rural), 2006.

Figure 3.3a Percentage of married youth who had discontinued schooling by class when discontinued and reasons for discontinuation, Tamil Nadu 2006.

Figure 3.3b Percentage of unmarried youth who had discontinued schooling by class when discontinued and reasons for discontinuation, Tamil Nadu, 2006.

Figure 4.1a Economic activity and schooling status among youth aged 15-24, by age, Tamil Nadu, 2006.

Figure 4.1b Economic activity and schooling status among married men aged 15-29 and married women aged 15-24, by age, Tamil Nadu, 2006.

Figure 4.1c Economic activity and schooling status among unmarried men and women aged 15-24, by age, Tamil Nadu, 2006

Figure 4.2 Percentage of youth who participated in domestic chores, according to residence, Tamil Nadu, 2006.

Figure 4.3 Percentage of youth who ever attended a vocational training programme and percentage who were interested in participating in such programmes, according to residence, Tamil Nadu, 2006

Figure 5.1 Percentage of youth exposed to television, films, print media and the internet, Tamil Nadu, 2006.

Figure 6.1 Percentage of youth reporting gendered socialisation experiences relative to an opposite-sex sibling/cousin, according to residence, Tamil Nadu, 2006.

Figure 6.2 Percentage of youth reporting that their father or mother, respectively, would disapprove if they brought same- and opposite-sex friends home, Tamil Nadu, 2006. 
Page No.

Figure 6.3a Percentage of youth who discussed various matters with their father, according to residence, Tamil Nadu, 2006

Figure 6.3b Percentage of youth who discussed various matters with their mother, according to residence, Tamil Nadu, 2006

Figure 6.4 Percentage of youth reporting at least one opposite-sex friend, according to residence, Tamil Nadu, 2006

Figure 7.1 Percent distribution of youth by participation in decision-making on selected matters, Tamil Nadu, 2006

Figure 7.2 Percentage of youth allowed to visit selected places within and outside the village/neighbourhood unescorted, Tamil Nadu, 2006.

Figure 7.3 Percentage of youth who expressed egalitarian gender role attitudes on selected issues, Tamil Nadu, 2006.

Figure 7.4 Percentage of youth who believed wife beating is justified in selected situations, Tamil Nadu, 2006.

Figure 8.1 Percentage of youth reporting awareness of selected sex- and pregnancy-related matters, according to residence, Tamil Nadu, 2006.

Figure 8.2 Percentage of youth who reported correct specific knowledge of oral pills and condoms, according to residence, Tamil Nadu, 2006

Figure 8.3 Percent distribution of youth by awareness of medical abortion, according to residence, Tamil Nadu, 2006

Figure 8.4a Comprehensive knowledge of HIV/AIDS by educational level, Tamil Nadu, 2006..........142

Figure 8.4b Comprehensive knowledge of HIV/AIDS by wealth quintile, Tamil Nadu, 2006.

Figure 8.5 Percentage of youth by awareness of HIV/AIDS, comprehensive knowledge about HIV/AIDS and awareness of STIs, Tamil Nadu, 2006

Figure 8.6 Percentage of youth who were aware of selected conditions under which abortion is legal, Tamil Nadu, 2006

Figure 8.7 Percentage of youth who received family life or sex education, according to residence, Tamil Nadu, 2006

Figure 8.8 Percentage of youth reporting knowledge of selected sexual and reproductive health matters according to whether they had or had not received family life or sex education, Tamil Nadu, 2006

Figure 9.1 Percentage of youth who had made or received a "proposal" for romantic partnership formation and percentage who had an opposite-sex romantic partner, according to residence, Tamil Nadu, 2006

Figure 9.2 Percentage of youth reporting experiences of physical intimacy and sex with a pre-marital romantic partner, Tamil Nadu, 2006

Figure 9.3 Percentage of youth reporting any pre-marital sexual experiences (in face-to-face interview or sealed envelope), according to residence, Tamil Nadu, 2006. 
Figure 10.1 Percentage of youth reporting that their parents had ever sought their opinion on timing of marriage, according to residence, Tamil Nadu, 2006

Figure 10.2 Percent distribution of married youth by degree of acquaintance with future spouse before marriage, according to residence, Tamil Nadu, 2006.

Figure 10.3 Percentage of married youth who reported receiving or giving dowry, according to residence, Tamil Nadu, 2006

Figure 10.4 Percentage of married youth who reported spousal communication on selected topics, according to residence, Tamil Nadu, 2006.

Figure 10.5 Percentage of married young women reporting experience of physical violence perpetrated by their husband and percentage of married young men reporting perpetration of physical violence against their wife, according to residence, Tamil Nadu, 2006.

Figure 10.6 Percentage of married youth reporting lifetime and current use of contraceptive methods within marriage, Tamil Nadu, 2006

Figure 11.1 Percentage of youth reporting symptoms/behaviours suggestive of mental health disorders in the month preceding the interview, according to residence, Tamil Nadu, 2006.

Figure 12.1 Percentage of youth reporting awareness of and participation in government-and NGO-sponsored programmes in the three years preceding the interview, according to residence, Tamil Nadu, 2006

Figure 12.2 Percentage of youth aged 20 or above who voted in the last election, according to residence, Tamil Nadu, 2006 


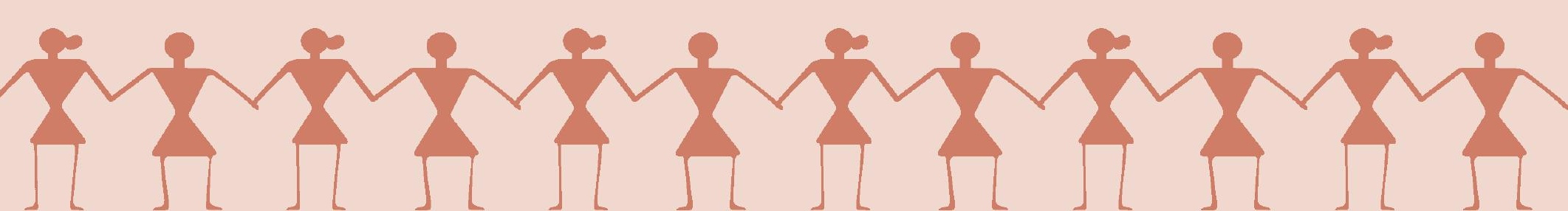




\section{Foreword}

The Government of India is committed to addressing the multiple needs of young people. The Eleventh Five Year Plan, the National Youth Policy, the National Population Policy 2000 and the National Rural Health Mission have all advocated special programmatic attention to addressing this population. National AIDS Control Programme, Reproductive and Child Health Programme and notably the National Adolescent Reproductive and Sexual Health Strategy provide the framework for a range of sexual and reproductive health services to be provided to youth.

Effective implementation of policies and programmes, however, has been difficult because of the lack of evidence on young people's situation and needs. The project Youth in India: Situation and Needs is intended to provide this evidence. Research has been conducted in a total of six states of India-Andhra Pradesh, Bihar, Jharkhand, Maharashtra, Rajasthan and Tamil Nadu. It provides a wealth of evidence on married and unmarried young women and young men from both rural and urban settings of each state. It covers almost every major dimension of youth life: education, work force participation, family life, sexual activity, marriage, health and civic participation. It provides state-level evidence on the magnitude and patterns of sexual and reproductive practices in and outside of marriage as well as related knowledge, decision-making and attitudes. Findings from the study provide important base-line indicators against which the long-term impact of programmes may be measured and will certainly go a long way in guiding policy, programmes and advocacy on youth issues.

This report focuses on findings from Tamil Nadu and is based on interviews with 7996 youth from all over the state. The report provides an enormous amount of information for the first time at the state level. The information will be useful to policy makers, programme implementers in government and non government sectors, rights activists and researchers alike who are committed to addressing the needs of Tamil Nadu's young generation. I appreciate the efforts put in by the International Institute for Population Sciences, Population Council and the technical advisory committee who guided the study.

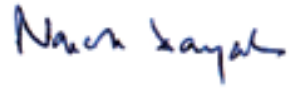

Naresh Dayal

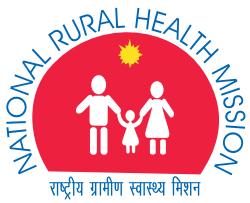




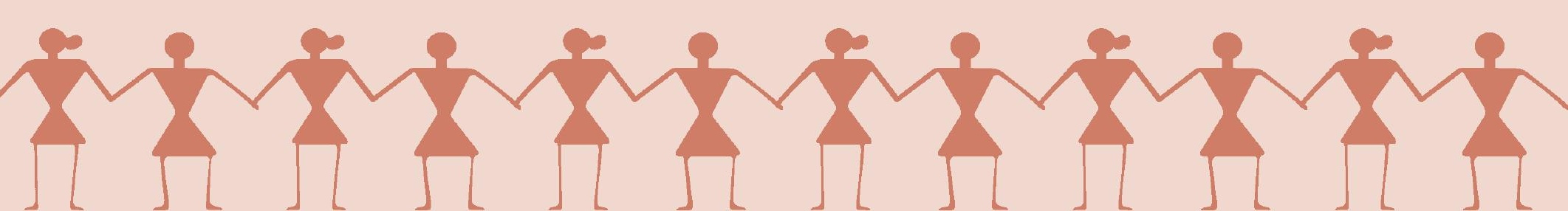




\section{Acknowledgements}

This report from the Youth in India: Situation and Needs study describes the transition to adulthood experienced by young men and women in Tamil Nadu. It covers multiple dimensions of their situation, ranging from education, work and marriage to sexual and reproductive health and behaviours. Evidence and recommendations contained in this report highlight, moreover, directions for programming and research that will enable youth in Tamil Nadu to make a successful transition to adulthood.

The Youth in India: Situation and Needs study has benefited immeasurably from the input of many. We are grateful to the Ministry of Health and Family Welfare, Government of India, for granting permission to conduct this study and to the Secretary, Shri Naresh Dayal, for his support throughout the project. We are also grateful to Shri G.C. Chaturvedi, Mission Director, National Rural Health Mission, Shrimati S. Jalaja, former Additional Secretary, Ministry of Health and Family Welfare, Shri V. K. Malhotra, Additional Director General, Dr. Rattan Chand, Chief Director, and Shri Rajesh Bhatia, Joint Director, Statistics Division, Ministry of Health and Family Welfare, Government of India for their support and guidance. We would also like to acknowledge the significant contribution of Shrimati S. Jalaja as chair of our Project Advisory Committee; and Shri S.K. Das, Director General, Central Statistical Organisation and former Additional Director General, Ministry of Health and Family Welfare, Government of India for support provided throughout the project.

We would also like to express our thanks to Thiru V. K. Subburaj, the Principal Secretary, Department of Health and Family Welfare, Government of Tamil Nadu, for facilitating the study in Tamil Nadu. The smooth functioning of fieldwork was due, in large part, to the support of the state Health Department, and we would like to acknowledge the contribution of all, including staff at the district headquarters level and primary health centre level.

The study received generous financial support from the John D. and Catherine T. MacArthur Foundation and the David and Lucile Packard Foundation; we are grateful for their financial support as well as for useful comments and suggestions provided by Lester Coutinho, Don Lauro and Lana Dakan of the Packard Foundation, and Poonam Muttreja and Dipa Nag Chowdhury of the MacArthur Foundation over the course of the project.

We would like to acknowledge the contribution of the late P.N. Mari Bhat, Director, International Institute for Population Sciences, during 2005-07. His input in the design and implementation of the study and in ensuring the progress of this challenging project contributed immensely to the quality of the study.

We are grateful to our Project Advisory Committee members for their input, which ensured that our study did indeed address all the key issues that require policy and programme attention. We appreciate their contribution both during meetings of the committee and in various one-on-one discussions during the course of the project. 
We acknowledge with gratitude the contribution of members of our Technical Advisory Committee. We were privileged that individuals with a wide range of expertise, from youth health and development to survey and qualitative approaches and ethics in research, agreed to serve as technical committee members. Our technical advisory group-Shalini Bharat, P.M. Kulkarni, Arvind Pandey, Pertti J. Pelto, T.K. Roy and Leela Visaria-supported the project from conceptualisation to completion. Their guidance at all stages of the study was central in enabling us to confront methodological, ethical and analytical challenges that arose over the course of the study and is gratefully acknowledged. We would like to record our deep appreciation, moreover, to P.M. Kulkarni for giving us so generously of his time in working through problems encountered during the design and implementation phases.

Several specialist group meetings were held over the course of the project that focused on study design, instrument development, qualitative component development and analysis, tabulation planning and report review;; several others who did not attend these meetings provided extensive comments on one or more of these issues. We are grateful to all these specialists—Dinesh Agarwal, Mallika Alexander, John Cleland, Nimesh Desai, Lalit Deshpande, Sudha Deshpande, Kamla Gupta, M.E. Khan, Sumati Kulkarni, Shiva Kumar, Cynthia Lloyd, S. Niranjan, Sulabha Parasuraman, Vikram Patel and Sunayana Walia-for their valuable contribution. John Cleland provided inputs at almost every phase of this study-design, instrument development and analysis - and his thought-provoking suggestions are gratefully acknowledged. In particular, we would like to acknowledge our external peer reviewers, P.M. Kulkarni and Leela Visaria, for their thoughtful and careful assessments of an earlier draft of this report.

Given that our study probed a number of highly sensitive matters, including young people's sexual and reproductive behaviours, it was an ethical imperative that those in need of information or services would be provided appropriate materials and referrals, respectively. A number of organisations came forward to support the study by accepting referrals made by study field teams. We would like to acknowledge in particular the Rural Women's Social Education Centre (RUWSEC) and Tamil Nadu State AIDS Control Society (TNSACS), whose materials and services were used by study participants.

We would like to express our gratitude to A. Subbaih, Department of Population Studies, Annamalai University for his support to the project at various stages, including training of field staff and during fieldwork. S. Ramachandran and K. Jyothi from Annamalai University, P. Balasubramanian from RUWSEC and S. Surender also participated in the training of field staff and we acknowledge their contribution. Support during fieldwork was also provided by the Gandhigram Population Research Centre and we would like to thank Lalitha Kabilan, its Director, for this support.

We would also like to express our appreciation to members of magalir manrams (women's self-help groups) and ilaingargal manrams (youth groups) in the survey areas for playing a key role in supporting the project. Several NGOs also played an important role in supporting fieldwork and we would like to acknowledge their support, notably, the AIDS Prevention and Control Project-Voluntary Health Services (APAC-VHS), Chennai; the Women's Organisation in Rural Development in Tamil Nadu, Pallipalayam, Erode district; the Social Awareness and Development Organisation for Women, Natham, Dindigul district; and the Association for Women Education and Rural Development, Madurai.

The Office of the Registrar General, New Delhi and the State Census Office, Tamil Nadu generously provided the project with information and maps pertaining to the 2001 Census. Their role in enabling the study to implement its sample design is gratefully acknowledged.

We would like to express our appreciation and gratitude to the International Institute for Population Sciences and the Population Council and all their staff members who helped in small and big ways in 
making this report possible. T.K. Roy and the late P.N. Mari Bhat as Directors of the International Institute for Population Sciences, and G. Rama Rao and S. Lahiri as officiating Directors, oversaw the activities of the project from the Institute's perspective. Saroj Pachauri, Regional Director, South and East Asia Office, Population Council oversaw the project on behalf of the Population Council. Their insight and supervision are gratefully acknowledged.

A number of research officers, consultants and administrative staff members, both at the International Institute for Population Sciences, Mumbai, and at the Population Council, New Delhi, contributed to the smooth implementation of the study as well as the data management, analysis and report writing phases. We would like to thank those responsible for the administrative aspects of this project. At the International Institute for Population Sciences, we would like to acknowledge the Registrar, Accounts Officer, Computer Centre In-Charge and Library In-Charge; and Jeba Kumar, Pranita H. Dalvi, Usha D. Sonawane, Seema Jadhav and Avadesh Kumar who were responsible for the smooth functioning of the project. From the Population Council, we are grateful to Komal Saxena, M.A. Jose, Anil Paul and Ashutosh Mishra who ably managed the administrative, financial and IT aspects of the project. We are grateful to our Senior Research Officers, Research Officers and Assistant Research Officers for their excellent supervision of fieldwork and data management as well as for their support in analysing the data and preparing the tables for this report. Shreeparna Ghosh and Prashant Kumar Singh from the International Institute for Population Sciences, and A.J. Francis Zavier and Shilpi Rampal from the Population Council, did a painstaking job in ensuring the accuracy of data presented in the report and their contribution is gratefully acknowledged. Deepika Ganju and Komal Saxena edited and ably managed the preparation of this report; we are grateful to them for their editorial contribution and meticulous attention to detail, which have made the report more readable and precise.

We would also like to acknowledge with thanks the contribution of our team of young and enthusiastic interviewers in eliciting information on difficult topics with sensitivity and skill. They were required to overcome discomfort when asking about intimate experiences and were required to record many disturbing experiences narrated by youth, which they did professionally and empathetically. It was due to their skill and ability to engage with youth in non-judgmental ways that this study was so well received by youth in Tamil Nadu.

We would also like to record our appreciation of the support and kindness of the people in the villages and urban neighbourhoods in which we conducted our study, and specifically panchayat members and community leaders. While initially sceptical about the study, community members opened their homes to us and acknowledged the importance of this study for the health and development of future generations. Indeed, despite the sensitive issues covered, not a single study community refused our field teams entry. The trust and support of the people are gratefully acknowledged.

Finally, and most importantly, we would like to thank the young women and men from Tamil Nadu who welcomed us, generously gave of their time and shared so many intimate details of their lives with us. We hope that the evidence generated in this report will be useful in influencing the design and content of programmes intended to meet their multiple needs and enable them to make a safe transition to adulthood.

K.G. Santhya

Shireen J. Jejeebhoy

Rajib Acharya

Population Council, New Delhi
Usha Ram

S. K. Mohanty

Abhishek Singh

F. Ram

International Institute for

Population Sciences, Mumbai 


\section{Executive summary}

The Youth in India: Situation and Needs study (referred to as the Youth Study), implemented by the International Institute for Population Sciences, Mumbai and the Population Council, New Delhi is the firstever sub-nationally representative study conducted to identify key transitions experienced by married and unmarried youth in India. Young people (aged 10-24) constituted almost 315 million and represented 31\% of the Indian population in 2001. Not only does this cohort represent India's future in the socio-economic and political realms, but its experiences will largely determine India's achievement of its goal of population stabilisation and the extent to which the nation will be able to harness its demographic dividend. While today's youth are healthier, more urbanised and better educated than earlier generations, social and economic vulnerabilities persist. In the course of the transition to adulthood, moreover, young people face significant risks related to sexual and reproductive health, and many lack the knowledge and power to make informed sexual and reproductive choices.

In recognition of the importance of investing in young people, several national policies and programmes formulated since 2000, including the National Population Policy 2000, the National Youth Policy 2003, the Tenth and Eleventh Five-Year Plans, the National Adolescent Reproductive and Sexual Health Strategy and the National Rural Health Mission, have underscored a commitment to addressing the multiple needs of this group in India. Effective implementation of both policies and programmes, however, has been handicapped by the lack of evidence on young people's situation and needs. Currently available evidence is limited, at best, and comes largely from small-scale and unrepresentative studies.

The Youth Study focused on married and unmarried young women and unmarried young men aged 15-24 and, because of the paucity of married young men in the younger ages, married men aged 15-29 in both rural and urban settings. The study collected information pertaining to key transitions experienced by youth, including those related to education, work force participation, sexual activity, marriage, health and civic participation; the magnitude and patterns of young people's sexual and reproductive practices within and outside of marriage as well as related knowledge, decision-making and attitudes.

The Youth Study comprised three phases, and included both a survey and qualitative data gathering exercises prior to and after the survey. The study was conducted in a phased manner in six states of India: Andhra Pradesh, Bihar, Jharkhand, Maharashtra, Rajasthan and Tamil Nadu.

This report focuses on findings from the survey conducted in Tamil Nadu. The survey was undertaken between May 2006 and January 2007. During the survey, 9,752 young people were contacted, of which a total of 7,996 married and unmarried young women and men were successfully interviewed. 


\section{Characteristics of the household population}

A total of 37,893 households were selected for interview. Among these, interviews were successfully completed in 35,880 sample households, and 146,973 individuals, who were usual residents in these households, were enumerated. The age distribution was typical of a population in which low levels of fertility have been reached, with relatively small proportions in both the younger (0-9 years) and older (60+ years) age groups. With regard to the youth population, the distribution suggests that at the time of the survey, the populations aged 10-14 years, 15-19 years and 20-24 years each comprised some $9 \%$ of the total population. A total of $18 \%$ of the population was aged 15-24 years. Overall, the sex ratio of the de jure population of the state was 999 females per 1,000 males.

Almost one-quarter of the population aged 6 years and above had no formal education. More females than males fell into this group: $32 \%$ and $15 \%$, respectively. At the other extreme, $18 \%$ and $13 \%$ of males and females, respectively, had received 12 or more years of education. The median years of schooling was 8 years for males and 5 years for females, but was three years higher in the urban compared to the rural population (8 and 5 years, respectively).

Overall, $16 \%$ of all households lived in kachcha houses (constructed from mud, thatch or other low-quality materials), 44\% lived in semi-pucca houses (constructed using a mix of low- and high-quality materials) and two-fifths lived in pucca houses (constructed entirely from cement, masonry or other high-quality materials). Over $90 \%$ of households had electricity, including almost all urban households (95\%) and $88 \%$ of rural households. Almost all households (96\%) reported that their main source of drinking water was either piped water, or water obtained from a hand-pump or a covered well. Access to a toilet facility of any kind was reported by over two-fifths of all households (42\%); $69 \%$ in urban areas and $20 \%$ in rural areas.

The distribution of households by wealth quintiles shows that one-third of urban households were in the wealthiest (fifth) quintile; in contrast, only $9 \%$ of rural households were in this quintile. Likewise, $29 \%$ of rural households were in the poorest (first) quintile compared to only $9 \%$ of urban households in this quintile.

\section{Situation of youth}

As mentioned earlier, a total of 7,996 youth were interviewed. Age profiles suggest that the unmarried were younger than the married, and rural youth were somewhat younger than their urban counterparts. About nine in 10 youth were Hindu and about 5\% were Muslim. Caste-wise distributions show that $71-74 \%$ of youth belonged to other backward castes, $23-27 \%$ to scheduled castes and the remaining (3\% or fewer) to general castes or scheduled tribes. Over four in five youth reported that both parents were surviving. For those with just one parent surviving, this parent was more likely to be the mother (11-13\%) than the father (2-3\%). Finally, $1 \%$ reported that neither parent was alive.

\section{Education}

Educational profiles indicate that the vast majority (91-94\%) of youth in the state had attained at least five years of schooling. Educational attainment levels suggest that irrespective of sex and marital status, youth had 8-10 years of schooling. At the time of interview, over two-fifths of all unmarried youth (and very few married) were still in school or college. Findings also indicate that $95-96 \%$ of youth who had completed Class 1 had completed Class 5, and 80\% had completed Class 8 . Following Class 8, declines became progressively steeper for both young men and women; for example, declines per year reached or exceeded $10 \%$ among 
both young men and young women between Classes 8 and 11. Married and rural youth were considerably less likely than their respective counterparts to have completed high school.

Findings suggest moreover that youth were considerably better educated than their parents. The median number of years of education completed by fathers of young men and women was 5 years; mothers of young men and women were far less educated, with a median of 2-3 years of education.

Leading reasons for discontinuation among young men and women who discontinued at middle and high school levels were economic issues (child required for work on the family farm/business or for outside wage earning work, or the family could not afford school-related expenses), attitudes and perceptions (such as for example, respondent's lack of interest in studies) and school-related factors (academic failure, distance to school, poor school quality and infrastructure). Of note is that school-related factors, particularly poor academic performance, were significant motivating reasons behind discontinuation, reported by $47 \%$ of young men and $51 \%$ of young women who discontinued schooling before completing Class 10. It is also notable that transitions into adult roles were rarely expressed as a reason for school discontinuation at these levels of education; even so, marriage was reported as a reason for school discontinuation at high school level by one-tenth of married young women.

Differences were observed in the availability of amenities among youth who were still in school and those who had discontinued their education at various levels. Most youth, irrespective of whether they were pursuing their education or not, had access to drinking water and playgrounds. However, for the most part, youth still studying were somewhat more likely to report the availability of toilets and libraries than were those who had discontinued schooling. The availability of all four amenities was, for the most part, considerably more likely to be reported by those who were studying at the time of interview than those who had discontinued their education, suggesting that the lack of amenities may have played a role in school discontinuation. Schooling experiences were also different; those who had discontinued their education were, for the most part, less likely than those who were still in school to report private tuition. They were considerably less likely, moreover, to have passed the last examination for which they had appeared, suggesting that poor school performance is a significant factor leading to school discontinuation among both young men and women.

\section{Work}

Work profiles suggest that about two-thirds of young men and half of young women had ever engaged in paid or unpaid work. Indeed, almost all married young men and over three-fifths of unmarried young men had done so, compared with over half and two-fifths of married and unmarried young women, respectively. Likewise, more rural than urban youth had ever worked. Economic activity was often initiated at an early age: $21 \%$ of young men and $17 \%$ of young women reported initiating work in childhood or early adolescence (before age 15). The majority of young men (all the married and 59\% of the unmarried) and a substantial proportion of young women (29\% and 37\%, respectively) had engaged in paid or unpaid work at some point in the 12 months preceding the survey. Almost nine in 10 young men and two in three young women who had worked in the year prior to interview had done so for the major part (at least six months) of the year.

Unemployment rates ranged from $7 \%$ among young men to $15 \%$ among young women. Unemployment rates tended to be considerably higher among the educated and economically better off than any other group. Youth were clearly interested in acquiring skills that would enable employment generation; $43 \%$ of young men and $53 \%$ of young women reported interest in vocational skills training. However, far fewer-one-quarter of young men and one-third of young women—had attended even one vocational training programme. 


\section{Media exposure}

Large proportions of youth were exposed to the media, typically newspapers, magazines or books ( $96 \%$ of young men and $78 \%$ of young women with five or more years of education), and television ( $96 \%$ of all young men and $92 \%$ of all young women). Exposure to the internet was reported by $26 \%$ of young men and $14 \%$ of young women with five or more years of education.

Findings also show that as many as two in five young men and hardly any young women had accessed pornographic or "blue" films, and almost four in five young men who had been exposed to pornographic films reported that they accessed these materials sometimes or frequently. One-quarter of young men had read or looked at pornographic books and magazines, and $29 \%$ of those exposed to the internet had accessed such materials on the internet, compared to far fewer young women. Finally, half or more young men and women acknowledged the influence that the media have on youth behaviours.

\section{Socialisation experiences and communication with parents}

Findings reveal a mixed scenario with regard to young people's socialisation experiences. Responses from both young men and women suggest that large proportions of households did not discriminate between their sons and daughters in terms of freedom of movement and expectations regarding housework. At the same time, far more consistently observed were gender differences in perceptions of parental control: young women were more likely than young men to perceive that their parents would disapprove of social activities in which youth participate, particularly those involving members of the opposite sex. For example, $62-68 \%$ of young women compared with $43-48 \%$ of young men reported that their mother or father would be angry if they talked with a person of the opposite sex from outside the home.

Findings show that communication with parents on issues relevant to youth—such as school performance, friendships, being teased or bullied, physical maturation, romantic relationships, contraception and reproductive processes-was not universal. Indeed, just $61-83 \%$ of youth reported discussing school performance or friendships, two relatively general topics, with their mother or father. Moreover, sensitive topics such as romantic relationships, reproductive processes and contraception were rarely discussed with either parent (reported by $9 \%$ or fewer youth). Nevertheless, among young women, mothers were reported as the most likely confidante on such matters as menstrual problems and the experience of being teased by a boy.

Young people's family lives were marked by violence, both experienced and witnessed. Over two in five young men and about one-third of young women had observed their father beating their mother. Many youth reported being beaten by a parent during adolescence; three in five young men and one-third of young women reported such experiences.

\section{Peer networks and interaction}

Growing up was associated with close peer networks. Almost all youth reported having same-sex friends. Young men reported larger networks of friends than did young women. Opposite-sex peer networks were less common but nonetheless reported by $29 \%$ of young men and $27 \%$ of young women. Interaction with friends tended to be restricted to activities such as chatting, studying and playing sports, especially among young women, although large proportions of young men did report engaging in outside activities such as going on picnics or to see films as well. An important measure of support was derived from these networks, however, with peers reported as the most likely confidante on issues related to boy-girl relationships for both young men and women, and on nocturnal emission for young men. 


\section{Agency and gender roles}

Substantial proportions of young men and many more young women did not exercise agency in their everyday lives. For example, decision-making was relatively limited: while $52 \%$ of young men reported independent decision-making on all three issues explored in the survey, namely, choice of friends, spending money and purchase of clothes, just $22 \%$ of young women reported so. Likewise, freedom of movement even within the village or neighbourhood was not universal, although young men reported considerably more freedom of movement than did young women. Indeed, only $79 \%$ of young women compared to $93 \%$ of unmarried young men could visit locations within their village or neighbourhood unescorted, and just $30 \%$ of young women compared to $71 \%$ of unmarried young men could visit at least one location outside their village or neighbourhood unescorted. Findings also show that control over financial resources among youth tended to be limited, and particularly so among young women. Although young women were more likely than young men to have money saved ( $31 \%$ and $19 \%$, respectively), they were somewhat less likely to own a bank or post office savings account ( $9 \%$ and $13 \%$, respectively) and less likely than their male counterparts to operate these accounts themselves ( $75 \%$ and $89 \%$, respectively, of those who had an account).

Gender role attitudes were mixed. However, young men were consistently more likely than young women to report unequal gender role attitudes. Considerable proportions of youth espoused egalitarian attitudes on such issues as whether girls are usually as good as boys in studies, whether the husband should be the main decision-maker with regard to spending money and whether girls should be allowed to decide about their own marriage. In contrast, the majority of youth expressed inegalitarian views on other matters. For example, just $26 \%$ of young men and $42 \%$ of young women disagreed with the view that a woman should obtain her husband's permission for most things. Moreover, 51\% of young men and 56\% of young women justified wife beating in at least one situation.

\section{Awareness of sexual and reproductive health matters}

Findings reiterate young people's limited awareness of sexual and reproductive matters, ranging from how pregnancy occurs to contraception, HIV and safe sex practices. For example, just half or fewer youth were aware that a woman can get pregnant at first sex, only about half had comprehensive knowledge of HIV and its transmission routes, and just $31 \%$ of young men and $12 \%$ of young women were aware of STIs other than HIV. Moreover, even on issues about which young people were generally aware, findings show that indepth understanding was limited. For example, in-depth awareness of condoms and oral contraceptives, the non-terminal methods most familiar to youth, was reported by $77 \%$ and $20 \%$ of young men, and $39 \%$ and $24 \%$ of young women, respectively. Findings suggest, moreover, that the unmarried were the most poorly informed about sexual and reproductive matters. Among the married too, young women were far less likely than young men to report pre-marital awareness of contraception. Taken together, these findings suggest that many young women, and fewer young men, enter marriage uninformed.

Many young women (22\%) and a few young men (6\%) reported that they had never received information on sexual and reproductive matters (prior to marriage among the married). Of those who had received such information, among the leading sources of information on both contraception and sexual matters were peers and the media. In contrast, few youth cited a family member as a source of information on either topic; the exception was married young women, several of whom cited their husband as a leading source of information on contraception. Teachers, charged with providing family life education to youth, were seldom cited as a source of information. Health care providers also played a limited role in providing youth information on contraception. These findings reflect the lack of attention that the RCH Programme has paid, thus far, to young people. Neither young men nor the unmarried appear to have come under the purview of health care 
providers. Among married young women, less than one in three were reached with any information from health care providers, underscoring the extent to which even this group has been neglected in the programme. In short, health care providers, teachers and family members-often considered more credible sources of information than peers and the media-were infrequently cited as sources of information on these sensitive topics by young people.

Few youth—just one in five young men and one in six young women—had attended family life or sex education programmes either in or outside the school setting. Despite this, youth were overwhelmingly in favour of the provision of family life or sex education to young people; typically, young people preferred to receive this education from a teacher, with smaller percentages citing friends, health care providers and other experts. Findings suggest, moreover, that youth who had received family life or sex education were more likely to have in-depth awareness of contraception and comprehensive knowledge of HIV/AIDS than those not exposed to this education.

\section{Pre-marital romantic relations}

Findings confirm that despite strict norms prohibiting pre-marital opposite-sex mixing, opportunities do exist for the formation of pre-marital romantic relations. Indeed, significant minorities of young men and women had received or made a "proposal" for a romantic relationship (25-28\%), and noteworthy, if smaller, percentages reported that they had been involved in a romantic partnership (23\% and $15 \%$ of young men and women, respectively). Patterns of pre-marital romantic partnerships suggest that where partnerships occurred, they were initiated at about age 18 among young men and age 16 among young women, and were usually hidden from parents but not from peers.

While the majority of youth had held hands with their romantic partner, consistently fewer reported more intimate behaviours. Gender differences in reporting of such experiences were evident: while $74 \%$ of young men had held hands with a romantic partner, about a quarter had engaged in sexual relations with that partner; and among young women, while three in five had held hands with a romantic partner, $10 \%$ had engaged in sexual relations with this partner. Notable gender disparities in expectations of a longer-term commitment emerged: young women were considerably more likely than young men to have expected a romantic relationship to lead to marriage. Partner communication and negotiation regarding safe sex were rare, and sex was unprotected for the overwhelming majority of sexually active youth. For almost one in three young women who had engaged in sexual relations with a romantic partner, sex was not consensual.

\section{Pre-marital sexual experiences in romantic and other relationships}

In total, $9 \%$ of young men and $2 \%$ of young women reported the experience of pre-marital sex within romantic and/or other partnerships. In general, life table estimates reveal that first pre-marital sex did not take place, for the most part, in adolescence: just $5 \%$ and $2 \%$ of young men and women had initiated sex before age 20. Initiation into pre-marital sexual activity increased as young people transitioned into young adulthood, sharply among young men and more gradually among young women. Also notable is the finding that sexual initiation took place earlier among rural than urban youth.

While sex with a romantic partner characterised pre-marital experiences for many of the sexually experienced, findings suggest that young men, but not young women, also engaged in sex in other contexts-mainly with sex workers, married women and casual partners. Many sexual experiences were risky, for example, about onethird of young men and women reporting pre-marital sex had engaged in sex with more than one partner. 
Moreover, consistent condom use was limited-just 5\% of sexually active young men and not a single young woman reported condom use in all pre-marital encounters.

While we acknowledge that youth, especially young women and unmarried young men, may not report sexual experience in a survey situation, the Youth Study experience suggests that a series of direct questions posed in a face-to-face interview, supplemented by an opportunity to report sexual experience in an anonymous format, using the sealed envelope technique, provides higher estimates of sexual experience than does faceto-face questioning alone, or, for the most part, anonymous third-party reporting of peer behaviours. On balance, findings suggest that the sealed envelope technique did indeed enable a considerable number of sexually active young men and women who opted not to disclose their sexual experiences in face-to-face questioning the opportunity to do so.

\section{Transitions to marriage and early married life}

Findings indicate that Tamil Nadu is characterised by a relatively late age at marriage: hardly any young men and fewer than one in five young women aged 20-24 (18\%) were married before age 18. While the majority of married youth reported an arranged marriage, it is notable that about one in five young men and women reported a love marriage, and about three-quarters reported that their approval of the prospective spouse had been sought. Likewise, considerable proportions reported some pre-marital acquaintance with their spouse; even so, about one-fifth of married young men and over one-third of married young women had met their spouse for the first time on their wedding day. Dowry characterised the marriages of $84 \%$ of young men and $88 \%$ of young women. Despite the fact that many were acquainted with their spouse prior to marriage and had played a role in determining who they would marry, large proportions-two-thirds of young men and three-quarters of young women-reported that they had lacked awareness of what to expect of married life.

Married life was characterised by considerable inter-spousal communication on most topics, yet only two-fifths of young men and three-fifths of young women had ever communicated with their spouse on matters relating to contraception. Moreover, physical violence and forced sex within marriage were reported by significant minorities of youth. For example, more than one-quarter of young women reported ever experiencing physical violence perpetrated by their husband, and an even larger percentage of young men (34\%) reported perpetrating physical violence on their wife. Recent physical violence was likewise reported by one-fourth of young women and $31 \%$ of young men. Sexual violence was also reported; indeed, one-fifth of young women reported that their first sexual experience within marriage was forced. Overall, $25 \%$ of young women reported ever being forced to engage in sex with their husband; in comparison, just $15 \%$ of young men reported forcing their wife to engage in sex.

While the Youth Study did not explore extra-marital sexual experiences in detail, the available data indicate that $4 \%$ of young men reported an extra-marital sexual encounter. In contrast, hardly any young women reported an extra-marital sexual encounter.

\section{Contraceptive practice and pregnancy experience}

Contraceptive use at any time within marriage was reported by $18 \%$ of young men and $21 \%$ of young women. Just $16 \%$ of young men and $17 \%$ of young women reported use of contraception at the time of 
interview. The limited percentages of youth practising contraception may be attributed to the relatively late age at marriage in Tamil Nadu and consequently, the fact that many married youth may not have initiated childbearing. The pattern of methods used suggests, however, a considerable reliance on terminal methods: female sterilisation was reported by $9-10 \%$ of young men and women. Use of non-terminal methods at the time of interview was reported by just 6-7\% of young men and women; the main methods used were the condom and the IUD. Few young people practised contraception to delay the first birth-reported by less than $3 \%$ of youth. Pregnancy typically occurred within the first six months following marriage among those who reported that they or their wife had been pregnant at least once. While just $1-2 \%$ of young men reported a mistimed or unwanted pregnancy, as many as $10-13 \%$ of young women reported experiencing an unintended pregnancy.

Circumstances of the first birth suggest that the overwhelming majority of first births were delivered in a health facility (81-84\%) and almost all were delivered by a skilled attendant (93\%).

Son preference was evident. Although most respondents wanted one child of each sex, of those who preferred more than two children, somewhat more preferred to have more sons than daughters.

\section{Substance use}

Findings show that substantial proportions of young men (23-25\%) reported the consumption of tobacco and alcohol. Drug use was reported by just $0.3 \%$ of young men. Hardly any young women reported consuming any of these substances.

\section{Health seeking behaviour}

Although youth is a generally healthy period of life, significant minorities reported experiencing general, mental, and sexual and reproductive health problems in the period preceding the interview. For example, $18 \%$ of young men and $33 \%$ of young women had experienced high fever, and $2 \%$ of and $21 \%$, respectively, reported the experience of symptoms of genital infection. Moreover, about one in 10 young women reported menstrual problems; at the same time, nearly one in three young men reported anxiety about nocturnal emission. Finally, responses indicative of mental health disorders were reported by some $13 \%$ of young men and $10 \%$ of young women.

With regard to care seeking for general and sexual and reproductive health problems, patterns varied by the type of problem experienced. While the large majority of those who had experienced high fever, for example, had sought care, many fewer had sought care for sexual and reproductive health problems. Of those who had sought treatment, the majority had sought advice or treatment from a private facility or provider, irrespective of the type of problem experienced. However, it is notable that in the case of anxiety about nocturnal emission, youth rarely sought advice from a health care provider, preferring to do so from peers.

Findings suggest that youth were uncomfortable about seeking sexual and reproductive health services. Many youth-minorities in the case of married young men, but larger proportions in the case of unmarried young men and both married and unmarried young women - would indeed find it difficult to seek appropriate care for sexual and reproductive problems. 
Finally, small minorities of youth reported that they had undergone HIV testing-10-13\% of the married and $1-3 \%$ of the unmarried. Youth were, however, overwhelmingly in favour of pre-marital HIV testing.

\section{Participation in civil society and political life}

Although a number of programmes are held to build youth skills, relatively few youth (one-fifth of young men and two-fifths of young women) reported familiarity with either government- or NGO-sponsored programmes organised at the community level in which youth could participate. Far fewer youth-14\% of young men and $9 \%$ of young women-reported participating in any such programme. Many more young men $(52 \%)$ and somewhat more young women $(13 \%)$ reported that they had participated in community-led activities such as cleanliness drives and the celebration of festivals and national days. Finally, $12 \%$ of young men compared to $16 \%$ of young women reported membership in organised groups.

Among those eligible to vote, $82 \%$ of young men and $66 \%$ of young women had cast their vote in the most recent election. While $91 \%$ of married young men had cast their vote, $82 \%$ of unmarried young men and two-thirds of young women, irrespective of marital status, had voted. Also of note is that while most youth perceived that elections were fair and permitted one to vote without fear, the large majority (64-73\%) reported disillusionment with the commitment of political parties to work for change at the community level.

By and large, youth reported secular attitudes: $97 \%$ or more reported that they mixed freely with individuals of different religions and castes. However, just half of young men and somewhat fewer young women agreed that it was better to tolerate rather than punish someone who showed disrespect to their religion. Findings typically suggest that rural youth were more likely than others to report conservative views. Similarly, among young women, the married were more likely than the unmarried to report so.

Considerable proportions of young men and women acknowledged that physical fights among young men as well as among young women did occur in their village or neighbourhood. However, just $10 \%$ of young men and 3\% of young women reported that they had been involved in a physical fight in the year preceding the interview.

Finding employment was expressed as the single most important problem facing youth in the state; reported by $69 \%$ of young men and $49 \%$ of young women. Additionally, $10 \%$ of young men and $14 \%$ of young women reported poverty as a major problem. Nine percent of young women also reported lack of amenities/ infrastructure as a major problem.

\section{Recommendations for programmes}

Findings presented in the sections above underscore the fact that youth face numerous challenges while making the transition to adulthood. These challenges call for programme interventions at the youth, family and service delivery levels. Key programme recommendations emerging from this study are outlined below.

\section{Address obstacles to universal secondary school completion}

Although young people in Tamil Nadu are spending much of their adolescence pursuing their education, concerted efforts are needed if the state is to meet its goal of achieving universal access to secondary education by the year 2015. Youth Study findings suggesting notable declines in school completion following Class 8 
call for efforts to address barriers to secondary school completion. A number of factors have been identified in the Youth Study that inhibit secondary school completion; leading among these were economic reasons, attitudes and perceptions, and school-related reasons. Multiple activities are needed to address these barriers. Efforts must be made, for example, to address the economic pressures that may lead parents to withdraw their children from school in favour of work. While a number of state government programmes are ongoing that aim to reduce the cost of education, additional inputs, by way of conditional grants that encourage school completion among disadvantaged groups, also need to be considered. Moreover, there is a need to ensure that government programmes do indeed reach the most disadvantaged groups. At the same time, activities are needed that sensitise parents about the importance of a secondary school education in expanding their children's livelihood opportunities.

Activities must also address school-level barriers, notably, poor infrastructure, quality of education and academic failure. There is a need to incorporate livelihoods skills building models within the school setting that will not only raise young people's aspirations regarding their education and careers but also provide them opportunities to gain market-driven job skills. Moreover, investments in improving the quality of the schooling experience are needed that focus on providing better training and ensuring the accountability of teachers.

While the stark gender divide in educational attainment levels seen elsewhere in the country is not observed in Tamil Nadu, findings suggest that married young men and women remain considerably disadvantaged. Interventions are needed that give the married a second chance to continue their education. Likewise, evidence that rural youth were more disadvantaged with regard to educational opportunities than their urban counterparts calls for efforts to provide those out of school an opportunity to complete their schooling.

\section{Enable opportunities for youth employment}

The Youth Study finding that between one in five young men and one in six young women had initiated work in childhood reiterates the recommendation highlighted above regarding the need to provide conditional grants and targeted subsidies to disadvantaged groups, which would encourage parents to opt for schooling over work for their children.

The finding that unemployment rates were particularly high among the educated suggests a possible disconnect between youth skills and market needs. Indeed, few youth were aware of employment generation programmes and even fewer had availed of these or vocational skills training. It is notable that while considerable proportions of urban youth reported exposure to computer skills, English language skills and so on, rural youth tended to opt for relatively traditional vocational skills and may not have had the opportunity to learn about market needs or develop appropriate skills for which a demand exists. Formal mechanisms need to be developed that enable youth—particularly rural youth — to acquire skills for which there is an established market demand, and that link eligible youth to market opportunities.

\section{Build upon youth's growing access to the internet}

Findings suggesting that one-quarter of young men and one in seven young women with five or more years of education-and considerably more in urban areas—-had accessed the internet highlight the role that this medium can play in building youth awareness of the world around them and opportunities available to them. The development of youth-friendly web-sites in Tamil may be a useful way to convey such information to youth. 


\section{Promote youth agency and gender equitable norms among youth}

Findings highlight that substantial proportions of young men and the majority of young women do not exercise agency in their everyday lives. Almost half of young men and over three-quarters of young women lacked decision-making authority even on such matters as choosing friends, purchasing clothes and spending money. Young women, in addition, lacked freedom of movement and opportunities to build peer networks. These findings call for attention to promote life skills education programmes for youth, especially young women, both unmarried and married, that will enable them to have an informed say in their own lives. Safe spaces should be identified in which young women can build social networks and find support among peers.

Inegalitarian gender role attitudes were expressed by many, notably young men but including young women. Moreover, as many as half of all young men and women justified wife-beating in at least one situation. Egalitarian attitudes must be promoted among young men and women, and programmes should be tailored to meet each group's situation and needs. These programmes should promote new concepts of masculinity and femininity among youth and at the same time, promote messages that build egalitarian relations between women and men.

An increasing number of intervention models to build agency and promote egalitarian gender role attitudes among young people have been tested in India. These models should be reviewed and replicated or scaled up as appropriate.

\section{Provide opportunities for formal saving, especially for young women}

Findings suggest that while young women were more likely than young men to report savings, they were less likely to own a savings account or to operate the account independently. At the same time, few youth owned a bank or post office account; just 13\% of young men and $9 \%$ of young women. Programmes are needed that inculcate a savings orientation among young people, that offer savings products that are attractive and appropriate to the small and erratic savings patterns of young people and that enable young women in particular to overcome obstacles related to owning and controlling savings products.

\section{Promote youth participation in civil society and political processes and reinforce secular attitudes}

Findings have noted that large proportions of youth have exercised their right to vote, that the majority hold secular attitudes with regard to mixing with a person from another caste and religion, and few engage in community-level violence. Nevertheless, not all youth expressed secular attitudes; half of young men and somewhat more young women reported that they would endorse violence against someone who showed disrespect to their religion. Relatively few, moreover, had participated in civil society, that is, government- or NGO-sponsored programmes or community-led activities. Programmes are needed-at the school, college and community levels, through national service programmes, sports and other non-formal mechanisms-that encourage civic participation, incorporate value building components and reinforce secular attitudes and values that espouse responsible citizenship.

\section{Provide family life or sex education for those in school and out of school}

Youth Study findings provide considerable evidence suggesting that family life or sex education is urgently needed among youth, both those in school and those who have discontinued their education. Findings 
demonstrate a limited understanding of sexual and reproductive matters among young people, including the married. Misconceptions abound on most topics: sex and pregnancy, contraceptive methods including condoms, STIs and HIV/AIDS, and the conditions under which abortion is legally available or restricted. Where awareness exists, it is typically superficial.

Youth themselves have called for family life or sex education. Findings highlight that large proportions recognised the need for information and education on these issues, and indicated a preference for receiving this education from teachers, health care providers or other experts, and in the case of young women, parents. However, few young people had been exposed to family life or sex education, notwithstanding the School AIDS Education Programme, the Red Ribbon Clubs and the special programme for out-of-school youth. Indeed, substantial proportions of married young women (and some young men) reported entering marriage unaware of what marriage entailed. At the same time, several young people had engaged in sexual risk taking.

As mentioned above, a number of state government programmes are ongoing that aim to impart sexual and reproductive health information to young people. What is needed is a strong commitment to ensuring that these programmes do indeed reach young people, including those in school and out-of-school, married and unmarried, and in rural and urban settings. Moreover, there is a need to expand the content of existing awareness raising programmes to include not just HIV-related information but broader sexual and reproductive topics. These programmes should be designed not only to raise awareness among youth but also to enable young people to correctly understand and assess the risks they face and to adopt appropriate protective actions.

In addition, special attention needs to be paid to the training of trainers. It is important that teachers, health care providers and other experts undergo training that enables them to overcome their reluctance to communicate with youth on sensitive sexual and reproductive matters, dispels their misconceptions on these matters and enhances their technical knowledge of these issues.

\section{Ensure that the transition to sexual life is safe and wanted}

While for the vast majority of young women sexual activity is initiated within the context of marriage, findings show that a small proportion of young men and women had engaged in sex before marriage. As documented in this report, many youth had initiated sexual activities uninformed, reiterating the need to provide family life or sex education to young people. Moreover, the finding that for many youth, premarital sexual experiences were unsafe or unwanted calls for programmes that focus on building sexual and reproductive health awareness among young people, and developing their skills in negotiating safe sex and communicating with their partners on sexual and reproductive health matters. At the same time, programmes must make available appropriate family planning and infection prevention services for both married and unmarried young men and women in a manner acceptable to them.

\section{Address power imbalances within marriage}

Findings confirm that early marriage was relatively rare in Tamil Nadu, and that the majority of youth did play a role in decisions relating to their own marriage and had some pre-marital acquaintance with their spouse. Within marriage, large proportions reported communication and interaction with their spouse; nevertheless, communication on sensitive matters such as contraception was limited for many. Indeed, married life was marked by considerable power imbalances; for example, notable proportions of young women had suffered physical and sexual violence perpetrated by their husband. 
Efforts are needed to encourage couple communication on sensitive issues (contraception, for example), negotiation and conflict management skills early in marriage. Efforts are also needed to inform married young women of their rights so that they have the opportunity to exercise control over their own lives; at the same time, efforts must be made to promote new concepts of masculinity and femininity and egalitarian couple relations among young men and women. Intervention models exist in India that have attempted to address these needs; these should be reviewed and up-scaled as appropriate.

\section{Create a supportive family environment}

Findings highlight the limited interaction and social distance between parents and young people while growing up, and the gendered nature of perceptions regarding parental control on youth behaviours. Efforts must be made to create a supportive environment for young people. While evidence on models that are effective in bridging the distance between parents and children or enabling parents to adopt more gender-egalitarian socialisation practices is not currently available, findings presented in this report call for programmes that address parental inhibitions about discussing sexual matters with their children, encourage greater openness and interaction between parents and children, and enable the adoption of gender-egalitarian child-rearing practices.

\section{Reorient service provision to address the unique needs of unmarried and married young women and men}

Although the RCH Programme has advocated special services for youth, including the unmarried, these services had not reached youth in our survey. For example, relatively small percentages of young people had ever practised contraception and the method most likely to be adopted was sterilisation. Few had sought care for symptoms of STI or gynaecological problems, and most youth who had sought care for the latter preferred private to public sector facilities. Lack of care seeking and the disconnect between the public health sector and youth underscores the need to sensitise health care providers about the special needs, heterogeneity and vulnerability of unmarried and married young women and men, and to orient them to the need for developing appropriate strategies to reach these diverse groups, including young newly-weds.

Programmes must be inclusive of unmarried as well as married young people, and recognise their need and right to sexual and reproductive health and related information and services. Counselling and contraceptive services must be made available to all young people, including the unmarried, in a non-threatening, nonjudgmental and confidential environment. Indeed, these findings call for the implementation of strategies outlined under the National Rural Health Mission's RCH Programme.

At the same time, mental health issues need to be addressed. While relatively few young men and women reported symptoms suggestive of mental health disorders, these symptoms were somewhat more apparent among the married than the unmarried. Efforts are needed to screen young people-particularly the married-for mental health disorders when they avail of other primary health services, including, for example, sexual and reproductive health services, and to refer youth with such symptoms to appropriate health facilities and providers.

\section{Directions for future research}

Findings presented in this report provide a broad picture of youth in Tamil Nadu. At the same time, findings have raised a number of issues that require further investigation, particularly with regard to the determinants 
and consequences of youth behaviours and practices during the transition to adulthood. While the Youth Study is indeed a rich source of data that will enable investigators to fill many of the information gaps identified, there are several gaps in knowledge that will require additional research.

Youth Study findings highlight the need for further study in terms of formative research that explores in greater depth the factors impeding successful transitions to adulthood, in the areas, for example, of secondary school completion, economic activity, sexual relations, and marriage and parenthood. Research is also needed that explores the role of peers, socialisation practices, young people's access to information and services, and the ways in which these factors may contribute to or impede young people's ability to make successful transitions to adulthood. A general research recommendation is the urgent need for prospective or panel study designs that follow a cohort of adolescents at regular intervals up to age 24 . Prospective study designs would enable researchers to take a life course approach, identify, with compelling data, the factors responsible for healthy transitions to adulthood and point to the ways in which the situation and experiences of youth influence their life course at later ages.

Operations research is also needed. While a number of interventions have been initiated in India intended to address the needs of youth-for example, addressing the needs of married girls, changing the norms of masculinity and femininity, encouraging education for girls, developing market-oriented vocational skills and providing family life of sex education-few have been rigorously evaluated. Urgently needed, therefore, are carefully designed and rigorously tested intervention models that not only pay attention to the content and delivery of the intervention but also measure its effectiveness and acceptability—in short, that will enable a shift from the implementation of promising to best practices in addressing young people's needs. Ultimately, research is needed that monitors the scaling up of successful interventions in terms of their impact on young people's lives.

In brief, the Youth Study has documented, for the first time, the multi-faceted situation of youth in Tamil Nadu. The study highlights several positive aspects of young people's lives but also alerts us to the many challenges confronting youth and their ability to make a successful transition to adulthood. It emphasises the heterogeneity of youth, not only in terms of their situation but also with regard to their stated needs and preferred mechanisms to address these needs. Programmes must recognise the heterogeneity of young people, and interventions and delivery mechanisms should be appropriately tailored to meet their needs. Evidence presented here provides not only a blue-print for the programming needs of youth in Tamil Nadu but also a base-line by which to measure the impact of programmes intended to address youth needs. 


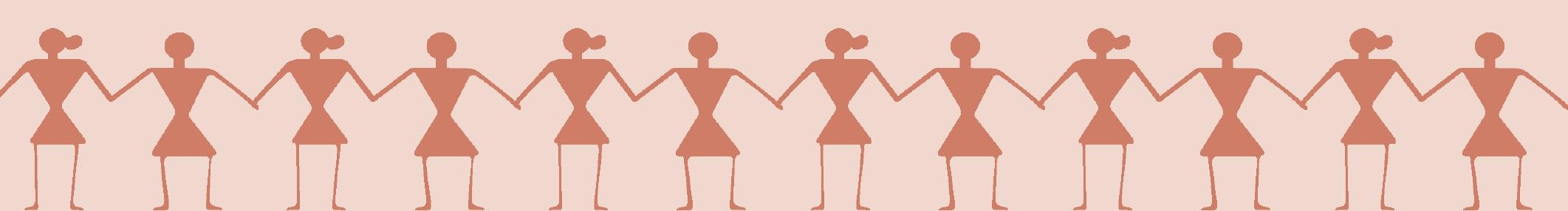




\subsection{Rationale}

The Youth in India: Situation and Needs study (referred to as the Youth Study) is the first-ever sub-nationally representative study conducted to identify key transitions experienced by married and unmarried youth in India. There is a strong rationale for this study. Young people (aged 10-24) constitute almost 315 million and represent $31 \%$ of the Indian population (Office of the Registrar General and Census Commissioner, 2001a). Numbers are projected to increase and peak at around 358 million in 2011 before stabilising at around 336 million by 2026 (Office of the Registrar General and Census Commissioner, 2006). Not only does this cohort represent India's future in the socio-economic and political realms, but its experiences will largely determine India's achievement of its goal of population stabilisation articulated in the National Population Policy 2000 (MOHFW, 2000) and the extent to which the nation will be able to harness its demographic dividend. In addition, it is clear that the realisation of the Millennium Development Goals (UNDP, 2000) depends, to a considerable extent, upon the situation of young people. While today's youth are healthier, more urbanised and better educated than earlier generations, social vulnerabilities persist and transitions to adulthood are too frequently marked by early entry into the labour force, abrupt and premature exit from school, early marriage and strongly-held gender norms. In the course of the transition to adulthood, moreover, young people face significant risks related to sexual and reproductive health, and many lack the knowledge and power to make informed sexual and reproductive choices (for a review, see Jejeebhoy and Sebastian, 2003).

In recognition of the importance of investing in young people, several national policies formulated since 2000 have underscored a commitment to addressing the multiple needs of this group in India. The National Population Policy 2000 recognised, for the first time, that adolescents constitute an under-served group with special sexual and reproductive health needs, and advocates special programme attention to addressing this population (MOHFW, 2000). The National Youth Policy 2003 focuses on the needs of those aged 13-35, but recognises adolescents (aged 13-19) as a special group requiring a different approach from that appropriate for young adults (aged 20-35), and promotes strategies to meet youth needs in areas including education, training and employment, health, recreation and sports, and good citizenship (Ministry of Youth Affairs and Sports, 2003). Also notable is the commitment to addressing the needs of adolescents and young people articulated in the Tenth and Eleventh Five-Year Plans (Planning Commission, 2002; 2006). In addition, the National Adolescent Reproductive and Sexual Health Strategy provides the framework for the adolescent sexual and reproductive health services proposed in the Reproductive and Child Health (RCH) Programme II (MOHFW, 2006). The National Rural Health Mission (2005-12) has incorporated adolescent health services as part of its service guarantees in health sub-centres, primary health centres and schools (MOHFW, 2005).

Effective implementation of both policies and programmes, however, has been handicapped by the lack of evidence on young people's situation and needs. Currently available evidence is limited, at best, and comes largely from small-scale and unrepresentative studies. The most recent National Family Health Survey (NFHS-3) obtained, for the first time, valuable data on unmarried young women and men (IIPS and Macro International, 
2007a). Even so, the information that it provides on young people's various transitions remains limited and the small sample sizes obtained in most states preclude the possibility of in-depth analysis and of obtaining state-representative estimates of behaviours and practices among different sub-groups of young people.

\subsection{Study objectives}

The objectives of the Youth Study were to identify key transitions experienced by youth, including those pertaining to education, work force participation, sexual activity, marriage, health and civic participation; provide state-level evidence on the magnitude and patterns of young people's sexual and reproductive practices within and outside of marriage as well as related knowledge, decision-making and attitudes; and, finally, identify key factors underlying young people's sexual and reproductive health knowledge, attitudes and life choices. Findings from the study are expected to guide policy, programmes and advocacy on youth issues, enable programmes and policies to recognise the heterogeneity of youth in India, and provide important base-line indicators against which the long-term impact of programmes may be measured.

The Youth Study focused on married and unmarried young women and unmarried young men aged 15-24 and, because of the paucity of married young men in the younger ages, married men aged 15-29 in both rural and urban settings. The study was conducted in a phased manner in six states of India: Andhra Pradesh, Bihar, Jharkhand, Maharashtra, Rajasthan and Tamil Nadu. This report focuses on findings from Tamil Nadu.

Funding for the Youth Study was provided by the David and Lucile Packard Foundation and the John D. and Catherine T. MacArthur Foundation. The Youth Study was conducted jointly by the International Institute for Population Sciences, Mumbai (IIPS) and the Population Council, New Delhi. The design and implementation of this study were guided by the Project Advisory Committee, headed by the Additional Secretary, Ministry of Health and Family Welfare (MOHFW), Government of India.

\subsection{Tamil Nadu: Overview of demographic and socio-economic features}

The state of Tamil Nadu, situated in the southern part of India, is India's eleventh largest state in terms of area, covering a total of 130,058 square kilometres. The state has 31 districts (30 at the time of the 2001 Census; http://www.tn.gov.in; Office of the Registrar General and Census Commissioner, 2001b). With a population of 62.4 million in 2001, the state ranks sixth in terms of total population among states in India (Office of the Registrar General and Census Commissioner, 2001b). The state's population almost doubled between 1961 and 2001 and is projected to have reached 66 million by 2008 (Office of the Registrar General and Census Commissioner, 2006). With 987 females per 1,000 males in 2001, the state registered the third highest sex ratio among states in India, which was considerably higher than the national average of 933. Population density in the state was 480 persons per square kilometre in 2001. The distribution of the state's population by religion indicates that $88 \%$ were Hindu, $6 \%$ Muslim and $6 \%$ Christian (Office of the Registrar General and Census Commissioner, 2001c). Almost one-fifth (19\%) of the state's population belonged to scheduled castes and $1 \%$ belonged to scheduled tribes (Office of the Registrar General and Census Commissioner, 2001b). With 44\% of the state's total population living in urban areas in 2001, Tamil Nadu ranked second (after Delhi) in terms of percentage of the population residing in urban areas (Office of the Registrar General and Census Commissioner, 2001b).

Tamil Nadu is one of the more economically progressive states in the country; in 2006-07, it accounted for $6.5 \%$ of the national Gross Domestic Product (GDP) (Ministry of Statistics and Programme Implementation, 2008). The state ranked seventh among major Indian states in terms of per capita income, at Rs. 29,958 
(Ministry of Finance, 2008). Tamil Nadu's Gross State Domestic Product (GSDP) at current prices stood at Rs. 246,266 crore in 2006-07 (Ministry of Statistics and Programme Implementation, 2008); at constant prices (1993-94), the GSDP increased by $7.4 \%$ between $2004-05$ and 2005-06. The primary, secondary and tertiary sectors contributed $13.9 \%, 28.5 \%$ and $57.6 \%$, respectively, to the state's economy in 2005-06 (Department of Evaluation and Applied Research, Government of Tamil Nadu, n.d.).

A little over one-fifth of the state's population (22.5\%, based on the Uniform Recall Period consumption distribution) was estimated to live below the poverty line in 2004-05, with little difference between those living in urban $(22.2 \%)$ and rural $(22.8 \%)$ areas (Planning Commission, 2007). Unemployment rates are low in Tamil Nadu. In 2004-05, $1.8 \%$ and $3.2 \%$ of rural and urban males, respectively, were unemployed for the major part of the year, as measured by the usual principal status definition; corresponding figures for females are $2.5 \%$ and $5.4 \%$, respectively (NSSO, 2006).

Tamil Nadu is also one of the most socially advanced states in India. For example, the state ranks seventh among Indian states in terms of literacy; the overall literacy rate was $74 \%$ in 2001 , ranging from $64 \%$ among females to $82 \%$ among males (Office of the Registrar General and Census Commissioner, 2001b). Literacy rates in Tamil Nadu are considerably higher than the national average of $54 \%$ for females and $75 \%$ for males (Office of the Registrar General and Census Commissioner, 2001b).

The state's achievements in the health sector are also notable. Life expectancy is higher in Tamil Nadu than in India in general: 67 and 65 years, respectively, for females and males during 2002-06 in Tamil Nadu compared to 64 and 63 years for females and males, respectively, for India as a whole (Office of the Registrar General, India, 2008a). Tamil Nadu's infant mortality rate was 30 in 2005-06, lower than the national infant mortality rate of 57. The fertility rate in the state reached replacement level in 2000 (Office of the Registrar General and Census Commissioner, 2006). The total fertility rate in Tamil Nadu was 1.8 in 2005-06 and current contraceptive use was $61 \%$, as compared to a total fertility rate of 2.7 for India as a whole and a contraceptive prevalence rate of 56\% (IIPS and Macro International, 2007a).

Tamil Nadu was, till recently, a high prevalence state in terms of HIV prevalence. However, recent evidence from antenatal surveillance estimates and the NFHS suggests that HIV prevalence has declined in the state (IIPS and Macro International, 2007a; NIHFW and NACO, 2007; TANSACS, Government of Tamil Nadu, 2006). During 2005-06, the HIV prevalence rate in the state was reported to be $0.39 \%$ for females aged $15-49$ and $0.27 \%$ for males aged $15-54$; the corresponding rates for India are $0.22 \%$ and $0.36 \%$ (IIPS and Macro International, 2007a).

\subsection{Situation of youth in Tamil Nadu}

Young people aged $10-24$ constituted a total of 18 million, accounting for $29 \%$ of the state's population in 2001. The youth population, that is, those aged 15-24, numbered 12 million in 2001, accounting for about $19 \%$ of the state's population (Office of the Registrar General and Census Commissioner, 2001a).

The state government has made concerted efforts to bring education within the reach of all. Hence, not surprisingly, educational attainment levels among youth are higher in Tamil Nadu than for India as a whole, and gender differences in enrolment are relatively narrow. In Tamil Nadu, among young people (aged $10-24$ ), $94 \%$ of men and $87 \%$ of women were literate in 2001 (Office of the Registrar General and Census Commissioner, 2001d). Data on gross enrolment ratios also highlight the state's achievement in the educational field; the gross enrolment ratio among children aged 6-11 years was $118 \%$ in $2004-05$, indicating that primary school enrolment was nearly universal. The corresponding figures for 11-14 year-olds and 14-16 year-olds 
were $107 \%$ and $81 \%$, respectively. The Gender Parity Index (GPI) at the elementary, secondary and higher secondary levels of education indicates that learning opportunities are nearly equally available to boys and girls in the state; the GPI score ranged from 0.97 at the elementary level to 0.98 at the secondary and higher secondary level in 2004-05 (Ministry of Human Resource Development, 2007).

However, as elsewhere in the country, unemployment rates in Tamil Nadu were much higher among young people than among the general population discussed above. For example, among the population aged 15-29, unemployment rates, as measured in terms of usual principal status, were $4.7 \%$ and $7.5 \%$ among young men in rural and urban settings, respectively, during 2004-05; the corresponding rates for young women were $5.6 \%$ and $13.4 \%$ (NSSO, 2006).

Evidence currently available on the sexual and reproductive health profile of young people in Tamil Nadu indicates their vulnerability. For example, behavioural surveillance surveys and small-scale studies report that sexual risk taking before or within marriage is not unknown among young people in the state. The recent National Behavioural Surveillance Survey reports that in Tamil Nadu, some 16\% and 6\% of young men and young women, respectively, aged 15-24 had engaged in sexual intercourse with a non-regular partner in the 12 months preceding the survey, and of these, just $32 \%$ had used condoms consistently with their non-regular partner(s) (National Institute of Medical Statistics and NACO, 2008). Moreover, for significant minorities of young women, sexual relations are initiated early even though within the context of marriage. Data from the recent NFHS show that in Tamil Nadu over one in five women aged 20-24 were married by age 18; in comparison, just $8 \%$ of men aged $25-29$ were married by age 21 . Also, $8 \%$ of $15-19$ year-old girls in the state have begun childbearing (IIPS and Macro International, 2008).

Studies have also documented young people's vulnerability to reproductive tract infections (RTIs) or sexually transmitted infections (STIs) in the state. According to a community-based study of the prevalence of RTIs and STIs among married young women aged 16-22 in rural settings, 38\% were diagnosed with an RTI and $15 \%$ were diagnosed with an STI following laboratory examination/testing (Prasad et al., 2005). In another community-based study of STIs among young women and men, 16-17\% of youth were diagnosed with an STI (Voluntary Health Services, 1998). Moreover, the NFHS-3 reports an HIV prevalence rate of $0.24 \%$ among 15-24 year-old women; however, no positive cases were reported among young men (IIPS and Macro International, 2007a).

Available evidence also suggests that young people's knowledge of sexual and reproductive health matters tends to be limited. For example, data from the NFHS-3 indicate that only $14 \%$ of young women and $41 \%$ of young men had comprehensive knowledge of HIV/AIDS (IIPS and Macro International, 2007a).

\subsection{Youth-related policy and programme environment in Tamil Nadu}

The Tamil Nadu state government's commitment to meeting the multiple needs of young people is evident from the large number of programmes being implemented for youth in the state. For example, the state has introduced several incentive schemes to promote universal secondary education, including the provision of free text-books to students enrolled in government schools, government-aided schools and Tamil-medium self-financing schools; the provision of free bicycles to students of Class 11; and the provision of subsidised or free bus passes to school students. Additionally, the state government has made budget allocations for implementing the Scheme for Universal Access and Quality at the Secondary Stage, a centrally-assisted scheme intended to provide high quality secondary education to all girls and boys in the state up to the age of 16 by 2015, and higher secondary education to young people up to the age of 18 by 2020 (Department of School Education, Government of Tamil Nadu, 2008). Likewise, in order to improve the employability of young people, 
the state government has proposed to introduce at school level computer-aided language and mathematics laboratories to develop the spoken English and numerical skills of students (Department of School Education, Government of Tamil Nadu, 2008). The state government has also launched a self-help group scheme for young people; as of March 2008, approximately 20,000 youth self-help groups have been set up under the scheme (Department of Rural Development and Panchayat Raj, Government of Tamil Nadu, 2008).

The Tamil Nadu state government has also implemented several programmes to impart information on sexual and reproductive health to young people, including the School AIDS Education Programme for school children, the Red Ribbon Club programme for college students and a corresponding programme in collaboration with the State Resource Centre for out-of-school youth (Department of Health and Family Welfare, Government of Tamil Nadu, 2008). The School AIDS Education Programme, launched in 1997, covers students in Classes 9 and 11; in 2006-07, the programme had been introduced in 9,423 schools in the state. The Red Ribbon Club programme aims to reduce the spread of HIV among youth by building awareness about HIV/AIDS among young people, imparting life skills and enabling youth to assess their risk and thereby adopt safe behaviours. Almost 700,000 students have been reached through this programme.

Programmes specifically targeting adolescent girls have also been implemented in the state. For example, the Kishori Shakthi Yojana has been implemented in all Integrated Child Development Services (ICDS) blocks in the state. Under this scheme, camps are organised for girls aged 11-15 to build awareness regarding nutrition and health, legal rights, home management and child care; and vocational training programmes are organised for girls aged 16-18 (Department of Social Welfare and Nutritious Meal Programme, Government of Tamil Nadu, 2008).

\subsection{Study phases}

The Youth Study comprised three phases and included both a survey and qualitative data gathering exercises.

\subsubsection{Pre-survey qualitative phase}

As the Youth Study was one of the first of its kind in India, precedents did not exist for youth terminologies, particularly in reference to sensitive issues (romantic relationships, sexual experience and so on), youth perceptions or youth willingness to share their experiences with study teams. In order to better understand these matters and to inform the design of the survey instrument, focus group discussions were conducted with married and unmarried young women and men, and key informant interviews conducted with teachers, health care providers, and community and youth leaders, in the first phase of the Youth Study. This phase also offered us an opportunity to explore community reactions to the kinds of issues to be raised by the survey.

In the course of this pre-survey qualitative phase, we also conducted in-depth interviews with parents of youth to collect parental perspectives on young people's situation and needs. In each site, eight categories of parents were selected (mothers and fathers of married and unmarried young men and women, respectively). The discussion focused on the life experiences of the child of interest.

The pre-survey qualitative phase was undertaken during July-September 2005 and covered at least one urban area and one rural area in all five regions of the state. In total, 16 focus group discussions were held with young people; 43 key informant interviews were held with community leaders, health care providers, teachers and youth leaders; and 60 in-depth interviews were held with mothers and fathers. 


\subsubsection{Survey phase}

Fieldwork was undertaken between May 2006 and January 2007. A total of 7,996 married and unmarried young women and men were interviewed during this phase.

\subsubsection{Post-survey qualitative phase}

In order to better understand the sexual and reproductive experiences of youth and the factors inhibiting and facilitating safe transitions to these behaviours, in-depth interviews were conducted with consenting survey respondents who reported certain experiences in the course of the survey interview. These experiences included, notably, having an opposite-sex romantic partner; having sexual relations with an opposite-sex romantic partner; experiencing same-sex, forced or exchange sexual relations; and among young men, engaging in relations with sex workers or married women. Among the married, in addition, experiences included exercising choice in spouse selection and practising contraception to delay the first pregnancy.

At the conclusion of the survey interview, interviewers sought the consent of respondents for an in-depth interview. Those who consented were then approached by a trained investigator who conducted the interview in the form of an unstructured conversation. In-depth interviews therefore took place at around the same time as did the survey. A total of 62 in-depth interviews were completed, 41 from among rural respondents and 21 from among urban respondents. Findings from the survey are presented in this report. ${ }^{1}$

\subsection{Study instruments}

\subsubsection{Interview guidelines}

For the pre-survey qualitative phase, three sets of guidelines were prepared for focus group discussions, key informant interviews and in-depth interviews, respectively. These guidelines were appropriately modified for each youth group (married and unmarried young women and men) and parent group (mothers and fathers of married and unmarried young women and men). As mentioned above, specific guidelines were not prepared for the post-survey in-depth interviews with youth reporting selected behaviours; instead, interviewers were trained to steer the interview to focus on the experience of interest, and obtain information on the circumstances surrounding the experience and the respondent's own perceptions about the experience.

\subsubsection{Questionnaires}

A total of six questionnaires were developed for the study: a community questionnaire; a household questionnaire, administered in each selected household; and four individual questionnaires, one each for married young men, married young women, unmarried young men and unmarried young women. The community questionnaire was administered in each village selected for the survey. This questionnaire collected information on different aspects of village life, including the village population, numbers engaged in agriculture, and the availability of various facilities and infrastructure in and around the village. Team supervisors administered the questionnaire to one or more individuals from each village who were well-informed about the village.

\footnotetext{
${ }^{1}$ Separate reports, drawn from in-depth interviews with parents and youth, respectively, will discuss parental perspectives on young people's experience of growing up and provide insights on the sexual and reproductive experiences of youth, as well as the factors inhibiting and facilitating safe transitions to these behaviours.
} 
The household questionnaire listed all usual residents of the selected households and collected basic information on each listed household member, including his or her age, sex, marital status, relationship to the head of the household, education and current activity status. Information was also obtained on the religion and caste of the head of the household as well as on ownership of the residential structure and agricultural land, number of rooms in the residence, and such amenities available as type of toilet facility, main source of lighting, main type of cooking fuel and main source of drinking water. The survey also inquired about ownership of 17 consumer durables. Finally, information was sought on marriages of any usual resident of the household in the three years preceding the interview as well as the sex and age of the person at the time of marriage.

The development of individual questionnaires was informed by other survey instruments, notably the World Health Organisation core questionnaire for youth surveys (Cleland, 2001) and a recent survey conducted in Pune district on the formation of partnerships among youth (Alexander et al., 2003). Other instruments consulted included surveys of youth conducted in India (Andrew, Patel and Ramakrishna, 2003; IIPS and Population Council, 2002; Sebastian et al., 2003), Pakistan (Sathar et al., 2003), the Philippines (DRDF and UPPI, 2002), Vietnam (Mensch, Anh and Clark, 2000) and sub-Saharan Africa (Guttmacher Institute, 2004a; 2004b; 2004c). Finally, our survey instrument drew upon the questionnaire used in the NFHS-3 (IIPS and Macro International, 2007b).

The development of individual questionnaires was also informed by insights obtained in the pre-survey qualitative phase. Once the pre-survey qualitative phase was completed in all six states, the data generated were analysed to identify the kinds of issues that would be explored in the survey, ways of presenting sensitive issues, and terminologies to be used that would be comprehensible and acceptable to youth. The survey instrument was finalised after extensive pre-testing in several states.

Individual questionnaires were employed to interview eligible youth who usually resided in selected households. Currently married young men and women aged 15-29 and 15-24, respectively, as well as unmarried young men and women aged 15-24, were eligible for interview. Widowed and divorced individuals were excluded from the survey. Keeping in mind the sensitive nature of the questions, the questionnaire was divided into several sections and arranged in such a way that the most sensitive questions were administered towards the middle of the interview. This strategy of asking a series of non-sensitive questions in the early part of the interview served two purposes: it enabled the interviewer and respondent to build rapport before sensitive questions were posed and it permitted the investigator to maintain privacy for sensitive questions, as interested bystanders would usually depart while questions in the early sections were posed. The individual questionnaires collected information on the following topics:

Background characteristics: Questions were asked regarding age, education and schooling, quality of school or college attended, work patterns including housework and paid employment, vocational training, short-term migration and characteristics of parents.

Additionally, a Life Event Calendar (LEC), adapted from that used in a nationally representative survey of adolescents and youth in Pakistan (Sathar et al., 2003), was administered to obtain information on education, work, living arrangements, marriage and family building (for married respondents), starting from the age of 12. This system of recording life events is considered one of the most effective approaches to minimise recall error.

Media exposure: Respondents were asked about whether they were exposed to newspapers, television or the internet, and whether they watched pornographic films or read pornographic magazines. They were also asked about their views on the influence of films and television on their own life as well as young people's lives in general. 
Puberty: In order to assess the age at which puberty was experienced, respondents were asked to report their age at key signs of maturation. Young women, therefore, were questioned about their first menstruation while young men were asked about the onset of voice change and growth of pubic hair.

Parental interaction/relationship: Detailed questions were asked on the extent of parent-child communication on everyday activities as well as sexual and reproductive issues. Questions were also asked that assessed the extent to which a respondent had witnessed parental violence or been the victim of violence perpetrated by a parent while growing up.

Communication, mobility and decision-making: This section collected information on the person with whom youth were most likely to confide matters related to getting a job, growing up, boy-girl relationships and personal problems. Detailed questions were also asked on decision-making and, for all groups except married males, mobility.

Gender and self-efficacy: In order to evaluate the respondent's gender role attitudes and level of self-efficacy, questions were asked to probe opinions about a range of gender-related issues, such as, for example, the importance of boys' vis-à-vis girls' education, housework and freedom of movement.

Awareness of sexual and reproductive matters: This section probed young people's awareness about sexual relations, pregnancy, contraceptive methods, HIV/AIDS and STIs as well as the legal minimum age at marriage and conditions under which abortion is legally permitted in India. This section also probed young people's sources of information on sexual matters and contraception, the extent to which they had obtained formal sex or family life education, and their experiences and perceptions about this education.

Connectedness and friendship: Questions relating to connectedness and friendship explored respondents' friendship networks among those of the same sex and activities in which they participated with their friends. This was followed in a gradual fashion by questions on interaction with the opposite sex, whether or not the respondent had exchanged a "proposal" of romantic partnership with someone of the opposite sex and whether the respondent had ever met someone of the opposite sex secretly in a number of likely places.

Pre-marital romantic heterosexual relationships: This was a highly sensitive section, conducted only if complete privacy was assured. The section started by probing the pre-marital romantic and sexual experiences of up to five of the respondent's best friends. This technique, known as anonymous third-party reporting (developed by Rossier, 2003), was used to assess the extent to which youth were more likely to report the romantic and sexual relationships of their peers than of themselves. Respondents were then asked about their own experiences of pre-marital romantic partnership and, if reported, detailed questions were asked on the nature of such relationships with the first partner and the last or most recent partner (if more than one partner was reported). Questions were designed to gradually probe sensitive behaviours, for example, starting with whether the respondent had ever held hands with a romantic opposite-sex partner, and continuing with questions on hugging, kissing and finally having sex with the partner. We believe this gradual progression of questions was more culturally appropriate than a single question on pre-marital sex and provided insights into the range of behaviours youth experienced. If sex with a pre-marital romantic partner was reported, a host of questions followed that probed the consensuality of first sex with this partner, condom use, frequency of such relations and experience of pre-marital pregnancy. Questions were also asked about the characteristics of the romantic partner and parental awareness and reactions to the romantic relationship.

Marriage process: In this section questions covered marriage planning, dowry, the participation of the respondent in decision-making related to marriage and the respondent's feelings about his or her own marriage. This section was administered, suitably modified, to both married and unmarried respondents. 
Married life: Married respondents were asked detailed questions on married life. These included the nature of marriage (love or arranged), acquaintance with spouse before marriage and age at cohabitation. Questions about the marital relationship were also covered, including spousal communication and joint decision-making, the nature of the first sexual experience with spouse, experience of forced sex within marriage, inter-spousal violence, pregnancy experiences and outcomes, and contraceptive practice.

Same-sex, paid and forced sexual experiences: This was a second highly sensitive section in which respondents were asked a series of questions on their personal experience of several types of sexual encounters, for example, paid or exchange sex, forced sex perpetrated on the respondent and casual sex. In the case of male respondents, additional questions were asked about sex with a same-sex partner, relations with sex workers and married women (other than their wife for married males) and whether they had ever perpetrated forced sex. All married respondents were also asked about the experience of extra-marital sexual relations. Respondents who reported any of these experiences were probed about their age at their first experience of such a sexual encounter and the extent to which they had used condoms in these encounters.

Attitudes: This section probed respondents' views on pre-marital physical intimacy and wife beating.

Health and health seeking: This section collected information on respondents' experience of common health problems, specifically high fever and injury, as well as symptoms of genital infections in the three months preceding the interview. In addition, respondents were asked whether they had sought treatment for these health issues and, if so, from what source. Respondents' mental health in the last one month was assessed using the 12-item General Health Questionnaire, developed for use in field conditions (Goldberg, 1992).

Substance use and violence: A series of questions were asked about consumption of tobacco products, alcohol or drugs. In each case, questions were asked about use and frequency of use of such substances by family members and by the respondents themselves. Additional questions sought respondents' assessments of the frequency with which young people in their neighbourhood engaged in violence (fights or beatings) and their own participation in such violence.

Programmes and participation: The final section of the questionnaire collected information on programmes available to young people in the village or neighbourhood in which they resided, and the extent to which youth participated in such programmes. In addition, rural respondents were asked about the role of panchayats in decisions affecting young people's lives. All respondents were asked about their participation in community activities, opinions about political issues, secular attitudes and participation in recent elections. Finally, respondents were asked to identify the most important problem facing youth in their village or neighbourhood.

Sealed envelope response: However carefully designed and culturally sensitive the survey questions may have been, the possibility that young people would deliberately withhold information about their sexual experiences in a face-to-face interview could not be discounted. Drawing from other research in the field, an anonymous reporting method was included in our survey to obtain responses to a single question: Have you ever had sex with anyone [for the unmarried]/Did you ever have sex with anyone before marriage [for the married]? Interviewers first explained the technique to respondents, noting in particular its confidential nature. The

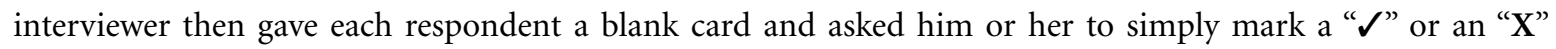
on the card to indicate that he/she had or had not experienced pre-marital sex. Once marked, the respondent placed the card inside an envelope provided by the interviewer; the envelope was sealed by the respondent and returned to the interviewer. Unique identification numbers linked the individual's questionnaire with his or her responses in the sealed envelope. Envelopes were opened only at the central office at the time of data entry. 
Draft tools were extensively reviewed at meetings of the study's Technical Advisory Committee and were then translated into four languages (Hindi, Marathi, Tamil and Telugu), extensively pre-tested and finalised after appropriate modification. Copies of all these instruments are provided in the CD enclosed with this report.

\subsection{Study design and sample size estimation for individual interviews}

The Youth Survey was designed to provide estimates for the state as a whole, as well as for urban and rural areas for each of the four categories of respondents, namely married and unmarried young men and women, separately. The study was not designed to provide estimates at district or sub-district levels.

While arriving at sample size estimates, on the basis of the scarce available evidence, the following assumptions were made:

- $10 \%$ of unmarried young women would report the experience of pre-marital sexual relations;

- Among married men, 20\% would report unsafe sexual relations (multiple partner sex or non-use of condoms, unintended pregnancy or experience of STI symptoms);

- The coefficient of variation was set at $10 \%$ (equivalent to fixing the absolute error at $20 \%$ of the true value and $95 \%$ confidence interval);

- The non-response rate for the individual interviews was assumed to be $25-30 \%$;

- Design effect was assumed to be in the range of 1.5 to 2 .

The chances of finding an unmarried young man were greater than the chances of finding a married young man in a given household, and conversely, the chances of finding a married young woman were greater than the chances of finding an unmarried young woman. As a result, in the case of the male sample, our strategy was to estimate the number of households required to obtain the target number of married young men aged 15-29, that is, the harder to reach group of males. Similarly, in the case of the female sample, the strategy was to identify the total number of households required based on the target number of unmarried young women aged 15-24, again, the harder to reach group of females.

Following from the assumptions described above, and in consultation with the study's Technical Advisory Committee, the required sample of each sub-group of youth was determined at 1,000 married young men, 1,250 unmarried young men, 1,250 married young women and 1,750 unmarried young women each for urban and rural areas, that is, a total sample size of 5,250 in each area. ${ }^{2}$ However, our early experience suggested that because of the considerable mobility of youth, there was likely to be a shortfall in achieving these numbers. Hence, in Tamil Nadu, the sample size in both rural and urban areas was revised to 1,200 married young men, 1,500 unmarried young men, 1,500 married young women and 2,100 unmarried young women, that

${ }^{2}$ In estimating the number of households required, the study used the age-sex-marital status distributions observed in rural and urban areas, respectively, in the 2001 Census. The following formula was used to estimate sample size:

$$
\text { Coefficient of Variation } \begin{aligned}
(c v) & =\sqrt{\frac{q}{n p}} \\
n & =\frac{q}{c v^{2} p}
\end{aligned}
$$

In order to obtain the actual number of respondents, the above numbers were multiplied by the design effect and a factor ' $K$ ' $(1+$ the non-response rate). 
is, a total sample size of 6,300 in each area. In order to achieve the above-mentioned number of individual interviews, an estimated 34,000 households were required to be covered in Tamil Nadu.

We further determined that a total of 300 primary sampling units (PSUs) — villages in rural areas and Census Enumeration Blocks (CEBs) in the urban areas-divided into 150 female PSUs and 150 male PSUs, would be visited in order to conduct interviews in the required number of households. Thus, the average number of household interviews to be conducted in each rural PSU was calculated to be 123 among female PSUs and 109 among male PSUs. Corresponding averages for each urban PSU were 105 and 116, respectively.

\subsubsection{Sample selection strategy}

The study treated rural and urban areas of each state as independent sampling domains and, therefore, drew sample units independently for each of these two domains. In order to avoid potential risks associated with interviewing both women and men from the same PSU, we decided to conduct interviews in separate PSUs for female and male respondents, that is, interviews with young women in 150 PSUs and young men in the remaining 150 PSUs. These 150 PSUs were further divided equally into rural and urban areas, that is, 75 for rural respondents and 75 for urban respondents. Within each sampling domain, a systematic, multi-stage stratified sampling design was adopted. Sample selection procedures differed somewhat in rural and urban areas, as described below.

\subsection{1.a Selection of households in rural areas}

In rural areas, the 2001 Census list of villages served as the sampling frame for the selection of villages. This list was stratified using four variables, namely, region, village size, proportion of the population belonging to scheduled castes and scheduled tribes, and female literacy. At the first level of stratification, the state of Tamil Nadu was stratified into five contiguous geographical regions, with districts (as defined in the 2001 Census) classified into these regions as follows:

Region I: $\quad$ Coimbatore, Dindigul, Madurai, Erode, the Nilgiris, Theni

Region II: Vellore, Dharmapuri, Thiruvannamalai, Salem, Tiruchirappalli, Karur, Perambalur, Ariyalur, Namakkal

Region III: $\quad$ Kanniyakumari

Region IV: Kancheepuram, Thiruvallur, Cuddalore, Villupuram, Thanjavur, Nagapattinam, Thiruvarur, Chennai

Region V: $\quad$ Pudukottai, Sivaganga, Virudhunagar, Ramanathapuran, Thoothukudi, Tirunelveli

In each region, except Region III, villages were further stratified by village size and the percentage of the population belonging to scheduled castes or scheduled tribes. Region III was smaller than all the other strata and hence was not further stratified. Table 1.1 gives detailed information on the stratification scheme in rural areas along with the population in each stratum. The last level of stratification was implicit for all strata, consisting of an ordering of villages within each stratum by level of female literacy, ordered alternatively in increasing and decreasing level of female literacy (obtained from the 2001 Census Village Directory).

The sample in rural areas was selected in two stages. At the first stage of selection, villages were selected systematically from the stratified list arranged as described above, with selection probability proportional to size (PPS). The 150 PSUs thus selected were then ordered by district and taluka codes and numbered from 1 to 150. Odd-numbered PSUs were designated for interviews with young men and even-numbered PSUs for interviews with young women. In the case of male PSUs, selected PSUs containing fewer than 75 households 
were then linked to one or more adjoining villages so that the PSU had approximately 75 households. In the case of female PSUs, selected PSUs containing fewer than 200 households were linked to one or more adjoining villages so that the PSU had approximately 200 households. Those containing more than 300 and fewer than 601 households were segmented into two approximately equal parts, and one was chosen randomly for the survey. In the case of even larger villages, that is, those containing more than 600 households, segments of 150-200 households were made and numbered in a clockwise manner. Two segments were then selected using probability proportional to size.

Table 1.1: Sampling stratification scheme

Details of the stratification used for sampling, Tamil Nadu (rural), 2006

\begin{tabular}{|c|c|c|c|c|}
\hline \multirow{2}{*}{$\begin{array}{l}\text { Stratum } \\
\text { number }\end{array}$} & \multicolumn{3}{|c|}{ Stratification variables } & \multirow{2}{*}{$\begin{array}{c}\text { Total } \\
\text { population }\end{array}$} \\
\hline & Region & $\begin{array}{l}\text { Village size (number of } \\
\text { residential households) }\end{array}$ & $\begin{array}{c}\text { Percent of SC/ST } \\
\text { population }\end{array}$ & \\
\hline 1 & 1 & $\leq 6,800$ & $\leq 21$ & $2,082,881$ \\
\hline 2 & 1 & $\leq 6,800$ & $>21$ & $1,974,114$ \\
\hline 3 & 1 & $>6,800$ & NA & $1,969,569$ \\
\hline 4 & 2 & $\leq 2,750$ & $\leq 24$ & $1,930,008$ \\
\hline 5 & 2 & $\leq 2,750$ & $>24$ & $1,987,593$ \\
\hline 6 & 2 & $>2,750 \& \leq 4780$ & $\leq 20$ & $1,926,945$ \\
\hline 7 & 2 & $>2,750 \& \leq 4,780$ & $>20$ & $2,031,421$ \\
\hline 8 & 2 & $>4,780$ & $\leq 18$ & $2,030,548$ \\
\hline 9 & 2 & $>4,780$ & $>18$ & $1,942,888$ \\
\hline 10 & 3 & NA & NA & $5,82,107$ \\
\hline 11 & 4 & $\leq 2,000$ & $\leq 38$ & $2,019,151$ \\
\hline 12 & 4 & $\leq 2,000$ & $>38$ & $2,042,344$ \\
\hline 13 & 4 & $>2,000 \& \leq 4,450$ & $\leq 30$ & $2,003,034$ \\
\hline 14 & 4 & $>2,000 \& \leq 4,450$ & $>30$ & $2,102,081$ \\
\hline 15 & 4 & $>4,450$ & NA & $2,034,061$ \\
\hline 16 & 5 & $\leq 4,500$ & $\leq 19$ & $2,083,367$ \\
\hline 17 & 5 & $\leq 4,500$ & $>19$ & $2,076,473$ \\
\hline 18 & 5 & $>4,500$ & NA & $2,041,409$ \\
\hline Total & NA & NA & NA & $34,277,887$ \\
\hline
\end{tabular}

Note: The level of female literacy (2001 Census) was used for implicit stratification. Villages with less than 50 households in the 2001 Census were excluded from the sampling frame. NA: Not applicable. SC: Scheduled caste. ST: Scheduled tribe. ${ }^{1} 2001$ Census population. 
The rural domain sampling fraction for a particular category, that is, the probability of selecting an eligible respondent of a particular category in rural Tamil Nadu $\left(f^{R}\right)$, was computed as:

$$
f^{R}=\frac{n^{R}}{N^{R}}
$$

where
$\mathrm{n}^{\mathrm{R}}=$ number of eligible respondents in a particular category to be interviewed (target number of interviews as described before), and
$\mathrm{N}^{\mathrm{R}}=$ projected rural population of eligible respondents in the state as of October 1, 2006.

The probability of selecting a PSU from rural Tamil Nadu $\left(f_{1}^{R}\right)$ was computed as:

$$
f_{1}^{R}=\frac{a \times v_{i}}{\sum v_{i}}
$$

where

$$
\begin{aligned}
& \mathrm{a}=\text { number of PSUs selected from rural areas for the particular category, } \\
& \mathrm{v}_{\mathrm{i}}=\text { population of the } \mathrm{i}^{\text {th }} \text { PSU, and } \\
& \sum \mathrm{v}_{\mathrm{i}}=\text { total rural population of the state. }
\end{aligned}
$$

A complete mapping and household listing operation was carried out in each selected PSU (or in selected segments or linked villages as appropriate). This list of households provided the necessary frame for selecting households at the second stage. Mapping and listing were conducted by teams, each comprising one mapper and one lister. Households to be interviewed were selected with equal probability from the list using systematic sampling.

The probability of selecting a household from a selected rural PSU $\left(f_{2}^{R}\right)$ was calculated as:

$$
f_{2}^{R}=\frac{f^{R}}{f_{1}^{R}}
$$

No replacement for selected households was allowed even if a selected household could not be contacted after several attempts.

All the sampling fractions $\left(f^{R}, f_{1}^{R}, f_{2}^{R}\right)$ described above were computed separately for male and female PSUs on the basis of the target sample of married males and unmarried females, respectively.

Because we expected more unmarried than married males in our age groups, we needed to visit fewer households to obtain the required number of unmarried compared to married males. Likewise, because we expected more married than unmarried females, we needed to visit fewer households to obtain the required number of married compared to unmarried females. Appropriate intervals were computed to operationalise each of these selection processes. 


\subsection{1.b Selection of households in urban areas}

In selecting the urban sample, the 2001 Census list of wards (each consisting of several CEBs of 100-200 households) provided the sampling frame. For operational convenience, the Youth Study first determined male PSUs (equivalent to a CEB) and followed this with the selection of female PSUs (another CEB) in CEBs adjacent to male CEBs. As a result, half the total required number of PSUs was first selected.

In urban areas, the 2001 Census list of wards was first arranged by district, and within each district by level of female literacy. The sample was then selected in three stages. At the first stage of selection, 75 wards were selected systematically with probability proportional to size. At the second stage, within each selected ward, CEBs were arranged by their administrative number and one CEB (designated as a male PSU) was selected using probability proportional to size. For each selected male CEB, an adjacent CEB was chosen to represent the female PSU in the same ward.

The urban domain sampling fraction for a particular category, that is, the probability of selecting an eligible respondent of a particular category in urban Tamil Nadu $\left(f^{U}\right)$, was computed as:

$$
f^{U}=\frac{n^{U}}{N^{U}}
$$

Where

$$
\begin{aligned}
\mathrm{n}^{\mathrm{U}}= & \begin{array}{l}
\text { number of eligible respondents in a particular category to be interviewed in urban areas (target } \\
\text { number of interviews as described before), and }
\end{array} \\
\mathrm{N}^{\mathrm{U}}= & \text { projected urban population of eligible respondents in the state as of October 1, } 2006 .
\end{aligned}
$$

The probability of selecting a ward (or section) from urban Tamil Nadu $\left(f_{1}^{U}\right)$ was computed as:

$$
f_{1}^{U}=\frac{a \times w_{i}}{\sum w_{i}}
$$

where

$$
\begin{aligned}
& \mathrm{a}=\text { number of wards selected from urban areas for the particular category, } \\
& \mathrm{w}_{\mathrm{i}}=\text { population of } \mathrm{i}^{\text {th }} \text { ward, and } \\
& \sum \mathrm{w}_{\mathrm{i}}=\text { total urban population of the state. }
\end{aligned}
$$

The probability of selecting a CEB from a selected ward $\left(f_{2}^{U}\right)$ was computed as:

where

$$
f_{2}^{U}=\frac{c_{i}}{\sum c_{i}}
$$

$$
\begin{aligned}
& \mathrm{c}_{\mathrm{i}}=\text { population of } \mathrm{i}^{\text {th }} \text { CEB from a selected ward, and } \\
& \sum \mathrm{c}_{\mathrm{i}}=\text { total population of the selected ward. }
\end{aligned}
$$

A complete mapping and household listing operation was carried out in each selected PSU and the resulting list provided the necessary frame for selecting households at the third stage. Households to be interviewed were selected with equal probability from the list using systematic sampling. In some CEBs the number of 
households listed was smaller than the minimum expected number of households, and in such cases, a part of an adjacent CEB was listed.

The probability of selecting a household from a selected urban PSU $\left(f_{3}^{U}\right)$ was calculated as:

$$
f_{3}^{U}=\frac{f^{U}}{f_{1}^{U} \times f_{2}^{U}}
$$

As in the case of rural areas, (a) no replacement of selected households was allowed under any circumstances; (b) all sampling fractions $\left(f^{U}, f_{1}^{U}, f_{2}^{U}, f_{3}^{U}\right)$ were computed separately for male and female PSUs on the basis of the target sample of married males and unmarried females, respectively; and (c) appropriate intervals were computed to enable us to select fewer households for the interview of unmarried compared to married males and married compared to unmarried females.

\subsubsection{Selection of individual respondents within selected households}

In each PSU, households to be interviewed were selected by systematic sampling. The value of the interval (between one selected household and the next) was determined in advance to ensure a self-weighing design. As mentioned earlier, fewer households needed to be selected in order to obtain our sample of unmarried males and married females. Hence, further intervals were computed, using the target sample for unmarried males and married females.

Within each selected household, no more than one married and one unmarried respondent was interviewed, resulting in a maximum of two interviews from any household. In case more than one respondent from a single category was found in the household, one respondent was selected randomly using the Kish table. ${ }^{3}$ No replacement of the respondent thus selected was allowed.

\subsubsection{Sample weights}

In Tamil Nadu, the sample was weighted at the level of the sampling domain, that is, urban and rural males and females, respectively, making for a total of four sampling domains. In order to consider differential nonresponse rates in different geographical areas, non-response rates were calculated in smaller sub-domains of 2-3 PSUs within each domain. If $\mathrm{W}_{\mathrm{Di}}$ is the design weight for the $\mathrm{i}^{\text {th }}$ domain $(\mathrm{i}=1 \ldots 4)$ and $\mathrm{R}_{\mathrm{Hij}}$ is the response rate for households in the $\mathrm{j}^{\text {th }}$ sub-domain within the $\mathrm{i}^{\text {th }}$ domain, then the household weight for the $\mathrm{j}^{\text {th }}$ sub-domain within the $\mathrm{i}^{\text {th }}$ domain $\left(\mathrm{W}_{\mathrm{Hij}}\right)$ was calculated as follows:

$$
W_{H i j}=\frac{W_{D i}}{R_{H i j}}
$$

where $\mathrm{W}_{\mathrm{Di}}$ was calculated as the inverse of the probability of selecting an eligible married male in urban and rural male domains, respectively; and similarly, of selecting an eligible unmarried female in urban and rural female domains.

\footnotetext{
${ }^{3}$ The probability of selection of individuals in rural areas is $\left(f^{R} / K_{i}^{R}\right)$ and in urban areas $\left(f^{U} / K_{i}^{U}\right)$, where $K_{i}^{R}$, and $K_{i}^{U}$ denote the number of individuals of the specified category (married and unmarried males and females, respectively) in the $i^{\text {th }}$ selected household in rural and urban areas, respectively.
} 
Weights were also calculated for eligible married males and unmarried females, denoted by $\mathrm{W}_{\mathrm{Eij}}$ and calculated as follows:

$$
W_{E i j}=\frac{W_{D i}}{R_{H i j} \times R_{E i j} \times K_{i j}}
$$

where

$$
\begin{aligned}
\mathrm{R}_{\mathrm{Eij}}= & \text { response rate for married males or unmarried females in the } \mathrm{j}^{\text {th }} \text { sub-domain within the } \mathrm{i}^{\text {th }} \\
& \text { domain, and } \\
\mathrm{K}_{\mathrm{ij}}= & \text { probability that a married male or an unmarried female is selected by the Kish table procedure } \\
& \text { in the } \mathrm{j}^{\text {th }} \text { sub-domain within the } \mathrm{i}^{\text {th }} \text { domain. }
\end{aligned}
$$

The design weight described above was also used in the case of unmarried males and married females in each domain. Also, since the survey did not attempt to interview an unmarried male or a married female in all selected households, an additional interval needed to be incorporated in the weight calculation. Hence, weights for eligible unmarried males and married females, denoted by $\mathrm{W}_{\mathrm{Eij}}$ were calculated using the following equation:

$$
W_{E i j}=\frac{W_{D i}}{R_{H i j} \times R_{E i j} \times K_{i j}} \times I_{i}
$$

where $I_{i}$ is the interval at which selected households were assigned for the interview of a married female (in female PSUs) or an unmarried male (in male PSUs) in the $\mathrm{i}^{\text {th }}$ domain.

The weights were then normalised so that the total number of cases was unchanged after weighting. Hence, the normalised weights for households and eligible respondents were:

$$
\begin{aligned}
& W_{H i j}^{\prime}=\frac{\sum n_{i j}}{\sum W_{H i j} \times n_{i j}} \times W_{H i j} \\
& W_{E i j}^{\prime}=\frac{\sum n_{i j}}{\sum W_{E i j} \times n_{i j}} \times W_{E i j}
\end{aligned}
$$

where $n_{i j}$ refers to the number of completed interviews in the $\mathrm{j}^{\text {th }}$ sub-domain within the $\mathrm{i}^{\text {th }}$ domain.

In order to provide estimates for all young males or females (married and unmarried), multiplication factors were computed for married and unmarried males and females (four categories) in urban and rural areas, which, when multiplied with existing individual weights, provided the combined weights for the male and female samples, respectively. For example, the multiplication factor for the male sample $\left(\mathrm{M}_{\mathrm{k}}^{1}\right)$ was computed as follows:

$$
M_{k}^{l}=\frac{\frac{p_{k}^{l}}{p^{l}}}{\frac{s_{k}^{l}}{s^{l}}}
$$


where

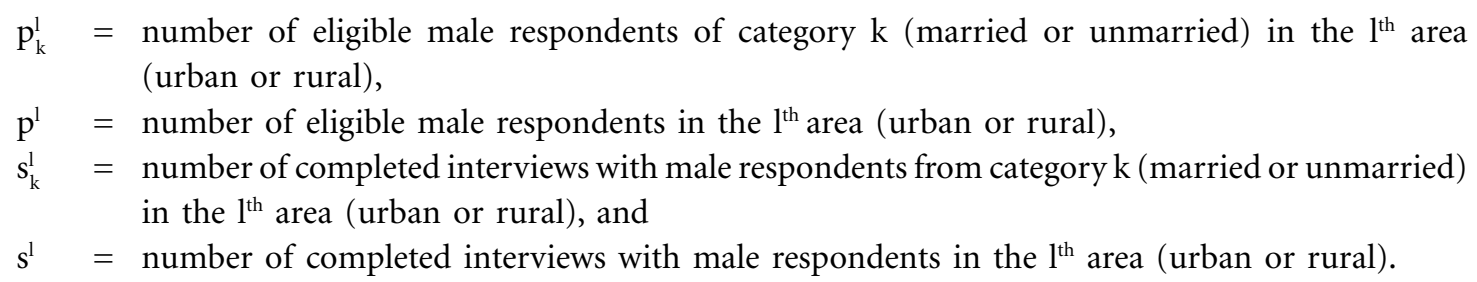

Similar fractions were computed for the female sample.

\subsection{Recruitment, training and fieldwork}

Some 40 young men and 40 young women underwent interviewer training. On the basis of their performance, 45 youth were recruited as field investigators. In addition, some 20 individuals were separately trained for mapping and house-listing exercises.

Training of interviewers was conducted jointly by principal investigators from IIPS and the Population Council. House-listing staff underwent a four-day training, during which trainees were familiarised with house-listing procedures in both classroom and field situations. Training for field investigators for the main survey lasted three weeks. It included lectures and interactive sessions on a range of issues, such as the sexual and reproductive health situation of youth in India, an overview of gender issues, ethical issues in research, violence against women, and mental health, as well as detailed explanations of sex and contraception. Efforts were also made to enable trainees to overcome their own inhibitions about discussing sexual and reproductive health matters. Trainees were provided opportunities to ask questions via an anonymous drop-box; questions were then answered in the course of training. Trainees were familiarised with each module of the questionnaire, complicated concepts and questions, and their underlying rationale. Role-plays and mock interviews were conducted in reference to each module. Towards the end of the training programme, field practice sessions were organised in which trainees were taken to a village and an urban slum setting and asked to conduct interviews. The training team monitored each trainee's progress on a regular basis and selected as interviewers only those trainees who demonstrated full understanding of the questionnaire as well as the ability to ask questions appropriately and record responses accurately.

Interviewers were divided into six teams, three each to interview young men and women, respectively. Male interviewers interviewed young men and female interviewers interviewed young women. Each team comprised one field editor to take care of field editing, back-checks and quality control of interviews; and one supervisor, responsible for the overall management of fieldwork and team-related logistics as well as assisting in field editing and back-checking. Interviewer and supervisor/editor manuals were prepared, translated into Tamil and provided to each team member as appropriate. These manuals clarified the meaning and appropriate coding of every question in the questionnaire.

Research officers were deputed to oversee fieldwork and ensure that correct survey procedures were followed and data quality maintained. Principal investigators from IIPS and the Population Council made monthly or bimonthly visits to monitor and supervise data collection operations. Each team filled quality control sheets regularly, giving the team, research officers and coordinators a quick view of the quality of ongoing fieldwork. These control sheets were designed to provide information on response rates in each PSU covered, track sensitive issue reporting and interviewer performance. 


\subsection{Ethical considerations}

As this was the first such study of its kind in India in which sensitive sexual and reproductive experiences were sought in a survey situation, it was unclear how youth respondents and community members would react. At the same time, it was clear that if youth participated in the interviews, its content was likely to prompt questions and problems for which support would be requested. A number of ethical issues arose which influenced the design and implementation of the Youth Study.

First, to address our concern that if interviews with young women and men were conducted in the same PSU, it could lead to teasing, harassment, harm to girls' reputations and even violence, we decided that the study would be undertaken in one set of PSUs for young men and in a completely different set for young women. Likewise, we also ensured that two unmarried brothers or sisters, two married brothers or sisters, or two sisters- or brothers-in-law would not be interviewed from the same household in case such a practice caused conflict within the family. Hence, just one individual from any category was selected for interview in each household. In case both a married and an unmarried individual were selected from a particular household, interviews were conducted separately but simultaneously.

Second, youth themselves contributed-albeit indirectly-to the development of the questionnaire. In the course of our pre-survey qualitative phase, youth and key informants informed our study teams of various youth behaviours; youth described the ways in which they referred to various sensitive behaviours and, in order to minimise discomfort during questioning, the scenarios and terminologies described by youth themselves were adapted for use in the most sensitive parts of our questionnaires.

Third, interviewers underwent extensive training in ethical issues. Emphasis was laid on explaining the content of the questionnaire, respondents' right to refuse to participate or answer any question and informed consent. At the same time, we trained interviewers on how to ask sensitive questions-regarding sexual experience, domestic violence and forced sex in particular-in empathetic and non-judgemental ways and emphasised the importance of offering to refer those in need to appropriate nearby organisations.

Fourth, before entering a PSU, teams were instructed to apprise community leaders of the study and seek their support for its implementation in the community. This step ensured that community support was forthcoming and enabled team members to build rapport within the community easily. We note that despite the sensitive nature of the questions, not a single PSU in Tamil Nadu refused permission to our teams on the grounds of study content.

Fifth, even though consent was sought from each individual to be interviewed, in the case of unmarried youth aged 15-17, consent was also sought from a parent or guardian.

Sixth, all questionnaires were anonymous and names were never recorded. In order to preserve the confidentiality of the respondent or the parent/guardian, signature on the consent form was optional; however, the interviewer was required to sign that she or he had explained the content of the consent form to the respondent or parent. Consent forms were detached and stored separately from the questionnaires.

Seventh, every effort was made to maintain privacy in the course of the interview. Interviewers were permitted to skip to relatively non-sensitive sections in case the interview was observed by parents or other family members. If possible, particularly in the case of young men, interviews were held outside the home-often in a nearby field-in order to ensure privacy. Each team was trained to assign one interviewer to conduct parallel discussion sessions with bystanders, thereby providing privacy to the interview. This proved particularly 
useful in the case of interviews with young women. Finally, interviewers were instructed that if privacy could not be ensured, the interview must be terminated without asking sensitive questions. Due to these strategies, few interviews had to be terminated for want of privacy and in no case was a young respondent's privacy breached.

Eighth, the study team realised that this was perhaps one of the first opportunities many youth would have to discuss intimate matters and that respondents might request information on sexual and reproductive issues or seek counselling or treatment for a health problem. In each state, therefore, the study team approached non-governmental organisations (NGOs) that conduct youth- or health-related activities at the district level and sought their consent for referring any youth in need to their organisation. Many NGOs agreed, and youth (and some adults) in need were later referred to these organisations, along with an indication that the individual had been part of the Youth Study. At the same time, research officers and team members themselves built rapport with public health authorities and referred to their facilities those who preferred to seek public services, again, along with the information that the individual had been part of the Youth Study.

Finally, many youth were in need of information on sexual and reproductive health matters. On occasion, interviewers themselves responded to their questions. In addition, easy-to-read booklets (for example, Paalvali Noyeingal STD/AIDS Adi Padi Vunmayamgal Velakkam prepared by the Tamil Nadu AIDS Control Society) were distributed to youth who requested them. In total, some 500 booklets were distributed.

\subsection{Data processing}

All completed questionnaires were sent to the project office at IIPS, Mumbai for editing and data processing. Completed questionnaires were rechecked and further edited in the office for omissions and consistency. Responses to open-ended questions were scrutinised and common responses were provided codes. For entering the edited data, a special software package was developed using CSPro 3.0. Data were entered twice by different entry operators to minimise entry problems. The raw data were validated and cleaned to remove possible inconsistencies. The analysis of data was carried out using SPSS 14.0.

\subsection{Interview outcomes}

Table 1.2 provides the outcome of household interviews by type of PSU (male or female) and residence. In all, of the 37,893 households selected for interview, $4 \%$ could not be contacted because the house was vacant or the entire household was absent over an extended period of time. In total, however, the response to the household questionnaire was high: $99 \%$ each in female and male PSUs. A total of 15,880 and 20,000 interviews were completed in urban and rural areas, respectively. Response rates in urban and rural areas were identical. We note that hardly any of the selected households in urban and rural areas refused to be interviewed. 
Table 1.2: Results of household interviews

Percent distribution of surveyed households by results of interviews, according to residence (unweighted), Tamil Nadu, 2006

\begin{tabular}{|c|c|c|c|c|c|c|}
\hline \multirow[t]{2}{*}{ Results of interviews } & \multicolumn{2}{|c|}{ All PSUs } & \multicolumn{2}{|c|}{ Male PSUs } & \multicolumn{2}{|c|}{ Female PSUs } \\
\hline & Percent & Number & Percent & Number & Percent & Number \\
\hline \multicolumn{7}{|c|}{ Combined } \\
\hline a. Interview completed & 94.7 & 35,880 & 94.3 & 17,348 & 95.0 & 18,532 \\
\hline $\begin{array}{l}\text { No respondent or no competent } \\
\text { b. respondent at home at the time of visit }\end{array}$ & 0.2 & 92 & 0.3 & 56 & 0.2 & 36 \\
\hline $\begin{array}{l}\text { Entire household absent for extended } \\
\text { c. period of time }\end{array}$ & 1.7 & 651 & 2.1 & 390 & 1.3 & 261 \\
\hline d. Refused & 0.1 & 22 & 0.1 & 10 & 0.1 & 12 \\
\hline e. Dwelling vacant/destroyed/not found & 2.4 & 903 & 2.3 & 419 & 2.5 & 484 \\
\hline f. Address not a dwelling & 0.1 & 52 & 0.2 & 29 & 0.1 & 23 \\
\hline g. Other & 0.8 & 293 & 0.7 & 136 & 0.8 & 157 \\
\hline Total households selected & 100.0 & 37,893 & 100.0 & 18,388 & 100.0 & 19,505 \\
\hline Response rate (HRR) & 98.9 & & 98.8 & & 98.9 & \\
\hline \multicolumn{7}{|c|}{ Urban } \\
\hline a. Interview completed & 95.2 & 15,880 & 94.7 & 8,257 & 95.7 & 7,623 \\
\hline $\begin{array}{l}\text { No respondent or no competent } \\
\text { b. respondent at home at the time of visit }\end{array}$ & 0.2 & 41 & 0.4 & 32 & 0.1 & 9 \\
\hline $\begin{array}{l}\text { Entire household absent for extended } \\
\text { c. period of time }\end{array}$ & 1.8 & 305 & 2.1 & 185 & 1.5 & 120 \\
\hline d. Refused & 0.1 & 18 & 0.1 & 8 & 0.1 & 10 \\
\hline e. Dwelling vacant/destroyed/not found & 2.0 & 326 & 1.9 & 167 & 2.0 & 159 \\
\hline f. Address not a dwelling & 0.1 & 17 & 0.1 & 7 & 0.1 & 10 \\
\hline g. Other & 0.6 & 95 & 0.7 & 59 & 0.5 & 36 \\
\hline Total households selected & 100.0 & 16,682 & 100.0 & 8,715 & 100.0 & 7,967 \\
\hline Response rate (HRR) & 99.0 & & 98.8 & & 99.3 & \\
\hline \multicolumn{7}{|c|}{ Rural } \\
\hline a. Interview completed & 94.3 & 20,000 & 94.0 & 9,091 & 94.5 & 10,909 \\
\hline $\begin{array}{l}\text { No respondent or no competent } \\
\text { b. respondent at home at the time of visit }\end{array}$ & 0.2 & 51 & 0.2 & 24 & 0.2 & 27 \\
\hline $\begin{array}{l}\text { Entire household absent for extended } \\
\text { c. period of time }\end{array}$ & 1.6 & 346 & 2.1 & 205 & 1.2 & 141 \\
\hline d. Refused & 0.0 & 4 & 0.0 & 2 & 0.0 & 2 \\
\hline e. Dwelling vacant/destroyed/not found & 2.7 & 577 & 2.6 & 252 & 2.8 & 325 \\
\hline f. Address not a dwelling & 0.2 & 35 & 0.2 & 22 & 0.1 & 13 \\
\hline g. Other & 0.9 & 198 & 0.8 & 77 & 1.0 & 121 \\
\hline Total households selected & 100.0 & 21,211 & 100.0 & 9,673 & 100.0 & 11,538 \\
\hline Response rate (HRR) & 98.8 & & 98.9 & & 98.8 & \\
\hline
\end{tabular}

Note: The household response rate (HRR) was calculated as: $H R R=(a / a+b+d+g)^{*} 100$. PSU: Primary sampling unit. 
Table 1.3 presents similar findings with regard to interviews with eligible respondents. In Tamil Nadu, 7,996 interviews were completed: 1,322 with married young men, 1,666 with unmarried young men, 2,007 with married young women and 3,001 with unmarried young women. Response rates for individual interviews were in the range of $76-87 \%$. The response rates for young women, both married and unmarried, were higher than those for young men ( $84-87 \%$ versus $76-78 \%)$ and response rates for urban respondents were higher than those for rural respondents, particularly for young men $(88 \%$ and $84 \%$ for married and unmarried men, respectively, in urban areas versus $70 \%$ and $69 \%$, respectively, in rural areas). The main reason for nonresponse was that the respondent was not at home, ranging from $12-15 \%$ among young women to $22-24 \%$ among young men. The high level of non-response for young men may be attributed to education- and work-related temporary migration. We attribute the low refusal rates to efforts described earlier that were implemented for ethical reasons, which, at the same time, enabled the development of considerable rapport and trust between study communities and our interview teams.

\section{Table 1.3: Results of eligible respondent interviews} Percent distribution of eligible respondents by results of interviews, according to residence
(unweighted), Tamil Nadu, 2006

\begin{tabular}{|c|c|c|c|c|c|c|c|c|c|c|c|c|}
\hline \multirow[t]{3}{*}{ Results of interviews } & \multicolumn{4}{|c|}{ Combined } & \multicolumn{4}{|c|}{ Urban } & \multicolumn{4}{|c|}{ Rural } \\
\hline & \multicolumn{2}{|c|}{ Married } & \multicolumn{2}{|c|}{ Unmarried } & \multicolumn{2}{|c|}{ Married } & \multicolumn{2}{|c|}{ Unmarried } & \multicolumn{2}{|c|}{ Married } & \multicolumn{2}{|c|}{ Unmarried } \\
\hline & Percent & Number & Percent & Number & Percent & Number & Percent & Number & Percent & Number & Percent & Number \\
\hline \multicolumn{13}{|c|}{ Men (15-24) } \\
\hline a. Interview completed & 77.6 & 1,322 & 75.6 & 1,666 & 87.7 & 653 & 83.9 & 789 & 69.8 & 669 & 69.3 & 877 \\
\hline b. Interview partially completed & 0.1 & 2 & 0.0 & 0 & 0.0 & 0 & 0.0 & 0 & 0.2 & 2 & 0.0 & 0 \\
\hline c. Respondent not at home & 21.7 & 369 & 23.8 & 525 & 11.7 & 87 & 15.6 & 147 & 29.4 & 282 & 29.9 & 378 \\
\hline d. Respondent refused & 0.2 & 3 & 0.1 & 2 & 0.4 & 3 & 0.2 & 2 & 0.0 & 0 & 0.0 & 0 \\
\hline e. Respondent's parent refused & 0.0 & 0 & 0.0 & 0 & 0.0 & 0 & 0.0 & 0 & 0.0 & 0 & 0.0 & 0 \\
\hline f. Respondent incapacitated & 0.4 & 6 & 0.5 & 12 & 0.3 & 2 & 0.2 & 2 & 0.4 & 4 & 0.8 & 10 \\
\hline g. No reason given & 0.1 & 1 & 0.0 & 0 & 0.0 & 0 & 0.0 & 0 & 0.1 & 1 & 0.0 & 0 \\
\hline Total selected & 100.0 & 1,703 & 100.0 & 2,205 & 100.0 & 745 & 100.0 & 940 & 100.0 & 958 & 100.0 & 1,265 \\
\hline Response rate (IRR) & 77.6 & & 75.6 & & 87.7 & & 83.9 & & 69.8 & & 69.3 & \\
\hline \multicolumn{13}{|c|}{ Women (15-24) } \\
\hline a. Interview completed & 84.4 & 2,007 & 86.6 & 3,001 & 88.3 & 804 & 88.3 & 1,347 & 82.1 & 1,203 & 85.2 & 1,654 \\
\hline b. Interview partially completed & 0.1 & 2 & 0.1 & 3 & 0.2 & 2 & 0.2 & 3 & 0.0 & 0 & 0.0 & 0 \\
\hline c. Respondent not at home & 15.2 & 361 & 12.1 & 421 & 11.0 & 100 & 10.0 & 153 & 17.8 & 261 & 13.8 & 268 \\
\hline d. Respondent refused & 0.1 & 2 & 0.1 & 3 & 0.1 & 1 & 0.1 & 2 & 0.1 & 1 & 0.1 & 1 \\
\hline e. Respondent's parent refused & 0.0 & 1 & 0.4 & 13 & 0.1 & 1 & 0.9 & 13 & 0.0 & 0 & 0.0 & 0 \\
\hline f. Respondent incapacitated & 0.1 & 3 & 0.7 & 25 & 0.2 & 2 & 0.5 & 8 & 0.1 & 1 & 0.9 & 17 \\
\hline g. No reason given & 0.0 & 1 & 0.0 & 1 & 0.1 & 1 & 0.0 & 0 & 0.0 & 0 & 0.1 & 1 \\
\hline Total selected & 100.0 & 2,377 & 100.0 & 3,467 & 100.0 & 911 & 100.0 & 1,526 & 100.0 & 1,466 & 100.0 & 1,941 \\
\hline Response rate (IRR) & 84.4 & & 86.6 & & 88.3 & & 88.3 & & 82.1 & & 85.2 & \\
\hline
\end{tabular}

Note: The individual response rate (IRR) was calculated as: $\operatorname{IRR}=(a / a+b+c+d+e+f+g)^{\star} 100$.

\subsection{Structure of the report}

This report is structured as follows. Chapter 2 provides a socio-demographic profile of the surveyed population and respondents, and the facilities available to the rural population. Chapters 3,4 and 5 discuss young people's educational attainment patterns, economic and non-economic activity experiences and media exposure, respectively. Chapter 6 discusses growing up issues, including young people's relationships with parents and peers. Chapters 7 and 8 focus, respectively, on young people's autonomy and gender role 
attitudes, and awareness of sexual and reproductive health matters. Chapter 9 describes the formation of pre-marital romantic relationships and pre-marital sexual experience with romantic and non-romantic partners. Chapter 10 discusses the transition to marriage and experiences in early married life. Chapter 11 presents information on health and health seeking behaviours and substance use. Chapter 12 focuses on civic and political participation and related attitudes. A summary of each chapter (3-12) is provided at its conclusion. Finally, Chapter 13 offers recommendations for programmes and research.

In view of the heterogeneity of youth by sex, marital status and rural-urban residence, in each chapter, tables are presented that describe findings, separately, on the situation of married and unmarried young men and women residing in urban and rural areas, respectively. In order to provide information on all youth in Tamil Nadu, we present findings for all young men and women aged 15-24 (that is, excluding married young men aged 25-29) to enable comparison.

All means, medians and percentages indicated in tables have been weighted using normalised weights for the total population. However, in order to show the total number of youth interviewed, unweighted numbers of respondents (Ns) are provided in each table. Because numbers are unweighted and percentages are weighted, we caution readers against deriving numbers based on percentages provided in tables. 
This chapter presents a summary of the community-level characteristics of the rural areas surveyed as well as household- and respondent-level profiles of the surveyed population. First, using data drawn from the community questionnaire, it describes the rural communities in which the survey was undertaken in terms of village size, agricultural land holding and access to facilities. Thereafter, drawing on data from the household questionnaire, the chapter profiles surveyed households in terms of socio-demographic and housing characteristics, agricultural land holding and economic status. Comparisons are drawn throughout between the distribution of the population as recorded in the present survey and that reported by the 2001 Census (Office of the Registrar General and Census Commissioner, 2001b) as well as the most recent NFHS (IIPS and Macro International, 2007a). Finally, we present the socio-demographic characteristics of youth respondents and their parents drawn from individual questionnaires.

\subsection{Profile of rural communities surveyed}

This section provides a profile of the rural PSUs (150 selected villages) in which the survey was conducted. It should be noted that as sampling of rural PSUs was conducted with the probability of selection proportional to size, the proportion of large villages in the Youth Study sample is likely to have been greater than the proportion of such villages in Tamil Nadu as a whole. However, because the selection of villages was made from a list of villages stratified by size, the effect of using the probability proportional to size sampling technique on village size distribution is likely to have been small.

As indicated in Table 2.1, 5\% of the villages surveyed were relatively small in size (less than 1,000 persons, or about 200 households), 33\% were large villages (5,000 or more persons, or about 1,000 households), and the remaining $63 \%$ of the surveyed villages were of medium size (1,000-4,999 persons). The majority of villages surveyed $(79 \%)$ contained less than 1,000 hectares of agricultural land. More than half of all agricultural land was irrigated in three-fifths of the surveyed villages.

Table 2.2 presents data regarding access to a variety of facilities among the rural population surveyed. Findings show that the median distance to the nearest town was 10 kilometres from the village of residence. Furthermore, $46 \%$ of the rural population had access to all-weather roads in their village; the median distance to the nearest all-weather road was 1 kilometre. Access to banks was limited: just $29 \%$ of the rural population had a bank located in their village. In contrast, three-fifths had a post office located in their village.

Primary schools were available in the village of residence of virtually the entire population (97\%). Middle, secondary and higher secondary schools were progressively less likely to be available within the village of residence $(65 \%, 33 \%$ and $21 \%$ of rural residents, respectively, resided in a village containing these facilities); however, these facilities were easily accessible. Median distances to the nearest secondary and higher secondary schools were 3 kilometres each. In contrast, colleges and technical institutions were much less accessible; just $2-4 \%$ of the population had such a facility within the village, and median distances to the nearest college and nearest technical institution were 18 kilometres each. 
Table 2.1: Profile of surveyed villages

\section{Percentage of surveyed villages and residents by village size and agricultural land holding, Tamil} Nadu (rural), 2006

\begin{tabular}{|c|c|c|c|c|}
\hline \multirow[t]{2}{*}{ Village characteristics } & \multicolumn{2}{|c|}{ Villages } & \multicolumn{2}{|c|}{ Residents } \\
\hline & Percent & Number & Percent & Number \\
\hline \multicolumn{5}{|c|}{ Current population (no. of persons) } \\
\hline Less than 1,000 & 4.7 & 7 & 4.4 & 3,335 \\
\hline $1,000-4,999$ & 62.7 & 94 & 63.3 & 52,424 \\
\hline $5,000-9,999$ & 20.0 & 30 & 19.3 & 15,493 \\
\hline 10,000 or more & 12.7 & 19 & 13.1 & 10,909 \\
\hline \multicolumn{5}{|c|}{ Size of agricultural land (hectares) } \\
\hline Less than 500 & 42.7 & 64 & 44.0 & 36,431 \\
\hline $500-999$ & 36.0 & 54 & 34.8 & 28,321 \\
\hline $1,000-4,999$ & 16.0 & 24 & 15.6 & 12,834 \\
\hline 5,000 and more & 2.0 & 3 & 1.9 & 1,581 \\
\hline \multicolumn{5}{|c|}{ Proportion of irrigated agricultural land owned } \\
\hline Less than $25 \%$ & 10.0 & 15 & 10.4 & 8,282 \\
\hline $25-49 \%$ & 26.7 & 40 & 25.6 & 20,505 \\
\hline $50-74 \%$ & 34.7 & 52 & 33.3 & 27,888 \\
\hline $75 \%$ or more & 25.3 & 38 & 27.2 & 22,405 \\
\hline Total & 100.0 & 150 & 100.0 & 82,161 \\
\hline
\end{tabular}

Note: All Ns are unweighted. Column totals may not equal 100\% or the total number due to missing cases or "don't know" responses.

With regard to health facilities, anganwadis were available in the village of residence of almost the entire population surveyed $(98 \%)$, and nearly three-fifths $(58 \%)$ had a sub-centre within the village. Primary health centres were far less likely to available within the village; only $29 \%$ of the population resided in a village containing a primary health centre. The median distance to the nearest primary health centre was just 3 kilometres and to the community health centre was 7 kilometres, highlighting the relatively easy access to government health facilities, notably primary health centres, in the rural areas of Tamil Nadu. It is interesting to note, moreover, that private clinics (including those practising Indian systems of medicine and homoeopathy) were available in almost one in four villages surveyed (23\%), and the median distance to such a facility was just 5 kilometres. Private hospitals were more distantly located: they were accessible in the village of residence to just $15 \%$ of rural residents and were located at a median distance of 8 kilometres.

The availability of civic organisations and entertainment or sports facilities was also assessed. Two-fifths of the population resided in villages containing at least one club or mandal/manram; about half reported a community hall within their village (48\%) and two-fifths had a playground. Other entertainment facilities were less likely to be available. Just $3-11 \%$ of the rural population had a sports club, a cinema theatre, a drama theatre or a video parlour within their village. Distances to the nearest such facilities varied. While the median distance to a community hall or playground was 1-2 kilometres, the nearest cinema theatre and sports club were located 8-9 kilometres from the village of residence. More distantly located were drama theatres and video parlours (18-19 kilometres). 
Table 2.2: Proximity of study residents to selected facilities

Percentage of residents covered by the survey by distance from the nearest facility/service, Tamil Nadu (rural), 2006

\begin{tabular}{|c|c|c|c|c|c|c|c|}
\hline \multirow[t]{2}{*}{ Nearest facility/service } & \multicolumn{6}{|c|}{$\%$ of residents } & \multirow{2}{*}{$\begin{array}{c}\text { Median } \\
\text { distance to } \\
\text { nearest facility/ } \\
\text { service }(\mathbf{k m})\end{array}$} \\
\hline & $\begin{array}{l}\text { Within } \\
\text { village }\end{array}$ & $\begin{array}{l}<2 \\
\mathrm{~km}\end{array}$ & $\begin{array}{l}2-5 \\
\mathrm{~km}\end{array}$ & $\begin{array}{l}6-9 \\
\mathrm{~km}\end{array}$ & $\begin{array}{c}10-19 \\
\text { km }\end{array}$ & $\begin{array}{c}20 \mathrm{~km} \\
\text { or more }\end{array}$ & \\
\hline Town & NA & 0.5 & 23.4 & 20.8 & 37.6 & 17.7 & 10.0 \\
\hline District headquarters & NA & 0.0 & 3.5 & 4.6 & 14.0 & 77.9 & 40.0 \\
\hline Railway station & 2.5 & 0.0 & 15.1 & 21.2 & 23.8 & 37.4 & 12.0 \\
\hline Transport service to other places & 40.8 & 9.9 & 20.8 & 7.3 & 9.1 & 12.1 & 1.0 \\
\hline All-weather road & 46.0 & 8.3 & 18.7 & 7.0 & 9.6 & 9.7 & 1.0 \\
\hline Post office & 59.8 & 15.6 & 19.8 & 1.2 & 1.7 & 0.7 & $\mathrm{NC}$ \\
\hline Bank & 29.2 & 7.2 & 32.3 & 22.5 & 7.0 & 1.4 & 3.0 \\
\hline \multicolumn{8}{|l|}{ Educational facilities } \\
\hline Primary school & 96.8 & 2.1 & 1.2 & 0.0 & 0.0 & 0.0 & $\mathrm{NC}$ \\
\hline Middle school & 65.3 & 5.9 & 22.3 & 2.8 & 3.1 & 0.7 & $\mathrm{NC}$ \\
\hline Secondary school & 32.7 & 3.6 & 45.3 & 12.4 & 4.6 & 1.3 & 3.0 \\
\hline Higher secondary school & 21.4 & 3.0 & 45.6 & 21.9 & 6.8 & 1.4 & 3.0 \\
\hline College & 2.3 & 0.6 & 12.2 & 11.4 & 24.0 & 49.3 & 18.0 \\
\hline Technical school/college & 3.8 & 1.4 & 8.0 & 9.7 & 28.8 & 48.3 & 18.0 \\
\hline Ashram school & 2.5 & 0.6 & 13.0 & 5.8 & 15.0 & 44.9 & 24.0 \\
\hline Madarsa & 2.2 & 0.6 & 7.9 & 9.2 & 17.6 & 42.0 & 21.0 \\
\hline Any of the above & 98.2 & 0.6 & 1.2 & 0.0 & 0.0 & 0.0 & $\mathrm{NC}$ \\
\hline \multicolumn{8}{|l|}{ Health facilities } \\
\hline ICDS (anganwadi) & 98.2 & 0.0 & 1.8 & 0.0 & 0.0 & 0.0 & $\mathrm{NC}$ \\
\hline Sub-centre & 57.9 & 3.4 & 19.8 & 9.0 & 9.3 & 0.0 & $\mathrm{NC}$ \\
\hline Primary health centre & 28.5 & 1.2 & 40.7 & 17.5 & 10.3 & 1.8 & 3.0 \\
\hline Community health centre & 12.9 & 1.2 & 28.7 & 22.2 & 23.1 & 9.2 & 7.0 \\
\hline Government dispensary & 17.8 & 1.3 & 21.8 & 20.3 & 26.0 & 10.9 & 7.0 \\
\hline Government hospital & 3.6 & 0.5 & 13.8 & 16.5 & 35.3 & 30.3 & 12.0 \\
\hline Private clinic, including ISMH & 22.5 & 1.8 & 26.1 & 19.5 & 17.9 & 12.3 & 5.0 \\
\hline Private hospital & 14.9 & 0.5 & 19.7 & 22.3 & 28.0 & 14.6 & 8.0 \\
\hline Any of the above & 98.2 & 0.5 & 1.3 & 0.0 & 0.0 & 0.0 & NC \\
\hline $\mathrm{Club} /$ mandal/manram & 39.9 & NA & NA & NA & NA & NA & NA \\
\hline \multicolumn{8}{|l|}{ Entertainment/sports facilities } \\
\hline Community hall & 47.9 & 1.1 & 23.3 & 10.6 & 8.4 & 6.1 & 1.0 \\
\hline Playground & 39.9 & 4.3 & 20.7 & 8.4 & 10.2 & 8.1 & 2.0 \\
\hline Sports club & 11.3 & 1.9 & 16.4 & 13.7 & 20.5 & 21.7 & 9.0 \\
\hline Video parlour & 2.8 & 0.8 & 8.1 & 7.0 & 13.9 & 30.2 & 18.0 \\
\hline Cinema theatre & 8.5 & 1.8 & 30.3 & 20.7 & 26.4 & 12.3 & 8.0 \\
\hline Drama theatre & 2.9 & 1.5 & 6.8 & 5.4 & 16.4 & 32.7 & 19.0 \\
\hline Any of the above & 64.2 & 4.3 & 18.7 & 6.8 & 4.1 & 2.0 & $\mathrm{NC}$ \\
\hline
\end{tabular}

Note: ICDS: Integrated Child Development Services. ISMH: Indian systems of medicine and homoeopathy. NA: Not applicable. NC: Median cannot be calculated. 


\subsection{Profile of the household population: Age-sex distribution}

Age and sex distributions play an important role in the study of demographic processes. Details of the age and sex distribution of the de jure population in the survey area are presented in Table 2.3. Corresponding distributions from the 2001 Census are provided to enable comparison.

The age distribution was typical of a population in which low levels of fertility have been reached. For example, a relatively small proportion— just $16 \%$ - of the population was aged $0-9$ years, and this proportion was almost identical to that reported in the 2001 Census (17\%). At the other end of the age spectrum, the population aged $60+$ years represents $10 \%$ of the population, compared to $9 \%$ as reported in the 2001 Census. These distributions are observed in both urban and rural areas. Data from consecutive NFHS confirm that the total fertility rate declined from 2.5 in $1992-93$ to 2.2 in 1998-99 and further to 1.8 in 2005-06, that is, a $28 \%$ decline in the last 13 years (IIPS and Macro International, 2007a). Sample Registration System data also show a decline in the total fertility rate from 2.0 in 1999 to 1.6 in 2007 (Office of the Registrar General, India, 2003; 2008b).

With regard to the age distribution of the youth population, results suggest that at the time of the survey, 9\% each were aged 10-14 years, 15-19 years and 20-24 years. Thus, a total of $18 \%$ of the population was aged 15-24 years, almost identical to that reported in the 2001 Census (19\%) (Office of the Registrar General and Census Commissioner, 2001a).

Table 2.3: Distribution of the surveyed population by age and sex

Percent distribution of the surveyed population by age and sex, according to residence, Tamil Nadu, 2006, and population distribution as reported in the 2001 Census for Tamil Nadu

\begin{tabular}{|c|c|c|c|c|c|c|}
\hline \multirow[t]{2}{*}{ Age (years) (\%) } & \multicolumn{3}{|c|}{ Youth Study, 2006} & \multicolumn{3}{|c|}{ Census, 2001} \\
\hline & Total & Male & Female & Total & Male & Female \\
\hline \multicolumn{7}{|c|}{ Combined } \\
\hline Below 1 & 1.4 & 1.5 & 1.3 & 1.2 & 1.2 & 1.2 \\
\hline $1-4$ & 6.4 & 6.7 & 6.0 & 7.0 & 7.1 & 6.8 \\
\hline $5-9$ & 8.5 & 8.7 & 8.4 & 9.0 & 9.2 & 8.8 \\
\hline $10-14$ & 8.9 & 9.2 & 8.6 & 9.6 & 9.8 & 9.4 \\
\hline $15-19$ & 9.0 & 9.1 & 8.9 & 9.9 & 10.0 & 9.8 \\
\hline $20-24$ & 9.2 & 9.0 & 9.3 & 9.3 & 9.1 & 9.4 \\
\hline $25-29$ & 9.2 & 8.6 & 9.8 & 9.2 & 8.7 & 9.6 \\
\hline $30-34$ & 8.0 & 8.2 & 7.8 & 7.5 & 7.5 & 7.6 \\
\hline $35-39$ & 8.2 & 8.0 & 8.4 & 7.9 & 7.6 & 8.1 \\
\hline $40-44$ & 6.4 & 6.7 & 6.2 & 6.1 & 6.3 & 5.8 \\
\hline $45-49$ & 6.1 & 6.1 & 6.1 & 5.8 & 5.9 & 5.7 \\
\hline $50-54$ & 4.8 & 4.8 & 4.8 & 4.5 & 4.6 & 4.4 \\
\hline $55-59$ & 4.1 & 4.0 & 4.2 & 3.6 & 3.5 & 3.6 \\
\hline $60-64$ & 3.7 & 3.5 & 3.9 & 3.3 & 3.2 & 3.3 \\
\hline $65-69$ & 2.6 & 2.4 & 2.7 & 2.2 & 2.1 & 2.3 \\
\hline $70-74$ & 1.9 & 1.9 & 1.9 & 1.7 & 1.7 & 1.6 \\
\hline 75 and above & 1.8 & 1.8 & 1.8 & 1.7 & 1.7 & 1.7 \\
\hline Age not stated & 0.0 & 0.0 & 0.0 & 0.7 & 0.7 & 0.7 \\
\hline Number & 146,973 & 73,538 & 73,435 & $62,405,679$ & $31,400,909$ & $31,004,770$ \\
\hline Median age (years) & 28.0 & 28.0 & 28.0 & 25.6 & 25.4 & 25.8 \\
\hline Sex ratio, all ages ${ }^{1}$ & 999 & NA & NA & 987 & NA & NA \\
\hline Sex ratio, age $0-6$ years ${ }^{1}$ & 925 & NA & NA & 942 & $\mathrm{NA}$ & NA \\
\hline
\end{tabular}


Table 2.3: (Cont'd)

\begin{tabular}{|c|c|c|c|c|c|c|}
\hline \multirow[t]{2}{*}{ Age (years) (\%) } & \multicolumn{3}{|c|}{ Youth Study, 2006} & \multicolumn{3}{|c|}{ Census, 2001} \\
\hline & Total & Male & Female & Total & Male & Female \\
\hline \multicolumn{7}{|c|}{ Urban } \\
\hline Below 1 & 1.4 & 1.5 & 1.3 & 1.1 & 1.2 & 1.1 \\
\hline $1-4$ & 6.1 & 6.3 & 5.8 & 6.5 & 6.6 & 6.4 \\
\hline $5-9$ & 8.2 & 8.4 & 8.0 & 8.3 & 8.4 & 8.3 \\
\hline $10-14$ & 8.3 & 8.5 & 8.0 & 9.2 & 9.3 & 9.1 \\
\hline $15-19$ & 8.8 & 8.7 & 8.8 & 9.8 & 9.8 & 9.9 \\
\hline $20-24$ & 9.3 & 9.0 & 9.6 & 9.8 & 9.5 & 10.1 \\
\hline $25-29$ & 9.6 & 9.0 & 10.1 & 9.7 & 9.2 & 10.2 \\
\hline $30-34$ & 8.4 & 8.7 & 8.1 & 8.1 & 8.1 & 8.0 \\
\hline $35-39$ & 8.5 & 8.3 & 8.6 & 8.1 & 8.0 & 8.2 \\
\hline $40-44$ & 6.8 & 7.1 & 6.5 & 6.3 & 6.6 & 6.0 \\
\hline $45-49$ & 6.3 & 6.4 & 6.2 & 5.8 & 6.0 & 5.6 \\
\hline $50-54$ & 4.8 & 4.9 & 4.7 & 4.5 & 4.7 & 4.3 \\
\hline $55-59$ & 4.2 & 4.0 & 4.3 & 3.4 & 3.4 & 3.4 \\
\hline $60-64$ & 3.5 & 3.4 & 3.6 & 3.0 & 3.0 & 3.1 \\
\hline $65-69$ & 2.5 & 2.3 & 2.6 & 2.1 & 2.0 & 2.2 \\
\hline $70-74$ & 1.8 & 1.7 & 1.9 & 1.5 & 1.5 & 1.6 \\
\hline 75 and above & 1.8 & 1.8 & 1.8 & 1.7 & 1.6 & 1.7 \\
\hline Age not stated & 0.0 & 0.0 & 0.0 & 1.0 & 1.0 & 0.9 \\
\hline Number & 64,812 & 32,400 & 32,412 & $27,483,998$ & $13,869,415$ & $13,614,583$ \\
\hline Median age (years) & 29.0 & 29.0 & 28.0 & 25.9 & 25.9 & 25.8 \\
\hline Sex ratio, all ages ${ }^{1}$ & 1,000 & NA & NA & 982 & NA & NA \\
\hline Sex ratio, age $0-6$ years $^{1}$ & 914 & NA & NA & 955 & NA & NA \\
\hline \multicolumn{7}{|c|}{ Rural } \\
\hline Below 1 & 1.4 & 1.4 & 1.3 & 1.3 & 1.3 & 1.2 \\
\hline $1-4$ & 6.6 & 6.9 & 6.2 & 7.3 & 7.5 & 7.1 \\
\hline $5-9$ & 8.8 & 8.9 & 8.7 & 9.5 & 9.7 & 9.2 \\
\hline $10-14$ & 9.4 & 9.6 & 9.1 & 10.0 & 10.2 & 9.7 \\
\hline $15-19$ & 9.2 & 9.4 & 9.0 & 10.0 & 10.1 & 9.8 \\
\hline $20-24$ & 9.1 & 9.0 & 9.1 & 8.9 & 8.8 & 8.9 \\
\hline $25-29$ & 8.9 & 8.3 & 9.5 & 8.7 & 8.3 & 9.2 \\
\hline $30-34$ & 7.7 & 7.8 & 7.5 & 7.1 & 6.9 & 7.2 \\
\hline $35-39$ & 8.0 & 7.7 & 8.2 & 7.7 & 7.4 & 8.1 \\
\hline $40-44$ & 6.1 & 6.3 & 5.9 & 5.9 & 6.1 & 5.7 \\
\hline $45-49$ & 6.0 & 5.9 & 6.1 & 5.8 & 5.8 & 5.8 \\
\hline $50-54$ & 4.8 & 4.6 & 4.9 & 4.5 & 4.6 & 4.5 \\
\hline $55-59$ & 4.0 & 4.0 & 4.1 & 3.7 & 3.6 & 3.8 \\
\hline $60-64$ & 3.8 & 3.6 & 4.0 & 3.5 & 3.4 & 3.5 \\
\hline $65-69$ & 2.6 & 2.5 & 2.8 & 2.3 & 2.2 & 2.4 \\
\hline $70-74$ & 1.9 & 2.0 & 1.9 & 1.7 & 1.8 & 1.7 \\
\hline 75 and above & 1.8 & 1.8 & 1.8 & 1.7 & 1.8 & 1.6 \\
\hline Age not stated & 0.0 & 0.0 & 0.0 & 0.5 & 0.5 & 0.4 \\
\hline Number & 82,161 & 41,138 & 41,023 & $34,921,681$ & $17,531,494$ & $17,390,187$ \\
\hline Median age (years) & 28.0 & 27.0 & 28.0 & 25.3 & 24.9 & 25.7 \\
\hline Sex ratio, all ages ${ }^{1}$ & 998 & NA & NA & 992 & NA & NA \\
\hline Sex ratio, age $0-6$ years ${ }^{1}$ & 934 & NA & NA & 933 & NA & NA \\
\hline
\end{tabular}

Note: All Ns are unweighted. NA: Not applicable. ${ }^{1}$ Sex ratio is defined as the number of females per 1,000 males. 
Overall, the sex ratio of the de jure population of the state was 999 females per 1,000 males. While the rural sex ratio was similar to that observed in the 2001 Census (998 and 992, respectively), the urban sex ratio observed in the Youth Study was somewhat higher (1,000 and 982, respectively).

The child sex ratio of the surveyed population was 925 females per 1,000 males aged 0-6 compared to 942 reported in the 2001 Census. While the child sex ratio in rural areas was similar to that obtained in the 2001 Census (934 and 933, respectively), the urban child sex ratio was considerably lower in the Youth Study than in the 2001 Census: 914 compared to 955 . However, the 95\% confidence interval ranged from 877 to 950 , suggesting that the decline in the child sex ratio in urban areas was likely to have been modest.

\subsection{Profile of the household population: Marital status}

Table 2.4 presents the marital status distribution of the surveyed population, classified by age, residence and sex. A comparison with the marital status distribution as obtained in the 2001 Census (data not shown in tabular form) suggests a similar distribution, except that proportions never married have increased somewhat in the period 2001-06 (Office of the Registrar General and Census Commissioner, 2001b). The currently married include both those who have married and cohabited with their spouse as well as those for whom cohabitation has not been initiated.

Findings suggest that marriage was delayed beyond adolescence for the overwhelming majority of youth but that wide gender differences persist in marriage age distributions, notably between the ages of 15 and 29 . Of those aged $15-19$ years, just $0.4 \%$ of young men as compared to $12 \%$ of young women were currently married. This increased to $11 \%$ and $59 \%$, respectively, for those aged $20-24$ years and further to $51 \%$ and $88 \%$ for those aged 25-29 years. Patterns were similar for both rural and urban areas, but larger percentages of both young men and women were married in each age group up to age 30 in rural versus urban areas.

Table 2.4 also provides estimates of the singulate mean age at marriage (SMAM), calculated from the age-specific proportion of never-married individuals obtained in the household survey. As suggested above, the singulate mean age at marriage was considerably higher among the male population compared to the female: 27 and 22 years, respectively. Differences were also observed by rural-urban residence, with the singulate mean age at marriage about one year higher among urban compared to rural males and females. Findings also suggest that women tended to marry men who were an average of six years older than themselves.

In order to assess age at marriage among those married more recently, the Youth Study household questionnaire asked specifically about marriages that had taken place in the three years prior to interview among the household's usual residents at that time. Table 2.5 suggests the median age at marriage for those who married in the recent past was 26 years among young men and 21 years among young women. Rural-urban differences were similar to those observed above, that is the median age at marriage was one year higher among urban youth than their rural counterparts. Findings also show that while $10 \%$ of young women had married before age 18 , that is, the legal minimum age at marriage for females, hardly any young men had married before age 18 . Notably, however, $6 \%$ of young men had married before age 21 , the legal minimum age at marriage for males. Rural-urban differences were relatively narrow: $11 \%$ of rural females compared to $7 \%$ of urban females had married before age 18 , and among young men, $7 \%$ and $4 \%$, respectively, had married before age 21 . 
Table 2.4: Marital status of the surveyed population

Percent distribution of the surveyed population aged 6 years and above by marital status and sex, according to residence, Tamil Nadu, 2006

\begin{tabular}{|c|c|c|c|c|c|c|}
\hline \multirow[t]{3}{*}{ Age (years) (\%) } & \multicolumn{6}{|c|}{ Marital status } \\
\hline & \multicolumn{3}{|c|}{ Male } & \multicolumn{3}{|c|}{ Female } \\
\hline & $\begin{array}{c}\text { Never } \\
\text { married }\end{array}$ & $\begin{array}{l}\text { Currently } \\
\text { married }^{1}\end{array}$ & $\begin{array}{l}\text { Separated/ } \\
\text { divorced/ } \\
\text { widowed }\end{array}$ & $\begin{array}{c}\text { Never } \\
\text { married }\end{array}$ & $\begin{array}{l}\text { Currently } \\
\text { married }^{1}\end{array}$ & $\begin{array}{l}\text { Separated/ } \\
\text { divorced/ } \\
\text { widowed }\end{array}$ \\
\hline \multicolumn{7}{|c|}{ Combined } \\
\hline $6-9$ & 99.3 & 0.6 & 0.1 & 99.5 & 0.5 & 0.0 \\
\hline $10-14$ & 99.6 & 0.4 & 0.0 & 99.7 & 0.3 & 0.0 \\
\hline $15-19$ & 99.6 & 0.4 & 0.0 & 88.3 & 11.6 & 0.1 \\
\hline $20-24$ & 89.0 & 10.8 & 0.2 & 40.0 & 59.1 & 0.8 \\
\hline $25-29$ & 49.1 & 50.6 & 0.3 & 9.6 & 87.8 & 2.6 \\
\hline 30 and above & 3.4 & 91.9 & 4.8 & 1.2 & 72.8 & 26.0 \\
\hline Total & 43.1 & 54.3 & 2.6 & 31.1 & 54.8 & 14.0 \\
\hline SMAM $^{2}$ (years) & \multicolumn{3}{|c|}{27.4} & \multicolumn{3}{|c|}{21.8} \\
\hline \multicolumn{7}{|c|}{ Urban } \\
\hline $6-9$ & 99.3 & 0.7 & 0.1 & 99.4 & 0.6 & 0.0 \\
\hline $10-14$ & 99.6 & 0.4 & 0.0 & 99.6 & 0.3 & 0.1 \\
\hline $15-19$ & 99.5 & 0.5 & 0.0 & 91.3 & 8.6 & 0.1 \\
\hline $20-24$ & 91.4 & 8.5 & 0.1 & 44.5 & 54.9 & 0.6 \\
\hline $25-29$ & 52.2 & 47.4 & 0.3 & 11.7 & 86.1 & 2.2 \\
\hline 30 and above & 4.1 & 91.8 & 4.0 & 1.7 & 73.6 & 24.7 \\
\hline Total & 42.8 & 55.0 & 2.2 & 31.4 & 55.2 & 13.4 \\
\hline SMAM $^{2}$ (years) & \multicolumn{3}{|c|}{27.9} & \multicolumn{3}{|c|}{22.4} \\
\hline \multicolumn{7}{|c|}{ Rural } \\
\hline $6-9$ & 99.4 & 0.5 & 0.1 & 99.5 & 0.4 & 0.1 \\
\hline $10-14$ & 99.7 & 0.3 & 0.0 & 99.7 & 0.3 & 0.0 \\
\hline $15-19$ & 99.7 & 0.3 & 0.0 & 85.9 & 14.0 & 0.1 \\
\hline $20-24$ & 87.2 & 12.6 & 0.2 & 36.4 & 62.6 & 1.0 \\
\hline $25-29$ & 46.5 & 53.2 & 0.3 & 7.9 & 89.2 & 2.9 \\
\hline 30 and above & 2.8 & 91.9 & 5.3 & 0.9 & 72.1 & 27.0 \\
\hline Total & 43.4 & 53.7 & 2.8 & 30.9 & 54.6 & 14.5 \\
\hline SMAM $^{2}$ (years) & \multicolumn{3}{|c|}{27.0} & \multicolumn{3}{|c|}{21.4} \\
\hline
\end{tabular}

Note: Row totals may not equal 100\% due to missing cases or "don't know" responses. ${ }^{1}$ Includes both those who are currently married and cohabiting as well as those who have not yet initiated cohabitation. ${ }^{2}$ SMAM: Singulate mean age at marriage (for those whose first marriage occurred between the ages of 6 and 55 years). 
Table 2.5: Age at marriage of usual residents of households

Age at marriage of usual residents of surveyed households who were married in the three years preceding the interview, according to residence, Tamil Nadu, 2006

\begin{tabular}{|c|c|c|c|}
\hline Age at marriage & Combined & Urban & Rural \\
\hline \multicolumn{4}{|l|}{$\begin{array}{l}\text { Median age at marriage of usual residents married in } \\
\text { the } 3 \text { years preceding the interview (years) }\end{array}$} \\
\hline Male & 26.0 & 27.0 & 26.0 \\
\hline Female & 21.0 & 21.0 & 20.0 \\
\hline \multicolumn{4}{|l|}{ Of those married in last 3 years, males married (\%): } \\
\hline Before age 18 & 0.2 & 0.0 & 0.3 \\
\hline Before age 21 & 5.9 & 3.9 & 7.3 \\
\hline $\begin{array}{l}\text { Of those married in last } 3 \text { years, females married before } \\
\text { age } 18(\%)\end{array}$ & 9.5 & 7.2 & 11.1 \\
\hline
\end{tabular}

\subsection{Profile of the household population: Educational attainment}

Table 2.6 shows the percent distribution of the surveyed population aged 6 years and above by educational level and median years of schooling according to sex, age and residence. Findings highlight that almost one-quarter of the population aged 6 years and above had no formal education. More females than males fell into this group: $32 \%$ and 15\%, respectively. Rural-urban differences were also wide: $17 \%$ of the urban population compared to $29 \%$ of the rural population had never been to school. At the other extreme, $15 \%$ of the total population had received 12 or more years of education. Gender differences were relatively narrow: $18 \%$ and $13 \%$ of males and females, respectively, had attained at least 12 years of education. In contrast, rural-urban differences were wide: $22 \%$ and $10 \%$ of the urban and rural populations, respectively, had attained this level of education. The median years of schooling was 8 years for males and 5 years for females, and was three years higher in the urban compared to the rural population ( 8 and 5 years, respectively).

\subsection{Profile of the household population: Work participation}

Table 2.7 presents the percentage distribution of the surveyed population aged 6 years and above reported to have been working in the seven days prior to interview according to sex and residence. While $49 \%$ of the total population was reported as working, a larger percentage of males than females $(67 \%$ and $30 \%$, respectively) and a larger proportion of the rural than urban population ( $52 \%$ and $44 \%$, respectively) were working. Rural-urban differences are attributable to the differences in work participation observed among rural and urban females (37\% and $22 \%$, respectively). In comparison, percentages of working males were identical (67\%) in urban and rural areas. A positive association between age and work was observed: $3 \%$ of those aged 10-14 reported working compared with $31 \%$ of those aged 15-19; this percentage increased to $54 \%$ in the $20-24$ year age group and to $64 \%$ thereafter. Among males, percentages working doubled between ages $15-19$ and $20-24$ (40\% to $80 \%)$, and similar patterns were observed in both rural and urban areas. Among females, age specific increases were milder. 
Table 2.6: Educational attainment

Percent distribution of the surveyed population aged 6 years and above by educational level and median years of schooling, according to age, sex and residence, Tamil Nadu, 2006

\begin{tabular}{|c|c|c|c|c|c|c|}
\hline \multirow{2}{*}{ Age (years) } & \multicolumn{4}{|c|}{ Completed years of schooling (\%) } & \multirow{2}{*}{$\begin{array}{c}\text { No. of } \\
\text { persons }\end{array}$} & \multirow{2}{*}{$\begin{array}{l}\text { Median } \\
\text { years of } \\
\text { schooling }\end{array}$} \\
\hline & None $^{1}$ & $1-7$ & $8-11$ & $\begin{array}{c}12 \\
\text { and above }\end{array}$ & & \\
\hline \multicolumn{7}{|c|}{ Combined } \\
\hline \multicolumn{7}{|l|}{ Total } \\
\hline $6-9$ & 11.4 & 88.6 & 0.0 & 0.0 & 9,950 & 3.0 \\
\hline $10-14$ & 1.4 & 68.3 & 30.3 & 0.0 & 13,068 & 7.0 \\
\hline $15-19$ & 3.8 & 14.1 & 57.9 & 24.1 & 13,223 & 10.0 \\
\hline $20-24$ & 7.3 & 19.9 & 37.1 & 35.7 & 13,501 & 10.0 \\
\hline $25-29$ & 13.4 & 23.5 & 36.0 & 27.0 & 13,485 & 9.0 \\
\hline 30 and above & 38.2 & 25.2 & 24.1 & 12.3 & 69,780 & 5.0 \\
\hline Total & 23.5 & 32.3 & 28.8 & 15.2 & $1,33,013$ & 6.0 \\
\hline \multicolumn{7}{|l|}{ Male } \\
\hline $6-9$ & 11.2 & 88.8 & 0.0 & 0.0 & 5,080 & 3.0 \\
\hline $10-14$ & 1.4 & 69.3 & 29.3 & 0.0 & 6,732 & 6.0 \\
\hline $15-19$ & 2.7 & 15.2 & 58.7 & 23.4 & 6,677 & 10.0 \\
\hline $20-24$ & 4.4 & 20.4 & 37.1 & 38.1 & 6,654 & 10.0 \\
\hline $25-29$ & 6.9 & 22.7 & 39.4 & 31.0 & 6,326 & 9.0 \\
\hline 30 and above & 24.5 & 27.8 & 30.8 & 16.7 & 34,790 & 7.0 \\
\hline Total & 15.2 & 34.2 & 32.5 & 17.9 & 66,260 & 8.0 \\
\hline \multicolumn{7}{|l|}{ Female } \\
\hline $6-9$ & 11.5 & 88.4 & 0.0 & 0.0 & 4,870 & 3.0 \\
\hline $10-14$ & 1.4 & 67.1 & 31.5 & 0.0 & 6,336 & 7.0 \\
\hline $15-19$ & 5.0 & 13.0 & 57.2 & 24.8 & 6,546 & 10.0 \\
\hline $20-24$ & 10.1 & 19.4 & 37.1 & 33.3 & 6,847 & 9.0 \\
\hline $25-29$ & 19.2 & 24.2 & 33.0 & 23.5 & 7,159 & 8.0 \\
\hline 30 and above & 51.9 & 22.6 & 17.5 & 8.0 & 34,990 & 0.0 \\
\hline Total & 31.8 & 30.5 & 25.1 & 12.6 & 66,753 & 5.0 \\
\hline \multicolumn{7}{|c|}{ Urban } \\
\hline \multicolumn{7}{|l|}{ Total } \\
\hline $6-9$ & 13.6 & 86.4 & 0.0 & 0.0 & 4,225 & 2.0 \\
\hline $10-14$ & 1.1 & 68.9 & 30.0 & 0.0 & 5,364 & 7.0 \\
\hline $15-19$ & 2.5 & 12.2 & 55.8 & 29.5 & 5,685 & 10.0 \\
\hline $20-24$ & 5.2 & 17.0 & 33.2 & 44.6 & 6,033 & 10.0 \\
\hline $25-29$ & 8.6 & 20.7 & 35.1 & 35.6 & 6,192 & 10.0 \\
\hline 30 and above & 26.1 & 23.8 & 30.3 & 19.6 & 31,385 & 8.0 \\
\hline Total & 16.7 & 30.2 & 31.3 & 21.6 & 58,886 & 8.0 \\
\hline \multicolumn{7}{|l|}{ Male } \\
\hline $6-9$ & 13.5 & 86.5 & 0.0 & 0.0 & 2,150 & 2.0 \\
\hline $10-14$ & 1.1 & 69.8 & 29.1 & 0.0 & 2,770 & 6.0 \\
\hline $15-19$ & 2.2 & 13.2 & 56.9 & 27.8 & 2,808 & 10.0 \\
\hline $20-24$ & 3.6 & 17.6 & 32.7 & 46.1 & 2,930 & 10.0 \\
\hline $25-29$ & 5.2 & 20.2 & 35.9 & 38.6 & 2,912 & 10.0 \\
\hline 30 and above & 15.0 & 23.5 & 35.9 & 25.4 & 15,730 & 9.0 \\
\hline Total & 10.2 & 30.6 & 34.3 & 24.7 & 29,300 & 8.0 \\
\hline
\end{tabular}

Cont'd on next page... 
Table 2.6: (Cont'd)

\begin{tabular}{|c|c|c|c|c|c|c|}
\hline \multirow[t]{2}{*}{ Age (years) } & \multicolumn{4}{|c|}{ Completed years of schooling (\%) } & \multirow{2}{*}{$\begin{array}{c}\text { No. of } \\
\text { persons }\end{array}$} & \multirow{2}{*}{$\begin{array}{c}\text { Median } \\
\text { years of } \\
\text { schooling }\end{array}$} \\
\hline & None $^{1}$ & $1-7$ & $8-11$ & $\begin{array}{c}12 \\
\text { and above }\end{array}$ & & \\
\hline \multicolumn{7}{|c|}{ Urban } \\
\hline \multicolumn{7}{|l|}{ Female } \\
\hline $6-9$ & 13.8 & 86.2 & 0.0 & 0.0 & 2,075 & 2.0 \\
\hline $10-14$ & 1.2 & 67.8 & 30.9 & 0.0 & 2,594 & 7.0 \\
\hline $15-19$ & 2.8 & 11.2 & 54.7 & 31.3 & 2,877 & 10.0 \\
\hline $20-24$ & 6.7 & 16.4 & 33.7 & 43.2 & 3,103 & 10.0 \\
\hline $25-29$ & 11.6 & 21.1 & 34.3 & 32.9 & 3,280 & 9.0 \\
\hline 30 and above & 37.3 & 24.1 & 24.7 & 13.8 & 15,655 & 5.0 \\
\hline Total & 23.1 & 29.9 & 28.4 & 18.5 & 29,586 & 7.0 \\
\hline \multicolumn{7}{|c|}{ Rural } \\
\hline Total & & & & & & \\
\hline $6-9$ & 9.7 & 90.2 & 0.0 & 0.0 & 5,725 & 3.0 \\
\hline $10-14$ & 1.5 & 67.8 & 30.6 & 0.0 & 7,704 & 7.0 \\
\hline $15-19$ & 4.8 & 15.6 & 59.5 & 20.1 & 7,538 & 10.0 \\
\hline $20-24$ & 9.0 & 22.2 & 40.2 & 28.5 & 7,468 & 9.0 \\
\hline $25-29$ & 17.5 & 25.9 & 36.7 & 19.8 & 7,293 & 8.0 \\
\hline 30 and above & 48.0 & 26.3 & 19.1 & 6.5 & 38,395 & 3.0 \\
\hline Total & 28.9 & 34.0 & 26.8 & 10.2 & 74,127 & 5.0 \\
\hline \multicolumn{7}{|l|}{ Male } \\
\hline $6-9$ & 9.5 & 90.4 & 0.0 & 0.0 & 2,930 & 3.0 \\
\hline $10-14$ & 1.6 & 69.0 & 29.4 & 0.0 & 3,962 & 7.0 \\
\hline $15-19$ & 3.0 & 16.6 & 60.0 & 20.3 & 3,869 & 10.0 \\
\hline $20-24$ & 5.0 & 22.6 & 40.5 & 31.9 & 3,724 & 9.0 \\
\hline $25-29$ & 8.3 & 24.9 & 42.2 & 24.6 & 3,414 & 9.0 \\
\hline 30 and above & 32.3 & 31.2 & 26.6 & 9.6 & 19,060 & 5.0 \\
\hline Total & 19.2 & 37.0 & 31.1 & 12.6 & 36,960 & 6.0 \\
\hline \multicolumn{7}{|l|}{ Female } \\
\hline $6-9$ & 9.9 & 90.1 & 0.0 & 0.0 & 2,795 & 3.0 \\
\hline $10-14$ & 1.5 & 66.6 & 31.8 & 0.0 & 3,742 & 7.0 \\
\hline $15-19$ & 6.6 & 14.4 & 59.1 & 19.9 & 3,669 & 10.0 \\
\hline $20-24$ & 13.0 & 21.8 & 39.9 & 25.1 & 3,744 & 8.0 \\
\hline $25-29$ & 25.6 & 26.8 & 31.9 & 15.6 & 3,879 & 7.0 \\
\hline 30 and above & 63.6 & 21.4 & 11.7 & 3.4 & 19,335 & 0.0 \\
\hline Total & 38.6 & 31.0 & 22.5 & 7.9 & 37,167 & 5.0 \\
\hline
\end{tabular}

Note: All Ns are unweighted. Row totals may not equal 100\% due to missing cases or "don't know" responses. 'Includes nonliterate and literate with no formal schooling. 
Table 2.7: Work participation

Percentage distribution of the surveyed population aged 6 years and above by work participation, according to age, sex and residence, Tamil Nadu, 2006

\begin{tabular}{|l|r|r|r|r|r|r|r|r|r|}
\hline \multirow{2}{*}{ Age (years) (\%) } & \multicolumn{3}{|c|}{ Combined } & \multicolumn{3}{c|}{ Urban } & \multicolumn{3}{c|}{ Rural } \\
\cline { 2 - 13 } & Total & Male & Female & Total & Male & Female & Total & Male & Female \\
\hline $6-9$ & 0.2 & 0.3 & 0.2 & 0.2 & 0.2 & 0.1 & 0.3 & 0.3 & 0.3 \\
$10-14$ & 3.3 & 3.9 & 2.7 & 2.5 & 3.3 & 1.7 & 3.9 & 4.2 & 3.5 \\
$15-19$ & 30.8 & 39.6 & 21.9 & 25.4 & 34.6 & 16.4 & 34.8 & 43.2 & 26.1 \\
$20-24$ & 54.1 & 79.5 & 29.5 & 48.7 & 76.3 & 22.6 & 58.5 & 82.0 & 35.2 \\
$25-29$ & 64.4 & 95.0 & 37.4 & 58.6 & 94.9 & 26.3 & 69.3 & 95.0 & 46.6 \\
30 and above & 63.1 & 87.0 & 39.3 & 57.2 & 86.8 & 27.5 & 67.9 & 87.2 & 48.9 \\
Total & $\mathbf{4 8 . 5}$ & $\mathbf{6 7 . 2}$ & $\mathbf{3 0 . 1}$ & $\mathbf{4 4 . 3}$ & $\mathbf{6 7 . 3}$ & $\mathbf{2 1 . 6}$ & $\mathbf{5 1 . 9}$ & $\mathbf{6 7 . 0}$ & $\mathbf{3 6 . 8}$ \\
\hline
\end{tabular}

Note: Work participation is defined as reported work activity in the seven days prior to interview.

\subsection{Socio-demographic characteristics of households and heads of households}

Table 2.8 presents selected characteristics pertaining to households and their heads, according to residence, for all households as well as for those containing youth eligible for interview (that is, all young women aged 15-24 years, unmarried young men aged 15-24 years and married young men aged 15-29 years).

Findings suggest that heads of all households and households containing youth eligible for interview were overwhelmingly male, with similar distributions observed for heads of both rural and urban households. Age differences suggest that heads of households that contained youth eligible for interview in the Youth Study were somewhat older than heads of all households: for example, the age of the head of the household was 45 years or more among $61 \%$ of households that contained an eligible youth for interview compared to $56 \%$ of all households. Largely similar patterns were observed in rural and urban areas.

Table 2.8: Socio-demographic characteristics of households and heads of households

Percent distribution of all surveyed households and households containing youth eligible for interview by selected socio-demographic characteristics of heads of households, household size and type of family, according to residence, Tamil Nadu, 2006

\begin{tabular}{|l|c|c|c|c|c|c|}
\hline \multirow{2}{*}{$\begin{array}{l}\text { Socio-demographic } \\
\text { characteristics (\%) }\end{array}$} & \multicolumn{2}{|c|}{ Combined } & \multicolumn{2}{c|}{ Urban } & \multicolumn{3}{c|}{ Rural } \\
\cline { 2 - 8 } & $\begin{array}{c}\text { All } \\
\text { households }\end{array}$ & $\begin{array}{c}\text { Households } \\
\text { with youth }\end{array}$ & $\begin{array}{c}\text { All } \\
\text { households }\end{array}$ & $\begin{array}{c}\text { Households } \\
\text { with youth }\end{array}$ & $\begin{array}{c}\text { All } \\
\text { households }\end{array}$ & $\begin{array}{c}\text { Households } \\
\text { with youth }\end{array}$ \\
\hline $\begin{array}{l}\text { Sex of household head } \\
\text { Male }\end{array}$ & 86.0 & 89.2 & 87.1 & 89.3 & 85.1 & 89.1 \\
Female & 14.0 & 10.8 & 12.9 & 10.7 & 14.9 & 10.9 \\
Current age of household & & & & & & \\
head (years) & & & & & & \\
Below 25 & 1.0 & 2.7 & 0.9 & 2.2 & 1.2 & 3.0 \\
25-34 & 16.0 & 16.7 & 16.1 & 16.8 & 15.9 & 16.7 \\
35-44 & 27.5 & 19.7 & 28.1 & 18.7 & 27.0 & 20.4 \\
$45-54$ & 24.1 & 36.5 & 24.7 & 38.3 & 23.6 & 35.0 \\
55 and above & 31.4 & 24.5 & 30.2 & 24.0 & 32.3 & 24.9
\end{tabular}

Cont'd on next page... 
Table 2.8 (Cont'd)

\begin{tabular}{|c|c|c|c|c|c|c|}
\hline \multirow{2}{*}{$\begin{array}{l}\text { Socio-demographic } \\
\text { characteristics (\%) }\end{array}$} & \multicolumn{2}{|c|}{ Combined } & \multicolumn{2}{|c|}{ Urban } & \multicolumn{2}{|c|}{ Rural } \\
\hline & $\begin{array}{c}\text { All } \\
\text { households }\end{array}$ & $\begin{array}{l}\text { Households } \\
\text { with youth }\end{array}$ & $\begin{array}{c}\text { All } \\
\text { households }\end{array}$ & $\begin{array}{l}\text { Households } \\
\text { with youth }\end{array}$ & $\begin{array}{c}\text { All } \\
\text { households }\end{array}$ & $\begin{array}{l}\text { Households } \\
\text { with youth }\end{array}$ \\
\hline Religion of household head & & & & & & \\
\hline Hindu & 90.4 & 90.0 & 86.9 & 85.9 & 93.2 & 93.2 \\
\hline Muslim & 4.4 & 5.3 & 7.3 & 8.9 & 2.1 & 2.4 \\
\hline Christian & 5.1 & 4.6 & 5.5 & 5.0 & 4.7 & 4.4 \\
\hline Other $^{1}$ & 0.1 & 0.1 & 0.2 & 0.2 & 0.0 & 0.0 \\
\hline \multicolumn{7}{|l|}{$\begin{array}{l}\text { Caste/tribe of household } \\
\text { head }\end{array}$} \\
\hline $\mathrm{SC}$ & 22.7 & 24.7 & 18.8 & 21.0 & 25.8 & 27.5 \\
\hline ST & 1.1 & 1.1 & 0.3 & 0.4 & 1.7 & 1.7 \\
\hline OBC & 73.6 & 72.1 & 76.2 & 74.9 & 71.6 & 70.0 \\
\hline General $^{2}$ & 2.5 & 2.0 & 4.7 & 3.7 & 0.8 & 0.6 \\
\hline Caste/tribe unknown & 0.0 & 0.0 & 0.0 & 0.0 & 0.0 & 0.0 \\
\hline \multicolumn{7}{|l|}{$\begin{array}{l}\text { Schooling of household head } \\
\text { (years) }\end{array}$} \\
\hline None $^{3}$ & 29.1 & 26.7 & 18.9 & 18.1 & 37.1 & 33.5 \\
\hline $1-7$ & 29.6 & 32.2 & 26.3 & 28.7 & 32.2 & 34.8 \\
\hline $8-10$ & 25.3 & 26.9 & 30.0 & 31.5 & 21.6 & 23.4 \\
\hline $11-12$ & 6.9 & 6.7 & 9.3 & 9.1 & 4.9 & 4.8 \\
\hline Above 12 & 8.9 & 7.3 & 15.3 & 12.5 & 4.0 & 3.3 \\
\hline \multicolumn{7}{|l|}{$\begin{array}{l}\text { Current work status } \\
\text { of household head }\end{array}$} \\
\hline Working & 83.6 & 87.8 & 82.5 & 86.5 & 84.4 & 88.7 \\
\hline Not working & 16.4 & 12.2 & 17.5 & 13.5 & 15.6 & 11.3 \\
\hline \multicolumn{7}{|l|}{$\begin{array}{l}\text { Number of members in the } \\
\text { household }\end{array}$} \\
\hline 1 & 5.3 & 0.1 & 4.0 & 0.1 & 6.3 & 0.0 \\
\hline 2 & 12.8 & 4.7 & 12.4 & 4.8 & 13.1 & 4.7 \\
\hline 3 & 16.9 & 15.2 & 18.2 & 15.8 & 15.9 & 14.8 \\
\hline 4 & 28.5 & 30.0 & 31.1 & 31.9 & 26.4 & 28.5 \\
\hline 5 & 19.6 & 24.4 & 19.0 & 23.9 & 20.1 & 24.8 \\
\hline 6 & 9.6 & 13.3 & 8.8 & 12.1 & 10.3 & 14.3 \\
\hline 7 or more & 7.3 & 12.3 & 6.6 & 11.4 & 8.0 & 12.9 \\
\hline Mean household size & 4.1 & 4.8 & 4.1 & 4.7 & 4.1 & 4.8 \\
\hline \multicolumn{7}{|l|}{ Type of family } \\
\hline Nuclear & 69.0 & 60.2 & 69.2 & 61.7 & 68.8 & 59.0 \\
\hline Non-nuclear & 31.0 & 39.8 & 30.8 & 38.3 & 31.2 & 41.0 \\
\hline $\begin{array}{l}\text { Households with at least one } \\
\text { literate member aged } 18 \\
\text { and above }\end{array}$ & 86.9 & 95.4 & 92.2 & 97.3 & 82.7 & 94.0 \\
\hline Number of households & 35,880 & 11,569 & 15,880 & 5,106 & 20,000 & 6,463 \\
\hline
\end{tabular}

Note: All Ns are unweighted. Column totals may not equal 100\% due to missing cases or "don't know" responses. OBC: Other backward caste. SC: Scheduled caste. ST: Scheduled tribe. ${ }^{1}$ Includes Sikh, Jain, Jewish, Parsi/Zoroastrian and no specified religion. No respondent reported belonging to the Buddhist/Neo-Buddhist religion. ${ }^{2}$ Includes all those not belonging to SC, ST or OBC. ${ }^{3}$ Includes non-literate and literate with no formal schooling. ${ }^{4}$ Defined as reported work activity in the seven days prior to interview. 
Distributions by religion suggest that $90 \%$ of all surveyed household heads were Hindu, $4 \%$ were Muslim, 5\% were Christian and just $0.1 \%$ belonged to other religions. Distributions were largely similar among households containing youth eligible for interview in the Youth Study. Rural-urban differences among all household heads suggest that Muslims were somewhat more likely to reside in urban than rural areas $(7 \%$ and $2 \%$, respectively). With regard to caste, two groups-other backward castes (74\%) followed by scheduled castes (23\%) — dominated among all household heads. Others—-general castes and scheduled tribes—comprised less than $4 \%$ of heads of all households.

Educational attainment levels suggest that about three-fifths of all heads of households had either no schooling or 1-7 years of schooling; just as educational distributions differed for the general population, here too, heads of households in urban areas were more likely to be well-educated than their rural counterparts. The vast majority of all heads of households reported working in the last seven days (84\%), with negligible ruralurban differences.

Households contained an average of 4.1 members. This number was slightly higher (4.8) among households containing youth eligible for interview in the Youth Study. Rural-urban differences were negligible. As far as family type was concerned, about $69 \%$ of all households, irrespective of rural-urban residence, consisted of a nuclear family; households containing youth eligible for interview in the Youth Study were somewhat more likely to be non-nuclear (40\%), ranging from $38 \%$ in urban areas to $41 \%$ in rural areas.

Finally, about $87 \%$ of all households contained at least one literate member aged 18 and above, a percentage that was somewhat higher (95\%) in households containing eligible youth. Urban households were somewhat more likely than rural households to report a literate member aged 18 and above ( $92 \%$ and $83 \%$, respectively), but this difference virtually disappeared when households containing eligible youth were considered (97\% and $94 \%$, respectively).

\subsection{Profile of the household population: Housing characteristics}

Table 2.9 provides information on ownership of residence, housing quality, access to basic amenities and indicators of crowding. Information was obtained from responses to the household questionnaire and, in the case of housing type, interviewer observations. Information is presented by rural-urban residence separately for all surveyed households and households containing youth eligible for the Youth Study.

The characteristics of both types of households were basically similar. About three-fourths of households, irrespective of whether or not they contained youth, owned the structure in which they resided. Considerably more rural than urban households, however, reported owning their residence ( $88 \%$ and $58 \%$, respectively). Overall, interviewers observed that $16 \%$ of all households lived in kachcha houses (constructed from mud, thatch or other low-quality materials), $44 \%$ lived in semi-pucca houses (constructed using a mix of low- and high-quality materials) and $40 \%$ lived in pucca houses (constructed entirely from cement, masonry or other high-quality materials).

Most residential structures contained 2-3 rooms (59\%); urban households were somewhat more likely to report 4 or more rooms than rural households (19\% and $11 \%$ respectively). The mean number of persons per room was 2.2 for all households and 2.5 for those containing eligible youth. Rural-urban differences were small. 
Table 2.9: Housing characteristics

Percent distribution of all surveyed households and households containing youth eligible for interview by selected housing characteristics, according to residence, Tamil Nadu, 2006

\begin{tabular}{|c|c|c|c|c|c|c|}
\hline \multirow{2}{*}{$\begin{array}{l}\text { Housing } \\
\text { characteristics (\%) }\end{array}$} & \multicolumn{2}{|c|}{ Combined } & \multicolumn{2}{|c|}{ Urban } & \multicolumn{2}{|c|}{ Rural } \\
\hline & $\begin{array}{c}\text { All } \\
\text { households }\end{array}$ & $\begin{array}{l}\text { Households } \\
\text { with youth }\end{array}$ & $\begin{array}{c}\text { All } \\
\text { households }\end{array}$ & $\begin{array}{l}\text { Households } \\
\text { with youth }\end{array}$ & $\begin{array}{c}\text { All } \\
\text { households }\end{array}$ & $\begin{array}{l}\text { Households } \\
\text { with youth }\end{array}$ \\
\hline Ownership of residence & & & & & & \\
\hline Yes & 74.7 & 76.6 & 57.5 & 59.9 & 88.2 & 89.6 \\
\hline No & 25.3 & 23.4 & 42.5 & 40.1 & 11.8 & 10.4 \\
\hline Type of house & & & & & & \\
\hline Kachcha & 15.6 & 13.5 & 7.4 & 6.9 & 21.9 & 18.7 \\
\hline Semi-pucca & 44.2 & 44.3 & 39.0 & 38.9 & 48.3 & 48.4 \\
\hline Pucca & 40.2 & 42.2 & 53.5 & 54.2 & 29.8 & 32.9 \\
\hline $\begin{array}{l}\text { Number of rooms } \\
\text { in the house }{ }^{1}\end{array}$ & & & & & & \\
\hline 1 & 26.7 & 23.3 & 21.5 & 19.4 & 30.9 & 26.4 \\
\hline $2-3$ & 58.9 & 60.7 & 59.8 & 61.1 & 58.2 & 60.3 \\
\hline $4-5$ & 12.5 & 14.0 & 16.1 & 17.0 & 9.7 & 11.6 \\
\hline 6 or more & 1.9 & 2.0 & 2.6 & 2.5 & 1.3 & 1.7 \\
\hline $\begin{array}{l}\text { Average number of } \\
\text { persons per room }\end{array}$ & & & & & & \\
\hline Up to 2 & 74.0 & 68.2 & 78.5 & 73.6 & 70.5 & 64.0 \\
\hline $3-4$ & 18.1 & 21.7 & 15.9 & 18.9 & 19.8 & 24.0 \\
\hline $5-6$ & 6.8 & 8.2 & 4.9 & 6.1 & 8.3 & 9.8 \\
\hline More than 6 & 1.1 & 1.8 & 0.7 & 1.4 & 1.4 & 2.1 \\
\hline $\begin{array}{l}\text { Mean number of } \\
\text { persons per room }\end{array}$ & 2.2 & 2.5 & 2.0 & 2.3 & 2.3 & 2.6 \\
\hline Source of lighting & & & & & & \\
\hline Electricity & 90.9 & 93.3 & 95.1 & 96.2 & 87.5 & 90.9 \\
\hline Kerosene & 9.0 & 6.7 & 4.8 & 3.6 & 12.3 & 9.0 \\
\hline Other lighting sources ${ }^{2}$ & 0.1 & 0.1 & 0.2 & 0.1 & 0.1 & 0.1 \\
\hline Source of drinking water & & & & & & \\
\hline $\begin{array}{l}\text { Own piped water/ } \\
\text { hand-pump/covered well }\end{array}$ & 28.9 & 27.9 & 42.5 & 40.6 & 18.3 & 18.1 \\
\hline $\begin{array}{l}\text { Public piped water/ } \\
\text { hand-pump/covered well }\end{array}$ & 67.1 & 67.9 & 54.0 & 55.8 & 77.4 & 77.3 \\
\hline Own open well & 0.6 & 0.6 & 0.8 & 0.7 & 0.5 & 0.5 \\
\hline Public open well & 0.9 & 0.9 & 0.2 & 0.2 & 1.4 & 1.5 \\
\hline Surface water ${ }^{3}$ & 1.0 & 1.0 & 0.2 & 0.3 & 1.5 & 1.6 \\
\hline Other water sources ${ }^{4}$ & 1.5 & 1.6 & 2.4 & 2.5 & 0.9 & 0.9 \\
\hline
\end{tabular}


Table 2.9: (Cont'd)

\begin{tabular}{|c|c|c|c|c|c|c|}
\hline \multirow{2}{*}{$\begin{array}{l}\text { Housing } \\
\text { characteristics (\%) }\end{array}$} & \multicolumn{2}{|c|}{ Combined } & \multicolumn{2}{|c|}{ Urban } & \multicolumn{2}{|c|}{ Rural } \\
\hline & $\begin{array}{c}\text { All } \\
\text { households }\end{array}$ & $\begin{array}{l}\text { Households } \\
\text { with youth }\end{array}$ & $\begin{array}{c}\text { All } \\
\text { households }\end{array}$ & $\begin{array}{l}\text { Households } \\
\text { with youth }\end{array}$ & $\begin{array}{c}\text { All } \\
\text { households }\end{array}$ & $\begin{array}{l}\text { Households } \\
\text { with youth }\end{array}$ \\
\hline Toilet facility & & & & & & \\
\hline Own flush toilet & 34.4 & 34.2 & 56.1 & 55.9 & 17.4 & 17.2 \\
\hline Shared flush toilet & 5.9 & 5.5 & 11.6 & 10.7 & 1.4 & 1.3 \\
\hline Own pit toilet & 1.0 & 1.0 & 0.8 & 1.0 & 1.1 & 1.1 \\
\hline Shared pit toilet & 0.2 & 0.2 & 0.3 & 0.2 & 0.1 & 0.1 \\
\hline No toilet facility ${ }^{5}$ & 58.4 & 59.2 & 31.1 & 32.1 & 79.9 & 80.2 \\
\hline $\begin{array}{l}\text { Main type of fuel } \\
\text { used for cooking }\end{array}$ & & & & & & \\
\hline Liquid petroleum gas & 32.1 & 31.5 & 53.3 & 52.6 & 15.3 & 15.1 \\
\hline Bio-gas & 0.1 & 0.1 & 0.2 & 0.2 & 0.1 & 0.1 \\
\hline Kerosene & 8.7 & 8.4 & 16.3 & 16.3 & 2.7 & 2.3 \\
\hline $\begin{array}{l}\text { Wood/crop residue/ } \\
\text { dung cakes/coal/charcoal }\end{array}$ & 58.8 & 59.6 & 29.7 & 30.4 & 81.7 & 82.4 \\
\hline Other types of fuel ${ }^{6}$ & 0.3 & 0.3 & 0.5 & 0.5 & 0.1 & 0.2 \\
\hline Number of households & 35,880 & 11,569 & 15,880 & 5,106 & 20,000 & 6,463 \\
\hline
\end{tabular}

Note: All Ns are unweighted. Column totals may not equal $100 \%$ due to missing cases or "don't know" responses. ${ }^{1}$ Excludes toilets/bathrooms but includes kitchen. ${ }^{2}$ Includes oil, gas, etc. ${ }^{3}$ Includes water of a spring, river, stream, pond, lake or dam. ${ }^{4}$ Includes rain water and tanker truck. ${ }^{5}$ Other facilities, such as twin pit/composting and dry toilets, were not reported by any respondent. ${ }^{6}$ Includes electricity, straw, shrubs and grass.

Respondents were asked about their household's main source of lighting and drinking water. In addition, information was gathered on toilet facilities typically accessed and cooking fuel generally used. As Table 2.9 shows, $91 \%$ of all households had electricity, including almost all urban households (95\%) and $88 \%$ of all rural households (compared with $89 \%$ for Tamil Nadu as a whole as assessed in NFHS-3; IIPS and Macro International, 2007a). The majority of all households (96\%) reported that their main source of drinking water was either piped water, water obtained from a hand-pump or a covered well (while definitions differ somewhat, this compares with $94 \%$ as assessed in NFHS-3; IIPS and Macro International, 2007a). These facilities were reported as self-owned for almost one-third of households reporting as such, and as public or shared facilities for the remainder. While rural-urban differences in access to these safe sources of drinking water were virtually identical among all households (96-97\%), urban households were more likely than rural households to report that the facility was owned by the household ( $43 \%$ and $18 \%$, respectively).

Access to a toilet facility of any kind was reported by two-fifths of all households (42\%, compared to $43 \%$ as assessed in NFHS-3; IIPS and Macro International, 2007a): these included owned or shared flush toilets (34\% and $6 \%$, respectively). Just $1 \%$ reported owned or shared pit toilets. Large rural-urban differences were observed: $80 \%$ of rural households compared to $31 \%$ of urban households had no access to toilet facilities.

Finally, the main source of cooking fuel was wood, crop residue, dung cakes, coal or charcoal, reported by $59 \%$ of all households (compared to $61 \%$ as assessed in NFHS-3; IIPS and Macro International, 2007a). Rural-urban differences were evident; $82 \%$ of all rural households compared to $30 \%$ of urban households reported using wood, crop residue, dung cakes, coal or charcoal as their main source of cooking fuel. Liquid petroleum gas was used by $32 \%$ of all households, ranging from $15 \%$ in rural areas to $53 \%$ in urban areas. 
Patterns of access to these facilities in households containing youth eligible for interview in the Youth Study were similar to those observed for all households, described above.

\subsection{Profile of the household population: Ownership of agricultural land}

Table 2.10 presents information on ownership of agricultural land for households in both rural and urban areas (irrigated and non-irrigated). Most households, irrespective of whether or not they contained youth eligible for interview, owned no land (77-79\%) or owned only marginal holdings (15-17\%). The proportion of landless households was much higher for urban than rural households: (94\% and 68\%, respectively, among all surveyed households). Just $4 \%$ owned between 2.51 and 5 acres of land, and $1 \%$ owned more than 5 acres of land. Moreover, land holdings were, by and large, not irrigated. Even in rural areas, only $15 \%$ of all households owned any irrigated land.

Table 2.10: Household ownership of agricultural land

Percent distribution of all surveyed households and households containing youth eligible for interview by ownership of agricultural land, according to residence, Tamil Nadu, 2006

\begin{tabular}{|c|c|c|c|c|c|c|}
\hline \multirow[t]{2}{*}{ Land holding (\%) } & \multicolumn{2}{|c|}{ Combined } & \multicolumn{2}{|c|}{ Urban } & \multicolumn{2}{|c|}{ Rural } \\
\hline & $\begin{array}{c}\text { All } \\
\text { households }\end{array}$ & $\begin{array}{l}\text { Households } \\
\text { with youth }\end{array}$ & $\begin{array}{c}\text { All } \\
\text { households }\end{array}$ & $\begin{array}{l}\text { Households } \\
\text { with youth }\end{array}$ & $\begin{array}{c}\text { All } \\
\text { households }\end{array}$ & $\begin{array}{l}\text { Households } \\
\text { with youth }\end{array}$ \\
\hline Land holding (in acres) & & & & & & \\
\hline Landless & 79.1 & 76.6 & 93.7 & 93.1 & 67.6 & 63.8 \\
\hline Marginal $(\leq 2.50)$ & 15.1 & 17.1 & 3.7 & 4.2 & 24.0 & 27.2 \\
\hline Small (2.51-5.00) & 3.9 & 4.3 & 1.3 & 1.4 & 6.0 & 6.4 \\
\hline Medium (5.01-10.00) & 1.0 & 1.0 & 0.5 & 0.3 & 1.4 & 1.5 \\
\hline Large $(>10.00)$ & 0.3 & 0.3 & 0.2 & 0.3 & 0.4 & 0.4 \\
\hline Own any irrigated land & 9.4 & 10.4 & 2.8 & 2.9 & 14.6 & 16.3 \\
\hline Number of households & 35,880 & 11,569 & 15,880 & 5,106 & 20,000 & 6,463 \\
\hline
\end{tabular}

Note: All Ns are unweighted. Column totals may not equal 100\% due to missing cases or "don't know" responses.

\subsection{Profile of the household population: Overall economic status}

Household economic status was measured using a wealth index, composed of household asset data on ownership of selected durable goods, including means of transportation, as well as data on access to a number of amenities. The wealth index was constructed by allocating the following scores to a household's reported assets or amenities:

Type of house: 2 for pucca; 1 for semi-pucca; 0 for kachcha

Agricultural land owned: 4 for more than 10 acres; 3 for 5.1-10.0 acres; 2 for 2.6-5.0 acres; 1 for less than 2.6 acres, or if the household owns some land but does not know how much; 0 for no land

Irrigated land owned: 1 for any irrigated land; 0 for no land

Access to toilet facility: 4 for own flush toilet; 2 for shared flush toilet or own pit toilet; 1 for shared pit toilet or other types of toilet; 0 for no toilet facility

Cooking fuel used: 2 for liquid petroleum gas, electricity or bio-gas; 1 for kerosene, wood, crop residue, dung cakes, coal or charcoal; 0 for other types of cooking fuel, for example, straw, shrubs or grass 
Access to drinking water facility: 4 for own piped water, hand-pump or covered well; 3 for own open well; 2 for public or shared piped water, hand-pump or covered well; 1 for public or shared open well; 0 for other sources of drinking water, for example, surface water, tanker/truck or rainwater

Access to electricity: 3 for electricity; 0 for no electricity

Ownership of household assets: 4 for car or truck; 3 each for motorcycle or scooter, refrigerator, personal computer/ laptop, telephone (landline or mobile), colour television; 2 each for bicycle, electric fan, radio or transistor, black and white television, sewing machine, water pump, animal-drawn cart; 1 for watch or clock; 0 for each of the above items that the household does not possess.

Index scores, so constructed, ranged from 0 to 54. Households were then ranked according to the index score. This ranked sample was divided into quintiles-i.e., five groups, each containing an equal number of households - with the first quintile representing households of the lowest (poorest) wealth status and the fifth quintile representing households with the highest (wealthiest) status. In the Youth Study, the wealth quintiles were developed at the state level on the basis of the weighted sample for the whole state.

Findings are presented in Table 2.11. As far as ownership of household assets is concerned, the two items most likely to be owned by all households were a watch or clock (85\%) and an electric fan (73\%). Half of all households owned a bicycle (51\%) and two-fifths owned a radio or transistor (39\%). More than onethird of all households owned a colour television and one-fifth owned a black and white television set. Other items owned by one-fifth or more of all households included a telephone (26\%) and a motorcycle or scooter (22\%). Rural households were considerably less likely than urban households to report ownership of most items. For example, while $52 \%$ of all urban households owned a colour television set, just $23 \%$ of all rural households did; and while about two-fifths of all urban households (39\%) owned a telephone, just 15\% of all rural households did. A negligible percentage of households ( $9 \%$ of all households and $4 \%$ of those containing eligible youth) did not own a single item; again, rural households were more likely than urban households to report so $(13 \%$ and $6 \%$ of all households and those containing youth did not own a single item in rural areas, compared to $4 \%$ and $2 \%$, respectively, in urban areas).

The distribution of households by wealth quintiles shows that one-third of urban households were in the wealthiest (fifth) wealth quintile; in contrast, only $9 \%$ of rural households were in this quintile. Likewise, $29 \%$ of rural households were in the poorest (first) quintile of the index compared to only $9 \%$ of urban households.

\subsection{Profile of surveyed youth: Background characteristics}

A total of 7,996 youth were interviewed. Table 2.12 presents the socio-demographic characteristics of surveyed youth. Age profiles suggest that the unmarried were younger than the married. Among married young women, about one-sixth were between 15 and 19 years of age and remaining were aged 20-24 years; among the unmarried, in contrast, almost two-thirds were aged 15-19. Among young men, few of the married were between the ages of 15 and $19(0.2 \%)$, and the majority were aged 25-29 (81\%); the unmarried, in contrast, were more evenly distributed, with $54 \%$ and $47 \%$ aged $15-19$ and $20-24$, respectively. Among the 15-24 yearold population, gender differences were small: for example, $49 \%$ of young men and $46 \%$ of young women were in the 15-19 year age group. Rural-urban differences suggest that rural youth were somewhat younger than their urban counterparts.

The distribution of youth by religion and caste were fairly similar to those observed in the household population. For example, about nine in 10 youth were Hindu (ranging from $84-88 \%$ among those in urban settings to $92-94 \%$ among those in rural settings), and $4-6 \%$ were Muslim (ranging from $8-10 \%$ in urban 
Table 2.11: Household assets and wealth status

Percentage of all surveyed households and households containing youth eligible for interview owning selected household assets and percent distribution of households by wealth quintile, according to residence, Tamil Nadu, 2006

\begin{tabular}{|c|c|c|c|c|c|c|}
\hline \multirow{2}{*}{$\begin{array}{l}\text { Housing } \\
\text { characteristics (\%) }\end{array}$} & \multicolumn{2}{|c|}{ Combined } & \multicolumn{2}{|c|}{ Urban } & \multicolumn{2}{|c|}{ Rural } \\
\hline & $\begin{array}{c}\text { All } \\
\text { households }\end{array}$ & $\begin{array}{l}\text { Households } \\
\text { with youth }\end{array}$ & $\begin{array}{c}\text { All } \\
\text { households }\end{array}$ & $\begin{array}{l}\text { Households } \\
\text { with youth }\end{array}$ & $\begin{array}{c}\text { All } \\
\text { households }\end{array}$ & $\begin{array}{l}\text { Households } \\
\text { with youth }\end{array}$ \\
\hline Assets owned & & & & & & \\
\hline Watch/clock & 84.8 & 90.8 & 92.9 & 95.9 & 78.4 & 86.8 \\
\hline Electric fan & 72.7 & 76.5 & 87.0 & 88.9 & 61.5 & 66.9 \\
\hline Bicycle & 51.1 & 58.9 & 54.0 & 60.4 & 48.8 & 57.7 \\
\hline Radio and/or transistor & 38.6 & 42.0 & 45.4 & 47.5 & 33.3 & 37.7 \\
\hline Colour television & 35.7 & 38.1 & 51.8 & 53.8 & 23.0 & 25.8 \\
\hline $\mathrm{B} / \mathrm{W}$ television & 19.8 & 22.9 & 20.7 & 22.6 & 19.1 & 23.1 \\
\hline $\begin{array}{l}\text { Telephone (landline/ } \\
\text { mobile) }\end{array}$ & 25.5 & 26.9 & 38.8 & 40.1 & 15.1 & 16.7 \\
\hline Refrigerator & 12.4 & 11.3 & 22.4 & 20.5 & 4.4 & 4.1 \\
\hline Motorcycle/scooter & 22.3 & 23.5 & 31.9 & 32.7 & 14.8 & 16.4 \\
\hline Sewing machine & 9.0 & 10.4 & 14.0 & 15.0 & 5.2 & 6.8 \\
\hline Animal-drawn cart & 1.3 & 1.7 & 0.5 & 0.6 & 1.9 & 2.5 \\
\hline Water pump & 14.8 & 15.0 & 20.9 & 20.7 & 10.1 & 10.6 \\
\hline $\begin{array}{l}\text { Personal computer/ } \\
\text { laptop }\end{array}$ & 3.3 & 3.2 & 6.9 & 6.9 & 0.4 & 0.4 \\
\hline Car/truck & 2.4 & 2.0 & 4.4 & 3.7 & 0.7 & 0.7 \\
\hline Tractor & 0.4 & 0.5 & 0.2 & 0.2 & 0.6 & 0.8 \\
\hline Thresher & 0.1 & 0.1 & 0.1 & 0.1 & 0.1 & 0.1 \\
\hline None of the above & 8.9 & 4.1 & 3.7 & 1.7 & 13.0 & 6.1 \\
\hline Wealth quintile & & & & & & \\
\hline First & 20.0 & 14.5 & 9.0 & 6.5 & 28.7 & 20.7 \\
\hline Second & 20.0 & 20.7 & 12.8 & 12.4 & 25.7 & 27.2 \\
\hline Third & 20.0 & 22.1 & 18.6 & 19.6 & 21.1 & 24.1 \\
\hline Fourth & 20.0 & 22.5 & 26.0 & 27.7 & 15.3 & 18.4 \\
\hline Fifth & 20.0 & 20.2 & 33.6 & 33.7 & 9.3 & 9.6 \\
\hline Number of households & 35,880 & 11,569 & 15,880 & 5,106 & 20,000 & 6,463 \\
\hline
\end{tabular}

Note: All Ns are unweighted.

areas to $1-3 \%$ in rural areas). Caste-wise distributions suggest that the largest groups were other backward castes $(71-74 \%)$ and scheduled castes $(23-27 \%)$; the remaining $3 \%$ were from general castes and scheduled tribes. In view of the small numbers of youth from general castes and scheduled tribes, caste-wise differentials presented in subsequent tables exclude information on these two groups.

Educational distributions suggest that youth were better educated than the population at large, and that gender differences were hardly discernible. In total, $2 \%$ of young men and $5 \%$ of young women had no formal education (compared to $15 \%$ and $32 \%$, respectively, of the total population described in Table 2.6), and 26\% each had 12 or more years of education (compared to $18 \%$ and $13 \%$ of the total population). Differences were, nonetheless evident by marital status and rural-urban residence. Among married youth, for example, 
Table 2.12: Background characteristics of surveyed youth

Percent distribution of surveyed youth by selected background characteristics, according to residence, Tamil Nadu, 2006

\begin{tabular}{|c|c|c|c|c|c|c|c|c|c|c|c|c|}
\hline \multirow[t]{2}{*}{$\begin{array}{l}\text { Background } \\
\text { characteristics }\end{array}$} & \multicolumn{2}{|c|}{ 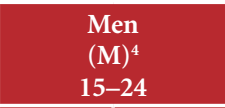 } & \multicolumn{2}{|c|}{$\begin{array}{c}\text { Women } \\
(\mathrm{W})^{4} \\
15-24 \\
\end{array}$} & \multicolumn{2}{|c|}{$\begin{array}{c}\text { Married } \\
\text { men }(\mathrm{MM})^{4} \\
15-29 \\
\end{array}$} & \multicolumn{2}{|c|}{$\begin{array}{c}\text { Married } \\
\text { women }(M W)^{4} \\
15-24 \\
\end{array}$} & \multicolumn{2}{|c|}{$\begin{array}{c}\text { Unmarried } \\
\text { men }(\mathrm{UM})^{4} \\
15-24 \\
\end{array}$} & \multicolumn{2}{|c|}{$\begin{array}{c}\text { Unmarried } \\
\text { women }(\mathrm{UW})^{4} \\
15-24 \\
\end{array}$} \\
\hline & Percent & Number & Percent & Number & Percent & Number & Percent & Number & Percent & Number & Percent & Number \\
\hline \multicolumn{13}{|c|}{ Combined } \\
\hline \multicolumn{13}{|l|}{ Age (years) } \\
\hline $15-19$ & 48.6 & 899 & 45.6 & 2,274 & 0.2 & 3 & 16.0 & 321 & 53.5 & 896 & 65.1 & 1,953 \\
\hline $20-24$ & 51.4 & 1,014 & 54.4 & 2,734 & 18.8 & 244 & 84.0 & 1,686 & 46.5 & 770 & 34.9 & 1,048 \\
\hline $25-29$ & NA & NA & NA & NA & 80.9 & 1,075 & NA & NA & NA & NA & $\mathrm{NA}$ & NA \\
\hline \multicolumn{13}{|l|}{ Religion } \\
\hline Hindu & 91.7 & 1,755 & 88.6 & 4,435 & 90.8 & 1,194 & 89.3 & 1,790 & 91.2 & 1,522 & 88.1 & 2,645 \\
\hline Muslim & 4.2 & 84 & 6.2 & 311 & 5.3 & 80 & 7.3 & 148 & 4.4 & 76 & 5.5 & 163 \\
\hline Christian & 3.9 & 70 & 5.2 & 260 & 3.6 & 43 & 3.3 & 68 & 4.1 & 64 & 6.4 & 192 \\
\hline Other $^{1}$ & 0.2 & 4 & 0.0 & 1 & 0.4 & 5 & 0.0 & 0 & 0.2 & 4 & 0.0 & 1 \\
\hline \multicolumn{13}{|l|}{ Caste } \\
\hline SC & 23.3 & 467 & 26.7 & 1,353 & 24.7 & 335 & 27.5 & 559 & 22.2 & 382 & 26.2 & 794 \\
\hline ST & 1.8 & 37 & 0.6 & 30 & 2.6 & 37 & 0.7 & 14 & 1.7 & 30 & 0.5 & 16 \\
\hline OBC & 73.7 & 1,385 & 70.8 & 3,532 & 71.9 & 939 & 70.4 & 1,406 & 74.8 & 1,231 & 71.1 & 2,126 \\
\hline General $^{2}$ & 1.0 & 19 & 1.9 & 92 & 0.8 & 11 & 1.4 & 27 & 1.1 & 18 & 2.2 & 65 \\
\hline No caste/do not know & 0.2 & 5 & 0.0 & 1 & 0.0 & 0 & 0.0 & 1 & 0.2 & 5 & 0.0 & 0 \\
\hline \multicolumn{13}{|l|}{ Educational level (years) } \\
\hline None $^{3}$ & 2.2 & 52 & 5.0 & 252 & 6.1 & 79 & 9.7 & 195 & 1.5 & 29 & 1.8 & 57 \\
\hline $1-7$ & 20.1 & 404 & 19.7 & 989 & 40.7 & 541 & 28.4 & 570 & 17.3 & 291 & 13.9 & 419 \\
\hline $8-11$ & 51.4 & 971 & 49.5 & 2,480 & 38.2 & 497 & 45.7 & 914 & 52.6 & 875 & 51.9 & 1,566 \\
\hline 12 and above & 26.2 & 485 & 25.9 & 1,287 & 15.0 & 205 & 16.1 & 328 & 28.5 & 470 & 32.3 & 959 \\
\hline \multicolumn{13}{|c|}{ Worked in last 12 months } \\
\hline Yes & 62.5 & 1,227 & 33.8 & 1,695 & 99.7 & 1,317 & 28.5 & 566 & 58.5 & 980 & 37.4 & 1,129 \\
\hline No & 37.4 & 684 & 66.1 & 3,312 & 0.3 & 5 & 71.5 & 1,441 & 41.4 & 684 & 62.6 & 1,871 \\
\hline \multicolumn{13}{|l|}{ Wealth quintile } \\
\hline First & 14.0 & 273 & 12.7 & 644 & 16.3 & 201 & 15.0 & 301 & 12.7 & 211 & 11.3 & 343 \\
\hline Second & 20.8 & 389 & 20.2 & 1,013 & 25.6 & 328 & 21.4 & 427 & 19.6 & 312 & 19.3 & 586 \\
\hline Third & 21.6 & 417 & 22.7 & 1,148 & 23.1 & 305 & 24.7 & 496 & 21.4 & 361 & 21.5 & 652 \\
\hline Fourth & 23.3 & 444 & 23.6 & 1,179 & 20.6 & 279 & 22.4 & 453 & 24.2 & 407 & 24.3 & 726 \\
\hline Fifth & 20.3 & 390 & 20.8 & 1,024 & 14.4 & 209 & 16.5 & 330 & 22.1 & 375 & 23.6 & 694 \\
\hline Total & 100.0 & 1,913 & 100.0 & 5,008 & 100.0 & 1,322 & 100.0 & 2,007 & 100.0 & 1,666 & 100.0 & 3,001 \\
\hline \multicolumn{13}{|c|}{ Urban } \\
\hline \multicolumn{13}{|l|}{ Age (years) } \\
\hline $15-19$ & 47.4 & 413 & 45.3 & 964 & 0.2 & 1 & 12.0 & 96 & 51.7 & 412 & 64.6 & 868 \\
\hline $20-24$ & 52.6 & 477 & 54.7 & 1,187 & 15.4 & 100 & 88.0 & 708 & 48.3 & 377 & 35.4 & 479 \\
\hline $25-29$ & NA & NA & NA & NA & 84.4 & 552 & NA & NA & NA & NA & NA & NA \\
\hline \multicolumn{13}{|l|}{ Religion } \\
\hline Hindu & 88.2 & 790 & 83.8 & 1,801 & 85.5 & 564 & 82.8 & 665 & 88.0 & 699 & 84.5 & 1,136 \\
\hline Muslim & 7.9 & 70 & 10.3 & 223 & 9.9 & 66 & 13.0 & 104 & 8.0 & 63 & 8.7 & 119 \\
\hline Christian & 3.6 & 28 & 5.8 & 125 & 4.1 & 19 & 4.1 & 34 & 3.7 & 25 & 6.8 & 91 \\
\hline Other $^{1}$ & 0.2 & 2 & 0.0 & 1 & 0.6 & 4 & 0.0 & 0 & 0.3 & 2 & 0.1 & 1 \\
\hline \multicolumn{13}{|l|}{ Caste } \\
\hline SC & 20.5 & 191 & 20.9 & 452 & 21.7 & 151 & 20.7 & 170 & 19.7 & 160 & 21.0 & 282 \\
\hline ST & 0.2 & 2 & 0.7 & 16 & 0.6 & 4 & 0.9 & 7 & 0.1 & 1 & 0.7 & 9 \\
\hline OBC & 77.2 & 680 & 74.6 & 1,601 & 75.9 & 487 & 75.1 & 601 & 78.1 & 612 & 74.3 & 1,000 \\
\hline General $^{2}$ & 2.0 & 17 & 3.7 & 81 & 1.8 & 11 & 3.2 & 25 & 2.1 & 16 & 4.1 & 56 \\
\hline No caste/do not know & 0.0 & 0 & 0.0 & 1 & 0.0 & 0 & 0.1 & 1 & 0.0 & 0 & 0.0 & 0 \\
\hline
\end{tabular}


Table 2.12: (Cont'd)

\begin{tabular}{|c|c|c|c|c|c|c|c|c|c|c|c|c|}
\hline \multirow[t]{2}{*}{$\begin{array}{l}\text { Background } \\
\text { characteristics }\end{array}$} & \multicolumn{2}{|c|}{ 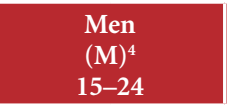 } & \multicolumn{2}{|c|}{$\begin{array}{l}\text { Women } \\
(W)^{4} \\
15-24\end{array}$} & \multicolumn{2}{|c|}{$\begin{array}{c}\text { Married } \\
\text { men }(\mathrm{MM})^{4} \\
15-29\end{array}$} & \multicolumn{2}{|c|}{$\begin{array}{c}\text { Married } \\
\text { women }(\mathrm{MW})^{4} \\
15-24\end{array}$} & \multicolumn{2}{|c|}{$\begin{array}{c}\text { Unmarried } \\
\text { men (UM) } \\
15-24\end{array}$} & \multicolumn{2}{|c|}{$\begin{array}{c}\text { Unmarried } \\
\text { women }(\mathrm{UW})^{4} \\
15-24\end{array}$} \\
\hline & Percent & Number & Percent & Number & Percent & Number & Percent & Number & Percent & Number & Percent & Number \\
\hline \multicolumn{13}{|c|}{ Urban } \\
\hline \multicolumn{13}{|l|}{ Educational level (years) } \\
\hline None $^{3}$ & 1.2 & 12 & 3.2 & 70 & 2.6 & 17 & 7.0 & 56 & 0.9 & 8 & 1.0 & 14 \\
\hline $1-7$ & 18.5 & 182 & 17.1 & 369 & 39.2 & 259 & 25.2 & 203 & 15.8 & 132 & 12.3 & 166 \\
\hline $8-11$ & 48.0 & 424 & 46.1 & 989 & 38.1 & 248 & 45.7 & 366 & 48.8 & 384 & 46.3 & 623 \\
\hline 12 and above & 32.3 & 272 & 33.6 & 723 & 20.1 & 129 & 22.1 & 179 & 34.5 & 265 & 40.4 & 544 \\
\hline Worked in last 12 months & & & & & & & & & & & & \\
\hline Yes & 59.0 & 539 & 24.0 & 510 & 99.4 & 649 & 15.3 & 122 & 55.2 & 438 & 29.0 & 388 \\
\hline No & 40.9 & 350 & 76.0 & 1,640 & 0.6 & 4 & 84.7 & 682 & 44.7 & 350 & 70.9 & 958 \\
\hline \multicolumn{13}{|l|}{ Wealth quintile } \\
\hline First & 6.5 & 62 & 5.5 & 121 & 7.5 & 50 & 7.4 & 60 & 6.2 & 51 & 4.4 & 61 \\
\hline Second & 11.9 & 109 & 11.7 & 252 & 17.6 & 115 & 13.1 & 105 & 10.4 & 81 & 11.0 & 147 \\
\hline Third & 18.7 & 171 & 19.9 & 430 & 21.3 & 143 & 22.6 & 183 & 18.3 & 149 & 18.3 & 247 \\
\hline Fourth & 27.6 & 245 & 28.7 & 615 & 28.3 & 181 & 28.8 & 231 & 27.7 & 219 & 28.7 & 384 \\
\hline Fifth & 35.4 & 303 & 34.2 & 733 & 25.2 & 164 & 28.1 & 225 & 37.3 & 289 & 37.7 & 508 \\
\hline Total & 100.0 & 890 & 100.0 & 2,151 & 100.0 & 653 & 100.0 & 804 & 100.0 & 789 & 100.0 & 1,347 \\
\hline \multicolumn{13}{|c|}{ Rural } \\
\hline Age (years) & & & & & & & & & & & & \\
\hline $15-19$ & 49.6 & 486 & 45.8 & 1,310 & 0.3 & 2 & 18.6 & 225 & 55.1 & 484 & 65.5 & 1,085 \\
\hline $20-24$ & 50.4 & 537 & 54.2 & 1,547 & 21.2 & 144 & 81.4 & 978 & 44.9 & 393 & 34.5 & 569 \\
\hline $25-29$ & NA & NA & NA & NA & 78.6 & 523 & NA & NA & NA & NA & NA & NA \\
\hline \multicolumn{13}{|l|}{ Religion } \\
\hline Hindu & 94.3 & 965 & 92.3 & 2,634 & 94.4 & 630 & 93.7 & 1,125 & 93.9 & 823 & 91.3 & 1,509 \\
\hline Muslim & 1.4 & 14 & 3.0 & 88 & 2.2 & 14 & 3.4 & 44 & 1.5 & 13 & 2.6 & 44 \\
\hline Christian & 4.1 & 42 & 4.7 & 135 & 3.3 & 24 & 2.8 & 34 & 4.4 & 39 & 6.1 & 101 \\
\hline Other $^{1}$ & 0.2 & 2 & 0.0 & 0 & 0.1 & 1 & 0.0 & 0 & 0.2 & 2 & 0.0 & 0 \\
\hline \multicolumn{13}{|l|}{ Caste } \\
\hline SC & 25.5 & 276 & 31.4 & 901 & 26.8 & 184 & 32.1 & 389 & 24.3 & 222 & 30.8 & 512 \\
\hline ST & 2.9 & 35 & 0.5 & 14 & 4.1 & 33 & 0.6 & 7 & 2.9 & 29 & 0.4 & 7 \\
\hline OBC & 70.9 & 705 & 67.8 & 1,931 & 69.1 & 452 & 67.2 & 805 & 72.0 & 619 & 68.2 & 1,126 \\
\hline General $^{2}$ & 0.3 & 2 & 0.4 & 11 & 0.0 & 0 & 0.2 & 2 & 0.3 & 2 & 0.5 & 9 \\
\hline No caste/do not know & 0.4 & 5 & 0.0 & 0 & 0.0 & 0 & 0.0 & 0 & 0.4 & 5 & 0.0 & 0 \\
\hline Educational level (years) & & & & & & & & & & & & \\
\hline None $^{3}$ & 3.0 & 40 & 6.3 & 182 & 8.6 & 62 & 11.5 & 139 & 2.0 & 21 & 2.6 & 43 \\
\hline $1-7$ & 21.3 & 222 & 21.7 & 620 & 41.8 & 282 & 30.6 & 367 & 18.6 & 159 & 15.4 & 253 \\
\hline $8-11$ & 54.1 & 547 & 52.2 & 1,491 & 38.1 & 249 & 45.7 & 548 & 55.8 & 491 & 56.9 & 943 \\
\hline 12 and above & 21.5 & 213 & 19.7 & 564 & 11.4 & 76 & 12.2 & 149 & 23.5 & 205 & 25.2 & 415 \\
\hline \multicolumn{13}{|l|}{ Worked in last 12 months } \\
\hline Yes & 65.2 & 688 & 41.7 & 1,185 & 99.9 & 668 & 37.4 & 444 & 61.2 & 542 & 44.7 & 741 \\
\hline No & 34.7 & 334 & 58.3 & 1,672 & 0.1 & 1 & 62.6 & 759 & 38.7 & 334 & 55.3 & 913 \\
\hline \multicolumn{13}{|l|}{ Wealth quintile } \\
\hline First & 19.7 & 211 & 18.5 & 523 & 22.5 & 151 & 20.2 & 241 & 17.9 & 160 & 17.2 & 282 \\
\hline Second & 27.6 & 280 & 26.9 & 761 & 31.1 & 213 & 27.0 & 322 & 27.0 & 231 & 26.8 & 439 \\
\hline Third & 23.8 & 246 & 25.0 & 718 & 24.4 & 162 & 26.0 & 313 & 23.9 & 212 & 24.3 & 405 \\
\hline Fourth & 20.0 & 199 & 19.5 & 564 & 15.3 & 98 & 18.1 & 222 & 21.5 & 188 & 20.5 & 342 \\
\hline Fifth & 8.8 & 87 & 10.1 & 291 & 6.8 & 45 & 8.7 & 105 & 9.8 & 86 & 11.2 & 186 \\
\hline Total & 100.0 & 1,023 & 100.0 & 2,857 & 100.0 & 669 & 100.0 & 1,203 & 100.0 & 877 & 100.0 & 1,654 \\
\hline
\end{tabular}

Note: All Ns are unweighted. Column totals may not equal 100\% due to missing cases or "don't know" responses. NA: Not applicable. OBC: Other backward caste. SC: Scheduled caste. ST: Scheduled tribe. ${ }^{1}$ Includes Sikh, Jain, Jewish, Parsi/Zoroastrian and no specified religion. No respondent reported belonging to the Buddhist/Neo-Buddhist religion. ${ }^{2}$ Includes all those not belonging to SC, ST or OBC. ${ }^{3}$ Includes non-literate and literate with no formal schooling. ${ }^{4}$ These abbreviations have been used in subsequent tables in this report. 
$6 \%$ of young men and $10 \%$ of young women had no formal education and $15 \%$ and $16 \%$, respectively, had attained 12 or more years of education. Among the unmarried, in contrast, even fewer-2\%—of both young men and women had no formal education while larger percentages-29-32\%—had more than 12 years of education. Urban youth were generally better educated than rural youth: for example, while about one-third of urban youth had completed 12 or more years of education, just one-fifth of rural youth had done so.

Gender differences were wide with regard to work status: $63 \%$ of young men compared to $34 \%$ of young women had ever worked in paid or unpaid activities in the 12 months preceding the interview. Marital status differences suggest that while among young men, it was the married who were more likely than the unmarried to be engaged in work activities, the opposite was true among young women. For example, while almost all married young men had worked in the year preceding the interview, 59\% of unmarried young men had done so. Among young women, in contrast, $29 \%$ of the married and $37 \%$ of the unmarried had worked in the year preceding the interview. Also evident is that while slightly more rural than urban young men were engaged in work activities (65\% and 59\%, respectively), women in rural areas were considerably more likely to report work than their urban counterparts ( $42 \%$ and $24 \%$, respectively).

Economic status distributions, as measured by wealth quintiles, show some variation from household distributions. Gender differences were narrow but the married were generally more likely than were the unmarried to be concentrated in households in the poorer quintiles. For example, $16 \%$ and $15 \%$ of married young men and women compared to $13 \%$ and $11 \%$, respectively, of the unmarried fell into households in the poorest (first) quintile; conversely, $14 \%$ and $17 \%$ of married young men and women compared to $22-24 \%$ of the unmarried fell into households in the wealthiest (fifth) quintile. Rural-urban differences were wide, with rural youth more likely than their urban counterparts to be concentrated in households in the poorer wealth quintiles (for example, 19-20\% of rural youth compared to 6-7\% of urban youth fell into the poorest quintile). Conversely, more urban than rural youth belonged to households in the wealthiest quintile (34-35\% and 9-10\%, respectively).

\subsection{Profile of surveyed youth: Parental characteristics}

The Youth Study inquired about the socio-demographic characteristics of respondents' parents, including their survival status, education and occupation. Findings presented in Table 2.13 suggest that among over four in five respondents both parents were surviving. While $86-87 \%$ of unmarried young men and women reported that both parents were alive, fewer married youth reported so ( $71 \%$ and $79 \%$, respectively). Married young men were least likely to report that both parents were living, clearly a function of the fact that married young men in our sample were older than married young women. Rural-urban differences were generally narrow. For those with just one parent surviving, this parent was more likely to be the mother (11-13\%) than the father $(2-3 \%)$. Finally, $1 \%$ of youth reported that neither parent was alive.

Parents' educational attainment was considerably lower than that of youth respondents. For example, the median number of years of education completed by fathers of young men and women was 5 years. While fathers of unmarried young men had an average of 5 years of education, the majority of fathers of married young men had never been to school. Likewise, fathers of unmarried young women were generally better educated than the fathers of married young women ( 7 and 5 years of education, respectively). Rural-urban differences were wide, with rural fathers having completed a median of 5 years of education compared to 8 years among urban fathers. Maternal education levels were much lower than those of fathers, with a median of 2-3 years of schooling attained. Wide differences were observed, however, by marital status and residence of respondents: mothers of the unmarried typically had 4 years of schooling while the majority of mothers of the married had never been to school. Mothers of urban youth were considerably better educated than 
Table 2.13: Parental characteristics of surveyed youth

Percent distribution of surveyed youth by parental characteristics, according to residence, Tamil Nadu, 2006

\begin{tabular}{|c|c|c|c|c|c|c|}
\hline Parental characteristics (\%) & $\begin{array}{c}\mathrm{M} \\
15-24\end{array}$ & $\begin{array}{c}\mathrm{W} \\
15-24\end{array}$ & $\begin{array}{c}\text { MM } \\
15-29\end{array}$ & $\begin{array}{c}\text { MW } \\
15-24\end{array}$ & $\begin{array}{c}\text { UM } \\
15-24\end{array}$ & $\begin{array}{c}\text { UW } \\
15-24\end{array}$ \\
\hline \multicolumn{7}{|c|}{ Combined } \\
\hline \multicolumn{7}{|l|}{ Survival status } \\
\hline Both parents dead & 1.1 & 1.4 & 4.5 & 2.3 & 0.8 & 0.8 \\
\hline Only father alive & 1.8 & 2.7 & 5.2 & 3.9 & 1.6 & 1.9 \\
\hline Only mother alive & 11.4 & 12.5 & 19.4 & 15.1 & 11.0 & 10.7 \\
\hline Both parents alive & 85.6 & 83.4 & 71.0 & 78.6 & 86.4 & 86.6 \\
\hline \multicolumn{7}{|l|}{ Educational attainment level } \\
\hline Median years of schooling of father & 5.0 & 5.0 & $\mathrm{NC}$ & 5.0 & 5.0 & 7.0 \\
\hline Median years of schooling of mother & 3.0 & 2.0 & $\mathrm{NC}$ & $\mathrm{NC}$ & 4.0 & 4.0 \\
\hline \multicolumn{7}{|l|}{ Current/last occupational status of father } \\
\hline Cultivator & 4.8 & 9.6 & 4.1 & 11.4 & 4.9 & 8.4 \\
\hline Agricultural labourer & 36.4 & 34.0 & 45.7 & 37.2 & 34.6 & 31.8 \\
\hline Administrative/executive/managerial/clerical & 7.6 & 7.8 & 4.1 & 4.8 & 8.0 & 9.7 \\
\hline Business & 5.3 & 7.3 & 4.2 & 6.9 & 5.6 & 7.6 \\
\hline Skilled manual/machinery & 25.6 & 22.5 & 22.6 & 21.4 & 26.4 & 23.2 \\
\hline Unskilled non-agricultural labourer & 17.4 & 17.1 & 16.9 & 16.6 & 17.6 & 17.4 \\
\hline Other & 0.9 & 0.5 & 1.1 & 0.5 & 0.9 & 0.6 \\
\hline Never worked & 1.1 & 0.8 & 1.2 & 0.8 & 1.0 & 0.8 \\
\hline \multicolumn{7}{|l|}{ Current/last occupational status of mother } \\
\hline Cultivator & 1.7 & 5.1 & 1.4 & 6.0 & 1.7 & 4.6 \\
\hline Agricultural labourer & 25.2 & 26.6 & 31.8 & 31.7 & 23.8 & 23.2 \\
\hline Administrative/executive/managerial/clerical & 1.4 & 2.2 & 1.2 & 1.1 & 1.6 & 3.0 \\
\hline Business & 0.2 & 1.5 & 0.3 & 1.8 & 0.2 & 1.3 \\
\hline Skilled manual/machinery & 7.1 & 7.8 & 5.4 & 6.8 & 7.1 & 8.5 \\
\hline Unskilled non-agricultural labourer & 5.2 & 7.2 & 5.3 & 7.7 & 5.1 & 6.9 \\
\hline Other & 0.2 & 0.1 & 0.2 & 0.2 & 0.2 & 0.1 \\
\hline Housewife/never worked & 58.4 & 49.0 & 54.0 & 44.3 & 59.8 & 52.0 \\
\hline Number of respondents & 1,913 & 5,008 & 1,322 & 2,007 & 1,666 & 3,001 \\
\hline \multicolumn{7}{|c|}{ Urban } \\
\hline \multicolumn{7}{|l|}{ Survival status } \\
\hline Both parents dead & 1.1 & 1.2 & 3.7 & 2.1 & 0.9 & 0.7 \\
\hline Only father alive & 1.1 & 2.5 & 5.1 & 3.7 & 1.1 & 1.8 \\
\hline Only mother alive & 12.4 & 12.0 & 22.1 & 15.5 & 12.3 & 10.0 \\
\hline Both parents alive & 85.5 & 84.3 & 69.1 & 78.7 & 85.7 & 87.5 \\
\hline \multicolumn{7}{|l|}{ Educational attainment level } \\
\hline Median years of schooling of father & 8.0 & 8.0 & 5.0 & 5.0 & 8.0 & 8.0 \\
\hline Median years of schooling of mother & 5.0 & 5.0 & NC & NC & 5.0 & 6.0 \\
\hline \multicolumn{7}{|l|}{ Current/last occupational status of father } \\
\hline Cultivator & 0.8 & 4.1 & 1.1 & 6.6 & 0.9 & 2.6 \\
\hline Agricultural labourer & 12.2 & 14.4 & 21.2 & 19.8 & 11.2 & 11.2 \\
\hline Administrative/executive/managerial/clerical & 11.9 & 13.1 & 6.1 & 7.2 & 12.4 & 16.5 \\
\hline
\end{tabular}




\begin{tabular}{|c|c|c|c|c|c|c|}
\hline Parental characteristics (\%) & $\begin{array}{c}M \\
15-24\end{array}$ & $\begin{array}{c}W \\
15-24\end{array}$ & $\begin{array}{c}\text { MM } \\
15-29\end{array}$ & $\begin{array}{c}\text { MW } \\
15-24\end{array}$ & $\begin{array}{c}\text { UM } \\
15-24\end{array}$ & $\begin{array}{c}\text { UW } \\
15-24\end{array}$ \\
\hline \multicolumn{7}{|c|}{ Urban } \\
\hline Business & 9.0 & 11.1 & 7.6 & 9.9 & 9.2 & 11.7 \\
\hline Skilled manual/machinery & 38.5 & 32.5 & 36.6 & 32.0 & 38.9 & 32.8 \\
\hline Unskilled non-agricultural labourer & 24.8 & 22.8 & 24.9 & 22.7 & 24.5 & 22.7 \\
\hline Other & 1.1 & 0.8 & 1.3 & 0.6 & 1.1 & 0.9 \\
\hline Never worked & 1.3 & 0.8 & 1.1 & 0.9 & 1.3 & 0.7 \\
\hline \multicolumn{7}{|l|}{ Current/last occupational status of mother } \\
\hline Cultivator & 0.1 & 1.3 & 0.4 & 2.0 & 0.1 & 0.9 \\
\hline Agricultural labourer & 7.7 & 7.4 & 11.4 & 11.5 & 7.0 & 5.0 \\
\hline Administrative/executive/managerial/clerical & 2.5 & 3.4 & 1.1 & 1.2 & 2.8 & 4.7 \\
\hline Business & 0.2 & 2.0 & 0.2 & 2.6 & 0.3 & 1.7 \\
\hline Skilled manual/machinery & 7.9 & 9.2 & 6.4 & 8.3 & 7.9 & 9.7 \\
\hline Unskilled non-agricultural labourer & 7.1 & 11.3 & 7.7 & 12.4 & 7.0 & 10.7 \\
\hline Other & 0.4 & 0.2 & 0.6 & 0.4 & 0.3 & 0.1 \\
\hline Housewife/never worked & 73.8 & 65.0 & 72.2 & 61.6 & 74.5 & 66.9 \\
\hline Number of respondents & 890 & 2,151 & 653 & 804 & 789 & 1,347 \\
\hline \multicolumn{7}{|c|}{ Rural } \\
\hline Survival status & & & & & & \\
\hline Both parents dead & 1.1 & 1.5 & 5.1 & 2.5 & 0.7 & 0.9 \\
\hline Only father alive & 2.3 & 2.9 & 5.3 & 4.1 & 2.1 & 2.1 \\
\hline Only mother alive & 10.7 & 12.9 & 17.6 & 14.9 & 10.1 & 11.3 \\
\hline Both parents alive & 85.6 & 82.7 & 72.1 & 78.5 & 86.8 & 85.7 \\
\hline \multicolumn{7}{|l|}{ Educational attainment level } \\
\hline Median years of schooling of father & 5.0 & 5.0 & $\mathrm{NC}$ & 4.0 & 5.0 & 5.0 \\
\hline Median years of schooling of mother & $\mathrm{NC}$ & NC & NC & NC & NC & NC \\
\hline \multicolumn{7}{|l|}{ Current/last occupational status of father } \\
\hline Cultivator & 7.8 & 13.9 & 6.3 & 14.6 & 8.1 & 13.5 \\
\hline Agricultural labourer & 55.0 & 49.5 & 62.8 & 48.9 & 53.5 & 50.0 \\
\hline Administrative/executive/managerial/clerical & 4.2 & 3.5 & 2.7 & 3.3 & 4.5 & 3.8 \\
\hline Business & 2.4 & 4.3 & 1.7 & 4.9 & 2.6 & 3.9 \\
\hline Skilled manual/machinery & 15.7 & 14.6 & 12.8 & 14.2 & 16.2 & 14.8 \\
\hline Unskilled non-agricultural labourer & 11.7 & 12.6 & 11.3 & 12.4 & 11.9 & 12.7 \\
\hline Other & 0.8 & 0.3 & 0.9 & 0.4 & 0.8 & 0.3 \\
\hline Never worked & 0.9 & 0.8 & 1.4 & 0.8 & 0.9 & 0.9 \\
\hline \multicolumn{7}{|l|}{ Current/last occupational status of mother } \\
\hline Cultivator & 2.9 & 8.2 & 2.3 & 8.8 & 2.9 & 7.8 \\
\hline Agricultural labourer & 38.7 & 41.9 & 46.1 & 45.4 & 37.5 & 39.3 \\
\hline Administrative/executive/managerial/clerical & 0.6 & 1.3 & 1.3 & 1.0 & 0.5 & 1.5 \\
\hline Business & 0.1 & 1.1 & 0.3 & 1.3 & 0.1 & 0.9 \\
\hline Skilled manual/machinery & 6.5 & 6.8 & 4.6 & 5.8 & 6.5 & 7.5 \\
\hline Unskilled non-agricultural labourer & 3.7 & 3.9 & 3.6 & 4.4 & 3.6 & 3.5 \\
\hline Other & 0.1 & 0.1 & 0.0 & 0.1 & 0.1 & 0.1 \\
\hline Housewife/never worked & 46.8 & 36.3 & 41.3 & 32.7 & 47.9 & 38.9 \\
\hline Number of respondents & 1,023 & 2,857 & 669 & 1,203 & 877 & 1,654 \\
\hline
\end{tabular}

Note: All Ns are unweighted. Column totals may not equal 100\% due to missing cases or "don't know" responses. NC: Not calculated, as more than $50 \%$ had no formal education. 
those of rural youth: mothers of urban youth typically had 5 years of schooling while the majority of mothers of rural youth had never been to school. The finding that parents of the unmarried were typically better educated than parents of the married may be attributed to the fact that better educated parents are more likely than the poorly educated to delay the marriage of their children.

The Youth Study also inquired about the current or last main occupation of respondents' parents. Main occupational distributions suggest that few parents were working on their own farm-fathers of just $5 \%$ and $10 \%$ of young men and women, respectively, and mothers of $2 \%$ and $5 \%$, respectively, of young men and women. Many more- $34-36 \%$ of fathers and $25-27 \%$ of mothers - were agricultural labourers. In addition, $23-26 \%$ of fathers and $7-8 \%$ of mothers were engaged in skilled manual occupations; and $17 \%$ of fathers and $5-7 \%$ of mothers were unskilled non-agricultural labourers. About $8 \%$ and $1-2 \%$ of fathers and mothers, respectively, were in administrative, executive, managerial or clerical occupations, and $5-7 \%$ of fathers and less than $2 \%$ of mothers were engaged in their own business. Finally, mothers of $58 \%$ and $49 \%$ of young men and women, respectively, were housewives; just a handful of fathers (1\%) had never worked. Differences by marital status were narrow, but more parents of the married than the unmarried were engaged in agricultural labour, and conversely more fathers of the unmarried than the married were engaged in administrative, executive, managerial or clerical occupations. Rural-urban differences were evident, particularly in the occupational distributions of fathers. While rural parents were largely cultivators and agricultural labourers, urban parents-particularly fathers-were more likely than their rural counterparts to be concentrated in skilled manual occupations, unskilled non-agricultural activities, and administrative, executive, managerial or clerical occupations, and in the case of mothers, in housework. 
Young people in India are spending more of their adolescent years acquiring an education than ever before. Educational attainment has increased, the percentage that has never been to school has declined and gender differences in educational attainment levels have diminished (Office of the Registrar General and Census Commissioner, 2001e). This does not mean, however, that schooling is universal or that gender differences are no longer a concern. Attainment of primary school education is still far from universal, especially among girls; differences by caste, religion, region and poverty levels persist; and the quality of education varies widely for different sub-groups of youth. This chapter examines the schooling experiences of youth in terms of educational attainment, quality of schools and colleges attended, and socio-economic differences in the type and quality of education experienced.

\subsection{Educational attainment}

The Youth Study obtained information on whether the respondent had ever been to school and, if so, the number of years of schooling successfully completed. Current schooling status was also assessed, and a Life Event Calendar inquired about the schooling status of all respondents from the age of 12. Findings are presented in Table 3.1 .

Findings highlight that the vast majority of youth in Tamil Nadu-94\% of young men and $91 \%$ of young women - had attained at least 5 years of schooling. Differences by marital status were wide: $96 \%$ of unmarried young men and women compared to $83 \%$ of their married counterparts had completed at least 5 years of schooling. Educational attainment levels suggest that irrespective of sex and marital status, youth had on average, 8-10 years of schooling; unmarried youth typically had 2 more years of schooling than married youth, and urban youth typically had 1 more year of schooling than rural youth.

It is notable that about half of all youth-51\% of young men and $48 \%$ of young women-had completed high school (Class 10). Wide differences were observed, by marital status and rural-urban residence. For example, married youth were considerably less likely than the unmarried to have completed high school (28\% and $55 \%$, respectively, among young men; $32 \%$ and $58 \%$, respectively, among young women). Likewise, rural youth were less likely than urban youth to have completed high school (46\% and 57\% among young men, respectively; $41 \%$ and $57 \%$ among young women, respectively). We note that disparities by marital status may be even wider than what is reflected here because the unmarried were younger and more likely to be pursuing their education at the time of interview.

At the time of interview, $38 \%$ of young men compared to $27 \%$ of young women were in school or college. These gender differences were strongly influenced by marital status distributions of youth. Indeed, gender differences disappeared when the married and unmarried were considered separately: $42 \%$ and $44 \%$ of unmarried young men and women, respectively, were still studying, compared to hardly any married youth ( $1 \%$ and $2 \%$ of young men and women, respectively). Among the unmarried, in addition, rural-urban 
differences were pronounced, with urban youth more likely to be studying at the time of interview than their rural counterparts: somewhat so among young men (45\% versus $39 \%)$ and considerably so among young women $(53 \%$ versus $36 \%)$.

Table 3.1: Educational attainment and current educational status

Percent distribution of youth by years of schooling successfully completed, median years of schooling and percentage currently in school, according to residence, Tamil Nadu, 2006

\begin{tabular}{|c|c|c|c|c|c|c|}
\hline Schooling status (\%) & $\underset{15-24}{M}$ & $\begin{array}{c}W \\
15-24\end{array}$ & $\begin{array}{c}\mathrm{MM} \\
15-29\end{array}$ & $\begin{array}{c}\text { MW } \\
15-24\end{array}$ & $\begin{array}{c}\text { UM } \\
15-24\end{array}$ & $\begin{array}{c}\text { UM } \\
15-24\end{array}$ \\
\hline \multicolumn{7}{|c|}{ Combined } \\
\hline \multicolumn{7}{|l|}{ Completed years of schooling } \\
\hline None $^{1}$ & 2.2 & 5.0 & 6.1 & 9.7 & 1.5 & 1.8 \\
\hline $1-4$ & 3.6 & 4.3 & 10.8 & 7.0 & 2.8 & 2.6 \\
\hline $5-7$ & 16.4 & 15.3 & 29.9 & 21.4 & 14.5 & 11.3 \\
\hline $8-9$ & 26.7 & 27.3 & 24.8 & 29.5 & 26.1 & 25.8 \\
\hline $10-11$ & 24.7 & 22.2 & 13.4 & 16.2 & 26.5 & 26.1 \\
\hline 12 and above & 26.2 & 25.9 & 15.0 & 16.1 & 28.5 & 32.3 \\
\hline Median years of schooling & 10.0 & 9.0 & 8.0 & 8.0 & 10.0 & 10.0 \\
\hline Currently in school & 37.7 & 27.1 & 0.7 & 2.0 & 41.6 & 43.7 \\
\hline Number of respondents & 1,913 & 5,008 & 1,322 & 2,007 & 1,666 & 3,001 \\
\hline \multicolumn{7}{|c|}{ Urban } \\
\hline \multicolumn{7}{|l|}{ Completed years of schooling } \\
\hline None $^{1}$ & 1.2 & 3.2 & 2.6 & 7.0 & 0.9 & 1.0 \\
\hline $1-4$ & 3.1 & 3.4 & 8.3 & 5.4 & 2.0 & 2.2 \\
\hline $5-7$ & 15.4 & 13.7 & 30.9 & 19.8 & 13.7 & 10.1 \\
\hline $8-9$ & 22.8 & 23.2 & 24.3 & 27.5 & 22.1 & 20.7 \\
\hline $10-11$ & 25.1 & 22.9 & 13.8 & 18.1 & 26.8 & 25.6 \\
\hline 12 and above & 32.3 & 33.6 & 20.1 & 22.1 & 34.5 & 40.4 \\
\hline Median years of schooling & 10.0 & 10.0 & 8.0 & 9.0 & 10.0 & 11.0 \\
\hline Currently in school & 40.9 & 34.2 & 0.7 & 2.6 & 44.6 & 52.5 \\
\hline Number of respondents & 890 & 2,151 & 653 & 804 & 789 & 1,347 \\
\hline \multicolumn{7}{|c|}{ Rural } \\
\hline \multicolumn{7}{|l|}{ Completed years of schooling } \\
\hline None $^{1}$ & 3.0 & 6.3 & 8.6 & 11.5 & 2.0 & 2.6 \\
\hline $1-4$ & 4.1 & 5.1 & 12.6 & 8.0 & 3.4 & 2.9 \\
\hline $5-7$ & 17.2 & 16.7 & 29.3 & 22.5 & 15.3 & 12.4 \\
\hline $8-9$ & 29.7 & 30.6 & 25.0 & 30.9 & 29.4 & 30.3 \\
\hline $10-11$ & 24.3 & 21.6 & 13.1 & 14.9 & 26.3 & 26.5 \\
\hline 12 and above & 21.6 & 19.7 & 11.4 & 12.2 & 23.6 & 25.2 \\
\hline Median years of schooling & 9.0 & 9.0 & 7.0 & 8.0 & 9.0 & 10.0 \\
\hline Currently in school & 35.3 & 21.6 & 0.6 & 1.7 & 39.2 & 36.0 \\
\hline Number of respondents & 1,023 & 2,857 & 669 & 1,203 & 877 & 1,654 \\
\hline
\end{tabular}

Note: All Ns are unweighted. Column totals may not equal 100\% due to missing cases or "don't know" responses. ${ }^{1}$ Includes non-literate and literate with no formal schooling. 


\subsection{Differentials in educational attainment}

Differentials in educational levels of young men and women, measured with respect to completed years of schooling, are presented in Tables 3.2 and 3.3, respectively. Findings show that the younger cohort (15-19 years) was better educated than the older cohort (20-24 years), irrespective of sex and place of residence. These patterns were less consistent between young men and women when the married and the unmarried were considered separately. Among married young men, the older cohort (aged 25-29) was more educated than the younger cohort, a finding that may be attributed to the fact that those married at younger ages were more likely to come from socially disadvantaged backgrounds than those married at later ages. In contrast, among unmarried young men, differences in educational attainment by age were muted, but we note that these differences may be wider than observed because many unmarried youth aged 15-19 were pursuing their education at the time of interview. Among young women, while age differences were muted among the married, the older cohort was more educated than the younger cohort among the unmarried, particularly in urban areas.

Differences by religion suggest that Muslims tended to be more disadvantaged than Hindus and those from other religions, irrespective of sex and place of residence. For example, 38-39\% of Muslim men and women had completed at least 10 years of education compared to $51-58 \%$ and $48-56 \%$ of young men and women, respectively, who were Hindu or from other religions. Marital status patterns reveal that religion-wise differences were negligible for the married; among the unmarried, however, Muslim youth were less likely to have completed at least 10 years of education than youth who were Hindu or from other religions.

Table 3.2: Educational attainment of young men by selected background characteristics

\section{Percent distribution of young men by educational level, according to selected background characteristics and residence, Tamil Nadu, 2006}

\begin{tabular}{|c|c|c|c|c|c|c|c|c|c|c|c|c|}
\hline \multirow{3}{*}{$\begin{array}{l}\text { Background } \\
\text { characteristics } \\
(\%)\end{array}$} & \multicolumn{4}{|c|}{ M, 15-24 } & \multicolumn{4}{|c|}{ MM, 15-29 } & \multicolumn{4}{|c|}{ UM, 15-24 } \\
\hline & \multicolumn{12}{|c|}{ Completed years of schooling } \\
\hline & None $^{1}$ & $1-7$ & $8-9$ & $10+$ & None $^{1}$ & $1-7$ & $8-9$ & $10+$ & None $^{1}$ & $1-7$ & 8-9 & $10+$ \\
\hline \multicolumn{13}{|c|}{ Combined } \\
\hline \multicolumn{13}{|l|}{ Age (years) } \\
\hline $15-19$ & 1.1 & 13.3 & 30.5 & 55.1 & * & * & * & * & 1.0 & 13.2 & 30.5 & 55.3 \\
\hline $20-24$ & 3.4 & 26.5 & 23.1 & 46.9 & 9.6 & 45.8 & 31.7 & 12.9 & 2.1 & 22.1 & 21.1 & 54.7 \\
\hline $25-29$ & NA & NA & NA & NA & 5.3 & 39.6 & 23.1 & 32.0 & NA & NA & NA & NA \\
\hline \multicolumn{13}{|l|}{ Religion } \\
\hline Hindu & 2.3 & 19.8 & 26.7 & 51.1 & 6.4 & 40.5 & 25.3 & 27.9 & 1.5 & 17.0 & 26.1 & 55.4 \\
\hline Muslim & 1.2 & 27.2 & 33.3 & 38.3 & 2.9 & 45.7 & 27.1 & 24.3 & 1.4 & 25.7 & 32.4 & 40.5 \\
\hline Other ${ }^{2}$ & 1.3 & 19.0 & 21.5 & 58.2 & $(3.8)$ & $(40.4)$ & $(9.6)$ & $(46.2)$ & 1.4 & 16.7 & 20.8 & 61.1 \\
\hline \multicolumn{13}{|l|}{ Caste } \\
\hline SC & 3.1 & 22.8 & 31.5 & 42.6 & 8.0 & 43.3 & 23.9 & 24.8 & 1.9 & 19.5 & 31.9 & 46.8 \\
\hline $\mathrm{OBC}$ & 1.6 & 19.2 & 25.3 & 53.8 & 4.3 & 40.0 & 25.9 & 29.9 & 1.1 & 16.6 & 24.5 & 57.7 \\
\hline \multicolumn{13}{|l|}{ Wealth quintile } \\
\hline First & 9.3 & 36.4 & 29.4 & 24.5 & 16.7 & 54.2 & 18.5 & 10.6 & 6.6 & 33.2 & 31.8 & 28.0 \\
\hline Second & 2.0 & 25.8 & 30.6 & 41.6 & 6.8 & 51.5 & 26.3 & 15.4 & 1.2 & 23.1 & 29.8 & 45.8 \\
\hline Third & 1.9 & 21.8 & 32.4 & 43.8 & 6.5 & 46.7 & 26.8 & 19.9 & 1.1 & 19.4 & 31.7 & 47.8 \\
\hline Fourth & 0.4 & 17.3 & 27.4 & 54.9 & 0.4 & 28.3 & 26.8 & 44.5 & 0.5 & 15.3 & 26.7 & 57.4 \\
\hline Fifth & 0.3 & 4.3 & 14.1 & 81.3 & 0.5 & 14.7 & 22.6 & 62.1 & 0.3 & 3.8 & 13.5 & 82.4 \\
\hline Total & 2.2 & 20.1 & 26.7 & 50.9 & 6.1 & 40.7 & 24.8 & 28.4 & 1.5 & 17.3 & 26.1 & 55.0 \\
\hline
\end{tabular}

Cont'd on next page... 
Table 3.2: (Cont'd)

\begin{tabular}{|c|c|c|c|c|c|c|c|c|c|c|c|c|}
\hline \multirow{3}{*}{$\begin{array}{l}\text { Background } \\
\text { characteristics } \\
(\%)\end{array}$} & \multicolumn{4}{|c|}{ M, 15-24 } & \multicolumn{4}{|c|}{ MM, 15-29 } & \multicolumn{4}{|c|}{ UM, 15-24 } \\
\hline & \multicolumn{12}{|c|}{ Completed years of schooling } \\
\hline & None $^{1}$ & $1-7$ & 8-9 & $10+$ & None $^{1}$ & $1-7$ & 8-9 & $10+$ & None $^{1}$ & $1-7$ & 8-9 & $10+$ \\
\hline \multicolumn{13}{|c|}{ Urban } \\
\hline \multicolumn{13}{|l|}{ Age (years) } \\
\hline $15-19$ & 0.8 & 12.4 & 26.4 & 60.4 & * & * & * & * & 0.8 & 12.4 & 26.4 & 60.4 \\
\hline $20-24$ & 1.6 & 24.0 & 19.6 & 54.8 & 4.8 & 48.8 & 32.1 & 14.3 & 1.1 & 19.1 & 17.2 & 62.6 \\
\hline $25-29$ & NA & NA & NA & NA & 2.4 & 37.3 & 22.9 & 37.5 & NA & NA & NA & NA \\
\hline \multicolumn{13}{|l|}{ Religion } \\
\hline Hindu & 1.2 & 17.7 & 22.2 & 58.8 & 2.6 & 38.4 & 24.8 & 34.3 & 0.9 & 14.9 & 21.3 & 62.9 \\
\hline Muslim & 1.5 & 28.8 & 31.8 & 37.9 & 3.7 & 44.4 & 22.2 & 29.6 & 1.7 & 26.7 & 31.7 & 40.0 \\
\hline Other $^{2}$ & $(0.0)$ & $(15.6)$ & $(18.8)$ & $(65.6)$ & * & * & * & * & $(0.0)$ & $(10.3)$ & $(17.2)$ & $(72.4)$ \\
\hline \multicolumn{13}{|l|}{ Caste } \\
\hline SC & 2.4 & 25.3 & 28.8 & 43.5 & 3.4 & 48.3 & 28.0 & 20.3 & 2.0 & 21.1 & 28.6 & 48.3 \\
\hline OBC & 0.9 & 17.1 & 21.5 & 60.5 & 2.4 & 37.1 & 23.3 & 37.1 & 0.7 & 14.6 & 20.7 & 64.0 \\
\hline \multicolumn{13}{|l|}{ Wealth quintile } \\
\hline First & 7.4 & 42.6 & 29.6 & 20.4 & 4.9 & 68.3 & 17.1 & 9.8 & 6.4 & 38.3 & 34.0 & 21.3 \\
\hline Second & 1.0 & 28.3 & 27.3 & 43.4 & 6.3 & 53.1 & 27.1 & 13.5 & 1.3 & 22.8 & 26.6 & 49.4 \\
\hline Third & 1.3 & 31.6 & 31.0 & 36.1 & 3.5 & 56.5 & 23.5 & 16.5 & 0.7 & 29.2 & 30.7 & 39.4 \\
\hline Fourth & 0.9 & 18.3 & 27.8 & 53.0 & 0.7 & 30.1 & 28.8 & 40.5 & 1.0 & 15.9 & 26.6 & 56.5 \\
\hline Fifth & 0.3 & 4.1 & 11.9 & 83.7 & 0.7 & 16.2 & 20.6 & 62.5 & 0.4 & 3.2 & 11.1 & 85.3 \\
\hline Total & 1.2 & 18.5 & 22.9 & 57.4 & 2.6 & 39.2 & 24.3 & 33.9 & 0.9 & 15.8 & 22.0 & 61.3 \\
\hline \multicolumn{13}{|c|}{ Rural } \\
\hline \multicolumn{13}{|l|}{ Age (years) } \\
\hline $15-19$ & 1.3 & 13.9 & 33.6 & 51.2 & * & * & * & * & 1.2 & 13.8 & 33.6 & 51.4 \\
\hline $20-24$ & 4.8 & 28.6 & 25.8 & 40.7 & 12.2 & 43.9 & 31.7 & 12.2 & 2.9 & 24.8 & 24.3 & 47.8 \\
\hline $25-29$ & NA & NA & NA & NA & 7.7 & 41.2 & 23.2 & 27.9 & NA & NA & NA & NA \\
\hline \multicolumn{13}{|l|}{ Religion } \\
\hline Hindu & 3.1 & 21.3 & 29.9 & 45.6 & 8.8 & 41.8 & 25.6 & 23.8 & 2.0 & 18.6 & 29.6 & 49.8 \\
\hline Muslim & * & * & * & * & * & * & * & * & * & * & * & * \\
\hline Other ${ }^{2}$ & $(2.1)$ & $(21.3)$ & $(23.4)$ & $(53.2)$ & (7.4) & $(37.0)$ & $(0.0)$ & $(55.6)$ & (2.4) & $(19.0)$ & (23.8) & $(54.8)$ \\
\hline \multicolumn{13}{|l|}{ Caste } \\
\hline SC & 3.6 & 21.4 & 33.0 & 42.0 & 10.5 & 40.2 & 21.5 & 27.8 & 1.8 & 18.4 & 34.1 & 45.7 \\
\hline OBC & 2.3 & 20.9 & 28.4 & 48.2 & 5.8 & 42.2 & 27.7 & 24.3 & 1.5 & 18.6 & 27.8 & 52.0 \\
\hline \multicolumn{13}{|l|}{ Wealth quintile } \\
\hline First & 9.4 & 35.4 & 29.2 & 25.5 & 19.4 & 50.3 & 19.4 & 10.9 & 7.3 & 31.5 & 30.9 & 29.7 \\
\hline Second & 2.3 & 25.0 & 31.7 & 41.0 & 7.0 & 50.4 & 26.0 & 16.5 & 1.6 & 22.9 & 30.9 & 44.6 \\
\hline Third & 2.3 & 16.2 & 33.2 & 48.3 & 7.9 & 41.3 & 29.1 & 21.7 & 1.4 & 13.2 & 32.4 & 53.0 \\
\hline Fourth & 0.0 & 16.1 & 27.1 & 56.9 & 0.0 & 26.9 & 23.5 & 49.6 & 0.0 & 14.7 & 26.9 & 58.4 \\
\hline Fifth & 0.0 & 4.2 & 20.8 & 75.0 & $(0.0)$ & $(11.3)$ & $(28.3)$ & $(60.4)$ & 0.0 & 4.4 & 21.1 & 74.4 \\
\hline Total & 3.0 & 21.3 & 29.7 & 45.9 & 8.6 & 41.8 & 25.0 & 24.5 & 2.0 & 18.6 & 29.4 & 49.8 \\
\hline
\end{tabular}

Note: Row totals may not equal 100\% due to missing cases or “don't know" responses. ( ) Based on 25-49 unweighted cases. ${ }^{*}$ Percentage not shown, based on fewer than 25 unweighted cases. NA: Not applicable. OBC: Other backward caste. SC: Scheduled caste. ${ }^{1}$ Includes non-literate and literate with no formal schooling. ${ }^{2}$ Includes Christian, Buddhist, Neo-Buddhist, Sikh, Jain, Jewish, Parsi/Zoroastrian and no specified religion. 
Caste differences show that youth belonging to other backward castes were considerably more likely than those from scheduled castes to have completed 10 or more years of schooling. This difference was evident among both young men and women, and for the most part, irrespective of marital status and rural-urban residence.

A positive association was also consistently observed between the economic status of young people's households, measured in wealth quintiles, and young people's educational attainment levels. For example, among young men, just $25 \%$ of those from households in the poorest (first) quintile had completed 10 or more years of schooling compared to $81 \%$ of those from households in the wealthiest (fifth) quintile. Among young women, $24 \%$ of those in households in the poorest quintile compared to $80 \%$ of those in households in the wealthiest quintile had completed 10 or more years of education. Patterns were similar for both the unmarried and the married, and those residing in rural and urban areas.

Table 3.3: Educational attainment of young women by selected background characteristics

Percent distribution of young women by educational level, according to selected background characteristics and residence, Tamil Nadu, 2006

\begin{tabular}{|c|c|c|c|c|c|c|c|c|c|c|c|c|}
\hline \multirow{3}{*}{$\begin{array}{l}\text { Background } \\
\text { characteristics } \\
(\%)\end{array}$} & \multicolumn{4}{|c|}{ W, 15-24 } & \multicolumn{4}{|c|}{ MW, 15-24 } & \multicolumn{4}{|c|}{ UW, 15-24 } \\
\hline & \multicolumn{12}{|c|}{ Completed years of schooling } \\
\hline & None $^{1}$ & $1-7$ & $8-9$ & $10+$ & None $^{1}$ & $1-7$ & $8-9$ & $10+$ & None $^{1}$ & $1-7$ & $8-9$ & $10+$ \\
\hline \multicolumn{13}{|c|}{ Combined } \\
\hline \multicolumn{13}{|l|}{ Age (years) } \\
\hline $15-19$ & 2.5 & 15.2 & 29.3 & 53.0 & 8.4 & 25.9 & 33.6 & 32.1 & 1.5 & 13.4 & 28.7 & 56.4 \\
\hline $20-24$ & 7.0 & 23.4 & 25.6 & 44.0 & 10.0 & 28.8 & 28.8 & 32.4 & 2.4 & 14.9 & 20.5 & 62.2 \\
\hline \multicolumn{13}{|l|}{ Religion } \\
\hline Hindu & 5.1 & 19.6 & 27.1 & 48.2 & 10.0 & 28.6 & 29.6 & 31.8 & 1.9 & 13.6 & 25.3 & 59.2 \\
\hline Muslim & 5.5 & 27.0 & 28.6 & 38.9 & 7.5 & 30.6 & 27.9 & 34.0 & 3.7 & 23.8 & 29.3 & 43.3 \\
\hline Other ${ }^{2}$ & 1.5 & 12.2 & 30.2 & 56.1 & 5.8 & 17.4 & 33.3 & 43.5 & 0.0 & 10.4 & 29.0 & 60.6 \\
\hline \multicolumn{13}{|l|}{ Caste } \\
\hline SC & 6.6 & 22.3 & 32.0 & 39.2 & 12.7 & 31.3 & 31.6 & 24.4 & 2.4 & 16.1 & 32.1 & 49.4 \\
\hline $\mathrm{OBC}$ & 4.3 & 18.8 & 26.0 & 50.9 & 8.4 & 27.1 & 29.2 & 35.2 & 1.7 & 13.3 & 23.8 & 61.2 \\
\hline \multicolumn{13}{|l|}{ Wealth quintile } \\
\hline First & 12.5 & 32.1 & 31.6 & 23.8 & 21.0 & 38.0 & 30.0 & 11.0 & 5.0 & 27.0 & 32.9 & 35.0 \\
\hline Second & 7.1 & 26.4 & 33.4 & 33.1 & 13.2 & 35.7 & 31.1 & 20.0 & 2.8 & 19.8 & 34.9 & 42.5 \\
\hline Third & 5.4 & 23.6 & 31.8 & 39.2 & 9.9 & 32.1 & 31.3 & 26.7 & 1.9 & 17.4 & 32.2 & 48.5 \\
\hline Fourth & 2.5 & 16.6 & 26.4 & 54.5 & 5.1 & 23.9 & 31.5 & 39.5 & 1.1 & 12.2 & 23.3 & 63.4 \\
\hline Fifth & 0.5 & 4.4 & 15.0 & 80.1 & 0.9 & 10.6 & 22.1 & 66.5 & 0.3 & 1.6 & 11.7 & 86.4 \\
\hline Total & 5.0 & 19.7 & 27.3 & 48.1 & 9.7 & 28.4 & 29.5 & 32.3 & 1.8 & 13.9 & 25.8 & 58.4 \\
\hline
\end{tabular}

Cont'd on next page... 
Table 3.3 (Cont'd)

\begin{tabular}{|c|c|c|c|c|c|c|c|c|c|c|c|c|}
\hline \multirow{3}{*}{$\begin{array}{l}\text { Background } \\
\text { characteristics } \\
(\%)\end{array}$} & \multicolumn{4}{|c|}{ W, 15-24 } & \multicolumn{4}{|c|}{ MW, 15-24 } & \multicolumn{4}{|c|}{ UW, 15-24 } \\
\hline & \multicolumn{12}{|c|}{ Completed years of schooling } \\
\hline & None $^{1}$ & $1-7$ & $8-9$ & $10+$ & None $^{1}$ & $1-7$ & $8-9$ & $10+$ & None $^{1}$ & $1-7$ & $8-9$ & $10+$ \\
\hline \multicolumn{13}{|c|}{ Urban } \\
\hline Age (years) & & & & & & & & & & & & \\
\hline $15-19$ & 1.3 & 14.0 & 25.1 & 59.6 & 5.2 & 26.0 & 26.0 & 42.7 & 0.9 & 12.7 & 25.0 & 61.5 \\
\hline $20-24$ & 4.8 & 19.6 & 21.6 & 54.0 & 7.3 & 25.1 & 27.6 & 40.0 & 1.2 & 11.6 & 12.9 & 74.3 \\
\hline \multicolumn{13}{|l|}{ Religion } \\
\hline Hindu & 3.5 & 16.7 & 22.3 & 57.5 & 7.6 & 24.9 & 27.0 & 40.4 & 1.1 & 12.0 & 19.6 & 67.3 \\
\hline Muslim & 1.8 & 25.1 & 30.8 & 42.3 & 2.9 & 30.5 & 30.5 & 36.2 & 0.8 & 20.5 & 31.1 & 47.5 \\
\hline Other $^{2}$ & 2.3 & 7.7 & 23.1 & 66.9 & (8.6) & (11.4) & $(28.6)$ & $(51.4)$ & 0.0 & 6.3 & 20.8 & 72.9 \\
\hline \multicolumn{13}{|l|}{ Caste } \\
\hline SC & 5.0 & 18.6 & 29.9 & 46.5 & 10.7 & 26.8 & 29.8 & 32.7 & 1.7 & 13.9 & 29.8 & 54.6 \\
\hline $\mathrm{OBC}$ & 2.7 & 16.7 & 21.9 & 58.7 & 5.9 & 24.0 & 28.1 & 41.9 & 0.9 & 12.4 & 18.3 & 68.5 \\
\hline \multicolumn{13}{|l|}{ Wealth quintile } \\
\hline First & 18.2 & 35.5 & 29.8 & 16.5 & 33.3 & 36.7 & 23.3 & 6.7 & 3.2 & 33.3 & 36.5 & 27.0 \\
\hline Second & 6.9 & 29.2 & 30.8 & 33.1 & 13.2 & 39.6 & 32.1 & 15.1 & 2.6 & 22.1 & 29.9 & 45.5 \\
\hline Third & 4.3 & 27.5 & 27.5 & 40.7 & 7.6 & 34.2 & 28.3 & 29.9 & 2.0 & 22.7 & 27.0 & 48.4 \\
\hline Fourth & 1.4 & 17.5 & 26.3 & 54.8 & 2.6 & 24.6 & 32.8 & 40.1 & 0.5 & 13.4 & 22.8 & 63.4 \\
\hline Fifth & 0.4 & 3.6 & 14.4 & 81.6 & 0.9 & 8.8 & 20.6 & 69.7 & 0.2 & 1.3 & 11.7 & 86.8 \\
\hline Total & 3.2 & 17.1 & 23.2 & 56.5 & 7.0 & 25.2 & 27.5 & 40.2 & 1.0 & 12.3 & 20.7 & 66.0 \\
\hline \multicolumn{13}{|c|}{ Rural } \\
\hline Age (years) & & & & & & & & & & & & \\
\hline $15-19$ & 3.4 & 16.1 & 32.7 & 47.8 & 9.9 & 26.0 & 36.8 & 27.4 & 2.1 & 14.1 & 31.9 & 52.0 \\
\hline $20-24$ & 8.8 & 26.5 & 28.8 & 35.9 & 11.9 & 31.6 & 29.6 & 26.9 & 3.5 & 17.8 & 27.5 & 51.3 \\
\hline \multicolumn{13}{|l|}{ Religion } \\
\hline Hindu & 6.3 & 21.7 & 30.5 & 41.5 & 11.5 & 30.8 & 31.1 & 26.6 & 2.5 & 14.9 & 30.0 & 52.6 \\
\hline Muslim & 15.7 & 31.3 & 22.9 & 30.1 & (19.5) & (29.3) & $(22.0)$ & $(29.3)$ & $(12.2)$ & $(34.1)$ & $(24.4)$ & $(29.3)$ \\
\hline Other ${ }^{2}$ & 0.8 & 15.9 & 37.9 & 45.5 & (2.9) & (23.5) & $(38.2)$ & $(35.3)$ & 0.0 & 13.5 & 37.5 & 49.0 \\
\hline \multicolumn{13}{|l|}{ Caste } \\
\hline SC & 7.4 & 24.2 & 33.1 & 35.3 & 13.5 & 33.2 & 32.5 & 20.8 & 2.9 & 17.3 & 33.4 & 46.4 \\
\hline OBC & 5.8 & 20.6 & 29.5 & 44.1 & 10.4 & 29.4 & 30.1 & 30.1 & 2.5 & 14.2 & 29.1 & 54.2 \\
\hline \multicolumn{13}{|l|}{ Wealth quintile } \\
\hline First & 11.2 & 31.4 & 32.0 & 25.4 & 17.9 & 38.3 & 31.7 & 12.1 & 5.5 & 25.5 & 32.4 & 36.7 \\
\hline Second & 7.1 & 25.6 & 34.3 & 33.1 & 13.0 & 34.7 & 30.7 & 21.7 & 2.8 & 19.0 & 36.8 & 41.5 \\
\hline Third & 6.0 & 21.2 & 34.6 & 38.2 & 11.2 & 30.8 & 33.0 & 25.0 & 2.1 & 13.7 & 35.8 & 48.5 \\
\hline Fourth & 4.0 & 15.6 & 26.4 & 53.9 & 7.4 & 23.0 & 30.4 & 39.2 & 1.8 & 10.7 & 23.9 & 63.6 \\
\hline Fifth & 0.7 & 7.1 & 16.6 & 75.6 & 1.0 & 14.4 & 25.0 & 59.6 & 0.6 & 2.8 & 11.8 & 84.8 \\
\hline Total & 6.3 & 21.7 & 30.6 & 41.4 & 11.5 & 30.6 & 30.9 & 27.0 & 2.6 & 15.4 & 30.3 & 51.8 \\
\hline
\end{tabular}

Note: Row totals may not equal 100\% due to missing cases or "don't know" responses. ( ) Based on 25-49 unweighted cases. OBC: Other backward caste. SC: Scheduled caste. ${ }^{1}$ Includes non-literate and literate with no formal schooling. ${ }^{2}$ Includes Christian, Buddhist, Neo-Buddhist, Sikh, Jain, Jewish, Parsi/Zoroastrian and no specified religion. 


\subsection{School attendance}

Figure 3.1 presents schooling status at ages 12 and 15 , representing periods before and after puberty was attained for many. Findings suggest that school attendance was far from universal: $86 \%$ and $83 \%$ of young men and women, respectively, were in school at age 12 , and far fewer- $68 \%$ and $60 \%$, respectively-at age 15 . Married youth were far less likely than unmarried youth to be in school at ages 12 or 15. Rural-urban differences were milder, with rural youth less likely than their urban counterparts to be in school at ages 12 and 15; differences were more notable for young women than men and at age 15 than age 12 .

Findings also imply different rates of retention in school between ages 12 and 15 among the married as compared to the unmarried. For example, while about two-thirds of both married young men and women were in school at age 12 , this percentage fell to $40 \%$ among married young men and to $42 \%$ among married young women at age 15. In contrast, among the unmarried there were, in contrast, considerably higher rates of retention: $89-90 \%$ of unmarried young men and women were in school at age 12 , and $72-73 \%$ remained in school at age 15 .

Figures 3.2a-c show graphically the cumulative percentages of youth (all youth who had completed at least one year of schooling) who had completed each year of education from Class 2 to Class 17, using life table techniques. Findings show that almost all youth remained in school up to Class 5 (95-96\% of young men and women had completed Class 5) and $80 \%$ had completed Class 8 . Patterns suggest considerable differences by marital status. For example, completion rates fell below $90 \%$ as early as in Class 5 among married young men and in Class 6 among married young women; these rates fell below $90 \%$, in contrast, by Classes 7 and 8 among unmarried young men and women, respectively.

Declines in completion rates became much steeper after Class 8 , and three notable declines were observed. The first set of declines occurred between Classes 8 and 11, where declines reached or exceeded $10 \%$ a year. The second and third declines occurred between Classes 12 and 13, and Classes 15 and 16, respectively.

Declines per year were considerably steeper among the married (particularly among married young women) than the unmarried. For example, among the married, just 30-36\% had completed Class 10, and 16-18\% had completed Class 12 . In contrast, among the unmarried, as many as $63-67 \%$ and $50-55 \%$ had completed Classes 10 and 12, respectively. These marital status differences persisted in percentages of youth completing each class thereafter as well.
Figure 3.1: Percentage of youth who were in school at ages 12 and 15 , according to residence, Tamil Nadu, 2006
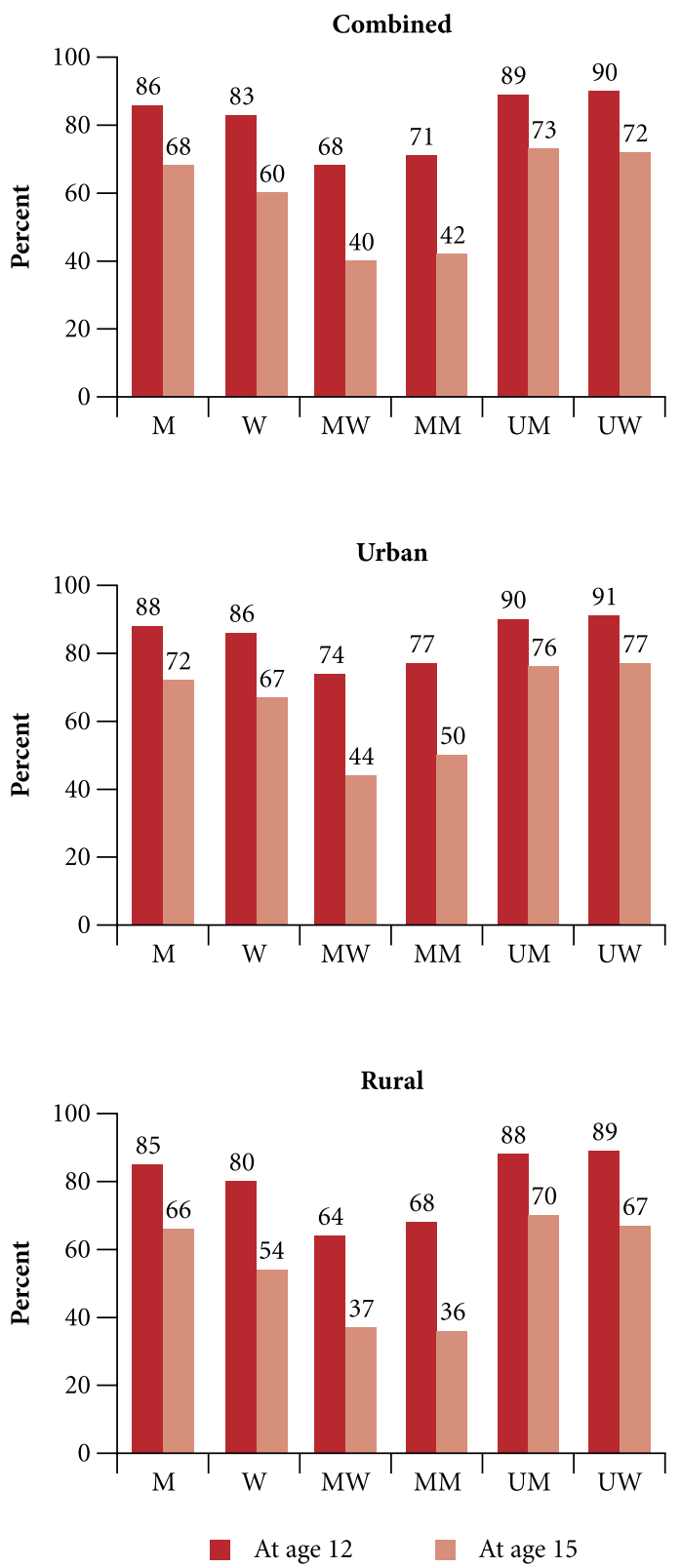
Rural and urban patterns of school completion (Figures 3.2b and 3.2c) were similar up to Class 8 and then diverged, more steeply among young women than young men. Hence, while $82-83 \%$ of urban youth and $77-79 \%$ of rural youth had completed Class $8,63-64 \%$ urban youth compared to $55 \%$ and $48 \%$ of rural young men and women, respectively, had completed Class 10. In other words, after Class 8, differences became apparent and youth, particularly rural young women, were much less likely to continue their education.

Figure 3.2a: Cumulative percentage of youth who had completed each year of education (Classes 1 to 17), Tamil Nadu (combined), 2006

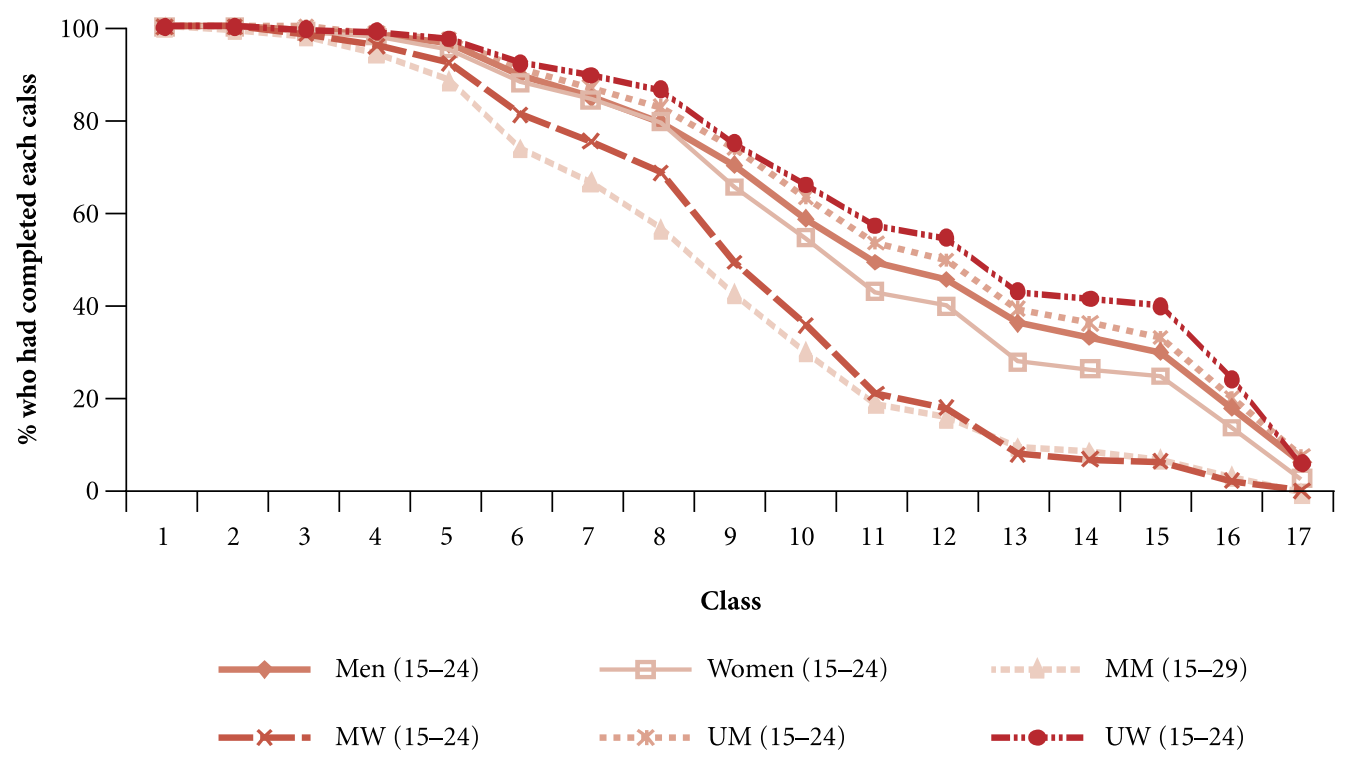

Figure 3.2b: Cumulative percentage of youth who had completed each year of education (Classes 1 to 17), Tamil Nadu (urban), 2006

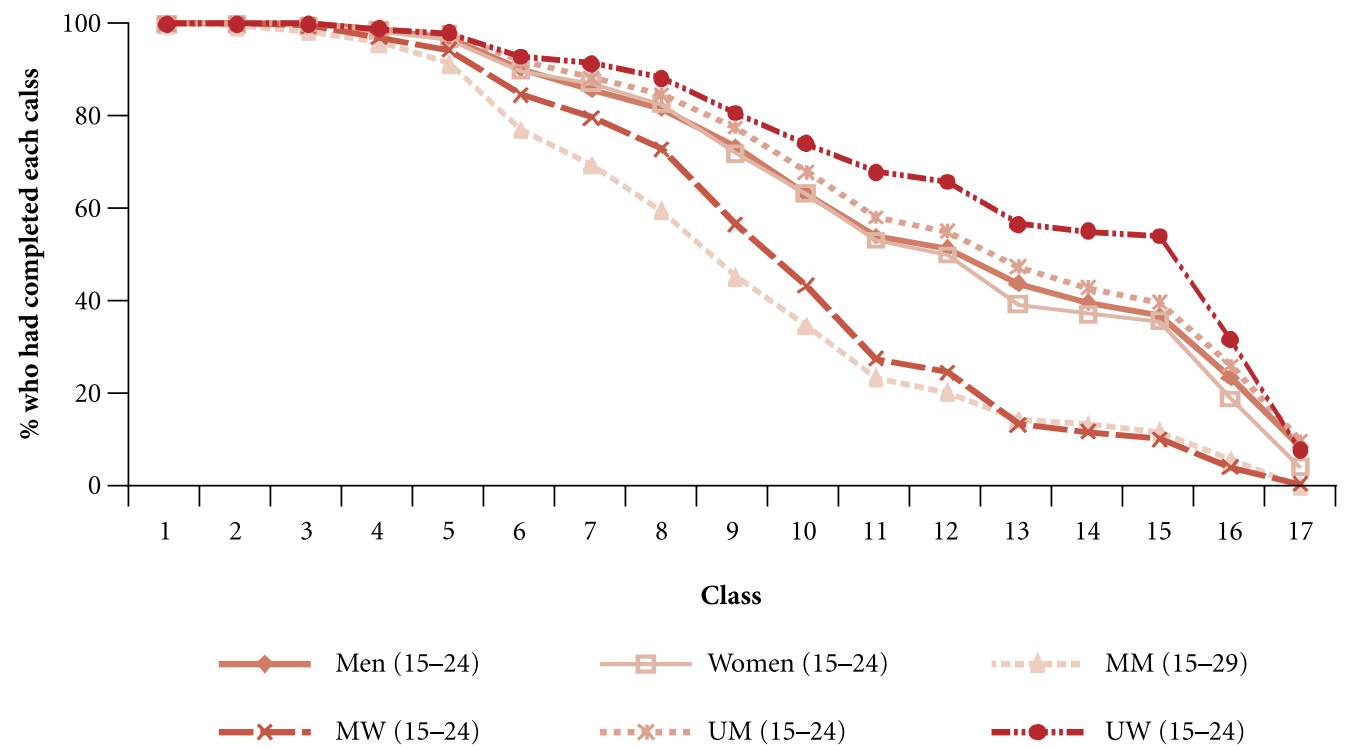


Figure 3.2c: Cumulative percentage of youth who had completed each year of education (Classes 1 to 17), Tamil Nadu (rural), 2006

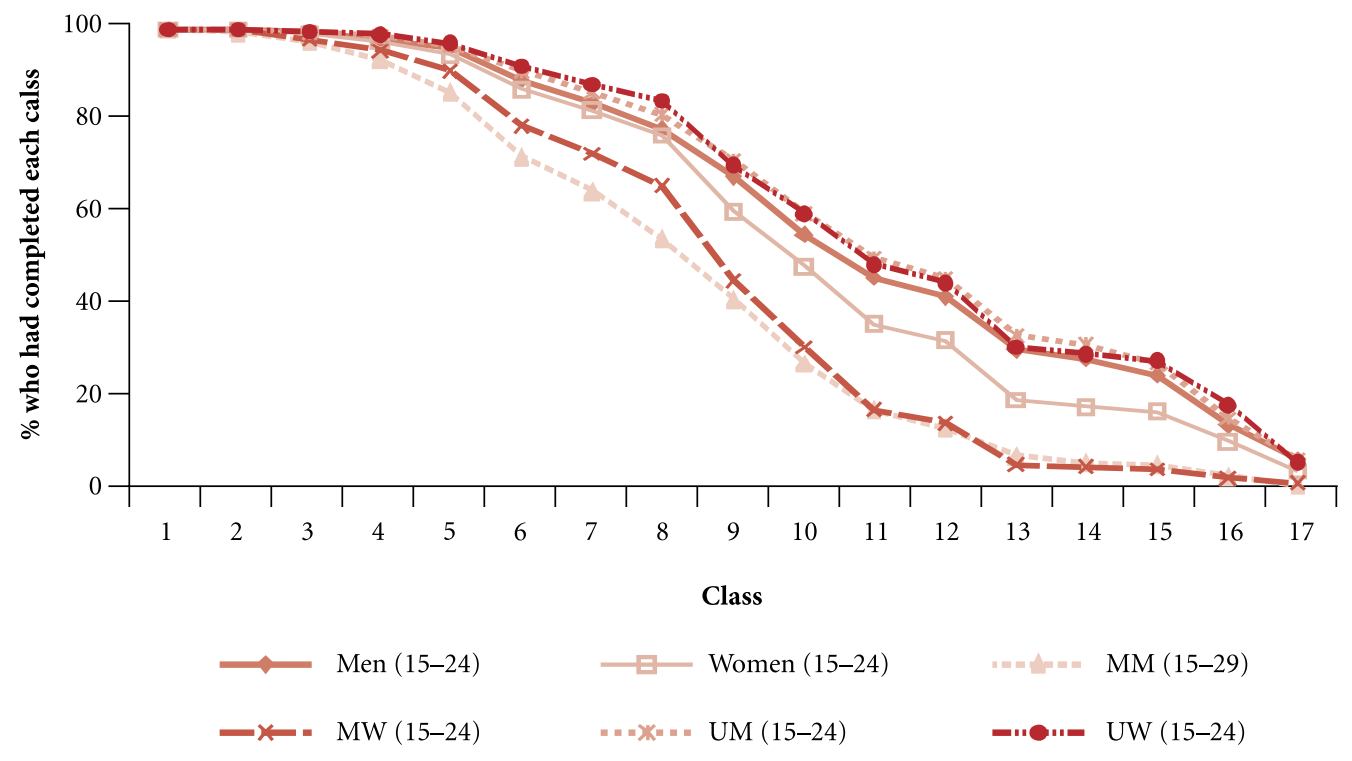

\subsection{Reasons for school non-attendance or discontinuation}

The Youth Study inquired about reasons for never going to school from all those who so reported, and reasons for discontinuing school from all those who had not completed Class 12. Responses are provided in Table 3.4a for those who had never gone to school, and have been grouped into five categories: economic reasons (work on the family farm or business, wage earning work, family poverty, i.e., the family could not afford to keep the respondent in school); housework-related reasons (required for care of siblings or housework); attitude or perception-related reasons (unsafe to send children to school, education not considered necessary, respondent's lack of interest); school-related reasons (school located too far away, appropriate transport not available, poor school quality and infrastructure, poor quality of teaching); and health-related reasons (health problems of respondent, illness or death of a family member). In view of the small numbers of youth who had never been to school, rural-urban differentials are not presented in Table 3.4a.

Findings suggest that, among the few youth who had never attended school, key reasons were economic, cited by $74 \%$ of young men and $45 \%$ of young women. Specifically, over half of young men and over onethird of young women reported that their families could not afford to send them to school; over two-fifths of young men (and many fewer, 9\%, of young women) reported that they were required to work on the family farm or business, and one-fourth of young men (and 7\% of young women) reported that they were required for wage earning activities. Housework-related factors were reported by somewhat larger percentages of young women than men (33\% and 23\%, respectively). Attitude or perception-related reasons for never attending school were also reported by large percentages of youth $(45 \%$ and $39 \%$ of young men and women, respectively) — the leading attitude or perception-related reason expressed was lack of interest in studies, reported by $43 \%$ of young men and $32 \%$ of young women. School-related reasons were cited by about one-quarter of youth (24-25\%); and among these reasons, the majority cited the poor quality of education available. Finally, a small but notable percentage of respondents-13-14\%—cited health-related reasons (mostly the 
sickness or death of a family member) for never attending school. Differences by marital status suggest that the married were more likely than the unmarried to report lack of interest in studies as a reason for never attending school. Conversely, unmarried young women were more likely than their married counterparts to report the poor quality of education available for never attending school.

Table 3.4a: Reasons for never attending school

Percentage of youth who never attended school by reasons for never attending school, Tamil Nadu, 2006

\begin{tabular}{|c|c|c|c|c|c|c|}
\hline Reasons (\%) & $\begin{array}{c}\text { M } \\
15-24\end{array}$ & $\begin{array}{c}\mathrm{W} \\
15-24\end{array}$ & $\begin{array}{c}\text { MM } \\
15-29\end{array}$ & $\begin{array}{c}\text { MW } \\
15-24\end{array}$ & $\begin{array}{c}\text { UM } \\
15-24\end{array}$ & $\begin{array}{c}\text { UW } \\
15-24\end{array}$ \\
\hline \multicolumn{7}{|l|}{ Economic reasons } \\
\hline Required for work on farm/family business & 44.2 & 8.9 & 33.3 & 8.7 & $(48.0)$ & 9.1 \\
\hline Required for outside work for payment in cash/kind & 26.2 & 7.3 & 23.5 & 8.2 & $(20.0)$ & 3.6 \\
\hline Family could not afford it (cost too much) & 53.5 & 36.7 & 42.7 & 36.1 & $(48.0)$ & 38.2 \\
\hline At least one economic reason & 74.4 & 45.2 & 66.7 & 45.4 & $(68.0)$ & 43.6 \\
\hline Housework-related reasons & 23.3 & 33.1 & 17.1 & 34.4 & $(28.0)$ & 29.1 \\
\hline \multicolumn{7}{|l|}{ Parental or youth attitudes and perceptions } \\
\hline Not safe to send girls/boys to school & 0.0 & 0.4 & 0.0 & 0.5 & $(0.0)$ & 0.0 \\
\hline Education not considered necessary & 2.4 & 8.5 & 0.0 & 8.2 & $(4.0)$ & 9.1 \\
\hline Respondent not interested in studies & 42.9 & 32.3 & 48.1 & 35.4 & $(32.0)$ & 21.8 \\
\hline At least one attitude/perception-related reason & 45.2 & 39.1 & 48.1 & 42.1 & $(36.0)$ & 29.1 \\
\hline \multicolumn{7}{|l|}{ School-related reasons } \\
\hline School too far away/transport not available & 4.7 & 4.8 & 1.2 & 5.6 & $(4.0)$ & 1.8 \\
\hline Poor quality of school facilities, teaching or education & 20.9 & 21.9 & 23.5 & 19.0 & $(20.0)$ & 32.7 \\
\hline At least one school-related reason & 23.8 & 25.4 & 25.9 & 23.1 & $(20.0)$ & 34.5 \\
\hline Health-related reasons & 14.0 & 12.9 & 11.1 & 11.8 & $(16.0)$ & 16.4 \\
\hline Number who never attended school & 52 & 252 & 79 & 195 & 29 & 57 \\
\hline
\end{tabular}

Note: All Ns are unweighted. Column totals may exceed 100\% due to multiple responses. ( ) Based on 25-49 unweighted cases.

Table 3.4b reports findings for youth who had discontinued their education before completing Class 12 . In addition to the five sets of reasons included above, an additional category, early transition into adult roles, has been included, containing such reasons as marriage and employment. Reasons are presented separately for those who had discontinued school before completing middle school (Class 7), high school (Class 10) and higher secondary education (Class 12), respectively. As evident also from Figures 3.3a and 3.3b, reasons varied considerably by level at which education was discontinued, as well as sex and marital status of the respondent.

Among those who had completed just 1-6 years of schooling, three main sets of reasons for school discontinuation were cited by both young men and women: economic, attitude or perception-related, and school-related. Gender differences were evident. Among young men, for example, economic considerations 
(69\%) and attitude or perception-related reasons (61\%) dominated; far fewer young men cited school-related reasons (26\%). Among young women, each of the three key reasons was cited by about or more than two in five: economic (47\%), attitude or perception-related (42\%), and school-related (38\%) reasons. Additionally, $23 \%$ of young women cited housework-related reasons. Similar patterns were observed among the married and the unmarried, except that married young men were less likely than their unmarried counterparts to report attitude or perception-related reasons (55\% versus 64\%). Although reasons reported by rural and urban youth were somewhat similar, some notable differences were evident: urban young men were considerably less likely than the rural to cite attitude or perception-related reasons (56\% versus 66\%), and conversely, considerably more likely to cite health-related reasons ( $18 \%$ versus $7 \%)$. Likewise, urban young women were more likely than their rural counterparts to report attitude or perception-related reasons ( $47 \%$ versus $39 \%$ ).

Among those who had completed Classes 7-9, gender differences were more pronounced. Among young men, leading reasons for school discontinuation were similar to those reported above: economic (67\%), attitude or perception-related (56\%), and school-related (47\%). All other reasons were reported by $10 \%$ or fewer young men. Among young women, leading reasons for discontinuation at this level were school-related, expressed by over half of all young women; other reasons were economic (43\%) and attitude or perception-related (31\%). It is notable that economic and attitude or perception-related reasons were cited by considerably more young men than women. School-related reasons were cited by similar proportions of young men and women; among school-related reasons, academic failure was most likely to be cited (reported by $36 \%$ and $32 \%$ of young men and women, respectively). Findings also show that transitions into adult roles were rarely expressed as a reason for discontinuation at this level of education. Even so, marriage was reported as a reason for school discontinuation by one-tenth of married young women. The leading sets of reasons indicated by married and unmarried youth as also urban and rural youth were by and large similar; nonetheless, married young women were less likely than unmarried young women to report economic (40\% versus $47 \%$ ) and school-related reasons ( $48 \%$ versus $55 \%$ ). In addition, more urban than rural youth reported attitude or perception-related reasons, and more rural than urban young men reported school-related reasons.

Among those who had discontinued their education after completing Classes 10 or 11, leading sets of reasons cited for discontinuation were also economic, attitude or perception-related, and school-related. However, considerable proportions of youth also cited transitions into adult roles as a reason for school discontinuation. Gender differences continued to be apparent. Among young men, leading reasons again were economic (77\%); attitude or perception-related (36\%) and school-related (29\%). Among young women also, economic reasons dominated (50\%); other important reasons cited by young women were school-related $(38 \%)$, attitude or perception-related (26\%), housework-related (14\%), and transitions into adult roles (14\%). Of note is the finding that fewer youth who discontinued their education at this level (15\% of young men and $12 \%$ of young women) cited academic failure as a reason for discontinuing their education than those who had discontinued their education in Classes 7-9. Differences by marital status were mild among young men; among young women, however, the married were less likely than the unmarried to cite economic (41\% versus $59 \%$ ) and school-related reasons (34\% versus $42 \%$ ), and conversely, more likely to report attitude or perception-related reasons ( $31 \%$ versus $20 \%$ ). Also notable is that a sizeable proportion of married young women-23\%-reported discontinuing their education in order to marry. Rural-urban differences were mild except that more rural than urban youth reported school-related reasons (34-41\% and $22-33 \%$, respectively), but fewer rural than urban youth reported attitude or perception-related reasons $(21-31 \%$ and $33-41 \%$, respectively). It is notable that an almost equal percentage of married young women in rural and urban areas $(22-23 \%)$ reported marriage as a reason for discontinuing their education. 


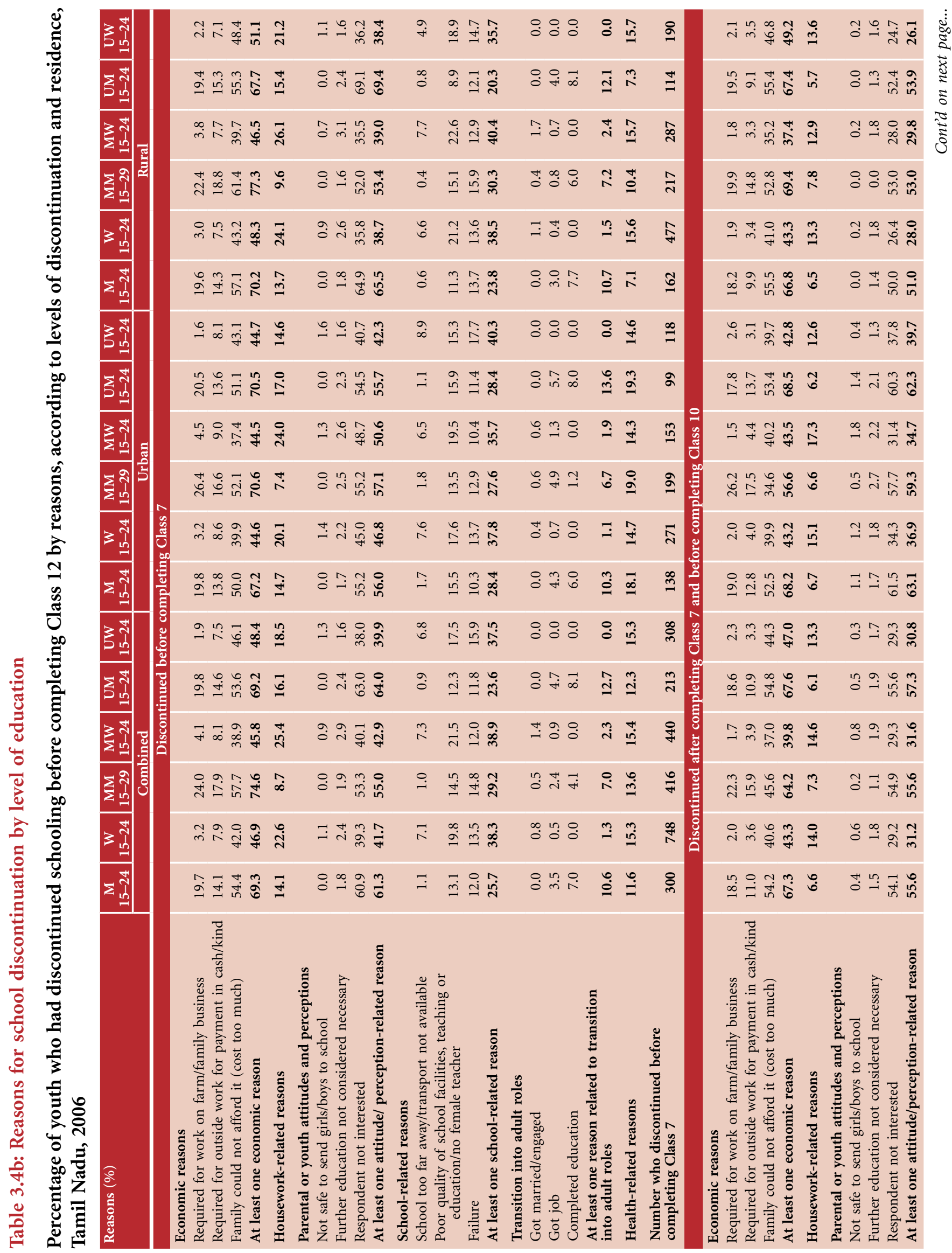




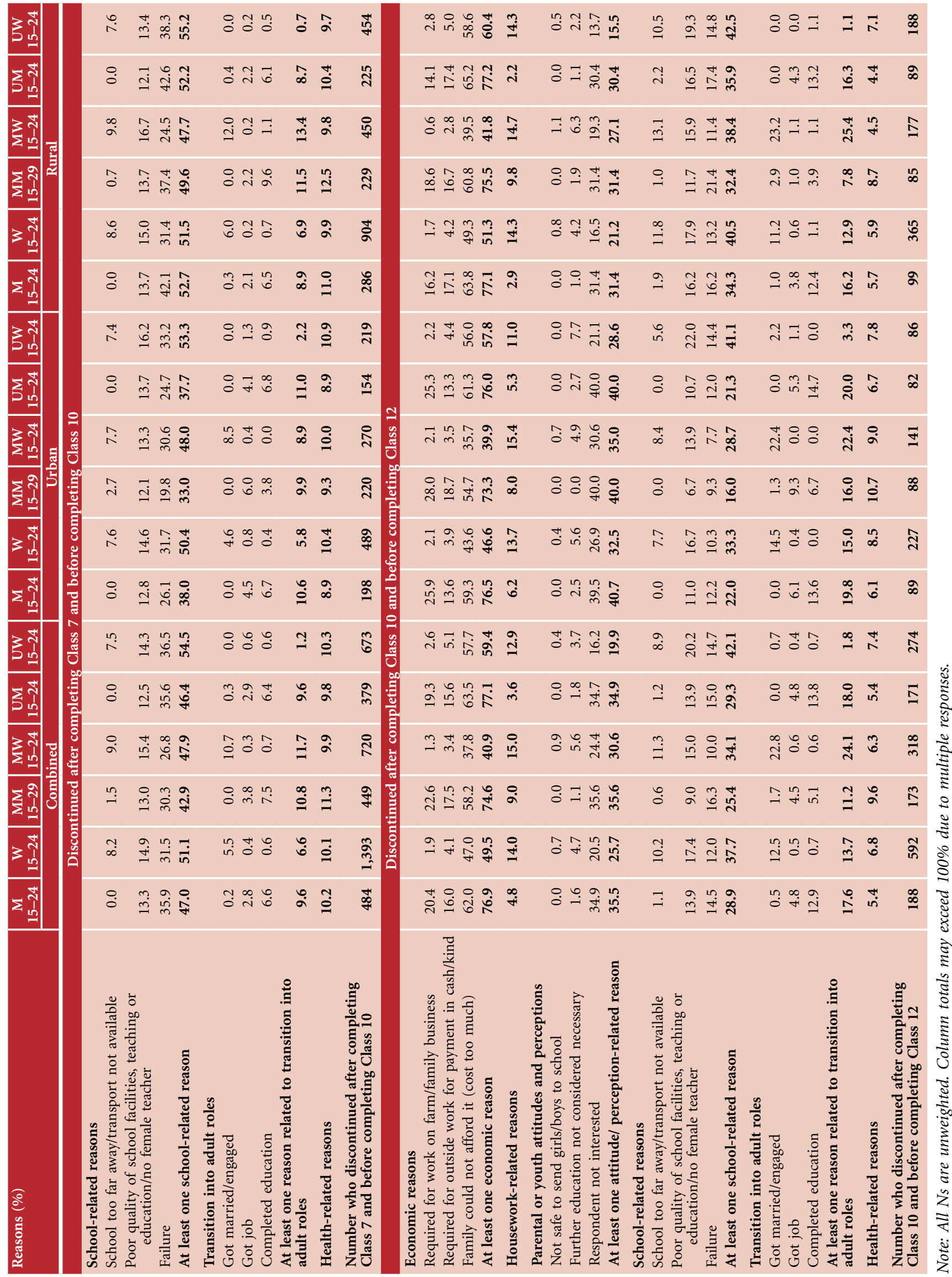


Figure 3.3a: Percentage of married youth who had discontinued schooling by class when discontinued and reasons for discontinuation, Tamil Nadu 2006
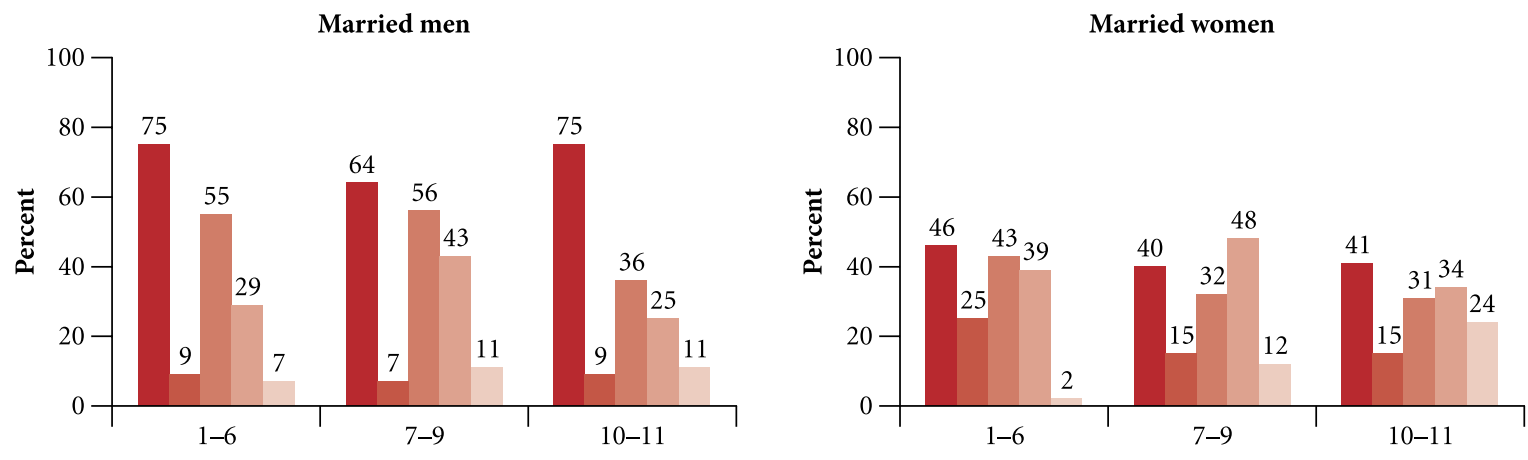

Class at discontinuation

At least one economic reason

At least one attitude/perception-related reason

At least one reason related to transition into adult roles
At least one housework-related reason

At least one school-related reason

Figure 3.3b: Percentage of unmarried youth who had discontinued schooling by class when discontinued and reasons for discontinuation, Tamil Nadu, 2006
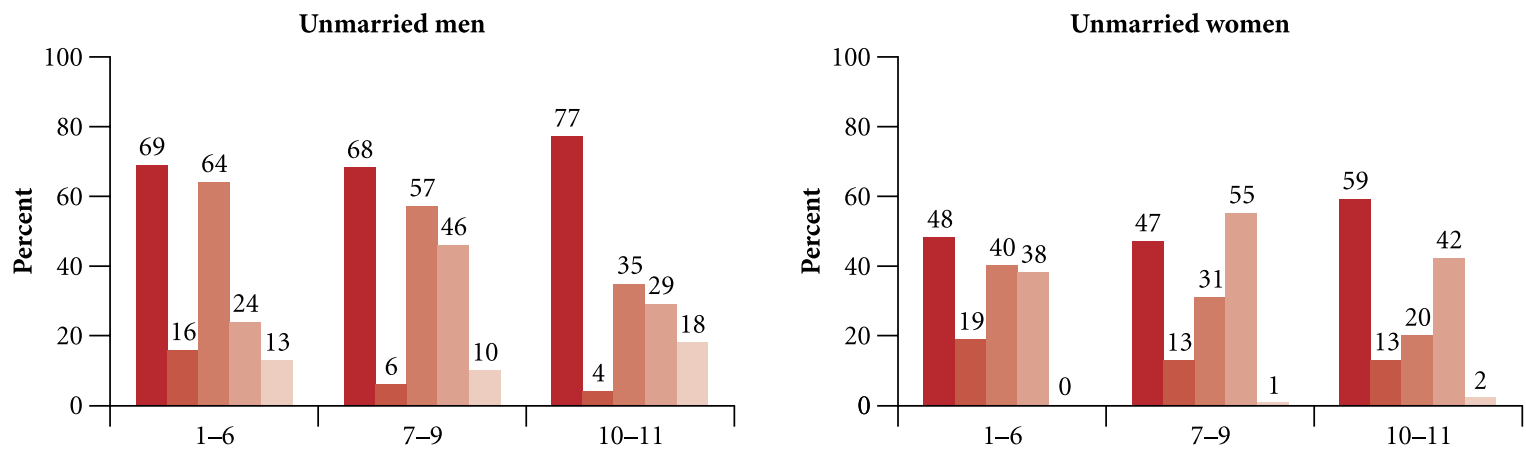

Class at discontinuation

At least one economic reason

At least one attitude/perception-related reason

At least one reason related to transition into adult roles
At least one housework-related reason

- At least one school-related reason

\subsection{School/college type, quality and experiences}

All respondents were asked about the kind of school or college they last attended or were attending at the time of interview, and the facilities available in that school or college. Respondents were also asked about their experiences: whether they attended classes regularly, their attitudes towards education and their performance in that school or college. Tables 3.5 and 3.6 present findings on type and quality of educational institutions most recently attended, and schooling experiences, respectively. Findings are presented separately for those who were still in school or college at the time of interview and for those who had discontinued their education before completing Class 12 in order to explore the extent to which school/college quality and 
experiences differed between these two groups. As school quality and experiences are unlikely to be different for the married and unmarried, Tables 3.5 and 3.6 present information by sex and rural-urban residence of respondents only. In addition, because experiences may vary according to the level of education attained, findings are presented separately for those currently in high school or higher secondary school or college (few youth were in primary or middle school at the time of interview) and those who had discontinued their education at primary or middle levels, high school level or before completing Class 12.

\subsubsection{School/college type and quality}

Findings presented in Table 3.5 show that the majority of youth irrespective of sex, level of education attained and current schooling status attended co-educational facilities. Among those currently studying in high school, or higher secondary school or college, young men were considerably more likely than young women to attend a co-educational facility ( $72-73 \%$ versus $57 \%)$; gender differences were wide in urban areas $(65-73 \%$ versus $40-51 \%)$ and relatively narrow in rural areas $(73-75 \%$ versus $64-74 \%)$. Among those who had discontinued their education, gender differences were narrow but percentages attending a co-educational facility declined with increasing levels of education. By and large, rural youth were more likely than their urban counterparts to have attended a co-educational facility.

Attendance at government versus private educational facilities also varied. The majority of youth who had discontinued their education tended to have attended a government school or college (79-93\%). Among those continuing their education, percentages attending a government facility declined from $71-73 \%$ among those at high school level to $47-53 \%$ among those at higher secondary or higher levels. More youth studying at higher secondary or higher levels were attending a private institution than those studying at high school level (39\% versus $21 \%$ ). Irrespective of current schooling status gender differences were typically mild. Ruralurban differences were relatively mild among those who had discontinued their education; among those still studying, considerably more urban than rural youth were attending a private educational institution at the time of interview; for example, among those studying at higher secondary levels and above, $50 \%$ and $46 \%$ of young men and women in urban areas compared to $28 \%$ and $29 \%$, respectively, in rural areas were attending a private educational institution.

School quality was assessed by questions on the availability of drinking water, toilets, playgrounds and library facilities. Findings from Table 3.5 show that among those pursuing their education at the time of interview, well over $90 \%$ of youth, irrespective of sex or rural-urban residence, had access to two of the four facilities, that is, drinking water and playgrounds, and between $84 \%$ and $98 \%$ had access to toilet facilities. Library facilities were less likely to be available, and differences emerged by level of education attained and ruralurban residence-while $52-61 \%$ of those in high school had access to library facilities, $79-82 \%$ of those in higher secondary school or college did. By and large, more urban than rural women reported library facilities ( $65 \%$ versus $40 \%$ of young women attending high school, and $86 \%$ versus $71 \%$ of those attending higher secondary school or college); in contrast, fewer urban than rural young men attending high school reported the availability of library facilities ( $55 \%$ and $65 \%$, respectively).

The situation was somewhat different among youth who had discontinued their education. Drinking water was available at schools/colleges attended by over $80 \%$ of youth, irrespective of the level at which they had discontinued their education, and irrespective of sex and rural-urban residence. Likewise, $69 \%$ or more youth, irrespective of the level at which they had discontinued their education, reported that a playground was available in the school/college they had attended. In contrast, while only about three-fifths of those who had discontinued their education at primary or middle levels reported that toilet facilities were available, considerably larger proportions of youth who had discontinued at high school or higher secondary levels 


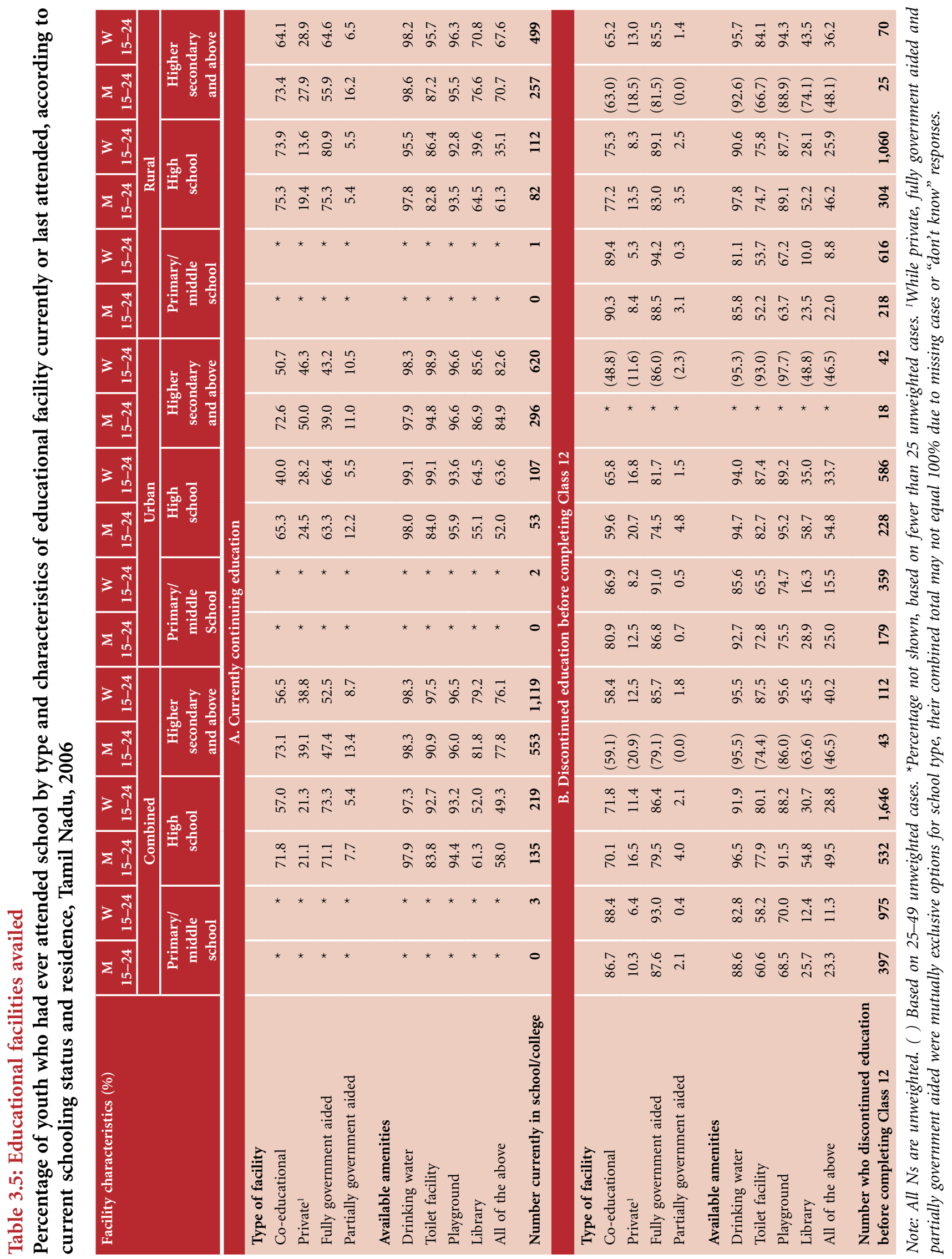


reported the availability of toilets (78-80\% and $74-88 \%$, respectively). Gender differences were narrow, but urban youth were somewhat more likely than rural youth to report access to toilet facilities. With regard to the availability of library facilities, similarly, access increased with level at which education was discontinued (26\%, $55 \%$ and $64 \%$, respectively, at each of the three levels of education among young men who had discontinued their education; and $12 \%, 31 \%$ and $46 \%$, respectively, among young women). Irrespective of the level at which education was discontinued, gender differences were apparent, with young women considerably less likely than young men to report access to libraries. Rural-urban differences were, however, relatively narrow.

The availability of all four amenities — drinking water, playgrounds, toilets and libraries—increased systematically with level of schooling attained among youth. Among those still in school, all four amenities were available to $58 \%$ of young men and $49 \%$ of young women in high school, and $76-78 \%$ of young men and women at higher levels. Among those who had discontinued their education, the availability of all four amenities among young women increased from $11 \%$ among those who had discontinued their education at primary or middle school levels, to $29 \%$ and $40 \%$ among those who had discontinued at high school and higher levels, respectively; larger proportions of young men reported the availability of all four amenities: $23 \%, 50 \%$ and $47 \%$, respectively. The availability of all four amenities was, for the most part, considerably more likely to be reported by those who were studying at the time of interview than those who had discontinued their education, suggesting that the lack of amenities may have played a role in school discontinuation.

Rural-urban differences suggest that, irrespective of whether or not they had discontinued their education, more urban than rural youth had access to all four amenities; the only exception was young men pursuing a high school education at the time of interview, among whom the rural were more likely than the urban to report so.

\subsubsection{School/college experiences}

Table 3.6 presents young people's schooling experiences, namely, whether or not they attended class regularly, took private tuition, considered the academic workload to be heavy and had passed the last examination for which they had appeared. Among those still in school or college, almost all youth (97\% or more) reported that they attended classes regularly, between one-third and two-fifths reported that they had taken private tuition, and over one-quarter reported feeling that the academic workload was heavy. Finally, between $87 \%$ and $99 \%$ reported that they had passed the last school or college examination for which they had appeared. Rural-urban differences were relatively narrow on most indicators; however, it is notable that urban youth were considerably more likely than rural youth to have attended coaching classes, and among those in high school, young men in rural areas were less likely than those in urban areas to have passed the last school or college examination for which they had appeared.

Among youth who had discontinued their education, regular attendance was reported by $85 \%$ or more youth, irrespective of sex, rural-urban residence and level at which education was discontinued. As far as private tuition was concerned, few (9-11\%) of those who discontinued at primary or middle school levels had taken private tuition, compared to $23-26 \%$ and $30-38 \%$ of those who discontinued at high school or higher levels, respectively. Between one-quarter and two-fifths of all youth perceived the academic workload to be heavy. Finally, percentages who passed the last examination for which they had appeared declined systematically as level of education increased among young men: $67 \%, 58 \%$ and $36 \%$ of those who discontinued at primary/ middle school, high school, or higher secondary or higher levels, respectively. Among young women, in contrast, percentages who passed the last examination remained similar among those who discontinued their education at primary/middle or high school levels ( $65 \%$ and $70 \%$, respectively), but fell to $29 \%$ among those who discontinued their education at higher levels. 


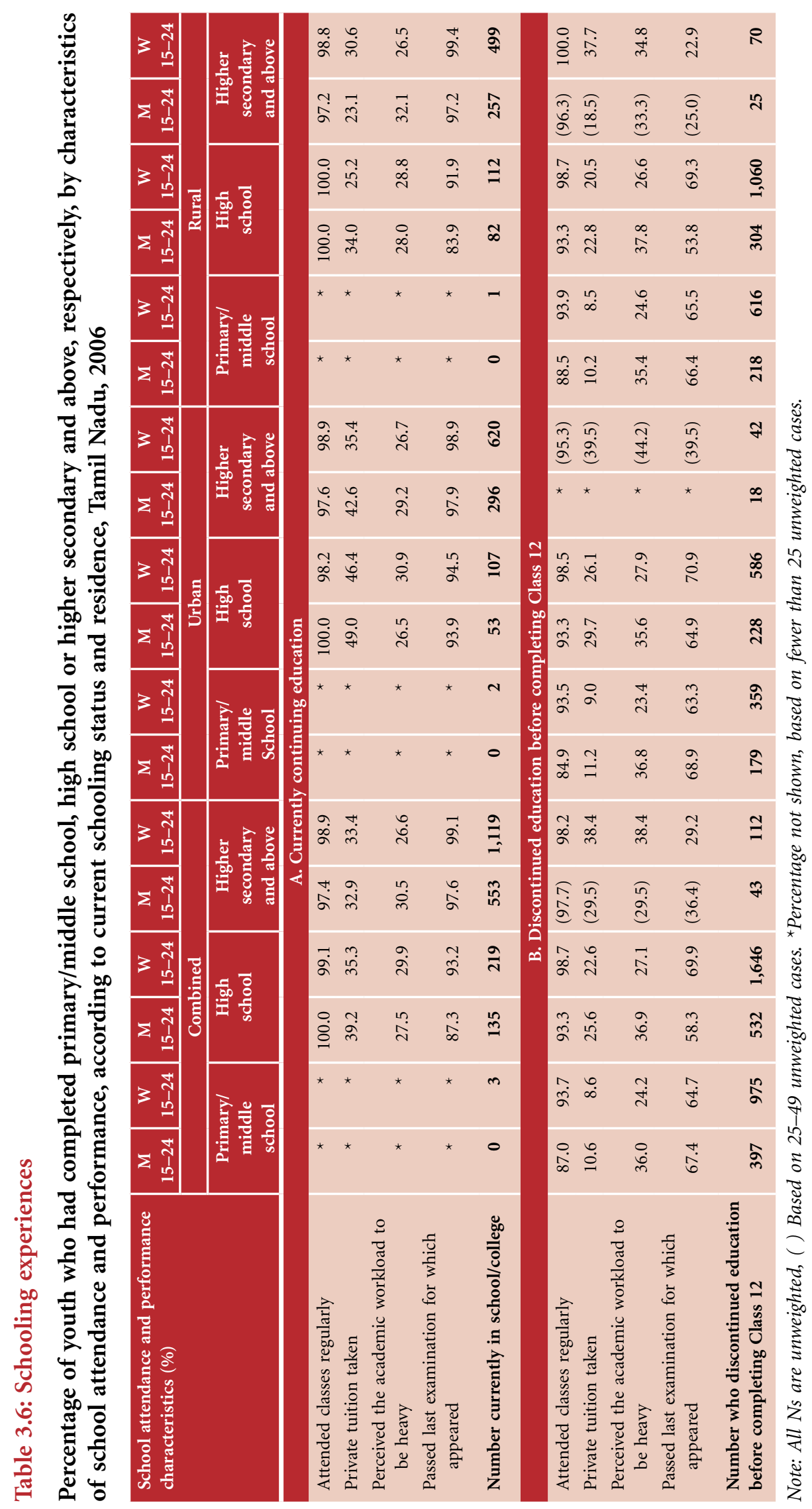


Although $85 \%$ or more youth reported regular attendance in school or college, other schooling experiences were different among those who had discontinued schooling and those who were studying at the time of interview. For example, youth who were pursuing a high school education at the time of interview were considerably more likely than those who had discontinued their education at these levels to report private tuition (35-39\% and 23-26\%, respectively); these differences were mild among those who had reached higher secondary education or higher levels. The widest difference was observed in reporting of school performance: while almost all youth who were still in school reported passing the last examination for which they had appeared (87-99\%), only $58 \%$ and $70 \%$ of young men and women, respectively, who had discontinued their education at high school level, and even fewer (36\% and $29 \%$, respectively) of those who had discontinued at higher levels, so reported. Clearly, academic failure was an important factor precipitating school discontinuation for both young men and young women.

\subsection{Summary}

The vast majority of youth in Tamil Nadu (91-94\%) had attained at least five years of schooling. Educational attainment levels suggest that irrespective of sex and marital status, youth had, on average, 8-10 years of schooling; unmarried youth typically had 2 more years of schooling than married youth, and urban youth typically had 1 more year of schooling than rural youth. Half of all youth had completed high school (Class 10). At the time of interview, about two-fifths of all unmarried youth (and very few married) were still in school or college, and gender differences were negligible.

Findings show, moreover, that $95-96 \%$ of youth who had completed at least one year of schooling had completed Class 5 and $80 \%$ had completed Class 8. Declines became much steeper after Class 8 for both young men and women. For example, declines per year reached or exceeded $10 \%$ among both young men and women between Classes 8 and 11. Cumulative percentages of youth completing each class suggest that the married were considerably less likely than the unmarried to have completed high school: just 30-36\% of married youth who had completed at least one year of schooling had completed Class 10, and 16-18\% had completed Class 12. In contrast, among the unmarried, as many as $63-67 \%$ and $50-55 \%$ had completed Classes 10 and 12, respectively. Likewise, rural youth, particularly rural young women, were less likely than their urban counterparts to have completed Class 10.

Leading reasons for school discontinuation among young men and women who discontinued at middle school level were economic; in addition, attitude or perception-related and school-related reasons were cited by considerable proportions. Among those who had completed Classes 7-9, gender differences in reasons for school discontinuation were pronounced. Among young men, economic considerations, and attitude or perception-related reasons dominated. Far fewer young men cited school-related reasons. Among young women, in contrast, leading reasons for discontinuation at this level were school-related, followed by economic, and attitude or perception-related reasons. Of note is that transitions into adult roles were rarely expressed as a reason for discontinuation at this level of education, although marriage was reported as a reason for school discontinuation by one-tenth of married young women.

Among youth who had discontinued their education after completing Classes 10 or 11, leading sets of reasons were economic, attitude or perception-related, and school-related; however, considerable proportions of youth also cited transitions into adult roles as a reason for discontinuation. Of note are findings that fewer youth who discontinued their education at this level cited academic failure as a reason for discontinuing their education than those who had discontinued their education earlier, and that almost one in four married young women reported discontinuing their education in order to marry. 
Differences were observed in the availability of amenities among youth who were still in school and those who had discontinued their education at various levels. Most youth, irrespective of whether they were pursuing their education or not, had access to drinking water and playgrounds. However, for the most part, youth still studying were somewhat more likely to report the availability of toilets and libraries than were those who had discontinued schooling. The availability of all four amenities was, for the most part, considerably more likely to be reported by those who were studying at the time of interview than those who had discontinued their education, suggesting that the lack of amenities may have played a role in school discontinuation. Schooling experiences were also different; those who had discontinued their education were, for the most part, less likely than those who were still in school to report private tuition. They were considerably less likely, moreover, to have passed the last examination for which they had appeared, suggesting that poor school performance was a significant factor leading to school discontinuation among both young men and women. 


\section{Economic
activity}

The period between the ages of 15 and 29 marks, for many young people, entry into the labour market and economic independence, acquisition of professional and technical skills, and new living arrangements. Economic uncertainty, however, dominates the lives of many youth. According to International Labour Organisation (ILO) estimates, although youth (aged 15-24) comprise around 25\% of the world's working-age population, they constitute around $44 \%$ of the unemployed (ILO, 2006). The unemployment rate among youth has also been identified as one of the key indicators for monitoring the progress towards achieving the UN Millennium Development Goals (UNDP, 2000). For many young people, this period also marks the discontinuation of education and increasing acceptance of domestic responsibilities. This chapter explores the economic activity of young people, their work-related mobility, their participation in non-economic activities (domestic work) and their vocational skill-building experiences and preferences.

\subsection{Economic activity}

During the survey, a number of questions were asked to assess the economic activity and occupational status of youth. Youth were asked whether they had ever worked, either for or without remuneration. They were also asked whether they had worked in the 12 months preceding the interview, the type of work in which they had engaged, whether they were seeking employment, and the number of months during which they had worked or sought work in the year preceding the interview.

Work profiles varied widely, as shown in Table 4.1. In total, about two-thirds of young men and half of young women reported that they had been engaged in paid or unpaid work at some point in their lives. Almost all married young men and over three-fifths of unmarried young men had at some time been engaged in paid or unpaid work; this compares with over half and two-fifths of married and unmarried young women, respectively. Rural-urban differences suggest, moreover, that more rural than urban youth had ever worked-69\% versus $62 \%$ of young men, and $55 \%$ versus $37 \%$ of young women.

We acknowledge that a large part of unpaid work may be considered housework, even though productive and, hence, despite our efforts to probe for information on unpaid work, we may not have succeeded in capturing accurate levels of unpaid work, especially among young women. Indeed, just $15 \%$ of young men and $10 \%$ of young women reported having ever engaged in unpaid work.

Considerable percentages of youth (21\% of young men and $17 \%$ of young women) reported that they had initiated either paid or unpaid work in childhood or early adolescence, that is, before age 15. More married than unmarried, and more rural than urban youth, had initiated economic activity before age 15 , irrespective of sex. 
Table 4.1: Economic activity

Percentage of youth who ever worked and who worked in the last 12 months, and percent distribution of youth by duration of work and main occupation in the last 12 months, according to residence, Tamil Nadu, 2006

\begin{tabular}{|c|c|c|c|c|c|c|}
\hline Economic activity (\%) & $\begin{array}{c}\mathrm{M} \\
15-24\end{array}$ & $\begin{array}{c}\text { W } \\
15-24\end{array}$ & $\begin{array}{c}\text { MM } \\
15-29\end{array}$ & $\begin{array}{c}\text { MW } \\
15-24\end{array}$ & $\begin{array}{c}\text { UM } \\
15-24\end{array}$ & $\begin{array}{c}\text { UW } \\
\text { 15-24 }\end{array}$ \\
\hline \multicolumn{7}{|c|}{ Combined } \\
\hline \multicolumn{7}{|l|}{ Ever worked } \\
\hline Paid work & 62.8 & 43.6 & 99.5 & 51.3 & 58.9 & 38.5 \\
\hline Unpaid work & 14.9 & 9.5 & 23.4 & 11.0 & 14.2 & 8.4 \\
\hline Either paid or unpaid work & 65.7 & 46.8 & 99.8 & 54.3 & 62.1 & 41.9 \\
\hline Started working before age 15 & 21.4 & 16.7 & 40.6 & 22.2 & 18.8 & 13.0 \\
\hline \multicolumn{7}{|l|}{ Ever worked in last 12 months } \\
\hline Paid work & 60.2 & 30.9 & 99.2 & 25.6 & 56.1 & 34.5 \\
\hline Unpaid work & 6.5 & 5.4 & 7.6 & 4.9 & 6.3 & 5.7 \\
\hline Either paid or unpaid work & 62.5 & 33.8 & 99.7 & 28.5 & 58.5 & 37.4 \\
\hline Number of respondents & 1,913 & 5,008 & 1,322 & 2,007 & 1,666 & 3,001 \\
\hline \multicolumn{7}{|l|}{ Duration of paid work in last 12 months } \\
\hline Most of the year (6 months or more) & 88.4 & 63.7 & 95.1 & 59.3 & 87.4 & 65.9 \\
\hline Part of the year ( $3-5$ months) & 6.1 & 21.1 & 4.2 & 27.9 & 6.2 & 17.7 \\
\hline Rarely (less than 3 months) & 5.1 & 14.1 & 0.4 & 12.3 & 6.0 & 15.0 \\
\hline \multicolumn{7}{|l|}{ Main occupation (paid work) } \\
\hline Cultivator & 0.4 & 0.5 & 0.7 & 0.2 & 0.4 & 0.7 \\
\hline Agricultural labourer & 16.0 & 38.0 & 20.1 & 54.6 & 14.9 & 29.9 \\
\hline Administrative/executive/managerial/clerical & 6.3 & 11.5 & 4.9 & 5.1 & 7.1 & 14.7 \\
\hline Business & 3.0 & 0.7 & 4.2 & 0.6 & 3.1 & 0.8 \\
\hline Skilled manual/machinery & 52.9 & 29.6 & 51.8 & 25.4 & 52.8 & 31.7 \\
\hline Unskilled non-agricultural labourer & 19.4 & 18.8 & 16.3 & 13.5 & 20.0 & 21.3 \\
\hline Other & 1.3 & 0.5 & 1.4 & 0.2 & 1.1 & 0.6 \\
\hline Number engaged in paid work in last 12 months & 1,186 & 1,550 & 1,311 & 509 & 942 & 1,041 \\
\hline \multicolumn{7}{|c|}{ Urban } \\
\hline \multicolumn{7}{|l|}{ Ever worked } \\
\hline Paid work & 59.7 & 34.8 & 99.4 & 41.2 & 56.1 & 31.1 \\
\hline Unpaid work & 11.2 & 5.6 & 16.9 & 6.7 & 10.7 & 5.0 \\
\hline Either paid or unpaid work & 62.0 & 37.0 & 99.6 & 43.4 & 58.5 & 33.3 \\
\hline Started working before age 15 & 18.7 & 10.5 & 37.4 & 14.6 & 16.5 & 8.1 \\
\hline \multicolumn{7}{|l|}{ Ever worked in last 12 months } \\
\hline Paid work & 57.2 & 22.0 & 99.3 & 13.5 & 53.3 & 26.9 \\
\hline Unpaid work & 4.6 & 3.0 & 4.2 & 2.6 & 4.4 & 3.2 \\
\hline Either paid or unpaid work & 59.0 & 24.0 & 99.4 & 15.3 & 55.2 & 29.0 \\
\hline Number of respondents & 890 & 2,151 & 653 & 804 & 789 & 1,347 \\
\hline
\end{tabular}


Table 4.1: (Cont'd)

\begin{tabular}{|c|c|c|c|c|c|c|}
\hline Economic activity (\%) & $\begin{array}{c}\mathrm{M} \\
15-24\end{array}$ & $\begin{array}{c}\mathrm{W} \\
15-24\end{array}$ & $\begin{array}{c}\text { MM } \\
15-29\end{array}$ & $\begin{array}{c}\text { MW } \\
15-24\end{array}$ & $\begin{array}{c}\text { UM } \\
15-24\end{array}$ & $\begin{array}{c}\text { UW } \\
15-24\end{array}$ \\
\hline \multicolumn{7}{|c|}{ Urban } \\
\hline \multicolumn{7}{|l|}{ Duration of paid work in last 12 months } \\
\hline Most of the year (6 months or more) & 92.4 & 78.6 & 96.7 & 74.5 & 92.0 & 79.6 \\
\hline Part of the year ( $3-5$ months) & 4.0 & 10.7 & 2.8 & 12.7 & 3.8 & 10.1 \\
\hline Rarely (less than 3 months) & 3.4 & 10.1 & 0.4 & 12.7 & 4.0 & 9.5 \\
\hline \multicolumn{7}{|l|}{ Main occupation (paid work) } \\
\hline Cultivator & 0.0 & 0.0 & 0.2 & 0.0 & 0.0 & 0.0 \\
\hline Agricultural labourer & 4.4 & 5.6 & 4.3 & 13.1 & 5.0 & 3.4 \\
\hline Administrative/executive/managerial/clerical & 9.9 & 24.0 & 7.4 & 11.2 & 11.0 & 27.8 \\
\hline Business & 4.6 & 1.0 & 6.9 & 0.0 & 4.8 & 1.3 \\
\hline Skilled manual/machinery & 55.0 & 34.7 & 59.0 & 36.4 & 53.4 & 34.1 \\
\hline Unskilled non-agricultural labourer & 23.9 & 33.3 & 19.6 & 37.4 & 24.1 & 32.0 \\
\hline Other & 1.9 & 0.8 & 1.9 & 0.9 & 1.5 & 0.8 \\
\hline Number engaged in paid work in last 12 months & 524 & 469 & 648 & 108 & 424 & 361 \\
\hline \multicolumn{7}{|c|}{ Rural } \\
\hline \multicolumn{7}{|l|}{ Ever worked } \\
\hline Paid work & 65.2 & 50.5 & 99.6 & 58.1 & 61.3 & 45.1 \\
\hline Unpaid work & 17.7 & 12.5 & 27.9 & 14.0 & 17.1 & 11.5 \\
\hline Either paid or unpaid work & 68.6 & 54.6 & 100.0 & 61.7 & 65.0 & 49.4 \\
\hline Started working before age 15 & 23.5 & 21.5 & 42.9 & 27.4 & 20.6 & 17.4 \\
\hline \multicolumn{7}{|l|}{ Ever worked in last 12 months } \\
\hline Paid work & 62.5 & 38.0 & 99.2 & 33.7 & 58.4 & 41.1 \\
\hline Unpaid work & 8.0 & 7.3 & 10.0 & 6.4 & 7.8 & 8.0 \\
\hline Either paid or unpaid work & 65.2 & 41.7 & 99.9 & 37.4 & 61.2 & 44.7 \\
\hline Number of respondents & 1,023 & 2,857 & 669 & 1,203 & 877 & 1,654 \\
\hline \multicolumn{7}{|l|}{ Duration of paid work in last 12 months } \\
\hline Most of the year (6 months or more) & 85.5 & 56.9 & 94.2 & 55.1 & 84.0 & 57.9 \\
\hline Part of the year ( $3-5$ months) & 7.7 & 25.8 & 5.2 & 32.0 & 7.8 & 22.1 \\
\hline Rarely (less than 3 months) & 6.3 & 15.9 & 0.4 & 12.2 & 7.6 & 18.1 \\
\hline \multicolumn{7}{|l|}{ Main occupation (paid work) } \\
\hline Cultivator & 0.7 & 0.8 & 0.9 & 0.2 & 0.7 & 1.1 \\
\hline Agricultural labourer & 24.0 & 52.7 & 31.1 & 65.8 & 22.3 & 45.2 \\
\hline Administrative/executive/managerial/clerical & 3.8 & 5.8 & 3.1 & 3.5 & 4.1 & 7.2 \\
\hline Business & 1.8 & 0.6 & 2.3 & 0.7 & 1.7 & 0.5 \\
\hline Skilled manual/machinery & 51.5 & 27.4 & 46.9 & 22.3 & 52.4 & 30.4 \\
\hline Unskilled non-agricultural labourer & 16.3 & 12.1 & 14.0 & 7.2 & 17.0 & 15.0 \\
\hline Other & 0.9 & 0.3 & 1.0 & 0.0 & 0.7 & 0.5 \\
\hline Number engaged in paid work in last 12 months & 662 & 1,081 & 663 & 401 & 518 & 680 \\
\hline
\end{tabular}

Note: All Ns are unweighted. Column totals may not equal 100\% due to missing cases or "don't know" responses. 
Table 4.1 also presents the percentages of youth reporting that they had worked any time in the 12 months prior to interview. We note that the measure of work in the year prior to interview covers a wide range of experiences that go beyond what is typically considered an employment rate (for example, as per the usual principal status definition, employment is defined as those who worked for the major part of the year preceding the interview as a fraction of those in the labour force, that is, those who worked or sought work for the major part of the year). Included in our measure of work are youth who worked for any length of time during the year as a proportion of all youth, irrespective of whether they had worked or sought work in the year preceding the interview.

A total of $63 \%$ of young men and $34 \%$ of young women had engaged in paid or unpaid work at some point in the 12 months preceding the interview. Percentages of youth who worked in the 12 months prior to interview largely mirrored lifetime economic activity for young men and unmarried young women. For example, all married young men, 59\% of unmarried young men and $37 \%$ of unmarried young women had done so. Many fewer married young women, however, reported economic activity in the last 12 months (29\%) compared to lifetime economic activity, a finding that may be attributed to conflict with childbearing and childrearing activities, on the one hand, and the tendency of married young women to be secluded from outside work, on the other.

Findings also suggest that among youth who had worked for remuneration in the year prior to interview, the majority had worked for at least six months of the year. Differences were, however, observed by sex, marital status and rural-urban residence of the respondent. Young men, for example, were considerably more likely than young women ( $88 \%$ compared to $64 \%)$ to have worked for six or more months in the year preceding the interview. Likewise, a larger proportion of married than unmarried men (95\% and $87 \%$, respectively)

reported working for most of the year; however, the reverse was true for young women $(59 \%$ and $66 \%$ of the married and unmarried, respectively). Finally, a larger proportion of urban than rural youth reported working for most of the year ( $92 \%$ and $86 \%$, respectively, among young men; $79 \%$ and $57 \%$, respectively, among young women).

Occupational distributions of those engaged in remunerated work in the 12 months preceding the interview were very different among rural and urban respondents. Among rural respondents, over $90 \%$ of both young men and women were engaged in three leading occupations: agriculture, skilled manual/machinery and unskilled non-agricultural labour. Distributions, however, differed: for example, the majority of rural young women (54\%) were engaged in agriculture (largely as labourers), while the majority of rural young men (52\%) were engaged in skilled manual/machinery-related occupations. Few rural youth reported administrative, executive, managerial or clerical occupations (4-6\%) or business-related occupations (1-2\%).

Among urban respondents, the leading occupations were skilled manual labour and unskilled non-agricultural labour, together reported by $79 \%$ of young men and $68 \%$ of young women. It is notable that administrative, executive, managerial and clerical occupations were reported by more urban young women than urban young men ( $24 \%$ and $10 \%$, respectively); also notable is that while just $7-11 \%$ of married and unmarried young men and married young women in urban settings reported these occupations, as many as $28 \%$ of unmarried young women so reported.

\subsection{Unemployment}

To measure unemployment rates among respondents, the Youth Study assessed (a) whether youth had worked in the 12 months preceding the interview and if so, the number of months worked; and (b) whether youth were seeking work and if so, the number of months during which they had been searching for work. Table 4.2 
reports unemployment rates, defined as those seeking employment for the major part of the year preceding the interview as a fraction of those in the labour force. Labour force refers to those who were working or seeking work for the major part of the year. It does not, therefore, include those exclusively studying, or those who may have either worked or had sought work for a short period in the year preceding the interview.

Measured in this way, the percentage of unemployed youth was $7 \%$ among young men and $15 \%$ among young women. These rates are similar, for the most part, to those observed by the National Sample Survey (NSS) (NSSO, 2006) among youth aged 15-29 using the usual principal status definition, namely 5\% and $8 \%$ among young men in rural and urban areas, respectively, and $6 \%$ and $13 \%$ among young women, respectively. Although rates obtained in the Youth Study are similar to those obtained by the NSS, we note certain differences in measurement: for example, questions were not identical; moreover, differences exist in the frequency with which information was obtained and correspondingly, in the recall period (quarterly in the NSS as compared to a 12-month recall period in the Youth Study); finally, differences also exist in terms of the household member eligible to provide information on youth unemployment (any household member in the NSS compared to the individual herself or himself in the Youth Study).

Table 4.2: Unemployment

Percentage of youth in the labour force who were unemployed, according to residence, Tamil Nadu, 2006

\begin{tabular}{|c|c|c|c|c|c|c|}
\hline Unemployment $(\%)^{1}$ & $\begin{array}{c}\mathrm{M} \\
15-24\end{array}$ & $\begin{array}{c}W \\
15-24\end{array}$ & $\begin{array}{c}\text { MM } \\
15-29\end{array}$ & $\begin{array}{c}\text { MW } \\
15-24\end{array}$ & $\begin{array}{c}\text { UM } \\
15-24\end{array}$ & $\begin{array}{c}\text { UW } \\
15-24\end{array}$ \\
\hline \multicolumn{7}{|c|}{ Combined } \\
\hline Unemployed & 7.0 & 14.6 & 0.9 & 15.5 & 7.9 & 14.0 \\
\hline Number in labour force & 1,153 & 1,219 & 1,275 & 383 & 918 & 836 \\
\hline \multicolumn{7}{|c|}{ Urban } \\
\hline Unemployed & 6.5 & 15.0 & 0.8 & 22.9 & 7.4 & 12.4 \\
\hline Number in labour force & 528 & 462 & 636 & 115 & 430 & 347 \\
\hline \multicolumn{7}{|c|}{ Rural } \\
\hline Unemployed & 7.2 & 14.3 & 1.1 & 12.6 & 8.3 & 15.3 \\
\hline Number in labour force & 625 & 757 & 639 & 268 & 488 & 489 \\
\hline
\end{tabular}

Note: All Ns are unweighted. ${ }^{1}$ Unemployment rate: Youth who were seeking work for the major part of the year preceding the interview as a proportion of those in the labour force (namely, those who were employed and/or seeking work for the major part of the year).

Findings suggest, moreover, that unmarried young men were somewhat more likely than their married counterparts to report unemployment ( $8 \%$ versus $1 \%)$; differences were, however, muted among young women ( $14 \%$ versus $16 \%$, respectively). Rural-urban differences were also narrow: $7 \%$ of young men and $14-15 \%$ of young women in both rural and urban areas were unemployed. However, it is notable that married young women in urban settings were almost twice as likely as their rural counterparts to report unemployment (23\% versus $13 \%)$.

Table 4.3 describes socio-economic differentials in reported unemployment among young men and women. Differences by age suggest that while unemployment rates were higher among the younger cohort (aged 15-19) than the older cohort (aged 20-24) among men (10\% and 6\%, respectively), the reverse was true for young women ( $8 \%$ and $18 \%$ among the younger and older cohort, respectively). Differences in unemployment by religion and caste were generally narrow. Differences by education were, in contrast, wide and consistent. Better educated youth were more likely to report unemployment than other categories of youth, suggesting the relative 
Table 4.3: Unemployment by selected background characteristics

Percentage of youth in the labour force who were unemployed by selected background characteristics, according to residence, Tamil Nadu, 2006

\begin{tabular}{|c|c|c|c|c|c|c|}
\hline Background characteristics (\%) & $\begin{array}{c}\mathrm{M} \\
15-24\end{array}$ & $\begin{array}{c}\text { W } \\
15-24\end{array}$ & $\begin{array}{c}\mathrm{MM} \\
15-29\end{array}$ & $\begin{array}{c}\text { MW } \\
15-24\end{array}$ & $\begin{array}{c}\text { UM } \\
15-24\end{array}$ & $\begin{array}{c}\text { UW } \\
15-24\end{array}$ \\
\hline \multicolumn{7}{|c|}{ Combined } \\
\hline \multicolumn{7}{|l|}{ Age (years) } \\
\hline $15-19$ & 9.5 & 8.2 & * & $(6.3)$ & 9.6 & 8.5 \\
\hline $20-24$ & 6.0 & 18.4 & 1.3 & 17.1 & 7.2 & 19.5 \\
\hline $25-29$ & NA & NA & 0.8 & NA & NA & NA \\
\hline \multicolumn{7}{|l|}{ Religion } \\
\hline Hindu & 7.0 & 14.7 & 1.0 & 15.4 & 8.0 & 14.3 \\
\hline Muslim & 7.3 & $(16.7)$ & 0.0 & * & 8.3 & $(15.4)$ \\
\hline Other $^{1}$ & $(4.8)$ & 11.3 & $(0.0)$ & * & $(5.4)$ & 10.0 \\
\hline \multicolumn{7}{|l|}{ Caste } \\
\hline SC & 7.2 & 14.4 & 0.6 & 15.0 & 8.5 & 13.7 \\
\hline $\mathrm{OBC}$ & 6.8 & 14.4 & 1.1 & 15.2 & 7.6 & 14.0 \\
\hline \multicolumn{7}{|l|}{ Educational level (years) } \\
\hline None $^{2}$ & 0.0 & 1.2 & 0.0 & 1.5 & $(0.0)$ & * \\
\hline $1-7$ & 2.5 & 4.1 & 0.6 & 5.6 & 3.4 & 3.3 \\
\hline $8-11$ & 5.7 & 13.0 & 0.6 & 15.5 & 6.2 & 12.0 \\
\hline 12 and above & 18.2 & 31.4 & 2.6 & 45.5 & 18.9 & 27.5 \\
\hline \multicolumn{7}{|l|}{ Wealth quintile } \\
\hline First & 5.4 & 10.1 & 0.5 & 7.2 & 6.7 & 11.8 \\
\hline Second & 7.9 & 9.9 & 1.3 & 7.5 & 8.9 & 11.2 \\
\hline Third & 4.9 & 12.2 & 0.7 & 17.5 & 5.5 & 9.9 \\
\hline Fourth & 6.1 & 20.9 & 0.0 & 23.6 & 7.1 & 20.0 \\
\hline Fifth & 12.8 & 25.0 & 2.2 & $(32.5)$ & 13.4 & 21.5 \\
\hline Total & 7.0 & 14.6 & 0.9 & 15.5 & 7.9 & 14.0 \\
\hline \multicolumn{7}{|c|}{ Urban } \\
\hline \multicolumn{7}{|l|}{ Age (years) } \\
\hline $15-19$ & 5.6 & 6.3 & * & * & 5.7 & 6.0 \\
\hline $20-24$ & 6.8 & 19.8 & 1.2 & 23.9 & 8.2 & 17.9 \\
\hline $25-29$ & NA & NA & 0.7 & NA & NA & NA \\
\hline \multicolumn{7}{|l|}{ Religion } \\
\hline Hindu & 6.3 & 14.1 & 0.9 & 21.4 & 7.2 & 11.9 \\
\hline Muslim & 8.9 & $(20.7)$ & 0.0 & * & $(10.0)$ & * \\
\hline Other $^{1}$ & * & (19.4) & * & * & * & * \\
\hline \multicolumn{7}{|l|}{ Caste } \\
\hline SC & 6.5 & 13.7 & 0.0 & * & 8.0 & 6.2 \\
\hline $\mathrm{OBC}$ & 6.3 & 14.4 & 1.0 & 16.7 & 6.8 & 14.0 \\
\hline
\end{tabular}


Table 4.3: (Cont'd)

\begin{tabular}{|c|c|c|c|c|c|c|}
\hline Background characteristics (\%) & $\begin{array}{c}\mathrm{M} \\
15-24\end{array}$ & $\begin{array}{c}\text { W } \\
15-24\end{array}$ & $\begin{array}{c}\text { MM } \\
15-29\end{array}$ & $\begin{array}{c}\text { MW } \\
15-24\end{array}$ & $\begin{array}{c}\text { UM } \\
15-24\end{array}$ & $\begin{array}{c}\text { UW } \\
\text { 15-24 }\end{array}$ \\
\hline \multicolumn{7}{|c|}{ Urban } \\
\hline \multicolumn{7}{|l|}{ Educational level (years) } \\
\hline None $^{2}$ & * & * & * & * & * & * \\
\hline $1-7$ & 2.1 & 3.2 & 0.5 & $(3.3)$ & 2.8 & 3.1 \\
\hline $8-11$ & 6.2 & 11.7 & 0.5 & $(21.3)$ & 6.6 & 7.0 \\
\hline 12 and above & 13.2 & 27.1 & 1.9 & $(46.7)$ & 13.3 & 23.0 \\
\hline \multicolumn{7}{|l|}{ Wealth quintile } \\
\hline First & 2.3 & $(8.1)$ & $(0.0)$ & * & $(2.8)$ & * \\
\hline Second & 7.4 & 8.1 & 1.1 & * & 8.2 & 9.0 \\
\hline Third & 5.4 & 13.3 & 0.9 & $(27.3)$ & 5.3 & 8.3 \\
\hline Fourth & 4.7 & 19.0 & 0.0 & $(30.0)$ & 5.4 & 15.2 \\
\hline Fifth & 11.5 & 20.4 & 1.5 & * & 13.0 & 17.6 \\
\hline Total & 6.5 & 15.0 & 0.8 & 22.9 & 7.4 & 12.4 \\
\hline \multicolumn{7}{|c|}{ Rural } \\
\hline \multicolumn{7}{|l|}{ Age (years) } \\
\hline $15-19$ & 12.1 & 9.4 & * & $(5.1)$ & 11.9 & 10.2 \\
\hline $20-24$ & 5.3 & 17.4 & 1.3 & 13.9 & 6.4 & 20.8 \\
\hline $25-29$ & NA & NA & 1.0 & NA & NA & NA \\
\hline \multicolumn{7}{|l|}{ Religion } \\
\hline Hindu & 7.4 & 15.0 & 1.1 & 13.3 & 8.6 & 16.0 \\
\hline Muslim & * & * & * & * & * & * \\
\hline Other $^{1}$ & * & 6.3 & * & * & * & (8.3) \\
\hline \multicolumn{7}{|l|}{ Caste } \\
\hline SC & 7.6 & 14.6 & 1.0 & 10.0 & 9.6 & 17.6 \\
\hline OBC & 7.5 & 14.4 & 1.2 & 14.5 & 8.4 & 14.1 \\
\hline \multicolumn{7}{|l|}{ Educational level (years) } \\
\hline None $^{2}$ & $(0.0)$ & 0.0 & 0.0 & 0.0 & * & * \\
\hline $1-7$ & 2.9 & 4.6 & 0.6 & 6.4 & 3.9 & 3.4 \\
\hline $8-11$ & 5.1 & 13.7 & 0.7 & 12.0 & 5.8 & 14.5 \\
\hline 12 and above & 24.8 & 37.3 & 3.5 & $(44.4)$ & 25.3 & 34.0 \\
\hline \multicolumn{7}{|l|}{ Wealth quintile } \\
\hline First & 6.4 & 10.5 & 0.6 & 7.0 & 8.2 & 12.6 \\
\hline Second & 8.1 & 10.6 & 1.3 & 8.0 & 9.1 & 11.6 \\
\hline Third & 5.2 & 11.5 & 0.5 & 12.3 & 4.9 & 11.0 \\
\hline Fourth & 8.1 & 23.3 & 0.0 & $(18.6)$ & 8.3 & 24.7 \\
\hline Fifth & $(15.8)$ & $(35.9)$ & $(5.7)$ & * & $(14.7)$ & * \\
\hline Total & 7.2 & 14.3 & 1.1 & 12.6 & 8.3 & 15.3 \\
\hline
\end{tabular}

Note: ( ) Based on 25-49 unweighted cases. ${ }^{*}$ Percentage not shown, based on fewer than 25 unweighted cases. NA: Not applicable. OBC: Other backward caste. SC: Scheduled caste. ${ }^{1}$ Includes Christian, Buddhist, Neo-Buddhist, Sikh, Jain, Jewish, Parsi/Zoroastrian and no specified religion. ${ }^{2}$ Includes non-literate and literate with no formal schooling. 
dearth of opportunities for the educated. Unemployment rates peaked at $18 \%$ and $31 \%$ among young men and women who had completed at least Class 12, a finding reiterated in other studies (Chandrasekhar, Ghosh and Roychowdhury, 2006; NSSO, 2006). Finally, unemployment rates increased, by and large, with household economic status. For young men, the increase was observed only among those in the wealthiest (fifth) quintile; among young women, increases were more uniformly observed. Patterns by rural-urban residence and marital status were, by and large, similar to patterns observed for young men and women in general.

\subsection{Work-related mobility}

Among young men who had ever worked, a notable segment-about one-third-reported the experience of work-related mobility, as shown in Table 4.4. Fewer young women, in contrast, had lived away from home for work-related reasons (9\%), a finding that may be attributed to the greater restrictions placed on the independent movement of young women than young men. Differences by marital status indicate that married young men were more likely than unmarried young men to have experienced work-related mobility ( $38 \%$ versus $30 \%$ ), perhaps a function of the fact that married men tended to be older and have more work experience than the unmarried. Finally, rural youth, particularly young men, were more likely than urban youth to report work-related mobility (38\% versus $22 \%$ among young men; $10 \%$ versus $5 \%$, respectively, among young women). This finding may be attributed to the more seasonal work opportunities in rural than urban areas, requiring rural young men to explore work opportunities outside their home settings.

\section{Table 4.4: Work-related mobility}

Percentage of youth who had ever lived outside their home village/area for work, according to residence, Tamil Nadu, 2006

\begin{tabular}{|c|c|c|c|c|c|c|}
\hline Mobility characteristics (\%) & $\begin{array}{c}\mathrm{M} \\
15-24\end{array}$ & $\begin{array}{c}\text { W } \\
15-24\end{array}$ & $\begin{array}{c}\text { MM } \\
15-29\end{array}$ & $\begin{array}{c}\text { MW } \\
15-24\end{array}$ & $\begin{array}{c}\text { UM } \\
15-24\end{array}$ & $\begin{array}{c}\text { UW } \\
15-24\end{array}$ \\
\hline \multicolumn{7}{|c|}{ Combined } \\
\hline $\begin{array}{l}\text { Work-related mobility } \\
\text { Ever stayed outside village/area for work }\end{array}$ & 31.2 & 8.5 & 38.2 & 8.7 & 30.1 & 8.3 \\
\hline Number ever worked & 1,285 & 2,345 & 1,320 & 1,080 & 1,038 & 1,265 \\
\hline Stayed outside village/area for 3 months or longer & 70.0 & 68.8 & 69.2 & 71.6 & 69.5 & 66.7 \\
\hline Number ever stayed out of home village/area for work & 397 & 199 & 479 & 93 & 308 & 106 \\
\hline \multicolumn{7}{|c|}{ Urban } \\
\hline $\begin{array}{l}\text { Work-related mobility } \\
\text { Ever stayed outside village/area for work }\end{array}$ & 22.0 & 5.2 & 27.3 & 4.3 & 20.6 & 6.0 \\
\hline Number ever worked & 565 & 793 & 651 & 347 & 464 & 446 \\
\hline Stayed outside village/area for 3 months or longer & 63.2 & $(79.1)$ & 61.1 & * & 64.4 & $(85.7)$ \\
\hline Number ever stayed out of home village/area for work & 127 & 41 & 175 & 14 & 96 & 27 \\
\hline \multicolumn{7}{|c|}{ Rural } \\
\hline $\begin{array}{l}\text { Work-related mobility } \\
\text { Ever stayed outside village/area for work }\end{array}$ & 37.5 & 10.2 & 45.8 & 11.0 & 37.0 & 9.6 \\
\hline Number ever worked & 720 & 1,552 & 669 & 733 & 574 & 819 \\
\hline Stayed outside village/area for 3 months or longer & 72.8 & 66.0 & 72.7 & 71.6 & 71.9 & 60.0 \\
\hline Number ever stayed out of home village/area for work & 270 & 158 & 304 & 79 & 212 & 79 \\
\hline
\end{tabular}

Note: All Ns are unweighted. ( ) Based on 25-49 unweighted cases. ${ }^{*}$ Percentage not shown, based on fewer than 25 unweighted cases. 
A large proportion of youth-69-70\% of young men and women-who reported work-related mobility had remained outside their home village or neighbourhood for three months or longer. Differences by marital status were negligible. Rural-urban differences suggest that while more rural than urban young men had stayed outside for three months or longer ( $73 \%$ versus $63 \%)$, the reverse was true for young women (66\% versus $79 \%)$.

\subsection{Economic activity and schooling status}

While the period of transition to adulthood is marked by discontinuation of schooling and entry into the labour market for many young people, some combine schooling and work and others are neither in school nor working. Data collected through the Life Event Calendar component of the Youth Study provided an opportunity to explore the pattern of these events (that is, studying, working, both studying and working, and neither studying nor working) in young people's lives from the age of 12, and are presented in Figures 4.1a-c. We note that Figures 4.1a and 4.1b convey the situation both prior to and following marriage for married youth.

A comparison of the two panels of Figure 4.1a shows, first, that the proportion of youth reporting school attendance declined steadily across all groups as young people transitioned out of childhood or early adolescence to late adolescence and young adulthood. For example, while $86 \%$ of young men and $83 \%$ of young women were in school (a small minority of these were also working) at age 12, the percentage who remained in school at age 15 fell to $68 \%$ for young men and $60 \%$ for young women. Second, very few young people ( $4 \%$ or fewer) reported having combined studying and working at any age. Third, exit from school was accompanied by a steady rise in work participation over the ages for both young men and young women. For young men, work participation increased consistently with age, reaching $96 \%$ by age 24 ; in contrast, among young women, the increase was more gradual and levelled off at 30-35\% between ages 17 and 23 , and reached $39 \%$ at age 24. Finally, significant proportions of young women but not young men were neither in school nor working from age 12 onwards. Among young men, small proportions (1-7\%) were neither working nor in school at any age. Among young women, there was a steady increase by age. At age $12,12 \%$ of young women were neither working nor in school; percentages increased to $21 \%$ at age 15 , $50 \%$ at age 20 and almost $60 \%$ by age 22 .

Figures $4.1 \mathrm{~b}$ and $4.1 \mathrm{c}$ suggest similar patterns for married and unmarried youth, with some notable exceptions. For one, the married were less likely to be in school at each age and the percentages of those who remained in school fell more steeply among the married than the unmarried for each age thereafter. For example, 68-71\% of the married and $89-90 \%$ of the unmarried were in school (a small minority of these were also working) at age 12 . By age 20 , in contrast, only $8 \%$ of married young men and $7 \%$ of married young women were pursuing their education, compared to $28 \%$ and $38 \%$ of unmarried young men and women, respectively. It is notable that among the unmarried, while at younger ages ( 16 and below) and at age 24 , gender differences in percentages pursuing their education were minor, they were fairly wide between the ages of 17 and 23 , with young women considerably more likely than young men to be pursuing their education. Second, while exit from school was accompanied by a steady rise in work participation by age among both married and unmarried young men, the pace of increase varied by marital status. Among married young men, for example, increases were steep and by age 21 , as many as $95 \%$ were working; increases were somewhat more gradual for unmarried young men, among whom, in comparison, $78 \%$ were working by age 21 . Among young women, while there was a steady increase in percentages of the unmarried reporting work (from $23 \%$ at age 16 to $40 \%$ at age 21 ), work participation rates plateaued among the married by about age 16; between ages 16 and 24 , about $30-35 \%$ of the married reported work participation. Finally, we note that considerably larger percentages of married than unmarried young women were neither in school nor working from age 12 onwards, and differences became more pronounced with age. 
Figure 4.1a: Economic activity and schooling status among youth aged 15-24, by age, Tamil Nadu, 2006
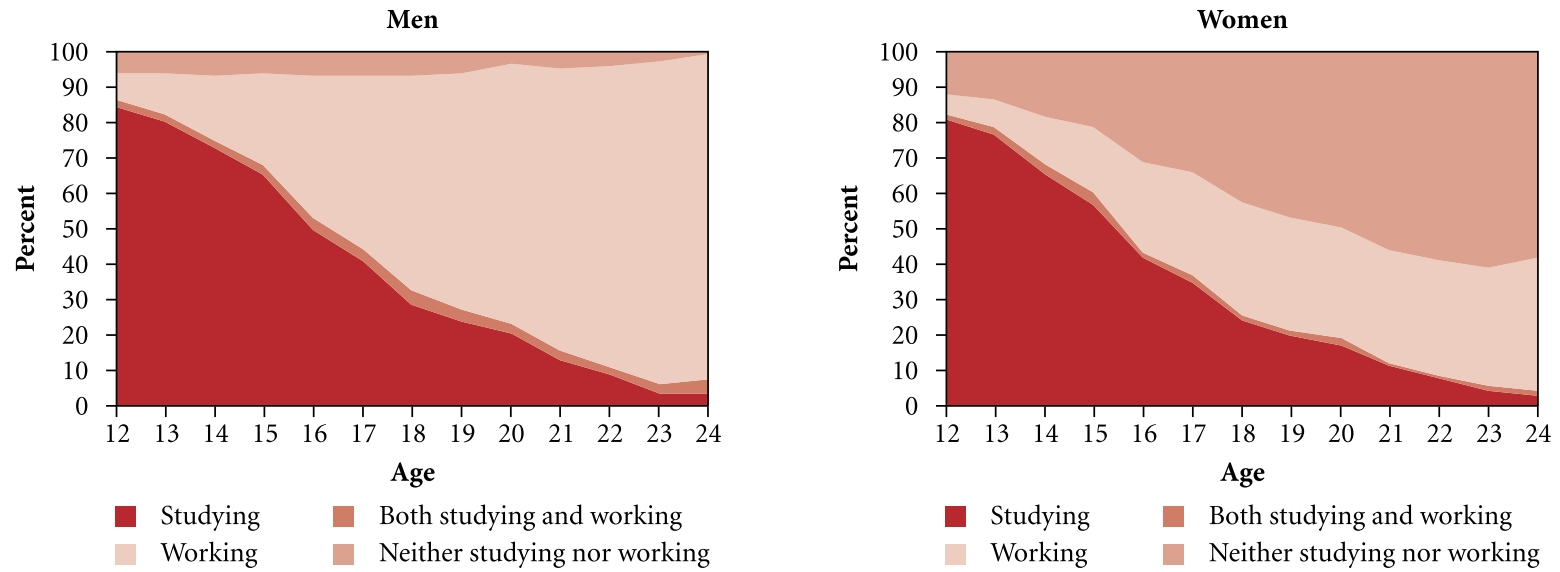

Note: For married youth, the figure conveys the situation prior to and following marriage.

Figure 4.1b: Economic activity and schooling status among married men aged 15-29 and married women aged 15-24, by age, Tamil Nadu, 2006
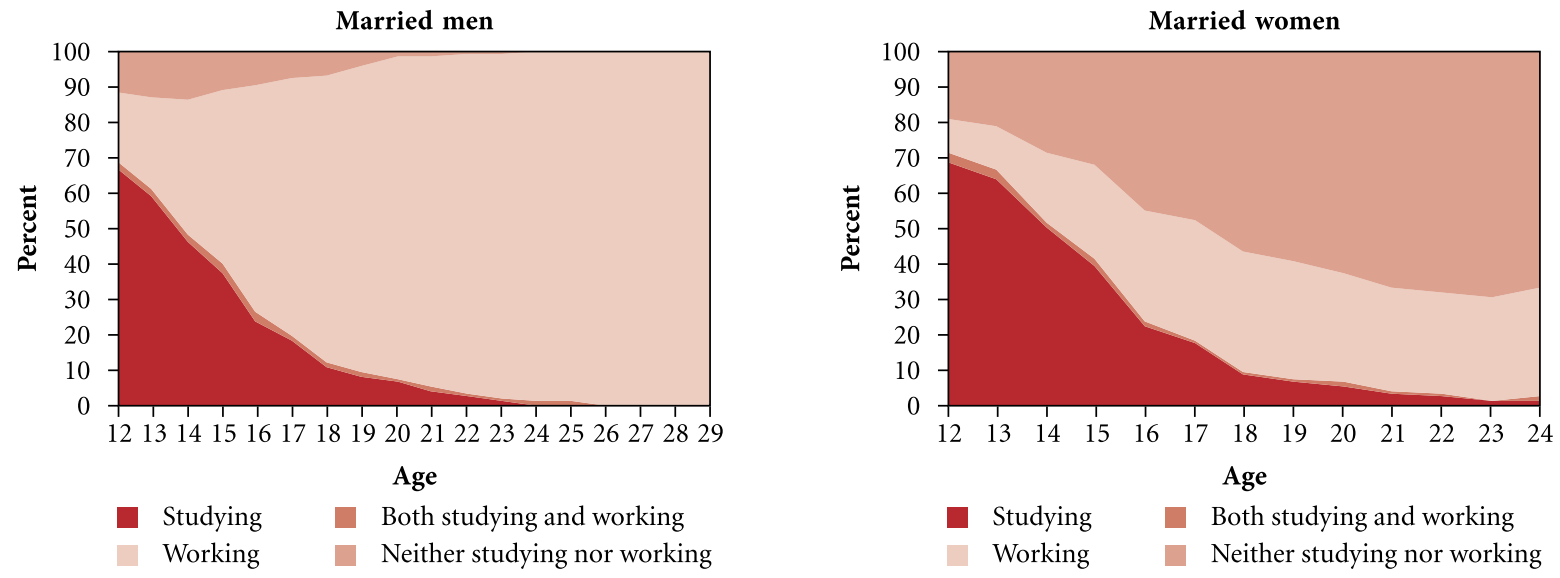

Note: For married youth, the figure conveys the situation prior to and following marriage.

Figure 4.1c: Economic activity and schooling status among unmarried men and women aged 15-24, by age, Tamil Nadu, 2006
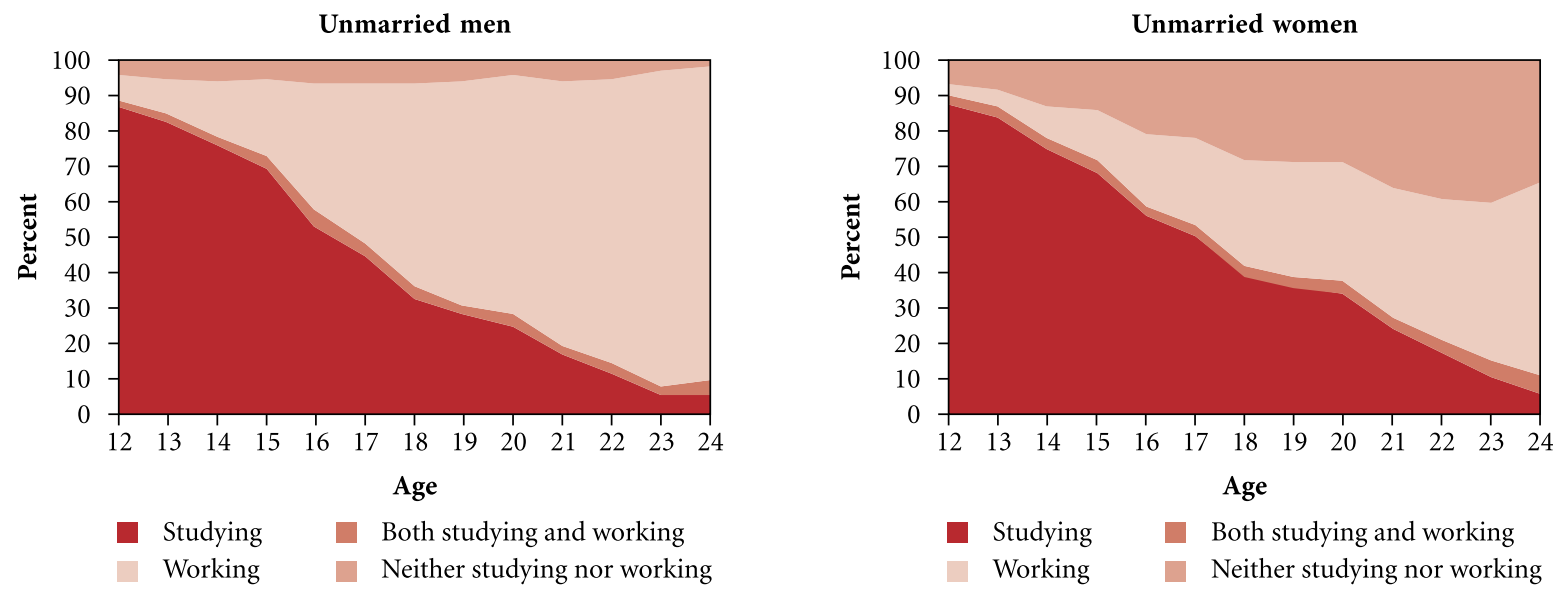


\subsection{Participation in non-economic activity}

The Youth Study also inquired about the extent to which young men and women participated in domestic chores. All youth were asked whether and how frequently they were engaged in activities such as housework (cooking, cleaning, child/sibling care), shopping for groceries for the family and tasks such as collecting firewood or fetching water, and paying electricity or phone bills (as appropriate for urban and rural areas). Findings, reported in Table 4.5 and Figure 4.2, highlight the gendered nature of young people's participation in domestic chores. Young women were more likely than young men to undertake each of the three tasks on a regular basis. For example, half of young women compared with just $3 \%$ of young men were often engaged in housework; one-fifth of young women compared to $7 \%$ of young men often shopped for groceries; and two-fifths of young women compared to just 5\% of young men performed such tasks as collecting firewood or fetching water (in rural areas), and paying electricity or phone bills (in urban areas). Young men did, however, report performing each of these three tasks "sometimes": $80 \%, 89 \%$ and $85 \%$, for each of the above activities, respectively. Few youth reported that they never conducted any of these tasks: it is notable, however, that $17 \%$ of young men (and $4 \%$ of young women) never did housework and $24 \%$ of young women (compared to $4 \%$ of young men) never shopped for household groceries.

In terms of differences in household work participation by marital status, married and unmarried young men were equally likely to report engaging in each task. Among young women, in contrast, the unmarried were consistently less likely than the married to be engaged in all three household tasks on a regular basis, and conversely, somewhat more likely to report never participating in these tasks.

Rural-urban differences were moderate but suggest that urban youth were considerably less likely than their rural counterparts to report engaging in such tasks as collecting firewood or fetching water, and paying bills. Moreover, rural young women were more likely than urban young women to have engaged in housework and other tasks on a regular basis.
Figure 4.2: Percentage of youth who participated in domestic chores, according to residence, Tamil Nadu, 2006
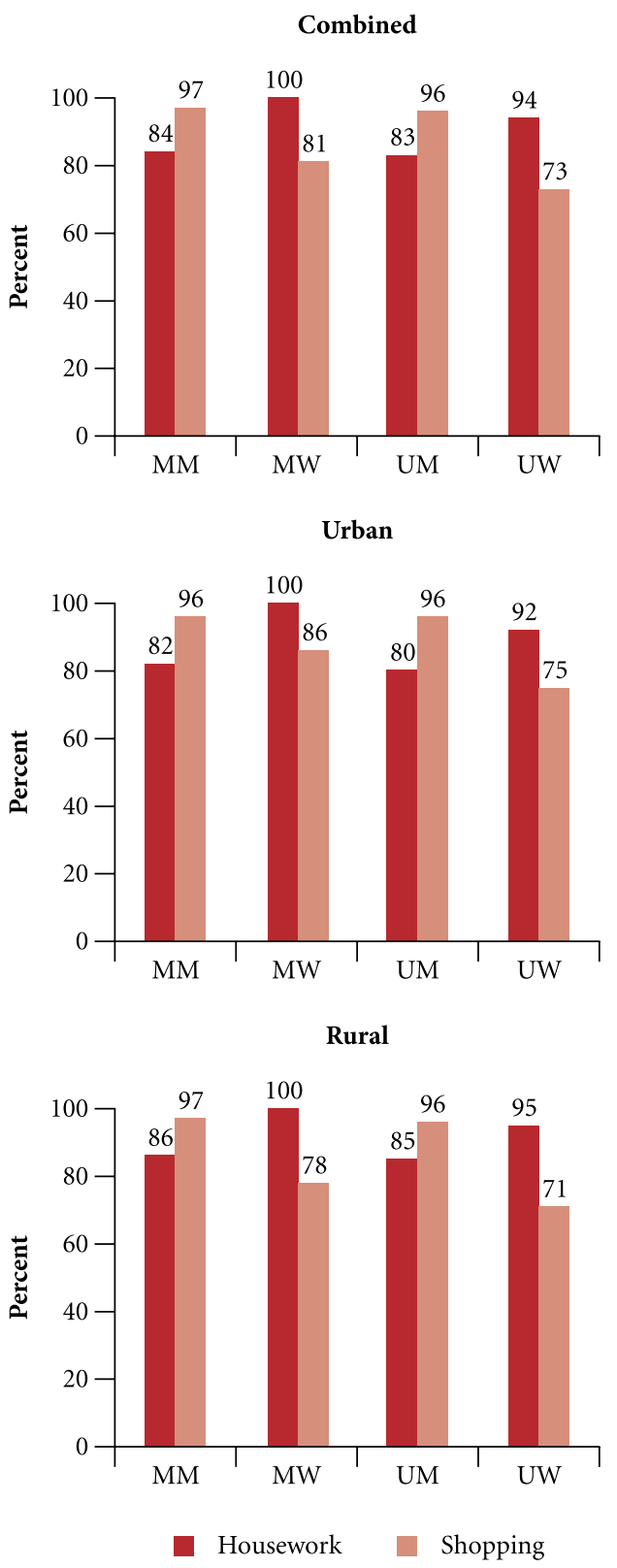
Table 4.5: Participation in household chores

Percent distribution of youth by extent of participation in various household chores, according to residence, Tamil Nadu, 2006

\begin{tabular}{|c|c|c|c|c|c|c|}
\hline Types of chores (\%) & $\begin{array}{c}\mathrm{M} \\
15-24\end{array}$ & $\begin{array}{c}\text { W } \\
15-24\end{array}$ & $\begin{array}{c}\text { MM } \\
15-29\end{array}$ & $\begin{array}{c}\text { MW } \\
15-24\end{array}$ & $\begin{array}{c}\text { UM } \\
15-24\end{array}$ & $\begin{array}{c}\text { UW } \\
\text { 15-24 }\end{array}$ \\
\hline \multicolumn{7}{|c|}{ Combined } \\
\hline \multicolumn{7}{|l|}{ Housework $^{1}$} \\
\hline Never & 17.0 & 4.1 & 15.4 & 0.5 & 17.5 & 6.4 \\
\hline Sometimes & 80.1 & 45.6 & 81.1 & 16.8 & 79.6 & 64.5 \\
\hline Often & 3.0 & 50.4 & 3.3 & 82.7 & 2.9 & 29.1 \\
\hline \multicolumn{7}{|l|}{ Shopping } \\
\hline Never & 4.3 & 23.7 & 3.3 & 19.0 & 4.2 & 26.8 \\
\hline Sometimes & 89.0 & 55.8 & 88.6 & 46.0 & 89.3 & 62.3 \\
\hline Often & 6.7 & 20.5 & 8.0 & 35.0 & 6.5 & 11.0 \\
\hline \multicolumn{7}{|l|}{ Other tasks ${ }^{2}$} \\
\hline Never & 10.0 & 12.9 & 8.9 & 9.4 & 10.4 & 15.2 \\
\hline Sometimes & 84.7 & 47.1 & 84.7 & 28.8 & 84.7 & 59.1 \\
\hline Often & 5.3 & 40.0 & 6.3 & 61.8 & 4.9 & 25.7 \\
\hline Number of respondents & 1,913 & 5,008 & 1,322 & 2,007 & 1,666 & 3,001 \\
\hline \multicolumn{7}{|c|}{ Urban } \\
\hline \multicolumn{7}{|l|}{ Housework $^{1}$} \\
\hline Never & 19.7 & 5.5 & 17.8 & 0.5 & 20.1 & 8.4 \\
\hline Sometimes & 77.4 & 52.8 & 80.5 & 20.0 & 77.0 & 71.8 \\
\hline Often & 2.9 & 41.8 & 1.5 & 79.5 & 2.9 & 19.8 \\
\hline \multicolumn{7}{|l|}{ Shopping } \\
\hline Never & 4.6 & 20.7 & 4.1 & 14.1 & 4.4 & 24.6 \\
\hline Sometimes & 90.6 & 59.2 & 91.5 & 47.0 & 90.9 & 66.3 \\
\hline Often & 4.8 & 20.1 & 4.2 & 38.9 & 4.7 & 9.1 \\
\hline \multicolumn{7}{|l|}{ Other tasks ${ }^{2}$} \\
\hline Never & 13.6 & 17.8 & 10.7 & 13.5 & 13.9 & 20.4 \\
\hline Sometimes & 82.8 & 49.6 & 86.6 & 30.5 & 82.5 & 60.7 \\
\hline Often & 3.6 & 32.6 & 2.6 & 56.0 & 3.6 & 18.9 \\
\hline Number of respondents & 890 & 2,151 & 653 & 804 & 789 & 1,347 \\
\hline \multicolumn{7}{|c|}{ Rural } \\
\hline \multicolumn{7}{|l|}{ Housework $^{1}$} \\
\hline Never & 14.8 & 2.9 & 13.8 & 0.5 & 15.4 & 4.7 \\
\hline Sometimes & 82.1 & 39.9 & 81.4 & 14.7 & 81.7 & 58.1 \\
\hline Often & 3.0 & 57.2 & 4.6 & 84.8 & 2.9 & 37.2 \\
\hline \multicolumn{7}{|l|}{ Shopping } \\
\hline Never & 4.1 & 26.0 & 2.8 & 22.4 & 4.0 & 28.6 \\
\hline Sometimes & 87.8 & 53.2 & 86.5 & 45.4 & 87.9 & 58.8 \\
\hline Often & 8.1 & 20.8 & 10.7 & 32.2 & 8.1 & 12.6 \\
\hline \multicolumn{7}{|l|}{ Other tasks ${ }^{2}$} \\
\hline Never & 7.3 & 9.1 & 7.7 & 6.7 & 7.4 & 10.7 \\
\hline Sometimes & 86.3 & 45.1 & 83.6 & 27.6 & 86.6 & 57.7 \\
\hline Often & 6.4 & 45.9 & 8.7 & 65.7 & 6.0 & 31.6 \\
\hline Number of respondents & 1,023 & 2,857 & 669 & 1,203 & 877 & 1,654 \\
\hline
\end{tabular}

Note: All Ns are unweighted. Column totals may not equal 100\% due to missing cases or "don't know" responses. 'Includes cooking, cleaning, etc. ${ }^{2}$ Respondents were given examples of other tasks such as collecting firewood, fetching water, grazing livestock, paying bills, etc. 


\subsection{Participation in vocational training programmes}

A number of vocational training opportunities are available to youth through government, non-government and private organisations. Our survey inquired whether respondents had attended any such programmes, and the kinds of programmes they would like to attend, if offered. Findings, presented in Table 4.6 and Figure 4.3 , indicate that $25 \%$ of young men and $32 \%$ of young women had ever attended a vocational training programme. The unmarried were more likely to have received training than the married, particularly among young women, and urban respondents were far more likely to have received training than their rural counterparts.

The kind of training received varied widely by sex of the respondent, marital status and rural-urban residence. Among young men, leading training programmes reported were focused on computer skills (53\%), English language, typing or shorthand (17\%), driving (15\%) and auto mechanic or electrical work (14\%). Key training programmes reported by young women were different: $54 \%$ reported training in tailoring, $39 \%$ in computer skills and 22\% in English language, typing or shorthand. The unmarried were more likely to report training in computer and English language, typing or shorthand skills than the married. For example, 57\% of unmarried young men compared to $21 \%$ of married young men reported computer training; corresponding figures for young women were $48 \%$ and $21 \%$. Training in English language, typing or shorthand skills was reported by $19 \%$ of unmarried young men compared to $11 \%$ of married young men; corresponding figures for young women were $24 \%$ and $16 \%$. In contrast, married young men were more likely than their unmarried counterparts to have undertaken training in driving (40\% compared to $13 \%)$, and married young women were more likely than their unmarried counterparts to report training in tailoring ( $73 \%$ and $45 \%$, respectively). Finally, training received by rural youth was considerably more likely than that obtained by urban youth to fall into more traditional activities, such as tailoring, auto mechanic and driving among young men, and tailoring among young women. Urban youth, in contrast, were considerably more likely than their rural counterparts to have received training in computer skills or English language, typing or shorthand.

Large proportions of youth- $43 \%$ of young men and $53 \%$ of young women—expressed interest in attending vocational training programmes, as shown in Table 4.7. More unmarried than married youth, and urban than rural youth, expressed interest in acquiring vocational skills. Skills in which youth wished to be trained virtually mirrored the patterns revealed above. The majority of young women continued to wish to be trained in areas such as tailoring, computer skills and English language, typing or shorthand; some 14\% also expressed interest in training in handicrafts, painting, embroidery or cooking. Young men's preferences, in contrast, were focused on computer training, English language, typing or shorthand, driving and auto mechanic or electrical work.

Figure 4.3: Percentage of youth who ever attended a vocational training programme and percentage who were interested in participating in such programmes, according to residence, Tamil Nadu, 2006
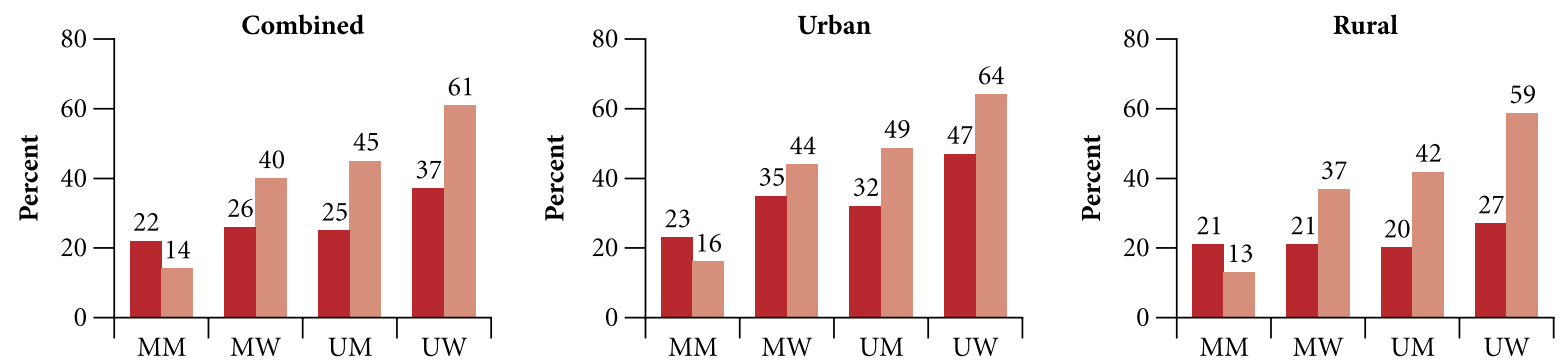

Ever attended a vocational training programme

Interested in participating in a vocational training programme 
Table 4.6: Participation in vocational training programmes

Percentage of youth who ever attended a vocational training programme and type of programme attended, according to residence, Tamil Nadu, 2006

\begin{tabular}{|c|c|c|c|c|c|c|}
\hline Programmes/courses attended (\%) & $\begin{array}{c}\mathrm{M} \\
15-24\end{array}$ & $\begin{array}{c}\mathrm{W} \\
15-24\end{array}$ & $\begin{array}{c}\text { MM } \\
15-29\end{array}$ & $\begin{array}{c}\text { MW } \\
15-24\end{array}$ & $\begin{array}{c}\text { UM } \\
15-24\end{array}$ & $\begin{array}{c}\text { UW } \\
15-24\end{array}$ \\
\hline \multicolumn{7}{|c|}{ Combined } \\
\hline Ever attended a vocational training programme & 24.9 & 32.4 & 21.9 & 26.2 & 25.4 & 36.6 \\
\hline Number of respondents & 1,913 & 5,008 & 1,322 & 2,007 & 1,666 & 3,001 \\
\hline \multicolumn{7}{|l|}{ Types of programmes/courses attended } \\
\hline Tailoring & 7.1 & 53.8 & 13.8 & 72.7 & 6.4 & 44.8 \\
\hline Auto mechanic/electrical work & 14.0 & 0.2 & 13.1 & 0.0 & 13.7 & 0.3 \\
\hline Driving & 14.9 & 1.0 & 40.3 & 1.1 & 12.5 & 1.0 \\
\hline Plumbing/masonry & 3.8 & 0.0 & 9.7 & 0.0 & 3.1 & 0.0 \\
\hline Poultry/goat farm & 0.0 & 0.0 & 0.0 & 0.0 & 0.0 & 0.0 \\
\hline Beauty parlour/salon & 0.6 & 0.7 & 0.3 & 0.6 & 0.5 & 0.7 \\
\hline Nurse's aid & 0.6 & 0.3 & 0.3 & 0.6 & 0.7 & 0.2 \\
\hline Computer training & 53.3 & 39.2 & 21.0 & 20.5 & 57.3 & 48.0 \\
\hline English language/typing/shorthand & 17.2 & 21.6 & 11.0 & 16.2 & 18.6 & 24.2 \\
\hline Handicrafts/painting/embroidery/cooking & 4.4 & 7.4 & 8.3 & 12.0 & 4.0 & 5.2 \\
\hline Number ever attended any vocational training & 482 & 1,614 & 298 & 526 & 430 & 1,088 \\
\hline \multicolumn{7}{|c|}{ Urban } \\
\hline Ever attended a vocational training programme & 31.0 & 42.7 & 23.2 & 34.7 & 31.9 & 47.4 \\
\hline Number of respondents & 890 & 2,151 & 653 & 804 & 789 & 1,347 \\
\hline \multicolumn{7}{|l|}{ Types of programmes/courses attended } \\
\hline Tailoring & 3.9 & 46.7 & 11.9 & 69.0 & 3.8 & 37.3 \\
\hline Auto mechanic/electrical work & 11.2 & 0.2 & 15.1 & 0.0 & 10.1 & 0.3 \\
\hline Driving & 12.8 & 1.4 & 32.5 & 1.8 & 11.3 & 1.2 \\
\hline Plumbing/masonry & 2.3 & 0.0 & 7.9 & 0.0 & 1.7 & 0.0 \\
\hline Poultry/goat farm & 0.0 & 0.0 & 0.0 & 0.0 & 0.0 & 0.0 \\
\hline Beauty parlour/salon & 0.8 & 1.2 & 0.0 & 1.1 & 0.8 & 1.2 \\
\hline Nurse's aid & 0.4 & 0.2 & 0.8 & 0.7 & 0.4 & 0.0 \\
\hline Computer training & 63.2 & 44.1 & 34.1 & 22.7 & 66.4 & 53.2 \\
\hline English language/typing/shorthand & 23.3 & 26.0 & 14.2 & 18.6 & 24.8 & 29.1 \\
\hline Handicrafts/painting/embroidery/cooking & 3.1 & 8.2 & 7.9 & 13.9 & 2.9 & 6.0 \\
\hline Number ever attended any vocational training & 269 & 920 & 154 & 280 & 248 & 640 \\
\hline \multicolumn{7}{|c|}{ Rural } \\
\hline Ever attended a vocational training programme & 20.3 & 24.3 & 21.1 & 20.5 & 20.1 & 27.0 \\
\hline Number of respondents & 1,023 & 2,857 & 669 & 1,203 & 877 & 1,654 \\
\hline \multicolumn{7}{|l|}{ Types of programmes/courses attended } \\
\hline Tailoring & 10.9 & 63.7 & 15.2 & 76.7 & 9.7 & 56.4 \\
\hline Auto mechanic/electrical work & 17.3 & 0.1 & 11.7 & 0.0 & 18.4 & 0.2 \\
\hline Driving & 17.3 & 0.6 & 47.0 & 0.4 & 14.1 & 0.7 \\
\hline Plumbing/masonry & 5.5 & 0.0 & 11.0 & 0.0 & 4.3 & 0.0 \\
\hline Poultry/goat farm & 0.0 & 0.0 & 0.0 & 0.0 & 0.0 & 0.0 \\
\hline Beauty parlour/salon & 0.5 & 0.0 & 0.6 & 0.0 & 0.5 & 0.0 \\
\hline Nurse's aid & 0.9 & 0.4 & 0.0 & 0.4 & 1.1 & 0.5 \\
\hline Computer training & 41.6 & 32.3 & 11.0 & 18.4 & 45.9 & 39.9 \\
\hline English language/typing/shorthand & 9.6 & 15.5 & 9.1 & 13.5 & 10.8 & 16.7 \\
\hline Handicrafts/painting/embroidery/cooking & 5.9 & 6.0 & 8.6 & 9.8 & 5.4 & 4.2 \\
\hline Number ever attended any vocational training & 213 & 694 & 144 & 246 & 182 & 448 \\
\hline
\end{tabular}

Note: All Ns are unweighted. Column totals may exceed 100\% due to multiple responses. 
Table 4.7: Willingness of youth to participate in vocational training programmes

Percentage of youth interested in participating in vocational training programmes and type of programme they were interested in participating in, according to residence, Tamil Nadu, 2006

\begin{tabular}{|c|c|c|c|c|c|c|}
\hline Programmes/courses (\%) & $\begin{array}{c}M \\
15-24\end{array}$ & $\begin{array}{c}\text { W } \\
15-24\end{array}$ & $\begin{array}{c}\text { MM } \\
15-29\end{array}$ & $\begin{array}{l}\text { MW } \\
15-24\end{array}$ & $\begin{array}{c}\text { UM } \\
15-24\end{array}$ & $\begin{array}{l}\text { UW } \\
15-24\end{array}$ \\
\hline \multicolumn{7}{|c|}{ Combined } \\
\hline $\begin{array}{l}\text { Interested in participating in a vocational } \\
\text { training programme }\end{array}$ & 42.5 & 52.6 & 14.2 & 39.8 & 45.1 & 61.1 \\
\hline Number of respondents & 1,913 & 5,008 & 1,322 & 2,007 & 1,666 & 3,001 \\
\hline \multicolumn{7}{|l|}{$\begin{array}{l}\text { Types of programmes in which youth } \\
\text { wished to participate }\end{array}$} \\
\hline Tailoring & 2.3 & 57.5 & 6.4 & 79.3 & 2.1 & 48.1 \\
\hline Auto mechanic/electric work & 13.8 & 0.3 & 17.0 & 0.1 & 13.3 & 0.3 \\
\hline Driving & 18.0 & 1.5 & 43.1 & 0.6 & 16.1 & 1.9 \\
\hline Plumbing/masonry & 3.6 & 0.2 & 12.8 & 0.1 & 3.2 & 0.2 \\
\hline Poultry/goat farm & 0.5 & 0.0 & 3.2 & 0.1 & 0.3 & 0.0 \\
\hline Beauty parlour/salon & 0.4 & 1.8 & 1.1 & 2.5 & 0.4 & 1.5 \\
\hline Nurse's aid & 0.6 & 1.6 & 0.0 & 1.0 & 0.7 & 1.9 \\
\hline Computer training & 65.4 & 45.9 & 24.1 & 21.7 & 68.1 & 56.3 \\
\hline English language/typing/shorthand & 27.1 & 21.8 & 12.2 & 10.8 & 28.1 & 26.6 \\
\hline Handicrafts/painting/embroidery/cooking & 4.7 & 13.5 & 8.0 & 19.2 & 4.8 & 11.1 \\
\hline $\begin{array}{l}\text { Number interested in participating in a } \\
\text { vocational training programme }\end{array}$ & 801 & 2,621 & 195 & 794 & 754 & 1,827 \\
\hline \multicolumn{7}{|c|}{ Urban } \\
\hline $\begin{array}{l}\text { Interested in participating in a vocational } \\
\text { training programme }\end{array}$ & 46.4 & 56.7 & 16.2 & 44.1 & 48.6 & 64.0 \\
\hline Number of respondents & 890 & 2,151 & 653 & 804 & 789 & 1,347 \\
\hline \multicolumn{7}{|l|}{$\begin{array}{l}\text { Types of programmes in which youth } \\
\text { wished to participate }\end{array}$} \\
\hline Tailoring & 2.1 & 47.5 & 6.8 & 70.7 & 1.9 & 38.2 \\
\hline Auto mechanic/electric work & 12.5 & 0.6 & 22.7 & 0.3 & 11.3 & 0.7 \\
\hline Driving & 17.3 & 2.5 & 42.0 & 1.1 & 15.7 & 3.1 \\
\hline Plumbing/masonry & 2.8 & 0.3 & 10.2 & 0.3 & 2.2 & 0.3 \\
\hline Poultry/goat farm & 0.3 & 0.1 & 1.1 & 0.3 & 0.3 & 0.0 \\
\hline Beauty parlour/salon & 0.5 & 2.5 & 0.0 & 3.4 & 0.5 & 2.1 \\
\hline Nurse's aid & 0.5 & 1.0 & 0.0 & 1.4 & 0.5 & 0.8 \\
\hline Computer training & 69.5 & 51.2 & 27.0 & 24.9 & 72.3 & 61.8 \\
\hline English language/typing/shorthand & 28.3 & 24.8 & 15.9 & 12.3 & 29.2 & 29.7 \\
\hline Handicrafts/painting/embroidery/cooking & 5.4 & 15.6 & 4.5 & 23.2 & 5.5 & 12.5 \\
\hline $\begin{array}{l}\text { Number interested in participating in a } \\
\text { vocational training programme }\end{array}$ & 401 & 1,218 & 106 & 357 & 379 & 861 \\
\hline
\end{tabular}


Table 4.7: (Cont'd)

\begin{tabular}{|c|c|c|c|c|c|c|}
\hline Programmes/courses (\%) & $\underset{15-24}{M}$ & $\begin{array}{c}W \\
15-24\end{array}$ & $\begin{array}{c}\text { MM } \\
15-29\end{array}$ & $\begin{array}{l}\text { MW } \\
15-24\end{array}$ & $\begin{array}{c}\mathrm{UM} \\
15-24\end{array}$ & $\begin{array}{c}\text { UW } \\
15-24\end{array}$ \\
\hline \multicolumn{7}{|c|}{ Rural } \\
\hline $\begin{array}{l}\text { Interested in participating in a vocational } \\
\text { training programme }\end{array}$ & 39.5 & 49.4 & 12.8 & 36.8 & 42.2 & 58.5 \\
\hline $\begin{array}{l}\text { Number of respondents } \\
\text { Types of programmes in which youth } \\
\text { wished to participate }\end{array}$ & 1,023 & 2,857 & 669 & 1,203 & 877 & 1,654 \\
\hline Tailoring & 2.6 & 66.6 & 5.1 & 86.4 & 2.3 & 57.6 \\
\hline Auto mechanic/electric work & 14.9 & 0.0 & 12.0 & 0.0 & 15.2 & 0.0 \\
\hline Driving & 18.4 & 0.5 & 44.0 & 0.2 & 16.5 & 0.6 \\
\hline Plumbing/masonry & 4.2 & 0.1 & 15.2 & 0.0 & 4.1 & 0.1 \\
\hline Poultry/goat farm & 0.7 & 0.0 & 5.0 & 0.0 & 0.3 & 0.0 \\
\hline Beauty parlour/salon & 0.2 & 1.2 & 2.0 & 1.6 & 0.3 & 1.0 \\
\hline Nurse's aid & 0.7 & 2.2 & 0.0 & 0.9 & 0.5 & 2.9 \\
\hline Computer training & 61.6 & 41.0 & 22.0 & 19.1 & 64.1 & 51.0 \\
\hline English language/typing/shorthand & 26.1 & 19.1 & 9.0 & 9.3 & 27.1 & 23.4 \\
\hline Handicrafts/painting/embroidery/cooking & 4.2 & 11.7 & 11.0 & 15.6 & 3.9 & 9.9 \\
\hline $\begin{array}{l}\text { Number interested in participating in a } \\
\text { vocational training programme }\end{array}$ & 400 & 1,403 & 89 & 437 & 375 & 966 \\
\hline
\end{tabular}

Note: All Ns are unweighted. Column totals may exceed 100\% due to multiple responses.

\subsection{Summary}

Work profiles suggest that about two-thirds of young men and half of young women had at some time engaged in paid or unpaid work. Indeed, almost all married young men and over three-fifths of unmarried young men had done so, compared with over half and two-fifths of married and unmarried young women, respectively. More youth in rural than urban areas had ever worked. Economic activity was often initiated at an early age: almost one in five (17-21\%) youth reported initiating work in childhood or early adolescence (before age 15). Data on work participation in the 12 months prior to interview indicate that the majority of young men (all the married and 59\% of the unmarried) and many fewer of young women (29\% and 37\%, respectively) had engaged in paid or unpaid work at some point in the 12 months preceding the interview. Almost nine in 10 young men and two in three young women who worked in the year prior to interview had done so for the major part (at least six months) of the year. Such regular work was far more likely to be reported by urban than rural youth.

Occupational profiles were very different among rural and urban respondents. Among rural respondents, over $90 \%$ of both young men and young women were engaged in three leading occupations: agriculture, skilled manual/machinery and unskilled non-agricultural labour. Distributions, however differed: for example, the majority of rural young women were engaged in agriculture (largely as labourers), while the majority of rural young men were engaged in skilled manual/machinery-related occupations. Among urban respondents, in 
comparison, leading occupations were skilled and unskilled non-agricultural labour, together reported by 79\% of young men and $68 \%$ of young women. It is notable that while about one in 10 married and unmarried young men and married young women in urban areas reported administrative, executive, managerial or clerical occupations, as many as $28 \%$ of unmarried young women so reported.

Unemployment rates ranged from $7 \%$ among young men to $15 \%$ among young women, and were notably higher among the educated and economically better off than any other group.

Youth were clearly interested in acquiring skills that would enable employment generation; $43 \%$ of young men and $53 \%$ of young women expressed interest in vocational skills training. However, far fewer-one-quarter of young men and one-third of young women-had ever attended a vocational training programme. 


\section{Chapter 5}

\section{Media exposure and access to}

pornographic materials

Media may play an important role in shaping the attitudes and behaviours of youth. Youth gain access to new information through a variety of sources, including print and visual media and, increasingly, the internet. Many are also exposed to pornography through these channels. The Youth Study probed young people's exposure to various media sources, the extent of their exposure to pornographic materials by way of books/magazines, films and the internet, and their perceptions about the influence of television and films on youth behaviours.

\subsection{Mass media exposure}

The survey asked a number of questions regarding youth exposure to mass media. These included whether and how frequently young people read newspapers, magazines or books, watched films or television programmes other than movies, and accessed the internet. Questions regarding exposure to print media and the internet were asked only among those who had attained at least five years of education, as this was considered a prerequisite for basic literacy and, thus, understanding of such materials. Youth were asked to rate the frequency of their exposure to each medium according to the categories "never," "sometimes" and "often". If any young person did not respond in this format but rather, in terms of days per week, three or more exposures per week were classified as "often" and less frequent exposure as "sometimes".

Findings are presented in Table 5.1 and Figure 5.1. They suggest that youth were exposed to a variety of media, but that typically, more young men than women reported media exposure. The largest proportion of youth was exposed to print materials (newspapers, magazines or books; $96 \%$ of young men and $78 \%$ of young women who had completed five or more years of education) and television (96\% of all young men and $92 \%$ of all young women). Young men were more likely than young women to report frequent exposure to print materials ( $27 \%$ and $11 \%$, respectively).
Figure 5.1: Percentage of youth exposed to television, films, print media and the internet, Tamil Nadu, 2006
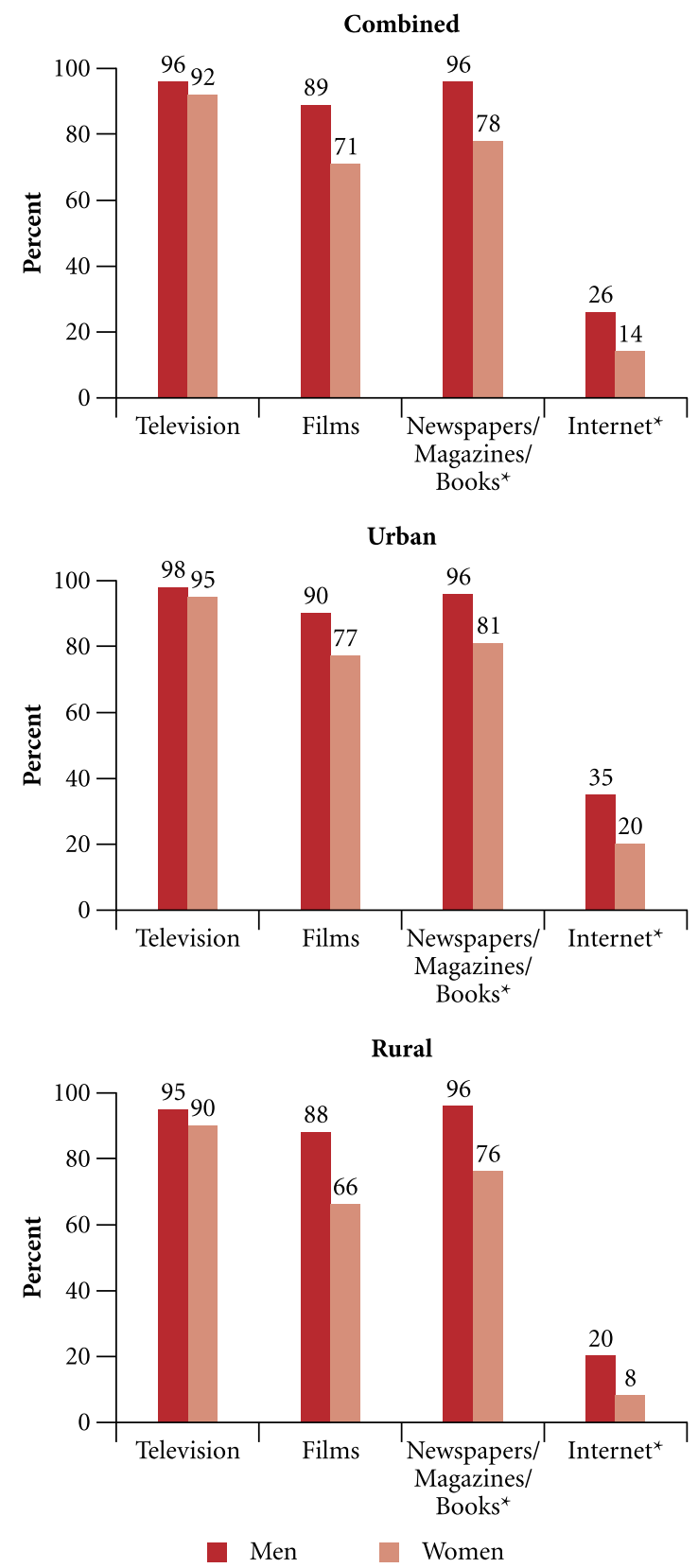

Note: ${ }^{*}$ Question asked only of respondents who had completed five or more years of education. 
Table 5.1: Mass media exposure

Percent distribution of youth exposed to various mass media by frequency of exposure, according to residence, Tamil Nadu, 2006

\begin{tabular}{|c|c|c|c|c|c|c|}
\hline Exposure indicators (\%) & $\begin{array}{c}\mathrm{M} \\
15-24\end{array}$ & $\begin{array}{c}\text { W } \\
15-24\end{array}$ & $\begin{array}{c}\mathrm{MM} \\
15-29\end{array}$ & $\begin{array}{c}\text { MW } \\
15-24\end{array}$ & $\begin{array}{c}\text { UM } \\
15-24\end{array}$ & $\begin{array}{l}\text { UW } \\
15-24\end{array}$ \\
\hline \multicolumn{7}{|c|}{ Combined } \\
\hline \multicolumn{7}{|l|}{ Frequency of watching television } \\
\hline Never & 3.5 & 8.1 & 5.2 & 9.2 & 3.1 & 7.4 \\
\hline Sometimes & 85.6 & 77.7 & 85.8 & 74.9 & 85.6 & 79.6 \\
\hline Often & 10.8 & 14.0 & 9.0 & 15.5 & 11.3 & 13.0 \\
\hline \multicolumn{7}{|l|}{ Frequency of watching films } \\
\hline Never & 10.8 & 29.0 & 11.9 & 28.5 & 10.4 & 29.2 \\
\hline Sometimes & 88.5 & 69.8 & 87.7 & 70.3 & 88.8 & 69.5 \\
\hline Often & 0.7 & 1.2 & 0.4 & 1.3 & 0.7 & 1.2 \\
\hline Number of respondents & 1,913 & 5,008 & 1,322 & 2,007 & 1,666 & 3,001 \\
\hline \multicolumn{7}{|l|}{$\begin{array}{l}\text { Frequency of reading newspapers/ } \\
\text { magazines/books }{ }^{1}\end{array}$} \\
\hline Never & 3.9 & 21.4 & 5.8 & 30.6 & 3.4 & 16.1 \\
\hline Sometimes & 68.8 & 66.8 & 69.3 & 62.9 & 68.5 & 69.1 \\
\hline Often & 27.1 & 11.3 & 24.6 & 5.7 & 27.9 & 14.5 \\
\hline \multicolumn{7}{|l|}{ Frequency of accessing the internet ${ }^{1}$} \\
\hline Never & 73.7 & 85.8 & 87.4 & 93.0 & 72.2 & 81.7 \\
\hline Sometimes & 24.5 & 11.7 & 11.6 & 5.6 & 26.0 & 15.2 \\
\hline Often & 1.7 & 2.0 & 0.8 & 0.4 & 1.8 & 2.9 \\
\hline Number with 5 or more years of education & 1,783 & 4,540 & 1,105 & 1,674 & 1,589 & 2,866 \\
\hline \multicolumn{7}{|c|}{ Urban } \\
\hline \multicolumn{7}{|l|}{ Frequency of watching television } \\
\hline Never & 1.9 & 5.4 & 3.1 & 5.8 & 1.7 & 5.1 \\
\hline Sometimes & 86.0 & 79.1 & 88.8 & 77.3 & 85.7 & 80.1 \\
\hline Often & 11.9 & 15.4 & 8.1 & 16.5 & 12.4 & 14.7 \\
\hline \multicolumn{7}{|l|}{ Frequency of watching films } \\
\hline Never & 9.6 & 22.9 & 10.7 & 23.0 & 9.4 & 22.8 \\
\hline Sometimes & 89.3 & 75.9 & 88.8 & 76.0 & 89.4 & 75.9 \\
\hline Often & 1.0 & 1.2 & 0.6 & 1.0 & 1.1 & 1.3 \\
\hline Number of respondents & 890 & 2,151 & 653 & 804 & 789 & 1,347 \\
\hline \multicolumn{7}{|l|}{$\begin{array}{l}\text { Frequency of reading newspapers/ } \\
\text { magazines/books }^{1}\end{array}$} \\
\hline Never & 3.8 & 19.1 & 5.6 & 28.5 & 3.3 & 14.2 \\
\hline Sometimes & 67.8 & 65.5 & 70.0 & 63.2 & 67.7 & 66.8 \\
\hline Often & 28.3 & 15.1 & 24.0 & 7.9 & 28.8 & 18.9 \\
\hline \multicolumn{7}{|l|}{ Frequency of accessing the internet ${ }^{1}$} \\
\hline Never & 65.5 & 79.5 & 81.6 & 91.0 & 63.7 & 73.5 \\
\hline Sometimes & 32.2 & 16.5 & 17.4 & 7.8 & 33.8 & 21.0 \\
\hline Often & 2.3 & 3.7 & 0.8 & 0.7 & 2.3 & 5.3 \\
\hline Number with 5 or more years of education & 845 & 2,009 & 582 & 706 & 763 & 1,303 \\
\hline
\end{tabular}


Table 5.1: (Cont'd)

\begin{tabular}{|c|c|c|c|c|c|c|}
\hline Exposure indicators (\%) & $\begin{array}{c}\mathrm{M} \\
15-24\end{array}$ & $\begin{array}{c}\text { W } \\
15-24\end{array}$ & $\begin{array}{c}\mathrm{MM} \\
15-29\end{array}$ & $\begin{array}{c}\text { MW } \\
15-24\end{array}$ & $\begin{array}{c}\text { UM } \\
15-24\end{array}$ & $\begin{array}{c}\text { UW } \\
15-24\end{array}$ \\
\hline \multicolumn{7}{|c|}{ Rural } \\
\hline Frequency of watching television & & & & & & \\
\hline Never & 4.7 & 10.3 & 6.7 & 11.5 & 4.1 & 9.4 \\
\hline Sometimes & 85.4 & 76.7 & 83.7 & 73.3 & 85.5 & 79.1 \\
\hline Often & 9.9 & 12.9 & 9.6 & 14.9 & 10.3 & 11.4 \\
\hline \multicolumn{7}{|l|}{ Frequency of watching films } \\
\hline Never & 11.8 & 33.7 & 12.6 & 32.1 & 11.2 & 34.9 \\
\hline Sometimes & 87.8 & 65.0 & 87.1 & 66.4 & 88.3 & 64.0 \\
\hline Often & 0.5 & 1.3 & 0.3 & 1.5 & 0.5 & 1.1 \\
\hline Number of respondents & 1,023 & 2,857 & 669 & 1,203 & 877 & 1,654 \\
\hline \multicolumn{7}{|l|}{$\begin{array}{l}\text { Frequency of reading newspapers/ } \\
\text { magazines/books }{ }^{1}\end{array}$} \\
\hline Never & 4.1 & 23.2 & 5.9 & 32.1 & 3.6 & 17.8 \\
\hline Sometimes & 69.6 & 67.9 & 69.0 & 62.7 & 69.3 & 71.2 \\
\hline Often & 26.3 & 8.1 & 25.0 & 4.1 & 27.0 & 10.6 \\
\hline \multicolumn{7}{|l|}{ Frequency of accessing the internet ${ }^{1}$} \\
\hline Never & 80.3 & 91.1 & 92.0 & 94.5 & 79.2 & 89.0 \\
\hline Sometimes & 18.4 & 7.6 & 7.0 & 4.0 & 19.4 & 9.9 \\
\hline Often & 1.2 & 0.6 & 0.8 & 0.2 & 1.3 & 0.8 \\
\hline Number with 5 or more years of education & 938 & 2,531 & 523 & 968 & 826 & 1,563 \\
\hline
\end{tabular}

Note: All Ns are unweighted. Column totals may not equal 100\% due to missing cases or "don't know" responses. 'Question asked only of respondents who had completed five or more years of education.

Compared to those who reported exposure to television, somewhat fewer- $89 \%$ of young men and $71 \%$ of young women-watched films either on CD/DVD or at a theatre or video parlour. Youth were less likely to be exposed to the internet than print or visual materials; even so, a considerable proportion of youth with five or more years of education accessed the internet: $26 \%$ of young men and $14 \%$ of young women.

Patterns by marital status suggest that unmarried youth were more likely to be exposed to the internet than the married; unmarried young women, in addition, were more likely than their married counterparts to report any as well as frequent exposure to print media. Exposure to television and films were about as likely to be reported by the married as the unmarried. Patterns by rural-urban residence suggest that urban young women were more likely than rural young women to be exposed to print media, television and films; differences were negligible among young men. With regard to accessing the internet, urban youth, both men and women, were more likely than rural youth to so report. Notably, some $35 \%$ of young men and $20 \%$ of young women in urban settings accessed the internet, compared to $20 \%$ and $8 \%$ of rural young men and women, respectively.

\subsection{Exposure to pornographic materials}

Youth were asked whether they were exposed to pornographic materials by way of films, books and magazines, and the internet (for those who accessed the internet). Table 5.2 reports that $39 \%$ of young men compared to about $1 \%$ of young women had ever watched "blue" or pornographic films. Rural-urban differences were negligible: $38 \%$ of rural young men compared to $41 \%$ of those residing in urban settings ever watched pornographic films. However, differences by marital status were wide: $55 \%$ of the married compared to $38 \%$ of the unmarried reported having ever watched pornographic films. 
Table 5.2: Exposure to pornographic materials

Percentage of youth exposed to different pornographic materials, according to residence, Tamil Nadu, 2006

\begin{tabular}{|c|c|c|c|c|c|c|}
\hline Exposure indicators (\%) & $\begin{array}{c}\text { M } \\
15-24\end{array}$ & $\begin{array}{c}\text { W } \\
15-24\end{array}$ & $\begin{array}{c}\text { MM } \\
15-29\end{array}$ & $\begin{array}{c}\text { MW } \\
\text { 15-24 }\end{array}$ & $\begin{array}{c}\text { UM } \\
15-24\end{array}$ & $\begin{array}{c}\text { UW } \\
\text { 15-24 }\end{array}$ \\
\hline \multicolumn{7}{|c|}{ Combined } \\
\hline Ever watched a "blue"/pornographic film & 39.3 & 0.5 & 54.8 & 1.0 & 37.9 & 0.2 \\
\hline Number of respondents & 1,913 & 5,008 & 1,322 & 2,007 & 1,666 & 3,001 \\
\hline \multicolumn{7}{|l|}{ Frequency of watching "blue"/pornographic films } \\
\hline Rarely & 22.1 & $(38.5)$ & 22.5 & * & 22.3 & * \\
\hline Sometimes & 77.6 & $(57.7)$ & 77.2 & * & 77.5 & * \\
\hline Often & 0.1 & $(0.0)$ & 0.3 & * & 0.0 & * \\
\hline \multicolumn{7}{|l|}{$\begin{array}{l}\text { Person accompanying when watching "blue"/ } \\
\text { pornographic films }\end{array}$} \\
\hline Alone & 12.6 & $(23.1)$ & 22.2 & * & 11.1 & * \\
\hline $\operatorname{Peer}(\mathrm{s})$ & 78.2 & $(34.6)$ & 66.9 & * & 79.2 & * \\
\hline Other(s) & 9.0 & $(38.5)$ & 10.9 & * & 9.5 & * \\
\hline $\begin{array}{l}\text { Ever forced by anyone to watch "blue"/ } \\
\text { pornographic films }\end{array}$ & 10.3 & $(23.1)$ & 9.4 & * & 10.8 & * \\
\hline $\begin{array}{l}\text { Number who ever watched "blue"/ } \\
\text { pornographic films }\end{array}$ & 774 & 26 & 750 & 21 & 642 & 5 \\
\hline Ever read/looked at pornographic books/magazines & 23.8 & 2.5 & 26.6 & 2.6 & 23.5 & 2.4 \\
\hline Number of respondents & 1,913 & 5,008 & 1,322 & 2,007 & 1,666 & 3,001 \\
\hline \multicolumn{7}{|l|}{$\begin{array}{l}\text { Frequency of reading/looking at pornographic } \\
\text { books/ magazines }\end{array}$} \\
\hline Rarely & 18.5 & 28.0 & 16.5 & 24.5 & 19.5 & 30.6 \\
\hline Sometimes & 80.6 & 69.6 & 83.2 & 75.5 & 79.5 & 65.3 \\
\hline Often & 0.7 & 1.6 & 0.3 & 0.0 & 0.8 & 2.8 \\
\hline $\begin{array}{l}\text { Number who ever read/looked at pornographic } \\
\text { books/magazines }\end{array}$ & 471 & 125 & 370 & 53 & 404 & 72 \\
\hline Ever accessed pornographic materials on the internet & 28.5 & 2.8 & 32.6 & 1.7 & 29.1 & 3.0 \\
\hline Number who ever accessed the internet & 462 & 634 & 153 & 116 & 443 & 518 \\
\hline \multicolumn{7}{|c|}{ Urban } \\
\hline Ever watched a "blue"/pornographic film & 40.6 & 0.5 & 61.9 & 1.1 & 39.0 & 0.2 \\
\hline Number of respondents & 890 & 2,151 & 653 & 804 & 789 & 1,347 \\
\hline \multicolumn{7}{|l|}{ Frequency of watching "blue"/pornographic films } \\
\hline Rarely & 21.5 & * & 23.8 & * & 21.2 & * \\
\hline Sometimes & 78.2 & * & 75.9 & * & 78.4 & * \\
\hline Often & 0.0 & * & 0.3 & * & 0.0 & * \\
\hline \multicolumn{7}{|l|}{$\begin{array}{l}\text { Person accompanying when watching "blue"/ } \\
\text { pornographic films }\end{array}$} \\
\hline Alone & 15.6 & * & 22.6 & * & 14.0 & * \\
\hline $\operatorname{Peer}(\mathrm{s})$ & 75.8 & * & 67.9 & * & 76.8 & * \\
\hline Other(s) & 8.3 & * & 9.5 & * & 8.9 & * \\
\hline $\begin{array}{l}\text { Ever forced by anyone to watch "blue"/ } \\
\text { pornographic films }\end{array}$ & 10.6 & * & 7.1 & * & 11.3 & * \\
\hline $\begin{array}{l}\text { Number who ever watched "blue"/ } \\
\text { pornographic films }\end{array}$ & 372 & 12 & 412 & 9 & 313 & 3 \\
\hline
\end{tabular}


Table 5.2: (Cont'd)

\begin{tabular}{|c|c|c|c|c|c|c|}
\hline Exposure indicators (\%) & $\underset{15-24}{M}$ & $\begin{array}{c}W \\
15-24\end{array}$ & $\begin{array}{c}\text { MM } \\
15-29\end{array}$ & $\begin{array}{c}\text { MW } \\
15-24\end{array}$ & $\begin{array}{c}\text { UM } \\
15-24\end{array}$ & $\begin{array}{c}\text { UW } \\
15-24\end{array}$ \\
\hline \multicolumn{7}{|c|}{ Urban } \\
\hline Ever read/looked at pornographic books/magazines & 25.2 & 2.7 & 31.9 & 3.2 & 24.7 & 2.3 \\
\hline Number of respondents & 890 & 2,151 & 653 & 804 & 789 & 1,347 \\
\hline \multicolumn{7}{|l|}{$\begin{array}{l}\text { Frequency of reading/looking at pornographic } \\
\text { books/ magazines }\end{array}$} \\
\hline Rarely & 18.5 & 25.4 & 16.8 & $(23.1)$ & 19.9 & $(25.0)$ \\
\hline Sometimes & 80.6 & 71.2 & 83.2 & $(76.9)$ & 79.0 & $(68.8)$ \\
\hline Often & 0.5 & 1.7 & 0.0 & $(0.0)$ & 0.5 & $(3.1)$ \\
\hline $\begin{array}{l}\text { Number who ever read/looked at pornographic } \\
\text { books/magazines }\end{array}$ & 229 & 57 & 212 & 26 & 197 & 31 \\
\hline Ever accessed pornographic materials on the internet & 33.5 & 2.4 & 38.9 & 1.6 & 33.8 & 2.5 \\
\hline Number who ever accessed the internet & 283 & 409 & 111 & 63 & 273 & 346 \\
\hline \multicolumn{7}{|c|}{ Rural } \\
\hline Ever watched a "blue"/pornographic film & 38.2 & 0.5 & 49.9 & 1.0 & 37.0 & 0.1 \\
\hline Number of respondents & 1,023 & 2,857 & 669 & 1,203 & 877 & 1,654 \\
\hline \multicolumn{7}{|l|}{ Frequency of watching "blue"/pornographic films } \\
\hline Rarely & 22.7 & * & 21.3 & * & 23.0 & * \\
\hline Sometimes & 77.1 & * & 78.4 & * & 77.0 & * \\
\hline Often & 0.2 & * & 0.3 & * & 0.0 & * \\
\hline \multicolumn{7}{|l|}{$\begin{array}{l}\text { Person accompanying when watching "blue"/ } \\
\text { pornographic films }\end{array}$} \\
\hline Alone & 10.1 & * & 21.6 & * & 8.8 & * \\
\hline Peer(s) & 80.2 & * & 66.1 & * & 81.2 & * \\
\hline Other(s) & 9.6 & * & 12.3 & * & 10.0 & * \\
\hline $\begin{array}{l}\text { Ever forced by anyone to watch "blue"/ } \\
\text { pornographic films }\end{array}$ & 10.1 & * & 11.3 & * & 10.3 & * \\
\hline $\begin{array}{l}\text { Number who ever watched "blue"/ } \\
\text { pornographic films }\end{array}$ & 402 & 14 & 338 & 12 & 329 & 2 \\
\hline Ever read/looked at pornographic books/magazines & 22.7 & 2.4 & 23.0 & 2.3 & 22.5 & 2.5 \\
\hline Number of respondents & 1,023 & 2,857 & 669 & 1,203 & 877 & 1,654 \\
\hline \multicolumn{7}{|l|}{$\begin{array}{l}\text { Frequency of reading/looking at pornographic } \\
\text { books/ magazines }\end{array}$} \\
\hline Rarely & 18.6 & 30.3 & 16.8 & $(23.1)$ & 19.1 & $(35.0)$ \\
\hline Sometimes & 80.6 & 68.2 & 82.7 & $(76.9)$ & 79.9 & $(62.5)$ \\
\hline Often & 0.8 & 1.5 & 0.6 & $(0.0)$ & 1.0 & (2.5) \\
\hline $\begin{array}{l}\text { Number who ever read/looked at pornographic } \\
\text { books/ magazines }\end{array}$ & 242 & 68 & 158 & 27 & 207 & 41 \\
\hline Ever accessed pornographic materials on the internet & 22.0 & 3.6 & $(20.4)$ & 1.9 & 22.1 & 4.2 \\
\hline Number who ever accessed the internet & 179 & 225 & 42 & 53 & 170 & 172 \\
\hline
\end{tabular}

Note: All Ns are unweighted. Column totals may not equal 100\% due to missing cases or "don't know" responses. ( ) Based on 25-49 unweighted cases. ${ }^{*}$ Percentage not shown, based on fewer than 25 unweighted cases. 
Among young men who had ever watched a pornographic film, almost four in five (78\%) reported having viewed such films sometimes or frequently (see Table 5.2); differences by marital status and rural-urban residence were negligible. For the most part, young men had watched films together with friends, but a small minority of young men (10\%, with little rural-urban difference) reported that they had been forced, at least once, to do so.

Exposure to pornographic books and magazines was reported by $24 \%$ of young men and $3 \%$ of young women, with little variation by marital status or rural-urban residence. Of those who had ever viewed pornographic books or magazines, $81 \%$ of young men and $71 \%$ of young women reported reading or looking at them sometimes or often.

Of those exposed to the internet, a significant proportion of young men $(29 \%)$ had accessed pornographic materials on the internet; this compared with just $3 \%$ of young women. Again, differences by marital status were negligible. However, considerably more young men in urban than rural areas reported having accessed pornographic materials on the internet; differences among women were negligible.

\subsection{Youth perceptions about the influence of television and films on youth behaviours}

The survey also questioned youth about their perceptions of the influence of television and films on youth behaviours. Specifically, youth were asked whether they believed that television and films influenced the way in which their friends dressed, whether violence on television and in films could make youth aggressive, and whether they had ever felt like having sex after watching certain films. Table 5.3 suggests that $56 \%$ of young men and $51 \%$ of young women believed that television and films influenced the way their friends dressed,

Table 5.3: Perceptions about the influence of television and films on youth behaviours

Percentage of youth reporting perceptions regarding the influence of television and films on youth behaviours, according to residence, Tamil Nadu, 2006

\begin{tabular}{|c|c|c|c|c|c|c|}
\hline $\begin{array}{l}\text { Perceptions about the influence of } \\
\text { television and films (\%) }\end{array}$ & $\underset{15-24}{M}$ & $\begin{array}{c}\text { W } \\
15-24\end{array}$ & $\begin{array}{c}\text { MM } \\
15-29\end{array}$ & $\begin{array}{l}\text { MW } \\
15-24\end{array}$ & $\begin{array}{c}\text { UM } \\
15-24\end{array}$ & $\begin{array}{l}\text { UW } \\
15-24\end{array}$ \\
\hline \multicolumn{7}{|c|}{ Combined } \\
\hline TV/films influence the way friends dress & 55.8 & 50.7 & 51.2 & 52.3 & 56.3 & 49.7 \\
\hline Violence on TV and in films can make youth aggressive & 59.2 & 49.0 & 61.5 & 51.6 & 59.1 & 47.3 \\
\hline Certain films make respondent want to have sex & 17.5 & 1.7 & 26.2 & 3.1 & 16.4 & 0.7 \\
\hline Number of respondents & 1,913 & 5,008 & 1,322 & 2,007 & 1,666 & 3,001 \\
\hline \multicolumn{7}{|c|}{ Urban } \\
\hline TV/films influence the way friends dress & 58.8 & 53.1 & 55.4 & 54.3 & 59.2 & 52.5 \\
\hline Violence on TV and in films can make youth aggressive & 58.5 & 48.1 & 61.6 & 49.9 & 58.2 & 47.0 \\
\hline Certain films make respondent want to have sex & 20.6 & 1.3 & 32.0 & 2.5 & 19.1 & 0.6 \\
\hline Number of respondents & 890 & 2,151 & 653 & 804 & 789 & 1,347 \\
\hline \multicolumn{7}{|c|}{ Rural } \\
\hline TV/films influence the way friends dress & 53.5 & 48.7 & 48.3 & 51.0 & 54.0 & 47.1 \\
\hline Violence on TV and in films can make youth aggressive & 59.8 & 49.7 & 61.4 & 52.8 & 59.8 & 47.4 \\
\hline Certain films make respondent want to have sex & 15.1 & 2.0 & 22.1 & 3.6 & 14.1 & 0.8 \\
\hline Number of respondents & 1,023 & 2,857 & 669 & 1,203 & 877 & 1,654 \\
\hline
\end{tabular}

Note: All Ns are unweighted. 
and similar percentages (59\% and 49\%, respectively) believed that violence on television and in films could make youth aggressive. Few youth reported that watching certain films had made them desire sex: considerably more young men $(18 \%)$ than young women $(2 \%)$. Differences in reported perceptions by marital status and rural-urban residence were generally negligible.

\subsection{Summary}

Findings suggest that large proportions of youth in Tamil Nadu were exposed to the media, typically newspapers, magazines or books ( $96 \%$ of young men and $78 \%$ of young women with five or more years of education) and television ( $96 \%$ and $92 \%$ of all young men and women, respectively). Exposure to the internet was reported by one in four young men and one in seven young women with five or more years of education. Gender differences were apparent, with young men typically more likely to be exposed to each medium than young women.

Findings also show that as many as two in five young men and hardly any young women had accessed pornographic or "blue" films, and almost four in five young men who had been exposed to pornographic films reported that they accessed these materials sometimes or frequently. One- quarter of young men had read or looked at pornographic books and magazines, and $29 \%$ of those exposed to the internet had accessed such materials on the internet, compared to far fewer young women. Finally, half or more young men and women acknowledged the influence that media have on youth behaviours. 


\section{Chapter 6}

\section{Growing up}

This chapter focuses on such experiences as puberty as well as youth interaction with parents and peers while growing up. Globally, studies have suggested a declining age at puberty for young men and women and stress that this, along with rising ages at marriage, provides a longer window in which young people can make same- and opposite-sex friends (National Research Council and Institute of Medicine, 2005). Several studies have highlighted the importance of close parental interaction for the healthy development of young people (Laird et al., 2003; Marta, 1997; Sroufe, 1991). Others note that young people's interaction with parents is particularly limited when it comes to discussion of sensitive issues, for example, girl-boy relations or sexual and reproductive matters (Alexander et al., 2006a; 2006b; Lambert and Wood, 2005; Mehra, Savithri and Coutinho, 2002). In addition, a few studies have shown that the peer group is, for many youth, a central source of both information and support, but at the same time, a source of misinformation and pressure to adopt risky behaviours (Bhuiya et al., 2003; Sachdev, 1998; Ul Haque and Faizunnisa, 2003).

The Youth Study included several questions relating to each of these issues. This chapter begins by describing the ages at which young people experienced signs of puberty. It then explores aspects of their family life and interaction with parents on various matters of importance to youth. It also addresses peer networks and interaction, specifically, the size of the same-and opposite-sex peer networks and peer activities in which respondents engaged. Finally, the chapter discusses young people's access to support networks for discussing personal matters.

\subsection{Puberty}

In order to examine ages at which puberty occurs among young men and women, the Youth Study included questions on age at menarche for young women, and age at which voice change and growth of pubic hair were noticed for young men. Table 6.1a shows that mean age at menarche was 13.5 years for young women. Urban young women experienced menarche slightly earlier than rural young women: for example, menarche occurred at or below age 13 for $59 \%$ of urban young women compared to half of rural young women.

Voice change and appearance of pubic hair for young men occurred one to one-and-a-half years later than did menarche for young women. Table $6.1 \mathrm{~b}$ shows that the average age at which young men reported voice change was 14.6 years, and 15.1 years for appearance of pubic hair growth. Rural-urban differences in the mean ages at which these changes occurred for young men were negligible.

\subsection{Family life and interaction with parents}

The Youth Study explored a variety of issues that capture the nature of family life, and youth interaction with parents in particular. Married respondents were specifically asked to recall the period before marriage. 
Table 6.1a: Age at puberty among young women

Percent distribution of young women aged 15-24 by age at puberty, according to residence, Tamil Nadu, 2006

\begin{tabular}{|c|c|c|c|}
\hline Puberty indicators (\%) & Combined & Urban & Rural \\
\hline \multicolumn{4}{|l|}{ Age at menarche (years) } \\
\hline Below 12 & 3.6 & 4.9 & 2.5 \\
\hline 12 & 15.0 & 16.6 & 13.8 \\
\hline 13 & 35.2 & 37.4 & 33.4 \\
\hline 14 & 29.0 & 28.2 & 29.6 \\
\hline 15 and above & 16.8 & 12.9 & 19.9 \\
\hline Not yet menstruated & 0.5 & 0.1 & 0.8 \\
\hline Mean age at menarche (years) $)^{1}$ & 13.5 & 13.3 & 13.6 \\
\hline Number of respondents & 5,008 & 2,151 & 2,856 \\
\hline
\end{tabular}

Note: All Ns are unweighted. Column totals may not equal 100\% due to missing cases or "don't know" responses. ${ }^{1}$ Excludes those who had not menstruated at the time of interview.

Table 6.1b: Age at puberty among young men

Percent distribution of young men aged 15-24 by age at puberty, according to residence, Tamil Nadu, 2006

\begin{tabular}{|c|c|c|c|}
\hline Puberty indicators (\%) & Combined & Urban & Rural \\
\hline \multicolumn{4}{|l|}{ Age at which voice change noticed (years) } \\
\hline Below 14 & 13.0 & 13.8 & 12.4 \\
\hline 14 & 25.1 & 24.6 & 25.4 \\
\hline 15 & 30.9 & 32.1 & 30.0 \\
\hline 16 & 10.0 & 10.8 & 9.3 \\
\hline 17 and above & 4.0 & 3.5 & 4.4 \\
\hline No voice change yet & 2.6 & 2.2 & 3.0 \\
\hline Did not notice/don't remember & 14.4 & 13.0 & 15.5 \\
\hline Mean age at voice change (years) ${ }^{1}$ & 14.6 & 14.6 & 14.6 \\
\hline \multicolumn{4}{|l|}{ Age at which pubic hair noticed (years) } \\
\hline Below 14 & 8.2 & 7.8 & 8.5 \\
\hline 14 & 23.7 & 23.0 & 24.2 \\
\hline 15 & 36.4 & 35.9 & 36.8 \\
\hline 16 & 17.2 & 18.5 & 16.2 \\
\hline 17 and above & 12.2 & 12.5 & 11.9 \\
\hline No pubic hair yet & 2.3 & 2.2 & 2.4 \\
\hline Mean age at which pubic hair noticed ${ }^{1}$ & 15.1 & 15.1 & 15.1 \\
\hline Number of respondents & 1,913 & 890 & 1,023 \\
\hline
\end{tabular}

Note: All Ns are unweighted. Column totals may not equal 100\% due to missing cases or "don't know" responses. 'Excludes those who had not noticed voice change/appearance of pubic hair at the time of interview or did not remember age at the time of voice change/appearance of pubic hair.

\subsubsection{Socialisation experiences}

Table 6.2 presents findings on the socialisation experiences of youth during their teenage years as compared with siblings, or cousins of the opposite sex if the respondent did not have an opposite-sex sibling. Almost three in five young men reported that they had more freedom to go out than their sisters or female cousins; only $24 \%$ of young women, in contrast, agreed that they had less freedom to go out than their brothers 
or male cousins. Likewise, $45 \%$ of young men reported that they were expected to do less housework than their sisters or female cousins, and just $22 \%$ of young women reported that they were expected to do more housework than their brothers or male cousins. In other words, it would appear that substantial proportions of households in Tamil Nadu did not discriminate between their sons and daughters in terms of freedom of movement (two-fifths by young men's assessment and three-quarters by young women's) and expectations regarding housework (over half by young men's assessment and three-quarters by young women's). Differences by marital status and rural-urban residence show that among young women, somewhat larger proportions of married and rural respondents than others reported gender unequal socialisation experiences; among young men, differences were negligible (see Figure 6.1).

\section{Table 6.2: Socialisation experiences}

Percent distribution of youth by degree of mobility and housework responsibilities relative to an opposite-sex sibling/cousin, according to residence, Tamil Nadu, 2006

\begin{tabular}{|c|c|c|c|c|c|c|}
\hline Socialisation experiences (\%) & $\begin{array}{c}M \\
15-24\end{array}$ & $\begin{array}{c}\text { W } \\
15-24\end{array}$ & $\begin{array}{c}\text { MM } \\
15-29\end{array}$ & $\begin{array}{c}\text { MW } \\
15-24\end{array}$ & $\begin{array}{c}\text { UM } \\
15-24\end{array}$ & $\begin{array}{c}\text { UW } \\
15-24\end{array}$ \\
\hline \multicolumn{7}{|c|}{ Combined } \\
\hline \multicolumn{7}{|l|}{$\begin{array}{l}\text { Respondent had less freedom }(\mathrm{W}) / \text { more freedom }(\mathrm{M}) \text { to } \\
\text { roam/go out than opposite-sex sibling or cousin }\end{array}$} \\
\hline Yes & 57.9 & 24.2 & 57.3 & 28.6 & 58.3 & 21.2 \\
\hline No & 40.8 & 74.8 & 41.4 & 70.6 & 40.3 & 77.5 \\
\hline \multicolumn{7}{|l|}{$\begin{array}{l}\text { Respondent was expected to do more housework (W)/ } \\
\text { less housework (M) than opposite-sex sibling or cousin }\end{array}$} \\
\hline Yes & 44.8 & 22.1 & 41.8 & 26.1 & 45.2 & 19.5 \\
\hline No & 53.8 & 76.9 & 56.9 & 73.0 & 53.4 & 79.4 \\
\hline Number of respondents & 1,913 & 5,008 & 1,322 & 2,007 & 1,666 & 3,001 \\
\hline \multicolumn{7}{|c|}{ Urban } \\
\hline \multicolumn{7}{|l|}{$\begin{array}{l}\text { Respondent had less freedom }(\mathrm{W}) / \text { more freedom }(\mathrm{M}) \text { to } \\
\text { roam/go out than opposite-sex sibling or cousin }\end{array}$} \\
\hline Yes & 59.2 & 19.1 & 57.5 & 22.8 & 59.6 & 16.9 \\
\hline No & 39.0 & 79.4 & 40.5 & 76.2 & 38.7 & 81.2 \\
\hline \multicolumn{7}{|l|}{$\begin{array}{l}\text { Respondent was expected to do more housework (W)/ } \\
\text { less housework (M) than opposite-sex sibling or cousin }\end{array}$} \\
\hline Yes & 41.9 & 18.1 & 40.3 & 21.4 & 42.0 & 16.2 \\
\hline No & 56.3 & 80.4 & 57.4 & 77.5 & 56.1 & 82.1 \\
\hline Number of respondents & 890 & 2,151 & 653 & 804 & 789 & 1,347 \\
\hline \multicolumn{7}{|c|}{ Rural } \\
\hline \multicolumn{7}{|l|}{$\begin{array}{l}\text { Respondent had less freedom }(\mathrm{W}) / \text { more freedom }(\mathrm{M}) \text { to } \\
\text { roam/go out than opposite-sex sibling or cousin }\end{array}$} \\
\hline Yes & 56.9 & 28.2 & 57.1 & 32.6 & 57.3 & 24.9 \\
\hline No & 42.2 & 71.2 & 42.1 & 66.8 & 41.7 & 74.3 \\
\hline \multicolumn{7}{|l|}{$\begin{array}{l}\text { Respondent was expected to do more housework (W)/ } \\
\text { less housework (M) than opposite-sex sibling or cousin }\end{array}$} \\
\hline Yes & 47.2 & 25.3 & 42.9 & 29.3 & 47.8 & 22.3 \\
\hline No & 51.9 & 74.1 & 56.6 & 69.9 & 51.1 & 77.0 \\
\hline Number of respondents & 1,023 & 2,857 & 669 & 1,203 & 877 & 1,654 \\
\hline
\end{tabular}

Note: All Ns are unweighted. Column totals may not equal 100\% due to "unsure" responses. For married respondents, questions referred to the period prior to marriage. 
Figure 6.1: Percentage of youth reporting gendered socialisation experiences relative to an opposite-sex sibling/cousin, according to residence, Tamil Nadu, 2006
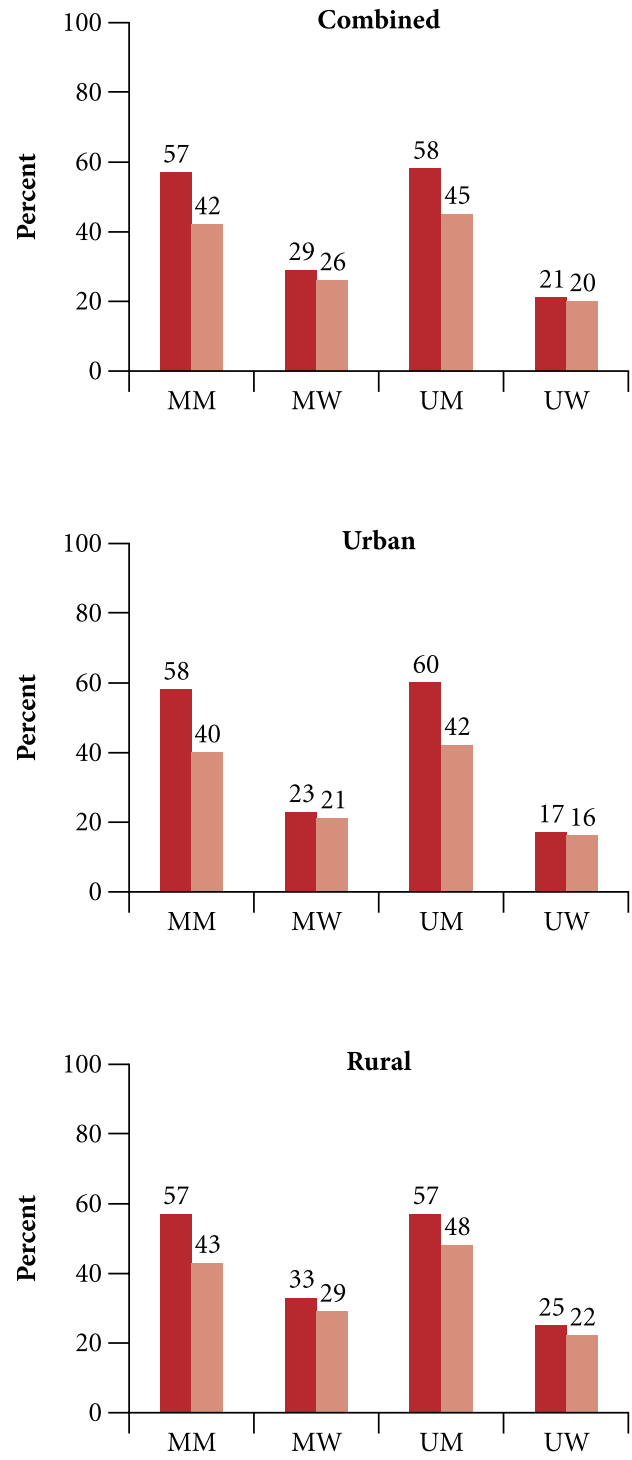

Respondent had less freedom (W)/ more freedom (M) to roam/go out than opposite-sex sibling or cousin

Respondent was expected to do more housework (W)/ less housework (M) than opposite-sex sibling or cousin

Note: For married respondents, questions referred to the period prior to marriage.
Parental attitudes towards youth friendships and social activities were probed by asking young men and women about whether their mother and father, respectively, would disapprove if they engaged in a series of activities, ranging from bringing a same-sex friend to their home to having a love marriage. Married youth were asked to respond according to their experience prior to marriage. Findings, presented in Table 6.3, suggest considerable variation in youth perceptions by activity. What is clearly noticeable is parents were most likely to be perceived to disapprove of love marriages for their children, as reported by $78 \%$ of young men and $92 \%$ of young women. Also noticeable is that youth perceived parents to be far more likely to disapprove of activities conducted with members of the opposite sex than those conducted with same-sex individuals (see Figure 6.2). For example, while 12\% or fewer young men and women reported that their mother or father would disapprove if they brought same-sex friends to their home, $60-61 \%$ of young men and $74-76 \%$ of young women reported expecting parental disapproval if they brought an opposite-sex friend to their home.

Also apparent from Table 6.3 is that young women were considerably more likely than young men to report the perception of parental disapproval with reference to almost every theme. For instance, $62 \%$ of young women compared with $43 \%$ of young men reported expecting disapproval from their mother, and $68 \%$ of young women compared to $48 \%$ of young men reported expecting disapproval from their father, if they talked with a person of the opposite sex who did not belong to the family. Similarly, $85-86 \%$ of young women compared to $71-72 \%$ of young men reported expecting parental disapproval if they went to a mela/film with a friend of the opposite sex. By and large, youth were about as likely to perceive disapproval from their father as from their mother for each activity probed. Nonetheless, somewhat larger proportions of young women expected disapproval from their father than from their mother with regard to a few selected activities; talking to a person of the opposite sex who did not belong to the family and joining a club or manram, for example. Differences by marital status were narrow but unmarried youth, particularly young women, were less likely than married youth to report parental disapproval of activities conducted with members of the opposite sex (see also Figure 6.2). Unmarried young women, in addition, were less likely than their married counterparts to report parental disapproval if they sought a job. At the same time, urban youth, particularly young men, were less likely than rural youth to expect disapproval from their father for most activities. 
Table 6.3: Perceptions of parental reactions to selected activities

Percentage of youth who perceived that their parents would disapprove of them engaging in selected activities, according to residence, Tamil Nadu, 2006

\begin{tabular}{|c|c|c|c|c|c|c|}
\hline \multirow[t]{2}{*}{ Perceptions of parental reactions (\%) } & $\underset{15-24}{M}$ & $\begin{array}{c}W \\
15-24\end{array}$ & $\begin{array}{c}\text { MM } \\
15-29\end{array}$ & $\begin{array}{l}\text { MW } \\
15-24\end{array}$ & $\begin{array}{c}\text { UM } \\
15-24\end{array}$ & $\begin{array}{l}\text { UW } \\
15-24\end{array}$ \\
\hline & \multicolumn{6}{|c|}{ Father } \\
\hline \multicolumn{7}{|c|}{ Combined } \\
\hline \multicolumn{7}{|l|}{ Father would disapprove if respondent: } \\
\hline Brought same-sex friends home & 12.1 & 7.7 & 13.8 & 8.1 & 11.5 & 7.5 \\
\hline Brought opposite-sex friends home & 61.2 & 76.1 & 66.1 & 80.5 & 60.9 & 73.4 \\
\hline $\begin{array}{l}\text { Talked to a person of the opposite sex from } \\
\text { outside the home }\end{array}$ & 47.8 & 68.3 & 50.6 & 71.5 & 47.3 & 66.3 \\
\hline Went to a mela/film with same-sex friends & 32.3 & 49.4 & 31.3 & 50.3 & 32.2 & 48.8 \\
\hline Went to a mela/film with opposite-sex friends & 71.7 & 86.3 & 69.5 & 88.0 & 72.0 & 85.2 \\
\hline Joined a club/mandal/manram & 40.8 & 44.2 & 39.2 & 45.1 & 40.1 & 43.6 \\
\hline Had a love marriage & 78.4 & 91.7 & 77.1 & 92.5 & 79.0 & 91.3 \\
\hline Found a job & NA & 28.5 & NA & 33.3 & NA & 25.6 \\
\hline Number of respondents ${ }^{1}$ & 1,660 & 4,311 & 998 & 1,656 & 1,460 & 2,655 \\
\hline \multicolumn{7}{|c|}{ Urban } \\
\hline \multicolumn{7}{|l|}{ Father would disapprove if respondent: } \\
\hline Brought same-sex friends home & 11.3 & 6.1 & 13.4 & 5.5 & 10.6 & 6.4 \\
\hline Brought opposite-sex friends home & 57.1 & 72.8 & 65.3 & 79.6 & 56.1 & 69.2 \\
\hline $\begin{array}{l}\text { Talked to a person of the opposite sex from } \\
\text { outside the home }\end{array}$ & 44.0 & 64.4 & 50.5 & 71.0 & 43.3 & 60.9 \\
\hline Went to a mela/film with same-sex friends & 27.6 & 47.9 & 28.5 & 51.1 & 27.4 & 46.2 \\
\hline Went to a mela/film with opposite-sex friends & 67.4 & 83.6 & 66.3 & 86.7 & 67.4 & 82.0 \\
\hline Joined a club/mandal/manram & 40.4 & 45.1 & 41.1 & 45.5 & 39.5 & 44.9 \\
\hline Had a love marriage & 74.6 & 89.6 & 77.2 & 91.0 & 75.0 & 88.8 \\
\hline Found a job & NA & 27.7 & NA & 34.1 & NA & 24.2 \\
\hline Number of respondents ${ }^{1}$ & 769 & 1,867 & 483 & 664 & 684 & 1,203 \\
\hline \multicolumn{7}{|c|}{ Rural } \\
\hline Father would disapprove if respondent: & & & & & & \\
\hline Brought same-sex friends home & 12.6 & 9.0 & 14.1 & 9.8 & 12.3 & 8.4 \\
\hline Brought opposite-sex friends home & 64.3 & 78.7 & 66.8 & 81.1 & 64.7 & 77.1 \\
\hline $\begin{array}{l}\text { Talked to a person of the opposite sex from } \\
\text { outside the home }\end{array}$ & 50.5 & 71.5 & 50.7 & 72.0 & 50.4 & 71.2 \\
\hline Went to a mela/film with same-sex friends & 35.7 & 50.6 & 33.2 & 49.7 & 36.1 & 51.1 \\
\hline Went to a mela/film with opposite-sex friends & 75.0 & 88.5 & 71.6 & 88.9 & 75.6 & 88.1 \\
\hline Joined a club/mandal/manram & 41.0 & 43.4 & 38.0 & 44.9 & 40.6 & 42.4 \\
\hline Had a love marriage & 81.3 & 93.5 & 77.1 & 93.5 & 82.3 & 93.4 \\
\hline Found a job & NA & 29.2 & NA & 32.8 & NA & 26.9 \\
\hline Number of respondents ${ }^{1}$ & 891 & 2,444 & 515 & 992 & 776 & 1,452 \\
\hline
\end{tabular}


Table 6.3: (Cont'd)

\begin{tabular}{|c|c|c|c|c|c|c|}
\hline \multirow[t]{2}{*}{ Perceptions of parental reactions (\%) } & $\begin{array}{c}M \\
15-24\end{array}$ & $\begin{array}{c}\text { W } \\
15-24\end{array}$ & $\begin{array}{c}\text { MM } \\
15-29\end{array}$ & $\begin{array}{l}\text { MW } \\
15-24\end{array}$ & $\begin{array}{c}\text { UM } \\
15-24\end{array}$ & $\begin{array}{l}\text { UW } \\
15-24\end{array}$ \\
\hline & \multicolumn{6}{|c|}{ Mother } \\
\hline \multicolumn{7}{|c|}{ Combined } \\
\hline \multicolumn{7}{|l|}{ Mother would disapprove if respondent: } \\
\hline Brought same-sex friends home & 9.3 & 3.8 & 12.7 & 4.7 & 8.8 & 3.3 \\
\hline Brought opposite-sex friends home & 60.0 & 73.7 & 66.1 & 79.7 & 59.6 & 69.9 \\
\hline $\begin{array}{l}\text { Talked to a person of the opposite sex from } \\
\text { outside the home }\end{array}$ & 42.7 & 62.2 & 46.4 & 66.1 & 42.3 & 59.7 \\
\hline Went to a mela/film with same-sex friends & 31.3 & 46.5 & 32.0 & 47.3 & 31.0 & 46.0 \\
\hline Went to a mela/film with opposite-sex friends & 71.1 & 85.0 & 71.0 & 87.0 & 71.4 & 83.7 \\
\hline Joined a club/mandal/manram & 37.5 & 36.6 & 34.8 & 35.9 & 37.4 & 37.0 \\
\hline Had a love marriage & 77.2 & 90.9 & 77.8 & 91.1 & 77.5 & 90.7 \\
\hline Found a job & NA & 24.1 & NA & 28.2 & NA & 21.5 \\
\hline Number of respondents ${ }^{1}$ & 1,852 & 4,803 & 1,194 & 1,882 & 1,624 & 2,921 \\
\hline \multicolumn{7}{|c|}{ Urban } \\
\hline \multicolumn{7}{|l|}{ Mother would disapprove if respondent: } \\
\hline Brought same-sex friends home & 9.7 & 2.7 & 12.7 & 3.7 & 9.0 & 2.2 \\
\hline Brought opposite-sex friends home & 57.2 & 71.4 & 63.8 & 77.4 & 56.3 & 68.0 \\
\hline $\begin{array}{l}\text { Talked to a person of the opposite sex from } \\
\text { outside the home }\end{array}$ & 42.4 & 58.7 & 46.9 & 63.4 & 41.9 & 56.1 \\
\hline Went to a mela/film with same-sex friends & 28.0 & 45.5 & 28.7 & 47.2 & 27.5 & 44.5 \\
\hline Went to a mela/film with opposite-sex friends & 68.8 & 83.2 & 68.1 & 86.2 & 69.0 & 81.5 \\
\hline Joined a club/mandal/manram & 38.6 & 38.2 & 35.3 & 37.5 & 38.5 & 38.5 \\
\hline Had a love marriage & 74.0 & 89.2 & 76.8 & 90.0 & 74.4 & 88.6 \\
\hline Found a job & NA & 23.7 & NA & 30.3 & NA & 19.9 \\
\hline Number of respondents ${ }^{1}$ & 870 & 2,071 & 597 & 757 & 774 & 1,314 \\
\hline \multicolumn{7}{|c|}{ Rural } \\
\hline Mother would disapprove if respondent: & & & & & & \\
\hline Brought same-sex friends home & 9.1 & 4.7 & 12.8 & 5.5 & 8.6 & 4.2 \\
\hline Brought opposite-sex friends home & 62.1 & 75.5 & 67.9 & 81.2 & 62.3 & 71.6 \\
\hline $\begin{array}{l}\text { Talked to a person of the opposite sex from } \\
\text { outside the home }\end{array}$ & 43.0 & 65.0 & 46.1 & 67.9 & 42.6 & 62.9 \\
\hline Went to a mela/film with same-sex friends & 33.9 & 47.4 & 34.3 & 47.4 & 34.0 & 47.4 \\
\hline Went to a mela/film with opposite-sex friends & 72.8 & 86.5 & 73.1 & 87.7 & 73.3 & 85.7 \\
\hline Joined a club/mandal/manram & 36.6 & 35.3 & 34.5 & 34.9 & 36.4 & 35.6 \\
\hline Had a love marriage & 79.6 & 92.2 & 78.7 & 91.8 & 80.2 & 92.5 \\
\hline Found a job & NA & 24.5 & NA & 26.8 & NA & 22.9 \\
\hline Number of respondents ${ }^{1}$ & 982 & 2,732 & 597 & 1,125 & 850 & 1,607 \\
\hline
\end{tabular}

Note: All Ns are unweighted. NA: Not applicable. For married respondents, questions referred to the period prior to marriage. ${ }^{1}$ Includes only those respondents reporting that their father or mother, respectively, was alive at the time of interview. 
Figure 6.2: Percentage of youth reporting that their father or mother, respectively, would disapprove if they brought same- and opposite-sex friends home, Tamil Nadu, 2006
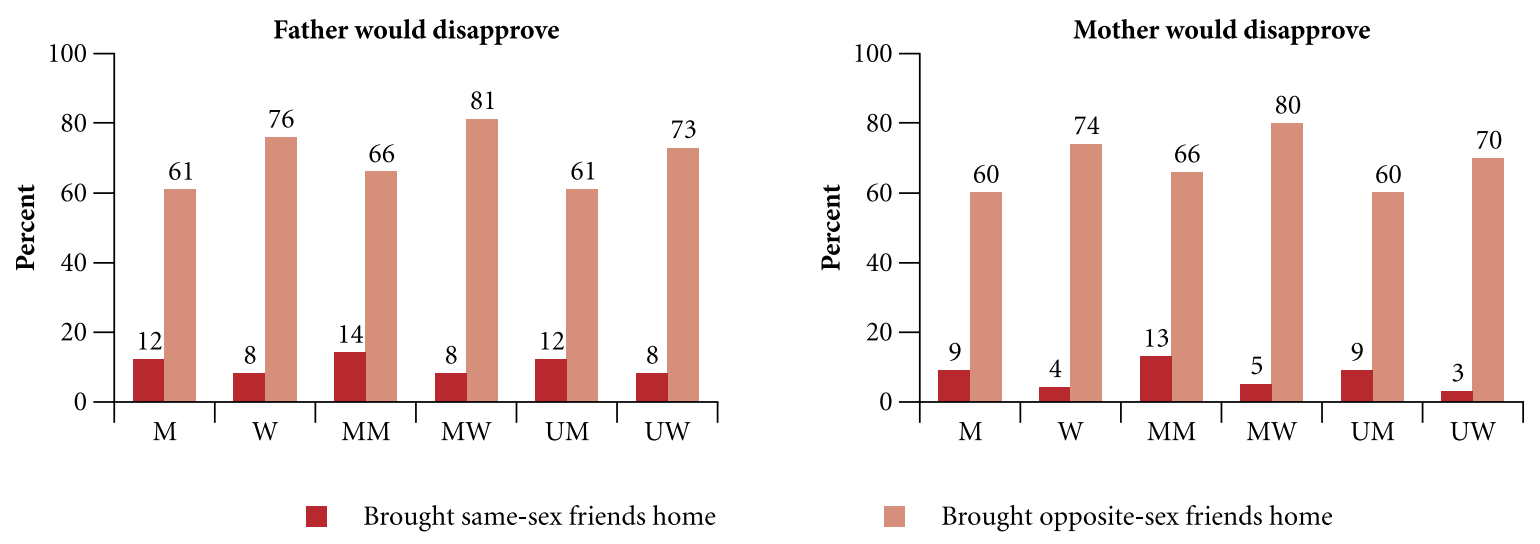

Note: For married respondents, questions referred to the period prior to marriage. Percentages were calculated only of those respondents reporting that their father or mother, respectively, was alive at the time of interview.

Youth were also asked about the extent to which family life was characterised by quarrels and domestic violence between parents, and whether they had witnessed their father beating their mother or vice versa. Findings are reported in Table 6.4. They suggest that $73 \%$ of young men and $76 \%$ of young women with both parents living acknowledged that they had ever witnessed quarrels between their parents. Just $2-3 \%$ of young men and women reported that they had ever witnessed their mother beating their father. Considerably larger proportions- $43 \%$ of young men and $31 \%$ of young women-reported ever witnessing their father beating their mother. Married young men and women were somewhat more likely than their unmarried counterparts to have witnessed their father beating their mother (53\% and $42 \%$, respectively, among young men; $34 \%$ and $28 \%$, respectively, among young women). Rural youth were considerably more likely than urban youth to have reported witnessing their father beating their mother: while $47 \%$ of young men and $36 \%$ of young women from rural areas had witnessed their father beating their mother, $38 \%$ and $24 \%$ of young men and women in urban areas so reported.

Youth were also asked whether one or both parents had ever beaten them since the age of 12. Findings, shown in Table 6.4, suggest that the majority of young men (62\%) and a sizeable proportion of young women (33\%) with at least one parent alive at the time of interview reported being beaten by a parent at any time since the age of 12. Differences by marital status and rural-urban residence were negligible.

\subsubsection{Communication with parents}

Information regarding communication with parents on issues relevant to youth-such as school performance, friendships, romantic relationships, being teased or bullied, physical maturation, reproductive processes and contraception-was elicited from all respondents reporting that their mother or father was alive at the time of interview. Findings, presented in Table 6.5 and Figures 6.3a-b, reveal that communication on any topic was far from universal. In general, sensitive topics-such as romantic relationships, reproduction and contraception—were rarely discussed with either parent.

Topics most likely to be discussed with fathers were schooling and friendships: two-thirds of young men and three-fifths of young women reported discussing schooling (69\% and 63\%, respectively) and friendships (70\% and $61 \%$, respectively) with their father. About one-fifth of young men and one-quarter of young women 
Table 6.4: Experience of domestic violence

Percentage of youth reporting violence between parents and being beaten by parents, according to residence, Tamil Nadu, 2006

\begin{tabular}{|c|c|c|c|c|c|c|}
\hline Experiences of domestic violence (\%) & $\begin{array}{c}\mathrm{M} \\
15-24\end{array}$ & $\begin{array}{c}\text { W } \\
15-24\end{array}$ & $\begin{array}{c}\text { MM } \\
15-29\end{array}$ & $\begin{array}{c}\text { MW } \\
15-24\end{array}$ & $\begin{array}{c}\text { UM } \\
15-24\end{array}$ & $\begin{array}{c}\text { UW } \\
15-24\end{array}$ \\
\hline \multicolumn{7}{|c|}{ Combined } \\
\hline Parents ever fought & 72.8 & 75.9 & 76.7 & 76.8 & 72.3 & 75.4 \\
\hline Mother ever beat father & 3.2 & 2.2 & 3.5 & 2.0 & 3.1 & 2.3 \\
\hline Father ever beat mother & 43.2 & 30.6 & 52.6 & 34.4 & 42.1 & 28.3 \\
\hline Number with both parents alive & 1,625 & 4,175 & 929 & 1,577 & 1,434 & 2,597 \\
\hline $\begin{array}{l}\text { Respondent beaten by father and/or mother } \\
\text { since age } 12\end{array}$ & 61.8 & 33.3 & 64.1 & 34.9 & 61.8 & 32.3 \\
\hline Number with at least one parent alive & 1,889 & 4,939 & 1,263 & 1,961 & 1,652 & 2,978 \\
\hline \multicolumn{7}{|c|}{ Urban } \\
\hline Parents ever fought & 70.3 & 72.6 & 77.7 & 74.8 & 69.4 & 71.5 \\
\hline Mother ever beat father & 3.2 & 1.7 & 3.7 & 1.7 & 3.3 & 1.7 \\
\hline Father ever beat mother & 38.3 & 24.1 & 52.7 & 28.4 & 36.6 & 21.9 \\
\hline Number with both parents alive & 759 & 1,813 & 450 & 634 & 676 & 1,179 \\
\hline $\begin{array}{l}\text { Respondent beaten by father and/or mother } \\
\text { since age } 12\end{array}$ & 62.3 & 32.0 & 62.1 & 33.7 & 61.9 & 31.0 \\
\hline Number with at least one parent alive & 880 & 2,125 & 630 & 787 & 782 & 1,338 \\
\hline \multicolumn{7}{|c|}{ Rural } \\
\hline Parents ever fought & 74.7 & 78.6 & 76.0 & 78.1 & 74.8 & 78.9 \\
\hline Mother ever beat father & 3.1 & 2.6 & 3.4 & 2.0 & 2.9 & 2.9 \\
\hline Father ever beat mother & 46.9 & 35.9 & 52.6 & 38.5 & 46.4 & 34.1 \\
\hline Number with both parents alive & 866 & 2,362 & 479 & 943 & 758 & 1,418 \\
\hline $\begin{array}{l}\text { Respondent beaten by father and/or mother } \\
\text { since age } 12\end{array}$ & 61.4 & 34.4 & 65.5 & 35.8 & 61.6 & 33.4 \\
\hline Number with at least one parent alive & 1,009 & 2,814 & 633 & 1,174 & 870 & 1,640 \\
\hline
\end{tabular}

Note: All Ns are unweighted. Domestic violence refers exclusively to physical violence.

(18\% and $24 \%$, respectively) discussed being teased/bullied and $11-14 \%$ discussed adolescent body changes with their father. Sensitive topics, such as romantic relationships, reproductive processes and contraception, were rarely discussed with fathers. For example, just $3-5 \%$ of youth reported having discussed romantic relationships with their father; and just $0.2-0.3 \%$ of young men and not a single young woman had discussed reproductive processes or contraception with their father.

The picture was somewhat different with regard to communication with mothers. As in the case of communication with fathers, the topics most likely to be discussed with mothers were schooling and friendships; schooling was discussed by $71-75 \%$ of young men and women, and friendships by $76-83 \%$ of young men and women. Gender differences emerged with regard to discussion with mothers about being teased or bullied and about adolescent body changes, with young women far more likely than young men to discuss these matters. For example, $51 \%$ of young women compared to $20 \%$ of young men had discussed being bullied or teased with their mother; and $71 \%$ compared to just $14 \%$, respectively, had discussed adolescent body changes with their mother. Once again, few young people had discussed sensitive topics such as romantic relationships (6-9\%), reproductive processes $(0-2 \%)$ or contraception $(0-2 \%)$ with their mother. 
Findings suggest that young men were about as likely to discuss almost every topic with their mother as with their father. The only exception was friendships, which a somewhat larger proportion discussed with their mother than their father $(76 \%$ versus $70 \%)$. In contrast, young women were more likely to discuss all matters, especially those related to being bullied/teased and adolescent body changes, with their mother than with their father.

Differentials by marital status and rural-urban residence suggest that unmarried and urban respondents were more likely than their married and rural counterparts to have discussed such topics as school performance and friendships with a parent. Unmarried young women, in addition, were more likely than their married counterparts to have discussed being teased or bullied. Differences were negligible with regard to discussion of sensitive topics.

\section{Table 6.5: Parental communication}

Percentage of youth who discussed selected matters with parents, according to residence, Tamil Nadu, 2006

\begin{tabular}{|c|c|c|c|c|c|c|c|c|c|c|c|c|}
\hline \multirow[t]{2}{*}{$\begin{array}{l}\text { Issues } \\
\text { discussed (\%) }\end{array}$} & $\begin{array}{c}\mathrm{M} \\
15-24 \\
\end{array}$ & $\begin{array}{c}\mathrm{W} \\
15-24\end{array}$ & $\begin{array}{c}\mathrm{MM} \\
15-29\end{array}$ & $\begin{array}{c}\text { MW } \\
15-24\end{array}$ & $\begin{array}{c}\text { UM } \\
15-24\end{array}$ & $\begin{array}{c}\text { UW } \\
15-24\end{array}$ & $\begin{array}{c}\mathrm{M} \\
15-24 \\
\end{array}$ & $\begin{array}{c}\text { W } \\
15-24\end{array}$ & $\begin{array}{c}\mathrm{MM} \\
15-29 \\
\end{array}$ & $\begin{array}{c}\text { MW } \\
15-24\end{array}$ & $\begin{array}{c}\text { UM } \\
15-24 \\
\end{array}$ & $\begin{array}{c}\text { UW } \\
15-24\end{array}$ \\
\hline & \multicolumn{6}{|c|}{ Father } & \multicolumn{6}{|c|}{ Mother } \\
\hline \multicolumn{13}{|c|}{ Combined } \\
\hline School performance & 69.1 & 62.9 & 52.5 & 53.5 & 71.3 & 68.7 & 70.6 & 75.3 & 53.2 & 66.1 & 72.2 & 81.1 \\
\hline Friendships & 70.0 & 60.5 & 56.8 & 52.0 & 71.6 & 65.7 & 75.9 & 82.5 & 63.2 & 76.4 & 77.1 & 86.4 \\
\hline Romantic relationships & 4.9 & 3.3 & 4.0 & 2.9 & 4.7 & 3.5 & 6.2 & 9.2 & 6.3 & 7.3 & 5.8 & 10.4 \\
\hline Being teased/bullied & 18.0 & 24.2 & 15.7 & 21.7 & 18.5 & 25.7 & 20.1 & 51.4 & 15.6 & 47.0 & 20.4 & 54.2 \\
\hline Adolescent body changes & 13.5 & 10.7 & 11.5 & 9.2 & 13.8 & 11.7 & 14.1 & 70.6 & 12.3 & 68.4 & 14.2 & 72.0 \\
\hline Reproductive processes & 0.2 & 0.0 & 0.1 & 0.1 & 0.2 & 0.0 & 0.1 & 2.0 & 0.1 & 3.7 & 0.1 & 1.0 \\
\hline Contraception & 0.3 & 0.0 & 0.2 & 0.1 & 0.3 & 0.0 & 0.2 & 2.4 & 0.2 & 4.5 & 0.2 & 1.1 \\
\hline Number of respondents ${ }^{1}$ & 1,660 & 4,311 & 998 & 1,656 & 1,460 & 2,655 & 1,852 & 4,803 & 1,194 & 1,882 & 1,624 & 2,921 \\
\hline \multicolumn{13}{|c|}{ Urban } \\
\hline School performance & 72.4 & 65.3 & 56.7 & 56.3 & 74.4 & 70.1 & 74.0 & 78.3 & 57.5 & 67.9 & 75.0 & 84.1 \\
\hline Friendships & 71.9 & 63.2 & 58.2 & 54.2 & 73.3 & 68.0 & 79.0 & 86.2 & 65.9 & 79.6 & 79.9 & 89.9 \\
\hline Romantic relationships & 6.1 & 4.4 & 5.2 & 3.4 & 6.2 & 4.9 & 8.2 & 12.0 & 7.7 & 8.5 & 7.8 & 13.9 \\
\hline Being teased/bullied & 19.0 & 23.6 & 15.8 & 20.8 & 19.4 & 25.1 & 20.9 & 53.3 & 15.2 & 48.0 & 21.2 & 56.2 \\
\hline Adolescent body changes & 14.0 & 9.7 & 11.1 & 6.3 & 14.0 & 11.5 & 14.8 & 75.5 & 12.3 & 72.4 & 14.7 & 77.3 \\
\hline Reproductive processes & 0.4 & 0.1 & 0.0 & 0.0 & 0.5 & 0.1 & 0.2 & 1.8 & 0.0 & 2.9 & 0.3 & 1.2 \\
\hline Contraception & 0.6 & 0.1 & 0.0 & 0.0 & 0.6 & 0.1 & 0.5 & 1.9 & 0.2 & 3.1 & 0.5 & 1.2 \\
\hline Number of respondents ${ }^{1}$ & 769 & 1,867 & 483 & 664 & 684 & 1,203 & 870 & 2,071 & 597 & 757 & 774 & 1,314 \\
\hline \multicolumn{13}{|c|}{ Rural } \\
\hline School performance & 66.6 & 61.0 & 49.7 & 51.6 & 68.8 & 67.5 & 68.0 & 72.9 & 50.1 & 64.9 & 69.9 & 78.4 \\
\hline Friendships & 68.6 & 58.4 & 55.9 & 50.6 & 70.2 & 63.7 & 73.5 & 79.6 & 61.4 & 74.2 & 74.8 & 83.4 \\
\hline Romantic relationships & 3.9 & 2.4 & 3.3 & 2.5 & 3.5 & 2.3 & 4.7 & 7.0 & 5.4 & 6.4 & 4.1 & 7.4 \\
\hline Being teased/bullied & 17.3 & 24.6 & 15.6 & 22.2 & 17.6 & 26.1 & 19.5 & 49.9 & 15.9 & 46.4 & 19.7 & 52.4 \\
\hline Adolescent body changes & 13.1 & 11.6 & 11.6 & 11.2 & 13.4 & 11.9 & 13.6 & 66.7 & 12.3 & 65.7 & 13.7 & 67.4 \\
\hline Reproductive processes & 0.0 & 0.0 & 0.2 & 0.1 & 0.0 & 0.0 & 0.0 & 2.2 & 0.1 & 4.3 & 0.0 & 0.8 \\
\hline Contraception & 0.1 & 0.0 & 0.3 & 0.1 & 0.1 & 0.0 & 0.1 & 2.8 & 0.1 & 5.5 & 0.1 & 1.0 \\
\hline Number of respondents ${ }^{1}$ & 891 & 2,444 & 515 & 992 & 776 & 1,452 & 982 & 2,732 & 597 & 1,125 & 850 & 1,607 \\
\hline
\end{tabular}

Note: All Ns are unweighted. For married respondents questions referred to the period prior to marriage. ${ }^{1}$ Includes only those respondents reporting that their father or mother, respectively, was alive at the time of interview. 
Figure 6.3a: Percentage of youth who discussed various matters with their father, according to residence, Tamil Nadu, 2006
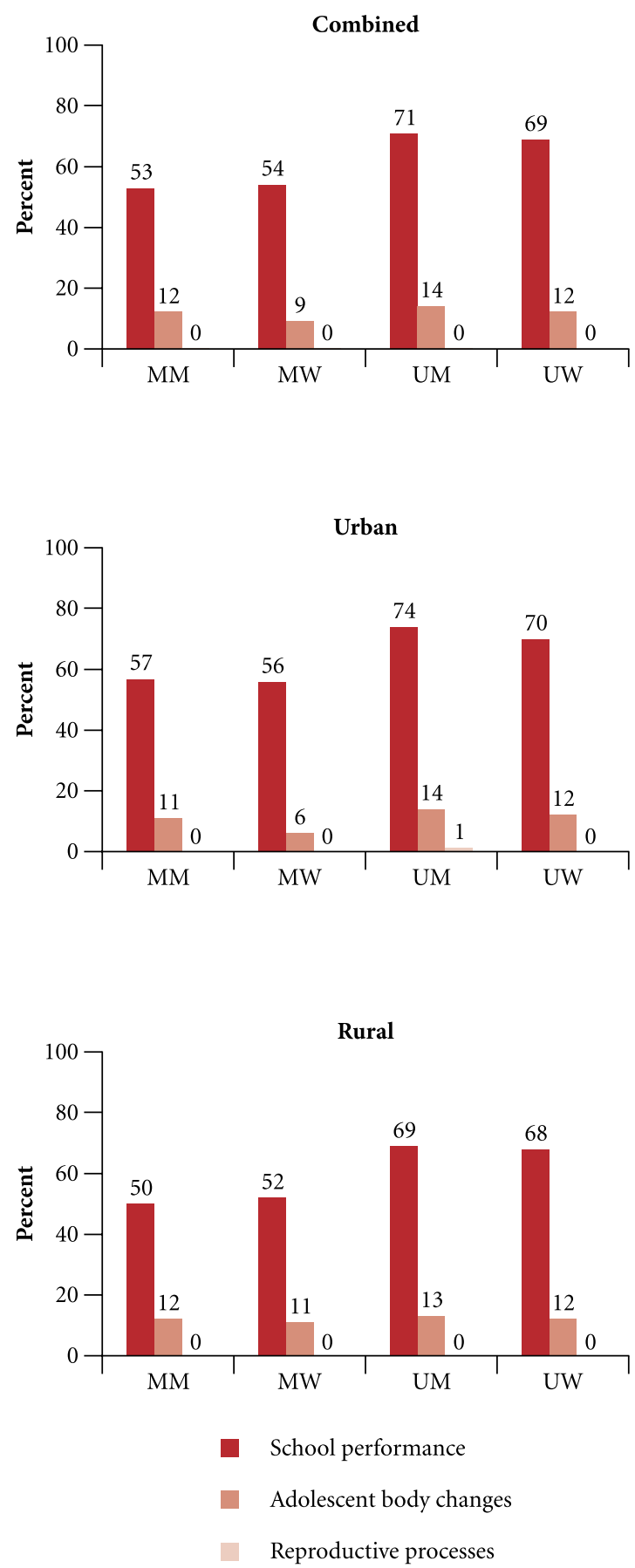

Note: For married respondents, questions referred to the period prior to marriage. Percentages were calculated only of those respondents reporting that their father was alive at the time of interview.
Figure 6.3b: Percentage of youth who discussed various matters with their mother, according to residence, Tamil Nadu, 2006
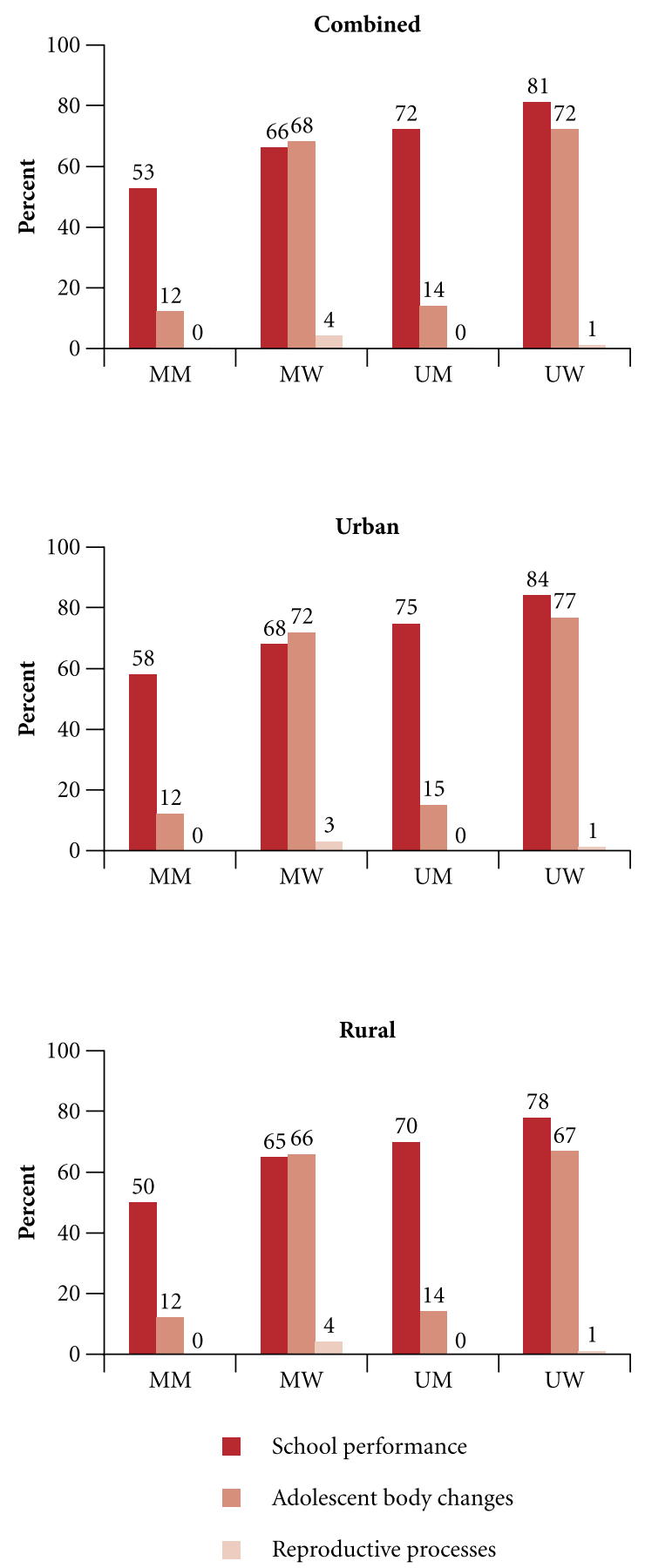

Note: For married respondents, questions referred to the period prior to marriage. Percentages were calculated only of those respondents reporting that their mother was alive at the time of interview. 


\subsection{Peer networks and interaction}

In order to assess the size of peer networks and the nature of peer interaction, the Youth Study asked young people about the number of same-sex friends they had, whether they had opposite-sex friends and the kinds of activities in which they engaged with their same- and opposite-sex friends. Married respondents were asked to recall the situation prior to marriage.

Table 6.6 reports findings on the size of peer networks. Same-sex peer networks of young men were typically wider than those of young women. The proportion of youth reporting five or more same-sex friends ranged from $36 \%$ among young women to $43 \%$ among young men, and the median number of same-sex friends reported by young men exceeded that reported by young women by one (4 versus 3 ). Unmarried and married young men both reported a median of four friends; in contrast, unmarried young women reported more same-sex friends-a median of one additional friend-than their married counterparts.

Rural-urban differences were negligible in the number of same-sex friends reported by young men (a median of 4 friends). However, young women in urban settings reported more same-sex friends than those in rural settings (4 versus 3 ).

Opposite-sex peer networks were reported by over one-quarter of all youth. Gender differences were narrow: $29 \%$ of young men and $27 \%$ of young women reported having at least one opposite-sex friend. Differences by marital status were not apparent among young men; however, unmarried young women were somewhat more likely than the married to report an opposite-sex friend (30\% and 23\%, respectively; see Figure 6.4). Rural-urban differences were negligible (30\% and $27 \%$ among rural and urban young men; $26 \%$ and $28 \%$, respectively, among young women).

Table 6.7 reports the nature of interaction with same- and opposite-sex friends. Again, the married were asked to recall the situation prior to marriage. Respondents were asked if they went on picnics or to see films with their peers, studied together, spent time chatting, engaged in sporting activities, or drank and gambled with their friends. As evident from Panel A of Table 6.7, the activity in which almost all young people engaged was chatting with their same-sex friends (reported by $99 \%$ and $95 \%$ of young men and women, respectively). Other activities in which large percentages of youth engaged with their same-sex friends included playing sports ( $91 \%$ and $80 \%$ of young men and women, respectively) and studying (79\% each), and in the case of young men, going on picnics or to films (87\%). Gender differences were apparent with regard to three activities: engaging in sports (as described above), and to a larger extent going on picnics or to see films ( $87 \%$ of young men versus $41 \%$ of young women) and drinking or gambling ( $24 \%$ of young men and hardly any young women).

Marital status differences suggest that the unmarried were more likely than the married to report studying ( $82 \%$ and $57 \%$, respectively, among young men; $84 \%$ and $72 \%$, respectively, among young women) and engaging in sports (92\% and 78\%, respectively, among young men; $82 \%$ and $77 \%$, respectively, among young women) with their same-sex friends. That the unmarried were more likely to report studying together with same-sex friends than their married counterparts is presumably a function of the higher levels of school attainment of the unmarried, on the one hand, and the relatively curtailed adolescent experience of the married, on the other. With regard to other activities, differences were apparent only among young men: for example, married young men were more likely than the unmarried to report going on picnics or to see films with their same-sex peers (93\% and $86 \%$, respectively) and far more likely to report drinking or gambling ( $47 \%$ and $21 \%$, respectively) with their same-sex peers. Rural-urban differences were negligible for young men. Among young women, differences were narrow; except that urban young women were more likely than their rural counterparts to go out on picnics or to see films with their same-sex friends (45\% versus $38 \%$ ). 
Table 6.6: Size of peer networks

Percent distribution of youth by number of same- and opposite-sex friends, according to residence, Tamil Nadu, 2006

\begin{tabular}{|c|c|c|c|c|c|c|}
\hline Number of friends (\%) & $\begin{array}{c}\mathrm{M} \\
15-24\end{array}$ & $\begin{array}{c}\mathrm{W} \\
15-24\end{array}$ & $\begin{array}{c}\text { MM } \\
15-29\end{array}$ & $\begin{array}{c}\text { MW } \\
15-24\end{array}$ & $\begin{array}{c}\text { UM } \\
15-24\end{array}$ & $\begin{array}{c}\text { UW } \\
15-24\end{array}$ \\
\hline \multicolumn{7}{|c|}{ Combined } \\
\hline \multicolumn{7}{|l|}{ Number of same-sex friends } \\
\hline None & 1.6 & 1.9 & 3.5 & 2.8 & 1.4 & 1.3 \\
\hline 1 & 10.9 & 10.2 & 12.3 & 10.5 & 10.3 & 10.0 \\
\hline 2 & 21.5 & 18.3 & 19.0 & 22.0 & 21.8 & 15.9 \\
\hline 3 & 14.3 & 19.7 & 14.9 & 21.6 & 14.2 & 18.5 \\
\hline 4 & 8.8 & 13.4 & 10.3 & 14.0 & 9.0 & 13.0 \\
\hline 5 or more & 42.9 & 36.4 & 40.0 & 29.2 & 43.4 & 41.2 \\
\hline Median number of same-sex friends & 4.0 & 3.0 & 4.0 & 3.0 & 4.0 & 4.0 \\
\hline At least one opposite-sex friend (\%) & 28.9 & 27.0 & 27.8 & 22.8 & 28.3 & 29.7 \\
\hline Number of respondents & 1,913 & 5,008 & 1,322 & 2,007 & 1,666 & 3,001 \\
\hline \multicolumn{7}{|c|}{ Urban } \\
\hline \multicolumn{7}{|l|}{ Number of same-sex friends } \\
\hline None & 1.2 & 1.6 & 1.7 & 1.5 & 1.2 & 1.6 \\
\hline 1 & 11.4 & 10.3 & 13.8 & 12.1 & 10.7 & 9.3 \\
\hline 2 & 21.1 & 17.5 & 19.5 & 21.1 & 21.3 & 15.4 \\
\hline 3 & 15.0 & 19.1 & 15.1 & 22.0 & 15.0 & 17.4 \\
\hline 4 & 8.9 & 12.8 & 9.2 & 14.6 & 9.4 & 11.7 \\
\hline 5 or more & 42.4 & 38.7 & 40.7 & 28.7 & 42.4 & 44.6 \\
\hline Median number of same-sex friends & 4.0 & 4.0 & 4.0 & 3.0 & 4.0 & 4.0 \\
\hline At least one opposite-sex friend (\%) & 27.0 & 27.8 & 23.4 & 23.1 & 26.8 & 30.5 \\
\hline Number of respondents & 890 & 2,151 & 653 & 804 & 789 & 1,347 \\
\hline \multicolumn{7}{|c|}{ Rural } \\
\hline \multicolumn{7}{|l|}{ Number of same-sex friends } \\
\hline None & 1.9 & 2.2 & 4.7 & 3.7 & 1.6 & 1.1 \\
\hline 1 & 10.6 & 10.1 & 11.4 & 9.3 & 10.0 & 10.7 \\
\hline 2 & 21.8 & 19.0 & 18.7 & 22.5 & 22.1 & 16.5 \\
\hline 3 & 13.7 & 20.2 & 14.7 & 21.3 & 13.4 & 19.5 \\
\hline 4 & 8.7 & 13.9 & 11.0 & 13.5 & 8.7 & 14.2 \\
\hline 5 or more & 43.3 & 34.6 & 39.4 & 29.6 & 44.2 & 38.2 \\
\hline Median number of same-sex friends & 4.0 & 3.0 & 4.0 & 3.0 & 4.0 & 4.0 \\
\hline At least one opposite-sex friend (\%) & 30.4 & 26.3 & 30.8 & 22.6 & 29.5 & 29.0 \\
\hline Number of respondents & 1,023 & 2,857 & 669 & 1,203 & 877 & 1,654 \\
\hline
\end{tabular}

Note: All Ns are unweighted. For married respondents, questions referred to the period prior to marriage. 
Figure 6.4: Percentage of youth reporting at least one opposite-sex friend, according to residence, Tamil Nadu, 2006
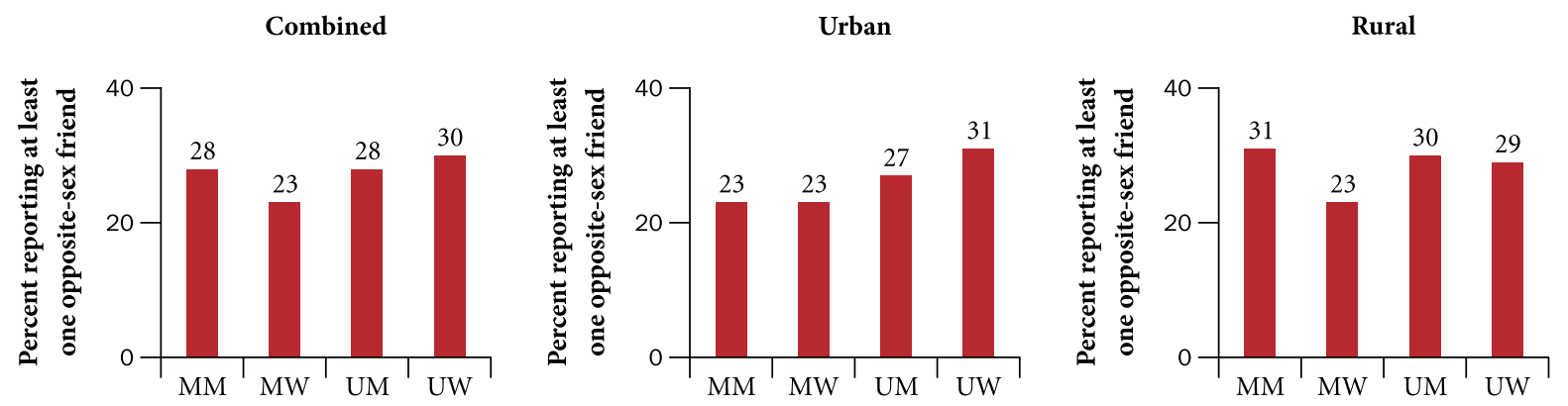

Note: For married respondents, questions referred to the period prior to marriage.

The range of activities in which youth engaged with their opposite-sex peers was much narrower. As shown in Panel B of Table 6.7, the only activity in which about as many youth engaged with their opposite-sex friends as their same-sex friends was chatting, mentioned by $94 \%$ of all respondents reporting opposite-sex friends. Other activities were less likely to be conducted with an opposite-sex friend, for example, $54-56 \%$ of young men and women reported studying together. Gender differences were evident in other activities: young women were more likely than young men to report engaging in sports (38\% versus $31 \%$ ), and young men were considerably more likely than young women to report going on picnics or to films (49\% and 19\%, respectively) with their opposite-sex friends. Differences by marital status were apparent in a few activities. For example, unmarried young men were less likely than their married counterparts to go on picnics or to see films with their opposite-sex friends; they were, however, far more likely to study and engage in sports with their opposite-sex friends. Among young women, the unmarried were more likely than the married to report studying together and chatting with their male friends but were equally likely to engage in all other activities. Finally, rural-urban differences were typically narrow; however, urban young men were somewhat more likely than rural young men to study together with their opposite-sex friends.

\subsection{Support networks}

The Youth Study also asked respondents about the individual with whom they would most likely discuss a range of personal matters, namely, taking a job, menstrual problems (females) and nocturnal emission or swapnadosh (males), and boy-girl relationships. All those aged 20 and above were asked to think back to the time they were aged 15-18 while responding to these questions.

Findings, reported in Table 6.8a, indicate that the person with whom youth would most likely discuss personal matters varied considerably by sex of the respondent. Young women tended to consider their mother as their leading confidante on matters relating to taking a job (53\%) and menstrual problems (84\%), but were most likely to confide in peers about matters pertaining to boy-girl relationships (49\%). Also notable is that large proportions of young women reported their father as the main confidante on issues relating to taking a job (27\%), and that $36 \%$ of young women would not confide in anyone about boy-girl relationships. Young men, in contrast, were far more likely to confide in their peers than their parents. For example, peers were cited as leading confidantes on such issues as nocturnal emission by $77 \%$ and boy-girl relationships by $83 \%$; in comparison, parents were rarely cited as key confidantes on these issues (less than 1\%). Even on the non-sensitive issue of taking a job, while fathers $(40 \%)$ and mothers $(27 \%)$ were leading confidantes for several young men, many $(26 \%)$ did indeed report a peer as a leading confidante. Again, it is notable that many young men would not confide in anyone about these issues ( $15 \%$ about boy-girl relationships and 
Table 6.7: Interaction with same- and opposite-sex friends

Percentage of youth reporting interaction with same- and opposite-sex friends by types of activities, according to residence, Tamil Nadu, 2006

\begin{tabular}{|c|c|c|c|c|c|c|}
\hline Activities (\%) & $\begin{array}{c}\mathrm{M} \\
15-24\end{array}$ & $\begin{array}{c}\text { W } \\
15-24\end{array}$ & $\begin{array}{c}\mathrm{MM} \\
15-29\end{array}$ & $\begin{array}{c}\text { MW } \\
\text { 15-24 }\end{array}$ & $\begin{array}{c}\text { UM } \\
15-24\end{array}$ & $\begin{array}{c}\text { UW } \\
15-24\end{array}$ \\
\hline \multicolumn{7}{|c|}{ A. Activities with same-sex friends } \\
\hline \multicolumn{7}{|c|}{ Combined } \\
\hline Going on picnics/ to see films & 86.6 & 41.0 & 93.3 & 40.3 & 85.9 & 41.6 \\
\hline Studying together & 79.1 & 79.3 & 56.8 & 71.5 & 81.9 & 84.3 \\
\hline Spending time chatting/gossiping & 98.5 & 94.7 & 98.4 & 93.4 & 98.4 & 95.5 \\
\hline Playing sports & 90.5 & 80.0 & 78.0 & 76.9 & 91.8 & 82.1 \\
\hline Drinking or gambling & 23.6 & 0.5 & 46.6 & 0.3 & 21.3 & 0.7 \\
\hline Number with at least one same-sex friend & 1,882 & 4,909 & 1,277 & 1,948 & 1,643 & 2,961 \\
\hline \multicolumn{7}{|c|}{ Urban } \\
\hline Going on picnics/ to see films & 87.9 & 44.6 & 95.3 & 39.4 & 87.1 & 47.6 \\
\hline Studying together & 81.3 & 80.6 & 60.9 & 71.9 & 84.3 & 85.7 \\
\hline Spending time chatting/gossiping & 98.7 & 95.5 & 99.4 & 93.4 & 98.5 & 96.7 \\
\hline Playing sports & 91.8 & 77.8 & 81.8 & 73.0 & 93.2 & 80.5 \\
\hline Drinking or gambling & 22.0 & 0.6 & 48.9 & 0.1 & 19.6 & 0.9 \\
\hline Number with at least one same-sex friend & 880 & 2,116 & 641 & 791 & 780 & 1,325 \\
\hline \multicolumn{7}{|c|}{ Rural } \\
\hline Going on picnics/to see films & 85.5 & 38.2 & 91.9 & 41.0 & 84.8 & 36.2 \\
\hline Studying together & 77.5 & 78.2 & 53.9 & 71.2 & 80.0 & 83.1 \\
\hline Spending time chatting/gossiping & 98.3 & 94.0 & 97.7 & 93.5 & 98.3 & 94.4 \\
\hline Playing sports & 89.4 & 81.9 & 75.3 & 79.6 & 90.8 & 83.5 \\
\hline Drinking or gambling & 24.9 & 0.5 & 44.9 & 0.3 & 22.6 & 0.6 \\
\hline Number with at least one same-sex friend & 1,002 & 2,793 & 636 & 1,157 & 863 & 1,636 \\
\hline \multicolumn{7}{|c|}{ B. Activities with opposite-sex friends } \\
\hline \multicolumn{7}{|c|}{ Combined } \\
\hline Going on picnics/ to see films & 49.3 & 19.0 & 53.4 & 20.4 & 48.4 & 18.4 \\
\hline Studying together & 55.7 & 54.2 & 33.6 & 45.3 & 59.3 & 58.7 \\
\hline Spending time chatting/gossiping & 93.5 & 93.7 & 90.7 & 90.2 & 94.1 & 95.5 \\
\hline Playing sports & 31.0 & 37.9 & 24.5 & 37.9 & 30.6 & 37.8 \\
\hline Drinking or gambling & 1.8 & 0.8 & 1.6 & 1.3 & 1.7 & 0.6 \\
\hline Number with at least one opposite-sex friend & 562 & 1,340 & 372 & 452 & 474 & 888 \\
\hline \multicolumn{7}{|c|}{ Urban } \\
\hline Going on picnics/ to see films & 51.1 & 21.3 & 58.3 & 20.9 & 50.5 & 21.7 \\
\hline Studying together & 59.1 & 54.4 & 36.2 & 45.5 & 62.5 & 58.3 \\
\hline Spending time chatting/gossiping & 94.6 & 94.6 & 92.9 & 90.3 & 95.0 & 96.7 \\
\hline Playing sports & 29.8 & 35.6 & 22.8 & 38.0 & 30.0 & 34.5 \\
\hline Drinking or gambling & 1.8 & 0.8 & 1.6 & 1.1 & 1.5 & 0.7 \\
\hline Number with at least one opposite-sex friend & 241 & 593 & 157 & 185 & 211 & 408 \\
\hline \multicolumn{7}{|c|}{ Rural } \\
\hline Going on picnics/ to see films & 47.9 & 17.1 & 50.8 & 20.0 & 46.9 & 15.3 \\
\hline Studying together & 53.3 & 54.0 & 32.1 & 45.2 & 57.2 & 59.1 \\
\hline Spending time chatting/gossiping & 92.7 & 92.9 & 89.6 & 90.0 & 93.4 & 94.6 \\
\hline Playing sports & 31.8 & 39.9 & 25.4 & 37.8 & 31.0 & 40.9 \\
\hline Drinking or gambling & 1.8 & 0.8 & 1.7 & 1.5 & 1.8 & 0.4 \\
\hline Number with at least one opposite-sex friend & 321 & 747 & 215 & 267 & 263 & 480 \\
\hline
\end{tabular}

Note: All Ns are unweighted. For married respondents, questions referred to the period prior to marriage. 


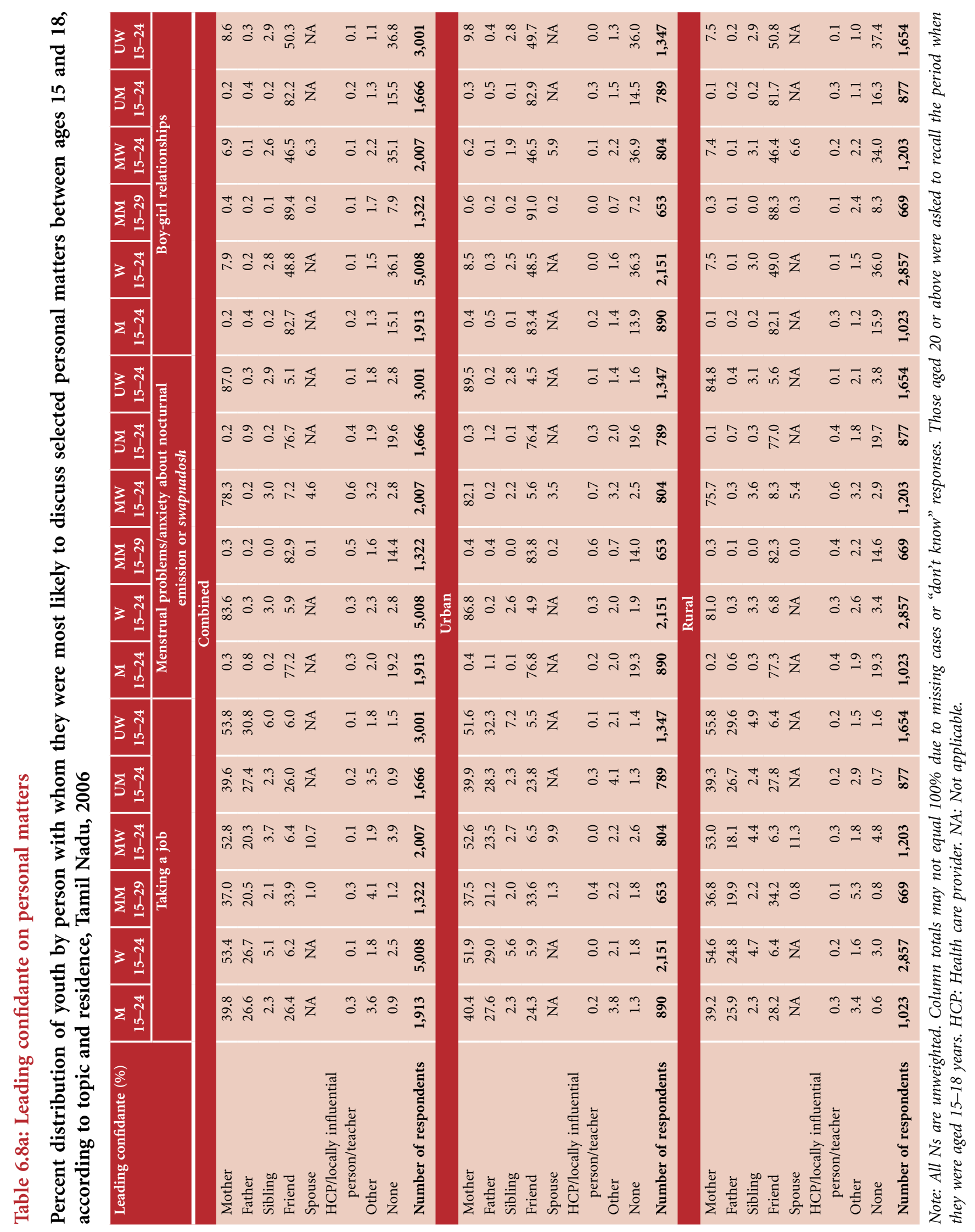


Table 6.8b: Leading confidante on matters relating to the experience of teasing among young women

Percent distribution of young women by person with whom they were most likely to discuss being teased by a boy between ages 15 and 18, according to residence, Tamil Nadu, 2006

\begin{tabular}{|c|c|c|c|c|c|c|c|c|c|}
\hline \multirow[t]{2}{*}{ Leading confidante (\%) } & $\begin{array}{c}\mathrm{W} \\
15-24 \\
\end{array}$ & $\begin{array}{c}\text { MW } \\
15-24 \\
\end{array}$ & $\begin{array}{c}\text { UW } \\
15-24 \\
\end{array}$ & $\begin{array}{c}W \\
15-24 \\
\end{array}$ & $\begin{array}{c}\text { MW } \\
15-24 \\
\end{array}$ & $\begin{array}{c}\text { UW } \\
15-24 \\
\end{array}$ & $\begin{array}{c}\mathrm{W} \\
15-24 \\
\end{array}$ & $\begin{array}{c}\text { MW } \\
15-24 \\
\end{array}$ & $\begin{array}{c}\text { UW } \\
15-24 \\
\end{array}$ \\
\hline & \multicolumn{3}{|c|}{ Combined } & \multicolumn{3}{|c|}{ Urban } & \multicolumn{3}{|c|}{ Rural } \\
\hline Mother & 38.9 & 37.5 & 39.8 & 38.0 & 35.7 & 39.3 & 39.6 & 38.7 & 40.2 \\
\hline Father & 7.2 & 7.0 & 7.4 & 7.1 & 6.6 & 7.5 & 7.3 & 7.3 & 7.3 \\
\hline Sibling & 7.3 & 7.7 & 7.0 & 7.9 & 8.0 & 7.8 & 6.8 & 7.5 & 6.4 \\
\hline Friend & 35.9 & 32.3 & 38.2 & 37.2 & 35.4 & 38.3 & 34.9 & 30.3 & 38.2 \\
\hline Spouse & NA & 5.6 & NA & NA & 5.4 & NA & NA & 5.6 & NA \\
\hline $\begin{array}{l}\text { HCP/locally influential } \\
\text { person/teacher }\end{array}$ & 0.0 & 0.0 & 0.0 & 0.1 & 0.1 & 0.1 & 0.0 & 0.0 & 0.0 \\
\hline Other person & 1.4 & 1.5 & 1.2 & 1.8 & 1.9 & 1.8 & 1.0 & 1.3 & 0.8 \\
\hline None & 7.0 & 8.2 & 6.2 & 5.9 & 6.9 & 5.3 & 7.9 & 9.0 & 7.0 \\
\hline Number of respondents & 5,008 & 2,007 & 3,001 & 2,151 & 804 & 1,347 & 2,857 & 1,203 & 1,654 \\
\hline
\end{tabular}

Note: All Ns are unweighted. Column totals may not equal 100\% due to missing cases or "don't know" responses. Those aged 20 or above were asked to recall the period when they were aged 15-18 years. HCP: Health care provider. NA: Not applicable.

$19 \%$ about nocturnal emission). Differences by marital status were generally narrow; however, some differences were notable. For example, married young men were more likely than the unmarried to confide in a friend on all three issues. Conversely, unmarried young men were more likely than the married to report that they would not discuss such matters as nocturnal emission and boy-girl relationships with anyone. Additionally, unmarried youth were more likely than the married to report their father as a leading confidante on matters relating to taking a job. Rural-urban differences were, however, negligible.

The Youth Study also asked young women about the individual in whom they were most likely to confide if they were teased by a boy. Findings, reported in Table $6.8 \mathrm{~b}$, show that almost half reported that they would confide in a parent: $39 \%$ in their mother and $7 \%$ in their father. About $36 \%$ of young women reported that they would confide in a friend if they were teased by a boy. Differences by marital status and residence were negligible; however, slightly larger proportions of unmarried than married young women reported they would confide in a friend (38\% and $32 \%$, respectively).

\subsection{Summary}

Youth Study findings reveal a mixed scenario with regard to young people's socialisation experiences. For example, responses from both young men and women indicate that large proportions of households did not discriminate between their sons and daughters in terms of freedom of movement and expectations regarding housework. Only about three in five young men reported that they had more freedom to go out than their sisters or female cousins, and just one in four young women agreed that they had less freedom to go out than their brothers or male cousins. Likewise, $45 \%$ of young men reported that they were expected to do less housework than their sisters or female cousins, and just $22 \%$ of young women reported that they were expected to do more housework than their brothers or male cousins. At the same time, far more consistently observed were gender differences in perceptions of parental control: young women were more likely than young men to perceive that their parents would disapprove of social activities in which youth participate, particularly those involving members of the opposite sex. 
Findings regarding communication with parents on issues relevant to youth-such as school performance, friendships, being teased or bullied, physical maturation, romantic relationships, contraception and reproductive processes-reiterate those from other studies, showing that such communication is not universal. For example, just $61-83 \%$ of young men and women had discussed school performance or friendships with either parent. Even fewer youth ( $9 \%$ or less) had discussed such sensitive topics as romantic relationships, reproductive processes and contraception with either parent. Nevertheless, among young women, mothers were identified as the most likely confidante on such matters as menstrual problems (84\%) and the experience of being teased by a boy $(39 \%)$.

Young people's family lives were marked by violence, both experienced and witnessed. About two in five young men and one in three young women had observed their father beating their mother. Many youth reported experiencing a beating by a parent since the age of 12 . Many more young men than young women reported such an experience: almost three in five young men and one in three young women.

In contrast, growing up was associated with close peer networks. Almost all youth reported having samesex friends. Young men, however, reported larger networks of friends than did young women. Opposite-sex peer networks were less common but nonetheless reported by over one-quarter of young men and women. Interaction with friends tended to be restricted to activities such as chatting, engaging in sports and studying, especially among young women, although large proportions of young men did report engaging in other activities with their peers such as going on picnics or to films as well. Indeed, findings suggest that youth derived an important measure of support from their peer networks on personal matters: friends were by far the leading confidante on boy-girl relationships for both young men and women, and on nocturnal emission for young men. 


\section{Agency and gender role attitudes}

Evidence on agency among youth, although sparse, suggests that in traditional settings such as India, young women and even some young men have limited agency in terms of decision-making on matters affecting their own lives, freedom of movement and access to resources. Gender role attitudes, similarly, tend to be traditional, assigning greater value to young men than young women (Alexander et al., 2006a; 2006b; Ram et al., 2006; Santhya, Jejeebhoy and Ghosh, 2008; Santhya et al., 2008; Sebastian, Grant and Mensch, 2005). This chapter discusses Youth Study findings on agency and gender role attitudes.

\subsection{Decision-making}

In order to assess young people's involvement in decision-making, the Youth Study asked all respondents about their involvement in decisions related to three specific matters: choice of friends, spending money and buying clothes for oneself. If youth reported that they were involved in decision-making on any issue, they were asked whether they made the decision entirely on their own or jointly with other family members.

Findings, presented in Table 7.1 and Figure 7.1, reveal that irrespective of sex, marital status and rural-urban residence, youth were overwhelmingly likely to choose their friends on their own. Gender differences were relatively narrow: $93 \%$ of young men compared to somewhat fewer young women (89\%) reported that they decided on their own who their friends would be. Findings also suggest that about $5 \%$ of young men and women did not have any say in choosing their own friends and that it was other family members who made these decisions for them. Differences by marital status and rural-urban residence were narrow.

Fewer youth were involved in making decisions on spending money than on choice of friends, and this was particularly evident among young women. For example, while $70 \%$ of young men reported that they made decisions on their own about spending money, only $44 \%$ of young women so reported. Conversely, a much larger proportion of young women than young men (23\% compared to $10 \%)$ reported that it was other family members who made decisions on spending money without their involvement. Moreover, as shown in Figure 7.1, marital status differences were negligible among young women but moderate among young men: $78 \%$ versus $70 \%$ of married and unmarried young men, respectively, made this decision independently. Rural-urban differences were narrow, with urban youth just slightly more likely than rural youth to make independent decisions about spending money; $73 \%$ versus $68 \%$ among young men, and $46 \%$ versus $42 \%$ among young women.

Even fewer youth were involved in making decisions about the purchase of clothes for themselves, and gender differences were particularly pronounced. For example, while 59\% of young men decided on their own about purchasing clothes, only $28 \%$ of young women did so. A sizeable proportion of young women (about onequarter), but only $14 \%$ of young men, reported that they did not have any say in decisions to buy clothes for themselves, and that it was other family members who made this decision for them. Differences by marital status were observed among young men but not young women (see also Figure 7.1). More married 
Table 7.1: Decision-making

Percent distribution of youth by participation in decision-making on selected matters, according to residence, Tamil Nadu, 2006

\begin{tabular}{|c|c|c|c|c|c|c|}
\hline Participation in decision-making (\%) & $\begin{array}{c}\mathrm{M} \\
15-24\end{array}$ & $\begin{array}{c}\mathrm{W} \\
15-24\end{array}$ & $\begin{array}{c}\text { MM } \\
15-29\end{array}$ & $\begin{array}{c}\text { MW } \\
15-24\end{array}$ & $\begin{array}{c}\text { UM } \\
15-24\end{array}$ & $\begin{array}{c}\text { UW } \\
15-24\end{array}$ \\
\hline \multicolumn{7}{|c|}{ A. Choice of friends } \\
\hline \multicolumn{7}{|c|}{ Combined } \\
\hline Respondent only & 92.8 & 89.4 & 94.7 & 87.9 & 92.7 & 90.4 \\
\hline Jointly with others & 2.2 & 6.0 & 1.4 & 6.3 & 2.3 & 5.7 \\
\hline Others only & 5.0 & 4.6 & 3.9 & 5.8 & 5.0 & 3.9 \\
\hline Number of respondents & 1,913 & 5,008 & 1,322 & 2,007 & 1,666 & 3,001 \\
\hline \multicolumn{7}{|c|}{ Urban } \\
\hline Respondent only & 93.5 & 89.8 & 97.2 & 89.0 & 93.6 & 90.3 \\
\hline Jointly with others & 2.2 & 6.4 & 0.6 & 6.3 & 2.3 & 6.4 \\
\hline Others only & 4.3 & 3.8 & 2.2 & 4.7 & 4.1 & 3.3 \\
\hline Number of respondents & 890 & 2,151 & 653 & 804 & 789 & 1,347 \\
\hline \multicolumn{7}{|c|}{ Rural } \\
\hline Respondent only & 92.3 & 89.0 & 92.9 & 87.2 & 91.9 & 90.4 \\
\hline Jointly with others & 2.3 & 5.7 & 1.9 & 6.3 & 2.4 & 5.2 \\
\hline Others only & 5.4 & 5.3 & 5.1 & 6.5 & 5.7 & 4.4 \\
\hline Number of respondents & 1,023 & 2,857 & 669 & 1,203 & 877 & 1,654 \\
\hline \multicolumn{7}{|c|}{ B. Spending money } \\
\hline \multicolumn{7}{|c|}{ Combined } \\
\hline Respondent only & 70.2 & 43.5 & 78.0 & 44.5 & 69.8 & 42.9 \\
\hline Jointly with others & 19.9 & 33.9 & 16.6 & 33.0 & 20.0 & 34.5 \\
\hline Others only & 9.9 & 22.6 & 5.4 & 22.5 & 10.2 & 22.7 \\
\hline Number of respondents & 1,913 & 5,008 & 1,322 & 2,007 & 1,666 & 3,001 \\
\hline \multicolumn{7}{|c|}{ Urban } \\
\hline Respondent only & 73.2 & 45.7 & 82.7 & 47.0 & 73.0 & 45.0 \\
\hline Jointly with others & 17.5 & 33.2 & 14.7 & 32.1 & 17.4 & 33.9 \\
\hline Others only & 9.3 & 21.0 & 2.6 & 20.9 & 9.6 & 21.1 \\
\hline Number of respondents & 890 & 2,151 & 653 & 804 & 789 & 1,347 \\
\hline \multicolumn{7}{|c|}{ Rural } \\
\hline Respondent only & 67.8 & 41.7 & 74.8 & 42.9 & 67.2 & 40.9 \\
\hline Jointly with others & 21.7 & 34.4 & 17.8 & 33.6 & 22.1 & 35.0 \\
\hline Others only & 10.5 & 23.9 & 7.3 & 23.5 & 10.7 & 24.1 \\
\hline Number of respondents & 1,023 & 2,857 & 669 & 1,203 & 877 & 1,654 \\
\hline
\end{tabular}


Table 7.1: (Cont'd)

\begin{tabular}{|c|c|c|c|c|c|c|}
\hline Participation in decision-making (\%) & $\begin{array}{c}\text { M } \\
15-24\end{array}$ & $\begin{array}{c}\text { W } \\
15-24\end{array}$ & $\begin{array}{c}\text { MM } \\
15-29\end{array}$ & $\begin{array}{c}\text { MW } \\
15-24\end{array}$ & $\begin{array}{c}\text { UM } \\
15-24\end{array}$ & $\begin{array}{c}\text { UW } \\
15-24\end{array}$ \\
\hline \multicolumn{7}{|c|}{ C. Buying clothes for oneself } \\
\hline \multicolumn{7}{|c|}{ Combined } \\
\hline Respondent only & 58.9 & 28.0 & 72.1 & 30.1 & 57.8 & 26.7 \\
\hline Jointly with others & 27.4 & 46.2 & 21.0 & 44.8 & 27.9 & 47.1 \\
\hline Others only & 13.7 & 25.8 & 6.9 & 25.1 & 14.3 & 26.3 \\
\hline Number of respondents & 1,913 & 5,008 & 1,322 & 2,007 & 1,666 & 3,001 \\
\hline \multicolumn{7}{|c|}{ Urban } \\
\hline Respondent only & 60.6 & 33.1 & 75.1 & 34.5 & 60.5 & 32.2 \\
\hline Jointly with others & 24.6 & 44.4 & 19.3 & 43.9 & 24.2 & 44.7 \\
\hline Others only & 14.8 & 22.5 & 5.5 & 21.6 & 15.3 & 23.1 \\
\hline Number of respondents & 890 & 2,151 & 653 & 804 & 789 & 1,347 \\
\hline \multicolumn{7}{|c|}{ Rural } \\
\hline Respondent only & 57.5 & 24.0 & 70.1 & 27.2 & 55.7 & 21.7 \\
\hline Jointly with others & 29.7 & 47.6 & 22.1 & 45.4 & 30.8 & 49.2 \\
\hline Others only & 12.9 & 28.3 & 7.8 & 27.4 & 13.5 & 29.1 \\
\hline Number of respondents & 1,023 & 2,857 & 669 & 1,203 & 877 & 1,654 \\
\hline
\end{tabular}

Note: All Ns are unweighted. Column totals may not equal 100\% due to missing cases or "don't know" responses.

Figure 7.1: Percent distribution of youth by participation in decision-making on selected matters, Tamil Nadu, 2006
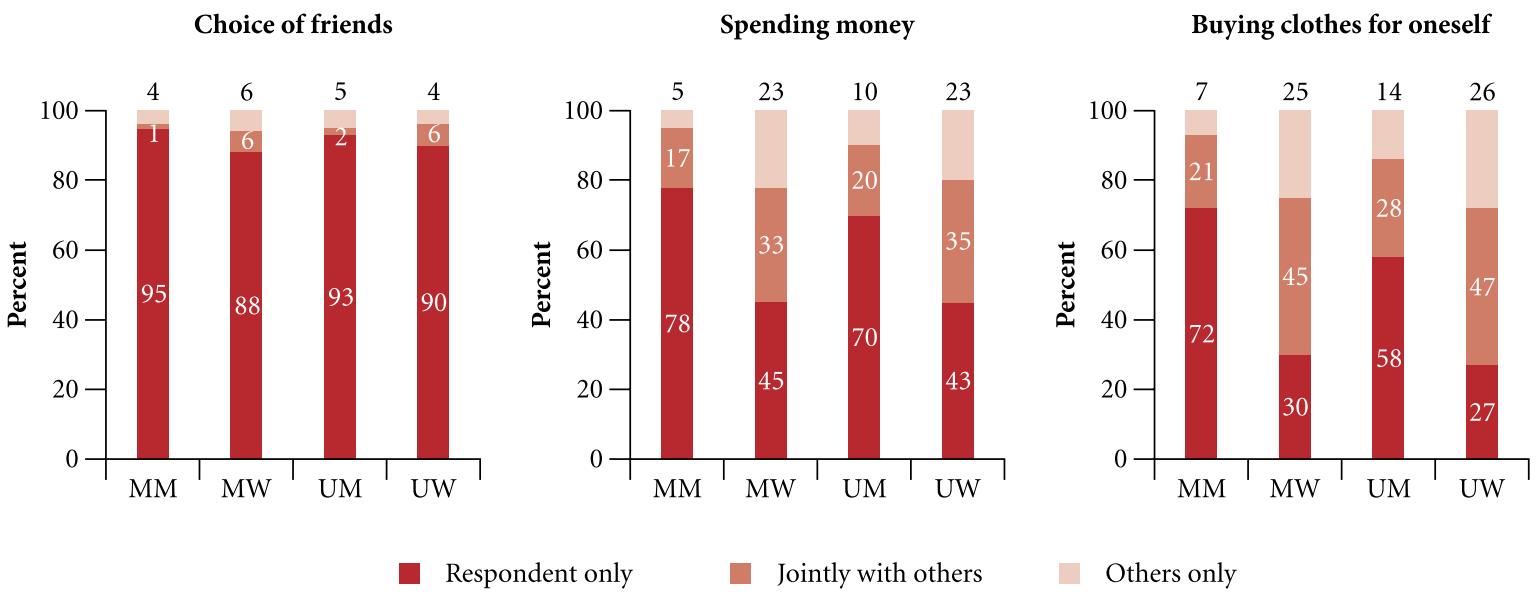

than unmarried young men ( $72 \%$ versus $58 \%$ ) reported that they decided on their own about the purchase of clothes; conversely, fewer married than unmarried young men ( $7 \%$ and $14 \%$, respectively) reported that they did not have any say in the purchase of clothes. Finally, rural-urban differences suggest that urban young women were more likely than their rural counterparts to make independent decisions relating to the purchase of clothes (33\% versus $24 \%$ ); differences were, however, mild among young men $(61 \%$ and $58 \%$, respectively). 
In order to assess the extent to which youth had independent decision-making authority on all three matters, Table 7.2 presents the percentage of youth who reported that they independently made decisions on choice of friends, spending money and purchase of clothes. In total, $52 \%$ of young men compared to $22 \%$ of young women reported independent decision-making on all three issues. Differences by marital status were negligible among young women but wide among young men; $65 \%$ of married young men compared to $51 \%$ of unmarried young men reported independent decision-making on all three issues. Rural-urban differences suggest that urban youth were more likely than rural youth to make decisions independently on all three issues.

Table 7.2 also presents combined responses on independent decision-making by selected background characteristics. Findings reveal that independent decision-making on all three matters was indeed higher among older than younger respondents, irrespective of sex, marital status or rural-urban residence. Differences by religion were narrow and inconsistent. Caste-wise differences were negligible, except that urban young men belonging to scheduled castes were somewhat less likely than those belonging to other backward castes to exercise independent decision-making on all three issues.

Table 7.2: Decision-making autonomy by selected background characteristics

Percentage of youth who independently made decisions on choice of friends, spending money and buying clothes for themselves by selected background characteristics, according to residence, Tamil Nadu, 2006

\begin{tabular}{|c|c|c|c|c|c|c|}
\hline Background characteristics (\%) & $\begin{array}{c}\mathrm{M} \\
15-24\end{array}$ & $\begin{array}{c}\mathrm{W} \\
15-24\end{array}$ & $\begin{array}{c}\text { MM } \\
15-29\end{array}$ & $\begin{array}{c}\text { MW } \\
15-24\end{array}$ & $\begin{array}{c}\text { UM } \\
15-24\end{array}$ & $\begin{array}{c}\text { UW } \\
15-24\end{array}$ \\
\hline \multicolumn{7}{|c|}{ Combined } \\
\hline Age (years) & & & & & & \\
\hline $15-19$ & 41.0 & 18.3 & * & 20.9 & 41.0 & 18.0 \\
\hline $20-24$ & 62.0 & 25.2 & 63.1 & 24.5 & 62.0 & 26.3 \\
\hline $25-29$ & NA & NA & 65.2 & NA & NA & NA \\
\hline \multicolumn{7}{|l|}{ Religion } \\
\hline Hindu & 51.9 & 22.4 & 64.4 & 23.8 & 50.9 & 21.5 \\
\hline Muslim & 49.4 & 18.0 & 71.8 & 24.7 & 47.3 & 12.2 \\
\hline Other ${ }^{1}$ & 53.2 & 22.1 & $(61.5)$ & 26.5 & 52.8 & 20.6 \\
\hline \multicolumn{7}{|l|}{ Caste } \\
\hline SC & 50.6 & 20.5 & 63.9 & 23.0 & 48.4 & 18.7 \\
\hline $\mathrm{OBC}$ & 51.6 & 22.4 & 64.5 & 24.1 & 50.7 & 21.3 \\
\hline \multicolumn{7}{|l|}{ Educational level (years) } \\
\hline None $^{2}$ & 85.7 & 14.9 & 81.5 & 16.0 & $(76.0)$ & 10.9 \\
\hline $1-7$ & 53.8 & 17.0 & 66.0 & 20.4 & 53.3 & 12.2 \\
\hline $8-11$ & 45.4 & 19.3 & 61.2 & 23.9 & 44.2 & 16.6 \\
\hline 12 and above & 59.8 & 32.8 & 63.1 & 35.2 & 59.7 & 32.0 \\
\hline \multicolumn{7}{|l|}{ Worked in last 12 months } \\
\hline Yes & 56.8 & 21.3 & 64.6 & 23.7 & 56.0 & 20.1 \\
\hline No & 43.4 & 22.5 & * & 24.1 & 43.4 & 21.2 \\
\hline \multicolumn{7}{|l|}{ Wealth quintile } \\
\hline First & 48.9 & 16.3 & 59.3 & 17.6 & 46.2 & 15.1 \\
\hline Second & 48.0 & 17.9 & 63.9 & 22.3 & 46.2 & 14.8 \\
\hline Third & 53.6 & 21.5 & 69.0 & 25.1 & 52.0 & 18.8 \\
\hline Fourth & 57.0 & 20.7 & 65.4 & 23.8 & 56.9 & 18.8 \\
\hline Fifth & 49.9 & 31.9 & 64.2 & 30.4 & 49.3 & 32.6 \\
\hline Total & 51.8 & 22.1 & 64.7 & 24.0 & 50.7 & 20.9 \\
\hline
\end{tabular}


Table 7.2: (Cont'd)

\begin{tabular}{|c|c|c|c|c|c|c|}
\hline Background characteristics (\%) & $\begin{array}{c}\mathrm{M} \\
15-24\end{array}$ & $\begin{array}{c}\text { W } \\
15-24\end{array}$ & $\begin{array}{c}\mathrm{MM} \\
15-29\end{array}$ & $\begin{array}{c}\text { MW } \\
15-24\end{array}$ & $\begin{array}{c}\text { UM } \\
15-24\end{array}$ & $\begin{array}{c}\text { UW } \\
15-24\end{array}$ \\
\hline \multicolumn{7}{|c|}{ Urban } \\
\hline \multicolumn{7}{|l|}{ Age (years) } \\
\hline $15-19$ & 41.6 & 22.3 & * & 23.7 & 41.6 & 22.1 \\
\hline $20-24$ & 66.1 & 29.5 & 59.5 & 28.8 & 67.3 & 30.6 \\
\hline $25-29$ & NA & NA & 71.7 & NA & NA & NA \\
\hline \multicolumn{7}{|l|}{ Religion } \\
\hline Hindu & 54.6 & 27.0 & 68.6 & 27.9 & 54.3 & 26.5 \\
\hline Muslim & 48.5 & 22.0 & 77.4 & 30.5 & 46.7 & 15.4 \\
\hline Other $^{1}$ & $(63.6)$ & 23.1 & * & $(29.4)$ & $(62.1)$ & 20.8 \\
\hline \multicolumn{7}{|l|}{ Caste } \\
\hline SC & 49.7 & 24.6 & 65.3 & 31.0 & 48.6 & 21.0 \\
\hline $\mathrm{OBC}$ & 56.2 & 26.3 & 71.6 & 27.3 & 55.7 & 25.7 \\
\hline \multicolumn{7}{|l|}{ Educational level (years) } \\
\hline None $^{2}$ & * & 15.3 & * & 15.8 & * & * \\
\hline $1-7$ & 54.5 & 19.9 & 71.4 & 24.5 & 55.1 & 14.5 \\
\hline $8-11$ & 47.1 & 23.2 & 67.8 & 27.3 & 45.8 & 20.7 \\
\hline 12 and above & 64.3 & 34.8 & 67.9 & 38.0 & 64.3 & 33.7 \\
\hline \multicolumn{7}{|l|}{ Worked in last 12 months } \\
\hline Yes & 62.4 & 25.6 & 69.8 & 26.4 & 62.9 & 25.2 \\
\hline No & 43.2 & 26.4 & * & 28.6 & 43.2 & 25.0 \\
\hline \multicolumn{7}{|l|}{ Wealth quintile } \\
\hline First & 48.1 & 18.9 & 60.0 & 20.3 & 47.8 & 17.7 \\
\hline Second & 58.6 & 18.8 & 71.9 & 21.7 & 57.7 & 16.9 \\
\hline Third & 56.1 & 25.5 & 72.2 & 30.6 & 56.6 & 21.8 \\
\hline Fourth & 58.5 & 21.7 & 70.8 & 25.9 & 58.5 & 19.4 \\
\hline Fifth & 50.0 & 34.2 & 68.6 & 33.8 & 49.5 & 34.3 \\
\hline Total & 54.5 & 26.2 & 69.8 & 28.2 & 54.0 & 25.1 \\
\hline \multicolumn{7}{|c|}{ Rural } \\
\hline \multicolumn{7}{|l|}{ Age (years) } \\
\hline $15-19$ & 40.5 & 15.2 & * & 19.7 & 40.5 & 14.4 \\
\hline $20-24$ & 58.8 & 21.8 & 64.5 & 21.5 & 57.3 & 22.5 \\
\hline $25-29$ & NA & NA & 60.4 & NA & NA & NA \\
\hline \multicolumn{7}{|l|}{ Religion } \\
\hline Hindu & 49.9 & 19.1 & 61.8 & 21.4 & 48.2 & 17.4 \\
\hline Muslim & * & 6.1 & * & $(9.8)$ & * & (2.4) \\
\hline Other $^{1}$ & $(44.7)$ & 21.2 & $(44.4)$ & $(23.5)$ & $(45.2)$ & 20.4 \\
\hline \multicolumn{7}{|l|}{ Caste } \\
\hline SC & 51.1 & 18.3 & 63.2 & 19.5 & 48.4 & 17.3 \\
\hline OBC & 47.7 & 19.0 & 59.1 & 21.7 & 46.4 & 17.1 \\
\hline \multicolumn{7}{|l|}{ Educational level (years) } \\
\hline None $^{2}$ & $(81.8)$ & 14.8 & 80.6 & 16.7 & * & $(9.8)$ \\
\hline $1-7$ & 53.2 & 15.2 & 62.3 & 18.0 & 52.3 & 11.0 \\
\hline $8-11$ & 44.3 & 16.6 & 56.6 & 21.5 & 43.2 & 13.7 \\
\hline 12 and above & 54.7 & 30.1 & 57.3 & 31.5 & 54.2 & 29.6 \\
\hline \multicolumn{7}{|l|}{ Worked in last 12 months } \\
\hline Yes & 52.9 & 19.4 & 61.1 & 23.0 & 50.9 & 17.2 \\
\hline No & 43.5 & 18.4 & * & 20.0 & 43.5 & 17.1 \\
\hline \multicolumn{7}{|l|}{ Wealth quintile } \\
\hline First & 49.1 & 15.7 & 59.4 & 17.0 & 45.7 & 14.5 \\
\hline Second & 44.5 & 17.6 & 61.0 & 22.3 & 42.7 & 14.1 \\
\hline Third & 51.7 & 19.0 & 66.8 & 21.8 & 49.1 & 16.8 \\
\hline Fourth & 55.3 & 19.4 & 58.0 & 21.7 & 55.1 & 18.0 \\
\hline Fifth & 49.0 & 26.1 & $(52.8)$ & 23.1 & 49.5 & 27.5 \\
\hline Total & 49.7 & 18.8 & 61.1 & 21.1 & 48.1 & 17.2 \\
\hline
\end{tabular}

Note: ${ }^{*}$ Percentage not shown, based on fewer than 25 unweighted cases. ( ) Based on 25-49 unweighted cases. NA: Not applicable. OBC: Other backward caste. SC: Scheduled caste. ${ }^{1}$ Includes Christian, Buddhist, Neo-Buddhist, Sikh, Jain, Jewish, Parsi/Zoroastrian and no specified religion. ${ }^{2}$ Includes non-literate and literate with no formal schooling. 
Independent decision-making increased with level of education attained only among young women. For example, $33 \%$ of young women with 12 or more years of schooling decided independently on all three issues, compared with $15 \%$ of non-literate young women or those without any formal education. Among young men, in contrast, it was the few uneducated men in the sample who were most likely to report independent decision-making on all three matters $(86 \%)$ and those with $8-11$ years of schooling who were least likely to so report $(45 \%)$. These patterns held true, irrespective of marital status or rural-urban residence of respondents.

Similarly, decision-making increased with household economic status only among young women: the proportion of young women who made independent decisions about all three matters increased from $16 \%$ among those in the poorest (first) quintile to $32 \%$ in the wealthiest (fifth) quintile.

In contrast to the pattern described above, the association between economic activity status and independent decision-making was noted only among young men. Young men who had worked in the last 12 months, irrespective of marital status or rural-urban residence, were more likely than others to make decisions independently ( $57 \%$ versus $43 \%$ ).

\subsection{Freedom of movement}

Freedom of movement was assessed only for all young women and unmarried young men because married young men generally have unrestricted mobility. Mobility was measured by a number of questions relating to whether the respondent was permitted to visit places within and outside the village (rural) or neighbourhood (urban) unescorted, only if accompanied by someone else, or was not permitted to visit the place at all. Places within the village or neighbourhood included a shop/market, the home of a friend/relative and a community programme. Places outside the village or neighbourhood included the home of a relative or friend, a movie theatre, video parlour or other place of entertainment and a community programme. Finally, all respondents were asked if they could go to a health facility unescorted if required. Table 7.3 and Figure 7.2 report findings relating to mobility.

Findings confirm that, by and large, more youth had freedom of movement to visit such locations within the village or neighbourhood as a shop or market, or the home of a friend or relative than any other location within or outside the area of residence. However, freedom of movement to visit even these places within the village or neighbourhood was not universal, and young women's mobility was more restricted than that of unmarried young men. For example, findings suggest that $73 \%$ of married and unmarried young women could go unescorted to a shop or market within the village or neighbourhood compared with $89 \%$ of unmarried young men. Mobility to attend programmes within the village or neighbourhood unescorted was similarly restricted among young women: only about $10 \%$ of young women ( $12 \%$ and just $7 \%$, respectively, of the married and unmarried) were allowed to attend such programmes unescorted compared with 41\% of unmarried young men. Rural-urban differences in freedom of movement were negligible for both young men and women.

Young women's mobility to visit places outside the village or neighbourhood unescorted was far more curtailed than that of unmarried young men. For example, just $29 \%$ of young women reported that they could visit a friend or relative outside the village or neighbourhood unescorted, only $3-4 \%$ were permitted to visit a place of entertainment and/or to attend a programme conducted outside their village or neighbourhood unescorted, and between $10 \%$ and $16 \%$ were not allowed to visit any of these locations unescorted. In contrast, $68 \%$ of unmarried young men reported that they could visit a friend or relative outside the village or neighbourhood unescorted and between $35 \%$ and $42 \%$ were free to visit unescorted nearby villages or 
neighbourhoods for entertainment or to attend programmes. Rural-urban differences were negligible among young women; however, larger proportions of unmarried young men in urban than in rural settings reported freedom to visit locations outside the village/neighbourhood.

With regard to freedom to visit a health facility unescorted, findings, presented in Table 7.3, similarly reflect women's restricted mobility: just $12 \%$ of young women, compared with $42 \%$ of unmarried young men, reported that they could do so. Differences by marital status indicate that a larger proportion of married

Table 7.3: Freedom of movement

Percent distribution of youth by extent of freedom to visit selected locations within or outside the village/neighbourhood, according to residence, Tamil Nadu, 2006

\begin{tabular}{|c|c|c|c|c|c|c|c|c|c|c|c|c|}
\hline \multirow[t]{2}{*}{ Mobility indicators (\%) } & $\begin{array}{c}W \\
15-24 \\
\end{array}$ & $\begin{array}{c}\text { MW } \\
15-24 \\
\end{array}$ & $\begin{array}{c}\text { UW } \\
15-24 \\
\end{array}$ & $\begin{array}{c}\text { UM } \\
15-24 \\
\end{array}$ & $\begin{array}{c}W \\
15-24 \\
\end{array}$ & $\begin{array}{c}\text { MW } \\
15-24 \\
\end{array}$ & $\begin{array}{c}\text { UW } \\
15-24 \\
\end{array}$ & $\begin{array}{c}\text { UM } \\
15-24 \\
\end{array}$ & $\begin{array}{c}W \\
15-24 \\
\end{array}$ & $\begin{array}{c}\text { MW } \\
15-24 \\
\end{array}$ & $\begin{array}{c}\text { UW } \\
15-24 \\
\end{array}$ & $\begin{array}{c}\text { UM } \\
15-24 \\
\end{array}$ \\
\hline & \multicolumn{4}{|c|}{ Combined } & \multicolumn{4}{|c|}{ Urban } & \multicolumn{4}{|c|}{ Rural } \\
\hline \multirow{2}{*}{\multicolumn{13}{|c|}{$\begin{array}{l}\text { Permitted to: } \\
\text { Visit shop/market within } \\
\text { village/neighbourhood }\end{array}$}} \\
\hline & & & & & & & & & & & & \\
\hline Alone & 72.9 & 73.4 & 72.5 & 88.6 & 73.4 & 74.7 & 72.5 & 89.3 & 72.5 & 72.5 & 72.6 & 88.1 \\
\hline Only with someone else & 14.8 & 15.6 & 14.2 & 10.3 & 16.1 & 16.0 & 16.1 & 9.6 & 13.7 & 15.4 & 12.5 & 10.7 \\
\hline Not allowed & 12.4 & 11.0 & 13.3 & 1.1 & 10.6 & 9.3 & 11.4 & 1.1 & 13.8 & 12.1 & 15.0 & 1.2 \\
\hline \multicolumn{13}{|l|}{$\begin{array}{l}\text { Visit friend/relative within } \\
\text { village/neighbourhood }\end{array}$} \\
\hline Alone & 67.4 & 65.2 & 68.8 & 79.5 & 65.5 & 63.0 & 66.9 & 81.8 & 68.9 & 66.8 & 70.6 & 77.6 \\
\hline Only with someone else & 23.6 & 26.2 & 21.9 & 19.9 & 25.7 & 28.4 & 24.2 & 17.5 & 22.0 & 24.8 & 19.9 & 21.9 \\
\hline Not allowed & 8.9 & 8.5 & 9.2 & 0.6 & 8.8 & 8.6 & 8.9 & 0.7 & 9.1 & 8.4 & 9.5 & 0.5 \\
\hline \multicolumn{13}{|l|}{$\begin{array}{l}\text { Attend programme within } \\
\text { village/neighbourhood }\end{array}$} \\
\hline Alone & 9.5 & 12.3 & 7.7 & 41.4 & 7.2 & 9.4 & 5.9 & 43.2 & 11.3 & 14.3 & 9.2 & 40.0 \\
\hline Only with someone else & 78.9 & 76.1 & 80.7 & 54.9 & 81.0 & 78.4 & 82.6 & 53.9 & 77.1 & 74.5 & 79.1 & 55.7 \\
\hline Not allowed & 11.6 & 11.6 & 11.6 & 3.7 & 11.7 & 12.2 & 11.5 & 2.9 & 11.5 & 11.3 & 11.7 & 4.2 \\
\hline \multicolumn{13}{|l|}{$\begin{array}{l}\text { Visit friend/relative outside } \\
\text { village/neighbourhood }\end{array}$} \\
\hline Alone & 29.1 & 28.7 & 29.4 & 67.8 & 29.6 & 29.4 & 29.7 & 71.4 & 28.7 & 28.2 & 29.0 & 64.9 \\
\hline Only with someone else & 60.5 & 62.0 & 59.5 & 30.8 & 60.5 & 62.1 & 59.7 & 27.5 & 60.5 & 62.0 & 59.5 & 33.4 \\
\hline Not allowed & 10.4 & 9.3 & 11.1 & 1.4 & 9.8 & 8.5 & 10.6 & 1.1 & 10.8 & 9.9 & 11.5 & 1.7 \\
\hline \multicolumn{13}{|l|}{$\begin{array}{l}\text { Visit nearby village/ } \\
\text { neighbourhood for } \\
\text { entertainment }\end{array}$} \\
\hline Alone & 4.3 & 5.0 & 3.9 & 41.6 & 4.4 & 4.6 & 4.3 & 47.0 & 4.3 & 5.4 & 3.4 & 37.2 \\
\hline Only with someone else & 81.3 & 83.3 & 79.9 & 55.0 & 85.1 & 85.6 & 84.7 & 50.2 & 78.3 & 81.7 & 75.7 & 58.9 \\
\hline Not allowed & 14.4 & 11.7 & 16.2 & 3.4 & 10.6 & 9.9 & 11.0 & 2.8 & 17.5 & 12.9 & 20.8 & 3.9 \\
\hline \multicolumn{13}{|l|}{$\begin{array}{l}\text { Attend programme outside } \\
\text { village/neighbourhood }\end{array}$} \\
\hline Alone & 3.4 & 4.3 & 2.9 & 35.2 & 3.6 & 4.4 & 3.1 & 38.3 & 3.3 & 4.3 & 2.6 & 32.6 \\
\hline Only with someone else & 81.1 & 79.7 & 81.9 & 60.3 & 80.7 & 79.4 & 81.6 & 57.8 & 81.3 & 80.0 & 82.3 & 62.2 \\
\hline Not allowed & 15.5 & 15.9 & 15.2 & 4.5 & 15.7 & 16.2 & 15.3 & 3.9 & 15.4 & 15.8 & 15.1 & 5.1 \\
\hline \multicolumn{13}{|l|}{ Visit health facility } \\
\hline Alone & 11.8 & 17.3 & 8.1 & 41.9 & 11.5 & 17.3 & 8.1 & 42.2 & 12.0 & 17.4 & 8.1 & 41.6 \\
\hline Only with someone else & 87.0 & 81.5 & 90.6 & 57.1 & 87.7 & 81.8 & 91.1 & 57.1 & 86.4 & 81.3 & 90.1 & 57.1 \\
\hline Not allowed & 1.2 & 1.1 & 1.3 & 1.0 & 0.8 & 0.9 & 0.8 & 0.7 & 1.6 & 1.3 & 1.8 & 1.2 \\
\hline Number of respondents & 5,008 & 2,007 & 3,001 & 1,666 & 2,151 & 804 & 1,347 & 789 & 2,857 & 1,203 & 1,654 & 877 \\
\hline
\end{tabular}

Note: All Ns are unweighted. Column totals may not equal 100\% due to missing cases or "don't know" responses. Questions regarding freedom of movement were not asked of married males, as their mobility is generally unrestricted. 
Figure 7.2: Percentage of youth allowed to visit selected places within and outside the village/ neighbourhood unescorted, Tamil Nadu, 2006

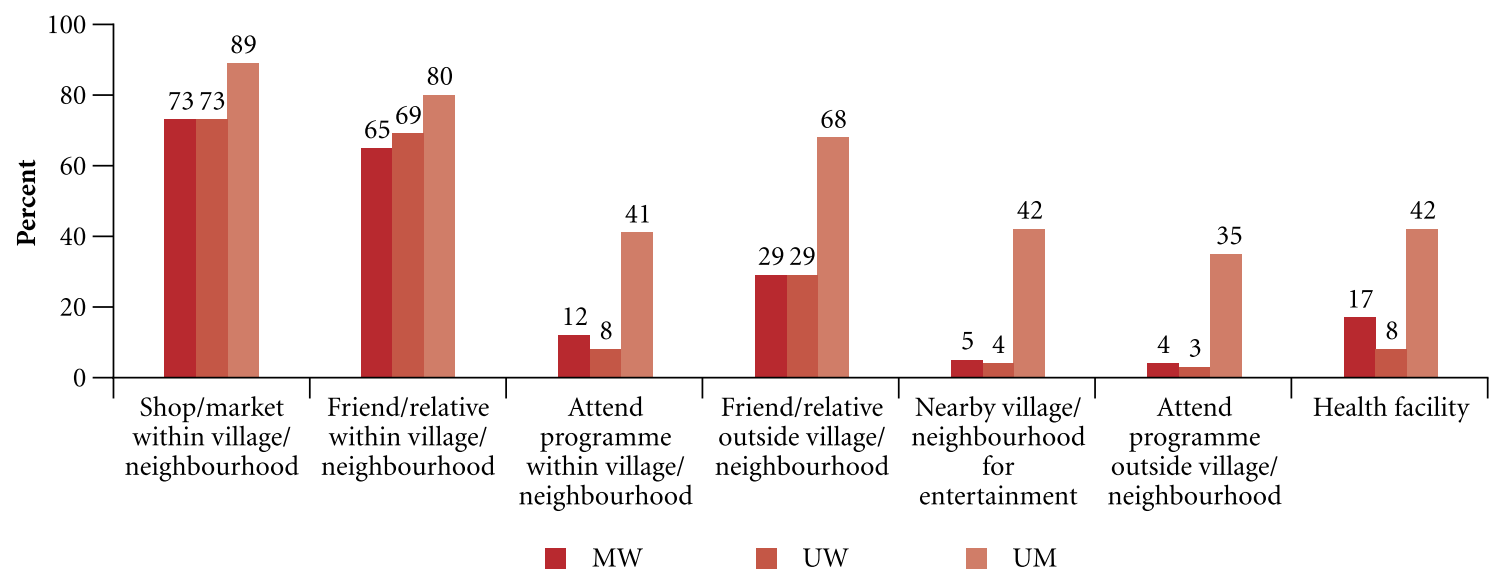

Note: Questions regarding freedom of movement were not asked of married males, as their mobility is generally unrestricted.

than unmarried young women reported freedom to visit a health facility unescorted (17\% versus $8 \%$ ). Rural-urban differentials were not observed.

Summary measures have been created from the range of questions relating to freedom to visit places unescorted within and outside the village or neighbourhood; namely, the percentage who were free to visit at least one place within the village or neighbourhood; at least one place outside the village or neighbourhood; and a health facility. Table 7.4 presents percentages of youth reporting each of these summary measures of freedom of movement by selected socio-economic and demographic characteristics.

As shown in Table 7.4, 93\% and 71\% of unmarried young men had freedom to visit unescorted at least one place within and outside the village or neighbourhood, respectively. In comparison, only $79 \%$ and $30 \%$ of young women, respectively, reported so. Marital status differences and rural-urban differences among young women were negligible. Among unmarried young men in contrast, differences were negligible with regard to freedom of movement within the village or neighbourhood, but those in urban settings were more likely than those in rural settings to report freedom to visit at least one place outside the village or neighbourhood unescorted.

Findings reveal that among unmarried young men, socio-demographic differentials were narrow in the case of mobility within the village. Freedom to visit places outside the village and to visit a health facility unescorted increased with age and work status and less consistently, with education and household economic status.

Among young women, in contrast, socio-demographic differentials were noted for several indicators of mobility. For example, freedom of movement within the village or neighbourhood was more restricted among Muslim women and those from other backward castes than other women. Moreover, mobility within the village was considerably more likely to be reported by those engaged in economic activity than those who were not. 
Table 7.4: Freedom of movement by selected background characteristics

Percentage of youth who could visit various places unescorted by selected background characteristics, according to residence, Tamil Nadu, 2006

\begin{tabular}{|c|c|c|c|c|c|c|c|c|c|c|c|c|}
\hline \multirow[t]{2}{*}{$\begin{array}{l}\text { Background } \\
\text { characteristics (\%) }\end{array}$} & $\begin{array}{c}W \\
15-24\end{array}$ & $\begin{array}{c}\text { MW } \\
15-24\end{array}$ & $\begin{array}{c}\text { UW } \\
15-24\end{array}$ & $\begin{array}{c}\text { UM } \\
15-24\end{array}$ & $\begin{array}{c}\text { W } \\
15-24\end{array}$ & $\begin{array}{c}\text { MW } \\
15-24\end{array}$ & $\begin{array}{c}\text { UW } \\
15-24\end{array}$ & $\begin{array}{c}\text { UM } \\
15-24\end{array}$ & $\begin{array}{c}W \\
15-24\end{array}$ & $\begin{array}{c}\text { MW } \\
15-24\end{array}$ & $\begin{array}{c}\text { UW } \\
15-24\end{array}$ & $\begin{array}{c}\text { UM } \\
15-24\end{array}$ \\
\hline & \multicolumn{4}{|c|}{ Within village/neighbourhood } & \multicolumn{4}{|c|}{ Outside village/neighbourhood } & \multicolumn{4}{|c|}{ Health facility } \\
\hline \multicolumn{13}{|c|}{ Combined } \\
\hline \multicolumn{13}{|l|}{ Age (years) } \\
\hline 15-19 & 77.6 & 75.1 & 77.9 & 92.3 & 26.6 & 23.4 & 27.1 & 66.1 & 6.4 & 7.8 & 6.1 & 36.5 \\
\hline $20-24$ & 79.5 & 78.7 & 80.8 & 93.7 & 33.0 & 31.3 & 35.7 & 76.4 & 16.3 & 19.2 & 11.6 & 47.9 \\
\hline \multicolumn{13}{|l|}{ Religion } \\
\hline Hindu & 80.9 & 80.9 & 81.0 & 93.0 & 31.2 & 31.3 & 31.1 & 71.0 & 12.4 & 18.4 & 8.4 & 41.8 \\
\hline Muslim & 44.2 & 44.5 & 43.9 & 95.9 & 14.8 & 15.1 & 14.6 & 73.0 & 4.5 & 6.1 & 3.0 & 41.9 \\
\hline Other $^{1}$ & 80.2 & 76.5 & 81.3 & 88.9 & 28.2 & 26.5 & 29.0 & 66.7 & 10.3 & 14.7 & 8.8 & 44.4 \\
\hline \multicolumn{13}{|l|}{ Caste } \\
\hline SC & 85.7 & 85.1 & 86.1 & 94.9 & 32.0 & 34.0 & 30.6 & 73.0 & 13.1 & 20.1 & 8.4 & 44.9 \\
\hline $\mathrm{OBC}$ & 75.9 & 75.5 & 76.1 & 92.5 & 28.9 & 28.5 & 29.2 & 70.4 & 11.2 & 16.4 & 7.9 & 40.9 \\
\hline \multicolumn{13}{|c|}{ Educational level (years) } \\
\hline None $^{2}$ & 79.0 & 82.6 & 66.1 & $(91.7)$ & 28.2 & 32.0 & 14.5 & $(58.3)$ & 10.5 & 11.9 & 5.5 & $(40.0)$ \\
\hline $1-7$ & 76.3 & 78.4 & 73.4 & 92.0 & 22.7 & 27.5 & 16.3 & 75.1 & 12.3 & 17.2 & 5.7 & 46.7 \\
\hline $8-11$ & 77.8 & 77.7 & 77.9 & 93.3 & 27.1 & 27.9 & 26.7 & 65.1 & 10.5 & 17.3 & 6.5 & 37.7 \\
\hline 12 and above & 81.9 & 76.2 & 83.8 & 93.2 & 41.6 & 38.9 & 42.5 & 79.7 & 14.0 & 21.0 & 11.8 & 46.8 \\
\hline \multicolumn{13}{|c|}{ Worked in last 12 months } \\
\hline Yes & 81.8 & 81.8 & 81.8 & 93.6 & 31.7 & 33.4 & 30.9 & 73.6 & 13.9 & 21.1 & 10.2 & 45.8 \\
\hline No & 77.0 & 76.7 & 77.2 & 92.0 & 29.2 & 28.6 & 29.6 & 67.2 & 10.7 & 15.9 & 6.8 & 36.4 \\
\hline \multicolumn{13}{|l|}{ Wealth quintile } \\
\hline First & 81.8 & 81.4 & 82.2 & 90.5 & 27.9 & 27.9 & 27.8 & 63.3 & 12.4 & 18.3 & 7.1 & 38.6 \\
\hline Second & 82.4 & 83.0 & 81.9 & 93.0 & 26.6 & 29.1 & 24.8 & 70.6 & 11.4 & 17.4 & 7.2 & 42.5 \\
\hline Third & 75.5 & 76.8 & 74.5 & 96.1 & 30.5 & 32.4 & 28.9 & 75.6 & 12.9 & 18.2 & 8.8 & 43.0 \\
\hline Fourth & 77.5 & 76.2 & 78.4 & 92.8 & 27.8 & 28.9 & 27.0 & 71.3 & 10.7 & 16.7 & 7.1 & 45.0 \\
\hline Fifth & 77.7 & 73.4 & 79.7 & 91.1 & 37.0 & 30.7 & 39.8 & 70.7 & 11.7 & 16.3 & 9.6 & 38.5 \\
\hline Total & 78.6 & 78.1 & 78.9 & 92.9 & 30.1 & 30.0 & 30.1 & 70.9 & 11.8 & 17.3 & 8.1 & 41.8 \\
\hline \multicolumn{13}{|c|}{ Urban } \\
\hline \multicolumn{13}{|l|}{ Age (years) } \\
\hline $15-19$ & 75.8 & 73.2 & 76.1 & 92.0 & 26.1 & 20.6 & 26.8 & 69.4 & 6.4 & 7.1 & 6.3 & 34.5 \\
\hline $20-24$ & 78.9 & 78.2 & 79.9 & 92.2 & 33.7 & 31.6 & 36.7 & 80.6 & 15.8 & 18.7 & 11.5 & 50.4 \\
\hline \multicolumn{13}{|l|}{ Religion } \\
\hline Hindu & 80.2 & 81.9 & 79.2 & 91.9 & 31.6 & 32.5 & 31.0 & 75.0 & 12.3 & 19.6 & 8.2 & 42.6 \\
\hline Muslim & 52.0 & 51.9 & 51.6 & 96.7 & 18.0 & 17.1 & 18.7 & 73.8 & 4.8 & 6.7 & 3.3 & 40.0 \\
\hline Other ${ }^{1}$ & 83.8 & $(70.6)$ & 88.5 & $(89.7)$ & 33.1 & $(26.5)$ & 36.5 & $(73.3)$ & 11.5 & $(5.9)$ & 13.5 & $(37.9)$ \\
\hline \multicolumn{13}{|l|}{ Caste } \\
\hline SC & 82.9 & 86.3 & 81.4 & 96.6 & 32.6 & 39.9 & 28.5 & 72.8 & 11.7 & 19.6 & 7.1 & 44.2 \\
\hline $\mathrm{OBC}$ & 75.8 & 75.6 & 76.0 & 91.1 & 29.1 & 28.0 & 29.7 & 75.5 & 11.3 & 16.6 & 8.1 & 42.1 \\
\hline \multicolumn{13}{|c|}{ Educational level (years) } \\
\hline None $^{2}$ & 85.9 & 91.1 & * & * & 19.4 & 21.1 & * & * & 7.0 & 7.0 & * & * \\
\hline $1-7$ & 77.7 & 83.3 & 71.3 & 92.3 & 22.5 & 28.9 & 14.5 & 78.6 & 12.5 & 18.6 & 5.2 & 48.7 \\
\hline $8-11$ & 73.2 & 73.8 & 72.8 & 92.3 & 25.9 & 28.6 & 24.2 & 67.7 & 10.0 & 16.8 & 6.3 & 37.8 \\
\hline 12 and above & 82.5 & 75.3 & 84.8 & 91.9 & 41.4 & 38.2 & 42.5 & 83.3 & 13.3 & 20.2 & 11.1 & 45.7 \\
\hline Work & & & & & & & & & & & & \\
\hline Yes & 81.4 & 81.5 & 81.3 & 92.5 & 32.7 & 34.7 & 32.1 & 76.9 & 14.7 & 24.8 & 11.5 & 45.9 \\
\hline No & 76.2 & 76.9 & 75.8 & 91.9 & 29.5 & 29.5 & 29.5 & 72.5 & 10.5 & 15.9 & 6.7 & 37.7 \\
\hline Wealth quintile & & & & & & & & & & & & \\
\hline First & 73.0 & 81.4 & 66.1 & 87.0 & 17.2 & 21.7 & 12.9 & 68.1 & 5.7 & 8.3 & 3.2 & 34.0 \\
\hline Second & 82.3 & 89.6 & 77.3 & 96.2 & 28.8 & 34.0 & 24.8 & 83.5 & 12.7 & 15.1 & 10.5 & 49.4 \\
\hline Third & 73.2 & 77.0 & 70.4 & 96.4 & 29.3 & 36.1 & 24.5 & 81.0 & 14.8 & 24.5 & 7.8 & 40.9 \\
\hline Fourth & 78.5 & 76.8 & 79.4 & 92.3 & 25.6 & 26.3 & 25.3 & 74.9 & 9.8 & 15.5 & 6.5 & 46.9 \\
\hline Fifth & 78.1 & 72.4 & 80.6 & 89.6 & 37.4 & 30.3 & 40.5 & 70.3 & 11.6 & 17.1 & 9.4 & 39.1 \\
\hline Total & 77.5 & 77.6 & 77.4 & 92.2 & 30.3 & 30.3 & 30.3 & 74.8 & 11.5 & 17.3 & 8.1 & 42.2 \\
\hline
\end{tabular}


Table 7.4: (Cont'd)

\begin{tabular}{|c|c|c|c|c|c|c|c|c|c|c|c|c|}
\hline \multirow[t]{2}{*}{$\begin{array}{l}\text { Background } \\
\text { characteristics (\%) }\end{array}$} & $\begin{array}{c}\mathrm{W} \\
15-24\end{array}$ & $\begin{array}{c}\text { MW } \\
15-24\end{array}$ & $\begin{array}{c}\text { UW } \\
15-24\end{array}$ & $\begin{array}{c}\text { UM } \\
15-24 \\
\end{array}$ & $\begin{array}{c}\text { W } \\
15-24\end{array}$ & $\begin{array}{c}\text { MW } \\
15-24\end{array}$ & $\begin{array}{c}\text { UW } \\
15-24\end{array}$ & $\begin{array}{c}\text { UM } \\
15-24 \\
\end{array}$ & $\begin{array}{c}\text { W } \\
15-24\end{array}$ & $\begin{array}{c}\text { MW } \\
15-24\end{array}$ & $\begin{array}{c}\text { UW } \\
15-24\end{array}$ & $\begin{array}{c}\text { UM } \\
15-24 \\
\end{array}$ \\
\hline & Withir & village/ & neighbo & rhood & Outsid & village & neighb & Irhood & & Health & facility & \\
\hline \multicolumn{13}{|c|}{ Rural } \\
\hline \multicolumn{13}{|l|}{ Age (years) } \\
\hline $15-19$ & 78.9 & 75.8 & 79.6 & 92.5 & 26.9 & 24.6 & 27.5 & 63.6 & 6.4 & 8.1 & 6.0 & 38.1 \\
\hline $20-24$ & 80.0 & 79.1 & 81.7 & 94.9 & 32.4 & 30.9 & 34.8 & 72.8 & 16.7 & 19.5 & 11.8 & 45.8 \\
\hline \multicolumn{13}{|l|}{ Religion } \\
\hline Hindu & 81.5 & 80.2 & 82.4 & 93.7 & 31.0 & 30.6 & 31.2 & 67.9 & 12.4 & 17.6 & 8.5 & 41.1 \\
\hline Muslim & 22.9 & $(26.8)$ & (19.0) & * & 6.0 & (9.5) & (4.8) & * & 3.6 & (4.9) & (2.4) & * \\
\hline Other $^{1}$ & 76.5 & (82.4) & 74.2 & (90.5) & 23.5 & (26.5) & 21.6 & (61.9) & 9.1 & (23.5) & 4.1 & (48.8) \\
\hline \multicolumn{13}{|l|}{ Caste } \\
\hline SC & 87.2 & 84.6 & 89.2 & 93.7 & 31.7 & 31.3 & 31.9 & 73.4 & 13.9 & 20.3 & 9.1 & 45.7 \\
\hline OBC & 75.9 & 75.5 & 76.2 & 93.8 & 28.8 & 28.9 & 28.7 & 65.9 & 11.2 & 16.1 & 7.6 & 39.7 \\
\hline \multicolumn{13}{|c|}{ Educational level(years) } \\
\hline None $^{2}$ & 76.3 & 79.0 & $(65.9)$ & * & 31.6 & 36.5 & (14.6) & * & 11.9 & 13.8 & $(4.9)$ & * \\
\hline $1-7$ & 75.5 & 76.0 & 74.7 & 91.8 & 22.9 & 26.8 & 17.2 & 73.1 & 12.0 & 16.4 & 5.7 & 45.0 \\
\hline $8-11$ & 81.1 & 80.3 & 81.5 & 93.8 & 28.1 & 27.4 & 28.4 & 63.3 & 10.8 & 17.7 & 6.8 & 37.6 \\
\hline 12 and above & 80.9 & 77.4 & 82.1 & 94.9 & 41.9 & 40.0 & 42.5 & 75.8 & 14.9 & 21.4 & 12.7 & 48.1 \\
\hline \multicolumn{13}{|c|}{ Worked in last 12 months } \\
\hline Yes & 82.0 & 81.9 & 82.2 & 94.5 & 31.3 & 33.0 & 30.3 & 71.4 & 13.5 & 20.1 & 9.5 & 45.8 \\
\hline No & 77.7 & 76.4 & 78.8 & 92.1 & 28.9 & 27.8 & 29.7 & 62.1 & 10.9 & 15.8 & 6.9 & 35.1 \\
\hline \multicolumn{13}{|l|}{ Wealth quintile } \\
\hline First & 83.9 & 81.7 & 85.9 & 91.5 & 30.4 & 29.5 & 31.2 & 61.8 & 14.0 & 20.7 & 8.0 & 40.0 \\
\hline Second & 82.4 & 80.8 & 83.6 & 91.9 & 25.9 & 27.2 & 24.8 & 66.5 & 11.1 & 18.0 & 5.9 & 40.3 \\
\hline Third & 77.0 & 76.6 & 77.1 & 95.9 & 31.0 & 30.2 & 31.7 & 71.8 & 11.7 & 14.7 & 9.5 & 44.7 \\
\hline Fourth & 76.3 & 75.6 & 77.1 & 93.4 & 30.3 & 31.8 & 29.3 & 67.3 & 11.7 & 17.9 & 7.9 & 43.4 \\
\hline Fifth & 76.3 & 75.2 & 77.0 & 95.6 & 35.7 & 31.7 & 38.2 & 72.2 & 12.0 & 14.4 & 10.1 & 36.7 \\
\hline Total & 79.5 & 78.4 & 80.3 & 93.6 & 29.9 & 29.7 & 30.0 & 67.7 & 12.0 & 17.4 & 8.1 & 41.6 \\
\hline
\end{tabular}

Note: ( ) Based on 25-49 unweighted cases. ${ }^{*}$ Percentage not shown, based on fewer than 25 unweighted cases. Questions regarding freedom of movement were not asked of married males, as their mobility is generally unrestricted. OBC: Other backward caste. SC: Scheduled caste. ${ }^{1}$ Includes Christian, Buddhist, Neo-Buddhist, Sikh, Jain, Jewish, Parsi/Zoroastrian and no specified religion. ${ }^{2}$ Includes non-literate and literate with no formal schooling.

Freedom to visit places outside the village or neighbourhood increased with age, and was more restricted among Muslim than other women. Differentials by education and household economic status were inconsistent, but patterns suggest that mobility was considerably higher among young women in the highest education category and wealthiest (fifth) quintile than in other groups. Similar patterns were by and large observed with regard to young women's freedom to visit a health facility (except that no relationship could be discerned between household economic status and mobility).

Patterns of mobility within and outside the village/neighbourhood were largely similar among married and unmarried young women. However, some differences did emerge. For example, among unmarried young women, mobility within the village/neighbourhood increased systematically with education: $66 \%$ of those with no schooling, $73-78 \%$ of those with 1-11 years of schooling and $84 \%$ of those who had completed 12 or more years of schooling reported mobility. In contrast, among the married, differences were mild and in the reverse direction. With regard to freedom of movement outside the village/neighbourhood, increases in mobility by education were evident for both the unmarried and the married; however, increases were much steeper among unmarried than married young women. For example, the proportion of unmarried young women who could move unescorted outside the village/neighbourhood increased from 15\% among women 
without any education to $43 \%$ among those who had competed 12 or more years of schooling (an increase of about $28 \%$ points); in comparison, among married young women, the increase was more gradual, from $32 \%$ to $39 \%$, respectively (an increase of about $7 \%$ points). The fact that educated married women had less freedom of movement than their unmarried counterparts suggests the likelihood that marriage may limit, to some extent, the positive association between education and mobility.

The association between household economic status and freedom to visit locations within and outside the village or neighbourhood differed among married and unmarried young women. Among the married, for example, household economic status was inversely associated with mobility within the village or neighbourhood but was positively but inconsistently associated with mobility outside the village or neighbourhood. In contrast, among the unmarried, household economic status was mildly associated with mobility within the village, but was generally positively associated with mobility outside the village or neighbourhood. For example, freedom to visit places outside the village or neighbourhood unescorted among unmarried young women increased from $28 \%$ among those from the poorest (first) quintile to $40 \%$ among those from the wealthiest (fifth) quintile. In contrast, patterns were inconsistent with regard to freedom to visit a health facility unescorted; while mobility increased with education among both unmarried and married young women, no pattern could be discerned with regard to household economic status.

Similar patterns of socio-demographic differentials were observed, by and large, for mobility among rural and urban respondents, as seen in Table 7.4.

\subsection{Access to money}

In order to understand access to financial resources among youth, information was obtained on whether they had any savings, whether they owned an account in a bank or a post office and if so, whether they operated the account themselves. Results are presented in Table 7.5.

Wide gender differences were observed. For example, young women were more likely than young men (31\% compared to 19\%) to have reported savings. Differences by marital status were observed among young men (but not among young women): $27 \%$ of married young men compared to $19 \%$ of unmarried young men reported some savings. Rural-urban differences suggest that young men in urban areas were more likely than those in rural areas ( $22 \%$ and $16 \%$, respectively) to report savings, and this difference was observed among both the married (35\% and $22 \%$, respectively) and the unmarried (22\% and $17 \%$, respectively). Among young women, rural-urban differences were narrow: $30 \%$ and $33 \%$, respectively, in rural and urban areas reported savings.

Findings on ownership of a bank/post office account reveal a different picture. Only a minority of youth reported owning a bank/post office account $-13 \%$ of young men and $9 \%$ of young women. Gender differences were narrow for the overall population; however, differences were pronounced among the married. About one in four married young men compared to just about one in 10 married young women owned an account. Differences by marital status were apparent only among young men: married young men were considerably more likely than unmarried young men to own an account (23\% and $13 \%$, respectively).

Rural-urban differences were also apparent, with urban youth more likely than rural youth to report owning a bank account (16\% versus $10 \%$ among young men, and $11 \%$ versus $7 \%$ among young women). Rural-urban differences were evident among married young men (31\% versus $18 \%$ in urban and rural areas, respectively), unmarried young men (16\% versus $11 \%)$ and unmarried young women (12\% versus $6 \%)$; and negligible among married young women (8-9\%). 
Table 7.5: Access to money

Percentage of youth who reported having any savings, owning an account in a bank or post office and operating the account themselves, according to residence, Tamil Nadu, 2006

\begin{tabular}{|c|c|c|c|c|c|c|}
\hline Savings indicators (\%) & $\underset{15-24}{M}$ & $\begin{array}{c}\text { W } \\
15-24\end{array}$ & $\begin{array}{c}\text { MM } \\
15-29\end{array}$ & $\begin{array}{c}\text { MW } \\
15-24\end{array}$ & $\begin{array}{c}\text { UM } \\
15-24\end{array}$ & $\begin{array}{c}\text { UW } \\
\text { 15-24 }\end{array}$ \\
\hline \multicolumn{7}{|c|}{ Combined } \\
\hline Has savings of any amount & 18.9 & 31.0 & 27.2 & 30.6 & 19.1 & 31.2 \\
\hline Ownership of a bank/post office account: & & & & & & \\
\hline In own (respondent's) name & 11.6 & 7.8 & 21.5 & 7.1 & 11.8 & 8.2 \\
\hline Jointly with someone else & 1.1 & 1.2 & 1.5 & 1.6 & 1.1 & 1.0 \\
\hline No account & 87.3 & 91.0 & 77.0 & 91.3 & 87.1 & 90.8 \\
\hline Number of respondents & 1,913 & 5,008 & 1,322 & 2,007 & 1,666 & 3,001 \\
\hline Operates bank/post office account themselves & 88.5 & 74.6 & 92.8 & 77.8 & 89.3 & 72.3 \\
\hline Number with an account & 245 & 449 & 312 & 174 & 216 & 275 \\
\hline \multicolumn{7}{|c|}{ Urban } \\
\hline Has savings of any amount & 22.4 & 32.6 & 35.2 & 29.4 & 22.1 & 34.4 \\
\hline Ownership of a bank/post office account: & & & & & & \\
\hline In own (respondent's) name & 14.6 & 10.0 & 28.5 & 7.8 & 14.5 & 11.3 \\
\hline Jointly with someone else & 1.2 & 1.3 & 2.0 & 1.6 & 1.2 & 1.1 \\
\hline No account & 84.4 & 88.7 & 69.4 & 90.6 & 84.5 & 87.5 \\
\hline Number of respondents & 890 & 2,151 & 653 & 804 & 789 & 1,347 \\
\hline Operates bank/post office account themselves & 89.3 & 72.9 & 92.8 & 77.3 & 89.7 & 71.0 \\
\hline Number with an account & 138 & 241 & 196 & 74 & 122 & 167 \\
\hline \multicolumn{7}{|c|}{ Rural } \\
\hline Has savings of any amount & 16.3 & 29.7 & 21.7 & 31.4 & 16.8 & 28.4 \\
\hline Ownership of a bank/post office account: & & & & & & \\
\hline In own (respondent's) name & 9.3 & 6.0 & 16.6 & 6.7 & 9.7 & 5.5 \\
\hline Jointly with someone else & 1.1 & 1.2 & 1.2 & 1.6 & 1.0 & 0.9 \\
\hline No account & 89.6 & 92.8 & 82.3 & 91.7 & 89.3 & 93.6 \\
\hline Number of respondents & 1,023 & 2,857 & 669 & 1,203 & 877 & 1,654 \\
\hline Operates bank/post office account themselves & 87.6 & 76.7 & 92.0 & 79.0 & 88.8 & 74.5 \\
\hline Number with an account & 107 & 208 & 116 & 100 & 94 & 108 \\
\hline
\end{tabular}

Note: All Ns are unweighted. Column totals may not equal 100\% due to missing cases or "don't know" responses.

With regard to operation of the account, gender differences were noted; $89 \%$ of all young men who owned an account operated it themselves whereas just three-fourths of young women who owned an account did so. Marital status differences were negligible but suggest that the married were more likely than the unmarried to operate their account themselves. Rural-urban differences were negligible. 


\subsection{Gender role attitudes}

In order to understand gender role attitudes, youth were asked seven questions reflecting attitudes, including the relative importance attached to educating boys versus girls, the role of the husband as the main decisionmaker with regard to spending money, girls' participation in decisions about their own marriage, a woman's need to take permission from her husband for any activity, the comparative performance of girls versus boys in studies, gender roles in domestic work and whether girls who dress provocatively deserve to be teased. Findings, presented in Table 7.6, highlight the extent to which inegalitarian gender views persist among both young men and young women.

Questions that were most likely to elicit egalitarian responses from all categories of youth included whether girls are usually as good as boys in studies, whether the husband should be the main decision-maker with regard to spending money and whether girls should be allowed to decide about their own marriage: $74-93 \%$

Table 7.6: Gender role attitudes

Percent distribution of youth by attitudes towards gender roles, according to residence, Tamil Nadu, 2006

\begin{tabular}{|c|c|c|c|c|c|c|}
\hline Gender role attitudes (\%) & $\underset{15-24}{M}$ & $\begin{array}{c}W \\
15-24\end{array}$ & $\begin{array}{c}\mathrm{MM} \\
15-29\end{array}$ & $\begin{array}{l}\text { MW } \\
15-24\end{array}$ & $\begin{array}{l}\text { UM } \\
15-24\end{array}$ & $\begin{array}{l}\text { UW } \\
15-24\end{array}$ \\
\hline \multicolumn{7}{|c|}{ Combined } \\
\hline \multicolumn{7}{|c|}{$\begin{array}{l}\text { Educating boys is more important than } \\
\text { educating girls }\end{array}$} \\
\hline Yes & 63.3 & 32.8 & 60.6 & 34.5 & 63.5 & 31.7 \\
\hline No & 36.3 & 67.0 & 39.3 & 65.4 & 36.1 & 68.0 \\
\hline \multicolumn{7}{|c|}{$\begin{array}{l}\text { Husband alone/mainly should decide about } \\
\text { spending money }\end{array}$} \\
\hline Yes & 25.4 & 16.5 & 29.9 & 22.4 & 24.8 & 12.5 \\
\hline No & 73.5 & 82.5 & 70.1 & 77.5 & 73.9 & 85.8 \\
\hline \multicolumn{7}{|c|}{$\begin{array}{l}\text { Girls should be allowed to decide about their own } \\
\text { marriage }\end{array}$} \\
\hline Yes & 74.5 & 83.6 & 73.4 & 84.5 & 75.0 & 83.0 \\
\hline No & 24.1 & 15.9 & 26.3 & 15.2 & 23.5 & 16.3 \\
\hline \multicolumn{7}{|c|}{$\begin{array}{l}\text { A woman should obtain her husband's permission } \\
\text { for most things }\end{array}$} \\
\hline Yes & 72.8 & 56.8 & 73.5 & 68.3 & 72.7 & 49.3 \\
\hline No & 25.6 & 41.9 & 26.3 & 31.4 & 25.5 & 48.8 \\
\hline \multicolumn{7}{|c|}{ Girls are usually as good as boys in studies } \\
\hline Yes & 93.0 & 95.7 & 93.2 & 95.6 & 93.0 & 95.8 \\
\hline No & 6.7 & 3.9 & 6.6 & 3.8 & 6.7 & 3.9 \\
\hline \multicolumn{7}{|c|}{ Boys should do as much domestic work as girls } \\
\hline Yes & 33.4 & 36.0 & 32.9 & 32.7 & 33.6 & 38.1 \\
\hline No & 66.1 & 63.7 & 66.8 & 67.1 & 65.8 & 61.5 \\
\hline \multicolumn{7}{|c|}{ Girls who dress provocatively deserve to be teased } \\
\hline Yes & 64.3 & 42.0 & 65.9 & 44.8 & 63.8 & 40.2 \\
\hline No & 34.7 & 56.3 & 33.7 & 53.8 & 35.1 & 57.9 \\
\hline Number of respondents & 1,913 & 5,008 & 1,322 & 2,007 & 1,666 & 3,001 \\
\hline
\end{tabular}


Table 7.6: (Cont'd)

\begin{tabular}{|c|c|c|c|c|c|c|}
\hline Gender role attitudes (\%) & $\begin{array}{c}M \\
15-24\end{array}$ & $\begin{array}{c}\text { W } \\
15-24\end{array}$ & $\begin{array}{c}\text { MM } \\
15-29\end{array}$ & $\begin{array}{c}\text { MW } \\
15-24\end{array}$ & $\begin{array}{c}\text { UM } \\
15-24\end{array}$ & $\begin{array}{c}\text { UW } \\
15-24\end{array}$ \\
\hline \multicolumn{7}{|c|}{ Urban } \\
\hline \multicolumn{7}{|c|}{$\begin{array}{l}\text { Educating boys is more important than } \\
\text { educating girls }\end{array}$} \\
\hline Yes & 62.5 & 31.0 & 61.3 & 31.4 & 62.7 & 30.7 \\
\hline No & 37.1 & 68.9 & 38.7 & 68.5 & 36.9 & 69.1 \\
\hline \multicolumn{7}{|c|}{$\begin{array}{l}\text { Husband alone/mainly should decide about } \\
\text { spending money }\end{array}$} \\
\hline Yes & 25.2 & 15.0 & 30.0 & 21.6 & 24.9 & 11.1 \\
\hline No & 73.1 & 84.1 & 70.0 & 78.3 & 73.4 & 87.5 \\
\hline \multicolumn{7}{|c|}{$\begin{array}{l}\text { Girls should be allowed to decide about their } \\
\text { own marriage }\end{array}$} \\
\hline Yes & 74.0 & 85.1 & 73.1 & 85.4 & 74.3 & 84.9 \\
\hline No & 24.5 & 14.4 & 26.9 & 14.1 & 24.1 & 14.6 \\
\hline \multicolumn{7}{|c|}{$\begin{array}{l}\text { A woman should obtain her husband's permission } \\
\text { for most things }\end{array}$} \\
\hline Yes & 70.1 & 53.1 & 69.5 & 65.6 & 70.1 & 45.8 \\
\hline No & 27.9 & 46.0 & 30.3 & 34.3 & 27.8 & 52.7 \\
\hline \multicolumn{7}{|c|}{ Girls are usually as good as boys in studies } \\
\hline Yes & 92.5 & 96.3 & 92.8 & 96.5 & 92.8 & 96.3 \\
\hline No & 7.0 & 3.2 & 7.0 & 3.1 & 6.7 & 3.3 \\
\hline \multicolumn{7}{|c|}{ Boys should do as much domestic work as girls } \\
\hline Yes & 32.1 & 35.1 & 27.3 & 30.7 & 32.4 & 37.7 \\
\hline No & 67.3 & 64.5 & 72.6 & 69.0 & 66.9 & 61.8 \\
\hline \multicolumn{7}{|c|}{ Girls who dress provocatively deserve to be teased } \\
\hline Yes & 66.1 & 42.2 & 68.3 & 45.4 & 65.6 & 40.4 \\
\hline No & 32.6 & 55.8 & 31.4 & 52.6 & 33.1 & 57.7 \\
\hline Number of respondents & 890 & 2,151 & 653 & 804 & 789 & 1,347 \\
\hline \multicolumn{7}{|c|}{ Rural } \\
\hline \multicolumn{7}{|c|}{$\begin{array}{l}\text { Educating boys is more important than } \\
\text { educating girls }\end{array}$} \\
\hline Yes & 63.9 & 34.3 & 60.1 & 36.7 & 64.2 & 32.5 \\
\hline No & 35.5 & 65.5 & 39.8 & 63.3 & 35.3 & 67.0 \\
\hline \multicolumn{7}{|c|}{$\begin{array}{l}\text { Husband alone/mainly should decide about } \\
\text { spending money }\end{array}$} \\
\hline Yes & 25.5 & 17.7 & 29.8 & 23.0 & 24.8 & 13.8 \\
\hline No & 73.8 & 81.2 & 70.2 & 76.9 & 74.4 & 84.3 \\
\hline \multicolumn{7}{|c|}{$\begin{array}{l}\text { Girls should be allowed to decide about their } \\
\text { own marriage }\end{array}$} \\
\hline Yes & 74.9 & 82.4 & 73.7 & 83.8 & 75.4 & 81.4 \\
\hline No & 23.8 & 17.0 & 25.9 & 15.9 & 23.1 & 17.8 \\
\hline \multicolumn{7}{|c|}{$\begin{array}{l}\text { A woman should obtain her husband's permission } \\
\text { for most things }\end{array}$} \\
\hline Yes & 74.8 & 59.8 & 76.3 & 70.1 & 74.8 & 52.3 \\
\hline No & 23.8 & 38.7 & 23.6 & 29.4 & 23.7 & 45.4 \\
\hline \multicolumn{7}{|c|}{ Girls are usually as good as boys in studies } \\
\hline Yes & 93.3 & 95.2 & 93.5 & 94.9 & 93.3 & 95.3 \\
\hline No & 6.5 & 4.4 & 6.3 & 4.3 & 6.6 & 4.4 \\
\hline \multicolumn{7}{|c|}{ Boys should do as much domestic work as girls } \\
\hline $\begin{array}{l}\text { Yes } \\
\text { No }\end{array}$ & $\begin{array}{l}34.4 \\
65.3\end{array}$ & $\begin{array}{l}36.6 \\
63.1\end{array}$ & $\begin{array}{l}36.7 \\
62.9\end{array}$ & $\begin{array}{l}34.1 \\
65.8\end{array}$ & $\begin{array}{l}34.6 \\
65.0\end{array}$ & $\begin{array}{l}38.5 \\
61.2\end{array}$ \\
\hline \multicolumn{7}{|c|}{ Girls who dress provocatively deserve to be teased } \\
\hline Yes & 62.7 & 41.9 & 64.3 & 44.4 & 62.4 & 40.1 \\
\hline No & 36.3 & 56.6 & 35.3 & 54.6 & 36.7 & 58.1 \\
\hline Number of respondents & 1,023 & 2,857 & 669 & 1,203 & 877 & 1,654 \\
\hline
\end{tabular}

Note: All Ns are unweighted. Column totals may not equal 100\% due to missing cases, "don't know" or "unsure" responses. 
of young men and $83-96 \%$ of young women expressed egalitarian views on these matters. Two questions were least likely to elicit egalitarian responses from youth. For example, just $26 \%$ of young men and $42 \%$ of young women disagreed with the view that a woman should obtain her husband's permission for most things. Likewise, just $33 \%$ of young men and $36 \%$ of young women agreed with the view that boys should do as much domestic work as girls.

Young men were consistently more likely than young women to report inegalitarian gender role attitudes in relation to most topics. For example, considerably more young men than women (63\% and 33\%, respectively) expressed the traditional attitude that boys should be given preference over girls in terms of education. Similarly, $73 \%$ of young men compared to $57 \%$ of young women agreed with the view that a woman should obtain her husband's permission for most things; and while $64 \%$ of young men believed that girls who dress provocatively deserve to be teased, many fewer $(42 \%)$ young women expressed this view.

Figure 7.3: Percentage of youth who expressed egalitarian gender role attitudes on selected issues, Tamil Nadu, 2006

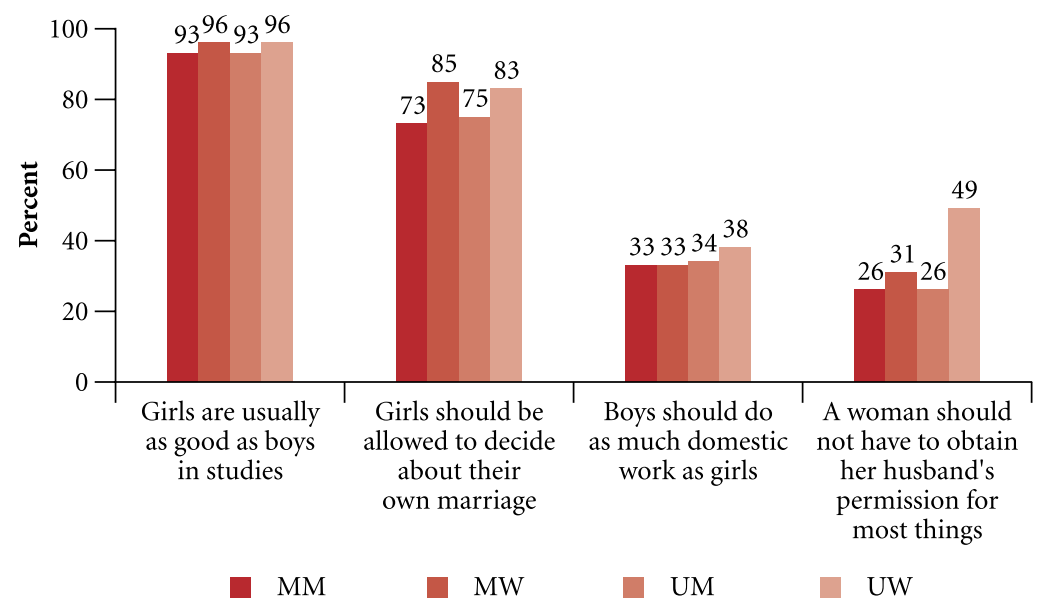

Variations in reporting of egalitarian attitudes by marital status and topic are highlighted in Figure 7.3. Differences by marital status were negligible among young men. In contrast, among young women, differences were wide on several issues, with the unmarried more likely to express gender egalitarian attitudes than the married. For example, more unmarried than married young women held the view that the husband should not be the main decision-maker with regard to spending money ( $86 \%$ versus $78 \%$ ), that women should not have to take their husband's permission for most things (49\% versus $31 \%$ ) and that boys should do as much housework as girls (38\% versus 33\%). Differences by rural-urban residence were narrow. The only exception was in young women's responses to whether a woman should obtain her husband's permission for most things: $39 \%$ of rural young women disagreed with this statement compared to $46 \%$ of urban young women.

\subsection{Attitudes towards wife beating}

Youth were asked a number of questions to gauge the extent to which beating one's wife was perceived to be an acceptable behaviour. Young people were asked whether they agreed that wife beating was a way of 
expressing love, and whether wife beating was justified in four situations, including refusal to have sex with the husband. Findings are presented in Table 7.7. Again, it is evident that expression of gender egalitarian attitudes was far from universal. For example, just over half of young men and women $(52 \%$ and $57 \%$, respectively) disagreed that wife beating was a sign of love; indeed, it is notable that $43 \%$ of young men and $38 \%$ of young women did conform to this view. Marital status differences were muted among young men; in contrast, among young women, the unmarried were considerably more likely than the married to disagree that wife beating was a sign of love (61\% versus $52 \%)$.

Findings show, moreover, that more than half of youth did justify wife beating in at least one of the four situations about which information was sought. A somewhat larger proportion of young women than men (56\% versus 51\%) justified wife beating. Gender differences were muted among the unmarried but wide among the married; $51 \%$ of married young men compared to $60 \%$ of married young women justified wife beating in at least one of the four situations explored. Of the four situations posed, young people, irrespective of sex, marital status and rural-urban residence, were most likely to perceive that wife beating was justified if a woman went out without telling her husband (31\% and $38 \%$ of young men and women, respectively) or if she disagreed with her husband's opinion ( $31 \%$ and $36 \%$, respectively). In contrast, youth were least likely to justify wife beating if a woman refused to have sexual relations with her husband $(4 \%$ and $8 \%$ of young men and women, respectively).

Differences by marital status were evident among young women but not among young men (see Figure 7.4). Unmarried young women were less likely than the married (52\% compared to 60\%) to report that wife beating was justified in at least one of the four situations explored.

Rural-urban differences were, in contrast, consistently wide. Larger percentages of rural than urban youth perceived that wife beating was a sign of love ( $46 \%$ of young men and $40 \%$ of young women in rural areas compared to $38 \%$ of young men and $35 \%$ of young women in urban areas). Irrespective of marital status and sex, more rural than urban youth justified wife beating in each situation: for example, $58 \%$ and $60 \%$ of young men and women, respectively, in rural areas compared to $42 \%$ and $50 \%$ of young men and women, respectively, in urban areas justified wife beating in at least one situation.

Figure 7.4: Percentage of youth who believed wife beating is justified in selected situations, Tamil Nadu, 2006

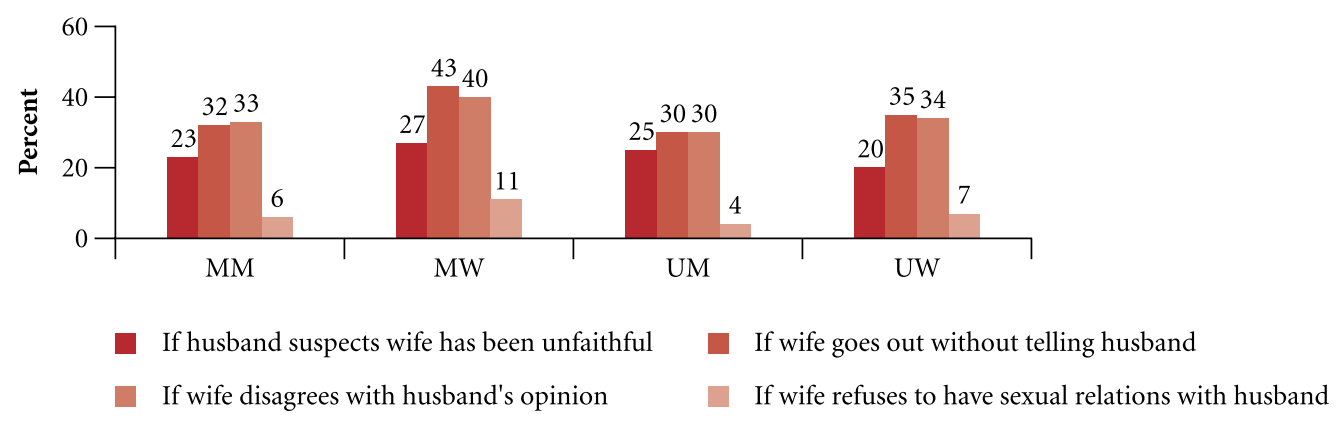


Table 7.7: Attitudes towards wife beating

Percent distribution of youth by attitudes towards wife beating in selected situations, according to residence, Tamil Nadu, 2006

\begin{tabular}{|c|c|c|c|c|c|c|}
\hline Attitudes towards wife beating (\%) & $\underset{15-24}{M}$ & $\underset{15-24}{W}$ & $\begin{array}{c}\text { MM } \\
15-29\end{array}$ & $\begin{array}{c}\text { MW } \\
15-24\end{array}$ & $\begin{array}{c}\text { UM } \\
15-24\end{array}$ & $\begin{array}{l}\text { UW } \\
15-24\end{array}$ \\
\hline \multicolumn{7}{|c|}{ Combined } \\
\hline \multicolumn{7}{|l|}{ Beating wife means husband loves her } \\
\hline Agree & 42.9 & 37.7 & 48.6 & 44.8 & 42.0 & 33.0 \\
\hline Disagree & 52.1 & 57.1 & 50.0 & 51.5 & 52.6 & 60.9 \\
\hline Don't know/can't say & 5.0 & 4.8 & 1.0 & 3.1 & 5.3 & 5.9 \\
\hline \multicolumn{7}{|l|}{ Beating wife is justified if: } \\
\hline \multicolumn{7}{|l|}{ Husband suspects wife has been unfaithful } \\
\hline Yes & 24.7 & 22.6 & 22.8 & 26.6 & 24.7 & 20.0 \\
\hline No & 73.3 & 75.3 & 76.8 & 72.7 & 73.0 & 77.0 \\
\hline Don't know/can't say & 2.1 & 2.1 & 0.5 & 0.7 & 2.2 & 3.0 \\
\hline \multicolumn{7}{|l|}{ Wife goes out without telling husband } \\
\hline Yes & 30.7 & 38.1 & 31.9 & 42.7 & 30.3 & 35.0 \\
\hline No & 67.6 & 60.2 & 67.9 & 56.8 & 68.0 & 62.5 \\
\hline Don't know/can't say & 1.7 & 1.7 & 0.2 & 0.5 & 1.7 & 2.4 \\
\hline \multicolumn{7}{|l|}{ Wife disagrees with husband's opinion } \\
\hline Yes & 30.6 & 36.4 & 32.7 & 39.5 & 30.1 & 34.4 \\
\hline No & 67.0 & 61.0 & 67.0 & 59.9 & 67.3 & 61.8 \\
\hline Don't know/can't say & 2.5 & 2.5 & 0.3 & 0.6 & 2.6 & 3.7 \\
\hline \multicolumn{7}{|l|}{ Wife refuses to have sexual relations with husband } \\
\hline Yes & 4.4 & 8.4 & 5.7 & 11.3 & 4.3 & 6.6 \\
\hline No & 91.3 & 86.1 & 93.7 & 87.6 & 91.1 & 85.1 \\
\hline Don't know/can't say & 4.2 & 5.4 & 0.5 & 1.1 & 4.6 & 8.3 \\
\hline $\begin{array}{l}\text { Believed that wife beating is justified in at least one } \\
\text { of the above situations }\end{array}$ & 50.8 & 55.5 & 50.5 & 60.4 & 50.6 & 52.1 \\
\hline Number of respondents & 1,913 & 5,008 & 1,322 & 2,007 & 1,666 & 3,001 \\
\hline \multicolumn{7}{|c|}{ Urban } \\
\hline \multicolumn{7}{|l|}{ Beating wife means husband loves her } \\
\hline Agree & 38.2 & 34.7 & 41.5 & 44.4 & 37.8 & 29.1 \\
\hline Disagree & 57.1 & 60.7 & 57.4 & 52.9 & 57.3 & 65.3 \\
\hline Don't know/can't say & 4.7 & 4.4 & 0.7 & 2.7 & 5.0 & 5.4 \\
\hline \multicolumn{7}{|l|}{$\begin{array}{l}\text { Beating wife is justified if: } \\
\text { Husband suspects wife has been unfaithful }\end{array}$} \\
\hline Yes & 20.1 & 19.1 & 18.6 & 21.1 & 20.7 & 17.9 \\
\hline No & 77.3 & 78.9 & 80.7 & 78.4 & 76.6 & 79.2 \\
\hline Don't know/can't say & 2.6 & 2.0 & 0.7 & 0.5 & 2.7 & 2.9 \\
\hline \multicolumn{7}{|l|}{ Wife goes out without telling husband } \\
\hline Yes & 21.5 & 32.0 & 28.7 & 36.7 & 21.2 & 29.2 \\
\hline No & 76.7 & 66.1 & 70.7 & 62.9 & 77.1 & 68.0 \\
\hline Don't know/can't say & 1.8 & 1.9 & 0.6 & 0.4 & 1.7 & 2.7 \\
\hline \multicolumn{7}{|l|}{ Wife disagrees with husband's opinion } \\
\hline Yes & 23.7 & 32.3 & 27.7 & 35.8 & 23.7 & 30.2 \\
\hline No & 73.6 & 65.0 & 71.8 & 63.7 & 73.5 & 65.8 \\
\hline Don't know/can't say & 2.8 & 2.7 & 0.6 & 0.5 & 2.8 & 3.9 \\
\hline \multicolumn{7}{|l|}{ Wife refuses to have sexual relations with husband } \\
\hline Yes & 2.9 & 6.7 & 5.2 & 9.3 & 2.9 & 5.3 \\
\hline No & 92.9 & 88.1 & 94.3 & 89.6 & 92.6 & 87.1 \\
\hline Don't know/can't say & 4.2 & 5.2 & 0.6 & 1.1 & 4.4 & 7.5 \\
\hline $\begin{array}{l}\text { Believed that wife beating is justified in at least one } \\
\text { of the above situations }\end{array}$ & 41.9 & 49.5 & 44.6 & 55.3 & 42.2 & 46.2 \\
\hline Number of respondents & 890 & 2,151 & 653 & 804 & 789 & 1,347 \\
\hline
\end{tabular}


Table 7.7: (Cont'd)

\begin{tabular}{|c|c|c|c|c|c|c|}
\hline Attitudes towards wife beating (\%) & $\begin{array}{c}M \\
15-24\end{array}$ & $\begin{array}{c}\text { W } \\
15-24\end{array}$ & $\begin{array}{c}\text { MM } \\
15-29\end{array}$ & $\begin{array}{c}\text { MW } \\
15-24\end{array}$ & $\begin{array}{c}\text { UM } \\
15-24\end{array}$ & $\begin{array}{l}\text { UW } \\
15-24\end{array}$ \\
\hline \multicolumn{7}{|c|}{ Rural } \\
\hline \multicolumn{7}{|l|}{ Beating wife means husband loves her } \\
\hline Agree & 46.4 & 40.1 & 53.5 & 45.1 & 45.3 & 36.4 \\
\hline Disagree & 48.3 & 54.3 & 44.9 & 50.6 & 48.9 & 57.0 \\
\hline Don't know/can't say & 5.2 & 5.1 & 1.2 & 3.4 & 5.7 & 6.3 \\
\hline \multicolumn{7}{|l|}{ Beating wife is justified if: } \\
\hline \multicolumn{7}{|l|}{ Husband suspects wife has been unfaithful } \\
\hline Yes & 28.2 & 25.3 & 25.7 & 30.2 & 28.0 & 21.8 \\
\hline No & 70.2 & 72.5 & 74.1 & 68.9 & 70.2 & 75.1 \\
\hline Don't know/can't say & 1.7 & 2.2 & 0.3 & 0.9 & 1.9 & 3.1 \\
\hline \multicolumn{7}{|l|}{ Wife goes out without telling husband } \\
\hline Yes & 37.7 & 42.9 & 34.1 & 46.7 & 37.6 & 40.1 \\
\hline No & 60.7 & 55.5 & 65.9 & 52.7 & 60.6 & 57.6 \\
\hline Don't know/can't say & 1.6 & 1.5 & 0.0 & 0.6 & 1.7 & 2.2 \\
\hline \multicolumn{7}{|l|}{ Wife disagrees with husband's opinion } \\
\hline Yes & 35.9 & 39.7 & 36.2 & 41.9 & 35.4 & 38.2 \\
\hline No & 61.9 & 57.9 & 63.7 & 57.4 & 62.2 & 58.2 \\
\hline Don't know/can't say & 2.2 & 2.4 & 0.1 & 0.8 & 2.4 & 3.6 \\
\hline \multicolumn{7}{|l|}{ Wife refuses to have sexual relations with husband } \\
\hline Yes & 5.6 & 9.8 & 6.2 & 12.6 & 5.3 & 7.8 \\
\hline No & 90.1 & 84.5 & 93.3 & 86.3 & 89.9 & 83.3 \\
\hline Don't know/can't say & 4.3 & 5.7 & 0.5 & 1.1 & 4.8 & 8.9 \\
\hline $\begin{array}{l}\text { Believed that wife beating is justified in at least one } \\
\text { of the above situations }\end{array}$ & 57.6 & 60.2 & 54.6 & 64.0 & 57.4 & $\mathbf{5 7 . 5}$ \\
\hline Number of respondents & 1,023 & 2,857 & 669 & 1,203 & 877 & 1,654 \\
\hline
\end{tabular}

Note: All Ns are unweighted. Column totals may not equal 100\% due to missing cases.

\subsection{Summary}

Findings suggest that substantial proportions of young men and many more young women did not exercise agency in their everyday lives. For example, decision-making was relatively limited: while $52 \%$ of young men reported independent decision-making on all three issues explored in the survey, namely, choice of friends, spending money and purchase of clothes, just $22 \%$ of young women reported so. Likewise, freedom to visit at least one location within and outside their own village or neighbourhood unescorted was not universal, although young men reported considerably more freedom of movement than did young women. Indeed, just $79 \%$ of young women compared to $93 \%$ of unmarried young men could visit locations within their own village or neighbourhood unescorted; and just $30 \%$ of young women compared to $71 \%$ of unmarried young men could visit at least one location outside their own village or neighbourhood unescorted. Findings also show that control over financial resources among youth tended to be limited, and particularly so among young women. Although young women were more likely than young men to have money saved $(31 \%$ and $19 \%$, respectively), they were somewhat less likely to own a bank or post office savings account ( $9 \%$ and $13 \%$, respectively) and less likely than their male counterparts to operate these accounts themselves (75\% and $89 \%$, respectively, of those who had an account). 
Gender role attitudes were mixed. However, young men were consistently more likely than young women to report unequal gender role attitudes. Considerable proportions of youth espoused egalitarian attitudes on such issues as whether girls are usually as good as boys in studies, whether the husband should be the main decision-maker with regard to spending money and whether girls should be allowed to decide about their own marriage. In contrast, the majority of youth expressed inegalitarian views on other matters. For example, as many as $73 \%$ of young men and $57 \%$ of young women agreed with the view that a woman should obtain her husband's permission for most things. Likewise, $66 \%$ of young men and $64 \%$ of young women disagreed with the view that boys should do as much domestic work as girls. A somewhat larger proportion of young women than young men ( $56 \%$ versus $51 \%$ ) justified wife beating in at least one situation explored in the survey. 


\section{Awareness of sexual and} reproductive health matters

A considerable body of research, including the NFHS (IIPS and Macro International, 2007a), has highlighted relatively low levels of awareness regarding selected sexual and reproductive health issues in both the general and youth populations. The Youth Study sought to explore awareness of a wide range of issues relating to sex, pregnancy, contraception and STIs, including HIV/AIDS, as well as knowledge of laws governing age at marriage and abortion. Where possible, further questions were posed to assess the extent of in-depth awareness of these matters. Along with the results of these items, this chapter presents findings on communication about and sources of information for sexual and reproductive health matters, as well as youth perceptions and experiences of family life or sex education.

\subsection{Awareness of sex and pregnancy, contraception, STIs and HIV}

In this section, we present evidence of the extent to which young people were aware of or held misconceptions about various issues related to sex and pregnancy, contraception, STIs and HIV.

\subsubsection{Sex and pregnancy}

In order to assess young people's knowledge about sex and pregnancy, the Youth Study asked youth whether they agreed or disagreed with four statements: (a) a woman can get pregnant after kissing or hugging; (b) a woman is most likely to get pregnant if she has sex half-way between her periods; (c) a woman has to bleed at first intercourse; and (d) a woman can get pregnant at first sex. Given the prevalence of sex-selective abortions in the country (Bhat and Zavier, 2007; Dagar, 2007), we also asked whether youth were aware of any tests that could determine the sex of the foetus.

Findings, presented in Table 8.1, clearly suggest that awareness of sex- and pregnancy-related matters was limited, with the exception of knowledge that women cannot become pregnant after kissing or hugging, and awareness about the availability of tests to determine the sex of the foetus; over $90 \%$ of young men and young women were aware of these two matters. Differences by marital status and rural-urban residence were negligible except that a somewhat larger percentage of unmarried than married youth were either unsure or believed that a woman can get pregnant after kissing or hugging ( $8 \%$ and $5 \%$ of unmarried young men and women compared to $1-2 \%$ of the married).

Awareness of the other three matters was reported by far smaller proportions of youth. Indeed, only between one-quarter and half of youth reported awareness of any of these three matters. Considerable differences were evident in awareness of all three issues by sex of the respondent. For example, one-quarter of young men $(26 \%)$ and two in five young women $(41 \%)$ were aware that a woman is most likely to become pregnant if she engages in sexual relations mid-cycle. While rural-urban differences were relatively narrow, married youth were more likely than the unmarried to report correct awareness of this issue: $58 \%$ and $70 \%$ of married young men and women, respectively, compared to $22 \%$ of unmarried young men and women, respectively (see Figure 8.1). 
Table 8.1: Awareness of sex- and pregnancy-related matters

Percent distribution of youth by awareness of sex- and pregnancy-related matters, according to residence, Tamil Nadu, 2006

\begin{tabular}{|c|c|c|c|c|c|c|}
\hline Awareness indicators (\%) & $\begin{array}{c}M \\
15-24\end{array}$ & $\begin{array}{c}W \\
15-24\end{array}$ & $\begin{array}{c}\text { MM } \\
15-29\end{array}$ & $\begin{array}{c}\text { MW } \\
15-24\end{array}$ & $\begin{array}{c}\text { UM } \\
15-24\end{array}$ & $\begin{array}{c}\text { UW } \\
15-24\end{array}$ \\
\hline \multicolumn{7}{|c|}{ Combined } \\
\hline A woman can get pregnant after kissing/hugging & & & & & & \\
\hline True & 0.5 & 0.6 & 0.3 & 0.7 & 0.5 & 0.5 \\
\hline False & 92.7 & 96.1 & 99.1 & 98.4 & 92.1 & 94.6 \\
\hline Don't know/not sure & 6.8 & 3.3 & 0.6 & 0.8 & 7.4 & 4.8 \\
\hline \multicolumn{7}{|l|}{$\begin{array}{l}\text { A woman is most likely to get pregnant if she has } \\
\text { sex half-way between her periods }\end{array}$} \\
\hline True & 25.8 & 40.9 & 57.7 & 69.8 & 22.3 & 22.0 \\
\hline False & 28.5 & 17.8 & 34.8 & 21.1 & 28.4 & 15.7 \\
\hline Don't know/not sure & 45.7 & 41.2 & 7.6 & 9.2 & 49.3 & 62.3 \\
\hline \multicolumn{7}{|l|}{ A woman has to bleed at first intercourse } \\
\hline True & 25.6 & 22.4 & 48.8 & 42.8 & 22.8 & 9.0 \\
\hline False & 29.3 & 30.2 & 44.9 & 47.7 & 27.9 & 18.7 \\
\hline Don't know/not sure & 45.2 & 47.4 & 6.4 & 9.6 & 49.2 & 72.3 \\
\hline \multicolumn{7}{|l|}{ A woman can get pregnant at first sex } \\
\hline True & 28.6 & 50.0 & 45.9 & 68.4 & 26.8 & 37.9 \\
\hline False & 41.6 & 21.6 & 50.9 & 27.4 & 40.7 & 17.8 \\
\hline Don't know/not sure & 29.8 & 28.4 & 3.2 & 4.2 & 32.5 & 44.3 \\
\hline \multicolumn{7}{|l|}{$\begin{array}{l}\text { It is possible to do a medical test to know the sex } \\
\text { of a foetus }\end{array}$} \\
\hline True & 91.8 & 91.9 & 91.8 & 92.1 & 92.2 & 91.8 \\
\hline False & 4.7 & 5.4 & 6.6 & 5.8 & 4.3 & 5.1 \\
\hline Don't know/not sure & 2.2 & 1.5 & 0.8 & 0.6 & 2.3 & 2.1 \\
\hline Had correct knowledge of all of the above & 6.6 & 11.8 & 14.8 & 21.7 & 6.0 & 5.2 \\
\hline Number of respondents & 1,913 & 5,008 & 1,322 & 2,007 & 1,666 & 3,001 \\
\hline \multicolumn{7}{|c|}{ Urban } \\
\hline $\begin{array}{l}\text { A woman can get pregnant after kissing/hugging } \\
\text { True }\end{array}$ & 0.4 & 0.4 & 0.2 & 0.2 & 0.4 & 0.4 \\
\hline False & 94.1 & 96.0 & 99.6 & 98.9 & 93.6 & 94.3 \\
\hline Don't know/not sure & 5.5 & 3.6 & 0.2 & 0.9 & 6.0 & 5.2 \\
\hline \multicolumn{7}{|l|}{$\begin{array}{l}\text { A woman is most likely to get pregnant if she has } \\
\text { sex half-way between her periods }\end{array}$} \\
\hline True & 29.9 & 39.1 & 61.8 & 69.8 & 26.3 & 21.2 \\
\hline False & 26.8 & 15.8 & 32.5 & 19.9 & 27.1 & 13.5 \\
\hline Don't know/not sure & 43.3 & 45.1 & 5.7 & 10.4 & 46.5 & 65.3 \\
\hline \multicolumn{7}{|l|}{ A woman has to bleed at first intercourse } \\
\hline True & 21.8 & 20.1 & 48.3 & 40.4 & 19.0 & 8.3 \\
\hline False & 33.8 & 28.3 & 45.1 & 48.3 & 33.2 & 16.6 \\
\hline Don't know/not sure & 44.5 & 51.6 & 6.6 & 11.4 & 47.7 & 75.0 \\
\hline \multicolumn{7}{|l|}{ A woman can get pregnant at first sex } \\
\hline True & 32.9 & 47.0 & 52.3 & 67.9 & 31.1 & 34.9 \\
\hline False & 38.1 & 20.9 & 44.9 & 27.5 & 37.8 & 17.1 \\
\hline Don't know/not sure & 29.0 & 32.0 & 2.8 & 4.6 & 31.2 & 47.9 \\
\hline \multicolumn{7}{|l|}{$\begin{array}{l}\text { It is possible to do a medical test to know the sex } \\
\text { of a foetus }\end{array}$} \\
\hline True & 91.7 & 92.8 & 93.4 & 92.3 & 91.8 & 93.1 \\
\hline False & 5.1 & 5.1 & 5.5 & 6.0 & 5.0 & 4.4 \\
\hline Don't know/not sure & 2.3 & 1.3 & 0.4 & 0.7 & 2.5 & 1.6 \\
\hline Had correct knowledge of all of the above & 8.9 & 10.8 & 16.9 & 22.0 & 8.3 & 4.3 \\
\hline Number of respondents & 890 & 2,151 & 653 & 804 & 789 & 1,347 \\
\hline
\end{tabular}


Table 8.1: (Cont'd)

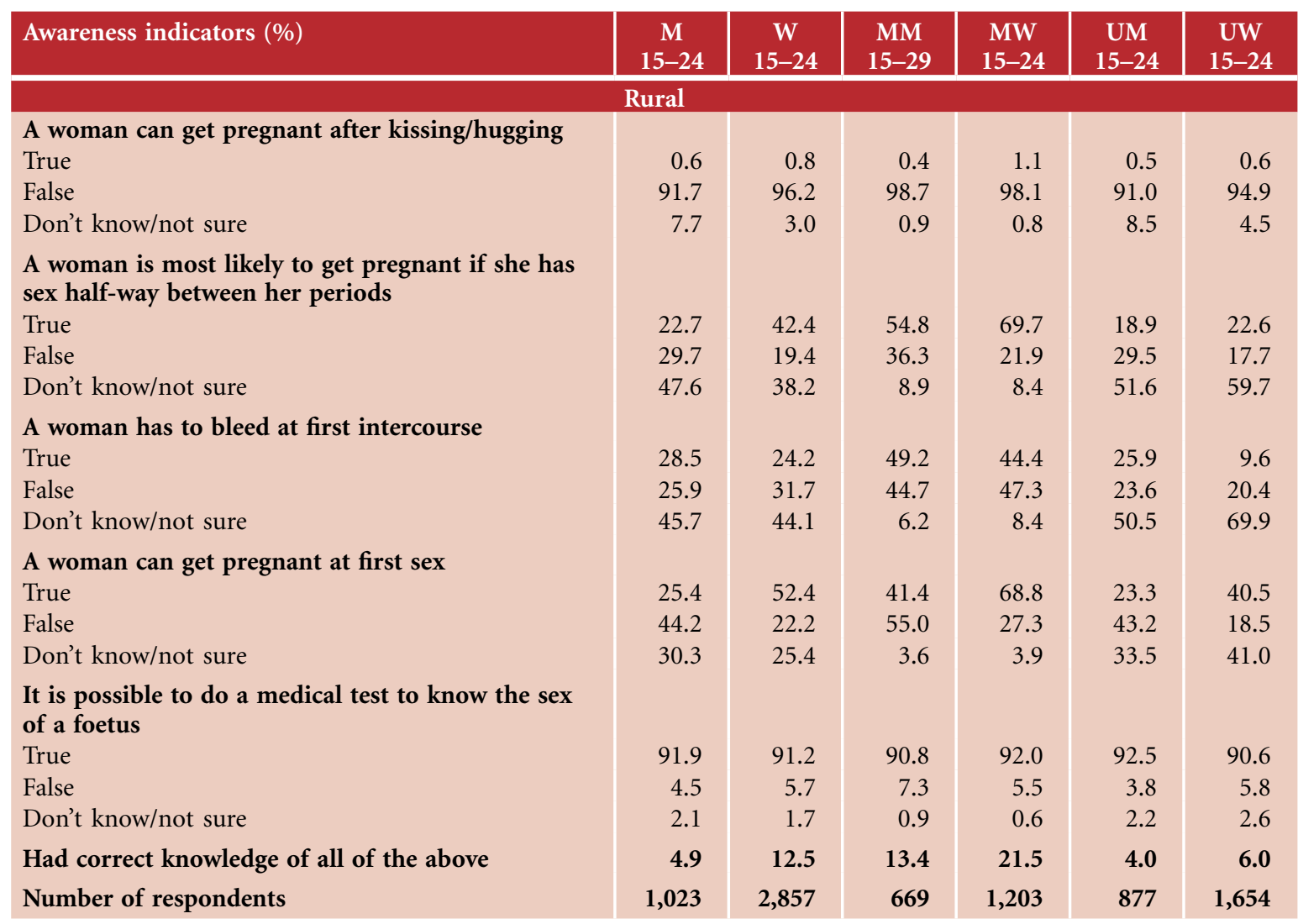

Note: All Ns are unweighted. Column totals may not equal 100\% due to missing cases.

Awareness that a woman does not have to bleed at first intercourse was reported by $29-30 \%$ of youth. While gender differences were negligible, differences by marital status were wide. Irrespective of place of residence and sex, more married than unmarried youth were informed about this issue; and differences were particularly wide among young women ( $48 \%$ and $19 \%$ of married and unmarried young women, respectively, and $45 \%$ and $28 \%$, respectively, of young men were aware of this issue). Rural-urban differences suggest that more urban young men than rural young men were informed about this issue (34\% compared to $26 \%$ ); among young women, in contrast, those in urban settings were mildly less likely than their rural counterparts to be informed about this issue (28\% versus $32 \%)$.

Over one-quarter (29\%) of young men and half of young women were aware that a woman can get pregnant at first sex. As observed in relation to other matters, awareness levels differed widely between the married and the unmarried. Unmarried youth were especially poorly informed about this issue, with just $27 \%$ of unmarried young men and $38 \%$ of unmarried young women, compared to $46 \%$ and $68 \%$, correspondingly, among the married, correctly reporting that a woman can become pregnant at first sex. Rural-urban differences indicate that more urban young men than their rural counterparts (33\% versus $25 \%$ ) reported awareness of this issue; more rural young women, in contrast, were correctly informed about this issue than their urban counterparts ( $52 \%$ versus $47 \%)$.

In order to examine overall knowledge regarding sex and pregnancy, a summary measure was computed that assessed the percentage of youth who were aware of all five matters, and is presented in Table 8.1. Findings 
Figure 8.1: Percentage of youth reporting awareness of selected sex- and pregnancy-related matters, according to residence, Tamil Nadu, 2006

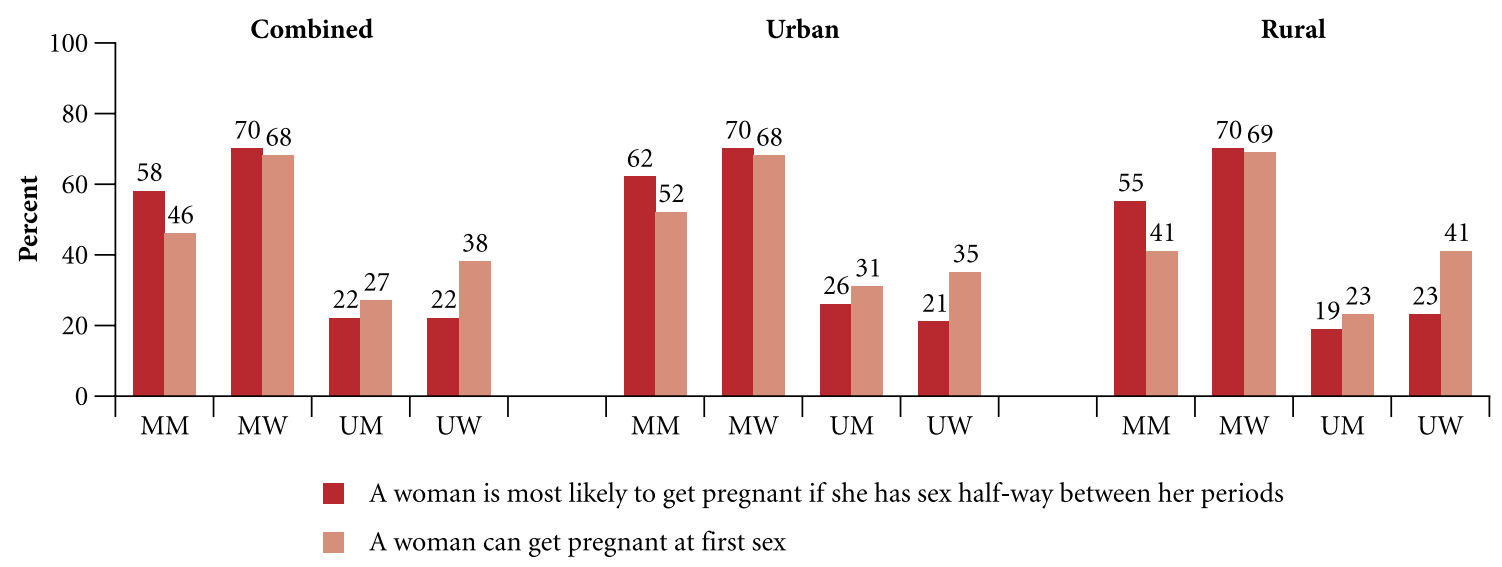

confirm that few youth had correct knowledge of all five issues: just $7 \%$ of young men and $12 \%$ of young women. Differences by marital status were wide: while $15 \%$ and $22 \%$ of married young men and women, respectively had correct knowledge of all five matters, just 5-6\% of the unmarried reported such awareness. Rural-urban differences were typically narrow.

\subsubsection{Socio-demographic differentials in awareness of sex- and pregnancy-related matters}

Differentials in awareness, measured with respect to the percentage aware of all five issues relating to sex and pregnancy discussed above, are presented in Table 8.2. Aside from a positive association between age and awareness of sex- and pregnancy-related matters for both young men and young women, other differentials were typically small. Moreover, patterns observed among young men and young women differed. For example, awareness levels increased moderately with education among young men; awareness of all five matters increased from $2 \%$ among uneducated young men to $7 \%$ among those with 12 or more years of schooling. Among young women, in contrast, a somewhat inverse association was observed. Associations were less consistent when rural and urban youth were analysed separately.

\subsubsection{Awareness of contraceptive methods}

The Youth Study explored young people's awareness of contraceptive methods in several ways. First, youth were asked to list all contraceptive methods about which they had heard; second, interviewers gave respondents a brief description of a variety of non-terminal contraceptive methods not mentioned spontaneously and inquired whether the respondent had heard of each; and third, further questioning probed for specific knowledge regarding the use of oral pills, emergency contraception, condoms, the intra-uterine device (IUD) and withdrawal. Table 8.3 presents percentages of youth reporting awareness-spontaneously or on prompting — of condoms, oral pills, emergency contraception, the IUD and withdrawal; and those spontaneously reporting awareness of such methods as sterilisation, implants, vaginal methods, injectables and herbal and other traditional methods. Also presented are percentages of respondents reporting correct specific knowledge of the five methods indicated above. 
Table 8.2: Awareness of sex- and pregnancy-related matters by selected background characteristics

Percentage of youth who had correct knowledge of all five sex- and pregnancy-related matters by selected background characteristics, according to residence, Tamil Nadu, 2006

\begin{tabular}{|c|c|c|c|c|c|c|}
\hline Background characteristics (\%) & $\underset{15-24}{M}$ & $\begin{array}{c}\text { W } \\
15-24\end{array}$ & $\begin{array}{c}\text { MM } \\
15-29\end{array}$ & $\begin{array}{c}\text { MW } \\
15-24\end{array}$ & $\begin{array}{c}\text { UM } \\
15-24\end{array}$ & $\begin{array}{c}\text { UW } \\
15-24\end{array}$ \\
\hline \multicolumn{7}{|c|}{ Combined } \\
\hline \multicolumn{7}{|l|}{ Age (years) } \\
\hline $15-19$ & 3.8 & 7.1 & * & 21.2 & 3.8 & 4.9 \\
\hline $20-24$ & 9.4 & 15.7 & 13.3 & 21.8 & 8.5 & 5.9 \\
\hline $25-29$ & NA & NA & 15.2 & NA & NA & NA \\
\hline \multicolumn{7}{|l|}{ Religion } \\
\hline Hindu & 6.8 & 12.0 & 14.8 & 21.9 & 6.1 & 5.4 \\
\hline Muslim & 4.9 & 12.6 & 7.1 & 21.9 & 5.4 & 4.3 \\
\hline Other $^{1}$ & 6.3 & 7.2 & $(24.5)$ & 16.2 & 5.6 & 3.6 \\
\hline \multicolumn{7}{|l|}{ Caste } \\
\hline SC & 5.1 & 11.7 & 13.5 & 21.7 & 4.6 & 4.8 \\
\hline $\mathrm{OBC}$ & 6.8 & 11.9 & 15.2 & 21.9 & 6.0 & 5.4 \\
\hline \multicolumn{7}{|l|}{ Educational level (years) } \\
\hline None $^{2}$ & 2.3 & 20.2 & 11.1 & 23.2 & $(0.0)$ & 9.1 \\
\hline $1-7$ & 9.1 & 12.5 & 14.9 & 19.5 & 7.3 & 3.3 \\
\hline $8-11$ & 5.6 & 11.2 & 14.1 & 23.6 & 4.9 & 4.0 \\
\hline 12 and above & 7.4 & 10.6 & 18.3 & 19.1 & 7.4 & 7.7 \\
\hline \multicolumn{7}{|l|}{ Worked in last 12 months } \\
\hline Yes & 8.1 & 9.0 & 14.9 & 18.7 & 7.2 & 4.1 \\
\hline No & 4.3 & 13.2 & * & 22.9 & 4.3 & 5.9 \\
\hline \multicolumn{7}{|l|}{ Wealth quintile } \\
\hline First & 5.6 & 13.5 & 9.3 & 22.9 & 4.7 & 5.3 \\
\hline Second & 5.8 & 12.9 & 15.9 & 24.2 & 4.9 & 4.8 \\
\hline Third & 5.1 & 11.2 & 14.4 & 19.8 & 3.9 & 4.7 \\
\hline Fourth & 7.6 & 10.3 & 15.8 & 18.9 & 6.4 & 5.1 \\
\hline Fifth & 9.0 & 11.9 & 18.9 & 24.2 & 9.2 & 6.1 \\
\hline Total & 6.6 & 11.8 & 14.8 & 21.7 & 6.0 & 5.2 \\
\hline \multicolumn{7}{|c|}{ Urban } \\
\hline \multicolumn{7}{|l|}{ Age (years) } \\
\hline $15-19$ & 5.3 & 5.6 & * & 21.6 & 5.2 & 4.0 \\
\hline $20-24$ & 12.3 & 15.2 & 15.7 & 22.2 & 11.6 & 5.2 \\
\hline $25-29$ & NA & NA & 17.2 & NA & NA & NA \\
\hline \multicolumn{7}{|l|}{ Religion } \\
\hline Hindu & 9.4 & 10.9 & 17.2 & 22.5 & 8.7 & 4.4 \\
\hline Muslim & 4.5 & 11.0 & 9.4 & 18.1 & 5.0 & 4.1 \\
\hline Other $^{1}$ & $(9.1)$ & 9.2 & * & (23.5) & (6.7) & 4.2 \\
\hline \multicolumn{7}{|l|}{ Caste } \\
\hline SC & 6.4 & 9.5 & 16.1 & 22.0 & 6.1 & 2.4 \\
\hline OBC & 9.6 & 11.3 & 17.0 & 22.2 & 8.9 & 4.8 \\
\hline
\end{tabular}


Table 8.2: (Cont'd)

\begin{tabular}{|c|c|c|c|c|c|c|}
\hline Background characteristics (\%) & $\begin{array}{c}\mathrm{M} \\
15-24\end{array}$ & $\begin{array}{c}\mathrm{W} \\
15-24\end{array}$ & $\begin{array}{c}\text { MM } \\
15-29\end{array}$ & $\begin{array}{c}\text { MW } \\
15-24\end{array}$ & $\begin{array}{c}\text { UM } \\
15-24\end{array}$ & $\begin{array}{c}\text { UW } \\
15-24\end{array}$ \\
\hline \multicolumn{7}{|c|}{ Urban } \\
\hline \multicolumn{7}{|l|}{ Educational level (years) } \\
\hline None $^{2}$ & * & 26.8 & * & 29.8 & * & * \\
\hline $1-7$ & 14.3 & 10.3 & 14.1 & 16.7 & 13.7 & 2.3 \\
\hline $8-11$ & 7.3 & 10.7 & 17.9 & 24.9 & 6.3 & 2.5 \\
\hline 12 and above & 8.6 & 9.9 & 21.1 & 19.1 & 8.9 & 6.9 \\
\hline \multicolumn{7}{|l|}{ Worked in last 12 months } \\
\hline Yes & 11.0 & 6.0 & 17.0 & 17.7 & 10.4 & 2.2 \\
\hline No & 5.9 & 12.4 & * & 22.8 & 6.0 & 5.2 \\
\hline \multicolumn{7}{|l|}{ Wealth quintile } \\
\hline First & 7.3 & 15.6 & 14.6 & 28.8 & 6.5 & 3.2 \\
\hline Second & 10.1 & 14.6 & 14.4 & 29.9 & 9.0 & 3.9 \\
\hline Third & 5.8 & 8.9 & 14.7 & 16.9 & 5.1 & 3.1 \\
\hline Fourth & 9.2 & 9.1 & 18.2 & 18.0 & 7.7 & 3.7 \\
\hline Fifth & 10.5 & 11.4 & 20.6 & 24.7 & 10.8 & 5.7 \\
\hline Total & 8.9 & 10.8 & 16.9 & 22.0 & 8.3 & 4.3 \\
\hline \multicolumn{7}{|c|}{ Rural } \\
\hline \multicolumn{7}{|l|}{ Age (years) } \\
\hline $15-19$ & 2.6 & 8.3 & * & 21.0 & 2.6 & 5.6 \\
\hline $20-24$ & 7.1 & 16.1 & 12.1 & 21.7 & 5.8 & 6.5 \\
\hline $25-29$ & NA & NA & 13.7 & NA & NA & NA \\
\hline \multicolumn{7}{|l|}{ Religion } \\
\hline Hindu & 4.9 & 12.7 & 13.3 & 21.5 & 3.9 & 6.2 \\
\hline Muslim & * & 16.9 & * & $(31.7)$ & * & $(4.8)$ \\
\hline Other $^{1}$ & (4.3) & 4.5 & (18.5) & $(8.8)$ & $(4.8)$ & 3.1 \\
\hline \multicolumn{7}{|l|}{ Caste } \\
\hline SC & 4.3 & 12.8 & 12.0 & 21.6 & 4.0 & 6.3 \\
\hline $\mathrm{OBC}$ & 4.4 & 12.5 & 13.6 & 21.6 & 3.5 & 5.9 \\
\hline \multicolumn{7}{|l|}{ Educational level (years) } \\
\hline None $^{2}$ & $(0.0)$ & 17.0 & 10.4 & 20.3 & * & $(7.3)$ \\
\hline $1-7$ & 5.6 & 14.0 & 15.3 & 21.0 & 2.9 & 4.1 \\
\hline $8-11$ & 4.4 & 11.7 & 11.4 & 22.8 & 3.9 & 5.2 \\
\hline 12 and above & 6.0 & 11.6 & 14.6 & 19.2 & 6.0 & 8.7 \\
\hline \multicolumn{7}{|l|}{ Worked in last 12 months } \\
\hline Yes & 6.1 & 10.3 & 13.4 & 19.0 & 5.0 & 5.2 \\
\hline No & 2.7 & 14.0 & * & 23.1 & 2.8 & 6.6 \\
\hline \multicolumn{7}{|l|}{ Wealth quintile } \\
\hline First & 5.6 & 13.0 & 8.0 & 21.2 & 4.3 & 5.8 \\
\hline Second & 4.3 & 12.3 & 16.5 & 22.3 & 3.6 & 4.9 \\
\hline Third & 4.6 & 12.6 & 14.2 & 21.5 & 3.6 & 5.7 \\
\hline Fourth & 6.0 & 11.7 & 12.6 & 19.8 & 5.1 & 6.4 \\
\hline Fifth & 4.2 & 13.1 & $(15.1)$ & 23.1 & 4.4 & 7.8 \\
\hline Total & 4.9 & 12.5 & 13.4 & 21.5 & 4.0 & 6.0 \\
\hline
\end{tabular}

Note: ( ) Based on 25-49 unweighted cases. ${ }^{*}$ Percentage not shown, based on fewer than 25 unweighted cases. NA: Not applicable. OBC: Other backward caste. SC: Scheduled caste. ${ }^{1}$ Includes Christian, Buddhist, Neo-Buddhist, Sikh, Jain, Jewish, Parsi/Zoroastrian and no specified religion. ${ }^{2}$ Includes non-literate and literate with no formal schooling. 
The vast majority of youth (97-98\%) reported awareness (spontaneous or prompted) of at least one method of contraception, and a similar range of youth were aware of at least one modern contraceptive method. The most widely known non-terminal method was the condom, reported by $96 \%$ of young men and $83 \%$ of young women. Other well-known methods included oral pills (reported by $57 \%$ of young men and $65 \%$ of young women) and the IUD (reported by $29 \%$ and $63 \%$, respectively). Although terminal method awareness was not probed, considerable proportions of youth spontaneously reported awareness of female sterilisation ( $68 \%$ of young men and $88 \%$ of young women) and fewer reported awareness of male sterilisation ( $48 \%$ and $22 \%$, respectively). Few youth reported awareness of emergency contraception (22\% and 19\% of young men and women, respectively), implants, vaginal methods or injectables (15-17\%). Compared to awareness of modern methods, awareness of traditional methods (mainly withdrawal) was relatively limited, reported by just $21 \%$ of young men and $16 \%$ of young women. Findings clearly show a significant gender divide in terms of contraceptive methods known; young women were generally more likely than young men to report awareness of female-oriented methods and vice versa. Notable exceptions included awareness of emergency contraceptive pills and such methods as implants, vaginal methods and injectables, and traditional methods about which almost equal percentages of young men and women reported awareness.

Marital status differences in terms of awareness of individual contraceptive methods consistently show that the married were more likely than the unmarried to report awareness. Patterns, however, varied. For example, with regard to awareness of the condom, differences were relatively narrow ( $98 \%$ and $96 \%$ among married and unmarried young men; $88 \%$ and $80 \%$, correspondingly, among young women). Differences were wider with regard to, for example, awareness about the IUD ( $48 \%$ and $28 \%$ among married and unmarried young men; $82 \%$ and $51 \%$, correspondingly, among young women) and traditional methods, mainly withdrawal (45\% and 19\% among married and unmarried young men; $29 \%$ and $7 \%$, correspondingly, among young women). Rural-urban differences were by and large negligible among young women and were apparent among young men only for some methods, such as emergency contraceptive pills, IUDs, male and female sterilisation, and implants, vaginal methods and injectables. Rural-urban differences were far more evident when married and unmarried respondents were considered separately, with the exception of unmarried young women among whom differences were negligible for the most part. For example, awareness of the IUD was reported by 55\% and $43 \%$, respectively, among married young men in urban and rural settings; by $88 \%$ and $77 \%$, respectively, among married young women, and $34 \%$ and $24 \%$ among unmarried young men.

In order to assess the extent to which youth had correct specific knowledge of contraceptive methods, and had not just heard of various methods, the Youth Study inquired whether youth were aware of the frequency with which oral contraceptives must be consumed (daily or weekly); the number of sex acts for which one condom could be used (one); the number of hours following sex that emergency contraceptive pills could be consumed (72 hours); where the IUD is placed (uterus); and when a man practising withdrawal should pull out of a woman (prior to ejaculation). Panel B of Table 8.3 presents percentages of youth reporting correct specific knowledge of these five methods.

Correct specific knowledge of at least one of these five methods was reported by almost four-fifths of young men and over half of young women. Gender differences in correct specific knowledge of contraceptive methods are evident from findings presented in Table 8.3. Overall young men were considerably more likely than young women to report correct specific knowledge of at least one method. However, young women were more likely than young men to report correct specific knowledge of female-oriented methods such as oral pills (24\% compared to $20 \%$ ) and the IUD (38\% compared to $19 \%)$; conversely, more young men than women reported correct specific knowledge of the condom (77\% compared to $39 \%)$ and withdrawal (16\% compared to $8 \%$ ). Differences by marital status suggest that the married were uniformly more likely than the unmarried to report correct specific knowledge of every method, and differences were generally wider 
Table 8.3: Awareness of contraceptive methods

Percentage of youth who repor awareness and correct specific knowledge of various contraceptive methods, according to residence, Tamil Nadu, 2006

\begin{tabular}{|c|c|c|c|c|c|c|}
\hline Awareness indicators (\%) & $\begin{array}{c}\mathrm{M} \\
15-24\end{array}$ & $\begin{array}{c}\text { W } \\
15-24\end{array}$ & $\begin{array}{c}\text { MM } \\
15-29\end{array}$ & $\begin{array}{c}\text { MW } \\
15-24\end{array}$ & $\begin{array}{c}\text { UM } \\
15-24\end{array}$ & $\begin{array}{c}\text { UW } \\
15-24\end{array}$ \\
\hline \multicolumn{7}{|c|}{ A. Awareness } \\
\hline \multicolumn{7}{|c|}{ Combined } \\
\hline Any method & 96.8 & 97.9 & 99.2 & 99.9 & 96.5 & 96.6 \\
\hline Any modern method & 96.7 & 97.8 & 99.2 & 99.8 & 96.5 & 96.6 \\
\hline Oral pills & 57.1 & 65.4 & 71.7 & 76.3 & 56.2 & 58.2 \\
\hline Emergency contraceptive pills & 22.2 & 19.1 & 32.1 & 24.9 & 21.4 & 15.3 \\
\hline Condom & 95.8 & 83.4 & 98.3 & 88.0 & 95.6 & 80.4 \\
\hline IUD & 29.0 & 63.3 & 48.0 & 81.6 & 28.3 & 51.2 \\
\hline Female sterilisation & 68.3 & 88.1 & 83.5 & 92.1 & 67.2 & 85.4 \\
\hline Male sterilisation & 48.0 & 21.8 & 58.6 & 23.9 & 47.5 & 20.4 \\
\hline Implant/vaginal methods/injectables & 15.1 & 16.5 & 17.7 & 20.7 & 15.1 & 13.7 \\
\hline Any traditional method & 21.1 & 15.7 & 44.7 & 29.1 & 18.8 & 6.8 \\
\hline Withdrawal & 19.1 & 13.3 & 42.5 & 26.4 & 16.9 & 4.7 \\
\hline Safe period & 0.6 & 3.4 & 2.1 & 5.1 & 0.5 & 2.3 \\
\hline Traditional/herbal methods & 2.4 & 0.9 & 3.2 & 0.9 & 2.1 & 0.9 \\
\hline Number of respondents & 1,913 & 5,008 & 1,322 & 2,007 & 1,666 & 3,001 \\
\hline \multicolumn{7}{|c|}{ Urban } \\
\hline Any method & 96.5 & 98.4 & 98.7 & 100.0 & 96.3 & 97.4 \\
\hline Any modern method & 96.5 & 98.3 & 98.7 & 99.9 & 96.3 & 97.4 \\
\hline Oral pills & 58.1 & 65.0 & 74.4 & 76.4 & 57.0 & 58.4 \\
\hline Emergency contraceptive pills & 26.1 & 19.6 & 36.8 & 26.5 & 25.3 & 15.7 \\
\hline Condom & 96.2 & 86.1 & 98.7 & 91.4 & 96.0 & 83.1 \\
\hline IUD & 35.1 & 64.7 & 55.1 & 87.8 & 34.1 & 51.2 \\
\hline Female sterilisation & 74.2 & 88.6 & 88.2 & 92.1 & 73.3 & 86.5 \\
\hline Male sterilisation & 53.8 & 24.0 & 65.6 & 26.7 & 53.5 & 22.3 \\
\hline Implant/vaginal methods/injectables & 17.8 & 16.2 & 21.0 & 20.5 & 17.7 & 13.7 \\
\hline Any traditional method & 21.9 & 16.5 & 45.7 & 30.8 & 19.9 & 8.3 \\
\hline Withdrawal & 21.0 & 14.0 & 44.6 & 28.5 & 19.1 & 5.6 \\
\hline Safe period & 0.7 & 3.9 & 2.8 & 5.6 & 0.8 & 2.9 \\
\hline Traditional/herbal methods & 1.0 & 0.8 & 2.0 & 0.7 & 0.8 & 0.9 \\
\hline Number of respondents & 890 & 2,151 & 653 & 804 & 789 & 1,347 \\
\hline \multicolumn{7}{|c|}{ Rural } \\
\hline Any method & 97.1 & 97.5 & 99.6 & 99.8 & 96.7 & 95.8 \\
\hline Any modern method & 96.9 & 97.4 & 99.5 & 99.7 & 96.5 & 95.8 \\
\hline Oral pills & 56.4 & 65.7 & 69.7 & 76.2 & 55.7 & 58.0 \\
\hline Emergency contraceptive pills & 19.2 & 18.7 & 28.8 & 23.8 & 18.1 & 15.0 \\
\hline Condom & 95.6 & 81.3 & 97.9 & 85.6 & 95.2 & 78.1 \\
\hline IUD & 24.4 & 62.2 & 43.0 & 77.4 & 23.6 & 51.3 \\
\hline Female sterilisation & 63.7 & 87.7 & 80.1 & 92.1 & 62.1 & 84.5 \\
\hline Male sterilisation & 43.6 & 20.0 & 53.8 & 22.0 & 42.7 & 18.6 \\
\hline Implant/vaginal methods/injectables & 13.0 & 16.8 & 15.4 & 20.8 & 12.9 & 13.8 \\
\hline Any traditional method & 20.5 & 15.0 & 44.0 & 28.0 & 17.9 & 5.6 \\
\hline Withdrawal & 17.7 & 12.7 & 41.1 & 24.9 & 15.0 & 3.9 \\
\hline Safe period & 0.4 & 3.0 & 1.7 & 4.8 & 0.3 & 1.7 \\
\hline Traditional/herbal methods & 3.5 & 1.0 & 4.0 & 1.0 & 3.2 & 1.0 \\
\hline Number of respondents & 1,023 & 2,857 & 669 & 1,203 & 877 & 1,654 \\
\hline
\end{tabular}


Table 8.3: (Cont'd)

\begin{tabular}{|c|c|c|c|c|c|c|}
\hline Awareness indicators (\%) & $\begin{array}{c}M \\
15-24\end{array}$ & $\begin{array}{c}W \\
15-24\end{array}$ & $\begin{array}{c}\text { MM } \\
15-29\end{array}$ & $\begin{array}{c}\text { MW } \\
15-24\end{array}$ & $\begin{array}{c}\text { UM } \\
15-24\end{array}$ & $\begin{array}{c}\text { UW } \\
15-24\end{array}$ \\
\hline \multicolumn{7}{|c|}{ B. Correct specific knowledge ${ }^{1}$} \\
\hline \multicolumn{7}{|c|}{ Combined } \\
\hline Any method & 79.4 & 53.5 & 95.2 & 74.9 & 78.0 & 39.4 \\
\hline At least one modern method & 78.3 & 52.4 & 91.1 & 72.2 & 77.3 & 39.4 \\
\hline Oral pills & 20.2 & 23.5 & 34.0 & 34.7 & 19.8 & 16.1 \\
\hline Emergency contraceptive pills & 8.6 & 6.4 & 15.5 & 9.8 & 8.5 & 4.3 \\
\hline Condoms & 77.0 & 38.6 & 89.4 & 49.5 & 76.1 & 31.4 \\
\hline IUD & 19.0 & 38.2 & 34.2 & 57.2 & 18.4 & 25.7 \\
\hline $\begin{array}{l}\text { Any traditional method } \\
\text { Withdrawal }\end{array}$ & 16.3 & 8.4 & 40.2 & 20.0 & 13.9 & 0.8 \\
\hline Number of respondents & 1,913 & 5,008 & 1,322 & 2,007 & 1,666 & 3,001 \\
\hline \multicolumn{7}{|c|}{ Urban } \\
\hline Any method & 81.1 & 54.0 & 94.3 & 79.5 & 80.1 & 39.2 \\
\hline At least one modern method & 80.4 & 53.3 & 92.8 & 77.6 & 79.5 & 39.2 \\
\hline Oral pills & 22.9 & 24.2 & 36.3 & 37.3 & 22.9 & 16.6 \\
\hline Emergency contraceptive pills & 10.9 & 7.2 & 18.0 & 10.9 & 11.0 & 5.1 \\
\hline Condoms & 79.2 & 40.0 & 92.1 & 54.4 & 78.3 & 31.7 \\
\hline IUD & 24.9 & 39.0 & 42.0 & 64.0 & 24.1 & 24.4 \\
\hline $\begin{array}{l}\text { Any traditional method } \\
\text { Withdrawal }\end{array}$ & 17.8 & 8.1 & 42.5 & 20.7 & 15.8 & 0.8 \\
\hline Number of respondents & 890 & 2,151 & 653 & 804 & 789 & 1,347 \\
\hline \multicolumn{7}{|c|}{ Rural } \\
\hline Any method & 78.1 & 53.1 & 95.8 & 71.8 & 76.3 & 39.6 \\
\hline At least one modern method & 76.7 & 51.8 & 90.0 & 68.6 & 75.5 & 39.6 \\
\hline Oral pills & 18.0 & 23.0 & 32.3 & 33.0 & 17.3 & 15.8 \\
\hline Emergency contraceptive pills & 6.8 & 5.8 & 13.8 & 9.0 & 6.4 & 3.5 \\
\hline Condoms & 75.4 & 37.5 & 87.5 & 46.2 & 74.2 & 31.2 \\
\hline IUD & 14.5 & 37.7 & 28.9 & 52.7 & 13.7 & 26.8 \\
\hline $\begin{array}{l}\text { Any traditional method } \\
\text { Withdrawal }\end{array}$ & 15.2 & 8.6 & 38.4 & 19.4 & 12.5 & 0.8 \\
\hline Number of respondents & 1,023 & 2,857 & 669 & 1,203 & 877 & 1,654 \\
\hline
\end{tabular}

Note: All Ns are unweighted. ${ }^{1}$ Correct specific knowledge was assessed for oral pills, emergency contraceptive pills, condoms, IUD and withdrawal. The following questions were asked (correct answers in brackets)—Oral pills: How often should a woman take pills? [Daily/Weekly]; Emergency contraceptive pills: How soon after sexual intercourse should these pills be taken? [72 hours]; Condoms: For how many acts of sexual intercourse can one condom be used? [One]; IUD: Where is the IUD placed? [Uterus]; Withdrawal: When should a man pull out of a woman during sexual intercourse? [Prior to ejaculation].

among young women than men (see Figure 8.2). In contrast, rural-urban differentials were narrow, with urban respondents moderately more likely than their rural counterparts to report correct specific knowledge of every method. Rural-urban differences were more pronounced among married young women than among all other groups.

\subsubsection{Condom-related perceptions}

Among youth who reported awareness of condoms, the Youth Study probed perceptions regarding three specific aspects of this method, namely, whether condoms are a suitable method for preventing pregnancy, 
Figure 8.2: Percentage of youth who reported correct specific knowledge of oral pills and condoms, according to residence, Tamil Nadu, 2006

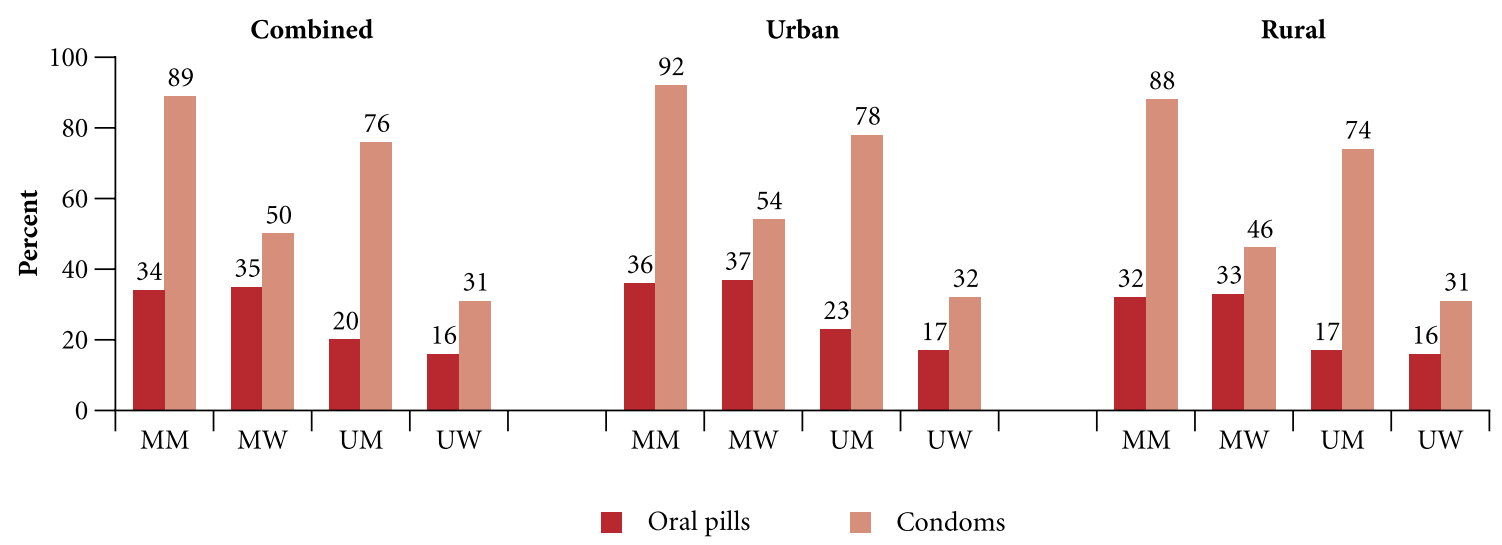

whether condoms can slip off a man and disappear inside a woman's body and whether condoms reduce sexual pleasure. Findings, presented in Table 8.4, show that $93 \%$ of young men and women agreed that condoms are a suitable method for preventing pregnancy. However, just $46 \%$ and $12 \%$ of young men and women were aware that condoms cannot disappear inside a woman's body and just $31 \%$ of young men and $21 \%$ of young women perceived that condoms do not reduce sexual pleasure. By and large findings confirm that more young men than young women were correctly informed about condoms.

While the married and the unmarried were equally likely to report that condoms are a suitable method for preventing pregnancy, wide differences were observed by marital status with regard to the remaining two statements. For example, the married were far more likely than the unmarried to know that condoms cannot disappear inside a woman's body; $67 \%$ of married young men compared to $44 \%$ of unmarried young men, and $19 \%$ of married young women compared to $7 \%$ of unmarried young women reported such awareness. Differences by marital status were also observed in the case of awareness that condoms do not reduce sexual pleasure: $41 \%$ and $31 \%$ of married young men and women compared to $31 \%$ and $13 \%$ of unmarried men and women reported such awareness. Rural-urban differences were negligible for the most part, except that urban young men were slightly more likely than their rural counterparts to report that condoms do not reduce sexual pleasure ( $34 \%$ and $29 \%$, respectively).

\subsubsection{Awareness of contraception prior to marriage}

Married youth were specifically asked whether they had been aware of contraception or had known where to obtain contraceptives prior to their marriage. Findings, presented in Table 8.5, suggest that of those who were aware of at least one method of contraception at the time of interview, pre-marital awareness of even one method of contraception was far from universal and young women were particularly poorly informed. For example, $72 \%$ of young men compared to just $22 \%$ of young women had been aware of a contraceptive method before marriage. Likewise, urban youth were somewhat more likely to report awareness of a contraceptive method before marriage than rural youth - differences were marginal among young men ( $74 \%$ and $70 \%$ for urban and rural young men, respectively) and somewhat wider among young women (27\% and $19 \%$, respectively). 
Table 8.4: Perceptions of selected issues related to condom use

Percent distribution of youth by their perceptions of condom use, according to residence, Tamil Nadu, 2006

\begin{tabular}{|c|c|c|c|c|c|c|}
\hline Perceptions (\%) & $\begin{array}{c}\text { M } \\
15-24\end{array}$ & $\begin{array}{c}W \\
15-24\end{array}$ & $\begin{array}{c}\text { MM } \\
15-29\end{array}$ & $\begin{array}{l}\text { MW } \\
15-24\end{array}$ & $\begin{array}{c}\text { UM } \\
15-24\end{array}$ & $\begin{array}{l}\text { UW } \\
15-24\end{array}$ \\
\hline \multicolumn{7}{|c|}{ Combined } \\
\hline \multicolumn{7}{|c|}{$\begin{array}{l}\text { Condoms are a suitable method for } \\
\text { preventing pregnancy }\end{array}$} \\
\hline Agree & 92.8 & 92.7 & 97.7 & 95.2 & 92.2 & 91.0 \\
\hline Disagree & 1.2 & 2.3 & 1.3 & 2.5 & 1.3 & 2.2 \\
\hline Don't know/can't say & 5.9 & 4.7 & 1.0 & 2.0 & 6.4 & 6.5 \\
\hline \multicolumn{7}{|c|}{$\begin{array}{l}\text { Condoms can slip off a man and disappear } \\
\text { inside a woman's body }\end{array}$} \\
\hline Agree & 4.2 & 2.5 & 5.9 & 4.8 & 3.8 & 0.9 \\
\hline Disagree & 45.8 & 12.0 & 66.9 & 19.0 & 44.2 & 6.9 \\
\hline Don't know/can't say & 49.9 & 85.2 & 27.1 & 75.9 & 51.9 & 91.9 \\
\hline \multicolumn{7}{|c|}{ Condoms reduce sexual pleasure } \\
\hline Agree & 25.6 & 12.3 & 41.9 & 19.7 & 23.3 & 7.0 \\
\hline Disagree & 31.2 & 20.6 & 41.1 & 30.8 & 31.1 & 13.3 \\
\hline Don't know/can't say & 43.2 & 66.8 & 17.0 & 49.3 & 45.6 & 79.4 \\
\hline Number aware of condoms & 1,835 & 4,174 & 1,300 & 1,767 & 1,591 & 2,407 \\
\hline \multicolumn{7}{|c|}{ Urban } \\
\hline \multicolumn{7}{|c|}{$\begin{array}{l}\text { Condoms are a suitable method for } \\
\text { preventing pregnancy }\end{array}$} \\
\hline Agree & 93.6 & 91.7 & 97.8 & 94.1 & 93.2 & 90.3 \\
\hline Disagree & 1.1 & 2.7 & 1.1 & 3.4 & 1.3 & 2.2 \\
\hline Don't know/can't say & 5.3 & 5.5 & 1.1 & 2.6 & 5.6 & 7.4 \\
\hline \multicolumn{7}{|c|}{$\begin{array}{l}\text { Condoms can slip off a man and disappear } \\
\text { inside a woman's body }\end{array}$} \\
\hline Agree & 2.6 & 1.5 & 4.5 & 2.8 & 2.4 & 0.6 \\
\hline Disagree & 48.2 & 12.5 & 71.8 & 20.9 & 46.6 & 7.1 \\
\hline Don't know/can't say & 49.1 & 85.9 & 23.7 & 76.1 & 50.9 & 92.2 \\
\hline \multicolumn{7}{|c|}{ Condoms reduce sexual pleasure } \\
\hline Agree & 23.5 & 11.8 & 39.4 & 20.4 & 21.8 & 6.4 \\
\hline Disagree & 34.2 & 18.7 & 45.3 & 27.6 & 34.1 & 13.0 \\
\hline Don't know/can't say & 42.3 & 69.4 & 15.3 & 52.0 & 44.1 & 80.5 \\
\hline Number aware of condoms & 858 & 1,850 & 646 & 734 & 758 & 1,116 \\
\hline \multicolumn{7}{|c|}{ Rural } \\
\hline \multicolumn{7}{|c|}{$\begin{array}{l}\text { Condoms are a suitable method for } \\
\text { preventing pregnancy }\end{array}$} \\
\hline Agree & 92.3 & 93.5 & 97.5 & 96.0 & 91.4 & 91.5 \\
\hline Disagree & 1.2 & 2.0 & 1.4 & 1.9 & 1.4 & 2.2 \\
\hline Don’t know/can't say & 6.5 & 4.0 & 1.0 & 1.8 & 7.1 & 5.9 \\
\hline \multicolumn{7}{|c|}{$\begin{array}{l}\text { Condoms can slip off a man and disappear } \\
\text { inside a woman's body }\end{array}$} \\
\hline Agree & 5.4 & 3.5 & 7.1 & 6.3 & 5.0 & 1.2 \\
\hline Disagree & 44.0 & 11.5 & 63.4 & 17.6 & 42.3 & 6.7 \\
\hline Don’t know/can't say & 50.5 & 84.5 & 29.5 & 75.6 & 52.6 & 91.7 \\
\hline \multicolumn{7}{|c|}{ Condoms reduce sexual pleasure } \\
\hline Agree & 27.2 & 12.7 & 43.7 & 19.1 & 24.5 & 7.7 \\
\hline Disagree & 28.8 & 22.2 & 38.2 & 33.2 & 28.6 & 13.4 \\
\hline Don't know/can't say & 43.9 & 64.6 & 18.2 & 47.3 & 46.8 & 78.4 \\
\hline Number aware of condoms & 977 & 2,324 & 654 & 1,033 & 833 & 1,291 \\
\hline
\end{tabular}

Note: All Ns are unweighted. Column totals may not equal 100\% due to missing cases. 
Table 8.5: Awareness of contraception prior to marriage

Percentage of married youth aware of any contraceptive method prior to marriage and percentage aware of a source of contraceptive supplies at that time, according to residence, Tamil Nadu, 2006

\begin{tabular}{|c|c|c|c|c|c|c|}
\hline \multirow[t]{2}{*}{ Knowledge (\%) } & $\begin{array}{c}\text { MM } \\
15-29\end{array}$ & $\begin{array}{c}\text { MW } \\
15-24\end{array}$ & $\begin{array}{c}\text { MM } \\
15-29\end{array}$ & $\begin{array}{c}\text { MW } \\
15-24\end{array}$ & $\begin{array}{c}\text { MM } \\
15-29\end{array}$ & $\begin{array}{c}\text { MW } \\
15-24\end{array}$ \\
\hline & \multicolumn{2}{|c|}{ Combined } & \multicolumn{2}{|c|}{ Urban } & \multicolumn{2}{|c|}{ Rural } \\
\hline $\begin{array}{l}\text { Aware of any contraceptive method } \\
\text { before marriage }\end{array}$ & 71.9 & 22.4 & 74.1 & 27.2 & 70.3 & 19.2 \\
\hline Aware of a contraceptive source before marriage & 69.7 & 11.4 & 73.1 & 13.1 & 67.3 & 10.2 \\
\hline $\begin{array}{l}\text { Number currently aware of at least one } \\
\text { contraceptive method }\end{array}$ & 1,311 & 2,005 & 646 & 804 & 665 & 1,201 \\
\hline
\end{tabular}

Note: All Ns are unweighted.

Awareness before marriage about where to obtain contraceptives was similarly far from universal and gender differences even wider. Among married young men, $70 \%$ reported awareness of where to obtain contraceptives. In contrast, among married young women, the percentage of those who were aware, prior to marriage, of a source of contraceptive supplies was considerably lower than those who were aware of a contraceptive method; just $11 \%$ knew where to obtain contraceptives. Rural-urban differentials, however, were mild.

\subsubsection{Awareness of medical abortion}

Given that medical abortion has been legal since 2002, youth were asked if they were aware of "any pills" that a woman could take to terminate a pregnancy. As evident from Figure $8.3,36 \%$ of young men and 54\% of young women reported that they were aware of such a method (since we did not probe further, some of these positive responses may not have been specifically referring to the mifepristone-misoprostol combination, but rather to the variety of herbal and ayurvedic medications and other home remedies available). About one-third of youth reported that they were unsure whether such a means of inducing abortion existed.

Figure 8.3: Percent distribution of youth by awareness of medical abortion, according to residence, Tamil Nadu, 2006

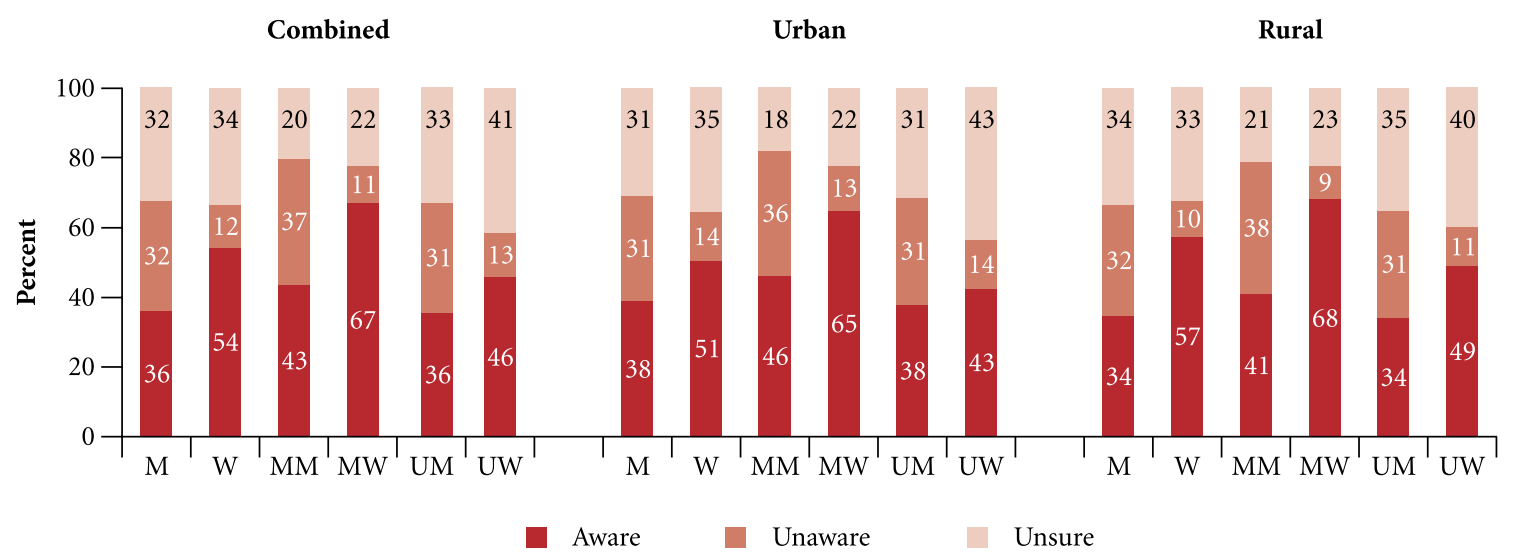


Marital status differences were evident, with the married more likely than the unmarried to be aware of medical abortion. Differences in awareness levels were narrower among young men ( $43 \%$ and $36 \%$ among the married and unmarried, respectively) than young women ( $67 \%$ and $46 \%$, respectively). Rural-urban differences were generally muted, however, somewhat more rural than urban young women (57\% versus $51 \%)$, and, conversely, somewhat more urban than rural young men (38\% versus 34\%) were aware of medical abortion.

\subsubsection{Awareness of sexually transmitted infections (STIs) and HIV/AIDS}

The Youth Study inquired whether youth had ever heard of infections that were transmitted through sexual contact. Findings, presented in Table 8.6, suggest that awareness of STIs other than HIV/AIDS was limited among young men, and particularly among young women; $31 \%$ of young men and only $12 \%$ of young women reported such awareness. Differences by marital status were evident: married youth were more likely to be aware of STIs (other than HIV) than were unmarried youth (37\% and 30\% among married and unmarried young men, respectively; and $16 \%$ and $9 \%$ among young women, respectively). Differences by rural-urban residence were by and large negligible for both young men and women.

Among those who were aware of STIs other than HIV, the vast majority (69-77\%) could identify at least one symptom of infection. Urban-rural differences were negligible among young women; however, urban young men were somewhat more likely than their rural counterparts to be aware of at least one symptom of infection ( $83 \%$ compared to $72 \%)$. Marital status differences were mild, but slightly more married than unmarried youth could identify one symptom of infection.

Questions exploring young people's awareness of HIV/AIDS were adapted from those used in the NFHS (IIPS and Macro International, 2007b). Findings, presented in Table 8.6, show that awareness levels of HIV were uniformly high, with little difference between young men and women (99\% and $97 \%$ of young men and women, respectively, had heard of HIV/AIDS), Differences by marital status and rural-urban residence were similarly negligible.

Notwithstanding these high overall levels of awareness of HIV/AIDS, among those who reported awareness of HIV/AIDS, knowledge of specific aspects of the disease was by no means complete. For example, $92 \%$ of young men and $90 \%$ of young women who had heard of HIV/AIDS were aware that one could reduce the chances of contracting HIV by being faithful to a single partner. Awareness that one can reduce the chances of contracting HIV by using a condom every time one has sex was reported by just $85 \%$ of young men and $76 \%$ of young women. Differences by marital status were by and large negligible. The unmarried were just slightly less likely than married youth to report awareness that one could reduce chances of acquiring HIV by staying faithful to a single partner ( $92 \%$ compared to $96 \%$ among young men, and $89 \%$ compared to $92 \%$ among young women) or consistently using condoms ( $85 \%$ compared to $89 \%$ among young men, and $74 \%$ compared to $81 \%$ among young women). Rural-urban differences were negligible in terms of awareness of ways of reducing HIV transmission.

Findings show, moreover, that rejection of common misconceptions about modes of HIV transmission was far from universal. Between $79 \%$ and $88 \%$ of young men and between $80 \%$ and $83 \%$ of young women believed that one cannot acquire HIV through mosquito bites, by sharing food with or by hugging a person with HIV and that one cannot tell if a person is infected by just looking at him or her. Differences by marital status and rural-urban residence were mild. 
Table 8.6: Awareness of STIs and HIV/AIDS

Percent distribution of youth who had heard of and had specific knowledge about STIs and HIV/ AIDS, according to residence, Tamil Nadu, 2006

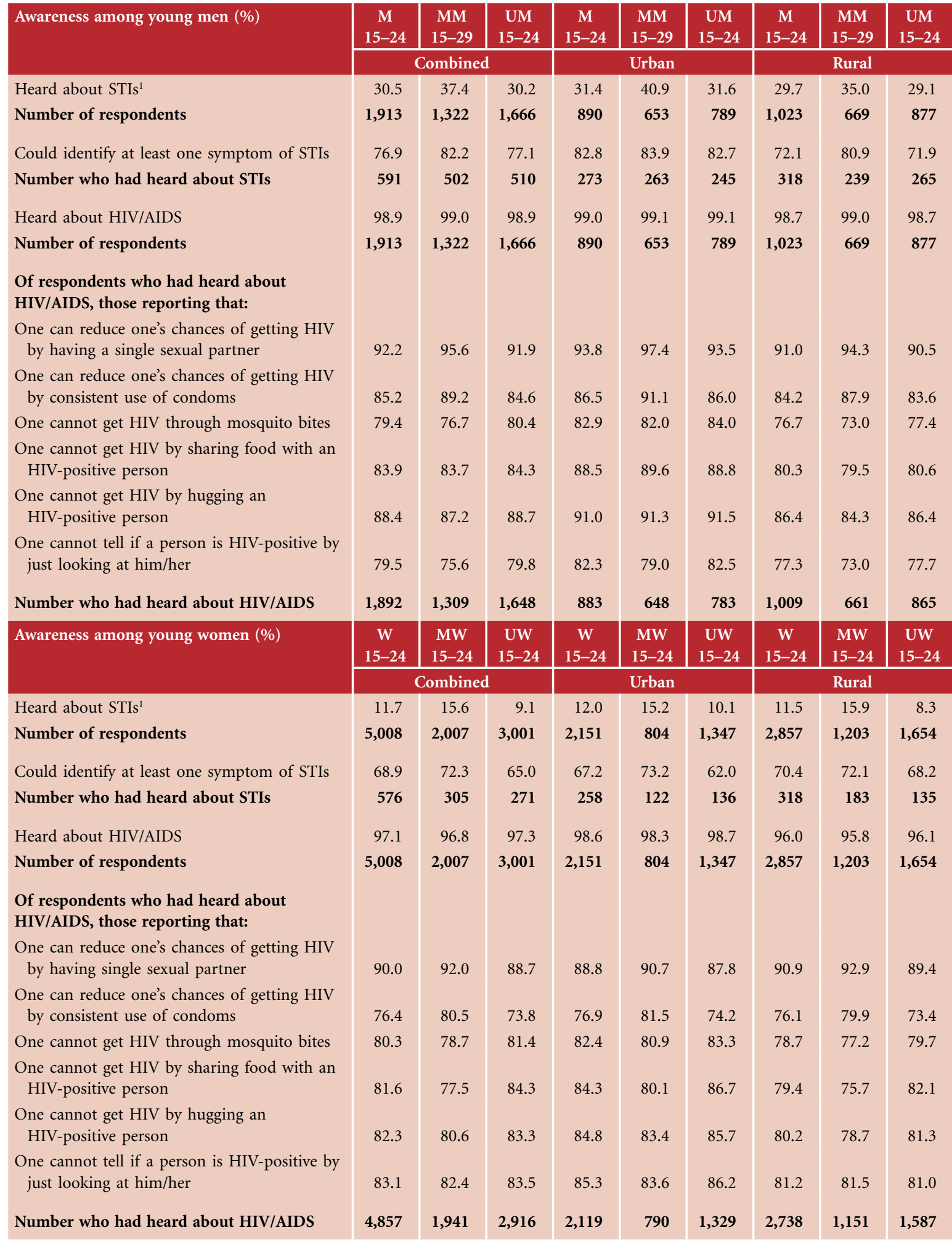

Note: All Ns are unweighted. ${ }^{1}$ Other than HIV. 


\subsubsection{Comprehensive awareness of HIV/AIDS}

We measure comprehensive awareness of HIV/AIDS on the basis of information obtained regarding respondents' knowledge of HIV prevention and transmission. Comprehensive awareness is defined as knowledge of two ways of preventing HIV (specifically, condom use and single partner relations), rejection of common misconceptions about HIV transmission (namely, that HIV can be transmitted through mosquito bites, sharing food or hugging) and awareness that one cannot tell by looking at a person whether he or she has HIV. Findings are presented in Table 8.7 and suggest limited comprehensive awareness of HIV/AIDS; half of young men $(50 \%)$ and $46 \%$ of young women reported comprehensive awareness. Variation by marital status was negligible (45-48\% among the married and 46-50\% among the unmarried). More urban youth than rural youth reported comprehensive awareness of HIV/AIDS; 55\% and 49\% of young men and women in urban settings, respectively, compared to $46 \%$ and $42 \%$ of young men and women, respectively, in rural settings reported so.

Comprehensive awareness of HIV/AIDS was greater among older, better educated and economically better off youth than others. For example, $37 \%$ of young men with no formal education displayed comprehensive HIV/AIDS awareness, compared to $66 \%$ of those with 12 or more years of education; comprehensive HIV/ AIDS awareness was reported likewise by $24 \%$ of young women with no formal education compared to $61 \%$ of those with 12 or more years of education. Similar patterns were observed among the married and unmarried as shown in Figure 8.4a. Likewise, comprehensive awareness increased from 36\% among young men in the poorest (first) wealth quintile to $62 \%$ among those in the wealthiest (fifth) quintile, and from $33 \%$ to $58 \%$, respectively, among young women. Similar patterns were observed among the married and unmarried as shown in Figure $8.4 \mathrm{~b}$.

Differentials with regard to religion suggest that fewer Hindu youth reported comprehensive awareness of HIV/AIDS than those of other religions (49\% and 56\%, respectively, in the case of young men; $45 \%$ and $47-53 \%$ among young women). Caste-wise differences indicate that youth from scheduled castes were somewhat less likely to report comprehensive awareness than were those from other backward castes (45\% and 52\%, respectively, among young men; $42 \%$ and $47 \%$ among young women). Differences by current economic activity indicate that those not engaged in any economic activity were better informed about HIV/AIDS than those who were engaged in work (55\% compared to $46 \%$ among young men, and $49 \%$ compared to $39 \%$, among young women), perhaps because many of those who were not working were in school or college and therefore more likely to be exposed to HIV-related information. Socio-demographic differences in rural and urban settings more or less mirrored the pattern observed for the combined sample.

A comparison of awareness of HIV and other STIs, presented in Figure 8.5, underscores the wide gap between awareness of HIV and comprehensive knowledge about its modes of transmission. It also shows that awareness of STIs other than HIV among youth was far more limited than awareness of HIV/AIDS and even comprehensive knowledge of HIV/AIDS. 
Figure 8.4a: Comprehensive knowledge of HIV/AIDS by educational level, Tamil Nadu, 2006

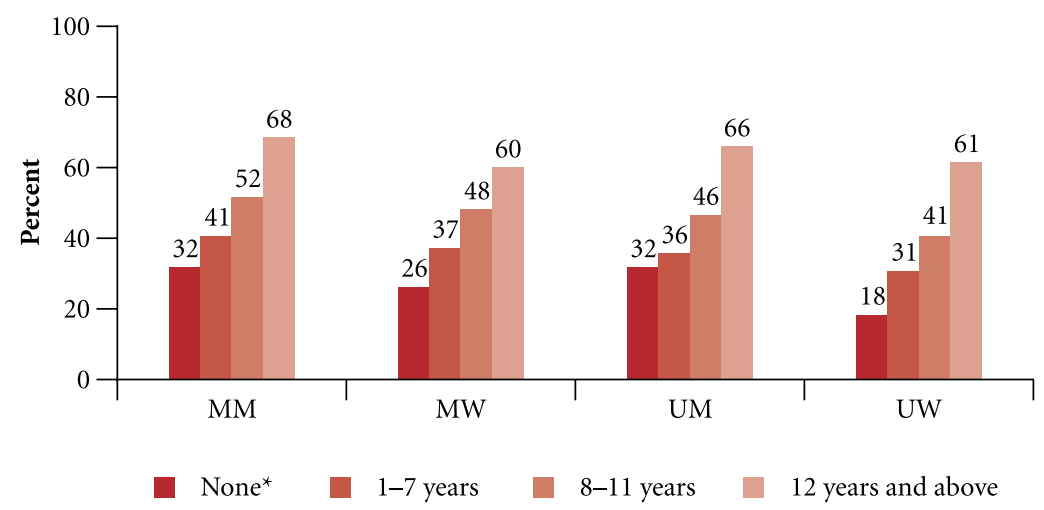

Note: ${ }^{\star}$ Includes non-literate and literate with no formal schooling.

Figure 8.4b: Comprehensive knowledge of HIV/AIDS by wealth quintile, Tamil Nadu, 2006

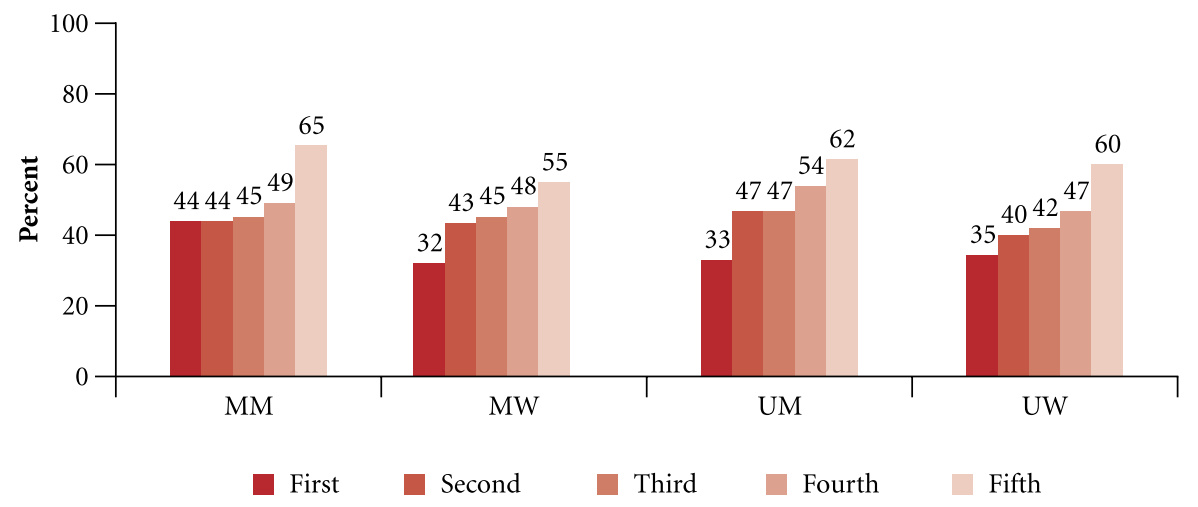

Figure 8.5: Percentage of youth by awareness of HIV/AIDS, comprehensive knowledge about HIV/AIDS and awareness of STIs, Tamil Nadu, 2006

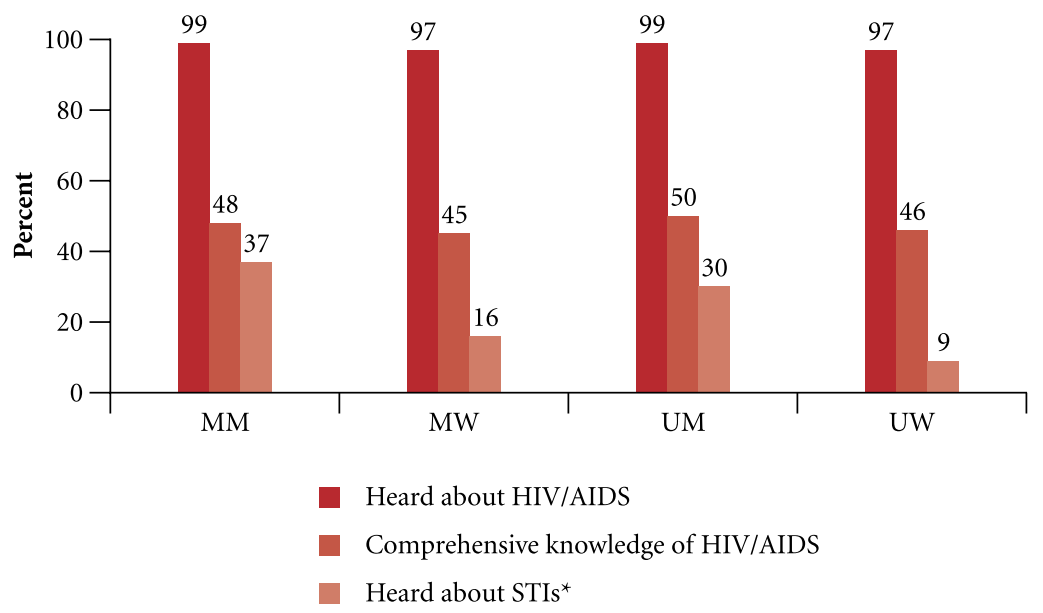

Note: ${ }^{\star}$ Other than HIV. 
Table 8.7: Comprehensive knowledge of HIV/AIDS by selected background characteristics

Percentage of youth who had comprehensive knowledge of HIV/AIDS by selected background characteristics, according to residence, Tamil Nadu, 2006

\begin{tabular}{|c|c|c|c|c|c|c|}
\hline Background characteristics (\%) & $\begin{array}{c}M \\
15-24\end{array}$ & $\begin{array}{c}\mathrm{W} \\
15-24\end{array}$ & $\begin{array}{c}\text { MM } \\
15-29\end{array}$ & $\begin{array}{c}\text { MW } \\
15-24\end{array}$ & $\begin{array}{c}\text { UM } \\
15-24\end{array}$ & $\begin{array}{c}\text { UW } \\
15-24\end{array}$ \\
\hline \multicolumn{7}{|c|}{ Combined } \\
\hline \multicolumn{7}{|l|}{ Age (years) } \\
\hline $15-19$ & 47.2 & 42.7 & * & 39.3 & 47.1 & 43.3 \\
\hline $20-24$ & 51.9 & 47.8 & 46.2 & 45.8 & 53.2 & 51.0 \\
\hline $25-29$ & NA & NA & 48.7 & NA & NA & NA \\
\hline \multicolumn{7}{|l|}{ Religion } \\
\hline Hindu & 49.0 & 44.9 & 48.2 & 43.4 & 49.3 & 46.0 \\
\hline Muslim & 55.6 & 47.3 & 55.7 & 53.1 & 55.4 & 42.1 \\
\hline Other $^{1}$ & 55.7 & 52.7 & $(41.5)$ & 61.8 & 56.9 & 49.5 \\
\hline \multicolumn{7}{|l|}{ Caste } \\
\hline SC & 44.6 & 41.6 & 49.8 & 39.7 & 43.8 & 42.9 \\
\hline OBC & 51.5 & 46.9 & 48.6 & 46.7 & 52.1 & 47.0 \\
\hline \multicolumn{7}{|l|}{ Educational level (years) } \\
\hline None $^{2}$ & 37.2 & 24.2 & 31.7 & 26.2 & $(32.0)$ & 18.2 \\
\hline $1-7$ & 37.1 & 34.4 & 40.6 & 37.2 & 35.6 & 30.8 \\
\hline $8-11$ & 46.5 & 43.9 & 51.5 & 48.1 & 46.3 & 41.4 \\
\hline 12 and above & 66.2 & 61.0 & 68.2 & 59.9 & 66.2 & 61.4 \\
\hline \multicolumn{7}{|l|}{ Worked in last 12 months } \\
\hline Yes & 46.2 & 38.9 & 48.3 & 40.7 & 46.2 & 38.1 \\
\hline No & 55.2 & 48.8 & * & 46.3 & 55.3 & 50.6 \\
\hline \multicolumn{7}{|l|}{ Wealth quintile } \\
\hline First & 35.8 & 33.4 & 43.5 & 31.9 & 32.9 & 34.6 \\
\hline Second & 47.0 & 41.0 & 43.8 & 42.8 & 46.9 & 39.7 \\
\hline Third & 46.4 & 43.2 & 45.4 & 45.1 & 46.6 & 41.9 \\
\hline Fourth & 52.6 & 47.0 & 48.9 & 47.6 & 53.7 & 46.7 \\
\hline Fifth & 61.6 & 58.1 & 65.3 & 54.8 & 61.5 & 59.6 \\
\hline Total & 49.6 & 45.5 & 48.3 & 44.7 & 49.9 & 46.0 \\
\hline \multicolumn{7}{|c|}{ Urban } \\
\hline \multicolumn{7}{|l|}{ Age (years) } \\
\hline $15-19$ & 52.5 & 47.3 & * & 46.4 & 52.3 & 47.4 \\
\hline $20-24$ & 56.6 & 51.2 & 47.6 & 48.5 & 58.4 & 55.2 \\
\hline $25-29$ & NA & NA & 57.5 & NA & NA & NA \\
\hline \multicolumn{7}{|l|}{ Religion } \\
\hline Hindu & 53.8 & 49.4 & 56.5 & 47.2 & 54.4 & 50.7 \\
\hline Muslim & 57.6 & 47.8 & 59.3 & 53.3 & 56.7 & 43.4 \\
\hline Other $^{1}$ & $(68.8)$ & 52.3 & * & $(54.3)$ & $(73.3)$ & 52.1 \\
\hline \multicolumn{7}{|l|}{ Caste } \\
\hline SC & 50.3 & 41.5 & 54.2 & 38.1 & 51.7 & 43.5 \\
\hline OBC & 55.8 & 51.8 & 57.1 & 51.4 & 56.0 & 52.0 \\
\hline \multicolumn{7}{|l|}{ Educational level (years) } \\
\hline None $^{2}$ & * & 26.8 & * & 24.6 & * & * \\
\hline $1-7$ & 40.6 & 35.8 & 44.1 & 38.7 & 39.8 & 32.4 \\
\hline $8-11$ & 49.9 & 46.9 & 60.9 & 51.4 & 49.5 & 44.4 \\
\hline 12 and above & 70.6 & 62.0 & 71.6 & 59.8 & 71.0 & 62.6 \\
\hline
\end{tabular}

Cont'd on next page... 
Table 8.7: (Cont'd)

\begin{tabular}{|c|c|c|c|c|c|c|}
\hline Background characteristics (\%) & $\begin{array}{c}\mathrm{M} \\
15-24\end{array}$ & $\begin{array}{c}\text { W } \\
15-24\end{array}$ & $\begin{array}{c}\text { MM } \\
15-29\end{array}$ & $\begin{array}{c}\text { MW } \\
\text { 15-24 }\end{array}$ & $\begin{array}{c}\text { UM } \\
15-24\end{array}$ & $\begin{array}{c}\text { UW } \\
15-24\end{array}$ \\
\hline \multicolumn{7}{|c|}{ Urban } \\
\hline \multicolumn{7}{|l|}{ Worked in last 12 months } \\
\hline Yes & 49.9 & 43.6 & 55.9 & 42.7 & 50.2 & 43.9 \\
\hline No & 61.5 & 51.2 & * & 49.2 & 61.4 & 52.7 \\
\hline \multicolumn{7}{|l|}{ Wealth quintile } \\
\hline First & 40.7 & 40.2 & 51.2 & 43.3 & 41.3 & 37.1 \\
\hline Second & 57.6 & 44.8 & 51.0 & 42.5 & 60.3 & 46.4 \\
\hline Third & 43.2 & 44.3 & 51.7 & 47.0 & 42.3 & 42.4 \\
\hline Fourth & 53.9 & 45.5 & 55.2 & 45.5 & 55.1 & 45.4 \\
\hline Fifth & 62.8 & 58.9 & 65.0 & 55.9 & 62.7 & 60.2 \\
\hline Total & 54.6 & 49.4 & 56.0 & 48.3 & 55.3 & 50.1 \\
\hline \multicolumn{7}{|c|}{ Rural } \\
\hline \multicolumn{7}{|l|}{ Age (years) } \\
\hline $15-19$ & 43.3 & 39.1 & * & 36.2 & 43.2 & 39.7 \\
\hline $20-24$ & 48.1 & 45.0 & 45.5 & 43.8 & 48.7 & 47.2 \\
\hline $25-29$ & NA & NA & 42.1 & NA & NA & NA \\
\hline \multicolumn{7}{|l|}{ Religion } \\
\hline Hindu & 45.6 & 41.7 & 43.0 & 41.2 & 45.5 & 42.1 \\
\hline Muslim & * & 45.8 & * & $(52.4)$ & * & $(38.1)$ \\
\hline Other $^{1}$ & $(46.8)$ & 53.0 & $(44.4)$ & $(70.6)$ & $(46.5)$ & 47.4 \\
\hline \multicolumn{7}{|l|}{ Caste } \\
\hline SC & 41.2 & 41.7 & 47.6 & 40.4 & 38.6 & 42.6 \\
\hline $\mathrm{OBC}$ & 47.9 & 42.6 & 42.1 & 43.2 & 48.6 & 42.2 \\
\hline \multicolumn{7}{|l|}{ Educational level (years) } \\
\hline None $^{2}$ & $(42.4)$ & 22.7 & 29.9 & 26.8 & * & $(12.2)$ \\
\hline $1-7$ & 34.6 & 33.6 & 38.3 & 36.3 & 32.7 & 29.8 \\
\hline $8-11$ & 44.1 & 41.8 & 45.0 & 45.8 & 44.1 & 39.4 \\
\hline 12 and above & 61.1 & 59.7 & 63.6 & 59.6 & 60.2 & 59.7 \\
\hline \multicolumn{7}{|l|}{ Worked in last 12 months } \\
\hline Yes & 43.7 & 36.9 & 42.9 & 40.2 & 43.2 & 34.7 \\
\hline No & 49.6 & 46.3 & * & 43.7 & 49.6 & 48.4 \\
\hline \multicolumn{7}{|l|}{ Wealth quintile } \\
\hline First & 34.6 & 31.8 & 41.7 & 29.0 & 30.5 & 34.1 \\
\hline Second & 43.3 & 39.6 & 40.9 & 42.7 & 42.7 & 37.2 \\
\hline Third & 48.3 & 42.6 & 41.6 & 43.9 & 49.5 & 41.5 \\
\hline Fourth & 51.2 & 48.7 & 40.7 & 49.5 & 52.0 & 48.3 \\
\hline Fifth & 58.3 & 55.8 & $(66.0)$ & 52.9 & 57.8 & 57.9 \\
\hline Total & 45.7 & 42.3 & 43.0 & 42.4 & 45.6 & 42.3 \\
\hline
\end{tabular}

Note: ( ) Based on 25-49 unweighted cases. ${ }^{*}$ Percentage not shown, based on fewer than 25 unweighted cases. Comprehensive knowledge of HIV/AIDS includes: (1) identifying two major ways of preventing HIV (using condoms and limiting sex to one partner); (2) rejecting three common misconceptions about HIV transmission (that HIV can be transmitted through mosquito bites, sharing food with a person who has HIV or hugging someone who has HIV); and (3) knowing that a healthy looking person can be HIV-positive. NA: Not applicable. OBC: Other backward caste. SC: Scheduled caste. ${ }^{1}$ Includes Christian, Buddhist, Neo-Buddhist, Sikh, Jain, Jewish, Parsi/Zoroastrian and no specified religion. ${ }^{2}$ Includes non-literate and literate with no formal schooling. 


\subsection{Knowledge of legal issues related to marriage and abortion}

Lack of awareness of such issues as the legal minimum age at marriage and the fact that abortion services are legally available may pose barriers to health promoting behaviours. In this section, we present young people's awareness about the law on each of these issues.

\subsubsection{Knowledge of the legal minimum age at marriage}

The Youth Study collected information on whether youth were aware of the existence of laws relating to the minimum age at marriage for males and females in India and probed specific knowledge of these laws. Findings are presented in Table 8.8 and suggest widespread awareness of the laws governing the minimum age at marriage for both males (89-95\%) and females (98-99\%); gender disparities were narrow, but young men were slightly more likely than young women to be aware of laws concerning the minimum age at marriage for males (95\% compared to $89 \%)$.

Table 8.8: Knowledge of the legal minimum age at marriage

Percentage of youth who had correct knowledge of the legal minimum age at marriage in India, according to residence, Tamil Nadu, 2006

\begin{tabular}{|c|c|c|c|c|c|c|}
\hline Knowledge (\%) & $\underset{15-24}{M}$ & $\begin{array}{c}\mathrm{W} \\
15-24\end{array}$ & $\begin{array}{c}\text { MM } \\
15-29\end{array}$ & $\begin{array}{c}\text { MW } \\
15-24\end{array}$ & $\begin{array}{c}\mathrm{UM} \\
15-24\end{array}$ & $\begin{array}{l}\text { UW } \\
15-24\end{array}$ \\
\hline \multicolumn{7}{|c|}{ Combined } \\
\hline $\begin{array}{l}\text { Aware that there is a legal age at marriage for: } \\
\text { Males }\end{array}$ & 94.5 & 88.6 & 95.9 & 87.8 & 94.5 & 89.1 \\
\hline Females & 98.6 & 97.6 & 98.9 & 97.1 & 98.6 & 97.9 \\
\hline Aware of correct legal age at marriage for: & & & & & & \\
\hline Males & 30.3 & 23.8 & 29.3 & 21.0 & 30.7 & 25.7 \\
\hline Females & 42.1 & 32.7 & 39.6 & 33.0 & 41.7 & 32.5 \\
\hline Number of respondents & 1,913 & 5,008 & 1,322 & 2,007 & 1,666 & 3,001 \\
\hline \multicolumn{7}{|c|}{ Urban } \\
\hline $\begin{array}{l}\text { Aware that there is a legal age at marriage for: } \\
\text { Males }\end{array}$ & 94.7 & 88.1 & 95.6 & 88.3 & 94.8 & 87.9 \\
\hline Females & 99.2 & 98.6 & 98.9 & 98.3 & 99.1 & 98.6 \\
\hline Aware of correct legal age at marriage for: & & & & & & \\
\hline Males & 31.3 & 22.8 & 31.5 & 20.5 & 31.7 & 24.2 \\
\hline Females & 40.7 & 30.6 & 39.2 & 31.9 & 40.4 & 29.9 \\
\hline Number of respondents & 890 & 2,151 & 653 & 804 & 789 & 1,347 \\
\hline \multicolumn{7}{|c|}{ Rural } \\
\hline $\begin{array}{l}\text { Aware that there is a legal age at marriage for: } \\
\text { Males }\end{array}$ & 94.3 & 89.0 & 96.1 & 87.6 & 94.2 & 90.1 \\
\hline Females & 98.2 & 96.8 & 99.0 & 96.2 & 98.2 & 97.2 \\
\hline Aware of correct legal age at marriage for: & & & & & & \\
\hline Males & 29.6 & 24.6 & 28.0 & 21.2 & 30.0 & 27.0 \\
\hline Females & 43.1 & 34.4 & 39.8 & 33.8 & 42.8 & 34.8 \\
\hline Number of respondents & 1,023 & 2,857 & 669 & 1,203 & 877 & 1,654 \\
\hline
\end{tabular}

Note: All Ns are unweighted. 
The correct legal minimum age at marriage for females and especially males was however, far less likely to be known. For example, $42 \%$ of young men and 33\% of young women correctly reported that 18 years is the legal minimum age at marriage for females; however, only $30 \%$ of young men and $24 \%$ of young women correctly reported that 21 is the legal minimum age at marriage for males. Differences by marital status and rural-urban residence of respondents were mild, except that slightly more unmarried young women than their married counterparts (26\% compared to $21 \%$ ) reported awareness of the correct legal minimum age at marriage for males.

In Tamil Nadu, the finding that relatively few youth were correctly informed about the minimum legal age at marriage can perhaps be explained by the fact that programmes in the state have actively encouraged marriage to be delayed beyond the legal minimum age-to 25 and 21 years, respectively, among young men and women-leading many youth to perceive these as minimum legal ages at marriage. Indeed, $27 \%$ of young men and $34 \%$ of young women reported 25 as the legal minimum age at marriage for males, and $39 \%$ and $49 \%$, respectively, reported 21 as the minimum legal age at marriage for females (not shown in tabular form).

\subsubsection{Awareness of the conditions under which abortion is legal}

The Youth Study posed a number of questions to gauge youth awareness of the conditions under which abortion is legal, for example, if the woman is married, if the woman is unmarried, if the pregnancy exceeds 20 weeks and if the foetus is female but the couple wants a son. Findings are presented in Table 8.9.

Of the four conditions probed, the largest percentages of youth-88-89\%-were aware that sex-selective abortion is illegal, presumably the result of widespread information campaigns against sex-selective abortion. A second issue about which large percentages of respondents were aware was that it is illegal to terminate a pregnancy that has gone beyond 20 weeks $(62-68 \%)$. Many fewer youth were aware that an unmarried woman is legally entitled to undergo an abortion (36\% and $49 \%$ of young men and women, respectively) and even fewer were aware that a married woman is legally entitled to undergo abortion ( $23 \%$ of both young men and women). The married were as or more likely than the unmarried to be aware of each of the legal conditions under which abortion is permitted (see also Figure 8.6). Rural-urban differences were mild, except that awareness that abortion is legal for unmarried women was more likely to be expressed by rural than

Figure 8.6: Percentage of youth who were aware of selected conditions under which abortion is legal, Tamil Nadu, 2006

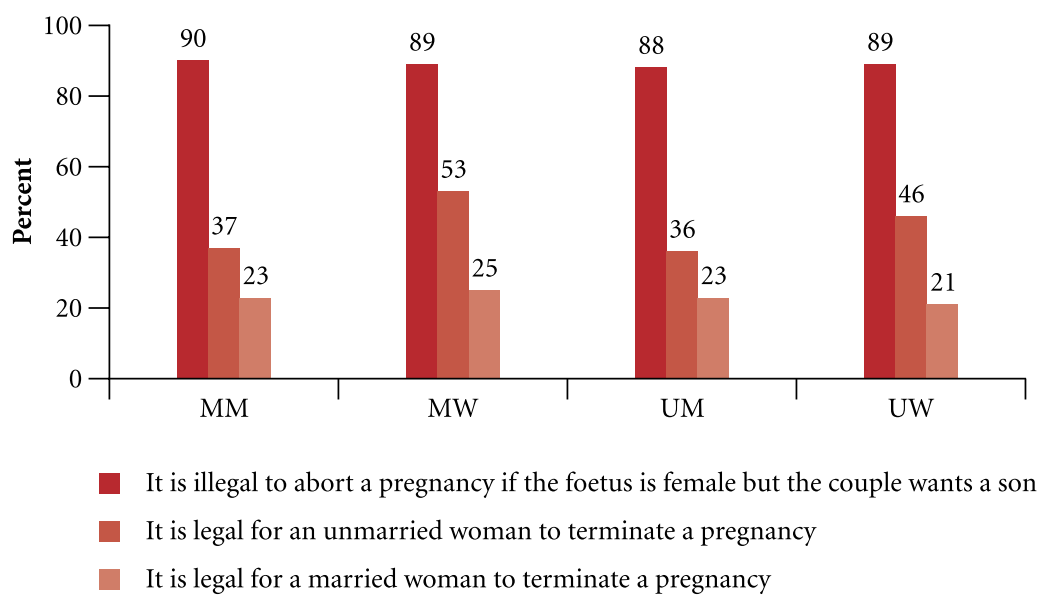


Table 8.9: Awareness of the conditions under which abortion is legal

Percent distribution of youth by knowledge of the conditions under which abortion is legal, according to residence, Tamil Nadu, 2006

\begin{tabular}{|c|c|c|c|c|c|c|}
\hline Knowledge (\%) & $\begin{array}{c}M \\
15-24\end{array}$ & $\begin{array}{c}\text { W } \\
15-24\end{array}$ & $\begin{array}{c}\text { MM } \\
15-29\end{array}$ & $\begin{array}{c}\text { MW } \\
15-24\end{array}$ & $\begin{array}{c}\text { UM } \\
15-24\end{array}$ & $\begin{array}{l}\text { UW } \\
15-24\end{array}$ \\
\hline \multicolumn{7}{|c|}{ Combined } \\
\hline $\begin{array}{l}\text { Agree that it is legal for a married woman to } \\
\text { terminate a pregnancy }\end{array}$ & 22.5 & 22.6 & 22.9 & 25.4 & 22.7 & 20.8 \\
\hline $\begin{array}{l}\text { Agree that it is legal for an unmarried woman to } \\
\text { terminate a pregnancy }\end{array}$ & 36.2 & 48.7 & 36.8 & 53.3 & 36.3 & 45.6 \\
\hline $\begin{array}{l}\text { Agree that it is illegal to undergo abortion after } 20 \\
\text { weeks of gestation }\end{array}$ & 61.6 & 68.1 & 68.0 & 69.9 & 61.1 & 66.9 \\
\hline $\begin{array}{l}\text { Disagree that it is legal to abort a pregnancy if the } \\
\text { foetus is female but the couple wants a son }\end{array}$ & 87.8 & 88.9 & 90.0 & 89.3 & 87.5 & 88.6 \\
\hline Had correct knowledge of all of the above & 6.0 & 5.8 & 6.6 & 6.9 & 6.3 & 5.1 \\
\hline Number of respondents & 1,913 & 5,008 & 1,322 & 2,007 & 1,666 & 3,001 \\
\hline \multicolumn{7}{|c|}{ Urban } \\
\hline $\begin{array}{l}\text { Agree that it is legal for a married woman to } \\
\text { terminate a pregnancy }\end{array}$ & 24.8 & 23.4 & 25.6 & 26.7 & 24.8 & 21.6 \\
\hline $\begin{array}{l}\text { Agree that it is legal for an unmarried woman to } \\
\text { terminate a pregnancy }\end{array}$ & 32.0 & 46.0 & 30.2 & 50.2 & 32.7 & 43.5 \\
\hline $\begin{array}{l}\text { Agree that it is illegal to undergo abortion after } 20 \\
\text { weeks of gestation }\end{array}$ & 66.1 & 69.6 & 69.7 & 70.7 & 65.6 & 69.0 \\
\hline $\begin{array}{l}\text { Disagree that it is legal to abort a pregnancy if the } \\
\text { foetus is female but the couple wants a son }\end{array}$ & 88.8 & 90.0 & 92.1 & 90.6 & 88.9 & 89.7 \\
\hline Had correct knowledge of all of the above & 7.9 & 6.4 & 7.4 & 7.8 & 8.6 & 5.6 \\
\hline Number of respondents & 890 & 2,151 & 653 & 804 & 789 & 1,347 \\
\hline \multicolumn{7}{|c|}{ Rural } \\
\hline $\begin{array}{l}\text { Agree that it is legal for a married woman to } \\
\text { terminate a pregnancy }\end{array}$ & 20.7 & 22.0 & 21.1 & 24.4 & 21.0 & 20.2 \\
\hline $\begin{array}{l}\text { Agree that it is legal for an unmarried woman to } \\
\text { terminate a pregnancy }\end{array}$ & 39.5 & 50.8 & 41.5 & 55.4 & 39.3 & 47.5 \\
\hline $\begin{array}{l}\text { Agree that it is illegal to undergo abortion after } 20 \\
\text { weeks of gestation }\end{array}$ & 58.1 & 66.9 & 67.0 & 69.3 & 57.4 & 65.2 \\
\hline $\begin{array}{l}\text { Disagree that it is legal to abort a pregnancy if the } \\
\text { foetus is female but the couple wants a son }\end{array}$ & 87.0 & 88.0 & 88.4 & 88.4 & 86.3 & 87.7 \\
\hline Had correct knowledge of all of the above & 4.5 & 5.3 & 6.0 & 6.3 & 4.5 & 4.6 \\
\hline Number of respondents & 1,023 & 2,857 & 669 & 1,203 & 877 & 1,654 \\
\hline
\end{tabular}

Note: All Ns are unweighted.

urban youth (40\% and 51\% compared to $32 \%$ and $46 \%$ of young men and women, respectively, of those in rural and urban areas). Conversely, more urban than rural youth reported awareness that it is illegal to terminate a pregnancy that has gone beyond 20 weeks (66-70\% versus $58-67 \%)$.

As is evident from Table 8.9 , few youth (6\%) could correctly report the legality of all four conditions probed. Differences by marital status and rural-urban residence were mild. 


\subsection{Sources of information on sex and reproduction}

The Youth Study questionnaire asked respondents about their sources of information on sexual matters and contraception. For the married, questions about sources of information on sexual matters referred to the situation prior to marriage; in contrast, questions relating to sources of information about contraception referred to the current situation, that is, around the time of interview.

\subsubsection{Sources of information on sexual matters}

Findings, presented in Table 8.10, suggest that the large majority of youth (for the married, prior to marriage) had access to information on sex and reproduction. However, gender differences were apparent: while just 6\% of young men reported that they had never received any information on sexual matters, many more-22\%—of young women so reported. While marital status differences were negligible among young men, they were wide among young women: $30 \%$ of married young women compared to many fewer (17\%) unmarried young women reported that they had never received information on sex or reproduction. Rural-urban differences were, in contrast, negligible, except that married young women in rural areas were more likely than their urban counterparts to report that they had never received information on sexual matters.

Leading sources of information on sex and reproduction varied between young men and women. Among young men, leading sources of information reported were friends and neighbours (74\%), followed by the media (56\%), teachers/schools (16\%) and posters/billboards (9\%). Among young women, leading sources of information were largely the media (60\%), followed by friends and neighbours (19\%) and teachers/schools $(10 \%)$. Posters and billboards were hardly ever cited by young women $(<1 \%)$.

Differences in patterns were noted among the married and the unmarried. Among young women, for example, more of the unmarried than the married cited the media a source of information (67\% compared to $49 \%$ ). Among young men, friends and neighbours were more likely to be cited as a source of information by the married than the unmarried ( $82 \%$ and $73 \%$, respectively). And among both young men and women, teachers and schools were much more likely to be reported by the unmarried than the married: $14-17 \%$ and $3-7 \%$, respectively.

Patterns were similar in urban and rural areas, yet urban youth were somewhat more likely than rural youth to cite the media as the main source of information. Additionally, urban young men were more likely than their rural counterparts to report posters/ billboards as sources of information.

\subsubsection{Current sources of information on contraception}

Table 8.11 describes current sources of information on contraception as reported by youth who were aware of at least one contraceptive method. Findings reiterate, as above, that friends and the media played an important role in conveying contraception-related information to young people.

Sources of information on contraception did however vary by sex of the respondent. For example, key sources of information for young men were male friends/neighbours (68\%) and the media (62\%), followed by teachers/ school/college (15\%), and posters or billboards (9\%). Young women in contrast reported a different pattern, and a greater variety of sources of information on contraceptives than young men. While the media were also a leading source of information on contraception for young women (69\%), large proportions additionally cited sources as female friends/neighbours (35\%) and family members other than spouse (23\%). Of interest also is the finding that among married young women a leading source of information was their husband 
Table 8.10: Sources of information on sexual matters before marriage

Percentage of youth by sources of information on sexual matters before marriage, according to residence, Tamil Nadu, 2006

\begin{tabular}{|c|c|c|c|c|c|c|}
\hline Sources of information (\%) & $\begin{array}{c}M \\
15-24\end{array}$ & $\begin{array}{c}W \\
15-24\end{array}$ & $\begin{array}{c}\text { MM } \\
15-29\end{array}$ & $\begin{array}{c}\text { MW } \\
15-24\end{array}$ & $\begin{array}{c}\text { UM } \\
15-24\end{array}$ & $\begin{array}{c}\text { UW } \\
15-24\end{array}$ \\
\hline \multicolumn{7}{|c|}{ Combined } \\
\hline Never received information & 5.7 & 21.7 & 3.6 & 29.6 & 6.0 & 16.6 \\
\hline A family member other than spouse & 2.1 & 5.7 & 2.7 & 6.8 & 1.9 & 4.9 \\
\hline Spouse/partner & 0.1 & 0.9 & 0.5 & 2.2 & 0.0 & 0.0 \\
\hline Friend/neighbour & 73.6 & 18.7 & 82.4 & 16.8 & 72.5 & 19.9 \\
\hline Teacher/school & 16.1 & 9.6 & 7.3 & 3.3 & 17.2 & 13.8 \\
\hline Health care provider & 4.8 & 3.4 & 7.0 & 3.3 & 4.7 & 3.4 \\
\hline Mass media ${ }^{1}$ & 56.0 & 59.7 & 57.0 & 48.8 & 56.4 & 66.8 \\
\hline $\begin{array}{l}\text { Youth/mahila mandal/magalir manrar } \\
\text { NGO worker }\end{array}$ & 1.3 & 2.5 & 2.0 & 1.3 & 1.4 & 3.3 \\
\hline Poster/billboard & 9.3 & 0.4 & 10.4 & 0.4 & 9.2 & 0.4 \\
\hline Don't remember & 2.1 & 8.8 & 2.1 & 11.7 & 1.9 & 7.0 \\
\hline Number of respondents & 1,913 & 5,008 & 1,322 & 2,007 & 1,666 & 3,001 \\
\hline \multicolumn{7}{|c|}{ Urban } \\
\hline Never received information & 5.9 & 19.8 & 4.1 & 26.3 & 6.0 & 16.0 \\
\hline A family member other than spouse & 1.6 & 6.5 & 1.7 & 9.1 & 1.2 & 5.0 \\
\hline Spouse/partner & 0.1 & 0.5 & 0.6 & 1.5 & 0.0 & 0.0 \\
\hline Friend/neighbour & 71.8 & 19.2 & 83.1 & 17.8 & 70.9 & 20.0 \\
\hline Teacher/school & 15.8 & 10.6 & 6.6 & 4.0 & 17.0 & 14.5 \\
\hline Health care provider & 4.2 & 3.3 & 5.5 & 3.6 & 4.3 & 3.2 \\
\hline Mass media ${ }^{1}$ & 59.9 & 66.5 & 59.1 & 56.4 & 60.1 & 72.5 \\
\hline $\begin{array}{l}\text { Youth/mahila mandal/magalir manrar } \\
\text { NGO worker }\end{array}$ & 1.1 & 1.3 & 1.3 & 0.7 & 1.1 & 1.6 \\
\hline Poster/billboard & 14.5 & 0.5 & 14.9 & 0.6 & 14.5 & 0.5 \\
\hline Don't remember & 2.0 & 6.7 & 3.1 & 8.9 & 1.9 & 5.4 \\
\hline Number of respondents & 890 & 2,151 & 653 & 804 & 789 & 1,347 \\
\hline \multicolumn{7}{|c|}{ Rural } \\
\hline Never received information & 5.5 & 23.2 & 3.2 & 31.7 & 6.0 & 17.0 \\
\hline A family member other than spouse & 2.5 & 5.0 & 3.5 & 5.2 & 2.5 & 4.8 \\
\hline Spouse/partner & 0.1 & 1.2 & 0.5 & 2.8 & 0.0 & 0.0 \\
\hline Friend/neighbour & 75.0 & 18.2 & 81.8 & 16.0 & 73.9 & 19.8 \\
\hline Teacher/school & 16.3 & 8.8 & 7.8 & 2.9 & 17.3 & 13.1 \\
\hline Health care provider & 5.2 & 3.4 & 8.1 & 3.1 & 5.0 & 3.6 \\
\hline Mass media ${ }^{1}$ & 53.0 & 54.2 & 55.5 & 43.7 & 53.4 & 61.8 \\
\hline $\begin{array}{l}\text { Youth/mahila mandal/magalir manrar } \\
\text { NGO worker }\end{array}$ & 1.5 & 3.4 & 2.4 & 1.7 & 1.6 & 4.7 \\
\hline Poster/billboard & 5.4 & 0.3 & 7.3 & 0.3 & 4.9 & 0.3 \\
\hline Don't remember & 2.1 & 10.6 & 1.4 & 13.5 & 2.0 & 8.5 \\
\hline Number of respondents & 1,023 & 2,857 & 669 & 1,203 & 877 & 1,654 \\
\hline
\end{tabular}

Note: All Ns are unweighted. Column totals may exceed 100\% due to multiple responses. For married respondents, questions referred to the period prior to marriage. ${ }^{1}$ Include newspapers, books/magazines, radio/television and the internet. 
(52\%); married young men in contrast rarely reported their wife as a source of information on contraception (14\%). Just $6 \%$ of young men and $15 \%$ of young women obtained their information from a health care provider, and $15 \%$ and $9 \%$, respectively, obtained this information from a teacher.

Marital status differences were evident. Among young men, the married were more likely than the unmarried to obtain information from friends and neighbours $(80 \%$ versus $67 \%)$ and health care providers $(13 \%$ versus $6 \%)$ and less likely to obtain their information from teachers (6\% versus $16 \%)$ and the media (56\% versus $64 \%)$. Among young women, the married were somewhat more likely than the unmarried to receive information on contraception from female friends and neighbours (38\% versus $33 \%$ ), other family members ( $27 \%$ versus $21 \%)$ and considerably more likely to receive information from health care providers ( $28 \%$ versus $5 \%$ ). In contrast, unmarried young women were more likely than the married to report the media ( $79 \%$ versus 56\%), and teachers (14\% versus $2 \%)$ as sources of information on contraception. As noted earlier, over half of married young women reported that they obtained information on contraception from their husband.

Rural-urban differences were by and large narrow. Among young men, those in rural settings were somewhat less likely than those in urban settings to obtain information from the media ( $58 \%$ versus $68 \%$ ) or posters and billboards ( $7 \%$ versus 13\%). Amongst young women, those in rural areas were more likely than their urban counterparts to cite friends and neighbours (37\% versus $32 \%$ ) but less likely to cite the media (63\% versus $77 \%$ ) as a source of information on contraception.

It is evident that leading sources of information on contraception among young people who were aware of at least one contraceptive method were largely similar to the sources of information on sexual matters reported by all youth (prior to marriage for the married) reported in the previous section. Among the leading sources of information on both contraception and sexual matters were peers and the media. In contrast, few youth cited a family member as a source of information on sex or contraception; the exception was married young women, half of whom cited their husband as a leading source of information on contraception. Teachers, charged with providing family life education to youth, were seldom cited as a source of information, reaching fewer than one in five unmarried youth. Health care providers also played a limited role in providing youth information on contraception. Indeed, that neither men nor the unmarried have come under the purview of health care providers, and health care providers were not even leading sources of information on contraception for married women, are possibly a consequence of the lack of attention that the RCH Programme has paid, thus far, to young people. Moreover, the finding that less than one in three married young women were reached with information on contraception underscores the extent to which the perception that information on contraception is useful only once childbearing is complete persists. In short, health care providers, teachers and family members - often considered more credible sources of information than peers and the media-were infrequently cited as sources of information on these sensitive topics by young people.

\subsection{Perceptions and experience of family life or sex education}

In the Youth Study, we asked respondents about their views on the importance of imparting family life or sex education to youth, the ideal age at which youth should receive information about sexual matters and the best person to provide that information. We also asked youth whether they had received formal family life or sex education and if so, the source of this education and their opinion about its quality.

Table 8.12 presents findings on young people's perceptions of family life or sex education. The majority of respondents perceived that it is important to impart family life or sex education to youth. Gender differences were evident: young men were more likely than young women (81\% compared to $71 \%$ ) to recognise the importance of providing family life or sex education to youth. Differences by marital status and rural-urban were, in contrast, negligible. 
Table 8.11: Current sources of information on contraception

Percentage of youth reporting awareness of contraceptives by current sources of information, according to residence, Tamil Nadu, 2006

\begin{tabular}{|c|c|c|c|c|c|c|}
\hline Current sources of information (\%) & $\begin{array}{c}M \\
15-24\end{array}$ & $\begin{array}{c}\text { W } \\
15-24\end{array}$ & $\begin{array}{c}\text { MM } \\
15-29\end{array}$ & $\begin{array}{l}\text { MW } \\
15-24\end{array}$ & $\begin{array}{c}\text { UM } \\
15-24\end{array}$ & $\begin{array}{l}\text { UW } \\
15-24\end{array}$ \\
\hline \multicolumn{7}{|c|}{ Combined } \\
\hline Family member other than spouse & 3.2 & 23.1 & 6.5 & 26.7 & 3.0 & 20.7 \\
\hline Spouse/partner & 1.1 & 20.9 & 14.3 & 51.5 & 0.0 & 0.0 \\
\hline Female friend/neighbour & 0.6 & 35.0 & 0.8 & 38.3 & 0.6 & 32.7 \\
\hline Male friend/neighbour & 68.3 & 0.2 & 79.9 & 0.2 & 66.5 & 0.1 \\
\hline Teacher/school/college & 14.8 & 9.0 & 5.8 & 2.0 & 15.9 & 13.7 \\
\hline Health care provider & 6.3 & 14.6 & 13.2 & 28.3 & 5.7 & 5.2 \\
\hline Mass media ${ }^{1}$ & 62.4 & 69.2 & 55.8 & 55.5 & 64.0 & 78.6 \\
\hline Poster/billboard & 9.4 & 1.6 & 9.2 & 1.0 & 9.4 & 2.1 \\
\hline $\begin{array}{l}\text { Youth/mahila mandal/magalir manram } \\
\text { NGO worker }\end{array}$ & 1.1 & 2.2 & 1.5 & 1.5 & 1.1 & 2.7 \\
\hline Number aware of contraceptives & 1,853 & 4,901 & 1,311 & 2,005 & 1,608 & 2,896 \\
\hline \multicolumn{7}{|c|}{ Urban } \\
\hline Family member other than spouse & 3.5 & 24.6 & 6.7 & 30.7 & 3.5 & 21.0 \\
\hline Spouse/partner & 1.1 & 19.8 & 15.5 & 52.9 & 0.0 & 0.1 \\
\hline Female friend/neighbour & 0.7 & 31.9 & 0.4 & 36.1 & 0.8 & 29.5 \\
\hline Male friend/neighbour & 68.8 & 0.1 & 83.0 & 0.1 & 67.1 & 0.1 \\
\hline Teacher/school/college & 15.2 & 10.3 & 4.7 & 2.5 & 16.3 & 15.0 \\
\hline Health care provider & 4.2 & 15.3 & 10.3 & 32.5 & 4.0 & 5.0 \\
\hline 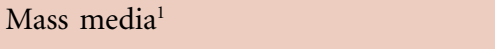 & 67.7 & 76.8 & 60.3 & 62.2 & 68.2 & 85.5 \\
\hline Poster/billboard & 12.8 & 2.1 & 12.9 & 0.9 & 12.7 & 2.8 \\
\hline $\begin{array}{l}\text { Youth/mahila mandal/magalir manram } \\
\text { NGO worker }\end{array}$ & 0.6 & 1.4 & 0.9 & 0.9 & 0.7 & 1.7 \\
\hline Number aware of contraceptives & 861 & 2,115 & 646 & 804 & 761 & 1,311 \\
\hline \multicolumn{7}{|c|}{ Rural } \\
\hline Family member other than spouse & 3.0 & 22.0 & 6.3 & 23.9 & 2.8 & 20.5 \\
\hline Spouse/partner & 1.1 & 21.7 & 13.5 & 50.5 & 0.0 & 0.0 \\
\hline Female friend/neighbour & 0.5 & 37.4 & 1.0 & 39.8 & 0.4 & 35.6 \\
\hline Male friend/neighbour & 67.9 & 0.3 & 77.7 & 0.3 & 66.0 & 0.2 \\
\hline Teacher/school/college & 14.5 & 8.0 & 6.5 & 1.8 & 15.5 & 12.6 \\
\hline Health care provider & 7.9 & 14.0 & 15.2 & 25.4 & 7.0 & 5.4 \\
\hline Mass medial & 58.3 & 63.1 & 52.8 & 50.8 & 60.6 & 72.4 \\
\hline Poster/billboard & 6.7 & 1.3 & 6.7 & 1.1 & 6.9 & 1.4 \\
\hline $\begin{array}{l}\text { Youth/mahila mandal/magalir manram } \\
\text { NGO worker }\end{array}$ & 1.4 & 2.8 & 1.9 & 2.0 & 1.6 & 3.5 \\
\hline Number aware of contraceptives & 992 & 2,786 & 665 & 1,201 & 847 & 1,585 \\
\hline
\end{tabular}

Note: All Ns are unweighted. Column totals may not equal 100\% due to multiple responses. ${ }^{1}$ Include newspapers, books/ magazines, radio/television and the internet. 
Of those who perceived family life or sex education to be important, the majority believed that this education should be provided to youth aged 15 or older. Indeed, $37 \%$ of young men and $46 \%$ of young women reported that such education should be provided to young people at ages between 15 and 17 years, and over half of young men (54\%) and $44 \%$ of young women believed that this information should be provided at age 18 or older. In contrast, just $8-9 \%$ of youth believed that it was appropriate to provide such education to adolescents under age 15 .

Differences by marital status were not wide, but typically the married were more likely than the unmarried (60\% and $49 \%$ of married young men and women, compared to $54 \%$ and $41 \%$ of the unmarried, respectively) to consider 18 or older appropriate ages to provide family life or sex education. Differences by rural-urban residence were negligible.

As shown in Table 8.12, among young people who perceived family life or sex education to be important, the leading preferred source of such education, cited by about half of both young men and women, was teachers. Somewhat smaller percentages cited friends (29\% and $15 \%$ of young men and women, respectively) and health care providers and other experts (16\% and 19\%, respectively) as preferred sources of this information; however, unlike young men, several women also mentioned their parents $(12 \%)$ as an important source of information.

Table 8.12: Perceptions about family life or sex education

Percentage of youth by perceptions about family life or sex education, according to residence, Tamil Nadu, 2006

\begin{tabular}{|c|c|c|c|c|c|c|}
\hline Perceptions (\%) & $\underset{15-24}{M}$ & $\begin{array}{c}\text { W } \\
15-24\end{array}$ & $\begin{array}{c}\text { MM } \\
15-29\end{array}$ & $\begin{array}{c}\text { MW } \\
15-24\end{array}$ & $\begin{array}{c}\text { UM } \\
15-24\end{array}$ & $\begin{array}{l}\text { UW } \\
15-24\end{array}$ \\
\hline \multicolumn{7}{|c|}{ Combined } \\
\hline Perceived family life/sex education to be important & 80.9 & 71.1 & 79.6 & 70.1 & 81.2 & 71.8 \\
\hline Number of respondents & 1,913 & 5,008 & 1,322 & 2,007 & 1,666 & 3,001 \\
\hline \multicolumn{7}{|l|}{$\begin{array}{l}\text { Perceived that family life/sex education } \\
\text { should be provided at age (years): }\end{array}$} \\
\hline Below 12 & 1.2 & 1.3 & 1.1 & 1.6 & 1.3 & 1.1 \\
\hline $12-14$ & 7.3 & 7.1 & 6.9 & 6.0 & 7.5 & 7.8 \\
\hline $15-17$ & 36.5 & 46.2 & 30.7 & 42.5 & 36.5 & 48.6 \\
\hline 18 or above & 54.4 & 43.9 & 60.0 & 48.5 & 54.1 & 40.9 \\
\hline \multicolumn{7}{|l|}{$\begin{array}{l}\text { Perceived that the best person to provide family } \\
\text { life/sex education was: }\end{array}$} \\
\hline Parent & 1.9 & 12.4 & 2.5 & 13.8 & 1.8 & 11.6 \\
\hline Sibling/sister-in-law & 0.0 & 0.7 & 0.3 & 0.6 & 0.0 & 0.8 \\
\hline Spouse/partner & 0.5 & 0.4 & 1.4 & 0.9 & 0.3 & 0.0 \\
\hline Teacher & 49.4 & 48.9 & 38.8 & 41.9 & 50.8 & 53.3 \\
\hline Friend & 29.1 & 14.5 & 37.2 & 15.6 & 28.5 & 13.7 \\
\hline Health care provider/expert & 16.2 & 18.9 & 17.9 & 22.2 & 15.7 & 16.8 \\
\hline Youth club/mandal/manram/NGO worker & 1.7 & 1.1 & 1.7 & 1.6 & 1.6 & 0.8 \\
\hline $\begin{array}{l}\text { Number who perceived family life/sex } \\
\text { education to be important }\end{array}$ & 1,543 & 3,551 & 1,049 & 1,402 & 1,348 & 2,149 \\
\hline
\end{tabular}


Table 8.12: (Cont'd)

\begin{tabular}{|c|c|c|c|c|c|c|}
\hline Perceptions (\%) & $\begin{array}{c}M \\
15-24\end{array}$ & $\begin{array}{c}\text { W } \\
15-24\end{array}$ & $\begin{array}{c}\text { MM } \\
15-29\end{array}$ & $\begin{array}{c}\text { MW } \\
15-24\end{array}$ & $\begin{array}{c}\text { UM } \\
15-24\end{array}$ & $\begin{array}{l}\text { UW } \\
15-24\end{array}$ \\
\hline \multicolumn{7}{|c|}{ Urban } \\
\hline Perceived family life/sex education to be important & 82.7 & 72.9 & 79.2 & 72.2 & 83.1 & 73.3 \\
\hline Number of respondents & 890 & 2,151 & 653 & 804 & 789 & 1,347 \\
\hline \multicolumn{7}{|l|}{$\begin{array}{l}\text { Perceived that family life/sex education } \\
\text { should be provided at age (years): }\end{array}$} \\
\hline Below 12 & 0.7 & 0.9 & 0.2 & 0.7 & 0.8 & 0.9 \\
\hline $12-14$ & 7.7 & 6.6 & 7.0 & 5.8 & 8.1 & 7.0 \\
\hline $15-17$ & 37.8 & 47.2 & 33.7 & 43.7 & 37.4 & 49.3 \\
\hline 18 or above & 53.3 & 44.4 & 58.4 & 49.0 & 53.3 & 41.8 \\
\hline \multicolumn{7}{|l|}{$\begin{array}{l}\text { Perceived that the best person to provide family } \\
\text { life/sex education was: }\end{array}$} \\
\hline Parent & 1.5 & 13.7 & 1.9 & 14.0 & 1.5 & 13.5 \\
\hline Sibling/sister-in-law & 0.0 & 0.6 & 0.5 & 0.7 & 0.0 & 0.6 \\
\hline Spouse/partner & 0.1 & 0.3 & 0.7 & 0.9 & 0.2 & 0.0 \\
\hline Teacher & 53.7 & 47.6 & 41.9 & 41.2 & 55.2 & 51.4 \\
\hline Friend & 28.2 & 16.2 & 36.7 & 17.1 & 27.1 & 15.7 \\
\hline Health care provider/expert & 14.1 & 17.6 & 17.4 & 20.5 & 13.7 & 16.0 \\
\hline Youth club/mandal/manram/NGO worker & 1.5 & 1.2 & 0.7 & 1.7 & 1.5 & 1.0 \\
\hline $\begin{array}{l}\text { Number who perceived family life/sex } \\
\text { education to be important }\end{array}$ & 728 & 1,562 & 512 & 579 & 650 & 983 \\
\hline \multicolumn{7}{|c|}{ Rural } \\
\hline Perceived family life/sex education to be important & 79.6 & 69.7 & 79.7 & 68.6 & 79.6 & 70.5 \\
\hline Number of respondents & 1,023 & 2,857 & 669 & 1,203 & 877 & 1,654 \\
\hline \multicolumn{7}{|l|}{$\begin{array}{l}\text { Perceived that family life/sex education } \\
\text { should be provided at age (years): }\end{array}$} \\
\hline Below 12 & 1.5 & 1.6 & 1.6 & 2.2 & 1.6 & 1.2 \\
\hline $12-14$ & 7.0 & 7.6 & 6.9 & 6.1 & 7.0 & 8.5 \\
\hline $15-17$ & 35.4 & 45.4 & 28.7 & 41.7 & 35.7 & 48.0 \\
\hline 18 or above & 55.2 & 43.5 & 61.1 & 48.2 & 54.7 & 40.2 \\
\hline \multicolumn{7}{|l|}{$\begin{array}{l}\text { Perceived that the best person to provide family } \\
\text { life/sex education was: }\end{array}$} \\
\hline Parent & 2.3 & 11.3 & 2.9 & 13.6 & 2.2 & 9.8 \\
\hline Sibling/sister-in-law & 0.0 & 0.8 & 0.2 & 0.6 & 0.0 & 0.9 \\
\hline Spouse/partner & 0.7 & 0.4 & 1.8 & 0.9 & 0.4 & 0.1 \\
\hline Teacher & 46.0 & 49.9 & 36.6 & 42.4 & 47.1 & 55.2 \\
\hline Friend & 29.7 & 13.0 & 37.6 & 14.7 & 29.6 & 11.9 \\
\hline Health care provider/expert & 17.9 & 19.9 & 18.2 & 23.3 & 17.5 & 17.6 \\
\hline Youth club/mandal/manram/NGO worker & 2.0 & 1.0 & 2.4 & 1.5 & 1.8 & 0.6 \\
\hline $\begin{array}{l}\text { Number who perceived family life/sex } \\
\text { education to be important }\end{array}$ & 815 & 1,989 & 537 & 823 & 698 & 1,166 \\
\hline
\end{tabular}

Note: All Ns are unweighted. Column totals may not equal 100\% due to missing cases and "don't know" responses. 
As far as differences by marital status were concerned, larger proportions of unmarried than married youth considered teachers best equipped to provide family life or sex education $(51-53 \%$ of the unmarried compared to $39-42 \%$ of the married). A few other notable differences were also observed. Among young men, larger proportions of the married than the unmarried considered friends (37\% versus 29\%) best for providing family life or sex education. Among young women, larger proportions of the married than the unmarried cited health care providers as ideal for this role (22\% versus $17 \%)$. Rural-urban differences were, for the most part, muted. The only notable differences were that young men in urban areas were more likely than their rural counterparts to consider teachers ( $54 \%$ versus $46 \%$ ) and less likely to prefer health care providers ( $14 \%$ and $18 \%$, respectively) as ideal for this role.

Few youth reported that they had received family life or sex education in school or through special programmes sponsored by the government or NGOs. As seen in Table 8.13, just $21 \%$ of young men and $17 \%$ of young women had received any formal family life or sex education. Differences were evident by marital status (see also Figure 8.7). The unmarried were considerably more likely than the married to have received such education (22\% and $13 \%$, respectively, among young men; $22 \%$ and $9 \%$, respectively, among young women). Rural-urban differences were negligible (16-21\% among rural youth, $18-22 \%$ among urban youth).

Figure 8.7: Percentage of youth who received family life or sex education, according to residence, Tamil Nadu, 2006
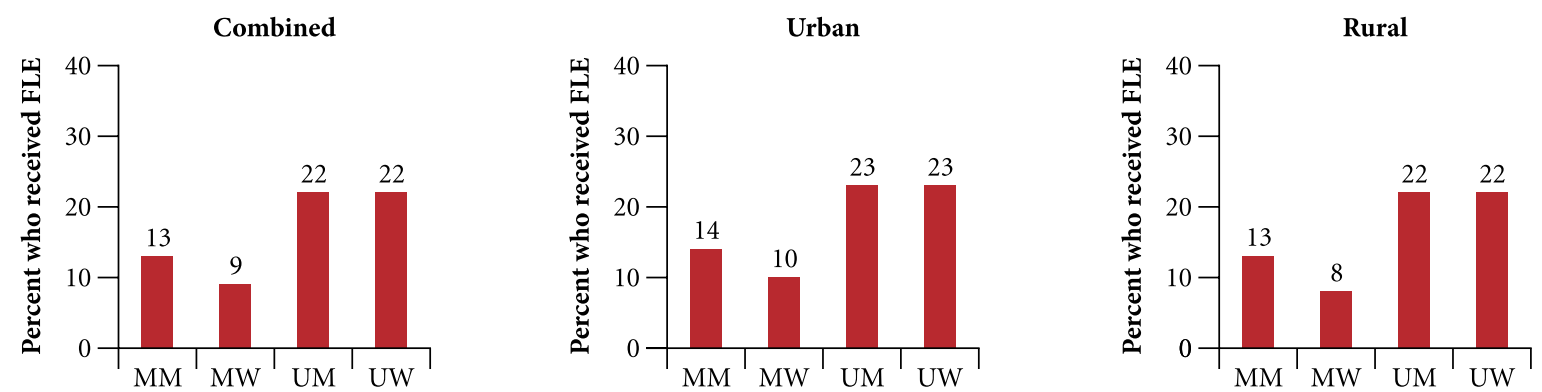

Note: FLE: Family life or sex education.

The large majority of youth who had received family life or sex education had done so in school or college ( $78 \%$ of young men and $83 \%$ of young women) rather than in government or NGO sponsored programmes or camps. Married young men were the least likely (51\%) and unmarried young women the most likely $(87 \%)$ to have obtained such education in school/college. Moreover, urban youth were more likely than rural youth to have obtained this education in school or college ( $82-90 \%$ and $76-77 \%$, respectively). Conversely, married and rural youth were more likely than their respective counterparts to have received family life or sex education through NGO or government programmes or camps.

Of those who reported receiving formal family life or sex education, the large majority felt that it had answered many of their questions (90-95\%) and that the teacher or trainer had explained matters well (87-90\%). Differences by sex, marital status and rural-urban residence of respondents were negligible, except that somewhat larger proportions of unmarried compared to married young men (88\% versus $75 \%)$ and somewhat larger proportions of rural compared to urban young men (90\% versus $83 \%)$ reported that the teacher/trainer had explained the topic well. Despite the fact that youth gave a generally positive assessment of the education they had received, considerable proportions- $16 \%$ of young men and $31 \%$ of young 
Table 8.13: Experiences of family life or sex education

Percentage of youth by experiences of family life or sex education, according to residence, Tamil Nadu, 2006

\begin{tabular}{|c|c|c|c|c|c|c|}
\hline Experiences (\%) & $\begin{array}{c}M \\
15-24\end{array}$ & $\begin{array}{c}\text { W } \\
15-24\end{array}$ & $\begin{array}{c}\text { MM } \\
15-29\end{array}$ & $\begin{array}{c}\text { MW } \\
\text { 15-24 }\end{array}$ & $\begin{array}{c}\text { UM } \\
15-24\end{array}$ & $\begin{array}{l}\text { UW } \\
\text { 15-24 }\end{array}$ \\
\hline \multicolumn{7}{|c|}{ Combined } \\
\hline Received formal family life/sex education & 21.4 & 17.0 & 13.1 & 8.6 & 22.4 & 22.4 \\
\hline Number of respondents & 1,913 & 5,008 & 1,322 & 2,007 & 1,666 & 3,001 \\
\hline \multicolumn{7}{|l|}{ Source of family life/sex education } \\
\hline NGO programme/camp & 9.5 & 9.0 & 26.0 & 13.9 & 8.6 & 7.7 \\
\hline Government programme/camp & 15.9 & 12.1 & 30.6 & 23.1 & 15.2 & 9.4 \\
\hline School/college & 78.3 & 82.9 & 50.9 & 67.1 & 80.3 & 86.9 \\
\hline \multicolumn{7}{|l|}{ Opinion about family life/sex education received } \\
\hline It answered many queries & 90.0 & 94.7 & 89.6 & 94.8 & 90.4 & 94.7 \\
\hline Teacher/trainer explained well & 87.3 & 90.4 & 75.1 & 88.4 & 87.5 & 90.9 \\
\hline Respondent felt embarrassed & 15.6 & 30.7 & 19.7 & 36.4 & 15.7 & 29.3 \\
\hline Number who received family life/sex education & 386 & 844 & 173 & 173 & 359 & 671 \\
\hline \multicolumn{7}{|c|}{ Urban } \\
\hline Received formal family life/sex education & 21.8 & 18.1 & 14.0 & 9.8 & 22.6 & 22.8 \\
\hline Number of respondents & 890 & 2,151 & 653 & 804 & 789 & 1,347 \\
\hline \multicolumn{7}{|l|}{ Source of family life/sex education } \\
\hline NGO programme/camp & 8.3 & 4.8 & 18.4 & 7.6 & 6.5 & 4.0 \\
\hline Government programme/camp & 12.7 & 9.0 & 26.3 & 16.5 & 12.4 & 6.9 \\
\hline School/college & 82.2 & 89.5 & 59.2 & 78.5 & 84.0 & 92.2 \\
\hline \multicolumn{7}{|l|}{ Opinion about family life/sex education received } \\
\hline It answered many queries & 90.6 & 95.0 & 94.7 & 94.9 & 90.5 & 95.0 \\
\hline Teacher/trainer explained well & 83.4 & 91.5 & 74.7 & 87.3 & 83.4 & 92.5 \\
\hline Respondent felt embarrassed & 13.3 & 32.3 & 17.3 & 39.2 & 13.6 & 30.5 \\
\hline Number who received family life/sex education & 185 & 384 & 92 & 79 & 172 & 305 \\
\hline \multicolumn{7}{|c|}{ Rural } \\
\hline Received formal family life/sex education & 21.1 & 16.1 & 12.5 & 7.8 & 22.3 & 22.1 \\
\hline Number of respondents & 1,023 & 2,857 & 669 & 1,203 & 877 & 1,654 \\
\hline \multicolumn{7}{|l|}{ Source of family life/sex education } \\
\hline NGO programme/camp & 10.9 & 12.7 & 32.0 & 19.1 & 10.2 & 11.1 \\
\hline Government programme/camp & 18.8 & 14.9 & 34.0 & 28.7 & 17.6 & 11.6 \\
\hline School/college & 75.5 & 77.1 & 44.3 & 57.0 & 77.6 & 82.1 \\
\hline \multicolumn{7}{|l|}{ Opinion about family life/sex education received } \\
\hline It answered many queries & 89.6 & 94.4 & 86.6 & 94.7 & 90.3 & 94.3 \\
\hline Teacher/trainer explained well & 90.4 & 89.5 & 76.3 & 89.4 & 90.8 & 89.5 \\
\hline Respondent felt embarrassed & 17.5 & 29.4 & 20.6 & 34.0 & 17.5 & 28.1 \\
\hline Number who received family life/sex education & 201 & 460 & 81 & 94 & 187 & 366 \\
\hline
\end{tabular}

Note: All Ns are unweighted. Column totals may not equal 100\% due to missing cases or "don't know" responses. 
Figure 8.8: Percentage of youth reporting knowledge of selected sexual and reproductive health matters according to whether they had or had not received family life or sex education, Tamil Nadu, 2006

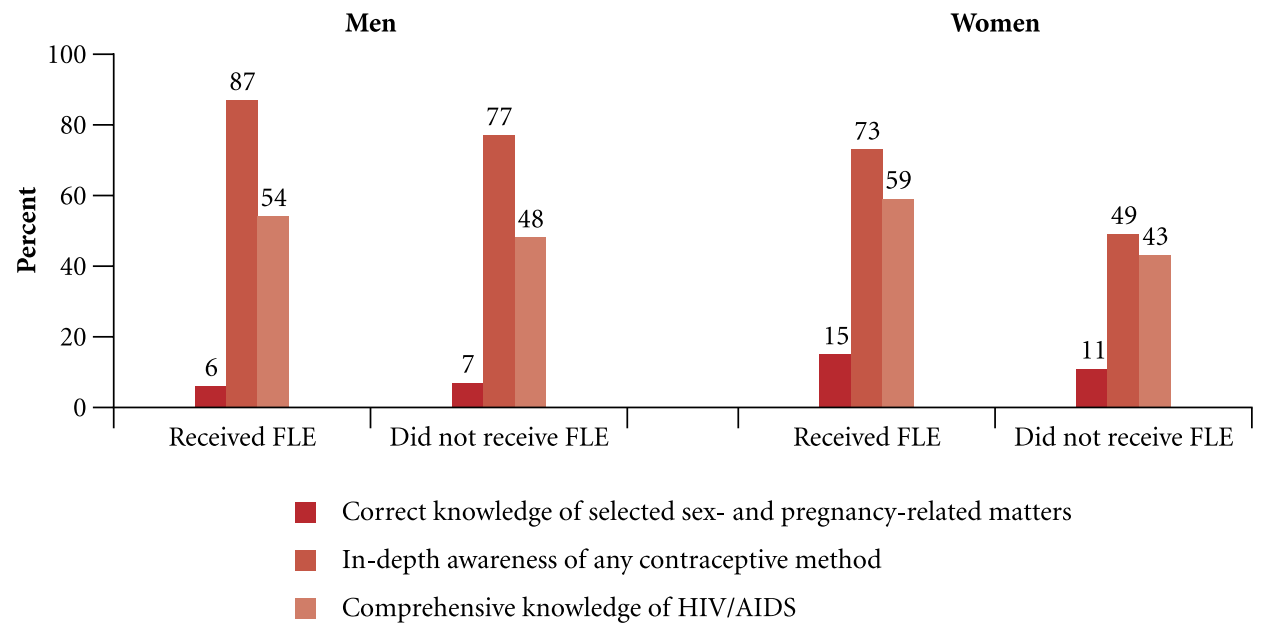

Note: FLE: Family life or sex education.

women-reported feeling uncomfortable or embarrassed in the course of family life or sex education, raising questions about the extent to which they were indeed able to participate freely and clarify doubts. Married youth were somewhat more likely to report embarrassment than their unmarried counterparts $(20 \%$ versus $16 \%$ among young men; $36 \%$ versus $29 \%$ among young women). Rural-urban differences were mild, except that rural young men were slightly more likely than their urban counterparts to report embarrassment (18\% compared to $13 \%)$.

Figure 8.8 compares the extent to which those who had received family life or sex education differed in terms of correct knowledge of selected sexual and reproductive health matters with those who had not (see Sections 8.1.1, 8.1.3 and 8.1.8 for details of items considered in each summary measure). Findings suggest that youth who had received family life or sex education were indeed more likely than those who had not to display in-depth awareness of contraception and comprehensive awareness of HIV/AIDS but were about as likely as those who did not receive this education to report correct knowledge of sex- and pregnancy-related matters. For example, in-depth awareness of contraception was reported by $87 \%$ of young men and $73 \%$ of young women of those who had received family life or sex education, compared to $77 \%$ and $49 \%$, respectively, of those who had not. Likewise, comprehensive awareness of HIV/AIDS was reported by $54 \%$ and $59 \%$ of young men and women, respectively, among those who had received family life or sex education, compared to $48 \%$ and $43 \%$, respectively, of those who had not. This pattern was, by and large, evident among both rural and urban respondents (not shown in figure).

\subsection{Summary}

Findings presented in this chapter reiterate young people's limited awareness of sexual and reproductive matters, ranging from how pregnancy occurs to contraception, HIV and safe sex practices. For example, just half or fewer youth were aware that a woman can get pregnant at first sex, only about half had comprehensive knowledge of HIV and its transmission routes, and just $31 \%$ of young men and $12 \%$ of young women were aware of STIs other than HIV. 
Even on topics about which young people were generally aware, findings show that in-depth understanding was limited. For example, while $97-98 \%$ of youth reported awareness of at least one contraceptive method, in-depth awareness of condoms and oral contraceptives, the methods most familiar to youth, was reported by just $77 \%$ and $20 \%$ of young men and $39 \%$ and $24 \%$ of young women, respectively. Findings suggest, moreover, that the unmarried were the most poorly informed about sexual and reproductive matters. Among the married too, young women were far less likely than young men to report pre-marital awareness of contraception. Taken together, these findings suggest that many young women, and fewer young men, enter marriage uninformed.

Many young women (22\%) and a few young men (6\%) reported that they had never received information on sexual and reproductive matters (prior to marriage among the married). Of those who had received such information, among the leading sources of information on both contraception and sexual matters were peers and the media. In contrast, few youth cited a family member as a source of information on either topic; the exception was married young women, several of whom cited their husband as a leading source of information on contraception. Teachers, charged with providing family life education to youth, were seldom cited as a source of information. Health care providers also played a limited role in providing youth information on contraception. These findings reflect the lack of attention that the RCH Programme has paid, thus far, to young people. Neither men nor the unmarried appear to have come under the purview of health care providers. Even among married young women, less than one in three were reached with any information from health care providers, underscoring the extent to which even this group has been neglected in the programme. In short, health care providers, teachers and family members-often considered more credible sources of information than peers and the media-were infrequently cited as sources of information on these sensitive topics by young people.

Few youth—just one in five young men and one in six young women—had attended family life or sex education programmes either in or outside the school setting. Despite this, large proportions of youth were in favour of the provision of family life or sex education to young people; typically, young people preferred to receive this education from a teacher, with smaller percentages citing friends, health care providers and other experts. Findings suggest, moreover, that youth who had received family life or sex education were more likely to have in-depth awareness of contraception and comprehensive knowledgeable about HIV/AIDS than those not exposed to this education. 


\section{Pre-marital romantic and} sexual relationships

While evidence is sparse, several studies have noted that despite socio-cultural taboos, youth in India do find opportunities to mix and form romantic relationships, and to engage in pre-marital sex with a range of partners and in a variety of situations (Abraham, 2001; 2002; Abraham and Kumar, 1999; Alexander et al., 2006a; 2006b; Awasthi, Nichter and Pande, 2000). This chapter begins by describing the development of questions intended to capture these youth relationships. The chapter then explores young people's attitudes toward pre-marital physical intimacy and sex, and the extent and nature of their pre-marital romantic experiences, followed by a description of their pre-marital sexual experiences, including those within romantic partnerships and other situations. Finally, the chapter compares pre-marital romantic and sexual experiences derived using three different methodological approaches, that is, face-to-face interviews, anonymous reporting of respondents' own experiences using a sealed envelope and anonymous third-party reporting of the experiences of respondents' friends.

\subsection{Development of the questionnaire module on pre-marital romantic and sexual relationships}

In view of the fact that social norms prohibiting pre-marital opposite-sex mixing may result in serious underreporting of romantic and sexual relationships by youth, the Youth Study initiated the development of this module with a series of focus group discussions among married and unmarried young men and women. In the course of these focus group discussions, youth confirmed that romantic relationships were indeed formed, and mapped a range of places in which youth met their romantic partners secretly. They also listed the vocabulary used by youth to describe their romantic relationships, including the commonly used term "to give a proposal" to describe the act of conveying romantic intentions to opposite-sex individuals.

Building on these insights, a romantic relationship was defined as one comprising a boyfriend-girlfriend relationship (worded culturally appropriately) in which an emotional, physical or sexual relationship was experienced; one in which a "proposal" was accepted, or one in which the couple spent time together alone and secretly. Correspondingly, all respondents were asked questions on whether or not they had ever had a boy-or girl-friend; whether they had "proposed" to anyone of the opposite sex or someone of the opposite sex had "proposed" to them and the "proposal" was accepted, and whether they had spent time alone and secretly with an opposite-sex person. Youth who reported any of the above experiences were considered to have experienced a romantic relationship. We note that our definition of romantic relationships precluded the possibility of reporting same-sex romantic relationships.

All respondents who had reported a romantic partner were then probed regarding the nature of the relationship and the extent of physical contact experienced in the relationship. Questions probing respondents' experience of physical intimacy were posed on a continuum, starting with hand-holding and extending to sexual relations. Thus, the instrument sought to ask potentially sensitive or embarrassing questions in a gradual way, thereby also enabling the interviewer to build rapport with the respondent. Detailed questions concerning the nature of the relationship were asked with reference to the first romantic partner as well as the most recent, if more than one was reported. 
Pre-survey focus group discussions also probed the nature of situations in which sex was experienced. Participants discussed an array of partners with whom youth engaged in sexual relations, including romantic and casual, heterosexual and homosexual, sex workers and older married women. Situations of forced and exchange sex were also discussed. Our survey, correspondingly, inquired about each of these different types of relationships after we had obtained detailed information on the nature of relationships with romantic partners.

Additionally, recognising the reluctance of youth to disclose sexual experience in a survey situation, at the conclusion of the interview, all respondents were asked a single question ("Have you ever had sex with anyone [for the unmarried]/Did you ever have sex with anyone before marriage [for the married]?") and asked to mark a blank card with a " $\boldsymbol{V}$ " or a "X," place the card in an envelope, seal it and return it to the interviewer. Respondents were informed that the envelope would not be opened in the field, and that only the principal investigators would be able to link the information provided in the envelope with what was provided in the main body of the questionnaire.

We also recognised that despite significant rapport building and a well-developed sequence of questions eliciting sexual behaviours, young people may not have wished to disclose sexual activity in either of the above formats. Other researchers have observed that respondents may be more forthcoming about reporting sensitive behaviours among their peer networks than about themselves and that responses relating to the peer network correspond closely to their own experiences (Rossier, 2003). Hence the Youth Study incorporated anonymous third-party reporting questions, in which respondents reported the romantic and sexual experiences of up to five same-sex peers.

In addition, efforts were made to ensure that youth were comfortable revealing sensitive behaviours. Interviewers were young and trained to build rapport, discuss sensitive experiences in empathetic and matter-of-fact ways and generally make respondents feel comfortable about the topics to be discussed during the interview. As far as possible, interviews were held at times and places that assured the respondent maximum confidentiality. In cases in which family members attempted to participate in or overhear the interview, another interviewer was called upon to conduct an informal discussion or interview with other family members so as to ensure privacy for the interview. Nevertheless, we acknowledge that ensuring privacy may have been a problem, especially in low-income urban settings characterised by cramped housing conditions, or that some youth may not have felt entirely at ease despite the extensive efforts made to ensure confidentiality. While findings are indeed in line with those observed in other small-scale and less representative studies (see Jejeebhoy and Sebastian, 2004 for a review), we acknowledge that romantic and sexual experiences may have been under-reported in the survey, notably by young women, and suggest that percentages presented here may be interpreted as conservative estimates.

\subsection{Attitudes toward pre-marital physical intimacy and sexual relations}

The Youth Study included a number of questions to assess young people's attitudes regarding the acceptability of pre-marital physical intimacy and sexual activity. Findings, presented in Table 9.1, suggest that young people's attitudes towards pre-marital physical intimacy and sex were generally negative; that is, most disapproved of kissing a partner before marriage, and agreed that a young person's future would be ruined if he or she had sex before marriage. Even so, notable proportions of young men and women considered pre-marital kissing and sexual activity acceptable. Young men were more likely than young women to report positive attitudes towards such behaviours. For example, $31 \%$ of young men compared to $14 \%$ of young women felt that it is all right for a boy and girl to kiss each other before marriage. Findings also indicate gendered attitudes towards pre-marital physical intimacy and sex; while over one-fourth of young men and about one-tenth of young women considered pre-marital sexual activity acceptable among young men, far fewer-just $11 \%$ of young men and $3 \%$ of young women—considered such behaviour acceptable among young women. 
Table 9.1: Attitudes toward pre-marital physical intimacy and sexual relations

Percent distribution of youth by attitudes towards pre-marital physical intimacy and sexual relations, according to residence, Tamil Nadu, 2006

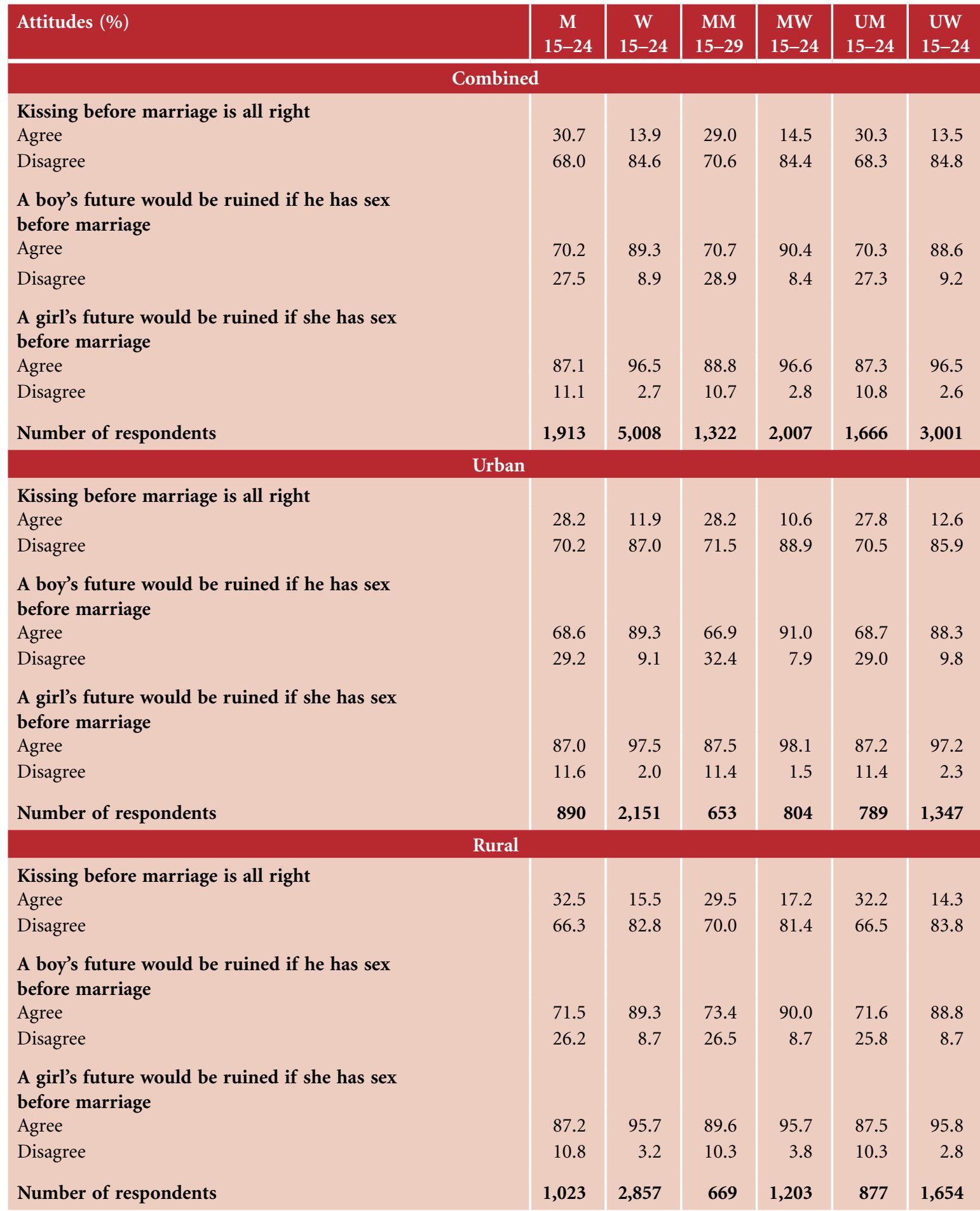

Note: All Ns are unweighted. Column totals may not equal 100\% due to missing cases or "can't say" responses. 
Marital status differences were negligible. Rural-urban differences were also negligible for the most part, except that more rural than urban youth considered pre-marital kissing acceptable. Among married women, for example, $17 \%$ of those in rural areas compared to $11 \%$ of those in urban areas considered it all right for a boy and girl to kiss each other before marriage.

\subsection{Pre-marital romantic relationships}

In this section we present findings on the prevalence of pre-marital opposite-sex romantic relationships among youth and a profile of those who engaged in such relationships. The section also describes parent and peer awareness of pre-marital romantic relationships, youth intentions regarding marriage with their romantic partner and the extent of physical contact experienced in these relationships.

\subsubsection{Prevalence of pre-marital romantic relationships}

Despite the fact that youth tended to report relatively traditional attitudes, opportunities to form romantic relationships did exist for them, irrespective of rural-urban residence or sex. As shown in Table 9.2, many youth had either made a romantic "proposal" to an opposite-sex individual or had received such a "proposal". In total, one-quarter of young men and $28 \%$ of young women reported that they had ever made or received such a "proposal". Irrespective of marital status, very few young women reported "proposing" to a man ( $5 \%$ or fewer); among young men, however, almost as many reported making a "proposal" as receiving one (14-16\%) (not shown in tabular form), suggesting the possibility that young men may have exaggerated the extent of their interaction with women or young women may have concealed behaviour that may be considered socially unacceptable.

Patterns of experience in initiating pre-marital romantic relationships by marital status indicate that many fewer unmarried than married young men and women reported making or receiving a "proposal" (35-37\% among married youth compared to $22-24 \%$ among unmarried youth) (see also Figure 9.1). While young women from rural and urban areas were equally likely to report having made or received a "proposal," young men in rural areas were somewhat more likely than urban young men to report having received or made a "proposal" (27\% versus $21 \%)$.

Figure 9.1: Percentage of youth who had made or received a "proposal" for romantic partnership formation and percentage who had an opposite-sex romantic partner, according to residence, Tamil Nadu, 2006

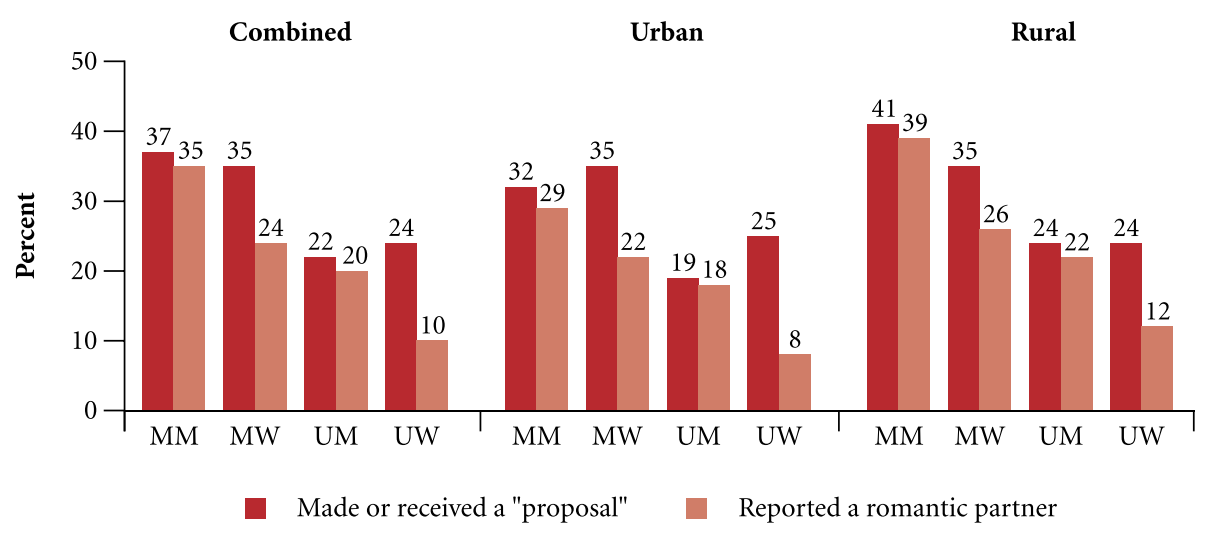


Table 9.2: Pre-marital romantic relationships

Percentage of youth reporting a pre-marital romantic relationship by relationship characteristics, according to residence, Tamil Nadu, 2006

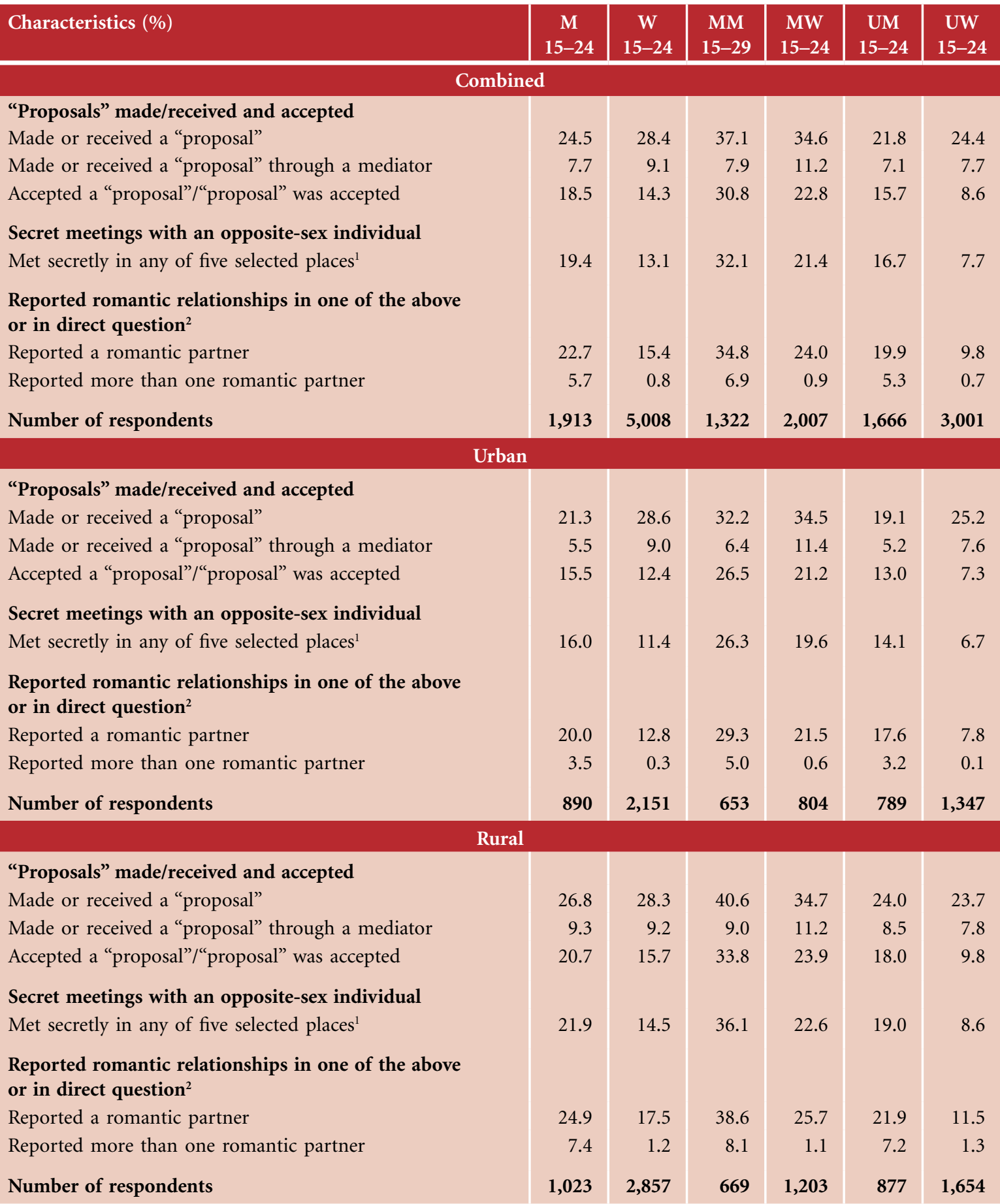

Note: All Ns are unweighted. ${ }^{1}$ Behind or around a temple/mosque/church; around a school/college; at own or someone else's home in the absence of parents; in fields/grazing areas (rural) and restaurants (urban); or in a garden/park/maidan/market or haat. ${ }^{2}$ Respondents were asked a direct question on whether or not they had ever had a boyfriend/girlfriend. 
"Proposals" were often conveyed through an intermediary—a friend, relative or sibling. Indeed, 8-9\% of all youth reported that the "proposal" was conveyed through a mediator. This corresponds to one-third of young men and women (31-32\%) who had ever made or received a "proposal" (not shown in tabular form). While there were no differences by either marital status or rural-urban residence among young women, differences were apparent among young men: more unmarried than married young men reported conveying a "proposal" through an intermediary (33\% and $22 \%$, respectively); likewise, more young men from rural than urban areas had done so ( $35 \%$ versus $26 \%)$.

Compared to those who had made or received "proposals," fewer youth, particularly young women, reported the acceptance of such a "proposal". About one in five young men and one in seven young women reported that they had accepted a "proposal" or that their own "proposal" had been accepted. A roughly equal percentage reported that they had met an opposite-sex individual secretly. In total, in response to the direct or indirect questions, $23 \%$ of young men and $15 \%$ of young women acknowledged the experience of a romantic partnership. Few respondents reported more than one romantic partner-just $6 \%$ of young men and $1 \%$ of young women.

Notable differences were evident by marital status and rural-urban residence. Married youth were consistently more likely than their unmarried counterparts to report a romantic partner. For example, $35 \%$ of married young men compared to $20 \%$ of unmarried young men reported a romantic partner. Among young women, $24 \%$ and $10 \%$ of the married and unmarried, respectively, reported so. Differences by rural-urban residence suggest that more youth in rural than urban areas reported a romantic partner: $25 \%$ and $20 \%$ of young men in rural and urban areas, respectively; and $18 \%$ and $13 \%$ of young women, respectively. Rural-urban differences were particularly pronounced among married young men, among whom $39 \%$ of those living in rural areas compared to $29 \%$ of those in urban areas reported having a romantic partner. While numbers are small, it would appear that the percentage reporting more than one romantic partner was twice as high among rural youth as among as their urban counterparts (7\% and $4 \%$ of young men in rural and urban areas, respectively; and $1 \%$ and $0.3 \%$, respectively, of young women).

Table 9.3 presents the percentage of youth reporting pre-marital romantic experience by background characteristics. By and large, findings suggest some consistent patterns among both young men and women. For example, we observe a positive association between age and the formation of romantic relationships among both young men and women: $32 \%$ of young men aged $20-24$ reported a romantic relationship, as opposed to just $13 \%$ of those aged 15-19; among young women, 18\% of those aged 20-24 reported a romantic partner as opposed to $12 \%$ among those aged $15-19$. Although differentials by religion and caste were not wide, findings show that young Muslim women were less likely than young women who were Hindu or from other religions to report a pre-marital romantic partnership (9\% versus 15-16\%); no such differences were evident among young men. Caste-wise differences suggest that those from scheduled castes were considerably more likely to report a pre-marital romantic experience than those from other backward castes (32\% and 19\%, respectively, among young men; $23 \%$ and $13 \%$, respectively, among young women). With regard to differences by level of education, among young women, a clear inverse association was observed, with $23 \%$ of those with no formal education reporting a romantic experience compared to $13 \%$ of those with 12 or more years of education. Among young men, the pattern was not as consistent: percentages reporting a pre-marital romantic experience fell from $40 \%$ among those with no formal education to $19 \%$ among those with $8-11$ years of education; and increased again thereafter to $24 \%$ among those with 12 or more years of education.

Findings also show that working young men and women were more likely than others to report the experience of a pre-marital romantic partnership: $28 \%$ of young men and $19 \%$ of young women who had worked in the last 12 months reported a romantic experience, compared to about $14 \%$ of non-working youth, perhaps a result of greater mobility, opportunities for social mixing and access to financial resources among those 
engaged in wage earning activities. In addition, the percentage of young men and women who reported a romantic partnership declined steadily as household economic status improved; for example, $28 \%$ and $20 \%$ of young men and women, respectively, of those belonging to the poorest (first) quintile compared to $17 \%$ and $9 \%$, respectively, of those belonging to the wealthiest (fifth) quintile reported the experience of a romantic relationship.

Table 9.3: Prevalence of pre-marital romantic relationships by selected background characteristics

Percentage of youth reporting a pre-marital romantic relationship by selected background characteristics, according to residence, Tamil Nadu, 2006

\begin{tabular}{|c|c|c|c|c|c|c|}
\hline Background characteristics (\%) & $\begin{array}{c}\mathrm{M} \\
15-24\end{array}$ & $\begin{array}{c}\text { W } \\
15-24\end{array}$ & $\begin{array}{c}\text { MM } \\
15-29\end{array}$ & $\begin{array}{c}\text { MW } \\
15-24\end{array}$ & $\begin{array}{c}\text { UM } \\
15-24\end{array}$ & $\begin{array}{c}\text { UW } \\
15-24\end{array}$ \\
\hline \multicolumn{7}{|c|}{ Combined } \\
\hline \multicolumn{7}{|l|}{ Age (years) } \\
\hline $15-19$ & 12.9 & 11.9 & * & 29.0 & 12.7 & 9.2 \\
\hline $20-24$ & 32.0 & 18.3 & 48.6 & 23.1 & 28.3 & 10.9 \\
\hline $25-29$ & NA & NA & 31.4 & NA & NA & NA \\
\hline \multicolumn{7}{|l|}{ Religion } \\
\hline Hindu & 22.7 & 15.9 & 34.8 & 24.7 & 19.9 & 10.1 \\
\hline Muslim & 23.5 & 8.7 & 30.0 & 11.6 & 21.6 & 5.5 \\
\hline Other $^{1}$ & 21.5 & 14.9 & $(42.3)$ & 31.9 & 19.4 & 9.3 \\
\hline \multicolumn{7}{|l|}{ Caste } \\
\hline SC & 31.5 & 22.7 & 48.9 & 36.4 & 26.2 & 13.2 \\
\hline OBC & 19.3 & 12.8 & 29.3 & 19.1 & 17.4 & 8.7 \\
\hline \multicolumn{7}{|l|}{ Educational level (years) } \\
\hline None $^{2}$ & 39.5 & 22.6 & 45.7 & 26.7 & $(36.0)$ & 7.3 \\
\hline $1-7$ & 28.6 & 18.1 & 37.3 & 23.2 & 22.1 & 11.5 \\
\hline $8-11$ & 18.8 & 15.1 & 32.9 & 24.9 & 16.5 & 9.4 \\
\hline 12 or more & 24.3 & 12.7 & 28.4 & 21.0 & 23.8 & 9.9 \\
\hline \multicolumn{7}{|l|}{ Worked in last 12 months } \\
\hline Yes & 27.9 & 19.1 & 34.8 & 28.1 & 24.0 & 14.6 \\
\hline No & 14.2 & 13.5 & * & 22.4 & 14.2 & 6.9 \\
\hline \multicolumn{7}{|l|}{ Wealth quintile } \\
\hline First & 28.0 & 20.2 & 48.1 & 30.2 & 20.4 & 11.5 \\
\hline Second & 24.1 & 19.0 & 36.6 & 28.6 & 19.9 & 12.1 \\
\hline Third & 25.6 & 19.0 & 35.3 & 26.9 & 23.3 & 13.0 \\
\hline Fourth & 20.4 & 11.7 & 28.3 & 18.9 & 19.6 & 7.3 \\
\hline Fifth & 17.2 & 9.3 & 25.3 & 15.1 & 16.8 & 6.6 \\
\hline Total & 22.7 & 15.4 & 34.8 & 24.0 & 19.9 & 9.8 \\
\hline \multicolumn{7}{|c|}{ Urban } \\
\hline \multicolumn{7}{|l|}{ Age ( years) } \\
\hline $15-19$ & 11.2 & 8.4 & * & 20.6 & 11.1 & 7.0 \\
\hline $20-24$ & 27.9 & 16.5 & 45.2 & 21.6 & 24.7 & 9.1 \\
\hline $25-29$ & NA & NA & 26.4 & NA & NA & NA \\
\hline \multicolumn{7}{|l|}{ Religion } \\
\hline Hindu & 19.3 & 12.8 & 29.7 & 21.9 & 17.0 & 7.6 \\
\hline Muslim & 25.8 & 11.0 & 29.6 & 14.3 & 23.3 & 7.4 \\
\hline Other $^{1}$ & $(25.0)$ & 16.2 & * & $(32.4)$ & $(20.0)$ & 10.4 \\
\hline
\end{tabular}


Table 9.3: (Cont'd)

\begin{tabular}{|c|c|c|c|c|c|c|}
\hline Background characteristics (\%) & $\begin{array}{c}\mathrm{M} \\
15-24\end{array}$ & $\begin{array}{c}\mathrm{W} \\
15-24\end{array}$ & $\begin{array}{c}\text { MM } \\
15-29\end{array}$ & $\begin{array}{c}\text { MW } \\
15-24\end{array}$ & $\begin{array}{c}\text { UM } \\
15-24\end{array}$ & $\begin{array}{c}\text { UW } \\
15-24\end{array}$ \\
\hline \multicolumn{7}{|c|}{ Urban } \\
\hline Caste & & & & & & \\
\hline SC & 30.0 & 20.7 & 44.9 & 38.1 & 25.7 & 10.5 \\
\hline OBC & 17.7 & 10.9 & 25.5 & 16.8 & 15.9 & 7.4 \\
\hline \multicolumn{7}{|l|}{ Educational level (years) } \\
\hline None $^{2}$ & * & 32.4 & * & 38.6 & * & * \\
\hline $1-7$ & 27.9 & 18.0 & 33.8 & 24.0 & 19.5 & 11.0 \\
\hline $8-11$ & 16.5 & 11.4 & 30.3 & 20.3 & 15.1 & 6.1 \\
\hline 12 or more & 20.8 & 10.3 & 17.4 & 15.2 & 20.9 & 8.8 \\
\hline \multicolumn{7}{|l|}{ Worked in last 12 months } \\
\hline Yes & 24.4 & 16.4 & 29.4 & 25.6 & 20.8 & 13.5 \\
\hline No & 13.5 & 11.7 & * & 20.7 & 13.5 & 5.4 \\
\hline \multicolumn{7}{|l|}{ Wealth quintile } \\
\hline First & 16.7 & 21.3 & 36.6 & 38.3 & 8.7 & 4.8 \\
\hline Second & 21.2 & 14.6 & 36.5 & 25.5 & 14.1 & 6.5 \\
\hline Third & 24.5 & 18.2 & 32.8 & 26.8 & 21.9 & 11.7 \\
\hline Fourth & 19.7 & 11.0 & 26.6 & 17.2 & 17.9 & 7.4 \\
\hline Fifth & 18.0 & 9.2 & 22.6 & 14.9 & 17.6 & 6.8 \\
\hline Total & 20.0 & 12.8 & 29.3 & 21.5 & 17.6 & 7.8 \\
\hline \multicolumn{7}{|c|}{ Rural } \\
\hline Age (years) & & & & & & \\
\hline $15-19$ & 14.1 & 14.7 & * & 32.7 & 13.8 & 11.0 \\
\hline $20-24$ & 35.4 & 19.8 & 50.6 & 24.1 & 31.6 & 12.5 \\
\hline $25-29$ & NA & NA & 35.1 & NA & NA & NA \\
\hline \multicolumn{7}{|l|}{ Religion } \\
\hline Hindu & 25.1 & 18.2 & 38.0 & 26.4 & 22.0 & 12.1 \\
\hline Muslim & * & 2.4 & * & $(4.9)$ & * & $(0.0)$ \\
\hline Other $^{1}$ & $(21.3)$ & 13.6 & $(60.7)$ & $(29.4)$ & (19.0) & 8.2 \\
\hline \multicolumn{7}{|l|}{ Caste } \\
\hline SC & 32.5 & 23.7 & 51.2 & 35.7 & 26.5 & 14.8 \\
\hline OBC & 20.6 & 14.5 & 32.2 & 20.9 & 18.7 & 9.9 \\
\hline \multicolumn{7}{|l|}{ Educational level (years) } \\
\hline None $^{2}$ & $(48.5)$ & 18.6 & 46.3 & 21.7 & * & (7.3) \\
\hline $1-7$ & 29.0 & 18.1 & 39.6 & 22.7 & 24.0 & 11.8 \\
\hline $8-11$ & 20.3 & 17.8 & 34.7 & 28.1 & 17.6 & 11.7 \\
\hline 12 or more & 28.2 & 15.8 & 42.0 & 28.1 & 27.4 & 11.4 \\
\hline \multicolumn{7}{|l|}{ Worked in last 12 months } \\
\hline Yes & 30.3 & 20.4 & 38.7 & 28.8 & 26.3 & 15.3 \\
\hline No & 14.8 & 15.4 & * & 23.9 & 14.9 & 8.5 \\
\hline \multicolumn{7}{|l|}{ Wealth quintile } \\
\hline First & 30.8 & 19.8 & 50.9 & 28.1 & 23.2 & 13.0 \\
\hline Second & 25.0 & 20.5 & 36.8 & 29.4 & 21.8 & 14.1 \\
\hline Third & 26.3 & 19.6 & 36.8 & 26.9 & 24.1 & 13.9 \\
\hline Fourth & 21.2 & 12.3 & 31.1 & 20.6 & 21.3 & 7.0 \\
\hline Fifth & 14.6 & 9.9 & $(30.2)$ & 16.2 & 14.4 & 6.2 \\
\hline Total & 24.9 & 17.5 & 38.6 & 25.7 & 21.9 & 11.5 \\
\hline
\end{tabular}

Note: ( ) Based on 25-49 unweighted cases. ${ }^{*}$ Percentage not shown, based on fewer than 25 unweighted cases. NA: Not applicable. OBC: Other backward caste. SC: Scheduled caste. ${ }^{1}$ Includes Christian, Buddhist, Neo-Buddhist, Sikh, Jain, Jewish, Parsi/Zoroastrian and no specified religion. ${ }^{2}$ Includes non-literate and literate with no formal schooling. 
As seen in Table 9.3, these patterns of socio-demographic differentials were by and large observed among the married and the unmarried as well as among rural and urban respondents. Nonetheless, some differences were notable by marital status. First, age was found to be inversely associated with the formation of romantic partnerships among the married, in contrast to the positive association observed for the overall sample as well as the unmarried sample. Second, the association between household economic status and the formation of romantic partnerships was less consistent among the unmarried, in contrast to the consistent inverse association observed for the overall sample and the married sample.

\subsubsection{Characteristics of pre-marital romantic relationships}

Selected characteristics of reported pre-marital romantic relationships are presented in Table 9.4; in cases in which more than one romantic partner was reported, only information relating to the respondent's first romantic relationship was included. Age at initiation of pre-marital romantic relationships was measured by the age at which youth first spent time alone with their partner.

Findings indicate that relationships were initiated at a young age for sizeable proportions of youth who had experienced pre-marital romantic relationships. About one-sixth of young men and one-third of young women reported that they had spent time alone with their first romantic partner at age 15 or below. Unmarried young men were more likely than the married to have initiated a romantic relationship at age 15 or below ( $18 \%$ versus $5 \%)$; differences were mild among young women but in this case, it was the married who were more likely to have initiated a romantic relationship at age 15 or below ( $35 \%$ and $31 \%$, respectively). Median ages of respondents when they first spent time alone with their pre-marital romantic partner was approximately two years older among young men (18 years) than among young women (16 years) and was identical for urban and rural youth. However, differences were apparent by marital status: the median age of married young men when they first spent time alone with their romantic partner was a year older than that reported by the unmarried (19 and 18 years, respectively); among young women, in contrast, the median age observed among the married was a year younger than that observed among the unmarried (16 and 17 years, respectively). Information on the relative ages of reported partners suggests that male partners were, for the most part, older than their female partners. For example, $70 \%$ of young men reported a female partner who was younger than themselves and $24 \%$ reported that their partner was their own age. In comparison, $94 \%$ of young women reported an older male partner. Overwhelmingly, the partner was unmarried (98-99\%).

Among young men who reported a romantic partner, the first partner was typically a fellow student or colleague $(33 \%)$, a neighbour or friend $(26 \%)$, an acquaintance from outside the village/neighbourhood $(19 \%)$ or a relative $(17 \%)$. Among young women, one-third reported that a relative or a neighbour or friend, respectively, was their first romantic partner; considerably fewer reported that the first partner was a person from outside the village or neighbourhood (17\%) or a fellow student or colleague (14\%). This gender difference may be attributed to young women's relatively limited mobility and fewer opportunities for social mixing as compared to young men, described in Chapter 7 . 
Table 9.4: Characteristics of pre-marital romantic relationships and partners

Percentage of youth reporting a pre-marital romantic relationship by age at initiation of relationship, partner's socio-economic and demographic characteristics, and nature and duration of prior acquaintance, according to residence, Tamil Nadu, 2006

\begin{tabular}{|c|c|c|c|c|c|c|}
\hline Characteristics $(\%)^{1}$ & $\begin{array}{c}M \\
15-24\end{array}$ & $\begin{array}{c}\text { W } \\
15-24\end{array}$ & $\begin{array}{c}\text { MM } \\
15-29\end{array}$ & $\begin{array}{c}\text { MW } \\
15-24\end{array}$ & $\begin{array}{c}\text { UM } \\
15-24\end{array}$ & $\begin{array}{c}\text { UW } \\
15-24\end{array}$ \\
\hline \multicolumn{7}{|c|}{ Combined } \\
\hline \multicolumn{7}{|c|}{$\begin{array}{l}\text { Age when respondent first spent time alone with } \\
\text { partner (years) }\end{array}$} \\
\hline 15 or below & 15.6 & 33.5 & 5.0 & 35.1 & 18.0 & 31.1 \\
\hline $\begin{array}{l}\text { Median age when respondent first spent time } \\
\text { with partner }\end{array}$ & 18.0 & 16.0 & 19.0 & 16.0 & 18.0 & 17.0 \\
\hline \multicolumn{7}{|l|}{ Age of partner } \\
\hline Younger than respondent & 69.7 & 0.9 & 82.4 & 0.8 & 65.9 & 1.0 \\
\hline Same age as respondent & 24.3 & 4.5 & 9.3 & 1.7 & 28.7 & 9.2 \\
\hline Older than respondent & 5.5 & 93.5 & 7.2 & 96.5 & 5.4 & 88.8 \\
\hline Don't remember & 0.5 & 1.0 & 1.1 & 1.0 & 0.0 & 1.0 \\
\hline \multicolumn{7}{|l|}{ Partner's marital status } \\
\hline Unmarried & 98.4 & 98.8 & 95.2 & 98.5 & 98.8 & 99.0 \\
\hline Married & 1.4 & 1.0 & 4.3 & 1.5 & 1.2 & 0.7 \\
\hline \multicolumn{7}{|l|}{ Nature of prior acquaintance with first partner } \\
\hline Relative & 16.7 & 32.1 & 22.1 & 36.0 & 16.8 & 26.3 \\
\hline Fellow student/colleague & 33.3 & 13.6 & 11.1 & 8.7 & 39.0 & 21.5 \\
\hline Neighbour/friend & 26.1 & 31.7 & 30.6 & 33.9 & 23.4 & 28.3 \\
\hline Family friend & 0.5 & 1.0 & 1.1 & 1.0 & 0.6 & 0.7 \\
\hline Person from outside village/neighbourhood & 18.8 & 17.4 & 31.2 & 16.4 & 15.0 & 18.8 \\
\hline Other $^{2}$ & 4.6 & 4.1 & 3.9 & 4.0 & 5.1 & 4.4 \\
\hline \multicolumn{7}{|l|}{ Duration of acquaintance } \\
\hline Less than 1 month & 1.6 & 2.8 & 1.7 & 3.9 & 1.8 & 1.0 \\
\hline 1-11 months & 11.5 & 12.2 & 9.8 & 12.2 & 11.7 & 11.9 \\
\hline 12 months or more & 72.7 & 60.9 & 67.3 & 57.3 & 73.8 & 66.6 \\
\hline Since childhood & 14.2 & 24.1 & 21.1 & 26.6 & 12.7 & 20.5 \\
\hline \multicolumn{7}{|l|}{ Partner's religion } \\
\hline Same as respondent & 84.2 & 88.1 & 87.6 & 89.4 & 82.6 & 85.7 \\
\hline Different from respondent & 15.6 & 11.4 & 12.4 & 10.6 & 17.1 & 12.9 \\
\hline \multicolumn{7}{|l|}{ Partner's caste } \\
\hline Same as respondent & 59.4 & 77.5 & 69.3 & 80.3 & 55.4 & 73.0 \\
\hline Different from respondent & 39.9 & 21.5 & 30.7 & 19.7 & 43.7 & 24.2 \\
\hline \multicolumn{7}{|l|}{ Partner's socio-economic status } \\
\hline Same as respondent & 58.6 & 55.8 & 63.0 & 57.7 & 56.0 & 52.9 \\
\hline Better than respondent & 25.5 & 29.1 & 22.4 & 25.5 & 26.8 & 34.8 \\
\hline Worse than respondent & 14.0 & 14.1 & 14.3 & 16.6 & 14.8 & 10.2 \\
\hline Number reporting a romantic relationship & 460 & 772 & 471 & 479 & 336 & 293 \\
\hline
\end{tabular}


Table 9.4: (Cont'd)

\begin{tabular}{|c|c|c|c|c|c|c|}
\hline Characteristics $(\%)^{1}$ & $\begin{array}{c}M \\
15-24\end{array}$ & $\begin{array}{c}\text { W } \\
15-24\end{array}$ & $\begin{array}{c}\text { MM } \\
15-29\end{array}$ & $\begin{array}{l}\text { MW } \\
15-24\end{array}$ & $\begin{array}{c}\text { UM } \\
15-24\end{array}$ & $\begin{array}{l}\text { UW } \\
15-24\end{array}$ \\
\hline \multicolumn{7}{|c|}{ Urban } \\
\hline \multicolumn{7}{|c|}{$\begin{array}{l}\text { Age when respondent first spent time alone with } \\
\text { partner (years) }\end{array}$} \\
\hline 15 or below & 15.2 & 32.0 & 5.0 & 34.5 & 17.4 & 28.2 \\
\hline $\begin{array}{l}\text { Median age when respondent first spent tim } \\
\text { with partner }\end{array}$ & 18.0 & 16.0 & 19.7 & 16.0 & 18.0 & 17.0 \\
\hline \multicolumn{7}{|l|}{ Age of partner } \\
\hline Younger than respondent & 65.7 & 0.7 & 81.1 & 1.1 & 59.1 & 0.0 \\
\hline Same age as respondent & 28.3 & 3.2 & 12.6 & 1.1 & 34.1 & 6.4 \\
\hline Older than respondent & 6.0 & 95.4 & 6.3 & 96.6 & 6.8 & 93.6 \\
\hline Don't remember & 0.0 & 0.7 & 0.0 & 1.1 & 0.0 & 0.0 \\
\hline \multicolumn{7}{|l|}{ Partner's marital status } \\
\hline Unmarried & 98.2 & 99.6 & 96.3 & 100.0 & 97.7 & 99.1 \\
\hline Married & 1.8 & 0.4 & 3.1 & 0.0 & 2.3 & 0.9 \\
\hline \multicolumn{7}{|l|}{ Nature of prior acquaintance with first partner } \\
\hline Relative & 13.3 & 25.4 & 19.4 & 26.0 & 13.6 & 24.5 \\
\hline Fellow student/colleague & 35.5 & 13.7 & 15.0 & 8.1 & 41.7 & 22.7 \\
\hline Neighbour/friend & 27.7 & 35.2 & 31.3 & 40.5 & 22.7 & 27.3 \\
\hline Family friend & 0.6 & 0.7 & 0.6 & 1.2 & 0.8 & 0.0 \\
\hline Person from outside village/neighbourhood & 17.5 & 19.4 & 28.1 & 20.8 & 15.2 & 16.4 \\
\hline Other ${ }^{2}$ & 5.4 & 5.6 & 5.6 & 3.5 & 6.1 & 9.1 \\
\hline \multicolumn{7}{|l|}{ Duration of acquaintance } \\
\hline Less than 1 month & 1.2 & 2.8 & 1.3 & 3.5 & 1.5 & 1.8 \\
\hline $1-11$ months & 9.0 & 13.4 & 7.6 & 14.5 & 8.3 & 11.0 \\
\hline 12 months or more & 79.5 & 65.0 & 74.1 & 61.3 & 79.5 & 71.6 \\
\hline Since childhood & 10.2 & 18.7 & 17.1 & 20.8 & 10.6 & 15.6 \\
\hline \multicolumn{7}{|l|}{ Partner's religion } \\
\hline Same as respondent & 83.7 & 80.3 & 85.5 & 81.0 & 81.8 & 79.1 \\
\hline Different from respondent & 16.3 & 19.0 & 14.5 & 19.0 & 18.2 & 19.1 \\
\hline \multicolumn{7}{|l|}{ Partner's caste } \\
\hline Same as respondent & 52.4 & 66.5 & 60.6 & 68.4 & 48.5 & 63.6 \\
\hline Different from respondent & 46.4 & 32.0 & 39.4 & 31.6 & 50.0 & 32.7 \\
\hline \multicolumn{7}{|l|}{ Partner's socio-economic status } \\
\hline Same as respondent & 62.0 & 54.4 & 66.3 & 56.3 & 58.0 & 51.4 \\
\hline Better than respondent & 23.5 & 30.4 & 21.9 & 26.4 & 25.2 & 36.7 \\
\hline Worse than respondent & 12.0 & 14.5 & 11.3 & 17.2 & 13.7 & 10.1 \\
\hline Number reporting a romantic relationship & 186 & 277 & 200 & 172 & 140 & 105 \\
\hline
\end{tabular}


Table 9.4: (Cont'd)

\begin{tabular}{|c|c|c|c|c|c|c|}
\hline Characteristics $(\%)^{1}$ & $\begin{array}{c}M \\
15-24\end{array}$ & $\begin{array}{c}\text { W } \\
15-24\end{array}$ & $\begin{array}{c}\text { MM } \\
15-29\end{array}$ & $\begin{array}{c}\text { MW } \\
15-24\end{array}$ & $\begin{array}{c}\text { UM } \\
15-24\end{array}$ & $\begin{array}{c}\text { UW } \\
15-24\end{array}$ \\
\hline \multicolumn{7}{|c|}{ Rural } \\
\hline \multicolumn{7}{|l|}{$\begin{array}{l}\text { Age when respondent first spent time alone with } \\
\text { partner (years) }\end{array}$} \\
\hline 15 or below & 15.6 & 34.5 & 5.0 & 35.4 & 18.4 & 32.8 \\
\hline $\begin{array}{l}\text { Median age when respondent first spent time } \\
\text { with partner }\end{array}$ & 18.0 & 16.0 & 19.0 & 16.0 & 18.0 & 17.0 \\
\hline \multicolumn{7}{|l|}{ Age of partner } \\
\hline Younger than respondent & 72.2 & 1.0 & 83.3 & 0.6 & 69.7 & 1.6 \\
\hline Same age as respondent & 21.9 & 5.3 & 7.7 & 1.9 & 25.4 & 10.9 \\
\hline Older than respondent & 5.2 & 92.4 & 7.3 & 96.4 & 5.0 & 85.9 \\
\hline Don't remember & 0.7 & 1.2 & 1.7 & 1.0 & 0.0 & 1.6 \\
\hline \multicolumn{7}{|l|}{ Partner's marital status } \\
\hline Unmarried & 98.5 & 98.4 & 94.4 & 97.7 & 99.5 & 98.9 \\
\hline Married & 1.1 & 1.4 & 5.3 & 2.3 & 0.5 & 0.5 \\
\hline \multicolumn{7}{|l|}{ Nature of prior acquaintance with first partner } \\
\hline Relative & 18.9 & 36.1 & 23.6 & 41.4 & 19.4 & 27.5 \\
\hline Fellow student/colleague & 31.9 & 13.5 & 9.0 & 9.1 & 37.3 & 20.9 \\
\hline Neighbour/friend & 25.2 & 29.7 & 30.2 & 30.4 & 23.4 & 28.6 \\
\hline Family friend & 0.4 & 1.0 & 1.3 & 1.0 & 0.5 & 1.1 \\
\hline Person from outside village/neighbourhood & 19.6 & 16.4 & 32.9 & 13.9 & 14.9 & 20.3 \\
\hline Other $^{2}$ & 4.1 & 3.3 & 3.0 & 4.2 & 4.5 & 1.6 \\
\hline \multicolumn{7}{|l|}{ Duration of acquaintance } \\
\hline Less than 1 month & 1.9 & 2.9 & 2.0 & 4.2 & 2.0 & 0.5 \\
\hline $1-11$ months & 13.0 & 11.5 & 10.7 & 10.7 & 14.4 & 12.5 \\
\hline 12 months or more & 68.8 & 58.5 & 64.0 & 55.2 & 69.7 & 64.1 \\
\hline Since childhood & 16.4 & 27.2 & 23.3 & 29.9 & 13.9 & 22.8 \\
\hline \multicolumn{7}{|l|}{ Partner's religion } \\
\hline Same as respondent & 84.4 & 92.4 & 88.7 & 94.2 & 83.1 & 89.7 \\
\hline Different from respondent & 15.2 & 7.2 & 11.3 & 5.8 & 16.4 & 9.2 \\
\hline \multicolumn{7}{|l|}{ Partner's caste } \\
\hline Same as respondent & 63.6 & 83.8 & 73.8 & 87.0 & 59.7 & 78.8 \\
\hline Different from respondent & 36.1 & 15.4 & 26.2 & 13.0 & 39.8 & 19.0 \\
\hline \multicolumn{7}{|l|}{ Partner's socio-economic status } \\
\hline Same as respondent & 56.3 & 56.6 & 61.1 & 58.4 & 54.7 & 53.6 \\
\hline Better than respondent & 27.0 & 28.3 & 22.6 & 24.7 & 27.9 & 33.9 \\
\hline Worse than respondent & 15.2 & 14.1 & 16.3 & 16.6 & 15.4 & 10.4 \\
\hline Number reporting a romantic relationship & 274 & 495 & 271 & 307 & 196 & 188 \\
\hline
\end{tabular}

Note: All Ns are unweighted. Column totals may not equal 100\% due to missing cases or "don't know" responses. ${ }^{1}$ First romantic partner, if more than one romantic partner reported. ${ }^{2}$ Includes employee, employer, teacher, other acquaintance and stranger. 
Patterns were fairly different among married and unmarried youth. Compared to married youth, for example, unmarried youth were considerably more likely to report that the first partner was a fellow student or colleague (39\% versus 11\% among young men; 22\% versus $9 \%$ among young women). They were, at the same time, less likely to report that the first partner was a relative (17\% versus $22 \%$ among young men; $26 \%$ versus $36 \%$ among young women) or a neighbour or friend (23\% versus 31\% among young men; $28 \%$ versus 34\% among young women). Unmarried young men, in addition, were less likely than married young men to report a person from outside the village or neighbourhood (15\% versus $31 \%$ ) as their first partner. Rural-urban differences were relatively modest with one exception: rural youth were more likely than their urban counterparts to report a relative as the first romantic partner (19\% versus $13 \%$ among young men; $36 \%$ versus $25 \%$ among young women).

Respondents had typically been acquainted with their first romantic partner for at least one year before becoming romantically linked; percentages ranged from $73 \%$ among young men to $61 \%$ among young women. Unmarried youth and urban youth were more likely than their respective counterparts to report so. Many-14\% of young men and $24 \%$ of young women-reported that they had been acquainted with their partner since childhood, a finding not surprising given that a sizeable proportion of partners were either from the same neighbourhood or, among young women, relatives.

The majority of youth reported that their first romantic partner came from a religious, caste and socio-economic background similar to their own. Nevertheless, it is notable that considerable proportions of young people did engage in a romantic relationship with someone from a different religious, caste or socio-economic background. For example, $16 \%$ of young men and $11 \%$ of young women reported that their romantic partner was someone from a different religion; and two in five young men and one in five young women reported a first romantic partner from a different caste. Likewise, one-quarter (26\%) of young men and 29\% of young women reported that their first partner was from a family that was economically better off than their own while $14 \%$ of all youth reported that their partner was from a family that was economically worse off than their own.

Differentials by marital status indicate that the unmarried, particularly young men, were more likely to report a first romantic partner from a different caste, religion and economic background than were the married. For example, $44 \%$ of unmarried young men compared to $31 \%$ of married young men reported a partner from a different caste, $17 \%$ and $12 \%$, respectively, reported a partner from a different religion, and $42 \%$ and $37 \%$, respectively, reported a partner from a different economic background. Rural-urban differences were also evident. Considerably more urban than rural young women reported that their partner was from a different religion (19\% versus 7\%): no such differences were observed among young men. Moreover, both young men and women residing in urban areas were substantially more likely than those in rural areas to report a partner from a different caste $(46 \%$ and $36 \%$, respectively, of young men, and $32 \%$ versus $15 \%$ of young women). And finally, young men in rural areas were considerably more likely than those in urban areas to report a partner from a different economic background than their own (42\% compared to $36 \%$ ); differences were negligible among young women.

Table 9.5 presents youth responses to questions regarding places in which young people met their first romantic partner secretly, without adults present. The vast majority of youth who reported romantic relationships met secretly in places that offered them privacy or anonymity, including in or around religious places (48-53\%), movie theatres (21-32\%), parks and gardens (23\%), restaurants (16-18\%), jungle/riverside (16-19\%) and fields or grazing areas (12-13\%). At the same time, a sizeable proportion of youth, particularly young women, reported that they met in each other's homes when other family members were absent (35\% of young men and $45 \%$ of young women). A minority of youth (16-18\%) reported never having met their romantic partner anywhere in secret. 
Table 9.5: Meeting places with pre-marital romantic partners

Percentage of youth reporting a pre-marital romantic relationship by places where they met their partner secretly, according to residence, Tamil Nadu, 2006

\begin{tabular}{|c|c|c|c|c|c|c|}
\hline Meeting places $(\%)^{1}$ & $\begin{array}{c}\mathrm{M} \\
15-24\end{array}$ & $\begin{array}{c}\text { W } \\
15-24\end{array}$ & $\begin{array}{c}\text { MM } \\
15-29\end{array}$ & $\begin{array}{c}\text { MW } \\
15-24\end{array}$ & $\begin{array}{c}\text { UM } \\
15-24\end{array}$ & $\begin{array}{c}\text { UW } \\
\text { 15-24 }\end{array}$ \\
\hline \multicolumn{7}{|c|}{ Combined } \\
\hline Each other's home & 34.6 & 44.6 & 39.6 & 49.3 & 35.2 & 36.9 \\
\hline Temple/mosque/church & 53.4 & 48.2 & 57.8 & 50.6 & 51.8 & 44.4 \\
\hline Cinema/theatre & 32.1 & 21.2 & 36.5 & 25.7 & 31.3 & 14.0 \\
\hline Park/garden & 23.4 & 22.8 & 26.1 & 25.7 & 22.3 & 18.0 \\
\hline Restaurant/eating place & 17.7 & 15.8 & 20.4 & 17.2 & 19.0 & 13.3 \\
\hline Jungle/riverside & 18.6 & 16.1 & 30.4 & 17.8 & 15.1 & 13.3 \\
\hline Field/grazing area & 12.4 & 13.2 & 17.8 & 15.6 & 8.7 & 9.6 \\
\hline Never met unaccompanied & 18.2 & 16.2 & 10.4 & 12.0 & 19.3 & 22.8 \\
\hline Number reporting a romantic relationship & 460 & 772 & 471 & 479 & 336 & 293 \\
\hline \multicolumn{7}{|c|}{ Urban } \\
\hline Each other's home & 31.9 & 43.0 & 40.3 & 44.8 & 32.1 & 40.0 \\
\hline Temple/mosque/church & 51.8 & 57.0 & 64.2 & 58.0 & 48.9 & 55.5 \\
\hline Cinema/theatre & 38.6 & 26.8 & 40.3 & 32.8 & 38.6 & 17.4 \\
\hline Park/garden & 27.7 & 29.6 & 30.6 & 32.9 & 28.8 & 23.6 \\
\hline Restaurant/eating place & 28.9 & 23.6 & 29.6 & 25.9 & 30.5 & 20.2 \\
\hline Jungle/riverside & 8.4 & 5.6 & 17.5 & 7.5 & 6.1 & 2.7 \\
\hline Field/grazing area & 5.4 & 4.6 & 7.5 & 5.7 & 3.1 & 2.7 \\
\hline Never met unaccompanied & 19.3 & 10.6 & 11.3 & 8.6 & 19.7 & 13.6 \\
\hline Number reporting a romantic relationship & 186 & 277 & 200 & 172 & 140 & 105 \\
\hline \multicolumn{7}{|l|}{${ }^{-4}$} \\
\hline Each other's home & 36.4 & 45.5 & 39.2 & 51.9 & 37.3 & 35.0 \\
\hline Temple/mosque/church & 54.4 & 43.0 & 54.7 & 46.4 & 53.5 & 37.7 \\
\hline Cinema/theatre & 28.1 & 17.9 & 34.6 & 21.8 & 26.5 & 11.5 \\
\hline Park/garden & 20.4 & 18.9 & 23.9 & 21.8 & 17.9 & 14.2 \\
\hline Restaurant/eating place & 10.7 & 11.3 & 15.6 & 12.3 & 11.0 & 9.3 \\
\hline Jungle/riverside & 25.2 & 22.1 & 37.2 & 23.4 & 21.0 & 19.7 \\
\hline Field/grazing area & 16.7 & 18.3 & 23.6 & 21.1 & 12.4 & 13.6 \\
\hline Never met unaccompanied & 17.8 & 19.5 & 10.3 & 14.0 & 19.4 & 28.3 \\
\hline Number reporting a romantic relationship & 274 & 495 & 271 & 307 & 196 & 188 \\
\hline
\end{tabular}

Note: All Ns are unweighted. Column totals may exceed 100\% due to multiple responses. ${ }^{1}$ First romantic partner, if more than one romantic partner reported.

Patterns were relatively similar among the married and the unmarried, with the married somewhat more likely than the unmarried to report meeting their partner secretly in almost every location, and conversely less likely to report that they had never met their romantic partner anywhere in secret. Rural-urban differences were noted, with more urban youth meeting their partners in secret in cinemas and restaurants and more rural youth meeting in jungles or the riverside and in fields. More rural than urban young women, moreover, had never met their romantic partner secretly. 


\subsubsection{Parental and peer awareness of romantic relationships}

Table 9.6 reports findings on peer and parental awareness of young people's romantic relationships. Youth overwhelmingly (84-90\%) reported that their peers were aware of their romantic relationships; in contrast, relatively fewer youth reported that their parents were aware of these partnerships. Young women were more likely than young men to report that parents were aware of their relationships (62\% versus 49\%), and the married were more likely to report parental awareness than the unmarried (62\% and $46 \%$ of young men, and $70 \%$ and $49 \%$ of young women, respectively). Rural-urban differences were not observed among young women and were mild among young men $(52 \%$ and $46 \%$ of urban and rural young men, respectively, reported parental awareness of their relationships). Gender differences may be attributed to the likelihood that young women, who tend to be more strictly supervised, have fewer opportunities to hide a relationship from their parents than young men. Differences by marital status may be attributed to the likelihood that revelation of the relationship could itself have triggered marriage, either to the same person or someone else, as seen in the panel on parental reactions.

The reported reactions of those parents who became aware of their children's pre-marital romantic relationships are presented in Table 9.6. Given the small numbers, we provide findings for the rural and urban populations together. Larger percentages of young women than men reported negative parental reactions. As many as $44 \%$ of young women compared to $34 \%$ of young men reported that their parents had shouted at them; and almost one-quarter of young women compared to just $8 \%$ of young men reported that their parents had beaten them. In contrast, considerably more young men than women reported that their parents had not reacted at all or had accepted the situation (48\% versus $31 \%$ ), or had advised them not to let school performance suffer as a result of the relationship (27\% versus $15 \%)$.

For considerable percentages of young women, parents reacted by arranging their marriage, more often to the romantic partner (33\%) than to someone else (10\%), perhaps in order to protect the family's reputation. About $10 \%$ of young men reported that their parents had arranged their marriage either to their romantic partner or to someone else.

Notably, larger proportions of married than unmarried youth reported that their parents' reactions were negative and conversely, more unmarried than married youth reported that their parents had accepted the situation.

\subsubsection{Marriage intentions and duration of pre-marital romantic relationships}

The questionnaire probed all respondents who reported a relationship about their intention to marry their romantic partner. Findings are reported in Table 9.7 and suggest that the majority of youth did intend to marry either their first or most recent partner. Far larger percentages of young women than young men reported an intention to marry their partner (93\% versus 76\%), a finding observed in other studies as well (Alexander et al., 2006a; 2006b). Differences by marital status suggest that married youth were more likely than the unmarried to have reported this intention (86\% versus $73 \%$ among young men, and $98 \%$ versus $85 \%$ among young women). Rural young men were slightly more likely than urban young men (78\% versus $73 \%$ ) to report marital intentions; in contrast, young women in urban areas were more likely than their rural counterparts to have reported this intention (96\% versus $91 \%$ ).

Reality, in terms of outcomes of romantic relationships, was far different from intention. For example, while $98 \%$ of married young women had intended to marry their pre-marital partner, just $82 \%$ reported having done so; among married young men, $86 \%$ reported an intention to marry their pre-marital partner, yet only 55\% reported doing so. Somewhat more married youth in urban than rural areas did indeed marry their pre-marital romantic partner (58\% and 54\%, respectively, of young men and $86 \%$ and $80 \%$, respectively, of young women). 
Table 9.6: Peer and parental awareness of first pre-marital romantic relationship

Percentage of youth reporting a pre-marital romantic relationship by peer and parental awareness of the first romantic relationship and parents' reaction, according to residence, Tamil Nadu, 2006

\begin{tabular}{|c|c|c|c|c|c|c|}
\hline Awareness and reactions $(\%)^{1}$ & $\begin{array}{c}\text { M } \\
15-24\end{array}$ & $\begin{array}{c}\text { W } \\
15-24\end{array}$ & $\begin{array}{c}\text { MM } \\
15-29\end{array}$ & $\begin{array}{c}\text { MW } \\
15-24\end{array}$ & $\begin{array}{c}\text { UM } \\
15-24\end{array}$ & $\begin{array}{l}\text { UW } \\
15-24\end{array}$ \\
\hline \multicolumn{7}{|c|}{ Combined } \\
\hline Friends aware of relationship & 89.9 & 84.3 & 86.5 & 81.3 & 90.7 & 89.1 \\
\hline Parents aware of relationship & 48.5 & 62.1 & 61.7 & 70.3 & 45.5 & 49.1 \\
\hline Number reporting a romantic relationship & 460 & 772 & 471 & 479 & 336 & 293 \\
\hline \multicolumn{7}{|c|}{ Urban } \\
\hline Friends aware of relationship & 89.2 & 87.7 & 82.5 & 83.3 & 90.9 & 94.5 \\
\hline Parents aware of relationship & 52.1 & 61.8 & 56.6 & 70.7 & 49.6 & 47.7 \\
\hline Number reporting a romantic relationship & 186 & 277 & 200 & 172 & 140 & 105 \\
\hline \multicolumn{7}{|c|}{ Rural } \\
\hline Friends aware of relationship & 90.4 & 82.2 & 88.7 & 79.9 & 90.5 & 85.8 \\
\hline Parents aware of relationship & 46.3 & 62.3 & 64.5 & 69.8 & 43.0 & 50.0 \\
\hline Number reporting a romantic relationship & 274 & 495 & 271 & 307 & 196 & 188 \\
\hline \multicolumn{7}{|c|}{ Combined } \\
\hline Parents' reaction & & & & & & \\
\hline Shouted at respondent & 33.6 & 43.5 & 43.3 & 45.9 & 29.6 & 38.2 \\
\hline Beat respondent & 8.0 & 22.5 & 12.7 & 25.7 & 6.0 & 16.0 \\
\hline Did not allow respondent to go out & 5.2 & 7.9 & 6.0 & 8.3 & 3.3 & 6.9 \\
\hline Stopped respondent from meeting partner & 11.8 & 11.1 & 18.2 & 11.2 & 8.6 & 11.1 \\
\hline Forced respondent to discontinue education & 0.0 & 1.3 & 0.0 & 1.2 & 0.0 & 1.4 \\
\hline Reported to/shouted at partner's family & 2.8 & 5.0 & 3.2 & 5.3 & 2.0 & 3.5 \\
\hline Arranged marriage with partner & 8.5 & 32.6 & 20.4 & 41.1 & 2.0 & 13.2 \\
\hline Arranged marriage with someone else & 1.4 & 9.8 & 6.7 & 12.1 & 0.0 & 4.2 \\
\hline No reaction/accepted the situation & 47.6 & 30.5 & 31.0 & 23.1 & 56.6 & 47.9 \\
\hline $\begin{array}{l}\text { Advised respondent, including not to let school/college } \\
\text { performance suffer }\end{array}$ & 26.9 & 15.0 & 26.8 & 13.9 & 27.2 & 18.1 \\
\hline Other $^{2}$ & 1.4 & 0.4 & 0.7 & 0.6 & 1.3 & 0.0 \\
\hline Number whose parents were aware of relationship & 227 & 481 & 283 & 338 & 152 & 143 \\
\hline
\end{tabular}

Note: All Ns are unweighted. Column totals may exceed 100\% due to multiple responses. Reporting of parents' reactions is presented for rural and urban combined due to small numbers. ${ }^{1}$ First romantic partner, if more than one romantic partner reported. ${ }^{2}$ Includes, for example, taking the matter to the panchayat or the police.

The majority of unmarried youth were still in a relationship at the time of interview ( $72 \%$ of young men and $82 \%$ of young women). Unmarried young men in urban areas were considerably more likely than their rural counterparts to be in a relationship ( $80 \%$ and $67 \%$, respectively); differences were mild among young women ( $85 \%$ and $80 \%$, respectively). Of note is that among the married, $7 \%$ of young men ( $8 \%$ and $4 \%$ in rural and urban areas, respectively) and $2 \%$ of young women reported continuing a relationship with their pre-marital partner even after marriage. 
Table 9.7: Marriage intentions and duration of pre-marital romantic relationships

Percentage of youth reporting a pre-marital romantic relationship by intention to marry partner, current relationship status and duration of relationship, according to residence, Tamil Nadu, 2006

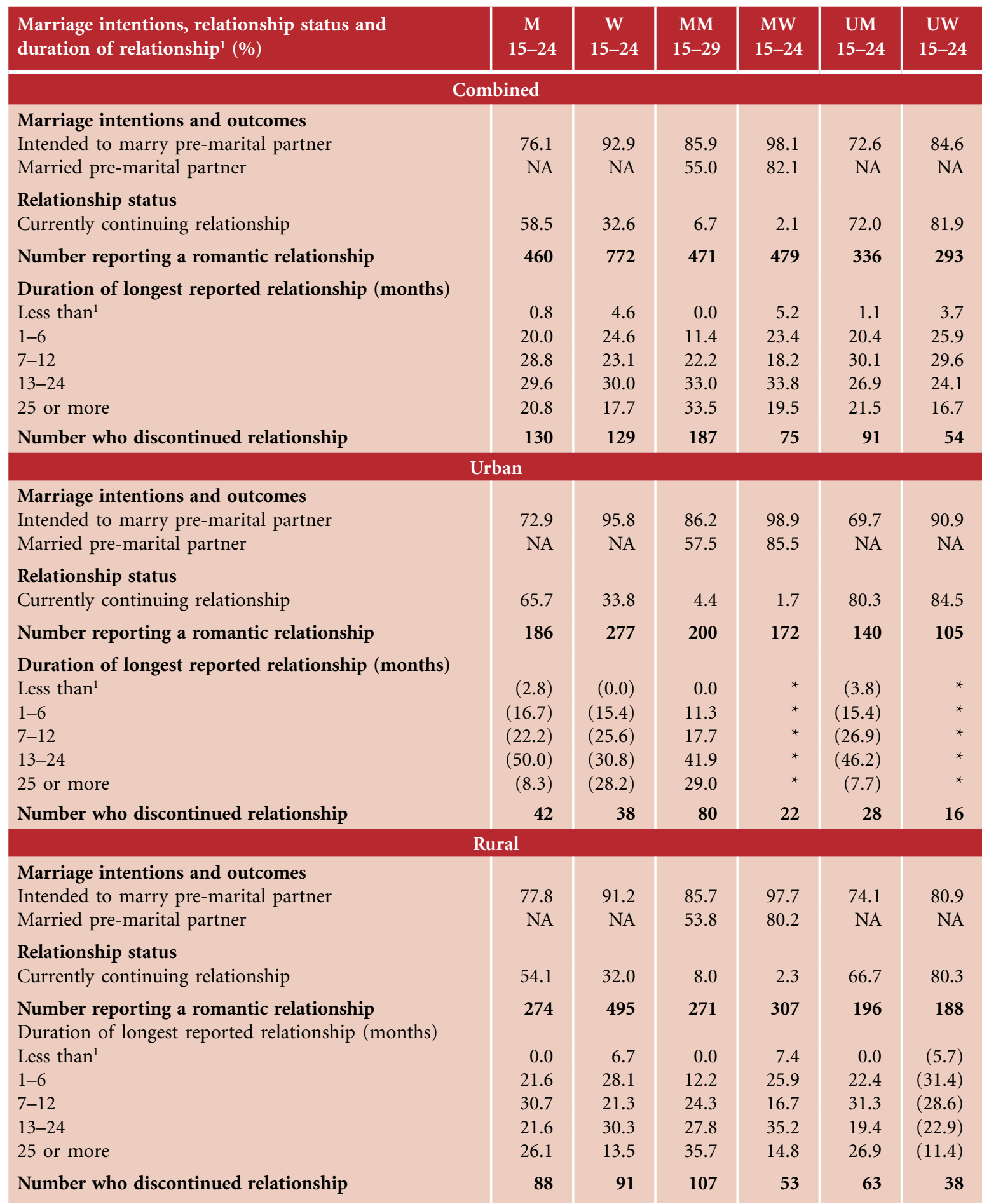

Note: All Ns are unweighted. Column totals may not equal 100\% due to missing cases or "don't know" responses. ( ) Based on 25-49 unweighted cases. ${ }^{*}$ Percentage not shown, based on fewer than 25 unweighted cases. NA: Not applicable. ${ }^{1}$ Data on marriage intentions, relationship status and duration of relationship were collected only with regard to the first and/or most recent partner. These data were not available for 183 young men and 40 young women who reported more than two romantic partners. 
Among those who had discontinued their romantic relationship (the longest relationship, if more than one romantic partner was reported), relationships extended over fairly long time periods, but gender differences suggest that compared to young men, young women reported shorter relationships: for example, $29 \%$ of young women, compared to $21 \%$ of young men, reported relationships of six months or less. These results may reflect the finding observed earlier that parents of young women were more likely than those of young men to become aware of the relationship and to have reacted negatively to the relationship. Differences by marital status were negligible for young women, while in the case of young men, considerably more unmarried than married young men reported relationships of six months or less (22\% versus $11 \%)$. Rural-urban differences were marginal among young men (22\% versus $20 \%$ in rural and urban areas) but substantial among young women, among whom $35 \%$ of those living in rural areas compared to $15 \%$ of those in urban areas reported relationships of six months or less.

\subsubsection{Pre-marital physical intimacy and sex with a romantic partner}

Respondents who reported a pre-marital romantic relationship were asked whether they had engaged in a number of intimate behaviours with their romantic partner. These ranged from behaviours reflecting minimal physical intimacy (hand-holding, hugging) to those reflecting increased physical intimacy (kissing on the lips) and finally, engaging in sexual relations. Findings, presented in Table 9.8, refer to youth experiences of physical intimacy with their first and/or most recent romantic partner, if more than one.

While the majority of youth had held hands with their romantic partner, consistently fewer reported more intimate behaviours. Gender differences in reporting of such experiences were evident. For example, 74\% of young men compared to $60 \%$ of young women reported holding hands with a romantic partner. About half of young men compared to one-fourth of young women reported hugging or kissing their romantic partner. And while about one-quarter of young men reported sex with a romantic partner, just $10 \%$ of young women so reported. Gender differences in reporting of sexual experience with a romantic partner are difficult to explain, although this pattern is observed in a number of studies in India and elsewhere (see, for example, Abraham and Kumar, 1999; Alexander et al., 2006a; Mensch, Clark and Anh, 2003). The possibility, however, that young men over-reported and young women under-reported sexual experience with a romantic partner cannot be ruled out.

Differences by marital status were noted. Married youth were more likely than the unmarried to report each more intimate behaviour (see also Figure 9.2). For example, among young men, $84 \%$ of the married compared to $74 \%$ of the unmarried reported holding hands with a romantic partner; correspondingly, $62 \%$ and $56 \%$ of married and unmarried young women so reported. Likewise, $35 \%$ of married young men compared to $23 \%$ of unmarried young men reported sex with a romantic partner; among young women, $11 \%$ and $9 \%$ of the married and the unmarried so reported. In a relatively late marrying setting such as Tamil Nadu, these differences by marital status may well be attributed to the fact that whereas at the time of interview, reports of the married covered all of their experiences as unmarried youth, for the unmarried, there was a truncation effect, that is, reported experiences covered only the period up to the date of interview. Ruralurban differences were also apparent, particularly among young men. Rural young men were more likely than their urban counterparts to report each intimate behaviour. Specifically, $28 \%$ of young men in rural areas compared with $22 \%$ of those in urban areas reported pre-marital sex with a romantic partner. Among young women, differences were apparent only with regard to hugging and engaging in sex, with rural women more likely to report these behaviours than their urban counterparts.

In short, findings suggest that pre-marital romantic relationships among youth did not always include some form of physical intimacy. Indeed, about one-quarter of young men and two-fifths of young women who reported a romantic relationship had never even held hands. At the same time, sexual relations among those 
in a romantic relationship were indeed observed: about one-quarter of young men and one in 10 young women who reported a pre-marital romantic relationship had experienced sex with a romantic partner.

Table 9.8: Physical intimacy and sexual experiences in pre-marital romantic relationships

Percentage of youth reporting a pre-marital romantic relationship by experiences of physical intimacy and sex with their partner, according to residence, Tamil Nadu, 2006

\begin{tabular}{|c|c|c|c|c|c|c|}
\hline Physical intimacy $(\%)^{1}$ & $\underset{15-24}{M}$ & $\begin{array}{c}\mathrm{W} \\
15-24\end{array}$ & $\begin{array}{c}\text { MM } \\
15-29\end{array}$ & $\begin{array}{c}\text { MW } \\
15-24\end{array}$ & $\begin{array}{c}\text { UM } \\
15-24\end{array}$ & $\begin{array}{c}\text { UW } \\
15-24\end{array}$ \\
\hline \multicolumn{7}{|c|}{ Combined } \\
\hline Ever held hands & 73.6 & 59.8 & 83.5 & 62.4 & 73.8 & 56.0 \\
\hline Ever hugged & 48.6 & 26.4 & 66.1 & 30.8 & 45.5 & 19.5 \\
\hline Ever kissed & 48.6 & 28.3 & 64.8 & 31.8 & 45.8 & 22.5 \\
\hline Ever had sexual relations & 25.7 & 10.2 & 34.6 & 11.2 & 23.2 & 8.5 \\
\hline Number reporting a romantic relationship & 460 & 772 & 471 & 479 & 336 & 293 \\
\hline \multicolumn{7}{|l|}{ 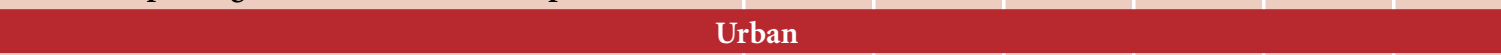 } \\
\hline Ever held hands & 69.9 & 61.6 & 83.6 & 57.5 & 71.2 & 68.2 \\
\hline Ever hugged & 43.4 & 22.9 & 63.1 & 23.6 & 42.0 & 21.1 \\
\hline Ever kissed & 43.4 & 25.7 & 61.9 & 26.4 & 42.7 & 24.5 \\
\hline Ever had sexual relations & 21.7 & 7.0 & 28.9 & 7.5 & 21.2 & 6.4 \\
\hline Number reporting a romantic relationship & 186 & 277 & 200 & 172 & 140 & 105 \\
\hline \multicolumn{7}{|c|}{ Rural } \\
\hline Ever held hands & 75.9 & 58.8 & 83.4 & 65.1 & 75.5 & 48.6 \\
\hline Ever hugged & 52.0 & 28.5 & 67.7 & 34.7 & 47.8 & 18.5 \\
\hline Ever kissed & 51.7 & 29.8 & 66.4 & 35.1 & 47.8 & 21.7 \\
\hline Ever had sexual relations & 28.3 & 12.1 & 37.7 & 13.6 & 24.4 & 9.8 \\
\hline Number reporting a romantic relationship & 274 & 495 & 271 & 307 & 196 & 188 \\
\hline
\end{tabular}

Note: All Ns are unweighted. ${ }^{1}$ Data on ever held hands, ever hugged and ever kissed pertain to the first or most recent partner, if more than one partner was reported. Data on pre-marital sexual relations pertain not only to the first or most recent partner, but also to other romantic partners, if more than two romantic partners were reported.

Figure 9.2: Percentage of youth reporting experiences of physical intimacy and sex with a premarital romantic partner, Tamil Nadu, 2006

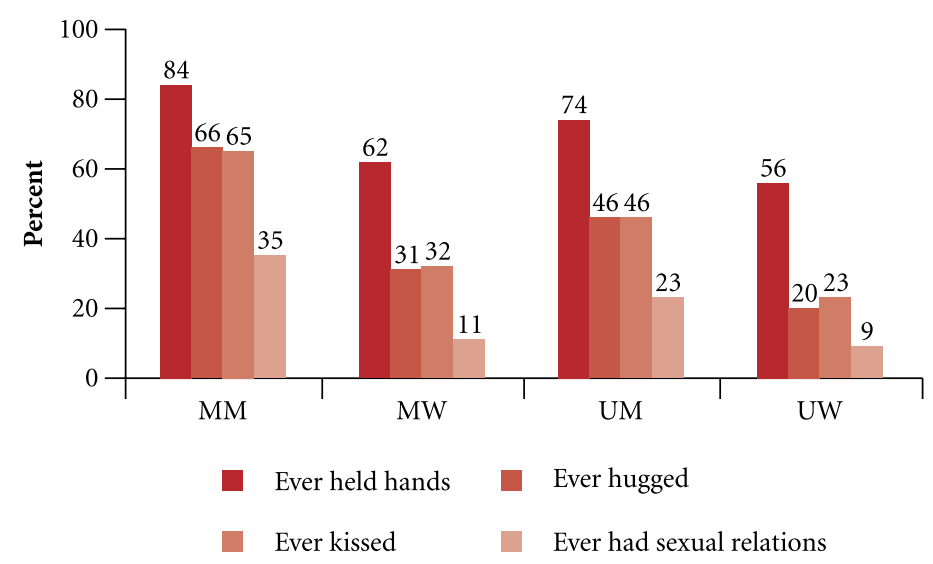




\subsubsection{Characteristics of sexual experiences within pre-marital romantic relationships}

The Youth Study asked all respondents reporting pre-marital sex with a romantic partner about fears of pregnancy or infection at the time of first sex, condom and contraceptive decision-making and use at first and subsequent sexual encounters with a romantic sexual partner, and the consensual nature of first sex. Findings are presented in Table 9.9. Given the small numbers of respondents reporting pre-marital sexual experience, particularly among young women, we provide combined rural-urban findings for married and unmarried young men, and for all young women, irrespective of marital status.

Among those who reported sexual experience within pre-marital romantic relationships, fear of pregnancy was reported by $40 \%$ of young men and $54 \%$ of young women. In contrast, fear of infection was reported by just $6 \%$ of young men (11\% of the married and $5 \%$ of the unmarried) and $13 \%$ of young women.

Table 9.9: Characteristics of sexual experiences within pre-marital romantic relationships

Percentage of youth reporting pre-marital sexual experiences with an opposite-sex romantic partner by selected characteristics of their first and subsequent sexual encounters with the partner, Tamil Nadu, 2006

\begin{tabular}{|c|c|c|c|c|}
\hline Characteristics $(\%)^{1}$ & $\begin{array}{c}\text { M } \\
15-24\end{array}$ & $\begin{array}{c}\text { MM } \\
15-29\end{array}$ & $\begin{array}{c}\text { UM } \\
15-24\end{array}$ & $\begin{array}{c}\text { W } \\
15-24\end{array}$ \\
\hline Anxiety associated with first sex & & & & \\
\hline Afraid of getting pregnant at first sex & 40.4 & 41.0 & 40.0 & 54.4 \\
\hline Afraid of getting infection at first sex & 6.4 & 10.9 & 5.3 & 12.7 \\
\hline Contraceptive use & & & & \\
\hline Practised contraception at first sex & 15.6 & 10.9 & 21.1 & 11.4 \\
\hline Practised contraception in all sexual encounters ${ }^{2}$ & 10.0 & 5.8 & 13.2 & 7.6 \\
\hline Condom use & & & & \\
\hline Used a condom at first sex to: & 10.9 & 7.7 & 14.5 & 2.5 \\
\hline Avoid pregnancy & 10.9 & 7.7 & 14.5 & 2.5 \\
\hline Avoid infection & 10.9 & 7.7 & 14.5 & 0.0 \\
\hline Used condoms in all sexual encounters ${ }^{2}$ & 5.5 & 3.8 & 7.9 & 0.0 \\
\hline Decision to use contraception at first sex taken by: & & & & \\
\hline Respondent & 11.8 & 6.4 & 14.5 & 3.8 \\
\hline Partner & 1.8 & 1.3 & 2.6 & 3.8 \\
\hline Jointly & 2.7 & 3.2 & 3.9 & 3.8 \\
\hline Consensuality of first sex & & & & \\
\hline Mutual consent & 68.2 & 69.7 & 64.0 & 57.0 \\
\hline Male partner forced & 11.8 & 12.3 & 13.3 & 29.1 \\
\hline Female partner forced & 2.7 & 3.9 & 2.7 & 8.9 \\
\hline Male partner persuaded & 7.3 & 5.2 & 9.3 & 1.3 \\
\hline Female partner persuaded & 10.0 & 9.0 & 10.7 & 3.8 \\
\hline $\begin{array}{l}\text { Number reporting pre-marital sex with an opposite-sex } \\
\text { romantic partner }\end{array}$ & 124 & 164 & 81 & 80 \\
\hline
\end{tabular}

Note: All Ns are unweighted. Column totals may not equal 100\% due to missing cases or "don't know" responses. ${ }^{1}$ In-depth probing of sexual experiences was restricted to respondents' first or most recent romantic partner. Therefore, if a respondent reported his/her first sexual experience as occurring with a romantic partner other than the first or the most recent, then age, consensuality and other characteristics at first sex were unknown. Information was not available in 4 such cases. ${ }^{2}$ Data were missing for 20 young men and 17 young women who reported sexual experiences with a romantic partner other than the first or most recent partner. 
Few youth reported contraceptive use at first pre-marital sex with a romantic partner, and consistent contraceptive use was even more limited. In total, $16 \%$ of young men and $11 \%$ of young women reported using contraception at first sex, and $10 \%$ and $8 \%$, respectively, reported that contraception was consistently practised in all sexual encounters with their opposite-sex romantic partner(s). More unmarried than married young men reported using contraception at first sex (21\% compared to $11 \%)$. Consistent contraceptive use was also more likely to be reported by unmarried than married young men.

Condom use was limited. Just 11\% of young men (8\% among the married and 15\% among the unmarried) and $3 \%$ of young women had used a condom during their first sexual encounter with a romantic partner. Even so, it is clear that the majority of young men who practised contraception at first sex had used a condom (70\%); however, just one in five young women, correspondingly, had done so. We note that just $6 \%$ of young men and not a single young woman reported using a condom in all sexual encounters with a romantic partner.

Youth reports of decision-making regarding contraceptive use at first pre-marital sex with an opposite-sex romantic partner reveal a difference in perceptions of young men and women. While the large majority of young men reported that the decision to practise contraception at first sex was theirs alone, this view was not corroborated by young women. Indeed, while $16 \%$ of young men and $11 \%$ of young women had practised contraception at first sex with an opposite-sex romantic partner, just $5 \%$ of young men and as many as $8 \%$ of young women reported that the female partner had participated in the decision.

Although the majority of young men and women reported that their first experience of pre-marital sex with an opposite-sex romantic partner was consensual, several youth reported that it occurred without consent. Gender differences were wide in this respect; for example, $68 \%$ of young men compared to $57 \%$ of young women reported that sex was consensual. A considerable proportion of young women (29\%) reported that their opposite-sex romantic partner had forced them to engage in sex the first time; in contrast, $12 \%$ of young men acknowledged that they had forced their partner to engage in sexual relations. A few young men (7\%) and women (1\%) reported that the male partner had persuaded the female partner to engage in sexual relations; and somewhat more reported that the female partner had persuaded the male partner to engage in sex (10\% and $4 \%$ of young men and women, respectively). Surprisingly, $3 \%$ of young men and $9 \%$ of young women reported that the female partner had forced the male partner to engage in sex.

\subsection{Pre-marital sexual experiences within romantic and other relationships}

Aside from the heterosexual romantic partnerships discussed in previous sections, the Youth Study also probed youth experiences of pre-marital sex with other partners, including casual partners and spouse before marriage, and in situations characterised by force and exchange of gifts or favours. In addition, in the case of male respondents, questions were asked about pre-marital sex with same-sex partners, sex workers and married women. In this and subsequent sections of this chapter, we present findings on the prevalence of pre-marital sexual experiences (irrespective of whether such experiences took place within romantic or other partnerships) among all youth in the sample.

\subsubsection{Extent of pre-marital sexual experiences}

Table 9.10 reports percentages of respondents reporting pre-marital sex in any of the situations described above. For $6 \%$ of young men and $2 \%$ of young women, pre-marital sex occurred in a romantic relationship with a person of the opposite sex. Forced sex and sex in exchange for money or favours were rarely reported. For example, less than $1 \%$ of youth reported that they were forced to engage in sex, and $0.3 \%$ of young men reported that they had forced sex on a female partner. Casual sex was reported by $2 \%$ of young men and hardly any $(0.2 \%)$ young women. 
Table 9.10: Overall pre-marital sexual experiences

\section{Percentage of youth reporting pre-marital sexual experiences with any partner and via different} reporting methods, according to residence, Tamil Nadu, 2006

\begin{tabular}{|c|c|c|c|c|c|c|}
\hline $\begin{array}{l}\text { Pre-marital sexual experiences and } \\
\text { reporting methods (\%) }\end{array}$ & $\begin{array}{c}\text { M } \\
15-24\end{array}$ & $\begin{array}{c}\text { W } \\
15-24\end{array}$ & $\begin{array}{c}\text { MM } \\
15-29\end{array}$ & $\begin{array}{c}\text { MW } \\
15-24\end{array}$ & $\begin{array}{c}\text { UM } \\
15-24\end{array}$ & $\begin{array}{c}\text { UW } \\
15-24\end{array}$ \\
\hline \multicolumn{7}{|c|}{ Combined } \\
\hline Reported pre-marital sex with: & & & & & & \\
\hline Opposite-sex romantic partner & 5.8 & 1.5 & 12.0 & 2.5 & 4.6 & 0.8 \\
\hline Same-sex partner & 0.1 & NA & 0.3 & NA & 0.1 & NA \\
\hline Someone who forced respondent to have sex & 0.2 & 0.6 & 0.8 & 0.9 & 0.2 & 0.4 \\
\hline Girl whom respondent forced & 0.3 & NA & 0.3 & NA & 0.3 & NA \\
\hline Someone in exchange for money/favour & 0.1 & 0.0 & 0.2 & 0.0 & 0.1 & 0.0 \\
\hline Sex worker & 1.0 & NA & 2.4 & NA & 0.9 & NA \\
\hline Married woman ${ }^{1}$ & 1.5 & NA & 3.0 & NA & 1.3 & NA \\
\hline Casual partner & 1.7 & 0.2 & 1.4 & 0.5 & 1.7 & 0.0 \\
\hline Spouse before marriage & NA & NA & 5.9 & 2.5 & NA & NA \\
\hline Reported any pre-marital sex via: & & & & & & \\
\hline Face-to-face interview & 8.1 & 1.8 & 16.0 & 3.1 & 6.6 & 0.9 \\
\hline Anonymous format (sealed envelope) & 8.6 & 2.0 & 16.6 & 3.2 & 7.3 & 1.2 \\
\hline $\begin{array}{l}\text { Face-to-face interview or anonymous format } \\
\text { (sealed envelope) }\end{array}$ & 9.2 & 2.4 & 18.2 & 4.1 & 7.7 & 1.3 \\
\hline Number of respondents & 1,913 & 5,008 & 1,322 & 2,007 & 1,666 & 3,001 \\
\hline \multicolumn{7}{|c|}{ Urban } \\
\hline Reported pre-marital sex with: & & & & & & \\
\hline Opposite-sex romantic partner & 4.3 & 0.9 & 8.5 & 1.4 & 3.7 & 0.5 \\
\hline Same-sex partner & 0.1 & NA & 0.2 & NA & 0.1 & NA \\
\hline Someone who forced respondent to have sex & 0.1 & 0.3 & 0.7 & 0.5 & 0.1 & 0.2 \\
\hline Girl whom respondent forced & 0.2 & NA & 0.0 & NA & 0.3 & NA \\
\hline Someone in exchange for money/favour & 0.0 & 0.0 & 0.0 & 0.1 & 0.0 & 0.0 \\
\hline Sex worker & 0.6 & NA & 2.8 & NA & 0.4 & NA \\
\hline Married woman ${ }^{1}$ & 0.7 & NA & 2.6 & NA & 0.4 & NA \\
\hline Casual partner & 0.8 & 0.0 & 0.9 & 0.1 & 0.5 & 0.0 \\
\hline Spouse before marriage & NA & NA & 4.1 & 1.4 & NA & NA \\
\hline Reported any pre-marital sex via: & & & & & & \\
\hline Face-to-face interview & 5.5 & 0.9 & 12.5 & 1.4 & 4.4 & 0.6 \\
\hline Anonymous format (sealed envelope) & 6.1 & 0.9 & 13.6 & 1.5 & 5.2 & 0.6 \\
\hline $\begin{array}{l}\text { Face-to-face interview or anonymous format } \\
\text { (sealed envelope) }\end{array}$ & 6.5 & 1.0 & 14.2 & 1.9 & 5.5 & 0.6 \\
\hline Number of respondents & 890 & 2,151 & 653 & 804 & 789 & 1,347 \\
\hline \multicolumn{7}{|c|}{ Rural } \\
\hline Reported pre-marital sex with: & & & & & & \\
\hline Opposite-sex romantic partner & 6.9 & 2.0 & 14.4 & 3.3 & 5.3 & 1.1 \\
\hline Same-sex partner & 0.1 & NA & 0.4 & NA & 0.0 & NA \\
\hline Someone who forced respondent to have sex & 0.3 & 0.8 & 0.9 & 1.3 & 0.2 & 0.5 \\
\hline Girl whom respondent forced & 0.4 & NA & 0.5 & NA & 0.3 & NA \\
\hline Someone in exchange for money/favour & 0.1 & 0.0 & 0.3 & 0.0 & 0.1 & 0.0 \\
\hline Sex worker & 1.4 & NA & 2.2 & NA & 1.2 & NA \\
\hline Married woman ${ }^{1}$ & 2.1 & NA & 3.2 & NA & 1.9 & NA \\
\hline Casual partner & 2.4 & 0.4 & 1.8 & 0.8 & 2.5 & 0.1 \\
\hline Spouse before marriage & NA & NA & 7.3 & 3.3 & NA & NA \\
\hline \multicolumn{7}{|l|}{ Reported any pre-marital sex via: } \\
\hline Face-to-face interview & 10.2 & 2.5 & 18.4 & 4.3 & 8.4 & 1.2 \\
\hline Anonymous format (sealed envelope) & 10.5 & 2.8 & 18.6 & 4.4 & 8.9 & 1.7 \\
\hline $\begin{array}{l}\text { Face-to-face interview or anonymous format } \\
\text { (sealed envelope) }\end{array}$ & 11.3 & 3.5 & 20.9 & 5.6 & 9.5 & 1.9 \\
\hline Number of respondents & 1,023 & 2,857 & 669 & 1,203 & 877 & 1,654 \\
\hline
\end{tabular}

Note: All Ns are unweighted. NA: Not applicable. ${ }^{1}$ Sex with a married woman excludes sex with wife before marriage. 
Young men were asked, in addition, about same-sex relations and relations with sex workers and married women (excluding their own wife, if married). Less than $1 \%$ reported same-sex relations, while relations with sex workers and married women were reported by $1 \%$ and $2 \%$ of young men, respectively. In addition, $6 \%$ of married young men and $3 \%$ of married young women reported sex with their spouse before marriage (some of these include youth who had sex with a romantic partner whom they later married). In this way, a total of $8 \%$ of young men and $2 \%$ of young women reported pre-marital sexual relations in the course of face-to-face interviews.

Several youth who had not admitted sexual experience in the face-to-face interview did so in the anonymous sealed envelope format. Including these, in total, $9 \%$ of young men and $2 \%$ of young women reported any pre-marital sexual experience. Differences by marital status (see also Figure 9.3) were wide, particularly among young men: $18 \%$ of married young men compared to $8 \%$ of unmarried young men reported pre-marital sexual experience; in comparison, $4 \%$ and $1 \%$ of married and unmarried young women reported so. Ruralurban differences were also evident: rural young men were nearly twice as likely as their urban counterparts to report having experienced pre-marital sex $(11 \%$ versus $7 \%)$ and rural young women four times as likely as urban young women to report so ( $4 \%$ versus $1 \%$ ). Young men in rural areas were also considerably more likely than their urban counterparts to report casual relations or relations with married women.

These findings suggest that percentages of married young men and all women reporting the experience of pre-marital sex fall within ranges observed in a variety of small case studies (15-30\% for males and fewer than $10 \%$ for females; Jejeebhoy and Sebastian, 2004). In contrast, rates observed among unmarried young men fall considerably below those observed in other studies. The possibility that youth opted not to disclose sexual experience in various situations cannot be discounted, particularly in the case of reporting by young women and unmarried young men, and in the reporting of forced, same-sex or sex worker relations.

Table 9.11 presents percentages of youth reporting pre-marital sexual experience by selected socio-demographic characteristics. In view of the small number of respondents reporting such experience, findings are presented for married and unmarried young men and all young women combined.

Age profiles confirm the positive association between age and pre-marital sexual experience among young men, with those aged 20-24 more likely than younger respondents aged 15-19 to report pre-marital sexual experience ( $14 \%$ and $4 \%$, respectively). While this association was also observed among unmarried young men, we note that married young men aged 25-29 were considerably less likely than those aged 20-24 to report any pre-marital sexual experience (17\% versus $24 \%)$. Among young women, age differences were not observed ( $3 \%$ and $2 \%$, respectively).

Figure 9.3: Percentage of youth reporting any pre-marital sexual experiences (in face-to-face interview or sealed envelope), according to residence, Tamil Nadu, 2006
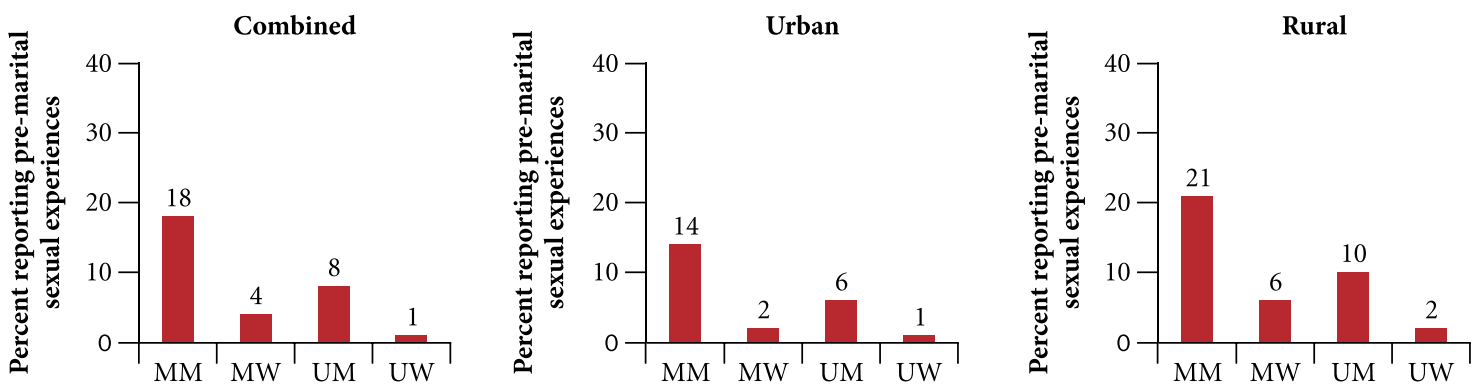
Table 9.11: Overall pre-marital sexual experiences by selected background characteristics

Percentage of youth reporting any pre-marital sexual experiences by selected background characteristics, Tamil Nadu, 2006

\begin{tabular}{|c|c|c|c|c|}
\hline Background characteristics (\%) & $\underset{15-24}{M}$ & $\begin{array}{c}\text { MM } \\
15-29\end{array}$ & $\begin{array}{c}\text { UM } \\
15-24\end{array}$ & $\begin{array}{c}\text { W } \\
15-24\end{array}$ \\
\hline \multicolumn{5}{|l|}{ Age (years) } \\
\hline $15-19$ & 3.9 & * & 3.7 & 1.9 \\
\hline $20-24$ & 14.3 & 23.7 & 12.3 & 2.9 \\
\hline $25-29$ & NA & 16.7 & NA & NA \\
\hline \multicolumn{5}{|l|}{ Religion } \\
\hline Hindu & 9.3 & 18.8 & 7.8 & 2.6 \\
\hline Muslim & 8.6 & 14.3 & 6.8 & 1.0 \\
\hline Other $^{1}$ & 7.6 & $(7.7)$ & 6.9 & 0.8 \\
\hline \multicolumn{5}{|l|}{ Caste } \\
\hline SC & 15.8 & 30.0 & 12.7 & 4.3 \\
\hline OBC & 6.2 & 13.5 & 5.2 & 1.8 \\
\hline \multicolumn{5}{|l|}{ Educational level (years) } \\
\hline None $^{2}$ & 32.6 & 33.3 & $(32.0)$ & 4.8 \\
\hline $1-7$ & 13.5 & 21.0 & 10.4 & 4.3 \\
\hline $8-11$ & 7.6 & 16.5 & 6.4 & 2.2 \\
\hline 12 and above & 7.0 & 8.6 & 6.9 & 0.8 \\
\hline \multicolumn{5}{|l|}{ Worked in last 12 months } \\
\hline Yes & 12.9 & 18.2 & 11.0 & 3.3 \\
\hline No & 3.1 & * & 3.0 & 1.9 \\
\hline \multicolumn{5}{|l|}{ Wealth quintile } \\
\hline First & 14.2 & 26.9 & 11.0 & 5.5 \\
\hline Second & 11.0 & 19.5 & 8.9 & 3.1 \\
\hline Third & 9.9 & 19.0 & 8.4 & 2.9 \\
\hline Fourth & 8.5 & 15.8 & 7.9 & 1.1 \\
\hline Fifth & 3.8 & 8.4 & 3.8 & 0.8 \\
\hline Total & 9.2 & 18.2 & 7.7 & 2.4 \\
\hline
\end{tabular}

Note: ( ) Based on 25-49 unweighted cases. ${ }^{*}$ Percentage not shown, based on fewer than 25 unweighted cases. NA: Not applicable. OBC: Other backward caste. SC: Scheduled caste. ${ }^{1}$ Includes Christian, Buddhist, Neo-Buddhist, Sikh, Jain, Jewish, Parsi/Zoroastrian and no specified religion. ${ }^{2}$ Includes non-literate and literate with no formal schooling.

Differentials by religion were negligible among young men, while among young women, Hindus were slightly more likely than those of other religions to report pre-marital sexual experience. Caste-wise differences were more apparent, with youth from scheduled castes consistently more likely to report sexual experience than others (16\% versus $6 \%$ among young men, and $4 \%$ versus $2 \%$ among young women).

Findings suggest an inverse relationship between educational attainment and reported pre-marital sexual experience; $33 \%$ of young men with no education reported pre-marital sexual activity, which declined to $14 \%$ among those with 1-7 years of education, to just 7\% among those with 12 or more years of education. Similarly, in the case of young women, percentages reporting pre-marital sexual experience declined from about 5\% among those with no formal education to less than $1 \%$ among those who had completed 12 or more years of education. A positive association with economic activity was consistently observed with working young men more likely than their non-working counterparts to report sexual experience (13\% versus 
$3 \%$ among young men); corresponding differences among young women were not observed, $3 \%$ and $2 \%$, respectively). These findings may be attributed to the greater mobility and relative freedom from parental supervision experienced by working as compared to non-working young men. Finally, findings suggest a consistent inverse association between wealth quintiles and pre-marital sexual experience; $14 \%$ of young men and $6 \%$ of young women in the poorest (first) quintile reported pre-marital sexual experiences compared to $4 \%$ and $1 \%$, respectively, among those in the wealthiest (fifth) quintile.

\subsubsection{Age at initiation of pre-marital sex}

Table 9.12 presents cumulative percentages of youth who experienced first pre-marital sex at selected ages (among all youth in the sample) calculated using life table techniques, with censoring taking place at the time of marriage for married youth and at the time of interview for unmarried youth. For youth who reported pre-marital sex only through the anonymous sealed envelope method, age at first pre-marital sex was imputed conservatively, using age at marriage (for the married) and current age (for the unmarried) as age at initiation of pre-marital sex.

Several findings are notable. First, initiation of pre-marital sexual relations did not take place, for the most part, in adolescence. Indeed, just $1.0 \%$ of both young men and women had initiated first sex before age 18, and only $2.0 \%$ and $4.5 \%$, respectively, had initiated sex before age 20 . Second, youth in rural areas were more likely to initiate pre-marital sexual relations earlier than their urban counterparts; for example, among young men, $1.3 \%$ of those from rural areas compared to $0.6 \%$ of those from urban areas had initiated sex before age 18 , and $6.3 \%$ and $2.2 \%$, respectively, had initiated sex before age 20 . Among young women, similarly, $1.5 \%$ of those in rural areas compared to $0.4 \%$ of urban young women had initiated sex before age 18 , and $2.9 \%$ and $1.0 \%$ had initiated sex before age 20 . Third, findings indicate increases in the initiation of pre-marital sexual activity as young people transitioned from early adolescence into young adulthood. As noted above, hardly any youth had engaged in pre-marital sexual activity in early adolescence (before age 15), and very few had done so by late adolescence (before age 20). Among young men, percentages reporting sexual initiation increased sharply thereafter: to $8.5 \%$ before age 21 and $19.7 \%$ by young adulthood (before age 25). Among young women, corresponding increases were more gradual: while $2.0 \%$ had experienced first pre-marital sex before age 20, 2.7\% had initiated pre-marital sexual relations before age 21 and $4.1 \%$ before age 25 .

Table 9.12: Age at initiation of pre-marital sex

\section{Cumulative percentage of youth by age at first pre-marital sexual experience, according to residence, Tamil Nadu, 2006}

\begin{tabular}{|c|c|c|c|c|c|c|}
\hline \multirow[t]{2}{*}{ Age at first pre-marital sex $(\%)^{1}$} & $\begin{array}{c}M \\
15-24\end{array}$ & $\begin{array}{c}W \\
15-24\end{array}$ & $\begin{array}{c}M \\
15-24\end{array}$ & $\begin{array}{c}\text { W } \\
15-24\end{array}$ & $\begin{array}{c}\text { M } \\
15-24\end{array}$ & $\begin{array}{c}\text { W } \\
15-24\end{array}$ \\
\hline & \multicolumn{2}{|c|}{ Combined } & \multicolumn{2}{|c|}{ Urban } & \multicolumn{2}{|c|}{ Rural } \\
\hline $\begin{array}{l}\text { First pre-marital sex occurred before age (years): } \\
15\end{array}$ & 0.0 & 0.1 & 0.0 & 0.0 & 0.0 & 0.1 \\
\hline 18 & 1.0 & 1.0 & 0.6 & 0.4 & 1.3 & 1.5 \\
\hline 20 & 4.5 & 2.0 & 2.2 & 1.0 & 6.3 & 2.9 \\
\hline 21 & 8.5 & 2.7 & 5.4 & 1.2 & 10.9 & 4.0 \\
\hline 25 & 19.7 & 4.1 & 13.6 & 2.0 & 24.6 & 5.9 \\
\hline Number of respondents & 1,913 & 5,008 & 890 & 2,151 & 1,023 & 2,857 \\
\hline
\end{tabular}

Note: All Ns are unweighted. ${ }^{1}$ Calculated using life table techniques. Age at first pre-marital sex among those who reported pre-marital sex only through the anonymous sealed envelope method was imputed conservatively, using age at marriage (for the married) and current age (for the unmarried). 
Rural-urban differences suggest that the age-specific increase in cumulative percentages of those who had initiated pre-marital sexual relations was steeper among rural than among urban youth. Among rural young men, for example, while 1.3\% had experienced first sex before age 18, $6.3 \%$ had experienced pre-marital sex before age 20, 10.9\% before they were aged 21 and $24.6 \%$ before age 25; corresponding percentages among urban young men were $0.6 \%, 2.2 \%, 5.4 \%$ and $13.6 \%$, respectively. Among rural women, $1.5 \%$ had initiated sex before age 18 and this percentage increased to $2.9 \%, 4.0 \%$ and further to $5.9 \%$ before ages 20,21 and 25 , respectively, compared to milder corresponding increases among young women in urban areas $(0.4 \%$, $1.0 \%, 1.2 \%$ and $2.0 \%$, respectively).

\subsubsection{Pre-marital sexual risk behaviours}

Table 9.13 presents findings relating to sexual risk behaviours of youth reporting pre-marital sexual experience, including multiple partner relations and inconsistent condom use. Findings confirm that where youth engaged in pre-marital sex, it was generally under unsafe conditions.

Sizeable proportions of sexually experienced youth had indeed engaged in sex with multiple partners before marriage; for example, nearly one-third of young men and women reported two or more partners (31\%). Unmarried youth were further probed about the number of partners with whom they had engaged in sex over the 12 months preceding the interview. Some $6 \%$ and $4 \%$ of sexually experienced young men and women, respectively, reported multiple sexual partners in the last year.

Table 9.13: Pre-marital sexual risk behaviours

\section{Percentage of sexually experienced youth who had pre-marital sex by number of partners and condom use, Tamil Nadu, 2006}

\begin{tabular}{|c|c|c|c|c|}
\hline Sexual behaviours (\%) & $\begin{array}{c}\text { M } \\
15-24\end{array}$ & $\begin{array}{c}\text { MM } \\
15-29\end{array}$ & $\begin{array}{c}\text { UM } \\
15-24\end{array}$ & $\begin{array}{c}\text { W } \\
15-24\end{array}$ \\
\hline \multicolumn{5}{|l|}{ Total number of pre-marital sexual partners } \\
\hline 1 & 68.6 & 67.6 & 70.9 & 69.3 \\
\hline 2 or more & 31.4 & 32.4 & 29.1 & 30.7 \\
\hline Consistent condom use with pre-marital sexual partners ${ }^{1}$ & 5.1 & 5.2 & 4.5 & 0.0 \\
\hline Number reporting pre-marital sex in face-to-face interview & 170 & 218 & 114 & 89 \\
\hline \multicolumn{5}{|l|}{ Number of sexual partners in last 12 months } \\
\hline None & NA & NA & 36.4 & $(28.6)$ \\
\hline 1 & NA & NA & 57.3 & $(67.9)$ \\
\hline 2 or more & NA & NA & 6.4 & $(3.6)$ \\
\hline Condom used at last pre-marital sex & NA & NA & 23.4 & $(7.1)$ \\
\hline $\begin{array}{l}\text { Number of unmarried respondents reporting pre-marital } \\
\text { sex in face-to-face interview }\end{array}$ & NA & NA & 114 & 28 \\
\hline
\end{tabular}

Note: All Ns are unweighted. ( ) Based on 25-49 unweighted cases. NA: Not applicable. ${ }^{1}$ Questions on consistent condom use were asked only with regard to sexual relationships with first and/or most recent romantic partner, exchange sex partner, sex worker or married woman and excluded experiences with romantic partners other than first or most recent romantic partner, same-sex romantic partner, casual partner, spouse before marriage and experiences of forced sex. 
The Youth Study questionnaire probed consistent condom use only with regard to sex with the first and/or most recent romantic partner, in exchange sex encounters, with sex workers and with married women. Information on condom use was not obtained for pre-marital sexual experiences with romantic partners other than the first or most recent, same-sex romantic partners, casual sex partners, spouse before marriage or among those who reported the experience of forced sex. Although few youth reported these latter relationships, we acknowledge that our consistent condom use indicator may not be comprehensive.

Findings suggest that among youth who reported pre-marital sex in the face-to-face interview, only 5\% of young men and not a single young woman reported that they had always used a condom. Condom use during the last pre-marital sexual encounter, assessed for unmarried respondents, suggests that $23 \%$ of unmarried young men and only $7 \%$ of unmarried young women reported condom use at last sex.

\subsubsection{Non-consensual sexual experiences}

The Youth Study questionnaire also probed the extent to which young people had experienced such nonconsensual sexual experiences as verbal harassment of a sexual nature, non-consensual sexual touch or forced sex. In addition, young men were asked if they had ever verbally harassed a girl or perpetrated non-consensual sexual touch or forced sex. Findings on non-consensual sexual experiences are presented in Table 9.14. For the married, these refer to the period before marriage. We acknowledge that forced sex is an extremely sensitive issue and hence, very likely to have been under-reported.

Verbal sexual harassment was experienced by substantial minorities of youth (15\% of young men and $4 \%$ of young women). Differences by marital status and rural-urban residence were narrow.

Non-consensual sexual touch was measured by questions that probed whether the respondent had ever been the victim of unwanted hugging or kissing in a sexual way, whether someone had touched their private parts without consent or had forced them to touch the perpetrator's private parts, and finally, whether someone had attempted to have sex with the respondent against her/his will using physical force or threats. As shown in Table 9.14, 3-4\% of young men and women admitted the experience of unwanted touch measured in these ways, with little difference between the married and the unmarried, and those residing in rural and urban areas.

Questions on forced sex were posed in two ways: in relation to first sex with a romantic opposite-or samesex partner, on the one hand, and with any non-romantic partner, on the other. Even measured in this way, forced sex was rarely reported, that is, by less than $1 \%$ of respondents in any category.

Young men's reports of perpetration of these acts, presented in Table 9.14, suggest that non-consensual sexual experiences may well have been considerably under-reported, especially by young women. Indeed, almost half of young men (47\%) admitted that they had verbally harassed a girl. Moreover, as many as $22 \%$ admitted touching or brushing past a girl without her consent. Just $0.3 \%$ of young men admitted forcing sex on a girl. Differences on all of these indicators by marital status and rural-urban residence were mild. 
Table 9.14: Pre-marital non-consensual sexual experiences

Percentage of youth reporting various pre-marital non-consensual sexual experiences, according to residence, Tamil Nadu, 2006

\begin{tabular}{|c|c|c|c|c|c|c|}
\hline Non-consensual sexual experiences (\%) & $\begin{array}{c}\text { M } \\
15-24\end{array}$ & $\begin{array}{c}\text { W } \\
15-24\end{array}$ & $\begin{array}{c}\text { MM } \\
15-29\end{array}$ & $\begin{array}{c}\text { MW } \\
15-24\end{array}$ & $\begin{array}{c}\text { UM } \\
15-24\end{array}$ & $\begin{array}{c}\text { UW } \\
\text { 15-24 }\end{array}$ \\
\hline \multicolumn{7}{|c|}{ Combined } \\
\hline \multicolumn{7}{|l|}{ Ever experienced } \\
\hline Verbal harassment & 15.4 & 4.2 & 13.8 & 3.1 & 15.4 & 4.9 \\
\hline Any non-consensual sexual touch ${ }^{1}$ & 4.3 & 2.7 & 4.1 & 2.1 & 4.1 & 3.0 \\
\hline Any forced sex & 0.2 & 0.6 & 0.8 & 0.9 & 0.2 & 0.4 \\
\hline \multicolumn{7}{|l|}{ Ever perpetrated the following: } \\
\hline Verbally harassed anyone ${ }^{2}$ & 47.1 & $\mathrm{NA}$ & 45.2 & NA & 46.8 & NA \\
\hline Touched or brushed past a girl ${ }^{2}$ & 21.7 & NA & 24.1 & NA & 20.8 & NA \\
\hline Forced sex on a girl & 0.3 & NA & 0.3 & NA & 0.3 & NA \\
\hline Number of respondents & 1,913 & 5,008 & 1,322 & 2,007 & 1,666 & 3,001 \\
\hline \multicolumn{7}{|c|}{ Urban } \\
\hline \multicolumn{7}{|l|}{ Ever experienced } \\
\hline Verbal harassment & 13.5 & 3.3 & 13.6 & 2.1 & 13.7 & 4.1 \\
\hline Any non-consensual sexual touch ${ }^{1}$ & 4.3 & 2.8 & 4.6 & 2.3 & 4.3 & 3.2 \\
\hline Any forced sex & 0.1 & 0.3 & 0.7 & 0.5 & 0.1 & 0.2 \\
\hline \multicolumn{7}{|l|}{ Ever perpetrated the following: } \\
\hline Verbally harassed anyone ${ }^{2}$ & 45.5 & NA & 47.5 & NA & 45.4 & NA \\
\hline Touched or brushed past a girl ${ }^{2}$ & 21.6 & NA & 24.1 & NA & 21.3 & NA \\
\hline Forced sex on a girl & 0.2 & NA & 0.0 & NA & 0.3 & NA \\
\hline Number of respondents & 890 & 2,151 & 653 & 804 & 789 & 1,347 \\
\hline \multicolumn{7}{|c|}{ Rural } \\
\hline \multicolumn{7}{|l|}{ Ever experienced } \\
\hline Verbal harassment & 16.9 & 4.9 & 13.9 & 3.8 & 16.8 & 5.6 \\
\hline Any non-consensual sexual touch ${ }^{1}$ & 4.2 & 2.5 & 3.9 & 2.1 & 3.9 & 2.8 \\
\hline Any forced sex & 0.3 & 0.8 & 0.9 & 1.3 & 0.2 & 0.5 \\
\hline \multicolumn{7}{|l|}{ Ever perpetrated the following: } \\
\hline Verbally harassed anyone ${ }^{2}$ & 48.3 & NA & 43.5 & NA & 48.0 & NA \\
\hline Touched or brushed past a girl ${ }^{2}$ & 21.7 & NA & 24.1 & NA & 20.5 & NA \\
\hline Forced sex on a girl & 0.4 & NA & 0.5 & NA & 0.3 & NA \\
\hline Number of respondents & 1,023 & 2,857 & 669 & 1,203 & 877 & 1,654 \\
\hline
\end{tabular}

Note: All Ns are unweighted. NA: Not applicable. ${ }^{1}$ Includes hugging in a sexual way, kissing in a sexual way, touching of private parts and attempted forced sex. ${ }^{2}$ It is possible that married young men may have reported the occurrence of these events post-marriage since age at occurrence was not probed. 


\subsection{Triangulation of data on pre-marital sexual experiences among young people}

Acknowledging that young people may have been reluctant to disclose behaviours perceived as socially unacceptable such as pre-marital sex, the Youth Study included three approaches to elicit data on sexual behaviours. These were face-to-face interviews, anonymous reporting of respondents' own experiences via the sealed envelope and anonymous third-party reporting of peer experiences. Anonymous third-party reporting of peer experiences is a useful method by which to assess sensitive behaviours that individuals may be reluctant to disclose about themselves; findings are intended to shed light on the behaviours of the peer network and not necessarily on those of the individual himself or herself (Rossier, 2003).

We note that in anonymous third-party reporting, respondents may have reported as peers individuals whose ages fell outside our sample ages (15-24 and, in the case of married males, 15-29); therefore, in estimating pre-marital romantic and sexual experiences of young people using this reporting method, these individuals were excluded. In addition, we recognise that in anonymous third-party reporting, friends reported by one respondent may also be reported by others. In estimating pre-marital romantic and sexual experiences of young people using this reporting method, our analysis sought to minimise the chances that the experience of an individual belonging to more than one peer network would be included multiple times. Specifically, we inversely weighted the total sample of friends by the number of friends reported by each respondent. As a result, each respondent's network was given equal weight irrespective of its size.

Findings presented in Table 9.15 compare the levels of pre-marital romantic and sexual experiences obtained through these different approaches. Specifically, three indicators are presented: (a) percent reporting a premarital opposite-sex romantic relationship, (b) percent reporting the experience of pre-marital sex with a romantic opposite-sex partner, and (c) percent reporting any pre-marital sexual experience. For indicators $a-b$, we compare two sets of estimates derived from the face-to-face interview: respondents' reports of their own experiences as well as third-party reporting of the experiences of their peers. For indicator $c$, we compare three sets of estimates: any pre-marital sex as reported in the face-to-face format; any pre-marital sex among peers as assessed through anonymous third-party reporting; and any pre-marital sex as reported in the face-to-face interview supplemented by reports of pre-marital sexual experience recorded in the anonymous format, using the sealed envelope.

Comparisons indicate differences in reporting level by sex of the respondent and type of behaviour under consideration. In terms of pre-marital opposite-sex romantic relationships, anonymous third-party reporting yielded higher rates than did face-to-face reporting for both young men and women. Differences were particularly evident among the unmarried compared to the married, and those residing in urban areas compared to those residing in rural areas.

As far as reporting of experience of pre-marital sex with a romantic partner is concerned, differences were narrower. Young men, irrespective of marital status and rural-urban residence, were about as likely to report sexual relations with a girlfriend in the face-to-face interview as in the anonymous third-party reporting method; the only exception was married men in urban areas who were less likely to report such experiences in the face-to face format than in the anonymous third-party reporting method ( $9 \%$ compared to $13 \%$ ) and married men in rural areas who were more likely to report such experiences in the face-to face format ( $14 \%$ compared to $11 \%)$. Among young women, while few reported sexual relations by either method, thirdparty reporting provided consistently higher estimates of sexual relations with a romantic partner than did self-reporting. 
Table 9.15: Levels of pre-marital romantic and sexual experiences by different reporting methods

Percentage of youth reporting pre-marital romantic relationships and percentage reporting sexual experiences within pre-marital romantic and other relationships by reporting method, according to residence, Tamil Nadu, 2006

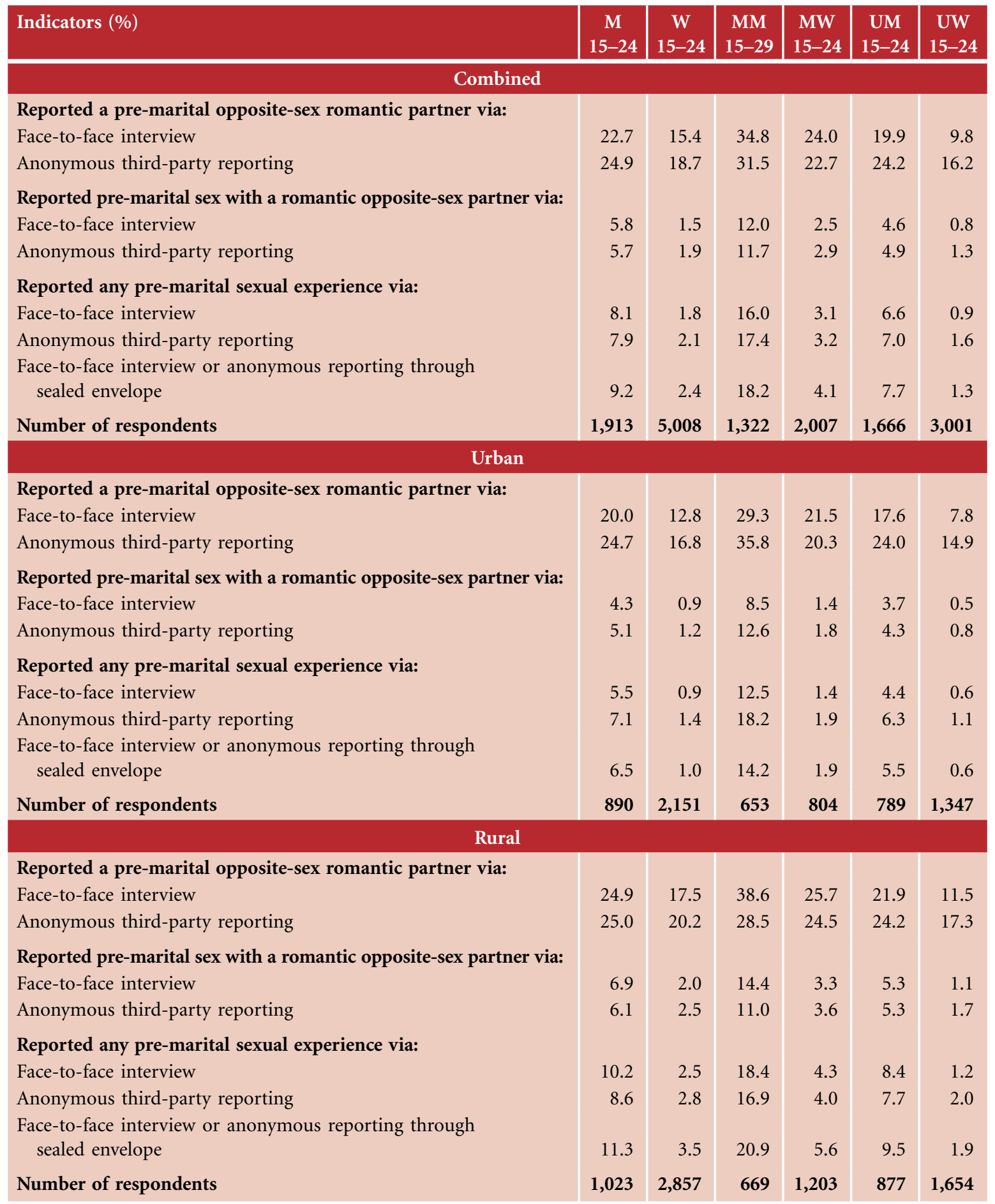

Note: All Ns are unweighted. Detailed information on friends' romantic and sexual experiences was collected for up to five of the respondent's closest same-sex friends. 
With regard to reporting of any pre-marital sexual experience, anonymous third-party reporting of peer behaviours yielded rates that were similar to those obtained by self-reports in response to questions posed face-to-face: $7.9-8.1 \%$ among young men and $1.8-2.1 \%$ among young women. While differences were mild, it is notable that among married young men and unmarried young men and women, slightly higher levels of pre-marital sex were reported in anonymous third-party reporting than in face-to-face interviews. Likewise, among youth in urban areas, reporting of peer behaviours consistently yielded higher rates than did selfreports in response to questions posed face-to-face among all four sub-groups of youth. In rural settings, a reverse pattern was evident for all sub-groups of youth, except unmarried young women.

At the same time, a comparison of any pre-marital sexual experience reported in face-to-face interviews and via the anonymous sealed envelope format suggests that $1 \%$ or fewer youth who had not admitted sexual experience in the face-to-face interview did so in the anonymous format. In other words, $12 \%$ of young men and about one-quarter of young women who reported sexual experience did so only in this more anonymous format (not shown in tabular form). Overall, it would appear that self-reports supplemented by reporting of sexual experiences in the anonymous sealed envelope yielded higher rates than did anonymous thirdparty reporting; nonetheless, exceptions were encountered. Youth in urban areas, for instance, consistently reported higher levels of pre-marital sexual experience among their peers, using the anonymous third-party reporting of pre-marital sexual experience than they admitted of themselves, via self-reporting supplemented by reporting through the anonymous sealed envelope technique. On balance, findings suggest that the sealed envelope technique did indeed enable a considerable number of sexually active young men and women who opted not to disclose their sexual experiences in face-to-face questioning the opportunity to do so.

\subsection{Summary}

Findings confirm that despite strict norms prohibiting pre-marital opposite-sex mixing, opportunities do exist for the formation of pre-marital romantic relations. Indeed, significant minorities of young men and women had received or made a "proposal" for a romantic relationship (25-28\%), and noteworthy, if smaller, percentages reported that they had been involved in a romantic partnership (23\% and $15 \%$ of young men and women, respectively). Patterns of pre-marital romantic partnerships suggest that where partnerships occurred, they were initiated at about age 18 among young men and age 16 among young women, and were usually hidden from parents but not from peers. While the majority of youth had held hands with their romantic partner, consistently fewer reported more intimate behaviours. Gender differences in reporting of such experiences were evident: while $74 \%$ of young men had held hands with a romantic partner, about a quarter had engaged in sexual relations with that partner; and among young women, while three in five had held hands with a romantic partner, $10 \%$ had engaged in sexual relations with this partner. Notable gender disparities in expectations of a longer-term commitment emerged; young women were considerably more likely than young men to have expected a romantic relationship to lead to marriage. Partner communication and negotiation regarding safe sex were rare, and sex was unprotected for the overwhelming majority of sexually active youth. Moreover, for almost one in three young women who had engaged in sexual relations with a romantic partner, sex was not consensual.

In total, $9 \%$ of young men-including $8 \%$ of the unmarried and $18 \%$ of the married-and $2 \%$ of young women reported the experience of pre-marital sex within romantic and/or other partnerships. In general, life table estimates reveal that first pre-marital sex did not take place, for the most part, in adolescence: just $5 \%$ and $2 \%$ of young men and women had initiated sex before age 20. Initiation of pre-marital sexual activity increased as young people transitioned into young adulthood, sharply among young men and more gradually among young women. Also notable is the finding that sexual initiation took place earlier among rural than urban youth. 
While sex with a romantic partner characterised pre-marital experiences for many of the sexually experienced, findings suggest that several young men, but not young women, also engaged in sex in other contexts - mainly with sex workers, married women and casual partners. Many sexual experiences were risky, for example, roughly one-third of young men and young women reporting pre-marital sex had engaged in sex with more than one partner. Moreover, consistent condom use was limited - just 5\% of sexually active young men and not a single woman reported condom use in all pre-marital encounters.

While we acknowledge that youth, especially young women and unmarried young men, may not report sexual experience in a survey situation, the Youth Study experience suggests that a series of direct questions posed in a face-to-face interview, supplemented by an opportunity to report sexual experience in an anonymous format, using the sealed envelope technique, provides higher estimates of sexual experience than does faceto-face questioning alone, or, for the most part, anonymous third party reporting of peer behaviours. On balance, findings suggest that the sealed envelope technique did indeed enable a considerable number of sexually active young men and women who opted not to disclose their sexual experiences in face-to-face questioning the opportunity to do so. 


\section{Transitions to marriage and early married life}

As is well known, the transition to marriage occurs early in India, both for young men and young women. The recent NFHS (IIPS and Macro International, 2007a) shows, for example, that in India, $47 \%$ of young women aged 20-24 had married before the age of 18 , the minimum legal age at marriage for females; $32 \%$ of young men aged 25-29 had, likewise, married before they reached the age of 21, the legal minimum age at marriage for males. In Tamil Nadu, however, the scenario is somewhat different. For example, age at marriage tends to be higher in Tamil Nadu than in India more generally (IIPS and Macro International, 2008). Moreover, in India in general while marriage-related planning occurs early, often as soon as a girl reaches menarche and, in many cases, even before she does so and without her participation, evidence from Tamil Nadu suggests that considerable percentages of young women play an active role in determining the timing of their marriage and choice of partner (Jejeebhoy and Halli, 2005). Unlike in other parts of India, in addition, marriages in Tamil Nadu tend to be consanguineous (Krishanmoorthy and Audinarayana, 2001).

Little is known, however, about marriage processes and the nature of early married life among young men and women in Tamil Nadu. This chapter captures some of these experiences, including young people's preferences regarding the timing and type of marriage, marriage preparation and planning, and young people's participation in these processes, as well as their experiences in early married life and the fertility and contraceptive behaviours of young couples.

\subsection{Young people's preferences regarding timing and type of marriage}

The Youth Study sought to assess young people's preferences about the age at which to marry and, among the unmarried, their preferences for a love or arranged marriage. Findings, presented in Table 10.1, indicate that few youth expressed a preference to marry in adolescence: just $1 \%$ of young men and $5 \%$ of young women. The majority of young women $(62 \%)$ and few young men (11\%) preferred to marry at ages 20-24. In contrast, the majority of young men $(87 \%)$ preferred to marry at age 25 or later, a preference articulated by just one-quarter of young women.

Disparities by marital status of respondents were notable. Unmarried youth were more likely than the married to report a preference for marriage at age 25 or later. For example, while $90 \%$ of unmarried young men preferred to marry at these older ages, just $73 \%$ of married young men expressed this preference. Among young women, one-third of unmarried young women compared to just $15 \%$ of married young women expressed a preference for marriage at age 25 or later. Rural-urban differences were much milder. For example, $86 \%$ of rural young men compared to $89 \%$ of urban young men preferred to marry at age 25 or later, as did $23 \%$ and $30 \%$, respectively, of young women. Although large majorities of unmarried young men and women had reported that in general, women should be allowed to decide about their own marriage (see Chapter 7), findings show that the vast majority of unmarried youth actually preferred to have an arranged rather than a love marriage for themselves. For example, just 13\% of unmarried young men and $7 \%$ of unmarried young women reported that they would prefer a love marriage; differences by rural-urban residence were negligible. 
Table 10.1: Preferences regarding timing and type of marriage

Percentage of youth reporting preferences regarding timing of marriage and percentage preferring a love marriage, according to residence, Tamil Nadu, 2006

\begin{tabular}{|c|c|c|c|c|c|c|}
\hline Indicators (\%) & $\begin{array}{c}M \\
15-24 \\
\end{array}$ & $\begin{array}{c}\text { W } \\
15-24 \\
\end{array}$ & $\begin{array}{c}\text { MM } \\
15-29\end{array}$ & $\begin{array}{c}\text { MW } \\
15-24\end{array}$ & $\begin{array}{c}\text { UM } \\
15-24\end{array}$ & $\begin{array}{c}\text { UW } \\
15-24\end{array}$ \\
\hline \multicolumn{7}{|c|}{ Combined } \\
\hline \multicolumn{7}{|l|}{ Preferred to marry at age: } \\
\hline 18 & 0.3 & 2.4 & 1.2 & 5.6 & 0.1 & 0.4 \\
\hline 19 & 0.2 & 1.5 & 1.1 & 2.3 & 0.1 & 1.0 \\
\hline 20 & 1.2 & 11.0 & 4.5 & 18.0 & 0.4 & 6.4 \\
\hline 21 & 1.2 & 21.9 & 3.9 & 24.7 & 0.7 & 20.0 \\
\hline 22 & 1.8 & 9.7 & 4.2 & 9.4 & 1.3 & 9.9 \\
\hline 23 & 2.1 & 11.7 & 4.5 & 8.6 & 1.8 & 13.7 \\
\hline 24 & 4.3 & 7.4 & 5.8 & 5.3 & 3.9 & 8.8 \\
\hline 25 or above & 87.2 & 25.8 & 72.9 & 15.3 & 90.0 & 32.7 \\
\hline Preferred not to marry & 1.6 & 7.9 & 1.7 & 9.4 & 1.7 & 6.9 \\
\hline Preferred a love marriage ${ }^{1}$ & NA & NA & NA & NA & 13.3 & 6.8 \\
\hline Number of respondents & 1,913 & 5,008 & 1,322 & 2,007 & 1,666 & 3,001 \\
\hline \multicolumn{7}{|c|}{ Urban } \\
\hline \multicolumn{7}{|l|}{ Preferred to marry at age: } \\
\hline 18 & 0.1 & 1.9 & 0.7 & 4.7 & 0.0 & 0.2 \\
\hline 19 & 0.0 & 1.0 & 0.2 & 2.0 & 0.0 & 0.4 \\
\hline 20 & 0.5 & 9.1 & 3.1 & 16.7 & 0.3 & 4.7 \\
\hline 21 & 1.0 & 20.9 & 2.0 & 24.3 & 0.7 & 18.9 \\
\hline 22 & 1.4 & 8.9 & 4.1 & 8.5 & 0.8 & 9.1 \\
\hline 23 & 2.4 & 13.0 & 2.4 & 10.9 & 2.3 & 14.2 \\
\hline 24 & 4.1 & 8.2 & 6.3 & 6.5 & 3.5 & 9.2 \\
\hline 25 or above & 88.8 & 29.5 & 79.5 & 17.0 & 90.8 & 36.7 \\
\hline Preferred not to marry & 1.7 & 7.1 & 1.5 & 8.5 & 1.7 & 6.4 \\
\hline Preferred a love marriage $^{1}$ & NA & NA & NA & NA & 12.6 & 6.6 \\
\hline Number of respondents & 890 & 2,151 & 653 & 804 & 789 & 1,347 \\
\hline \multicolumn{7}{|c|}{ Rural } \\
\hline $\begin{array}{l}\text { Preferred to marry at age: } \\
17 \text { or below }\end{array}$ & 0.1 & 0.9 & 0.1 & 1.9 & 0.0 & 0.2 \\
\hline 18 & 0.5 & 2.9 & 1.5 & 6.2 & 0.2 & 0.4 \\
\hline 19 & 0.3 & 1.9 & 1.8 & 2.5 & 0.1 & 1.5 \\
\hline 20 & 1.7 & 12.6 & 5.5 & 19.0 & 0.4 & 8.0 \\
\hline 21 & 1.4 & 22.7 & 5.3 & 25.0 & 0.8 & 21.1 \\
\hline 22 & 2.2 & 10.3 & 4.2 & 9.9 & 1.7 & 10.6 \\
\hline 23 & 1.8 & 10.6 & 5.9 & 7.0 & 1.4 & 13.3 \\
\hline 24 & 4.6 & 6.8 & 5.5 & 4.4 & 4.2 & 8.4 \\
\hline 25 or above & 85.8 & 22.8 & 68.4 & 14.0 & 89.3 & 29.1 \\
\hline Preferred not to marry & 1.6 & 8.5 & 1.7 & 9.9 & 1.7 & 7.5 \\
\hline Preferred a love marriage ${ }^{1}$ & NA & NA & NA & NA & 13.9 & 7.0 \\
\hline Number of respondents & 1,023 & 2,857 & 669 & 1,203 & 877 & 1,654 \\
\hline
\end{tabular}

Note: All Ns are unweighted. NA: Not applicable. ${ }^{1}$ Excludes those who reported a preference not to marry. 


\subsection{Marriage planning and extent of youth involvement}

Several questions were put to both married and unmarried youth to understand the process of marriage planning as well as their involvement in it. While questions on marriage planning were similar for the married and the unmarried, some questions were unique to one or the other group. For example, the Youth Study asked unmarried respondents whether their parents or family members had begun discussing plans for their marriage; and asked all married youth, and those unmarried youth for whom discussions had been initiated, about their age at that time and whether their parents sought their opinion about the age at which they wished to marry.

Findings presented in Table 10.2 reaffirm the practice of relatively late marriages in the state; among those whose parents had initiated marriage-related discussions (88-97\% of married youth, and $10 \%$ and $33 \%$ of unmarried young men and women, respectively), findings indicate that these discussions were initiated at age 18 or later for the majority of youth. Vast gender differences were, however, evident: $94 \%$ of young men compared to $57 \%$ of young women reported that marriage-related discussions were initiated at age 18 or later. Marital status differences were narrow for young men; in contrast, discussions were initiated at age 18 or later for larger proportions of unmarried than married young women ( $72 \%$ and $50 \%$, respectively). Rural-urban differences were negligible, except that a somewhat larger proportion of urban than rural young women reported that marriage-related discussions were initiated at age 18 or later (62\% versus 54\%).

Among youth whose parents had already initiated marriage-related discussions, large proportions reported that they were consulted on the timing of marriage. Gender differences were, however, evident: young men were more likely than young women to have been consulted on the timing of marriage ( $83 \%$ versus $61 \%$ ). Disparities by marital status were narrow (see Figure 10.1). For example, 58\% and 65\%, respectively, of married and unmarried young women, and $87 \%$ and $82 \%$, respectively, of young men were consulted about when they wished to marry. Rural-urban differences, once more, were negligible.

Figure 10.1: Percentage of youth reporting that their parents had ever sought their opinion on timing of marriage, according to residence, Tamil Nadu, 2006
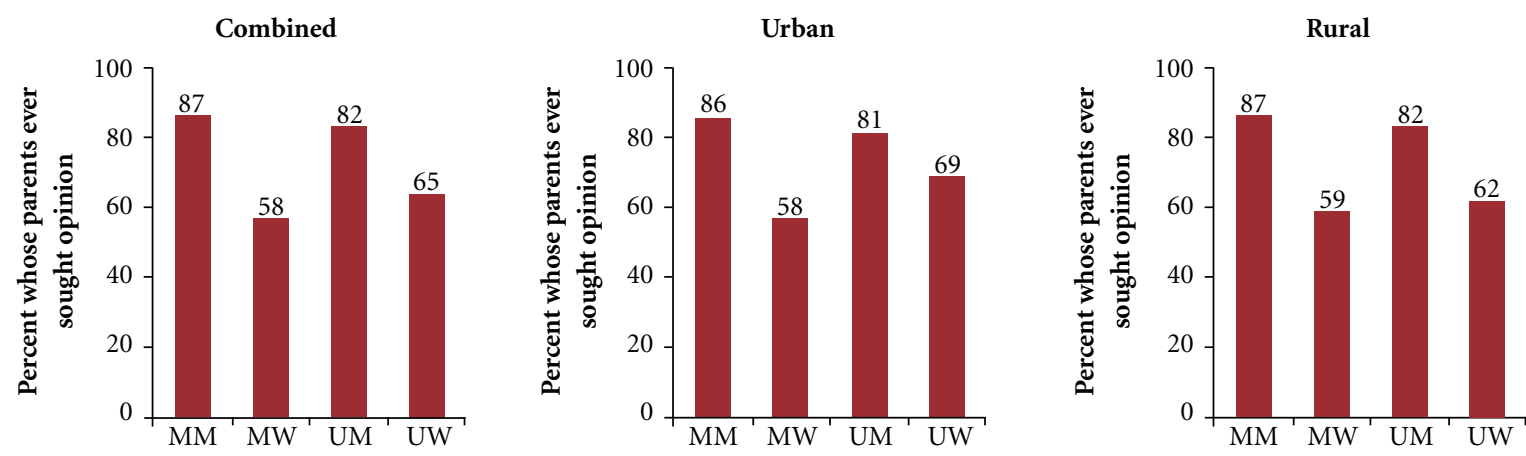

Note: Includes respondents whose parents had initiated marriage-related discussion. 
Table 10.2: Initiation of discussion on marriage and extent of youth involvement

Percentage of youth by age at initiation of marriage-related discussion, percentage whose opinion had been sought on timing of marriage and percentage who would find it difficult to tell parents if they did not like the match chosen, according to residence, Tamil Nadu, 2006

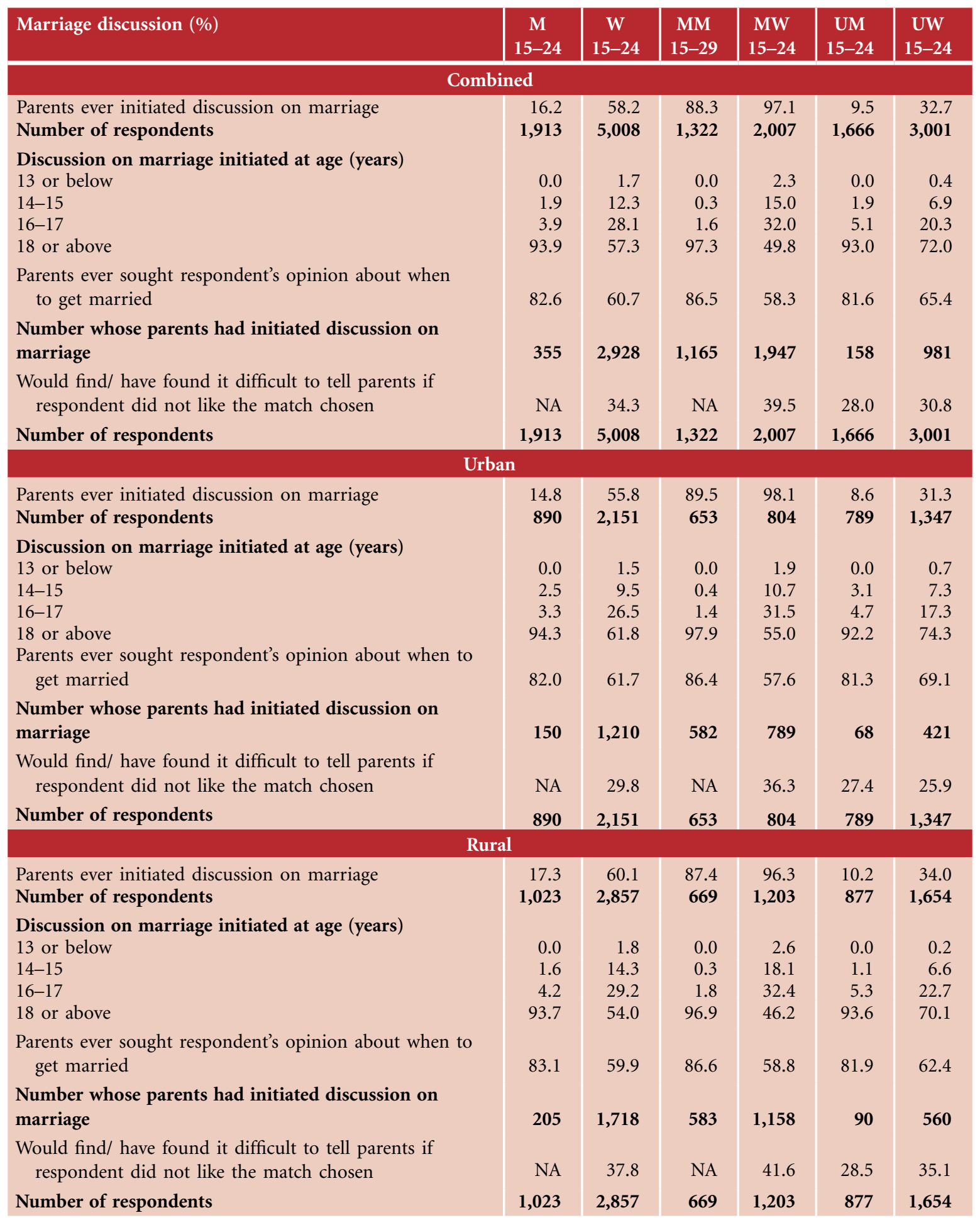

Note: All Ns are unweighted. Column totals may not equal 100\% due to missing cases or "don't know"/“don't remember" responses. NA: Not applicable. 
The Youth Study also sought to assess the extent to which youth (other than married young men) perceived that they could express or, among the married, could have expressed their preference not to marry the prospective spouse selected for them. Findings suggest that relatively few youth perceived that it would be/was difficult to oppose their parents if they did not approve of the match chosen for them; gender differences were relatively narrow and just one-third of young women and $28 \%$ of unmarried young men reported difficulty. Marital status differences among young women suggest that unmarried young women were somewhat less likely than the married to report difficulty in opposing their parents (31\% and $40 \%$, respectively). This difference may reflect the tendency for the married to report actual experiences, and for many unmarried whose families had not yet initiated discussions, to report perceptions. At the same time, it may suggest a trend towards greater self-determination among the unmarried. Finally, and perhaps for reasons pertaining to the gendered nature of family life in rural areas, rural young women were somewhat more likely than their urban counterparts to report difficulty in confronting their parents on marriage-related issues (38\% compared to $30 \%$ ); differences were negligible among young men. In short, these findings confirm that large proportions of youth did perceive that they would play a role in decision-making with regard to their own marriage.

\subsection{Age at marriage and cohabitation}

Youth Study findings underscore the fact that Tamil Nadu is characterised by relatively late age at marriage among young women and men (Table 10.3). Among young women aged 20-24, just 2\% were married before age $15,18 \%$ before age 18 and $38 \%$ before age 20. Findings from the NFHS-3 are similar; they indicate that $22 \%$ of $20-24$ year-old women in the state were married before age 18 (IIPS and Macro International, 2009). Rural-urban differences were narrow: in rural areas, $20 \%$ and $42 \%$ of women aged $20-24$ years were married before ages 18 and 20, respectively; corresponding percentages in urban areas were $15 \%$ and $33 \%$. Even fewer young men were married in adolescence: just $4 \%$ of those aged 20-24 were married before they reached age 20. Almost all youth (99.9\%) had been married just once (not shown in tabular form). The mean age at marriage among those who were married was 23.2 years among young men and 18.4 years among young women. Again, rural-urban differences in the mean age at marriage were negligible; under one year for both young men and women. The mean age at cohabitation was almost identical to the mean age at marriage.

\subsection{Marriage preparedness}

Several questions were put to both married and unmarried youth who were engaged to be married to understand their preparedness for marriage. Questions ranged from whether the proposed spouse was chosen by the young person or by his/her parents; whether the young person's approval of the prospective spouse was sought, if chosen by the parents; and how much contact the young person and the prospective spouse had prior to marriage. As just $1 \%$ and $2 \%$ of unmarried young men and women reported that they were engaged to be married (not shown in tabular form), we restrict our discussion to the currently married.

Table 10.4 describes marriage-related preparedness among the married. While the majority of youth, whether male or female, married a partner chosen by their parents, it is notable that one in five young men and women married a person of their own choice. Even among those who reported an arranged marriage, the majority reported that their approval of the prospective spouse had been sought. Gender and rural-urban differences were narrow. The gap between the point at which marriage arrangements were fixed and the date of the actual marriage was short: on average two months, with about nine in 10 respondents reporting that they married within three months of the completion of marriage negotiations, irrespective of sex of the respondent (not shown in tabular form).

Even though just two in five young men and one in three young women reported that they had ever had a chance to meet and interact with their spouse-to-be alone prior to marriage, large proportions of youth 
Table 10.3: Age at marriage and cohabitation

Percentage of youth aged 15-24 who were married before selected ages, percentage never married and mean age at marriage and cohabitation among those married, according to current age and residence, Tamil Nadu, 2006

\begin{tabular}{|c|c|c|c|c|c|c|c|}
\hline \multirow[t]{2}{*}{$\begin{array}{l}\text { Current age } \\
\text { (years) }(\%)\end{array}$} & \multicolumn{3}{|c|}{$\begin{array}{c}\text { Percentage first married before age } \\
\text { (years): }\end{array}$} & \multirow{2}{*}{$\begin{array}{c}\text { Percentage } \\
\text { never } \\
\text { married }\end{array}$} & \multicolumn{2}{|c|}{ Among those married: } & \multirow[t]{2}{*}{$\begin{array}{l}\text { Number of } \\
\text { respondents }\end{array}$} \\
\hline & 15 & 18 & 20 & & $\begin{array}{c}\text { Mean age } \\
\text { at marriage } \\
\text { (years) }\end{array}$ & $\begin{array}{c}\text { Mean age at } \\
\text { cohabitation } \\
\text { (years) }\end{array}$ & \\
\hline \multicolumn{8}{|c|}{ Combined } \\
\hline $\begin{array}{l}\text { Men } \\
15-19\end{array}$ & 0.0 & NA & NA & 99.8 & * & * & 899 \\
\hline $20-24$ & 0.0 & 0.3 & 3.8 & 81.7 & 21.0 & 21.1 & 1,014 \\
\hline $15-24$ & 0.0 & NA & NA & 90.5 & $23.2^{1}$ & $23.3^{1}$ & 1,913 \\
\hline \multicolumn{8}{|l|}{ Women } \\
\hline $15-19$ & 1.1 & NA & NA & 86.2 & 16.7 & 16.8 & 2,274 \\
\hline $20-24$ & 1.8 & 18.1 & 37.8 & 38.8 & 18.8 & 18.9 & 2,734 \\
\hline $15-24$ & 1.5 & NA & NA & 60.4 & 18.4 & 18.5 & 5,008 \\
\hline \multicolumn{8}{|c|}{ Urban } \\
\hline Men & & & & & & & \\
\hline $15-19$ & 0.0 & NA & NA & 99.7 & * & * & 413 \\
\hline $20-24$ & 0.0 & 0.2 & 3.2 & 84.0 & 21.3 & 21.4 & 477 \\
\hline $15-24$ & 0.0 & NA & NA & 91.5 & $23.7^{1}$ & $23.8^{1}$ & 890 \\
\hline \multicolumn{8}{|l|}{ Women } \\
\hline $15-19$ & 0.6 & NA & NA & 90.2 & 16.7 & 16.7 & 964 \\
\hline $20-24$ & 1.6 & 15.3 & 33.1 & 40.9 & 19.0 & 19.1 & 1,187 \\
\hline $15-24$ & 1.1 & NA & NA & 63.3 & 18.7 & 18.8 & 2,151 \\
\hline \multicolumn{8}{|c|}{ Rural } \\
\hline Men & & & & & & & \\
\hline $15-19$ & 0.0 & NA & NA & 99.8 & * & * & 486 \\
\hline $20-24$ & 0.0 & 0.4 & 4.2 & 79.9 & 20.8 & 21.0 & 537 \\
\hline $15-24$ & 0.0 & NA & NA & 89.8 & $22.9^{1}$ & $23.0^{1}$ & 1,023 \\
\hline Women & & & & & & & \\
\hline $15-19$ & 1.5 & NA & NA & 83.0 & 16.7 & 16.8 & 1,310 \\
\hline $20-24$ & 1.9 & 20.4 & 41.6 & 37.0 & 18.6 & 18.7 & 1,547 \\
\hline $15-24$ & 1.7 & NA & NA & 58.1 & 18.2 & 18.3 & 2,857 \\
\hline
\end{tabular}

Note: All Ns are unweighted. ${ }^{*}$ Mean not shown, based on fewer than 25 unweighted cases. NA: Not applicable due to censoring. ${ }^{1}$ Includes married men aged 25-29 years.

reported a certain degree of pre-marital acquaintance. Four-fifths of young men and about two-thirds of young women reported that they knew their spouse somewhat or well prior to marriage (see Figure 10.2), a finding attributable to the practice of consanguineous marriage in the state. The remaining one-fifth (21\%) of young men and $36 \%$ of young women reported that they had met their spouse for the first time on their wedding day. Rural-urban differences were muted among young men, but somewhat wide among young women. Young women in urban areas were somewhat more likely than their rural counterparts to report pre-marital acquaintance (68\% versus $62 \%$ ). In short, findings suggest that considerable proportions of youth, irrespective of sex or rural-urban residence, had married a person of their own choice or had approved of the prospective spouse chosen by their parents and had some pre-marital acquaintance with their spouse. 
Table 10.4: Marriage preparedness

Percent distribution of married youth by type of marriage and selected indicators of their preparedness for marriage, according to residence, Tamil Nadu, 2006

\begin{tabular}{|c|c|c|c|c|c|c|}
\hline \multirow[t]{2}{*}{ Marriage indicators (\%) } & $\begin{array}{c}\text { MM } \\
15-29\end{array}$ & $\begin{array}{c}\text { MW } \\
15-24\end{array}$ & $\begin{array}{c}\text { MM } \\
15-29\end{array}$ & $\begin{array}{c}\text { MW } \\
15-24\end{array}$ & $\begin{array}{c}\text { MM } \\
15-29\end{array}$ & $\begin{array}{c}\text { MW } \\
15-24\end{array}$ \\
\hline & \multicolumn{2}{|c|}{ Combined } & \multicolumn{2}{|c|}{ Urban } & \multicolumn{2}{|c|}{ Rural } \\
\hline Type of marriage & & & & & & \\
\hline $\begin{array}{l}\text { Marriage fixed by respondent himself/herself } \\
\text { (love marriage) }\end{array}$ & 20.1 & 19.1 & 18.4 & 17.9 & 21.3 & 20.0 \\
\hline $\begin{array}{l}\text { Marriage arranged by parents, with respondent's } \\
\text { approval of choice of spouse }\end{array}$ & 72.7 & 77.4 & 76.1 & 79.0 & 70.3 & 76.4 \\
\hline Marriage fixed by parents without respondent's approval & 7.2 & 3.4 & 5.5 & 3.1 & 8.3 & 3.7 \\
\hline Ever had a chance to meet/talk with fiancé/fiancée alone & 41.0 & 33.6 & 38.9 & 35.8 & 42.5 & 32.1 \\
\hline Acquaintance with spouse before marrige & & & & & & \\
\hline Met on wedding day & 21.0 & 35.5 & 22.3 & 32.3 & 20.2 & 37.6 \\
\hline Knew somewhat before wedding day & 40.4 & 32.4 & 44.0 & 37.1 & 37.9 & 29.2 \\
\hline Knew well before wedding day & 38.6 & 31.7 & 33.7 & 30.7 & 42.0 & 32.5 \\
\hline Feelings about getting married & & & & & & \\
\hline Excited/looked forward to it & 76.3 & 30.8 & 78.4 & 31.7 & 74.9 & 30.2 \\
\hline Nothing special & 17.2 & 15.0 & 15.5 & 14.9 & 18.5 & 15.0 \\
\hline Very scared & 3.0 & 42.6 & 2.8 & 45.3 & 3.2 & 40.8 \\
\hline Anxious & 2.4 & 10.8 & 2.2 & 7.7 & 2.4 & 12.9 \\
\hline Unhappy & 0.9 & 0.4 & 0.9 & 0.1 & 0.9 & 0.7 \\
\hline Number of respondents & 1,322 & 2,007 & 653 & 804 & 669 & 1,203 \\
\hline Did not know what to expect of married life & 65.2 & 76.1 & 60.0 & 74.3 & 68.8 & 77.2 \\
\hline $\begin{array}{l}\text { Agree that youth do not get accurate information } \\
\text { about married life before marriage }\end{array}$ & 68.9 & 77.3 & 64.9 & 75.1 & 71.6 & 78.8 \\
\hline Number who had begun cohabiting & 1,321 & 2,006 & 652 & 803 & 669 & 1,203 \\
\hline
\end{tabular}

Note: All Ns are unweighted. Column totals may not equal 100\% due to missing cases or "don't know" responses.

Figure 10.2: Percent distribution of married youth by degree of acquaintance with future spouse before marriage, according to residence, Tamil Nadu, 2006

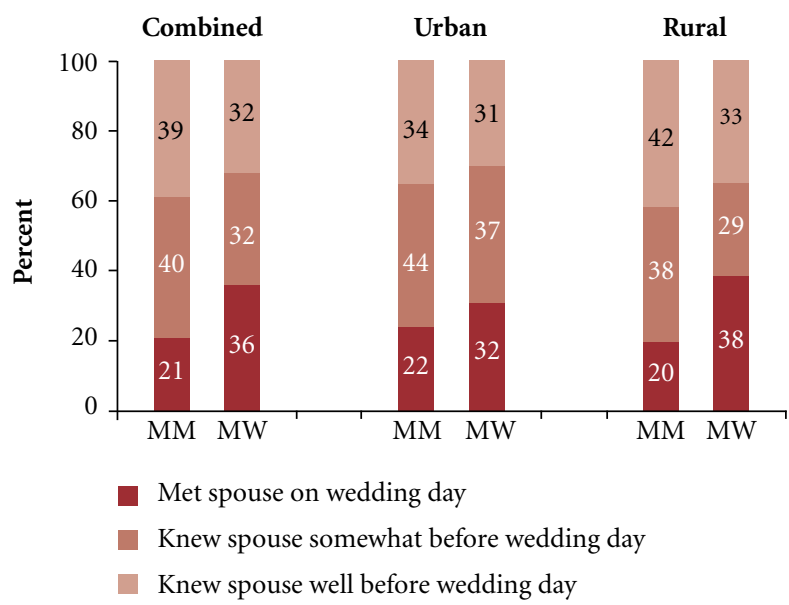


Nevertheless, large proportions of youth who had already cohabited reported they were unaware at the time of their marriage or what to expect of married life. Young women were more likely than young men (76\% and $65 \%$, respectively), and rural youth were more likely than urban youth (69\% and $60 \%$ respectively, of young men; $77 \%$ and $74 \%$, respectively, of young women), to report they were poorly informed. Over two-thirds of youth reported that young people in general were poorly informed about married life prior to marriage, highlighting the need for family life or sex education and pre-marital counselling for young people.

Moreover, not all youth reported that they had looked forward to or had been excited about their marriage. Gender differences were pronounced: while $76 \%$ of young men said that they had been excited about their marriage, only $31 \%$ of young women so reported. In contrast, just $3 \%$ of young men compared to over twofifths of young women $(43 \%)$ reported that they had been very scared about getting married. Urban-rural differences were negligible.

\subsection{Payment of dowry}

Despite the existence of laws against dowry, Figure 10.3 shows that $84-88 \%$ of all respondents reported giving or taking dowry. Gender differences were negligible: $84 \%$ of young men reported that their families had received dowry at marriage and $88 \%$ of young women reported that their families had paid dowry at the time of their marriage. Rural-urban differences, once again, were negligible. Clearly, while many traditional marriage-related practices discussed above have changed in Tamil Nadu, adherence to the practice of dowry remains widespread.

Figure 10.3: Percentage of married youth who reported receiving or giving dowry, according to residence, Tamil Nadu, 2006

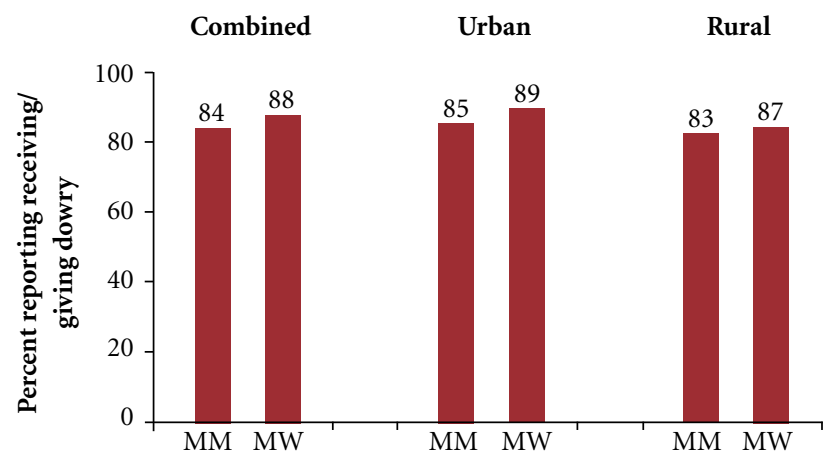

\subsection{Early marital experiences: Spousal communication and interaction}

Table 10.5 describes the extent of communication and interaction among young couples. Findings suggest considerable inter-spousal communication; however, the extent of communication varied considerably by topic (see also Figure 10.4). For example, over $90 \%$ of young men and women reported that they regularly discussed how to spend money with their spouse, and had ever discussed when/whether to have children and how many children to have with their spouse. In comparison, about three-quarters of young men and twothirds of young women reported discussing in-law issues, and just $37 \%$ and $59 \%$, respectively, reported ever discussing contraceptive use with their spouse. Rural-urban differences suggest that somewhat more urban 
than rural youth (40\% and 35\%, respectively, among young men, and $64 \%$ and 55\%, respectively, among young women) reported ever discussing contraception with their spouse.

Spousal interaction was also measured by questions regarding whether, in the six months preceding the interview, respondents had gone with their spouse to a movie, been on an outing or gone to their own (for young women) or their wife's (for young men) natal home. These types of interaction were pervasive, but varied by type of interaction. For example, over $90 \%$ of young men and women had visited their wife's/own natal home together with their spouse. Somewhat fewer youth- $85 \%$ and $76 \%$ of young men and women, respectively - had been on an outing with their spouse, and even fewer $(76 \%$ and $57 \%$, respectively) had been to a movie or other places of entertainment. Gender and rural-urban differences were apparent. As seen above, young women were considerably less likely to report going on outings, and especially to places of entertainment with their husband, than young men were to report visiting these places with their wife. Rural youth were less likely than urban youth to report going with their spouse on an outing ( $82 \%$ and $89 \%$, respectively, among young men; $73 \%$ and $80 \%$, respectively, among young women) or to a theatre/video parlour $(70 \%$ and $84 \%$, respectively, among young men; $51 \%$ and $67 \%$, respectively, among young women).

\section{Table 10.5: Early marital experiences}

Percentage of married youth by selected characteristics of the marital relationship, according to residence, Tamil Nadu, 2006

\begin{tabular}{|c|c|c|c|c|c|c|}
\hline \multirow[t]{2}{*}{ Characteristics (\%) } & $\begin{array}{c}\text { MM } \\
15-29\end{array}$ & $\begin{array}{c}\text { MW } \\
15-24\end{array}$ & $\begin{array}{c}\text { MM } \\
15-29\end{array}$ & $\begin{array}{c}\text { MW } \\
15-24\end{array}$ & $\begin{array}{c}\text { MM } \\
15-29\end{array}$ & $\begin{array}{c}\text { MW } \\
15-24\end{array}$ \\
\hline & \multicolumn{2}{|c|}{ Combined } & \multicolumn{2}{|c|}{ Urban } & \multicolumn{2}{|c|}{ Rural } \\
\hline $\begin{array}{l}\text { Usually communicates with spouse on: } \\
\text { How to spend money }\end{array}$ & 95.6 & 92.8 & 95.9 & 92.2 & 95.3 & 93.2 \\
\hline In-law issues & 76.8 & 68.9 & 78.6 & 67.5 & 75.6 & 69.9 \\
\hline \multicolumn{7}{|l|}{ Ever communicated with spouse on: } \\
\hline When/whether to have a baby & 91.7 & 91.6 & 93.4 & 92.0 & 90.6 & 91.2 \\
\hline Number of children to have & 94.5 & 93.5 & 94.3 & 93.9 & 94.7 & 93.2 \\
\hline Contraceptive use & 37.0 & 58.7 & 40.2 & 63.9 & 34.8 & 55.3 \\
\hline \multicolumn{7}{|l|}{ Went with spouse to the following in last 6 months: } \\
\hline Festival/yatra/tamasha/play/tour/picnic/restaurant & 84.6 & 75.6 & 88.9 & 79.5 & 81.8 & 73.0 \\
\hline Woman's/wife's natal home & 92.0 & 90.8 & 91.3 & 91.2 & 92.4 & 90.6 \\
\hline \multicolumn{7}{|l|}{ Assessment of married life } \\
\hline Very happy & 82.0 & 62.8 & 81.2 & 68.2 & 82.5 & 59.2 \\
\hline Reasonably happy & 15.3 & 31.0 & 16.8 & 28.7 & 14.2 & 32.6 \\
\hline Unhappy & 0.5 & 0.7 & 0.7 & 0.1 & 0.5 & 1.2 \\
\hline Very unhappy & 2.1 & 5.4 & 1.3 & 3.0 & 2.7 & 7.0 \\
\hline Number who had begun cohabiting & 1,321 & 2,006 & 652 & 803 & 669 & 1,203 \\
\hline
\end{tabular}

Note: All Ns are unweighted. Column totals may not equal 100\% due to missing cases or "don't know" responses. 
Figure 10.4: Percentage of married youth who reported spousal communication on selected topics, according to residence, Tamil Nadu, 2006
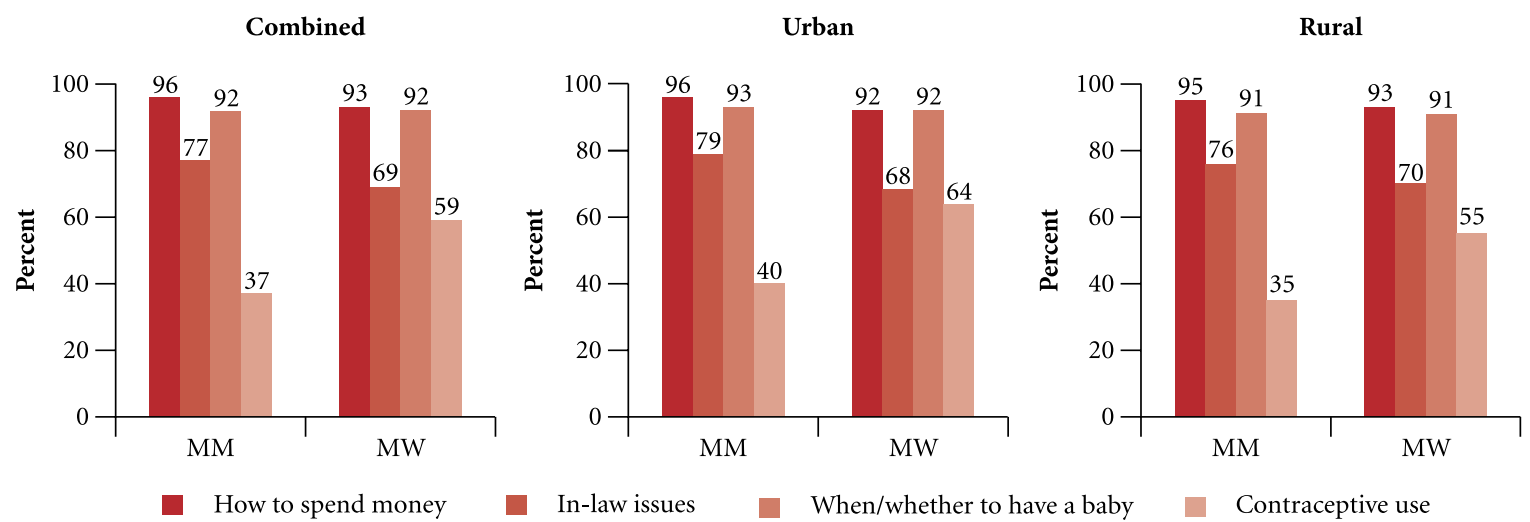

Youth were also asked to assess their relative contentment with married life. While the majority reported that they were very happy, responses suggest wide gender differences: substantially more young men than young women reported that they were happy with married life (82\% versus $63 \%)$. A small minority of young women and men (6\% and 3\%, respectively) reported that they were unhappy with married life. Rural-urban differences were negligible among young men but rural young women were considerably less likely than their urban counterparts to report that they were very happy with married life $59 \%$ versus $68 \%)$ and somewhat more likely to report they were very unhappy with married life $(7 \%$ and $3 \%$, respectively).

\subsection{Nature of marital sexual experiences}

In several previous studies, significant minorities of young women reported the experience of forced sex within marriage, including at initiation (see, for example, Santhya and Jejeebhoy, 2006; Santhya et al., 2007). The Youth Study explored the extent to which early marital sexual experiences were enjoyable or forced. Findings, presented in Table 10.6, suggest that while virtually all young men reported enjoying their first marital sexual experience, fewer young women so reported: $99 \%$ compared to $86 \%$, with little rural-urban variation.

A comparison of responses to questions regarding whether the spouse had enjoyed the first sexual experience suggests a disconnect: $96 \%$ of young men perceived that their wife had enjoyed the first sexual experience (compared to $86 \%$ young women who reported that they had enjoyed the first sexual experience), and $79 \%$ of young women perceived that their husband had enjoyed the experience (compared to $99 \%$ of young men who reported that they had enjoyed their first experience). While $52 \%$ of young women reported that they had cried and $81 \%$ reported that their first sexual experience had been painful, just $34 \%$ of young men reported that their wife had cried and half that it had been painful for their wife. Likewise, while $20 \%$ of young women reported that first sex was forced, just $8 \%$ of young men reported that they had forced their wife to engage in sex the first time. 
Table 10.6: Sexual experiences within marriage

Percentage of married youth by nature of first and lifetime sexual experiences with spouse, according to residence, Tamil Nadu, 2006

\begin{tabular}{|c|c|c|c|c|c|c|}
\hline \multirow[t]{2}{*}{ Experiences (\%) } & $\begin{array}{c}\text { MM } \\
15-29\end{array}$ & $\begin{array}{c}\text { MW } \\
15-24\end{array}$ & $\begin{array}{c}\text { MM } \\
15-29\end{array}$ & $\begin{array}{c}\text { MW } \\
15-24\end{array}$ & $\begin{array}{c}\text { MM } \\
15-29\end{array}$ & $\begin{array}{c}\text { MW } \\
15-24\end{array}$ \\
\hline & \multicolumn{2}{|c|}{ Combined } & \multicolumn{2}{|c|}{ Urban } & \multicolumn{2}{|c|}{ Rural } \\
\hline Nature of first sexual experience with spouse & & & & & & \\
\hline Respondent enjoyed it & 98.8 & 85.9 & 98.7 & 87.1 & 98.7 & 85.1 \\
\hline Spouse enjoyed it & 96.2 & 78.7 & 97.8 & 73.8 & 95.1 & 82.0 \\
\hline Wife cried & 34.0 & 52.0 & 36.5 & 44.8 & 32.3 & 56.9 \\
\hline Painful for wife & 50.2 & 81.0 & 52.2 & 78.0 & 48.8 & 83.1 \\
\hline Wife unwilling and husband forced her & 8.3 & 19.9 & 8.9 & 17.1 & 7.8 & 21.7 \\
\hline Husband ever forced wife to have sex & 14.7 & 25.3 & 15.3 & 23.3 & 14.2 & 26.6 \\
\hline Number who had begun cohabiting & 1,321 & 2,006 & 652 & 803 & 669 & 1,203 \\
\hline Husband forced wife to have sex in last 12 months & 4.1 & 13.6 & 3.3 & 12.2 & 4.6 & 14.6 \\
\hline Number who had cohabited for at least 12 months & 1,119 & 1,758 & 541 & 713 & 578 & 1,045 \\
\hline
\end{tabular}

Note: All Ns are unweighted.

Rural-urban differences were, for the most part, negligible among young men, but apparent for young women, among whom those in rural areas were consistently more likely than their urban counterparts to report negative experiences at first sex. For example, 57\% of young women in rural areas compared to $45 \%$ of those in urban areas reported that they had cried at first sex; and $22 \%$ compared to $17 \%$ reported that they had been forced to have sex the first time.

Over the course of their marital lives, somewhat more young people acknowledged the experience (young women) or perpetration (young men) of forced sex within marriage: $25 \%$ of young women reported that they had ever experienced forced sex within marriage and $15 \%$ of young men reported that they had ever perpetrated it. Rural-urban differences were negligible. Of those who had cohabited for at least one year, just $4 \%$ of young men and $14 \%$ of young women reported such an incident in the 12 month preceding the interview; rural-urban differences were, again, negligible.

\subsection{Experience of domestic violence within marriage}

The Youth Study explored the extent of domestic violence or verbal abuse perpetrated by young men on their wife and in less detail, by women on their husband. Table 10.7 shows that fewer than $5 \%$ of youth, irrespective of rural-urban residence, reported that the wife had verbally humiliated her husband in the presence of others or had perpetrated physical violence on her husband. Verbal humiliation by the husband on his wife was reported by $3 \%$ and $8 \%$ of young men and women, respectively.

More widespread was the perpetration of physical violence by young men on their wife: $34 \%$ of young men and $27 \%$ of young women reported the perpetration (men) or experience (women) of some form of physical violence. Rural-urban differences were apparent, with slightly more young men in rural than urban areas reporting the perpetration of physical violence on their wife (36\% and $32 \%$, respectively), and considerably more young women in rural than urban areas reporting the experience of physical violence perpetrated by their husband (30\% and 22\%, respectively) (see also Figure 10.5). Gender differences in reporting were, however, wider among urban than rural youth. 
Of all forms of physical violence, slapping was most commonly reported (24-33\%), followed by twisting of the wife's arm or pulling her hair (6-11\%), and kicking, dragging or beating the wife (3-8\%). Other violent behaviours were reported by $4 \%$ or fewer youth. Between $1 \%$ and $4 \%$ of young women reported the experience of being pushed, and, notably, about $1 \%$ reported that they had been burnt or choked by their husband or threatened with a knife or gun. Also notable is the finding that $8 \%$ of young men reported perpetrating more than one form of violence on their wife, and $12 \%$ of young women reported experiencing more than one form of violence at the hands of their husband. Rural young women were twice as likely as urban young women to have experienced more than one form of violence.

\section{Table 10.7: Domestic violence within marriage}

Percentage of married youth reporting experience of verbal abuse or physical violence within marriage by type of violence, according to residence, Tamil Nadu, 2006

\begin{tabular}{|c|c|c|c|c|c|c|}
\hline \multirow[t]{2}{*}{ Types of violence (\%) } & $\begin{array}{c}\text { MM } \\
15-29\end{array}$ & $\begin{array}{c}\text { MW } \\
15-24\end{array}$ & $\begin{array}{c}\text { MM } \\
15-29\end{array}$ & $\begin{array}{c}\text { MW } \\
15-24\end{array}$ & $\begin{array}{c}\text { MM } \\
15-29\end{array}$ & $\begin{array}{c}\text { MW } \\
15-24\end{array}$ \\
\hline & \multicolumn{2}{|c|}{ Combined } & \multicolumn{2}{|c|}{ Urban } & \multicolumn{2}{|c|}{ Rural } \\
\hline \multicolumn{7}{|c|}{ A. Verbal abuse or physical violence perpetrated by wife } \\
\hline $\begin{array}{l}\text { Wife verbally abused husband in the presence of others } \\
\text { Wife ever perpetrated any physical violence on husband } \\
\text { Wife perpetrated any physical violence on husband in } \\
\text { last } 12 \text { months }\end{array}$ & $\begin{array}{l}1.7 \\
0.9\end{array}$ & $\begin{array}{l}4.5 \\
0.8\end{array}$ & $\begin{array}{l}1.1 \\
0.6\end{array}$ & $\begin{array}{l}4.1 \\
0.6\end{array}$ & $\begin{array}{l}2.2 \\
1.3\end{array}$ & $\begin{array}{l}4.9 \\
1.0\end{array}$ \\
\hline Number who had begun cohabiting & 1,321 & 2,006 & 652 & 803 & 669 & 1,203 \\
\hline \multicolumn{7}{|c|}{ B. Verbal abuse or physical violence perpetrated by husband } \\
\hline $\begin{array}{l}\text { Husband verbally abused wife in the presence of others } \\
\text { Physical violence ever perpetrated by husband }\end{array}$ & 3.2 & 7.7 & 2.6 & 5.9 & 3.6 & 8.8 \\
\hline Slapped wife & 32.8 & 23.9 & 30.3 & 18.8 & 34.5 & 27.4 \\
\hline Twisted wife's arm or pulled her hair & 6.1 & 10.7 & 4.6 & 8.5 & 7.3 & 12.1 \\
\hline Pushed/shook or threw something at wife & 1.9 & 4.4 & 0.9 & 2.7 & 2.6 & 5.6 \\
\hline Punched wife & 1.4 & 3.2 & 0.6 & 1.9 & 1.9 & 4.2 \\
\hline Kicked, dragged or beat wife & 3.4 & 8.0 & 3.1 & 5.0 & 3.6 & 10.0 \\
\hline Choked or burnt wife on purpose & 0.0 & 0.8 & 0.0 & 0.6 & 0.0 & 0.9 \\
\hline Threatened or attacked wife with knife/gun & 0.2 & 0.5 & 0.0 & 0.5 & 0.4 & 0.6 \\
\hline $\begin{array}{l}\text { Perpetrated/experienced at least one of the above } \\
\text { forms of violence }\end{array}$ & 34.3 & 27.0 & 31.9 & 22.0 & 36.0 & 30.3 \\
\hline $\begin{array}{l}\text { Perpetrated/experienced more than one of the above } \\
\text { forms of violence }\end{array}$ & 7.9 & 12.0 & 5.7 & 7.5 & 9.5 & 15.0 \\
\hline \multicolumn{7}{|l|}{$\begin{array}{l}\text { Experience of violence perpetrated by husband in } \\
\text { last } 12 \text { months } \\
\text { Slapped wife }\end{array}$} \\
\hline Never & 70.6 & 78.7 & 73.8 & 83.3 & 68.3 & 75.5 \\
\hline Sometimes & 29.1 & 19.8 & 25.8 & 15.8 & 31.3 & 22.5 \\
\hline Often & 0.0 & 0.7 & 0.0 & 0.1 & 0.0 & 1.1 \\
\hline \multicolumn{7}{|l|}{ Twisted wife's arm or pulled her hair } \\
\hline Never & 94.4 & 90.2 & 96.3 & 92.2 & 93.1 & 88.8 \\
\hline Sometimes & 5.5 & 9.0 & 3.5 & 7.5 & 6.9 & 10.0 \\
\hline Often & 0.0 & 0.3 & 0.0 & 0.1 & 0.0 & 0.5 \\
\hline
\end{tabular}


Table 10.7: $\left(\right.$ Cont'd $^{\mathrm{d}}$

\begin{tabular}{|c|c|c|c|c|c|c|}
\hline \multirow[t]{2}{*}{ Types of violence (\%) } & $\begin{array}{c}\text { MM } \\
15-29\end{array}$ & $\begin{array}{c}\text { MW } \\
15-24\end{array}$ & $\begin{array}{c}\text { MM } \\
15-29\end{array}$ & $\begin{array}{c}\text { MW } \\
\text { 15-24 }\end{array}$ & $\begin{array}{c}\text { MM } \\
15-29\end{array}$ & $\begin{array}{c}\text { MW } \\
15-24\end{array}$ \\
\hline & \multicolumn{2}{|c|}{ Combined } & \multicolumn{2}{|c|}{ Urban } & \multicolumn{2}{|c|}{ Rural } \\
\hline \multicolumn{7}{|c|}{ B. Verbal abuse or physical violence perpetrated by husband } \\
\hline \multicolumn{7}{|c|}{ Pushed/shook or threw something at wife } \\
\hline Never & 98.3 & 95.9 & 99.3 & 97.5 & 97.7 & 94.8 \\
\hline Sometimes & 1.7 & 3.8 & 0.7 & 2.4 & 2.3 & 4.7 \\
\hline Often & 0.0 & 0.1 & 0.0 & 0.0 & 0.0 & 0.3 \\
\hline \multicolumn{7}{|l|}{ Punched wife } \\
\hline Never & 98.7 & 97.1 & 99.6 & 98.4 & 98.1 & 96.2 \\
\hline Sometimes & 1.3 & 2.4 & 0.4 & 1.5 & 1.9 & 3.0 \\
\hline Often & 0.0 & 0.2 & 0.0 & 0.0 & 0.0 & 0.3 \\
\hline \multicolumn{7}{|l|}{ Kicked, dragged or beat wife } \\
\hline Never & 96.7 & 92.9 & 97.0 & 95.7 & 96.4 & 90.9 \\
\hline Sometimes & 3.1 & 6.4 & 2.6 & 4.0 & 3.5 & 8.2 \\
\hline Often & 0.0 & 0.4 & 0.0 & 0.2 & 0.0 & 0.5 \\
\hline \multicolumn{7}{|l|}{ Choked or burnt wife on purpose } \\
\hline Never & 100.0 & 99.4 & 100.0 & 99.5 & 100.0 & 99.2 \\
\hline Sometimes & 0.0 & 0.5 & 0.0 & 0.5 & 0.0 & 0.6 \\
\hline Often & 0.0 & 0.1 & 0.0 & 0.0 & 0.0 & 0.2 \\
\hline \multicolumn{7}{|l|}{ Threatened or attacked wife with knife/gun } \\
\hline Never & 99.8 & 99.5 & 100.0 & 99.6 & 99.6 & 99.4 \\
\hline Sometimes & 0.2 & 0.4 & 0.0 & 0.4 & 0.4 & 0.5 \\
\hline Often & 0.0 & 0.0 & 0.0 & 0.0 & 0.0 & 0.1 \\
\hline $\begin{array}{l}\text { Perpetrated/experienced at least one of the above for } \\
\text { of violence in last } 12 \text { months }\end{array}$ & 30.9 & 24.2 & 27.5 & 19.7 & 33.2 & 27.2 \\
\hline Number who had begun cohabiting & 1,321 & 2,006 & 652 & 803 & 669 & 1,203 \\
\hline Experienced violence in first 12 months of marriage & 20.8 & 12.5 & 21.4 & 9.8 & 20.4 & 14.4 \\
\hline Number who had cohabited for at least 12 months & 1,119 & 1,758 & 541 & 713 & 578 & 1,045 \\
\hline
\end{tabular}

Note: All Ns are unweighted. Column totals may not equal 100\% due to missing cases or "don't know" responses.

Figure 10.5: Percentage of married young women reporting experience of physical violence perpetrated by their husband and percentage of married young men reporting perpetration of physical violence against their wife, according to residence, Tamil Nadu, 2006

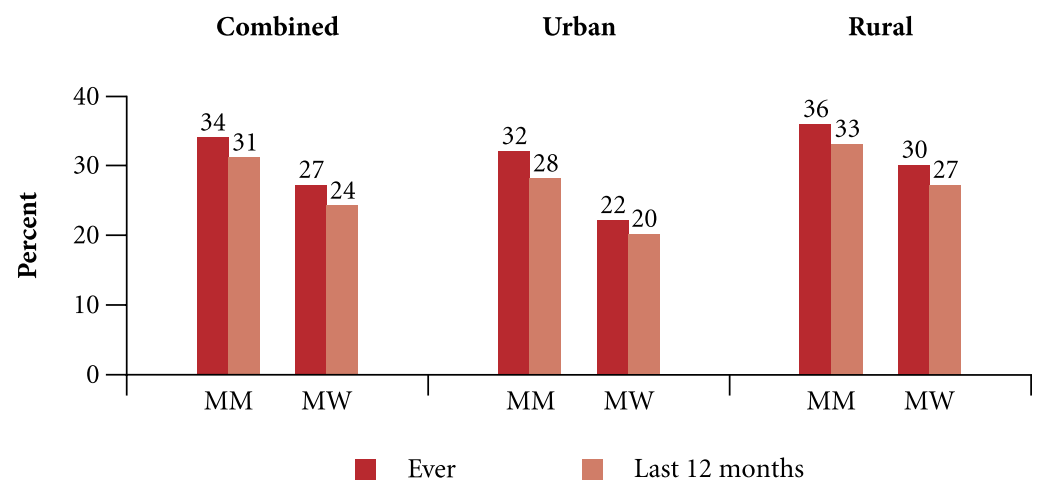


Findings also suggest that almost as many youth (31\% of young men and $24 \%$ of young women) reported the perpetration or experience of any form of physical violence within marriage in the 12 months preceding the interview. As earlier, slapping was most commonly reported; $29 \%$ of young men reported slapping their wife in the last year, while $21 \%$ of young women reported being slapped by their husband in the 12 months preceding the interview.

Findings on the occurrence of physical violence within the first year of marriage (among those who had cohabited for at least one year) indicate that a sizeable proportion of young men (21\%) had perpetrated physical violence within a year of marriage, with no differences by place of residence. Somewhat fewer young women reported that their first experience of physical violence had occurred within a year of marriage (13\%); rural young women were more likely than urban young women to report so (14\% compared to $10 \%$ ).

\subsection{Extent of extra-marital sexual relations}

The Youth Study did not probe as extensively about extra-marital sexual experiences as it did about premarital sex, discussed in Chapter 9. A single direct question was asked to all married youth about whether they had experienced sexual relations with someone other than their spouse following marriage. In addition, youth reporting same-sex, exchange, forced or sex worker sex were probed about the timing of the first such encounter; for very few, it occurred following marriage. Given the lack of extensive probing, we caution readers that percentages of youth reporting extra-marital sexual experience, indicated in Table 10.8, may be particularly under-reported.

Table 10.8: Extent of extra-marital sexual experiences

Percentage of married youth by extent of extra-marital sexual experiences, according to residence, Tamil Nadu, 2006

\begin{tabular}{|c|c|c|c|c|c|c|}
\hline \multirow[t]{2}{*}{ Experiences (\%) } & $\begin{array}{c}\text { MM } \\
15-29\end{array}$ & $\begin{array}{c}\text { MW } \\
15-24\end{array}$ & $\begin{array}{c}\text { MM } \\
15-29\end{array}$ & $\begin{array}{c}\text { MW } \\
15-24\end{array}$ & $\begin{array}{c}\text { MM } \\
15-29\end{array}$ & $\begin{array}{c}\text { MW } \\
15-24\end{array}$ \\
\hline & \multicolumn{2}{|c|}{ Combined } & \multicolumn{2}{|c|}{ Urban } & \multicolumn{2}{|c|}{ Rural } \\
\hline Had sex with someone other than spouse after marriage & 3.5 & 0.1 & 3.3 & 0.2 & 3.6 & 0.1 \\
\hline $\begin{array}{l}\text { Reported at least one extra-marital sexual partner in last } \\
12 \text { months }\end{array}$ & 2.0 & 0.2 & 1.5 & 0.2 & 2.3 & 0.2 \\
\hline Number who had begun cohabiting & 1,321 & 2,006 & 652 & 803 & 669 & 1,203 \\
\hline
\end{tabular}

Note: All Ns are unweighted.

Hardly any young women $(0.1 \%)$ reported an extra-marital sexual encounter. In contrast, $4 \%$ of young men reported an extra-marital sexual encounter, with no differences by place of residence. Among young men, about $2 \%$ reported extra-marital sex in the one year (or months since marriage for those married for less than one year) preceding the interview.

\subsection{Contraceptive practice within marriage: Lifetime, current and prior to first pregnancy}

The practise of contraception at any time during marital life was limited, reported by just $18 \%$ of young men and $21 \%$ of young women, with almost identical percentages reporting use of any modern method (see Table 10.9 and Figure 10.6). The limited percentages of youth practising contraception may be attributed to the relatively late age at marriage in Tamil Nadu and consequently, the fact that many married youth 
may not yet have initiated childbearing in the state. While gender differences were negligible in rural areas, somewhat larger percentages of young women than men in urban areas reported ever practising any method of contraception ( $27 \%$ and $21 \%$, respectively), again, with almost identical percentages reporting use of any modern method.

It is notable that despite the young age of female respondents and the relatively late age at marriage in the state, $9-10 \%$ of youth reported that they or their wife had undergone sterilisation. Indeed, female sterilisation was the method practised by $44-53 \%$ of youth who had ever practised contraception (not presented in tabular form). Among non-terminal modern methods, the methods most likely to have been used by young women were the condom and the IUD (6-7\%). While similar proportions of young men reported using the condom (7\%), just $1 \%$ of young men reported IUD use. Oral pills and the use of traditional contraceptive methods were rarely reported by either young men or women (1-2\%). Rural-urban differences in the use of non-terminal methods were evident: young women in urban areas were more likely than their rural counterparts to report both IUD use (10\% and $4 \%$, respectively) and condom use ( $8 \%$ and $4 \%$, respectively), and young men in urban areas were more likely than their rural counterparts to report condom use (11\% and $5 \%$, respectively).

Table 10.9: Contraceptive use within marriage

Percentage of married youth by ever and current contraceptive use, percent distribution by duration between marriage and initiation of contraceptive use and percentage who used different contraceptive methods to delay first pregnancy, according to residence, Tamil Nadu, 2006

\begin{tabular}{|c|c|c|c|c|c|c|}
\hline \multirow[t]{2}{*}{ Contraceptive use (\%) } & $\begin{array}{c}\text { MM } \\
15-29\end{array}$ & $\begin{array}{c}\text { MW } \\
15-24\end{array}$ & $\begin{array}{c}\text { MM } \\
15-29\end{array}$ & $\begin{array}{c}\text { MW } \\
15-24\end{array}$ & $\begin{array}{c}\text { MM } \\
15-29\end{array}$ & $\begin{array}{c}\text { MW } \\
15-24\end{array}$ \\
\hline & \multicolumn{2}{|c|}{ Combined } & \multicolumn{2}{|c|}{ Urban } & \multicolumn{2}{|c|}{ Rural } \\
\hline \multicolumn{7}{|c|}{ Ever use of contraception } \\
\hline Any method & 18.3 & 21.1 & 20.5 & 26.9 & 16.9 & 17.2 \\
\hline Any modern method & 17.7 & 20.8 & 19.7 & 26.4 & 16.2 & 17.0 \\
\hline Female sterilisation & 9.7 & 9.3 & 8.9 & 10.5 & 10.4 & 8.4 \\
\hline Male sterilisation & 0.0 & 0.1 & 0.0 & 0.0 & 0.0 & 0.3 \\
\hline Oral pills & 0.5 & 2.4 & 0.6 & 2.5 & 0.6 & 2.4 \\
\hline IUD & 1.3 & 6.7 & 1.5 & 10.4 & 1.2 & 4.3 \\
\hline Condom & 7.4 & 5.6 & 10.5 & 8.2 & 5.3 & 3.9 \\
\hline Other $^{1}$ & 0.3 & 0.1 & 0.2 & 0.1 & 0.4 & 0.2 \\
\hline Any traditional method ${ }^{2}$ & 1.9 & 0.6 & 2.0 & 1.0 & 1.8 & 0.4 \\
\hline Number who had begun cohabiting & 1,321 & 2,006 & 652 & 803 & 669 & 1,203 \\
\hline \multicolumn{7}{|c|}{ Current use of contraception } \\
\hline Any method & 15.7 & 16.9 & 17.5 & 21.7 & 14.5 & 13.8 \\
\hline Any modern method & 15.2 & 16.6 & 17.0 & 21.0 & 14.0 & 13.5 \\
\hline Female sterilisation & 9.7 & 9.3 & 8.9 & 10.5 & 10.4 & 8.4 \\
\hline Male sterilisation & 0.0 & 0.1 & 0.0 & 0.0 & 0.0 & 0.3 \\
\hline Oral pills & 0.3 & 0.7 & 0.2 & 0.6 & 0.3 & 0.8 \\
\hline IUD & 1.0 & 3.7 & 0.9 & 6.2 & 1.0 & 2.0 \\
\hline Condom & 4.5 & 2.9 & 7.4 & 4.2 & 2.6 & 2.1 \\
\hline Other $^{1}$ & 0.3 & 0.1 & 0.2 & 0.0 & 0.4 & 0.2 \\
\hline Any traditional method ${ }^{2}$ & 1.1 & 0.5 & 1.5 & 0.9 & 0.8 & 0.3 \\
\hline Number who had begun cohabiting & 1,321 & 2,006 & 652 & 803 & 669 & 1,203 \\
\hline
\end{tabular}


Table 10.9: (Cont'd)

\begin{tabular}{|c|c|c|c|c|c|c|}
\hline \multirow[t]{2}{*}{ Contraceptive use (\%) } & $\begin{array}{c}\mathrm{MM} \\
15-29\end{array}$ & $\begin{array}{c}\text { MW } \\
15-24\end{array}$ & $\begin{array}{c}\mathrm{MM} \\
15-29\end{array}$ & $\begin{array}{c}\text { MW } \\
15-24\end{array}$ & $\begin{array}{c}\text { MM } \\
15-29\end{array}$ & $\begin{array}{c}\text { MW } \\
15-24\end{array}$ \\
\hline & \multicolumn{2}{|c|}{ Combined } & \multicolumn{2}{|c|}{ Urban } & \multicolumn{2}{|c|}{ Rural } \\
\hline \multicolumn{7}{|c|}{ Duration between marriage and first use of contraception } \\
\hline \multicolumn{7}{|l|}{ Duration } \\
\hline Less than 6 months & 2.2 & 1.3 & 2.6 & 1.6 & 1.9 & 1.1 \\
\hline 6-11 months & 0.7 & 0.4 & 0.9 & 0.5 & 0.5 & 0.3 \\
\hline 12 months to 3 years & 6.0 & 10.6 & 7.9 & 15.0 & 4.6 & 7.6 \\
\hline More than 3 years & 8.9 & 7.8 & 8.1 & 8.9 & 9.4 & 7.0 \\
\hline Don't know/don't remember & 0.5 & 0.8 & 0.6 & 0.5 & 0.4 & 1.1 \\
\hline Never used contraception & 81.7 & 78.9 & 79.5 & 73.2 & 83.2 & 82.7 \\
\hline Number who had begun cohabiting & 1,321 & 2,006 & 652 & 803 & 669 & 1,203 \\
\hline \multicolumn{7}{|c|}{ Ever use of contraception to delay first pregnancy } \\
\hline Any method & 2.5 & 1.6 & 2.8 & 1.7 & 2.3 & 1.5 \\
\hline Any modern method & 2.2 & 1.5 & 2.8 & 1.6 & 1.8 & 1.4 \\
\hline Oral pills & 0.4 & 0.6 & 0.2 & 0.5 & 0.5 & 0.8 \\
\hline IUD & 0.0 & 0.2 & 0.0 & 0.4 & 0.0 & 0.1 \\
\hline Condom & 1.9 & 0.7 & 2.6 & 0.9 & 1.4 & 0.7 \\
\hline Other $^{1}$ & 0.1 & 0.0 & 0.0 & 0.0 & 0.1 & 0.1 \\
\hline Any traditional method ${ }^{2}$ & 0.4 & 0.1 & 0.4 & 0.1 & 0.4 & 0.1 \\
\hline Number who had begun cohabiting & 1,321 & 2,006 & 652 & 803 & 669 & 1,203 \\
\hline
\end{tabular}

Note: All Ns are unweighted. Column totals may not equal 100\% due to missing cases. ${ }^{1}$ Includes female condoms, injectables, implants, diaphragm and foam/jelly. ${ }^{2}$ Includes periodic abstinence/rhythm and withdrawal.

Figure 10.6: Percentage of married youth reporting lifetime and current use of contraceptive methods within marriage, Tamil Nadu, 2006

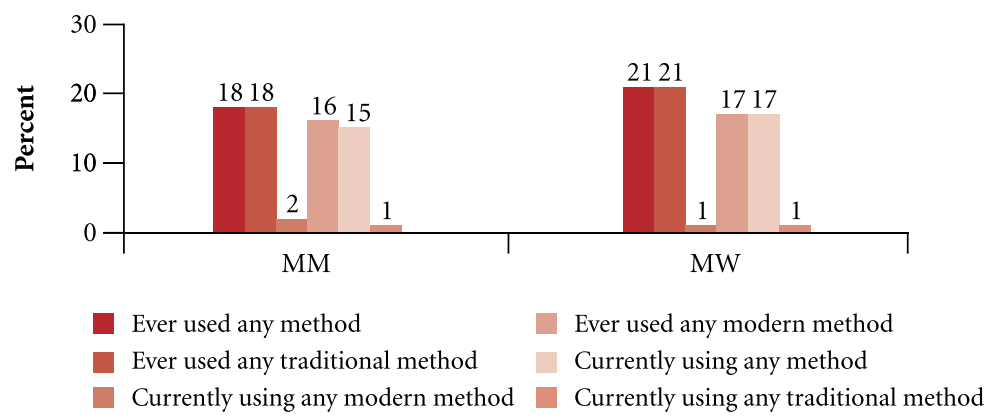

Relatively fewer youth reported practising contraception at the time of interview: $16 \%$ of young men and $17 \%$ of young women. Rural-urban differences indicate that rural young women were considerably less likely to report current use of contraception than their urban counterparts ( $14 \%$ versus $22 \%$ ). Differences among young men were negligible. Reporting of methods currently used did not differ between young men and women. In total, just $6 \%$ of young men and $7 \%$ of young women were using a non-terminal modern method at the time of interview. Indeed, female sterilisation was reported by $53-67 \%$ of youth who were practising contraception at the time of interview. Rural-urban differences resembled those described above with regard to ever use of contraception within marriage. 
The duration between marriage and first use of contraception was also explored. Just 2-3\% of young men and women reported that they had initiated contraceptive use in the first year of marriage. In contrast, $6 \%$ of young men and $11 \%$ of young women reported initiation of contraceptive use between one and three years following marriage and $8-9 \%$ reported that they had initiated contraception three or more years following marriage. While initiation of contraception was equally rare among rural and urban youth within the first year of marriage, somewhat larger percentages of urban than rural youth reported initiation of contraceptive use between one and three years following marriage ( $8 \%$ versus $5 \%$ among young men; $15 \%$ versus $8 \%$ among young women). Consistent with this profile, just $2-3 \%$ of youth reported the practise of contraception to delay the first pregnancy.

\subsection{Reproductive history}

This section addresses young people's reproductive history, namely, the first pregnancy and its outcome, children ever born and surviving, experience of pregnancy loss and the wantedness of recent pregnancies. As reported in Table 10.10, 83\% of young women and the wives of young men had experienced at least one pregnancy, while the remaining $17 \%$ had not yet initiated childbearing. Rural-urban differences were negligible.

\subsubsection{First pregnancy experiences}

Of those who reported that they or their wife had ever been pregnant, significant minorities reported a current first pregnancy (13\% of young men and 10\% of young women). Among those who had experienced at least one pregnancy, the first pregnancy occurred within three months of marriage for one-quarter of young men (26\%) and one-third of young women (34\%), and within 3-6 months of marriage for $41 \%$ and $36 \%$ of young men and women, respectively. Indeed, the first pregnancy occurred within the first year of marriage for $84-85 \%$ of youth. While there was no difference by place of residence among young women, more urban than rural young men reported that the first pregnancy occurred within the first six months of marriage (73\% versus 63\%). The median duration between marriage and first pregnancy was 4 months, with young men in urban areas reporting a slightly shorter median duration than their rural counterparts (3 and 4 months, respectively).

Pregnancy outcomes were reported by all respondents who had completed their first pregnancy. The vast majority had experienced a live birth $(82-84 \%)$, with urban youth only slightly more likely than rural youth to report a live birth. Among other outcomes, $0.5-0.8 \%$ had aborted their first pregnancy; for $2-3 \%$ the pregnancy ended in a stillbirth and for $13-15 \%$ in a miscarriage. Rural youth were slightly more likely than their urban counterparts to report a miscarriage (14-16\% versus $13 \%)$ or a stillbirth (3-4\% versus $1-2 \%)$.

Institutional delivery was experienced by the large majority of youth but even so, 16-18\% reported that the first delivery had not taken place in a health care facility. Rural-urban differences were notable only among young women; $88 \%$ in urban areas compared to $81 \%$ in rural areas reported an institutional delivery.

The vast majority of youth (93\%) reported skilled attendance at first delivery. We note that just 3-5\% reported that their first delivery had been attended by an untrained dai or traditional birth attendant, and $1 \%$ by a friend, relative or other individual. Rural-urban differences show that $97-98 \%$ of urban youth compared to $90-91 \%$ of rural youth reported skilled attendance at delivery. 
Table 10.10: First pregnancy experience

Percentage of married youth by duration from cohabitation to first pregnancy, outcome of first pregnancy, place of first delivery and type of attendance at first delivery, according to residence, Tamil Nadu, 2006

\begin{tabular}{|c|c|c|c|c|c|c|}
\hline \multirow[t]{2}{*}{ First pregnancy experience (\%) } & $\begin{array}{c}\mathrm{MM} \\
15-29\end{array}$ & $\begin{array}{c}\text { MW } \\
15-24\end{array}$ & $\begin{array}{c}\mathrm{MM} \\
15-29\end{array}$ & $\begin{array}{c}\text { MW } \\
15-24\end{array}$ & $\begin{array}{c}\text { MM } \\
15-29\end{array}$ & $\begin{array}{c}\text { MW } \\
15-24\end{array}$ \\
\hline & \multicolumn{2}{|c|}{ Combined } & \multicolumn{2}{|c|}{ Urban } & \multicolumn{2}{|c|}{ Rural } \\
\hline Ever been pregnant & 82.7 & 82.8 & 83.2 & 83.9 & 82.3 & 82.1 \\
\hline Number who had begun cohabiting & 1,321 & 2,006 & 652 & 803 & 669 & 1,203 \\
\hline Currently pregnant for the first time & 12.6 & 9.6 & 12.8 & 10.2 & 12.6 & 9.3 \\
\hline \multicolumn{7}{|l|}{ Duration from cohabitation to first pregnancy (months) } \\
\hline Up to 3 & 25.8 & 33.8 & 28.7 & 35.1 & 23.8 & 32.9 \\
\hline $3-6$ & 41.0 & 35.7 & 43.8 & 34.5 & 39.1 & 36.4 \\
\hline $7-12$ & 16.8 & 15.1 & 14.7 & 15.0 & 18.4 & 15.2 \\
\hline $13-24$ & 11.0 & 9.7 & 9.8 & 10.2 & 11.9 & 9.4 \\
\hline More than 24 & 4.8 & 4.9 & 2.7 & 4.6 & 6.3 & 5.3 \\
\hline Do not know/can't remember & 0.5 & 0.7 & 0.4 & 0.6 & 0.5 & 0.8 \\
\hline Median duration & 4.0 & 4.0 & 3.0 & 4.0 & 4.0 & 4.0 \\
\hline Number who had ever been pregnant & 1,093 & 1,661 & 542 & 674 & 551 & 987 \\
\hline \multicolumn{7}{|l|}{ Outcome of first pregnancy } \\
\hline Live birth & 81.7 & 83.6 & 85.5 & 85.4 & 79.2 & 82.4 \\
\hline Still birth & 3.0 & 2.2 & 1.3 & 1.6 & 4.1 & 2.6 \\
\hline Induced abortion & 0.5 & 0.8 & 0.3 & 0.3 & 0.5 & 1.0 \\
\hline Miscarriage & 14.8 & 13.3 & 13.0 & 12.6 & 16.1 & 13.8 \\
\hline Number who completed first pregnancy & 953 & 1,502 & 470 & 604 & 483 & 898 \\
\hline \multicolumn{7}{|l|}{ Place of first delivery } \\
\hline Respondent's parental home & 6.9 & 12.5 & 7.3 & 9.6 & 6.6 & 14.5 \\
\hline Spouse's parental home & 11.3 & 3.4 & 11.1 & 2.6 & 11.3 & 4.0 \\
\hline Health institution & 81.2 & 83.8 & 80.9 & 87.5 & 81.4 & 81.2 \\
\hline In transit & 0.0 & 0.1 & 0.0 & 0.2 & 0.0 & 0.0 \\
\hline \multicolumn{7}{|l|}{ Type of attendance at first delivery ${ }^{1}$} \\
\hline Doctor/ANM/nurse/LHV & 91.5 & 86.2 & 95.9 & 90.8 & 88.4 & 83.0 \\
\hline Midwife (trained) & 1.1 & 6.8 & 1.5 & 6.6 & 0.9 & 7.0 \\
\hline Other health personnel & 0.4 & 0.4 & 0.3 & 0.0 & 0.4 & 0.7 \\
\hline Dai/traditional birth attendant & 5.2 & 2.8 & 1.5 & 0.8 & 7.7 & 4.2 \\
\hline Friend/relative & 1.0 & 1.3 & 0.0 & 0.4 & 1.7 & 2.0 \\
\hline Other person ${ }^{2}$ & 0.0 & 0.1 & 0.0 & 0.2 & 0.0 & 0.0 \\
\hline None & 0.0 & 0.5 & 0.0 & 0.2 & 0.0 & 0.7 \\
\hline $\begin{array}{l}\text { Number whose first pregnancy outcome was a live or } \\
\text { still birth }\end{array}$ & 816 & 1,292 & 411 & 527 & 405 & 765 \\
\hline
\end{tabular}

Note: All Ns are unweighted. Column totals may not equal 100\% due to missing cases or "don't know" responses. ANM: Auxiliary nurse midwife; LHV: Lady health visitor. ${ }^{1}$ If the respondent reported that the delivery had occurred in a health institution, then it was assumed that a doctor/ANM/nurse/LHV had attended the birth. ${ }^{2}$ If the delivery was reported in transit, attendance at delivery was categorised as "other person". 


\subsubsection{Children ever born and surviving}

Findings, revealed in Table 10.11, show that married youth had experienced an average of about 1.5 pregnancies and just over one live birth. Gender and rural-urban differences were negligible. The distribution of respondents by number of surviving children resembles that of children ever born, reported above. Youth typically reported about as many daughters as sons.

\section{Table 10.11: Reproductive history}

Mean number of pregnancies experienced, percent distribution by children ever born and children surviving, and mean number of child deaths, stillbirths, miscarriages and abortions among married youth, according to residence, Tamil Nadu, 2006

\begin{tabular}{|c|c|c|c|c|c|c|}
\hline \multirow[t]{2}{*}{ Pregnancy outcomes (\%) } & $\begin{array}{c}\mathrm{MM} \\
15-29\end{array}$ & $\begin{array}{c}\text { MW } \\
15-24\end{array}$ & $\begin{array}{c}\mathrm{MM} \\
15-29\end{array}$ & $\begin{array}{c}\text { MW } \\
15-24\end{array}$ & $\begin{array}{c}\mathrm{MM} \\
15-29\end{array}$ & $\begin{array}{c}\text { MW } \\
15-24\end{array}$ \\
\hline & \multicolumn{2}{|c|}{ Combined } & \multicolumn{2}{|c|}{ Urban } & \multicolumn{2}{|c|}{ Rural } \\
\hline Mean number of lifetime pregnancies & 1.5 & 1.5 & 1.4 & 1.5 & 1.5 & 1.6 \\
\hline Number of children ever born & & & & & & \\
\hline 0 & 33.8 & 30.5 & 33.6 & 29.5 & 33.9 & 31.2 \\
\hline 1 & 33.2 & 37.8 & 36.0 & 43.3 & 31.3 & 34.1 \\
\hline 2 & 26.1 & 24.8 & 25.0 & 21.1 & 27.0 & 27.3 \\
\hline 3 & 6.4 & 6.4 & 5.2 & 5.8 & 7.3 & 6.8 \\
\hline 4 or more & 0.5 & 0.5 & 0.2 & 0.2 & 0.5 & 0.7 \\
\hline Mean number of children ever born & 1.1 & 1.1 & 1.0 & 1.0 & 1.1 & 1.1 \\
\hline Number of children surviving & & & & & & \\
\hline 0 & 34.4 & 31.0 & 34.4 & 29.7 & 34.3 & 31.8 \\
\hline 1 & 34.1 & 38.7 & 36.1 & 43.9 & 32.7 & 35.2 \\
\hline 2 & 25.9 & 24.2 & 24.3 & 20.8 & 27.0 & 26.5 \\
\hline 3 & 5.3 & 5.8 & 5.0 & 5.3 & 5.6 & 6.1 \\
\hline 4 or more & 0.3 & 0.3 & 0.2 & 0.2 & 0.4 & 0.4 \\
\hline Mean number of children surviving & 1.0 & 1.1 & 1.0 & 1.0 & 1.1 & 1.1 \\
\hline Mean number of sons surviving & 0.5 & 0.6 & 0.5 & 0.5 & 0.5 & 0.6 \\
\hline Mean number of daughters surviving & 0.5 & 0.5 & 0.5 & 0.5 & 0.5 & 0.5 \\
\hline Mean number of children dead & 0.0 & 0.0 & 0.0 & 0.0 & 0.0 & 0.0 \\
\hline Reported one or more still births & 2.6 & 2.3 & 1.1 & 1.9 & 3.7 & 2.6 \\
\hline Reported one or more miscarriages & 12.7 & 15.0 & 12.0 & 15.0 & 13.4 & 14.9 \\
\hline Reported one or more induced abortions & 1.5 & 4.2 & 1.7 & 3.6 & 1.4 & 4.6 \\
\hline Number who had begun cohabiting & 1,321 & 2,006 & 652 & 803 & 669 & 1,203 \\
\hline
\end{tabular}

Note: All Ns are unweighted. Column totals may not equal 100\% due to missing cases or "don't know" responses.

While the experience of infant or child death was negligible, somewhat more youth reported the experience of pregnancy wastage. For example, stillbirths were reported by about $2-3 \%$ of all respondents, $3-4 \%$ of those in rural areas and $1-2 \%$ of those in urban areas; at least one miscarriage was reported by $13-15 \%$ of youth and induced abortion by $2-4 \%$ of all respondents.

Table 10.12 reports mean numbers of children ever born and surviving by respondents' socio-demographic characteristics. As expected, age was positively associated with both fertility indicators, and young people's educational attainment levels and household economic status were inversely associated with both. Religion- and caste-specific differences were negligible. Patterns remained relatively similar in both rural and urban settings. 
Table 10.12: Children ever born and surviving by selected background characteristics

Mean number of children ever born and children surviving among married youth by selected background characteristics, according to residence, Tamil Nadu, 2006

\begin{tabular}{|c|c|c|c|c|c|c|c|c|c|c|c|c|}
\hline \multirow{3}{*}{$\begin{array}{l}\text { Background } \\
\text { characteristics } \\
\text { (mean number) }\end{array}$} & \multicolumn{2}{|c|}{$\begin{array}{c}\text { MM } \\
15-29\end{array}$} & \multicolumn{2}{|c|}{$\begin{array}{l}\text { MW } \\
15-24\end{array}$} & \multicolumn{2}{|c|}{$\begin{array}{c}\text { MM } \\
15-29\end{array}$} & \multicolumn{2}{|c|}{$\begin{array}{c}\text { MW } \\
15-24\end{array}$} & \multicolumn{2}{|c|}{$\begin{array}{c}\text { MM } \\
15-29\end{array}$} & \multicolumn{2}{|c|}{$\begin{array}{c}\text { MW } \\
15-24\end{array}$} \\
\hline & \multicolumn{4}{|c|}{ Combined } & \multicolumn{4}{|c|}{ Urban } & \multicolumn{4}{|c|}{ Rural } \\
\hline & CEB & CS & CEB & CS & CEB & CS & CEB & CS & CEB & CS & CEB & $\mathrm{CS}$ \\
\hline $\begin{array}{l}\text { Age (years) } \\
15-19\end{array}$ & * & * & 0.5 & 0.5 & * & * & 0.5 & 0.5 & * & * & 0.5 & 0.5 \\
\hline $20-24$ & 0.7 & 0.7 & 1.2 & 1.2 & 0.6 & 0.6 & 1.1 & 1.1 & 0.7 & 0.7 & 1.3 & 1.2 \\
\hline $25-29$ & 1.2 & 1.1 & NA & NA & 1.1 & 1.1 & NA & NA & 1.2 & 1.2 & NA & NA \\
\hline Religion & & & & & & & & & & & & \\
\hline Hindu & 1.1 & 1.0 & 1.1 & 1.1 & 1.0 & 1.0 & 1.0 & 1.0 & 1.1 & 1.0 & 1.1 & 1.1 \\
\hline Muslim & 1.2 & 1.2 & 1.2 & 1.2 & 1.1 & 1.0 & 1.2 & 1.1 & * & * & (1.4) & (1.4) \\
\hline Other $^{1}$ & (1.1) & $(1.1)$ & 0.9 & 0.9 & * & * & $(0.8)$ & $(0.8)$ & (1.4) & (1.3) & (1.1) & $(1.0$ \\
\hline Caste & & & & & & & & & & & & \\
\hline SC & 1.2 & 1.2 & 1.2 & 1.1 & 1.2 & 1.2 & 1.3 & 1.2 & 1.2 & 1.2 & 1.2 & 1.1 \\
\hline OBC & 1.0 & 1.0 & 1.1 & 1.0 & 1.0 & 1.0 & 1.0 & 1.0 & 1.1 & 1.0 & 1.1 & 1.1 \\
\hline $\begin{array}{l}\text { Educational } \\
\text { level (years) }\end{array}$ & & & & & & & & & & & & \\
\hline None $^{2}$ & 1.2 & 1.2 & 1.4 & 1.3 & * & * & 1.6 & 1.5 & 1.2 & 1.2 & 1.3 & 1.3 \\
\hline $1-7$ & 1.2 & 1.2 & 1.3 & 1.3 & 1.2 & 1.2 & 1.2 & 1.2 & 1.2 & 1.2 & 1.4 & 1.3 \\
\hline $8-11$ & 1.0 & 1.0 & 1.0 & 1.0 & 1.0 & 0.9 & 1.0 & 1.0 & 1.0 & 1.0 & 1.0 & 1.0 \\
\hline 12 and above & 0.8 & 0.8 & 0.7 & 0.7 & 0.8 & 0.8 & 0.7 & 0.7 & 0.7 & 0.7 & 0.6 & 0.6 \\
\hline $\begin{array}{l}\text { Worked in last } \\
12 \text { months }\end{array}$ & & & & & & & & & & & & \\
\hline Yes & 1.1 & 1.0 & 1.1 & 1.1 & 1.0 & 1.0 & 1.2 & 1.1 & 1.1 & 1.1 & 1.1 & 1.0 \\
\hline No & * & * & 1.1 & 1.1 & * & * & 1.0 & 1.0 & * & * & 1.1 & 1.1 \\
\hline Wealth quintile & & & & & & & & & & & & \\
\hline $\begin{array}{l}\text { First } \\
\text { Second }\end{array}$ & $\begin{array}{l}1.3 \\
1.2\end{array}$ & $\begin{array}{l}1.2 \\
1.2\end{array}$ & $\begin{array}{l}1.3 \\
1.2\end{array}$ & $\begin{array}{l}1.2 \\
1.1\end{array}$ & $\begin{array}{l}1.2 \\
1.4\end{array}$ & $\begin{array}{l}1.2 \\
1.4\end{array}$ & $\begin{array}{l}1.5 \\
1.2\end{array}$ & $\begin{array}{l}1.4 \\
1.1\end{array}$ & $\begin{array}{l}1.3 \\
1.1\end{array}$ & $\begin{array}{l}1.3 \\
1.1\end{array}$ & $\begin{array}{l}1.3 \\
1.2\end{array}$ & $\begin{array}{l}1.2 \\
1.1\end{array}$ \\
\hline Third & 1.1 & 1.1 & 1.2 & 1.1 & 1.1 & 1.1 & 1.2 & 1.2 & 1.1 & 1.1 & 1.2 & 1.1 \\
\hline Fourth & 0.9 & 0.9 & 1.0 & 1.0 & 0.9 & 0.9 & 1.0 & 1.0 & 0.9 & 0.9 & 0.9 & 0.9 \\
\hline Fifth & 0.7 & 0.7 & 0.8 & 0.8 & 0.7 & 0.7 & 0.8 & 0.8 & $(0.6)$ & $(0.6)$ & 0.9 & 0.9 \\
\hline Total & 1.1 & 1.0 & 1.1 & 1.1 & 1.0 & 1.0 & 1.0 & 1.0 & 1.1 & 1.1 & 1.1 & 1.1 \\
\hline
\end{tabular}

Note: ( ) Based on 25-49 unweighted cases. ${ }^{\star}$ Mean not shown, based on fewer than 25 unweighted cases. CEB: Children ever born. CS: Children surviving. NA: Not applicable. OBC: Other backward caste. SC: Scheduled caste. ${ }^{1}$ Includes Christian, Buddhist, Neo-Buddhist, Sikh, Jain, Jewish, Parsi/Zoroastrian and no specified religion. ${ }^{2}$ Includes non-literate and literate with no formal schooling.

\subsubsection{Wantedness of recent pregnancies}

All youth who reported at least one pregnancy were asked about the wantedness of their current (for those currently pregnant) or last pregnancy. Findings, presented in Table 10.13, suggest that while the large majority of pregnancies were planned, considerably more young women than men reported a mistimed or unwanted pregnancy. For example, among young men whose wife was not pregnant and young women who were not pregnant at the time of interview, just $2 \%$ and $13 \%$, respectively, reported that the last pregnancy was mistimed or unwanted. Likewise, among those pregnant at the time of interview or whose wife was pregnant at the time of interview, just $1 \%$ of young men and $10 \%$ of young women reported that the pregnancy was unwanted or mistimed. These findings suggest that young men tend to prefer larger families than young women. Rural-urban differences, in both cases, were negligible. 
Table 10.13: Wantedness of most recent pregnancy

Percentage of married youth by wantedness of most recent pregnancy in the three years preceding the interview, according to residence, Tamil Nadu, 2006

\begin{tabular}{|c|c|c|c|c|c|c|}
\hline \multirow[t]{2}{*}{ Status (\%) } & $\begin{array}{c}\text { MM } \\
15-29\end{array}$ & $\begin{array}{c}\text { MW } \\
15-24\end{array}$ & $\begin{array}{c}\text { MM } \\
15-29\end{array}$ & $\begin{array}{c}\text { MW } \\
15-24\end{array}$ & $\begin{array}{c}\text { MM } \\
15-29\end{array}$ & $\begin{array}{c}\text { MW } \\
15-24\end{array}$ \\
\hline & \multicolumn{2}{|c|}{ Combined } & \multicolumn{2}{|c|}{ Urban } & \multicolumn{2}{|c|}{ Rural } \\
\hline \multicolumn{7}{|l|}{ Wantedness status of last pregnancy ${ }^{1}$} \\
\hline Planned & 97.2 & 86.6 & 97.5 & 87.0 & 97.1 & 86.3 \\
\hline Mistimed & 2.0 & 11.1 & 1.8 & 10.8 & 2.1 & 11.2 \\
\hline Unwanted & 0.2 & 1.9 & 0.5 & 2.1 & 0.0 & 1.8 \\
\hline Number who had experienced at least one pregnancy & 953 & 1,501 & 470 & 604 & 483 & 897 \\
\hline \multicolumn{7}{|l|}{ Wantedness status of current pregnancy } \\
\hline Planned & 98.8 & 88.5 & 98.9 & 89.0 & 98.7 & 88.1 \\
\hline Mistimed & 0.8 & 9.0 & 0.0 & 8.9 & 1.3 & 9.0 \\
\hline Unwanted & 0.0 & 1.4 & 0.0 & 1.4 & 0.0 & 1.4 \\
\hline Number currently pregnant & 241 & 356 & 112 & 145 & 129 & 211 \\
\hline
\end{tabular}

Note: All Ns are unweighted. Column totals may not equal 100\% due to missing cases or "don't know" responses. ${ }^{1}$ Excludes respondents/respondents' wives currently pregnant for the first time or never been pregnant.

\subsection{Ideal family size}

All respondents were asked to report the number of children they considered ideal, and among these the number of sons and daughters considered ideal. As several respondents reported that they were unconcerned about the sex of children, a third response "children of either sex" was also recorded.

As seen in Table 10.14, young men and women typically considered two children as ideal. While about $14 \%$ of young men reported three or more children as ideal, slightly fewer (11\%) young women so reported. Young men in rural areas were slightly more likely than those in urban areas to report a preference for three or more children; no such differences were observed among young women.

Table 10.14: Ideal family size

Percentage of married youth by their reported ideal number of children, according to residence, Tamil Nadu, 2006

\begin{tabular}{|c|c|c|c|c|c|c|}
\hline \multirow[t]{2}{*}{ Ideal family size (\%) } & $\begin{array}{c}\text { MM } \\
15-29\end{array}$ & $\begin{array}{c}\text { MW } \\
15-24\end{array}$ & $\begin{array}{c}\text { MM } \\
15-29\end{array}$ & $\begin{array}{c}\text { MW } \\
15-24\end{array}$ & $\begin{array}{c}\text { MM } \\
15-29\end{array}$ & $\begin{array}{c}\text { MW } \\
15-24\end{array}$ \\
\hline & \multicolumn{2}{|c|}{ Combined } & \multicolumn{2}{|c|}{ Urban } & \multicolumn{2}{|c|}{ Rural } \\
\hline \multicolumn{7}{|l|}{ Ideal number of children: } \\
\hline 0 & 0.0 & 0.0 & 0.0 & 0.0 & 0.0 & 0.0 \\
\hline 1 & 5.0 & 5.8 & 5.2 & 6.9 & 4.9 & 5.0 \\
\hline 2 & 79.3 & 82.1 & 81.1 & 81.2 & 78.3 & 82.6 \\
\hline 3 or more & 14.0 & 11.4 & 11.8 & 11.0 & 15.4 & 11.6 \\
\hline Other $^{1}$ & 1.7 & 0.8 & 1.8 & 0.9 & 1.4 & 0.8 \\
\hline Mean ideal number of children ${ }^{2}$ & 2.1 & 2.1 & 2.1 & 2.1 & 2.1 & 2.1 \\
\hline Number who had begun cohabiting & 1,321 & 2,006 & 652 & 803 & 669 & 1,203 \\
\hline
\end{tabular}

Note: All Ns are unweighted. Column totals may not equal 100\% due to missing cases or "don't know" responses. ${ }^{1}$ Includes "it's up to God," "difficult to say," etc. "Includes only respondents who gave numeric responses. 
Tables $10.15 \mathrm{a}$ and $10.15 \mathrm{~b}$ present the ideal number of sons and daughters reported by young people by selected socio-demographic characteristics. The majority of youth-79\% of young men and $84 \%$ of young women-reported a preference for an equal number of sons and daughters (with an average of slightly less than 1 of each). There was, however, a slight indication of son preference: for example, $13 \%$ of young men and $11 \%$ of young women reported a preference for more sons than daughters; in contrast, fewer youth reported a preference for more daughters than sons ( $8 \%$ of young men and $6 \%$ of young women). Rural-urban differences were negligible. These patterns persisted, irrespective of the socio-demographic characteristics under consideration, but varied somewhat between young men and women. Among young women, son preference was more common among older than younger women: $12 \%$ of those aged 20-24 compared to 5\% of those aged 15-19 reported a preference for more sons than daughters; among young men, age-specific differences were muted. Again, among young women, son preference was more common among those belonging to scheduled castes (14\%) compared to those belonging to other backward castes (9\%); differences among young men were negligible. Finally, among both young men and women, son preference was consistently more common among less educated youth, and among those from poorer families compared to other youth.

Table 10.15a: Married young men's preferences for sons and daughters by selected background characteristics

Mean ideal number of sons, daughters and children of either sex and some indicators of sex preference by selected background characteristics of married young men, according to residence, Tamil Nadu, 2006

\begin{tabular}{|c|c|c|c|c|c|c|c|}
\hline \multirow{3}{*}{$\begin{array}{l}\text { Background } \\
\text { characteristics }\end{array}$} & \multirow{2}{*}{\multicolumn{3}{|c|}{ Mean ideal number of: }} & \multicolumn{4}{|c|}{ Indicators of sex preference } \\
\hline & & & & \multicolumn{4}{|c|}{ Percent who wanted: } \\
\hline & Sons & Daughters & $\begin{array}{l}\text { Children } \\
\text { of either } \\
\text { sex }\end{array}$ & $\begin{array}{c}\text { More } \\
\text { sons than } \\
\text { daughters }\end{array}$ & $\begin{array}{c}\text { More } \\
\text { daughters } \\
\text { than sons }\end{array}$ & $\begin{array}{c}\text { At least } \\
\text { one } \\
\text { son }\end{array}$ & $\begin{array}{l}\text { At least } \\
\text { one } \\
\text { daughter }\end{array}$ \\
\hline Residence & & & & & & & \\
\hline Urban & 0.8 & 0.7 & 0.6 & 12.2 & 7.0 & 70.9 & 69.5 \\
\hline Rural & 0.9 & 0.8 & 0.5 & 13.4 & 8.7 & 75.0 & 72.7 \\
\hline Age (years) & & & & & & & \\
\hline $15-19$ & * & * & * & * & * & * & * \\
\hline $20-24$ & 0.9 & 0.8 & 0.4 & 13.2 & 7.0 & 75.6 & 74.4 \\
\hline $25-29$ & 0.8 & 0.8 & 0.5 & 13.0 & 8.3 & 72.9 & 70.8 \\
\hline Religion & & & & & & & \\
\hline Hindu & 0.8 & 0.8 & 0.5 & 12.6 & 7.6 & 72.7 & 71.1 \\
\hline Muslim & 1.0 & 0.8 & 0.4 & 17.6 & 8.7 & 81.2 & 76.8 \\
\hline Other $^{1}$ & $(0.9)$ & $(0.8)$ & $(0.4)$ & $(15.4)$ & $(15.4)$ & $(75.0)$ & $(73.1)$ \\
\hline Caste & & & & & & & \\
\hline SC & 0.9 & 0.8 & 0.5 & 14.2 & 9.8 & 74.1 & 74.7 \\
\hline $\mathrm{OBC}$ & 0.8 & 0.8 & 0.5 & 12.0 & 7.8 & 72.7 & 70.2 \\
\hline
\end{tabular}


Table 10.15a: (Cont'd)

\begin{tabular}{|c|c|c|c|c|c|c|c|}
\hline \multirow{3}{*}{$\begin{array}{l}\text { Background } \\
\text { characteristics }\end{array}$} & \multirow{2}{*}{\multicolumn{3}{|c|}{ Mean ideal number of: }} & \multicolumn{4}{|c|}{ Indicators of sex preference } \\
\hline & & & & \multicolumn{4}{|c|}{ Percent who wanted: } \\
\hline & Sons & Daughters & $\begin{array}{l}\text { Children } \\
\text { of either } \\
\text { sex }\end{array}$ & $\begin{array}{c}\text { More } \\
\text { sons than } \\
\text { daughters }\end{array}$ & $\begin{array}{c}\text { More } \\
\text { daughters } \\
\text { than sons }\end{array}$ & $\begin{array}{c}\text { At least } \\
\text { one } \\
\text { son }\end{array}$ & $\begin{array}{c}\text { At least } \\
\text { one } \\
\text { daughter }\end{array}$ \\
\hline Educational level (years) & & & & & & & \\
\hline None $^{2}$ & 1.1 & 0.9 & 0.3 & 19.0 & 7.6 & 83.5 & 82.3 \\
\hline $1-7$ & 0.9 & 0.8 & 0.4 & 14.6 & 7.6 & 77.8 & 75.0 \\
\hline $8-11$ & 0.8 & 0.7 & 0.6 & 11.1 & 8.5 & 70.6 & 68.8 \\
\hline 12 and above & 0.7 & 0.7 & 0.6 & 10.7 & 8.2 & 63.5 & 64.0 \\
\hline Worked in last 12 month & & & & & & & \\
\hline Yes & 0.8 & 0.8 & 0.5 & 13.0 & 8.0 & 73.2 & 71.4 \\
\hline No & * & * & * & * & * & * & * \\
\hline Wealth quintile & & & & & & & \\
\hline First & 1.0 & 0.9 & 0.4 & 17.5 & 9.4 & 79.7 & 77.4 \\
\hline Second & 0.9 & 0.8 & 0.5 & 16.0 & 10.2 & 76.4 & 72.2 \\
\hline Third & 0.9 & 0.8 & 0.4 & 12.7 & 5.7 & 78.0 & 74.8 \\
\hline Fourth & 0.8 & 0.7 & 0.6 & 9.7 & 7.1 & 67.0 & 67.8 \\
\hline Fifth & 0.7 & 0.7 & 0.6 & 7.4 & 7.4 & 61.7 & 62.8 \\
\hline Total & 0.8 & 0.8 & 0.5 & 13.0 & 8.0 & 73.3 & 71.4 \\
\hline
\end{tabular}

Note: ( ) Based on 25-49 unweighted cases. ${ }^{*}$ Percentage/mean not shown, based on fewer than 25 unweighted cases. OBC: Other backward caste. SC: Scheduled caste. ${ }^{1}$ Includes Christian, Buddhist, Neo-Buddhist, Sikh, Jain, Jewish, Parsi/Zoroastrian and no specified religion. ${ }^{2}$ Includes non-literate and literate with no formal schooling.

Table 10.15b: Married young women's preferences for sons and daughters by selected background characteristics

Mean ideal number of sons, daughters and children of either sex and some indicators of sex preference by selected background characteristics of married young women, according to residence, Tamil Nadu, 2006

\begin{tabular}{|c|c|c|c|c|c|c|c|}
\hline \multirow{3}{*}{$\begin{array}{l}\text { Background } \\
\text { characteristics }\end{array}$} & \multirow{2}{*}{\multicolumn{3}{|c|}{ Mean ideal number of: }} & \multicolumn{4}{|c|}{ Indicators of sex preference } \\
\hline & & & & \multicolumn{4}{|c|}{ Percent who wanted: } \\
\hline & Sons & Daughters & $\begin{array}{l}\text { Children } \\
\text { of either } \\
\text { sex }\end{array}$ & $\begin{array}{c}\text { More } \\
\text { sons than } \\
\text { daughters }\end{array}$ & $\begin{array}{c}\text { More } \\
\text { daughters } \\
\text { than sons }\end{array}$ & $\begin{array}{c}\text { At least } \\
\text { one } \\
\text { son }\end{array}$ & $\begin{array}{c}\text { At least } \\
\text { one } \\
\text { daughter }\end{array}$ \\
\hline Residence & & & & & & & \\
\hline Urban & 0.9 & 0.8 & 0.4 & 9.5 & 6.4 & 79.1 & 77.3 \\
\hline Rural & 0.9 & 0.8 & 0.3 & 11.4 & 5.3 & 82.8 & 80.2 \\
\hline Age (years) & & & & & & & \\
\hline $15-19$ & 0.9 & 0.9 & 0.3 & 5.3 & 4.7 & 81.8 & 82.3 \\
\hline $20-24$ & 0.9 & 0.8 & 0.3 & 11.7 & 5.9 & 81.2 & 78.4 \\
\hline Religion & & & & & & & \\
\hline Hindu & 0.9 & 0.8 & 0.3 & 11.0 & 5.8 & 81.6 & 79.2 \\
\hline Muslim & 0.9 & 0.9 & 0.4 & 8.9 & 5.4 & 82.9 & 80.8 \\
\hline Other ${ }^{1}$ & 0.8 & 0.7 & 0.5 & 5.9 & 5.9 & 70.6 & 70.6 \\
\hline
\end{tabular}




\begin{tabular}{|c|c|c|c|c|c|c|c|}
\hline \multirow{3}{*}{$\begin{array}{l}\text { Background } \\
\text { characteristics }\end{array}$} & \multirow{2}{*}{\multicolumn{3}{|c|}{ Mean ideal number of: }} & \multicolumn{4}{|c|}{ Indicators of sex preference } \\
\hline & & & & \multicolumn{4}{|c|}{ Percent who wanted: } \\
\hline & Sons & Daughters & $\begin{array}{l}\text { Children } \\
\text { of either } \\
\text { sex }\end{array}$ & $\begin{array}{c}\text { More } \\
\text { sons than } \\
\text { daughters }\end{array}$ & $\begin{array}{c}\text { More } \\
\text { daughters } \\
\text { than sons }\end{array}$ & $\begin{array}{c}\text { At least } \\
\text { one } \\
\text { son }\end{array}$ & $\begin{array}{c}\text { At least } \\
\text { one } \\
\text { daughter }\end{array}$ \\
\hline Caste & & & & & & & \\
\hline SC & 0.9 & 0.8 & 0.3 & 14.2 & 6.8 & 81.6 & 78.6 \\
\hline OBC & 0.9 & 0.8 & 0.3 & 9.4 & 5.1 & 81.6 & 79.2 \\
\hline Educational lev & & & & & & & \\
\hline None $^{2}$ & 1.0 & 1.0 & 0.3 & 12.0 & 8.9 & 87.4 & 85.3 \\
\hline $1-7$ & 1.0 & 0.9 & 0.3 & 14.2 & 5.5 & 83.2 & 79.5 \\
\hline $8-11$ & 0.9 & 0.9 & 0.3 & 9.5 & 6.0 & 83.1 & 81.6 \\
\hline 12 and above & 0.7 & 0.7 & 0.5 & 6.8 & 3.4 & 69.7 & 67.4 \\
\hline Worked in last & & & & & & & \\
\hline Yes & 0.9 & 0.9 & 0.3 & 11.6 & 5.3 & 82.0 & 80.6 \\
\hline No & 0.9 & 0.8 & 0.3 & 10.3 & 5.9 & 81.0 & 78.4 \\
\hline Wealth quintile & & & & & & & \\
\hline First & 1.0 & 0.9 & 0.3 & 13.0 & 7.0 & 84.3 & 80.3 \\
\hline Second & 0.9 & 0.9 & 0.3 & 10.1 & 6.6 & 82.4 & 82.6 \\
\hline Third & 0.9 & 0.9 & 0.3 & 11.0 & 5.5 & 83.1 & 80.4 \\
\hline Fourth & 0.9 & 0.8 & 0.3 & 11.2 & 5.6 & 80.9 & 77.5 \\
\hline Fifth & 0.8 & 0.8 & 0.5 & 7.9 & 3.9 & 75.2 & 73.0 \\
\hline Total & 0.9 & 0.8 & 0.3 & 10.7 & 5.7 & 81.3 & 79.0 \\
\hline
\end{tabular}

Note: OBC: Other backward caste. SC: Scheduled caste. ${ }^{1}$ Includes Christian, Buddhist, Neo-Buddhist, Sikh, Jain, Jewish, Parsi/Zoroastrian and no specified religion. ${ }^{2}$ Includes non-literate and literate with no formal schooling.

\subsection{Summary}

Findings confirm that Tamil Nadu is characterised by a relatively late age at marriage: hardly any young men and fewer than one in five young women aged 20-24 (18\%) were married before age 18. While the majority of youth reported an arranged marriage, it is notable that about one in five young men and women reported a love marriage and about three-quarters had approved of the prospective spouse chosen by their parents. Likewise, considerable proportions reported some pre-marital acquaintance with their spouse-even so, some one-fifth of young men and over one-third of young women had met their spouse for the first time on their wedding day. Dowry characterised the marriages of $84 \%$ of young men and $88 \%$ of young women. Despite the fact that many youth were acquainted with their spouse prior to marriage and had played a role in determining whom they would marry, large proportions-two-thirds of young men and three-quarters of young women-reported they had lacked awareness of what to expect of married life.

Married life was characterised by considerable inter-spousal communication on most topics, yet, only twofifths of young men and three-fifths of young women had ever communicated with their spouse on matters relating to contraception. Moreover, physical violence and forced sex within marriage were reported by significant minorities of youth. For example, more than one-quarter of young women reported that they had ever experienced physical violence perpetrated by their husband and an even larger percentage of young men (34\%) reported perpetrating physical violence on their wife. Recent physical violence was likewise reported by one-fourth of young women and $31 \%$ of young men. Sexual violence was also reported. Indeed, one-fifth 
of young women reported that the first sexual experience within marriage had been forced. Overall, $25 \%$ of young women reported ever being forced to engage in sex with their husband; in comparison, just $15 \%$ of young men reported forcing their wife to engage in sex.

While the Youth Study did not explore extra-marital sexual experiences in detail, the available data indicate that $4 \%$ of young men reported an extra-marital sexual encounter. In contrast, hardly any young women reported an extra-marital sexual encounter.

Contraceptive use within marriage was reported by relatively few youth: $18 \%$ of young men and $21 \%$ of young women had ever practised contraception and just $16 \%$ of young men and $17 \%$ of young women reported practising contraception at the time of interview. The limited percentage of youth practising contraception may be attributed to the relatively late age at marriage in Tamil Nadu and consequently, the fact that many married youth may not yet have initiated childbearing. The pattern of methods used suggests, however, a considerable reliance on terminal methods: female sterilisation was reported by $9-10 \%$ of young men and women. Use of non-terminal methods at the time of interview was reported by just $6-7 \%$ of young men and women; the main methods used were the condom and the IUD. Just $2-3 \%$ of young people had used a contraceptive method to delay the first birth, and pregnancy typically occurred within six months following marriage among those who reported that they or their wife had been pregnant at least once. While just $2 \%$ of young men reported a mistimed or unwanted pregnancy, as many as $13 \%$ of young women reported experiencing an unintended pregnancy.

Circumstances of the first birth suggest that the overwhelming majority of first births were delivered in a health facility (81-84\%) and almost all were delivered by a skilled attendant (93\%). Findings also show that most respondents wanted one child of each sex and just a small minority of young men and women expressed a preference for more sons than daughters. 


\section{Health and health seeking} behaviour

This chapter focuses on young people's patterns of substance use, health status and treatment-seeking for health problems experienced. The Youth Study probed alcohol, drug and tobacco use as well as, among those who reported substance use, consumption characteristics, including recent use and extent of use. The study also included questions relating to the experience of problems in the areas of general, sexual and reproductive health and mental health. It also explored young people's care seeking practices for general and sexual and reproductive health problems as well as their attitudes towards pre-marital HIV testing for boys and girls and the extent to which youth had undergone HIV testing. Where numbers are small, we present combined findings for rural and urban respondents.

\subsection{Substance use}

Research has shown that substance use can directly compromise young people's health. For example, evidence suggests that the use of alcohol and drugs among youth is associated with physical fights, risky sexual activity, depression and suicide as well as irregular school or work attendance and other negative outcomes (DiClemente, 1992; Ellickson, Saner and McGuigan, 1997; Gruber et al., 1996; Lowry et al., 1994; Mohan, Sankara Sarma and Thankappan, 2005; Singh and Saini, 2007).

Youth Study findings on the extent of substance use among young people suggest that while hardly any youth $(0.3 \%$ of young men and not a single young woman) reported drug use (including, for example, ganja, charas, brown sugar, cocaine and bhang), a substantial proportion of young men but hardly any young women reported consumption of tobacco and alcohol (Table 11.1). Among young men, 24\% and 17\%, respectively, reported ever and recent use of tobacco products. Married young men were more than twice as likely as the unmarried to report ever use of tobacco products ( $49 \%$ and $21 \%$, respectively) and recent tobacco use (38\% and $15 \%$, respectively), and rural young men were somewhat more likely than the urban to report ever use of tobacco products ( $26 \%$ and $22 \%$, respectively) and recent tobacco use (19\% and $15 \%$, respectively).

About as many young men reported ever consuming alcohol (26\%) as using tobacco products, but many fewer reported current consumption of alcohol (7\%). As in the case of tobacco use, married young men were far more likely to have ever consumed alcohol than the unmarried (55\% and 23\%, respectively); many fewer reported alcohol use once a week or more frequently in the month prior to interview $(18 \%$ and $6 \%$ among married and unmarried young men, respectively). Rural-urban differences were negligible. The large majority of young men who reported having ever consumed alcohol reported that they usually consumed alcohol with their peers ( $81 \%$ and $86 \%$ of the married and unmarried, respectively) and about one-quarter of young men ( $23 \%$ and $26 \%$ among the married and unmarried, respectively) reported that they sometimes or often became drunk (not shown in tabular form). 
Table 11.1: Substance use

Percentage of youth reporting lifetime and recent substance use, according to residence, Tamil Nadu, 2006

\begin{tabular}{|c|c|c|c|c|c|c|}
\hline Substance use (\%) & $\begin{array}{c}\mathrm{M} \\
15-24\end{array}$ & $\begin{array}{c}\mathrm{W} \\
15-24\end{array}$ & $\begin{array}{c}\mathrm{MM} \\
15-29\end{array}$ & $\begin{array}{c}\text { MW } \\
15-24\end{array}$ & $\begin{array}{c}\text { UM } \\
15-24\end{array}$ & $\begin{array}{c}\text { UW } \\
15-24\end{array}$ \\
\hline \multicolumn{7}{|c|}{ Combined } \\
\hline \multicolumn{7}{|l|}{ Ever consumed } \\
\hline Tobacco and its products & 24.4 & 0.8 & 49.2 & 1.2 & 21.3 & 0.5 \\
\hline Alcohol & 25.7 & 0.2 & 54.8 & 0.3 & 22.8 & 0.1 \\
\hline Drugs $^{1}$ & 0.3 & 0.0 & 0.5 & 0.0 & 0.3 & 0.0 \\
\hline \multicolumn{7}{|c|}{ Consumed once a week or more frequently in last month } \\
\hline Tobacco and its products & 17.4 & 0.4 & 37.5 & 0.7 & 14.6 & 0.2 \\
\hline Alcohol & 7.4 & 0.0 & 17.7 & 0.0 & 6.1 & 0.0 \\
\hline Drugs $^{1}$ & 0.1 & 0.0 & 0.1 & 0.0 & 0.1 & 0.0 \\
\hline Number of respondents & 1,913 & 5,008 & 1,322 & 2,007 & 1,666 & 3,001 \\
\hline \multicolumn{7}{|c|}{ Urban } \\
\hline \multicolumn{7}{|l|}{ Ever consumed } \\
\hline Tobacco and its products & 22.4 & 0.7 & 49.4 & 1.1 & 20.1 & 0.4 \\
\hline Alcohol & 23.6 & 0.1 & 56.4 & 0.2 & 20.7 & 0.1 \\
\hline Drugs $^{1}$ & 0.4 & 0.0 & 0.4 & 0.0 & 0.4 & 0.1 \\
\hline \multicolumn{7}{|c|}{ Consumed once a week or more frequently in last month } \\
\hline Tobacco and its products & 15.4 & 0.5 & 39.0 & 0.9 & 13.1 & 0.2 \\
\hline Alcohol & 6.1 & 0.0 & 17.3 & 0.0 & 5.2 & 0.0 \\
\hline Drugs $^{1}$ & 0.1 & 0.0 & 0.0 & 0.0 & 0.1 & 0.0 \\
\hline Number of respondents & 890 & 2,151 & 653 & 804 & 789 & 1,347 \\
\hline \multicolumn{7}{|c|}{ Rural } \\
\hline \multicolumn{7}{|l|}{ Ever consumed } \\
\hline Tobacco and its products & 26.0 & 0.8 & 49.2 & 1.3 & 22.3 & 0.5 \\
\hline Alcohol & 27.3 & 0.2 & 53.7 & 0.3 & 24.4 & 0.1 \\
\hline Drugs $^{1}$ & 0.3 & 0.0 & 0.4 & 0.0 & 0.2 & 0.0 \\
\hline \multicolumn{7}{|c|}{ Consumed once a week or more frequently in last month } \\
\hline Tobacco and its products & 18.9 & 0.4 & 36.5 & 0.7 & 15.9 & 0.2 \\
\hline Alcohol & 8.3 & 0.1 & 18.0 & 0.1 & 6.9 & 0.1 \\
\hline Drugs $^{1}$ & 0.0 & 0.0 & 0.1 & 0.0 & 0.0 & 0.0 \\
\hline Number of respondents & 1,023 & 2,857 & 669 & 1,203 & 877 & 1,654 \\
\hline
\end{tabular}

Note: All Ns are unweighted. 'Includes ganja, charas, brown sugar, cocaine, bhang, etc.

\subsection{General and sexual and reproductive health problems}

General health problems about which youth were questioned included high fever and injury. Sexual and reproductive health problems included symptoms of genital infection (burning during urination, genital ulcers, genital itching, swelling in the groin, and genital discharge, for example), anxiety about nocturnal emission or swapnadosh (for young men) and menstrual problems (for young women). Findings related to recent experiences of various general, and sexual and reproductive health problems are presented in Table 11.2.

\subsubsection{General health problems}

Findings show that a sizeable proportion of young people-18\% of young men and $33 \%$ of young women-had experienced high fever in the three months preceding the interview. We note the fact that the 
survey period covered the peak infection months, that is the summer and monsoon period, which may to some extent explain the prevalence of high fever among the youth surveyed. Differences by marital status and rural-urban residence were negligible. Injuries in the three months preceding the interview were experienced by $3 \%$ of respondents, with little variation by either sex or place of residence of respondents.

\subsubsection{Sexual and reproductive health problems}

Table 11.2 presents young people's reported experiences of symptoms of genital infection in the three months preceding the interview. We note that these findings are based on self-reports and not on clinical examination or laboratory testing and therefore must be interpreted with caution. Young women were more likely than young men to report symptoms of genital infection ( $21 \%$ versus $2 \%$ ), a finding also observed in the NFHS (IIPS and Macro International, 2007a). While married and unmarried young men appeared equally likely to have experienced symptoms of genital infection, married young women were more likely than the unmarried to report so (24\% versus $19 \%)$. Rural-urban differences were again negligible among young men but suggest that young women in rural areas were more likely than their urban peers to experience symptoms of genital infection (26\% versus $15 \%)$.

\section{Table 11.2: Self-reported health problems}

Percentage of youth reporting recent experiences of selected general and sexual and reproductive health problems, according to residence, Tamil Nadu, 2006

\begin{tabular}{|c|c|c|c|c|c|c|}
\hline $\begin{array}{l}\text { General/sexual and reproductive health } \\
\text { problems experienced (\%) }\end{array}$ & $\begin{array}{c}\text { M } \\
15-24\end{array}$ & $\begin{array}{c}\text { W } \\
15-24\end{array}$ & $\begin{array}{c}\text { MM } \\
15-29\end{array}$ & $\begin{array}{c}\text { MW } \\
15-24\end{array}$ & $\begin{array}{c}\text { UM } \\
15-24\end{array}$ & $\begin{array}{l}\text { UW } \\
15-24\end{array}$ \\
\hline \multicolumn{7}{|c|}{ Combined } \\
\hline High fever in last 3 months & 18.1 & 33.3 & 17.1 & 34.5 & 18.1 & 32.6 \\
\hline Injury in last 3 months & 3.2 & 2.5 & 2.7 & 1.8 & 3.3 & 3.0 \\
\hline Symptoms of genital infection in last 3 months ${ }^{1}$ & 1.7 & 21.0 & 1.4 & 24.1 & 1.7 & 18.9 \\
\hline $\begin{array}{l}\text { Anxiety about swapnadosh/nocturnal emission in } \\
12 \text { months }\end{array}$ & 29.3 & NA & 8.9 & NA & 31.3 & NA \\
\hline Menstrual problems in last 3 months & NA & 9.0 & NA & 8.4 & NA & 9.5 \\
\hline Number of respondents & 1,913 & 5,008 & 1,322 & 2,007 & 1,666 & 3,001 \\
\hline \multicolumn{7}{|c|}{ Urban } \\
\hline High fever in last 3 months & 17.4 & 32.5 & 16.6 & 34.1 & 17.1 & 31.6 \\
\hline Injury in last 3 months & 2.6 & 1.7 & 3.5 & 1.0 & 2.8 & 2.1 \\
\hline Symptoms of genital infection in last 3 months $^{1}$ & 1.1 & 15.3 & 1.1 & 19.1 & 0.9 & 13.0 \\
\hline $\begin{array}{l}\text { Anxiety about swapnadosh/nocturnal emission in } \\
12 \text { months }\end{array}$ & 31.6 & NA & 10.1 & NA & 33.5 & NA \\
\hline Menstrual problems in last 3 months & NA & 7.7 & NA & 7.2 & NA & 8.0 \\
\hline Number of respondents & 890 & 2,151 & 653 & 804 & 789 & 1,347 \\
\hline \multicolumn{7}{|c|}{ Rural } \\
\hline High fever in last 3 months & 18.6 & 34.0 & 17.5 & 34.8 & 18.7 & 33.5 \\
\hline Injury in last 3 months & 3.6 & 3.2 & 2.2 & 2.4 & 3.7 & 3.8 \\
\hline Symptoms of genital infection in last 3 months $^{1}$ & 2.1 & 25.5 & 1.7 & 27.5 & 2.3 & 24.1 \\
\hline $\begin{array}{l}\text { Anxiety about swapnadosh/nocturnal emission in } \\
12 \text { months }\end{array}$ & 27.5 & NA & 8.0 & NA & 29.6 & NA \\
\hline Menstrual problems in last 3 months & NA & 10.1 & NA & 9.1 & NA & 10.7 \\
\hline Number of respondents & 1,023 & 2,857 & 669 & 1,203 & 877 & 1,654 \\
\hline
\end{tabular}

Note: All Ns are unweighted. NA: Not applicable. ${ }^{1}$ Includes genital ulcers, genital itching, swelling in the groin, discharge, burning during urination, etc. 
Previous research has documented the extent to which semen loss is associated with anxiety regarding masculine weakness and ill-health in South Asian cultures (Bhatia and Choudhary, 1998; Bhatia and Malik, 1991; Bhende, 1995; Collumbien et al., 2004; Khan et al., 2006; Pelto, 1999; Verma et al., 2003). Youth Study findings suggest that more than one-quarter of young men $(29 \%)$ had indeed experienced anxiety about swapnadosh, or nocturnal emission in the 12 months preceding the interview. Vast differences were, however, observed by marital status: $9 \%$ of married men reported anxiety about nocturnal emission compared to $31 \%$ of unmarried young men. Differences by rural-urban residence were narrow, but suggest that urban men were somewhat more likely to report anxiety than were rural men (32\% versus $28 \%$ ).

With regard to young women's experience of other reproductive health problems in the three months preceding the interview, findings suggest that $9 \%$ of young women experienced menstrual problems. In this case, differences by marital status and rural-urban residence were negligible.

\subsection{Mental health disorders}

The mental health status of young people was assessed based on their responses to the General Health Questionnaire (GHQ-12) (Goldberg, 1992; Patel and Andrew, 2001). This questionnaire, designed to identify the presence of possible mental health disorders, is based on 12 questions that assess the extent to which a respondent experienced, for example, happiness, depression, anxiety and sleep disturbance in the one month preceding the interview. Threshold scores of 2, 3, 4 or more have been variously used to identify the possible presence of common mental health disorders (Bashir et al., 1996; Donath, 2001; Jacob, Bhugra and Mann, 1997). Table 11.3 presents responses on each item of the GHQ-12, and a summary measure indicating the percentage who gave three or more responses suggestive of mental health disorders.

An identical set of three questions were most likely to elicit responses suggestive of mental health disorders, for both young men and women, for the married as well as the unmarried, and for those residing in rural and urban areas: losing sleep due to worry, feeling unhappy and depressed, and feeling constantly under strain. Even so, differences were evident. Young men were more likely than young women to report symptoms: for example, $18-20 \%$ of young men reported that they had experienced each of these symptoms as compared to $10-13 \%$ of young women. Likewise, the married were more likely to report each of these symptoms than were the unmarried $(21-25 \%$ and $17-19 \%$, respectively, among married and unmarried young men; $13-17 \%$ and $8-11 \%$ among young women, respectively). Finally, rural youth were somewhat more likely than their urban counterparts to report each of these symptoms (19-22\% compared to $17-18 \%$ among young men; $12-6 \%$ and $7-11 \%$, respectively, among young women). Other symptoms were reported by fewer youth, but the same patterns were evident: on balance, it was young men compared to women, the married compared to the unmarried, and the rural compared to the urban who were more likely to report each of these symptoms as well.

Overall, $13 \%$ of young men and $10 \%$ young women reported three or more of the 12 symptoms/behaviours probed in the GHQ-12, indicative of mental health disorders. Marital status differences suggest that the married were more likely than the unmarried to report three or more symptoms-differences were mild for young men (15\% and $12 \%$ among the married and unmarried, respectively), but wide among young women (14\% versus $8 \%$ ). Differences were also apparent by rural-urban residence, with rural youth more likely than their urban counterparts to display scores indicative of mental health disorders (15\% versus $10 \%$ among young men; $13 \%$ and 7\%, correspondingly, among young women) (see Figure 11.1). 
Table 11.3: Reported symptoms or behaviours suggestive of mental health disorders

Percentage of youth reporting symptoms or behaviours suggestive of mental health disorders experienced in the month preceding the interview, according to residence, Tamil Nadu, 2006

\begin{tabular}{|c|c|c|c|c|c|c|}
\hline Symptoms/behaviours (\%) & $\underset{15-24}{M}$ & $\begin{array}{c}W \\
15-24\end{array}$ & $\begin{array}{c}\text { MM } \\
15-29\end{array}$ & $\begin{array}{c}\text { MW } \\
15-24\end{array}$ & $\begin{array}{c}\text { UM } \\
15-24\end{array}$ & $\begin{array}{c}\text { UW } \\
15-24\end{array}$ \\
\hline \multicolumn{7}{|c|}{ Combined } \\
\hline Unable to concentrate on whatever he/she was doing & 6.3 & 5.0 & 6.7 & 6.2 & 6.2 & 4.2 \\
\hline Lost much sleep over worry & 19.8 & 13.1 & 24.5 & 16.9 & 19.2 & 10.6 \\
\hline Felt that he/she was not playing a useful role & 4.7 & 3.6 & 3.5 & 4.8 & 4.7 & 2.9 \\
\hline Felt incapable of making decisions & 6.4 & 5.8 & 6.5 & 7.4 & 6.4 & 4.7 \\
\hline Felt constantly under strain & 18.1 & 13.0 & 23.7 & 16.8 & 17.3 & 10.5 \\
\hline Felt that he/she could not overcome his/her difficulties & 3.5 & 3.1 & 3.3 & 3.4 & 3.7 & 2.9 \\
\hline Unable to enjoy normal day-to-day activities & 4.4 & 4.7 & 5.0 & 5.4 & 4.4 & 4.2 \\
\hline Unable to face up to his/her problems & 2.7 & 5.1 & 3.0 & 6.5 & 2.7 & 4.2 \\
\hline Been feeling unhappy and depressed & 18.9 & 9.9 & 20.8 & 12.9 & 18.4 & 8.1 \\
\hline Been losing confidence in himself/herself & 4.7 & 2.9 & 5.0 & 3.5 & 4.7 & 2.4 \\
\hline Been thinking of himself/herself as a worthless person & 3.6 & 2.6 & 4.4 & 3.1 & 3.4 & 2.3 \\
\hline Not feeling reasonably happy, all things considered & 3.3 & 3.6 & 2.7 & 4.4 & 3.3 & 3.1 \\
\hline Three or more symptoms/behaviours & 12.6 & 10.2 & 14.8 & 13.5 & 12.1 & 8.0 \\
\hline Number of respondents & 1,913 & 5,008 & 1,322 & 2,007 & 1,666 & 3,001 \\
\hline \multicolumn{7}{|c|}{ Urban } \\
\hline Unable to concentrate on whatever he/she was doing & 4.0 & 3.4 & 4.4 & 3.8 & 4.0 & 3.3 \\
\hline Lost much sleep over worry & 16.6 & 9.7 & 20.3 & 13.2 & 15.4 & 7.6 \\
\hline Felt that he/she was not playing a useful role & 4.0 & 2.5 & 3.7 & 3.8 & 3.9 & 1.8 \\
\hline Felt incapable of making decisions & 6.9 & 5.3 & 7.6 & 6.2 & 6.6 & 4.8 \\
\hline Felt constantly under strain & 17.2 & 11.2 & 20.3 & 15.7 & 16.6 & 8.7 \\
\hline Felt that he/she could not overcome his/her difficulties & 2.6 & 2.4 & 3.1 & 2.6 & 2.7 & 2.3 \\
\hline Unable to enjoy normal day-to-day activities & 4.0 & 3.3 & 4.2 & 3.5 & 3.9 & 3.2 \\
\hline Unable to face up to his/her problems & 2.9 & 4.0 & 3.7 & 4.4 & 2.7 & 3.8 \\
\hline Been feeling unhappy and depressed & 18.4 & 6.9 & 19.5 & 8.8 & 18.6 & 5.8 \\
\hline Been losing confidence in himself/herself & 2.9 & 1.5 & 3.7 & 2.1 & 2.7 & 1.3 \\
\hline Been thinking of himself/herself as a worthless person & 2.6 & 1.1 & 3.3 & 1.2 & 2.4 & 1.0 \\
\hline Not feeling reasonably happy, all things considered & 1.9 & 2.9 & 2.8 & 3.3 & 1.9 & 2.7 \\
\hline Three or more symptoms/behaviours & 9.5 & 7.0 & 12.3 & 9.1 & 8.8 & 5.8 \\
\hline Number of respondents & 890 & 2,151 & 653 & 804 & 789 & 1,347 \\
\hline \multicolumn{7}{|c|}{ Rural } \\
\hline Unable to concentrate on whatever he/she was doing & 8.1 & 6.2 & 8.2 & 7.8 & 8.1 & 5.0 \\
\hline Lost much sleep over worry & 22.4 & 15.8 & 27.6 & 19.4 & 22.2 & 13.2 \\
\hline Felt that he/she was not playing a useful role & 5.2 & 4.5 & 3.3 & 5.5 & 5.4 & 3.8 \\
\hline Felt incapable of making decisions & 6.1 & 6.2 & 5.8 & 8.2 & 6.3 & 4.7 \\
\hline Felt constantly under strain & 18.8 & 14.4 & 26.0 & 17.5 & 17.8 & 12.0 \\
\hline Felt that he/she could not overcome his/her difficulties & 4.3 & 3.6 & 3.3 & 3.8 & 4.5 & 3.4 \\
\hline Unable to enjoy normal day-to-day activities & 4.8 & 5.7 & 5.4 & 6.7 & 4.8 & 5.1 \\
\hline Unable to face up to his/her problems & 2.6 & 5.9 & 2.4 & 7.8 & 2.7 & 4.6 \\
\hline Been feeling unhappy and depressed & 19.2 & 12.4 & 21.7 & 15.6 & 18.3 & 10.0 \\
\hline Been losing confidence in himself/herself & 6.2 & 3.9 & 5.8 & 4.4 & 6.3 & 3.5 \\
\hline Been thinking of himself/herself as a worthless person & 4.3 & 3.8 & 5.1 & 4.3 & 4.2 & 3.4 \\
\hline Not feeling reasonably happy, all things considered & 4.3 & 4.1 & 2.7 & 5.2 & 4.5 & 3.3 \\
\hline Three or more symptoms/behaviours & 15.0 & 12.7 & 16.7 & 16.5 & 14.8 & 10.0 \\
\hline Number of respondents & 1,023 & 2,857 & 669 & 1,203 & 877 & 1,654 \\
\hline
\end{tabular}

Note: All Ns are unweighted. 
Figure 11.1: Percentage of youth reporting symptoms/behaviours suggestive of mental health disorders in the month preceding the interview, according to residence, Tamil Nadu, 2006
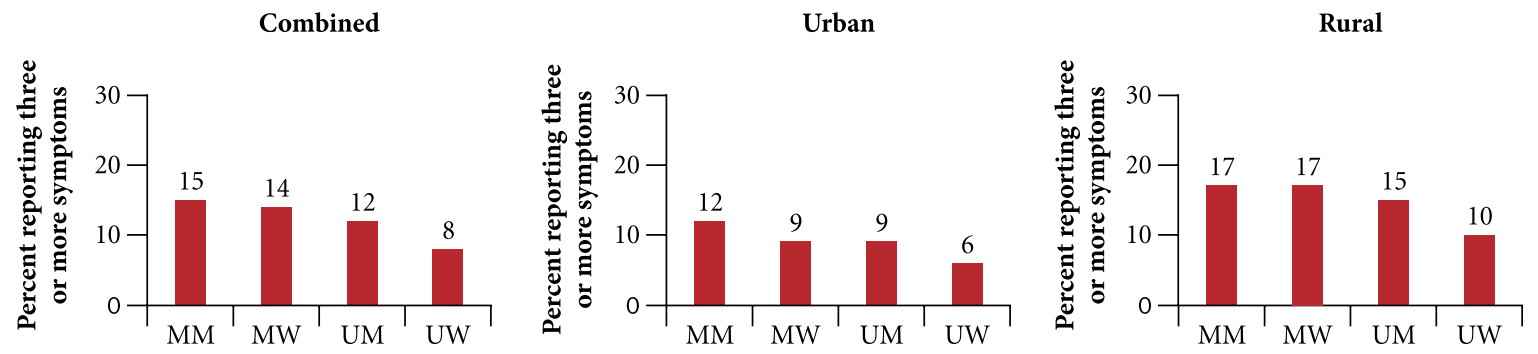

\subsection{Care and advice seeking}

Young people who reported physical or sexual and reproductive health problems were probed about whether they had sought care or advice for the problem and the source of this care or advice. Findings are presented in Table 11.4 and suggest that care and advice seeking differed by the kind of problem experienced as well as, in several instances, sex and marital status of the respondent.

\subsubsection{General health problems}

According to findings presented in Table 11.4, 92-97\% of young people experiencing high fever had sought treatment. Differences by respondents' sex and marital status were marginal. Treatment was sought from a government health care facility or provider by a relatively small percentage of those who had sought care: $39 \%$ of young men and $35 \%$ of young women. The majority of respondents had reportedly sought care from private sector providers (59\% of young men and $64 \%$ of young women), reflecting the pattern of health care seeking behaviour in India more generally. We note that respondents may not always have been able to discern whether the private sector provider from whom they had sought care had been trained and was licensed to provide such care.

Fewer had sought care for their reported injuries (68\% of young men and $56 \%$ of young women), but again, those who did tended to seek care from private sector providers $(57 \%$ of young men and $46 \%$ of young women). A few respondents (2-6\%) reported seeking care from traditional health care providers or using home remedies. Patterns of treatment seeking were quite similar by marital status.

\subsubsection{Sexual and reproductive health problems}

Responses regarding treatment seeking for sexual and reproductive health problems depict a somewhat different picture than that for general health ailments. In general, fewer young people had sought care for these problems than for general health problems. As in the case of general health problems, however, the majority who had sought care did so from a private sector provider.

Of those young men who had experienced symptoms of genital infection, $59 \%$ had sought care. Young men who experienced anxiety about swapnadosh or nocturnal emission were asked whether they had sought advice for this anxiety. About $72 \%$ of young men had done so. The most common source was friends, from whom $93 \%$ of young 
Table 11.4: Care and advice seeking for reported health problems

Percentage of youth who experienced selected health problems by reported care and advice seeking and place of treatment, Tamil Nadu, 2006

\begin{tabular}{|c|c|c|c|c|c|c|}
\hline Care and advice seeking (\%) & $\underset{15-24}{M}$ & $\begin{array}{l}\text { W } \\
15-24\end{array}$ & $\begin{array}{c}\text { MM } \\
15-29\end{array}$ & $\begin{array}{l}\text { MW } \\
15-24\end{array}$ & $\begin{array}{l}\text { UM } \\
15-24\end{array}$ & $\begin{array}{l}\text { UW } \\
15-24\end{array}$ \\
\hline $\begin{array}{l}\text { Sought treatment for high fever } \\
\text { Number reporting high fever }\end{array}$ & $\begin{array}{r}96.6 \\
341\end{array}$ & $\begin{array}{r}91.9 \\
1,652\end{array}$ & $\begin{array}{r}96.5 \\
229\end{array}$ & $\begin{array}{r}93.1 \\
684\end{array}$ & $\begin{array}{r}96.7 \\
295\end{array}$ & $\begin{array}{r}91.1 \\
968\end{array}$ \\
\hline $\begin{array}{l}\text { Place treatment sought for high fever }{ }^{1} \\
\text { Government facility/doctor } \\
\text { Private facility/doctor } \\
\text { Other }^{2} \\
\text { Number who sought treatment for high fever }\end{array}$ & $\begin{array}{r}39.3 \\
58.9 \\
1.8 \\
330\end{array}$ & $\begin{array}{r}35.2 \\
63.8 \\
0.9 \\
1,518\end{array}$ & $\begin{array}{r}41.5 \\
57.1 \\
1.4 \\
222\end{array}$ & $\begin{array}{r}33.9 \\
65.4 \\
0.8 \\
636\end{array}$ & $\begin{array}{r}38.7 \\
59.2 \\
2.1 \\
286\end{array}$ & $\begin{array}{r}36.0 \\
62.9 \\
1.0 \\
882\end{array}$ \\
\hline $\begin{array}{l}\text { Sought treatment for injury } \\
\text { Number reporting injury }\end{array}$ & $\begin{array}{r}68.3 \\
64\end{array}$ & $\begin{array}{r}56.3 \\
137\end{array}$ & $\begin{array}{r}(71.1) \\
42\end{array}$ & $\begin{array}{r}(63.4) \\
42\end{array}$ & $\begin{array}{r}69.0 \\
60\end{array}$ & $\begin{array}{r}53.2 \\
95\end{array}$ \\
\hline $\begin{array}{l}\text { Place treatment sought for injury } \\
\text { Government facility/doctor } \\
\text { Private facility/doctor } \\
\text { Other }{ }^{2} \\
\text { Number who sought treatment for injury }\end{array}$ & $\begin{array}{r}(34.8) \\
(56.5) \\
(2.2) \\
47\end{array}$ & $\begin{array}{r}38.6 \\
45.8 \\
6.0 \\
86\end{array}$ & $\begin{array}{r}(34.5) \\
(58.6) \\
(0.0) \\
33\end{array}$ & $\begin{array}{r}(36.7) \\
(46.7) \\
(3.3) \\
31\end{array}$ & $\begin{array}{r}(34.9) \\
(55.8) \\
(2.3) \\
45\end{array}$ & $\begin{array}{r}38.9 \\
44.4 \\
7.4 \\
55\end{array}$ \\
\hline $\begin{array}{l}\text { Sought treatment for symptoms of genital infection } \\
\text { Number reporting symptoms of genital infection }\end{array}$ & $\begin{array}{r}(59.4) \\
31\end{array}$ & $\begin{array}{r}50.4 \\
\mathbf{1 , 0 6 8}\end{array}$ & $\begin{array}{r}* \\
18\end{array}$ & $\begin{array}{r}60.2 \\
487\end{array}$ & $\begin{array}{r}(60.7) \\
28\end{array}$ & $\begin{array}{r}42.3 \\
581\end{array}$ \\
\hline $\begin{array}{l}\text { Place treatment sought for symptoms of genital } \\
\text { infection } 1,3,4 \\
\text { Government facility/doctor } \\
\text { Private facility/doctor } \\
\text { Other } \\
\text { Number who sought treatment for symptoms of } \\
\text { genital infection }\end{array}$ & $\begin{array}{l}* \\
* \\
*\end{array}$ & $\begin{array}{r}42.4 \\
56.0 \\
2.8\end{array}$ & $\begin{array}{l}* \\
* \\
*\end{array}$ & $\begin{array}{r}39.4 \\
60.3 \\
2.4\end{array}$ & $\begin{array}{l}* \\
* \\
*\end{array}$ & $\begin{array}{r}45.6 \\
51.0 \\
3.3\end{array}$ \\
\hline $\begin{array}{l}\text { Sought advice on swapnadosh/nocturnal emission } \\
\text { Number reporting anxiety over swapnadosh/nocturnal } \\
\text { emission }\end{array}$ & 71.5 & NA & 54.7 & NA & 72.2 & NA \\
\hline $\begin{array}{l}\text { Person from whom advice was sought on swapnadosh/ } \\
\text { nocturnal emission }\end{array}$ & & & & & & \\
\hline $\begin{array}{l}\text { Friend } \\
\text { Parent }\end{array}$ & $\begin{array}{r}93.3 \\
0.7\end{array}$ & $\begin{array}{l}\text { NA } \\
\text { NA }\end{array}$ & $\begin{array}{r}73.8 \\
1.5\end{array}$ & $\begin{array}{l}\text { NA } \\
\text { NA }\end{array}$ & $\begin{array}{r}93.6 \\
0.8\end{array}$ & $\begin{array}{l}\text { NA } \\
\text { NA }\end{array}$ \\
\hline Relative & 3.0 & NA & 7.7 & NA & 2.9 & NA \\
\hline Traditional healer & 0.7 & NA & 3.1 & NA & 0.8 & NA \\
\hline $\begin{array}{l}\text { Medical professional } \\
\text { Number who sought advice for swapnadosh/nocturnal } \\
\text { emission }\end{array}$ & 397 & NA & 10.8 & NA & 383 & NA \\
\hline $\begin{array}{l}\text { Sought treatment for menstrual problems } \\
\text { Number reporting menstrual problems }\end{array}$ & $\begin{array}{l}\text { NA } \\
\text { NA }\end{array}$ & $\begin{array}{r}57.0 \\
461\end{array}$ & $\begin{array}{l}\text { NA } \\
\text { NA }\end{array}$ & $\begin{array}{r}65.1 \\
172\end{array}$ & $\begin{array}{l}\text { NA } \\
\text { NA }\end{array}$ & $\begin{array}{r}52.3 \\
289\end{array}$ \\
\hline $\begin{array}{l}\text { Place treatment sought for menstrual problems }{ }^{1} \\
\text { Government facility/doctor } \\
\text { Private facility/doctor } \\
\text { Other }{ }^{2} \\
\text { Number who sought treatment for menstrual problems }\end{array}$ & $\begin{array}{l}\text { NA } \\
\text { NA } \\
\text { NA } \\
\text { NA }\end{array}$ & $\begin{array}{r}30.2 \\
67.2 \\
1.1 \\
267\end{array}$ & $\begin{array}{l}\text { NA } \\
\text { NA } \\
\text { NA } \\
\text { NA }\end{array}$ & $\begin{array}{r}30.1 \\
66.4 \\
1.8 \\
114\end{array}$ & $\begin{array}{l}\text { NA } \\
\text { NA } \\
\text { NA } \\
\text { NA }\end{array}$ & $\begin{array}{r}30.3 \\
67.8 \\
0.7 \\
153\end{array}$ \\
\hline
\end{tabular}

Note: All Ns are unweighted. Column totals may not equal 100\% due to missing cases or "don't know" responses. ( ) Based on 25-49 unweighted cases. ${ }^{*}$ Percentage not shown, based on fewer than 25 unweighted cases. NA: Not applicable. ${ }^{1}$ Refers to the last time the respondent sought treatment. ${ }^{2}$ Includes registered medical practitioner, unregistered medical practitioner, vaid/traditional healer and home remedies. ${ }^{3}$ Includes genital ulcers, genital itching, swelling in the groin, genital discharge, burning during urination, etc. ${ }^{4}$ Multiple responses were given. 
men reported seeking advice. In contrast, a minority sought advice from a medical professional ( $2 \%)$, a traditional health care provider generally known to "treat" such symptoms (1\%), a relative (3\%) or a parent $(1 \%)$.

Seeking treatment for sexual and reproductive health problems was even more limited among young women than among young men. For example, 57\% of young women experiencing menstrual problems had sought care for this problem, as did 50\% of those who had experienced symptoms of genital infection. That fewer young women had sought care for symptoms of genital infection than menstrual problems suggests that problems perceived to be associated with sex or sexual health matters were likely to go untreated by many. The married were considerably more likely than the unmarried to have sought treatment for symptoms of genital infection ( $60 \%$ versus $42 \%$ ) and menstrual problems ( $65 \%$ versus $52 \%$ ), a finding that can be attributed to the likelihood that sexual and reproductive health conditions evoke greater embarrassment among the unmarried and their families than their married counterparts.

As in the case of general health problems, care was most likely to be sought from a private sector provider: $56 \%$ of young women who had sought care for symptoms of genital infection and $67 \%$ of those who had sought care for menstrual problems had approached a private sector provider. Difference by marital status suggest that the married were about as likely as the unmarried to seek care from the private sector for menstrual problems but considerably more likely than the unmarried to do so in the case of genital infections ( $60 \%$ and $51 \%$, respectively).

\subsection{Hesitation to access contraceptive supplies}

In order to capture the extent to which young people perceived that they could approach health care professionals for sexual and reproductive health services, the Youth Study posed two questions relating to accessing contraceptives, namely, whether the respondent would feel shy to approach a health care provider and a pharmacist, respectively, for contraceptives. Findings are presented in Table 11.5 and confirm that large proportions of young people would indeed feel shy to approach a health care provider or pharmacy/medical shop for contraceptive supplies. Young men were consistently and considerably less likely than young women to report discomfort in approaching either a health care provider (54\% versus $62 \%$ ) or pharmacy/medical shop $(51 \%$ versus $66 \%)$ for contraceptive supplies. The married, moreover, were much less likely to report discomfort than the unmarried; for example, among young men, $36 \%$ of the married compared to $55 \%$ of the unmarried reported feeling shy to approach a health care provider for contraceptive supplies. Among young women, likewise, $55 \%$ of the married compared with $67 \%$ of the unmarried reported discomfort. Rural-urban differences were evident only among young women, and only with regard to approaching a health care provider for contraceptive supplies: urban young women were less likely than their rural counterparts to feel hesitation in approaching a health care provider for contraceptive supplies (59\% versus $65 \%)$. Findings confirm that many youth—ranging from about one-third of married young men to over two-thirds of unmarried young women—would indeed find it difficult to seek appropriate care for sexual and reproductive matters.

\subsection{Attitudes towards pre-marital HIV testing and extent of HIV testing}

Youth who were aware of HIV/AIDS were asked whether they approved of pre-marital HIV testing for boys and girls, and whether they had ever undergone an HIV test. Findings, presented in Table 11.6, suggest that over three in four youth-75-77\% of young men and $83-87 \%$ of young women-agreed that boys and girls should be tested for HIV before marriage. Despite favourable attitudes towards HIV testing, only a small minority of youth had ever undergone an HIV test: $3 \%$ of young men and $6 \%$ of young women. Married youth were considerably more likely than unmarried youth to report having undergone an HIV test: 10-13\% and $1-3 \%$, respectively. Rural-urban differences were negligible, except that more married young women in urban settings than in rural settings had undergone an HIV test (16\% versus $10 \%)$. 
Table 11.5: Hesitation to access contraceptive supplies

Percentage of youth reporting hesitation to access contraceptive supplies from a health care provider or medical shop, according to residence, Tamil Nadu, 2006

\begin{tabular}{|c|c|c|c|c|c|c|}
\hline Indicators (\%) & $\begin{array}{c}\mathrm{M} \\
15-24\end{array}$ & $\begin{array}{c}\mathrm{W} \\
15-24\end{array}$ & $\begin{array}{c}\text { MM } \\
15-29\end{array}$ & $\begin{array}{c}\text { MW } \\
15-24\end{array}$ & $\begin{array}{c}\text { UM } \\
15-24\end{array}$ & $\begin{array}{c}\text { UW } \\
15-24\end{array}$ \\
\hline \multicolumn{7}{|c|}{ Combined } \\
\hline $\begin{array}{l}\text { Would feel shy to approach an HCP for contraceptives } \\
\text { Would feel shy to approach a pharmacy/medical shop for } \\
\text { contraceptives }\end{array}$ & 53.6 & 62.0 & 36.4 & 54.8 & 54.9 & 66.8 \\
\hline Number of respondents & 1,913 & 5,008 & 1,322 & 2,007 & 1,666 & 3,001 \\
\hline \multicolumn{7}{|c|}{ Urban } \\
\hline $\begin{array}{l}\text { Would feel shy to approach an HCP for contraceptives } \\
\text { Would feel shy to approach a pharmacy/medical shop for } \\
\text { contraceptives }\end{array}$ & 51.6 & 58.8 & 34.6 & 50.9 & 53.3 & 63.3 \\
\hline Number of respondents & 890 & 2,151 & 653 & 804 & 789 & 1,347 \\
\hline \multicolumn{7}{|c|}{ Rural } \\
\hline $\begin{array}{l}\text { Would feel shy to approach an HCP for contraceptives } \\
\text { Would feel shy to approach a pharmacy/medical shop for } \\
\text { contraceptives }\end{array}$ & 50.6 & 66.5 & 31.8 & 59.8 & 51.4 & 71.4 \\
\hline Number of respondents & 1,023 & 2,857 & 669 & 1,203 & 877 & 1,654 \\
\hline
\end{tabular}

Note: All Ns are unweighted. HCP: Health care provider.

Table 11.6: Attitudes towards pre-marital HIV testing and extent of HIV testing

Percentage of youth aware of HIV/AIDS who believe that boys/girls should be tested for HIV before marriage and percentage who have ever had an HIV test, according to residence, Tamil Nadu, 2006

\begin{tabular}{|c|c|c|c|c|c|c|}
\hline Attitudes/experiences (\%) & $\begin{array}{c}\mathrm{M} \\
15-24\end{array}$ & $\begin{array}{c}\text { W } \\
15-24\end{array}$ & $\begin{array}{c}\text { MM } \\
15-29\end{array}$ & $\begin{array}{c}\text { MW } \\
15-24\end{array}$ & $\begin{array}{c}\text { UM } \\
15-24\end{array}$ & $\begin{array}{c}\text { UW } \\
15-24\end{array}$ \\
\hline \multicolumn{7}{|c|}{ Combined } \\
\hline \multicolumn{7}{|l|}{ Boys should be tested for HIV before marriage } \\
\hline Yes & 76.7 & 86.9 & 77.4 & 86.6 & 76.7 & 87.2 \\
\hline No & 22.1 & 9.9 & 22.2 & 10.8 & 21.9 & 9.3 \\
\hline \multicolumn{7}{|l|}{ Girls should be tested for HIV before marriage } \\
\hline Yes & 75.3 & 82.7 & 75.6 & 81.6 & 75.4 & 83.4 \\
\hline No & 23.1 & 13.9 & 23.9 & 15.6 & 22.9 & 12.8 \\
\hline Youth who underwent an HIV test & 3.4 & 5.8 & 10.2 & 12.6 & 3.0 & 1.4 \\
\hline Number aware of HIV/AIDS & 1,892 & 4,857 & 1,309 & 1,941 & 1,648 & 2,916 \\
\hline \multicolumn{7}{|c|}{ Urban } \\
\hline \multicolumn{7}{|l|}{ Boys should be tested for HIV before marriage } \\
\hline Yes & 77.8 & 87.6 & 77.5 & 87.4 & 78.0 & 87.8 \\
\hline No & 21.2 & 9.5 & 22.3 & 9.8 & 20.9 & 9.3 \\
\hline \multicolumn{7}{|l|}{ Girls should be tested for HIV before marriage } \\
\hline Yes & 75.5 & 82.1 & 75.5 & 81.0 & 75.6 & 82.8 \\
\hline No & 22.9 & 14.7 & 24.0 & 16.2 & 22.6 & 13.8 \\
\hline Youth who underwent an HIV test & 2.9 & 6.6 & 12.3 & 16.4 & 2.7 & 0.9 \\
\hline Number aware of HIV/AIDS & 883 & 2,119 & 648 & 790 & 783 & 1,329 \\
\hline
\end{tabular}


Table 11.6: (Cont'd)

\begin{tabular}{|c|c|c|c|c|c|c|}
\hline Attitudes/experiences (\%) & $\begin{array}{c}\mathrm{M} \\
15-24\end{array}$ & $\begin{array}{c}\text { W } \\
15-24\end{array}$ & $\begin{array}{c}\text { MM } \\
15-29\end{array}$ & $\begin{array}{c}\text { MW } \\
15-24\end{array}$ & $\begin{array}{c}\text { UM } \\
15-24\end{array}$ & $\begin{array}{l}\text { UW } \\
15-24\end{array}$ \\
\hline \multicolumn{7}{|c|}{ Rural } \\
\hline \multicolumn{7}{|c|}{ Boys should be tested for HIV before marriage } \\
\hline Yes & 75.7 & 86.3 & 77.3 & 86.1 & 75.6 & 86.6 \\
\hline No & 22.9 & 10.2 & 22.2 & 11.3 & 22.8 & 9.3 \\
\hline \multicolumn{7}{|c|}{ Girls should be tested for HIV before marriage } \\
\hline Yes & 75.2 & 83.1 & 75.6 & 82.0 & 75.1 & 83.9 \\
\hline No & 23.2 & 13.3 & 23.9 & 15.3 & 23.2 & 11.8 \\
\hline Youth who underwent an HIV test & 3.7 & 5.2 & 8.7 & 9.9 & 3.3 & 1.8 \\
\hline Number aware of HIV/AIDS & 1,009 & 2,738 & 661 & 1,151 & 865 & 1,587 \\
\hline
\end{tabular}

Note: All Ns are unweighted. Column totals may not equal 100\% due to missing cases or "don't know" responses.

\subsection{Summary}

Findings show that substantial proportions of young men reported the consumption of tobacco and alcohol; about one-fourth of young men reported tobacco consumption and alcohol consumption. Drug use was reported by just $0.3 \%$. In contrast, hardly any young women reported that they consumed any of these substances (less than $1 \%$ ).

Although youth is a generally healthy period of life, significant minorities reported experiencing general, mental, and sexual and reproductive health problems in the period preceding the interview. For example, $18 \%$ of young men and 33\% of young women had experienced high fever. Sexual problems were also reported. Among young women, one in five reported the experience of symptoms of genital infection and one in 10 reported menstrual problems. Among young men, while just $2 \%$ reported genital infection, more than one-quarter reported anxiety about nocturnal emission. Finally, responses indicative of mental health disorders were reported by some $13 \%$ of young men and $10 \%$ of young women. An identical set of three questions were most likely to elicit responses suggestive of mental disorders for both young men and women, namely, losing sleep over worry (13-20\%), feeling constantly under strain (13-18\%) and feeling unhappy and depressed (10-19\%).

With regard to care seeking for general and sexual and reproductive health problems, patterns varied by the type of problem experienced. While the large majority of those who had experienced high fever, for example, had sought care, many fewer had sought care for sexual and reproductive health problems. Of those who sought treatment, the majority had sought advice or treatment from a private facility or provider, irrespective of the type of problem experienced. However, it is notable that in the case of anxiety about nocturnal emission, youth rarely sought advice from a health care provider, preferring to do so from peers.

Findings suggest that youth were uncomfortable about seeking sexual and reproductive health services. Many youth-minorities in the case of married young men, but larger proportions in the case of unmarried young men and both married and unmarried young women-would indeed find it difficult to seek appropriate care for sexual and reproductive problems.

Finally, small minorities reported that they had undergone HIV testing-10-13\% of the married and 1-3\% of the unmarried. Youth were, however, overwhelmingly in favour of pre-marital HIV testing. 


\section{Participation in civil society} and political life

The National Youth Policy 2003 has underscored the role of India's youth in political decision-making, and argued for greater representation of youth in appropriate bodies and more extensive youth participation in the design and implementation of programmes (Ministry of Youth Affairs and Sports, 2003). Indeed, there is a recognition that today's youth, who have better access to skills and information than those of earlier generations, can play an important role in influencing political processes and the socio-economic development of the country.

This chapter presents a profile of youth involvement in government-and NGO-sponsored programmes, community activities and political processes. It also explores young people's behaviours and attitudes towards individuals of different religions and caste groups, violence within their community and their own participation in such violence, and their perceptions about the most important problem facing youth in India.

\subsection{Awareness of and participation in government-and NGO-sponsored programmes}

Youth were asked whether they were aware of programmes in which youth could participate that had taken place in their village or urban neighbourhood in the three years preceding the interview. They were also asked whether they had participated in these programmes and whether these programmes had been organised by government agencies or NGOs. Findings are presented in Table 12.1.

In total, one-fifth of young men and two-fifths of young women reported awareness of one or more programmes that addressed youth needs organised in the three years prior to interview (see also Figure 12.1). Differences by marital status of respondents were negligible. Rural-urban differences were negligible for young men; however, rural young women were more likely to be aware of such programmes than their urban counterparts (46\% versus $35 \%$ ). It appears, therefore, that community-level programmes are more likely to be directed towards young women than young men, and more likely to be conducted in rural than urban settings.

Findings suggest a gender divide also in the kinds of programmes about which youth were aware. The leading programmes about which young men were aware related to leadership and life skills (9\%), followed by sports and recreation (6\%), employment, such as the Employment Guarantee Scheme or the Jawahar Rozgar Yojna (5\%), and self-help groups (3\%). In contrast, the largest proportions of young women were aware of selfhelp groups (34\%), followed by employment programmes (5\%) and leadership and life skills programmes $(3 \%)$. Patterns observed among all young men and women were also observed among both married and unmarried men and women as well as those from both rural and urban areas.

Over two-thirds of the programmes with which youth were familiar were organised by government agencies. Nevertheless, a large percentage of youth (31\% of young men and $24 \%$ of young women) also reported awareness of programmes organised by the NGO sector. Unmarried young women were more likely than the married (27\% versus $20 \%$ ) to report awareness of NGO-sponsored programmes, a difference not observed 
among young men. Rural-urban differences suggest that young men in urban areas were more likely than those in rural areas to report awareness of NGO-sponsored programmes (34\% versus 29\%). In contrast, rural young women were more likely than their urban counterparts to be aware of NGO-sponsored programmes ( $27 \%$ versus $20 \%)$.

Table 12.1: Awareness of and participation in government-and NGO-sponsored programmes

Percentage of youth reporting awareness of and participation in government- and NGO-sponsored programmes conducted in the village/neighbourhood in the three years preceding the interview, according to residence, Tamil Nadu, 2006

\begin{tabular}{|c|c|c|c|c|c|c|}
\hline $\begin{array}{l}\text { Awareness of and participation in } \\
\text { programmes (\%) }\end{array}$ & $\underset{15-24}{M}$ & $\begin{array}{c}W \\
15-24\end{array}$ & $\begin{array}{c}\text { MM } \\
15-29\end{array}$ & $\begin{array}{l}\text { MW } \\
15-24\end{array}$ & $\begin{array}{c}\text { UM } \\
15-24\end{array}$ & $\begin{array}{l}\text { UW } \\
15-24\end{array}$ \\
\hline \multicolumn{7}{|c|}{ Combined } \\
\hline Aware of programme(s) held & 21.7 & 40.8 & 20.3 & 42.1 & 22.0 & 40.0 \\
\hline Focus of programmes held & & & & & & \\
\hline Health promotion & 1.8 & 0.9 & 2.0 & 0.5 & 1.7 & 1.2 \\
\hline Awareness/leadership/vocational/life skills & 9.1 & 3.4 & 7.3 & 2.5 & 9.5 & 3.9 \\
\hline Employment $^{1}$ & 4.6 & 5.2 & 5.7 & 5.5 & 4.6 & 5.0 \\
\hline Self-help group & 3.4 & 34.1 & 4.3 & 35.5 & 3.4 & 33.2 \\
\hline Literacy & 1.5 & 1.5 & 1.2 & 0.7 & 1.5 & 2.0 \\
\hline Sports and recreation & 6.4 & 2.0 & 3.9 & 1.2 & 6.7 & 2.5 \\
\hline Number of respondents & 1,913 & 5,008 & 1,322 & 2,007 & 1,666 & 3,001 \\
\hline \multicolumn{7}{|l|}{ Organising agency } \\
\hline Government & 69.9 & 68.6 & 74.3 & 71.5 & 69.7 & 66.7 \\
\hline $\mathrm{NGO}$ & 30.8 & 24.3 & 29.9 & 20.3 & 31.1 & 27.1 \\
\hline Don't know & 1.9 & 7.1 & 0.7 & 8.6 & 2.2 & 6.2 \\
\hline Number aware of any programme(s) & 413 & 2,054 & 270 & 851 & 366 & 1,203 \\
\hline Participated in programme(s) held & 13.9 & 9.1 & 11.6 & 15.9 & 14.1 & 4.6 \\
\hline Number of respondents & 1,913 & 5,008 & 1,322 & 2,007 & 1,666 & 3,001 \\
\hline \multicolumn{7}{|l|}{ Participation in specific programmes } \\
\hline Health promotion & 9.7 & 1.8 & 11.1 & 0.6 & 9.0 & 4.4 \\
\hline Awareness/leadership/vocational/life skills & 48.5 & 6.8 & 37.3 & 3.8 & 49.6 & 13.9 \\
\hline Employment $^{1}$ & 13.2 & 10.8 & 24.8 & 11.6 & 13.2 & 8.8 \\
\hline Self-help group & 4.9 & 74.0 & 9.8 & 81.9 & 3.8 & 56.2 \\
\hline Literacy & 4.1 & 2.6 & 3.3 & 0.6 & 4.3 & 6.6 \\
\hline Sports and recreation & 35.2 & 4.0 & 21.6 & 0.0 & 36.3 & 13.1 \\
\hline Number who participated in any programme(s) & 264 & 470 & 156 & 331 & 232 & 139 \\
\hline \multicolumn{7}{|c|}{ Urban } \\
\hline Aware of programme(s) held & 21.3 & 34.7 & 19.2 & 36.2 & 21.0 & 33.9 \\
\hline Focus of programmes held & & & & & & \\
\hline Health promotion & 2.2 & 0.8 & 2.0 & 0.6 & 2.3 & 0.9 \\
\hline Awareness/leadership/vocational/life skills & 11.3 & 2.5 & 8.3 & 2.0 & 11.4 & 2.8 \\
\hline Employment $^{1}$ & 3.7 & 4.7 & 4.6 & 5.6 & 3.7 & 4.2 \\
\hline Self-help group & 2.8 & 29.1 & 2.8 & 29.9 & 2.5 & 28.7 \\
\hline Literacy & 1.0 & 1.1 & 0.6 & 0.6 & 0.9 & 1.4 \\
\hline Sports and recreation & 7.3 & 2.2 & 5.0 & 0.9 & 7.5 & 2.9 \\
\hline Number of respondents & 890 & 2,151 & 653 & 804 & 789 & 1,347 \\
\hline
\end{tabular}


Table 12.1: (Cont'd)

\begin{tabular}{|c|c|c|c|c|c|c|}
\hline $\begin{array}{l}\text { Awareness of and participation in } \\
\text { programmes (\%) }\end{array}$ & $\begin{array}{c}\text { M } \\
15-24\end{array}$ & $\begin{array}{c}\text { W } \\
15-24\end{array}$ & $\begin{array}{c}\text { MM } \\
15-29\end{array}$ & $\begin{array}{c}\text { MW } \\
15-24\end{array}$ & $\begin{array}{c}\text { UM } \\
15-24\end{array}$ & $\begin{array}{c}\text { UW } \\
15-24\end{array}$ \\
\hline \multicolumn{7}{|c|}{ Urban } \\
\hline \multicolumn{7}{|l|}{ Organising agency } \\
\hline Government & 67.2 & 74.3 & 65.0 & 74.1 & 67.7 & 74.4 \\
\hline NGO & 33.9 & 20.3 & 36.9 & 19.8 & 33.1 & 20.6 \\
\hline Don't know & 2.3 & 6.5 & 1.0 & 7.2 & 2.5 & 6.1 \\
\hline Number aware of any programme(s) & 189 & 744 & 128 & 293 & 164 & 451 \\
\hline Participated in programme(s) held & 15.4 & 6.1 & 12.2 & 11.4 & 15.2 & 3.1 \\
\hline Number of respondents & 890 & 2,151 & 653 & 804 & 789 & 1,347 \\
\hline \multicolumn{7}{|l|}{ Participation in specific programmes } \\
\hline Health promotion & 11.6 & 1.5 & 10.6 & 1.1 & 11.5 & $(2.3)$ \\
\hline Awareness/leadership/vocational/life skills & 52.3 & 4.4 & 34.8 & 3.3 & 53.5 & $(6.8)$ \\
\hline Employment $^{1}$ & 14.8 & 12.5 & 22.7 & 16.3 & 14.9 & $(4.5)$ \\
\hline Self-help group & 2.3 & 72.8 & 6.1 & 79.3 & 0.9 & $(59.1)$ \\
\hline Literacy & 1.6 & 1.5 & 3.0 & 1.1 & 1.8 & $(2.3)$ \\
\hline Sports and recreation & 38.3 & 6.6 & 30.3 & 0.0 & 39.8 & $(22.7)$ \\
\hline Number who participated in any programme(s) & 137 & 135 & 82 & 93 & 119 & 42 \\
\hline \multicolumn{7}{|l|}{ 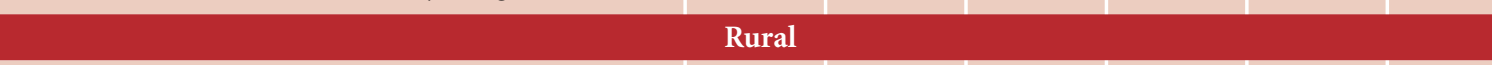 } \\
\hline Aware of programme(s) held & 21.9 & 45.6 & 21.1 & 45.9 & 22.8 & 45.4 \\
\hline \multicolumn{7}{|l|}{ Focus of programmes held } \\
\hline Health promotion & 1.5 & 1.0 & 2.1 & 0.5 & 1.3 & 1.4 \\
\hline Awareness/leadership/vocational/life skills & 7.5 & 4.0 & 6.8 & 2.9 & 7.9 & 4.8 \\
\hline Employment $^{1}$ & 5.2 & 5.7 & 6.5 & 5.5 & 5.2 & 5.8 \\
\hline Self-help group & 4.0 & 38.1 & 5.4 & 39.2 & 4.0 & 37.2 \\
\hline Literacy & 1.9 & 1.8 & 1.5 & 0.8 & 2.0 & 2.5 \\
\hline Sports and recreation & 5.7 & 1.8 & 3.3 & 1.4 & 6.0 & 2.2 \\
\hline Number of respondents & 1,023 & 2,857 & 669 & 1,203 & 877 & 1,654 \\
\hline \multicolumn{7}{|l|}{ Organising agency } \\
\hline Government & 71.8 & 65.2 & 80.5 & 70.2 & 71.0 & 61.6 \\
\hline NGO & 28.6 & 26.8 & 25.0 & 20.5 & 29.7 & 31.4 \\
\hline Don't know & 1.7 & 7.5 & 0.6 & 9.3 & 1.9 & 6.2 \\
\hline Number aware of any programme(s) & 224 & 1,310 & 142 & 558 & 202 & 752 \\
\hline Participated in programme(s) held & 12.7 & 11.4 & 11.2 & 19.0 & 13.2 & 5.8 \\
\hline Number of respondents & 1,023 & 2,857 & 669 & 1,203 & 877 & 1,654 \\
\hline \multicolumn{7}{|l|}{ Participation in specific programmes } \\
\hline Health promotion & 7.9 & 1.9 & 11.5 & 0.4 & 6.6 & 5.4 \\
\hline Awareness/leadership/vocational/life skills & 44.6 & 7.9 & 39.1 & 3.9 & 45.5 & 17.2 \\
\hline Employment $^{1}$ & 11.6 & 9.7 & 26.7 & 9.6 & 11.6 & 10.8 \\
\hline Self-help group & 7.2 & 74.8 & 12.6 & 82.9 & 6.6 & 54.8 \\
\hline Literacy & 6.5 & 2.8 & 3.4 & 0.4 & 6.6 & 8.6 \\
\hline Sports and recreation & 32.6 & 2.8 & 14.9 & 0.0 & 33.1 & 9.7 \\
\hline Number who participated in any programme(s) & 127 & 335 & 74 & 238 & 113 & 97 \\
\hline
\end{tabular}

Note: All Ns are unweighted. ( ) Based on 25-49 unweighted cases. Column total may exceed 100\% due to multiple responses. ${ }^{1}$ Includes Employment Guarantee Scheme (EGS), Jawahar Rozgar Yojana (JRY), National Rural Employment Programme (NREP), Pradhan Mantri Rozgar Yojana (PMRY), (Training for Rural Youth for Self Employment (TRYSEM), etc. 
Figure 12.1: Percentage of youth reporting awareness of and participation in government-and NGO-sponsored programmes in the three years preceding the interview, according to residence, Tamil Nadu, 2006

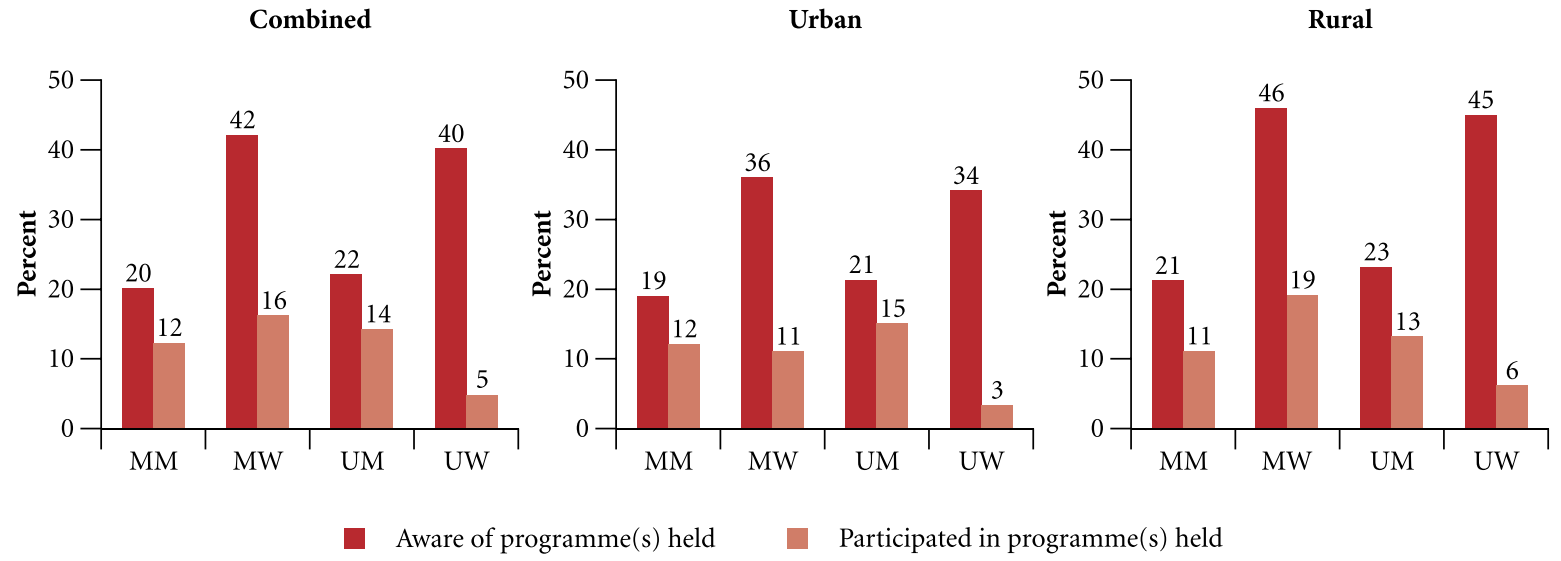

Few youth reported participation in a programme in the preceding three years. Moreover, although young women were far more likely than young men to be aware of programmes, they were less likely than young men to have participated in any programmes in the preceding three years: $9 \%$ compared to $14 \%$. Unmarried young women were much less likely to participate in a programme (5\%) than married young women (16\%) or married and unmarried young men (12-14\%). Rural-urban differences were negligible among young men (13-15\%), but among young women, just $6 \%$ of those in urban areas and $11 \%$ of those in rural areas had participated in any programme. The pattern was reversed however, among married young women: those in rural areas were considerably more likely to have participated in such programmes than their urban counterparts (19\% versus $11 \%)$.

Of those who reported participation in any programme, irrespective of marital status or residence, the largest percentage of young men had participated in leadership and life skills, sports and recreation, and employment-related programmes $(49 \%, 35 \%$, and $13 \%$, respectively). In contrast, leading programmes in which young women had participated were self-help groups (74\%), employment-related programmes (11\%) and leadership and life skills programmes (7\%). Differences by marital status were evident among both young men and women. Among young men, the married were considerably more likely than the unmarried to have participated in employment-related programmes (25\% versus $13 \%)$ and self-help group programmes $(10 \%$ versus $4 \%$ ), and considerably less likely to have participated in leadership and life skills programmes (37\% versus $50 \%)$ and sports and recreation programmes (22\% versus $36 \%)$. Among young women, the married were far more likely than the unmarried to have participated in self-help group programmes $(82 \%$ versus $56 \%$ ), and much less likely to have participated in leadership and life skills programmes (4\% versus $14 \%$ ), and sports and recreation programmes (none versus 13\%).

Rural-urban differences were relatively muted. Even so, among young men, those in urban areas were somewhat more likely than those in rural areas to have participated in leadership and life skills programmes (52\% versus $45 \%)$ and sports and recreation programmes (38\% and $33 \%$, respectively), and less likely to have participated in self-help group programmes ( $2 \%$ versus $7 \%$ ) and literacy programmes ( $2 \%$ versus $7 \%)$. Among young women, differences were even milder. 


\subsection{Participation in community-or panchayat-sponsored programmes}

In many villages and urban neighbourhoods, community-led activities include, for example, cleanliness drives, health promotion activities, and the celebration of festivals and national days. As part of the Youth Study, youth were asked whether they had participated in any community-led activities organised by the panchayat/ community leaders in the 12 months prior to interview. Findings, reported in Table 12.2, suggest that young women were far less likely than young men to have participated in these activities. More than half of young men, compared to only $13 \%$ of young women, reported having participated in a community-led programme in the last year. Unmarried youth were somewhat more likely than married youth to have participated in community-led programmes (53\% versus $46 \%$ among young men, and $16 \%$ versus $8 \%$ among young women). Participation was, moreover, more likely to be reported by rural than urban residents $(60 \%$ and $15 \%$ of rural young men and women, respectively, compared to $42 \%$ and $10 \%$ of urban young men and women).

Table 12.2: Participation in community-led programmes

Percentage of youth who attended community-led programmes in the village/urban neighbourhood and types of programmes attended in the 12 months preceding the interview, according to residence, Tamil Nadu, 2006

\begin{tabular}{|c|c|c|c|c|c|c|}
\hline Participation in community-led programmes (\%) & $\begin{array}{c}M \\
15-24\end{array}$ & $\begin{array}{c}\text { W } \\
15-24\end{array}$ & $\begin{array}{c}\text { MM } \\
15-29\end{array}$ & $\begin{array}{c}\text { MW } \\
15-24\end{array}$ & $\begin{array}{c}\text { UM } \\
15-24\end{array}$ & $\begin{array}{c}\text { UW } \\
\text { 15-24 }\end{array}$ \\
\hline \multicolumn{7}{|c|}{ Combined } \\
\hline Attended any programme(s) organised & 52.2 & 12.5 & 46.2 & 7.9 & 52.7 & 15.5 \\
\hline Number of respondents & 1,913 & 5,008 & 1,322 & 2,007 & 1,666 & 3,001 \\
\hline \multicolumn{7}{|l|}{ Specific programmes attended } \\
\hline Cleanliness/sanitation & 48.8 & 16.8 & 50.5 & 18.1 & 47.7 & 16.4 \\
\hline Health promotion & 3.2 & 4.2 & 3.6 & 4.4 & 3.4 & 4.1 \\
\hline Festival celebration & 52.4 & 12.3 & 56.0 & 15.6 & 53.3 & 11.4 \\
\hline National day celebration & 60.8 & 80.2 & 48.0 & 76.3 & 62.5 & 81.5 \\
\hline Number who attended above programmes & 970 & 629 & 585 & 161 & 862 & 468 \\
\hline \multicolumn{7}{|c|}{ Urban } \\
\hline Attended any programme(s) organised & 42.4 & 9.8 & 39.0 & 4.7 & 43.2 & 12.9 \\
\hline Number of respondents & 890 & 2,151 & 653 & 804 & 789 & 1,347 \\
\hline \multicolumn{7}{|l|}{ Specific programmes attended } \\
\hline Cleanliness/sanitation & 41.6 & 12.4 & 41.0 & $(21.1)$ & 41.0 & 11.0 \\
\hline Health promotion & 4.2 & 5.0 & 6.6 & $(10.5)$ & 4.0 & 3.9 \\
\hline Festival celebration & 51.6 & 12.8 & 60.2 & $(18.4)$ & 51.1 & 11.6 \\
\hline National day celebration & 67.4 & 88.5 & 59.0 & $(86.8)$ & 69.0 & 89.0 \\
\hline Number who attended above programmes & 371 & 207 & 248 & 37 & 337 & 170 \\
\hline \multicolumn{7}{|c|}{ Rural } \\
\hline Attended any programme(s) organised & 59.7 & 14.6 & 51.3 & 10.2 & 60.5 & 17.7 \\
\hline Number of respondents & 1,023 & 2,857 & 669 & 1,203 & 877 & 1,654 \\
\hline \multicolumn{7}{|l|}{ Specific programmes attended } \\
\hline Cleanliness/sanitation & 52.7 & 19.2 & 55.5 & 17.2 & 51.6 & 19.9 \\
\hline Health promotion & 2.6 & 3.7 & 2.0 & 2.5 & 2.9 & 4.2 \\
\hline Festival celebration & 52.9 & 12.1 & 53.8 & 14.8 & 54.7 & 11.0 \\
\hline National day celebration & 57.3 & 75.7 & 42.3 & 73.0 & 58.8 & 76.7 \\
\hline Number who attended above programmes & 599 & 422 & 337 & 124 & 525 & 298 \\
\hline
\end{tabular}

Note: All Ns are unweighted. ( ) Based on 25-49 unweighted cases. Column totals may exceed 100\% due to multiple responses. 
Findings suggest that the activity in which the largest percentage of youth participated was the celebration of national days ( $61 \%$ of young men and $80 \%$ of young women). While $52 \%$ and $49 \%$ of young men reported participating in celebrations of festivals and cleanliness drives, few young women so reported (12\% and $17 \%$, respectively). Corresponding with the small numbers of youth aware of health promotion programmes, few youth $(3-4 \%)$ reported participating in a community-sponsored health promotion programme. Patterns were somewhat similar among married and unmarried youth and those residing in rural and urban areas.

\subsection{Membership in organised groups}

Youth were asked whether they belonged to any organised group, ranging from self-help groups to youth groups to sports and social clubs. Findings, reported in Table 12.3, suggest that relatively small proportions of youth were members of any group. Young women were mildly more likely than young men to report such membership (16\% compared to 12\%). Marital status differences were narrow for young men but wide for young women; married young women were three times more likely to have reported such membership than unmarried young women ( $26 \%$ versus $9 \%$ ). Rural-urban differences were narrow among young men (11-12\%); among young women, those in rural areas were slightly more likely to report group membership than those in urban areas (18\% and $14 \%$, respectively).

The types of groups in which youth reported membership varied widely by sex of the respondent. Young men reported membership in youth groups $(6 \%)$ and social or sports clubs $(4 \%)$, with little variation by marital status or rural-urban residence. Young women, in contrast, were most likely to report membership in selfhelp groups (10\%), followed by women's groups (magalir manram) and social or sports clubs (3\% each). Just $1 \%$ of young women reported membership in youth groups. Differences by marital status and rural-urban residence were by and large narrow, with one exception: considerably larger proportions of married compared to unmarried young women reported membership in self-help groups ( $20 \%$ and $3 \%$, respectively).

Table 12.3: Membership in organised groups

Percentage of youth reporting membership in organised groups, according to residence, Tamil Nadu, 2006

\begin{tabular}{|c|c|c|c|c|c|c|}
\hline Membership in organised groups (\%) & $\underset{15-24}{M}$ & $\begin{array}{c}\text { W } \\
15-24\end{array}$ & $\begin{array}{c}\text { MM } \\
15-29\end{array}$ & $\begin{array}{c}\text { MW } \\
15-24\end{array}$ & $\begin{array}{c}\text { UM } \\
15-24\end{array}$ & $\begin{array}{c}\text { UW } \\
15-24\end{array}$ \\
\hline \multicolumn{7}{|c|}{ Combined } \\
\hline Member of an organised group & 11.5 & 15.7 & 12.0 & 26.3 & 11.5 & 8.9 \\
\hline Self-help group & 1.0 & 9.8 & 2.4 & 19.9 & 0.9 & 3.1 \\
\hline Mahila mandal/magalir manram & NA & 3.1 & NA & 5.9 & NA & 1.2 \\
\hline Social or sports club & 4.3 & 2.7 & 3.0 & 0.9 & 4.5 & 4.0 \\
\hline Youth group/yuva/tarun/kishor/kishori mandal & 6.4 & 0.8 & 6.7 & 0.3 & 6.4 & 1.1 \\
\hline Number of respondents & 1,913 & 5,008 & 1,322 & 2,007 & 1,666 & 3,001 \\
\hline \multicolumn{7}{|l|}{ Became member of an organised group ${ }^{1}$} \\
\hline Before marriage & NA & NA & 67.5 & 10.0 & NA & NA \\
\hline After marriage & NA & NA & 32.5 & 89.6 & NA & NA \\
\hline Number reporting membership in an organised group & NA & NA & 161 & 534 & NA & NA \\
\hline \multicolumn{7}{|c|}{ Urban } \\
\hline Member of an organised group & 11.0 & 13.5 & 9.4 & 20.7 & 11.2 & 9.2 \\
\hline Self-help group & 0.7 & 6.7 & 1.3 & 15.1 & 0.7 & 1.9 \\
\hline Mahila mandal/magalir manram & NA & 2.5 & NA & 4.9 & NA & 1.1 \\
\hline
\end{tabular}

Cont'd on next page... 
Table 12.3: (Cont'd)

\begin{tabular}{|c|c|c|c|c|c|c|}
\hline Membership in organised groups (\%) & $\begin{array}{c}\mathrm{M} \\
15-24 \\
\end{array}$ & $\begin{array}{c}\text { W } \\
15-24\end{array}$ & $\begin{array}{c}\text { MM } \\
15-29 \\
\end{array}$ & $\begin{array}{c}\text { MW } \\
15-24\end{array}$ & $\begin{array}{c}\text { UM } \\
15-24 \\
\end{array}$ & $\begin{array}{c}\text { UW } \\
\text { 15-24 }\end{array}$ \\
\hline \multicolumn{7}{|c|}{ Urban } \\
\hline Social or sports club & 5.8 & 3.8 & 2.2 & 1.0 & 6.2 & 5.5 \\
\hline Youth group/yuva/tarun/kishor/kishori mandal & 4.8 & 0.9 & 6.3 & 0.4 & 4.7 & 1.3 \\
\hline Number of respondents & 890 & 2,151 & 653 & 804 & 789 & 1,347 \\
\hline \multicolumn{7}{|l|}{ Became member of an organised group ${ }^{1}$} \\
\hline Before marriage & NA & NA & 72.5 & 10.1 & NA & NA \\
\hline After marriage & NA & NA & 27.5 & 89.9 & NA & NA \\
\hline Number reporting membership in an organised group & NA & NA & 64 & 169 & NA & NA \\
\hline \multicolumn{7}{|c|}{ Rural } \\
\hline Member of an organised group & 11.9 & 17.5 & 13.7 & 30.0 & 11.8 & 8.5 \\
\hline Self-help group & 1.3 & 12.2 & 3.2 & 23.3 & 1.1 & 4.1 \\
\hline Mahila mandal/magalir manram & NA & 3.5 & NA & 6.6 & NA & 1.3 \\
\hline Social or sports club & 3.2 & 1.9 & 3.6 & 0.9 & 3.2 & 2.6 \\
\hline Youth group/yuva/tarun/kishor/kishori mandal & 7.6 & 0.7 & 7.1 & 0.3 & 7.8 & 1.0 \\
\hline Number of respondents & 1,023 & 2,857 & 669 & 1,203 & 877 & 1,654 \\
\hline \multicolumn{7}{|l|}{ Became member of an organised group ${ }^{1}$} \\
\hline Before marriage & NA & NA & 65.1 & 9.7 & NA & NA \\
\hline After marriage & NA & NA & 34.9 & 89.7 & NA & NA \\
\hline Number reporting membership in an organised group & NA & NA & 97 & 365 & NA & NA \\
\hline
\end{tabular}

Note: All Ns are unweighted. NA: Not applicable. ${ }^{1}$ Column total may not equal $100 \%$ due to missing cases.

Among married young men who reported group membership, the majority had become members prior to marriage (68\%), a pattern that was observed among both rural (65\%) and urban $(73 \%)$ residents. The opposite was true among married young women, of whom $90 \%$, irrespective of residence, had joined an organised group after marriage, confirming young women's limited exposure to organised groups prior to marriage.

\subsection{Perceptions about action taken by panchayats in addressing defiance of social norms}

In the course of pre-survey qualitative investigations, researchers noted that in several rural areas, village panchayats took action in various situations in which youth did not adhere to social norms. Hence, youth in rural areas were asked whether they believed that the panchayat in their village would taken action if someone was reported to have teased a girl or woman, if parents refused to permit their sons or daughters to marry someone of their choice, if youth were found to have engaged in pre-marital or extra-marital sex or if an unmarried girl became pregnant. Responses are reported in Table 12.4.

Considerable proportions of youth perceived that their village panchayat would force a boy to marry a girl whom he had made pregnant ( $77 \%$ and $55 \%$ of young men and women, respectively), punish those accused of teasing a girl or woman ( $65 \%$ and $55 \%$, respectively), fine youth who had engaged in pre-or extra-marital sex (58\% and 37\%, respectively), and arrange the marriage of youth whose parents had refused to permit them to marry someone of their choice ( $51 \%$ and $42 \%$, respectively). In all cases, young men were more likely than young women to report panchayat involvement. Differences by marital status were mild, but usually it was the married who were more likely than the unmarried to report panchayat action. 
Table 12.4: Perceptions about actions taken by the panchayat in case of defiance of social norms

Percent distribution of youth by perceptions about actions taken by the panchayat in case of defiance of social norms in selected situations, Tamil Nadu (rural), 2006

\begin{tabular}{|c|c|c|c|c|c|c|}
\hline Perceptions (\%) & $\begin{array}{c}M \\
15-24\end{array}$ & $\begin{array}{c}\mathrm{W} \\
15-24\end{array}$ & $\begin{array}{c}\text { MM } \\
15-29\end{array}$ & $\begin{array}{c}\text { MW } \\
15-24\end{array}$ & $\begin{array}{c}\text { UM } \\
15-24\end{array}$ & $\begin{array}{l}\text { UW } \\
15-24\end{array}$ \\
\hline \multicolumn{7}{|c|}{$\begin{array}{l}\text { Panchayat would punish anyone who teases a } \\
\text { girl/woman }\end{array}$} \\
\hline Yes & 65.3 & 55.3 & 70.9 & 58.8 & 64.2 & 52.8 \\
\hline No & 33.4 & 40.1 & 28.6 & 36.4 & 34.4 & 42.8 \\
\hline Can't say & 1.3 & 4.6 & 0.5 & 4.8 & 1.4 & 4.4 \\
\hline \multicolumn{7}{|c|}{$\begin{array}{l}\text { Panchayat would fine a boy/girl who had } \\
\text { engaged in pre-/extra-marital sexual relations }\end{array}$} \\
\hline Yes & 58.3 & 36.8 & 55.2 & 41.1 & 57.3 & 33.7 \\
\hline No & 38.0 & 52.3 & 44.0 & 48.7 & 38.5 & 54.9 \\
\hline Can't say & 3.7 & 10.9 & 0.8 & 10.3 & 4.1 & 11.3 \\
\hline \multicolumn{7}{|c|}{$\begin{array}{l}\text { Panchayat would arrange the marriage of youth } \\
\text { if parents refused to let them marry }\end{array}$} \\
\hline Yes & 50.6 & 41.6 & 54.6 & 46.6 & 50.0 & 38.1 \\
\hline No & 46.0 & 51.4 & 44.0 & 46.7 & 46.4 & 54.8 \\
\hline Can't say & 3.4 & 6.9 & 1.4 & 6.7 & 3.6 & 7.1 \\
\hline \multicolumn{7}{|c|}{$\begin{array}{l}\text { Panchayat had ever forced a boy to marry a } \\
\text { girl who he had made pregnant }\end{array}$} \\
\hline Yes & 77.3 & 54.7 & 81.4 & 58.1 & 76.4 & 52.4 \\
\hline No & 18.9 & 32.8 & 17.9 & 30.6 & 19.4 & 34.4 \\
\hline Can't say & 3.9 & 12.5 & 0.8 & 11.3 & 4.2 & 13.3 \\
\hline Number of respondents & 1,023 & 2,857 & 669 & 1,203 & 877 & 1,654 \\
\hline
\end{tabular}

Note: All Ns are unweighted. Column totals may not equal 100\% due to missing cases. Questions were asked only of respondents in rural areas.

\subsection{Voting behaviour and perceptions of political matters}

Table 12.5 presents the percentage of eligible youth-that is, those at least 20 years of age at the time of interview who would have been eligible to vote prior to interview-who voted in the last election. Findings suggest that voting behaviour was far from universal and gender differences were apparent (see also Figure 12.2). Larger proportions of eligible young men (82\%) than women (66\%) reported that they had voted in the last election. Marital status differences were not observed among young women, but among young men, $91 \%$ of the married compared to $82 \%$ of the unmarried reported that they had voted in the last election. As shown in Figure 12.2, rural-urban differences were negligible.

Table 12.5 also reports youth perceptions about political processes, notably the extent of disillusionment with the ability of any political party to achieve change at the community level and the extent to which respondents believed that people could vote freely and without fear, pressure or influence.

The large majority of youth-64\% of young men and $73 \%$ of young women-agreed that there would be no improvement in their village/neighbourhood irrespective of the political party governing the state. The married were somewhat more likely than the unmarried to report disillusionment $(67 \%$ and $63 \%$ of young men, $77 \%$ and $71 \%$ of young women), and those in rural areas were somewhat more likely than their urban counterparts to report disillusionment ( $69 \%$ and $57 \%$ of rural and urban young men; $76 \%$ and $70 \%$, 
correspondingly, of young women). At the same time, most young people- $90 \%$ and $87 \%$ of young men and women, respectively-felt that one could vote freely and without fear or pressure; differences by marital status and rural-urban residence were negligible.

Figure 12.2: Percentage of youth aged 20 or above who voted in the last election, according to residence, Tamil Nadu, 2006
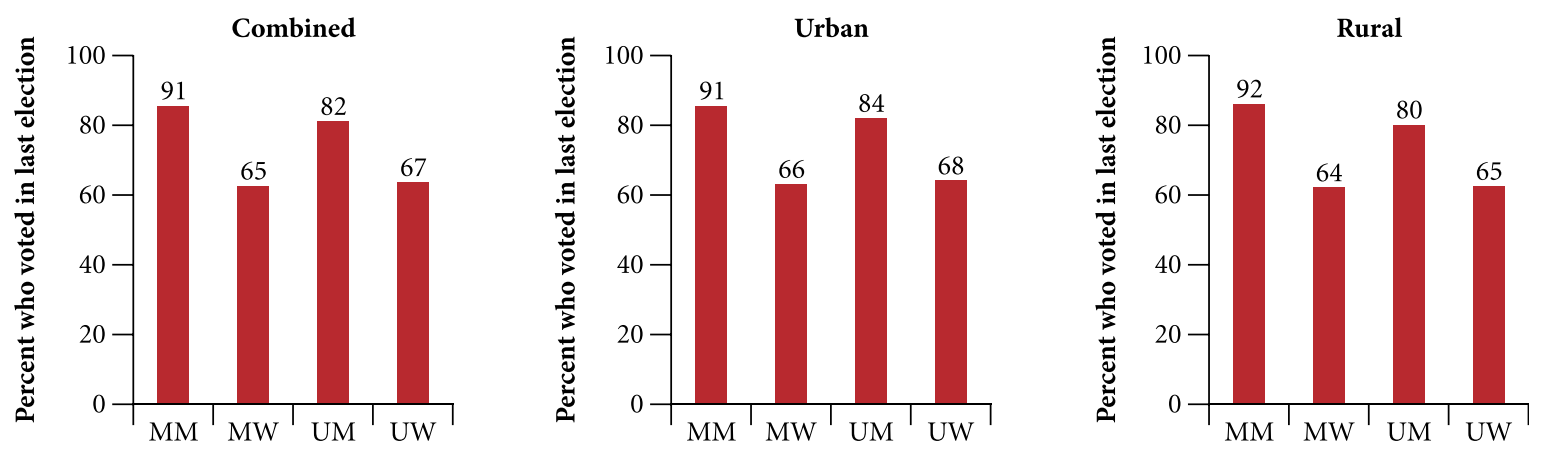

Table 12.5: Voting behaviour of eligible youth and perceptions about political matters

Percentage of youth aged 20 or above who voted in the last election and percent distribution of all youth by their perceptions about political matters, according to residence, Tamil Nadu, 2006

\begin{tabular}{|c|c|c|c|c|c|c|}
\hline Indicators (\%) & $\begin{array}{c}\mathrm{M} \\
15-24\end{array}$ & $\begin{array}{c}\text { W } \\
15-24\end{array}$ & $\begin{array}{c}\text { MM } \\
15-29\end{array}$ & $\begin{array}{c}\text { MW } \\
15-24\end{array}$ & $\begin{array}{c}\text { UM } \\
15-24\end{array}$ & $\begin{array}{c}\text { UW } \\
15-24\end{array}$ \\
\hline \multicolumn{7}{|c|}{ Combined } \\
\hline Voted in last election & 81.9 & 65.6 & 91.4 & 65.0 & 81.7 & 66.5 \\
\hline Number aged 20 or above & 1,014 & 2,734 & 1,319 & 1,686 & 770 & 1,048 \\
\hline \multicolumn{7}{|l|}{$\begin{array}{l}\text { Perceptions about political matters } \\
\text { Irrespective of the political party governing the state, there } \\
\text { would be no improvement in the village/neighbourhood }\end{array}$} \\
\hline Agree & 63.9 & 73.1 & 67.2 & 76.7 & 63.4 & 70.8 \\
\hline Disagree & 35.3 & 23.9 & 32.2 & 20.8 & 35.8 & 26.0 \\
\hline Can't say & 0.6 & 2.9 & 0.5 & 2.4 & 0.6 & 3.3 \\
\hline \multicolumn{7}{|l|}{ One can vote freely, without fear, pressure or influence } \\
\hline Disagree & 9.9 & 11.7 & 10.7 & 11.3 & 9.6 & 12.0 \\
\hline Can't say & 0.2 & 1.5 & 0.2 & 0.6 & 0.2 & 2.1 \\
\hline Number of respondents & 1,913 & 5,008 & 1,322 & 2,007 & 1,666 & 3,001 \\
\hline \multicolumn{7}{|c|}{ Urban } \\
\hline Voted in last election & 83.8 & 67.0 & 90.8 & 66.0 & 83.7 & 68.4 \\
\hline Number aged 20 or above & 477 & 1,187 & 652 & 708 & 377 & 479 \\
\hline \multicolumn{7}{|l|}{$\begin{array}{l}\text { Perceptions about political matters } \\
\text { Irrespective of the political party governing the state, there } \\
\text { would be no improvement in the village/neighbourhood }\end{array}$} \\
\hline Agree & 57.2 & 70.0 & 63.7 & 74.5 & 56.7 & 67.4 \\
\hline Disagree & 41.8 & 25.7 & 35.4 & 21.9 & 42.2 & 27.9 \\
\hline Can't say & 0.8 & 4.2 & 0.7 & 3.5 & 0.9 & 4.7 \\
\hline
\end{tabular}


Table 12.5: (Cont'd)

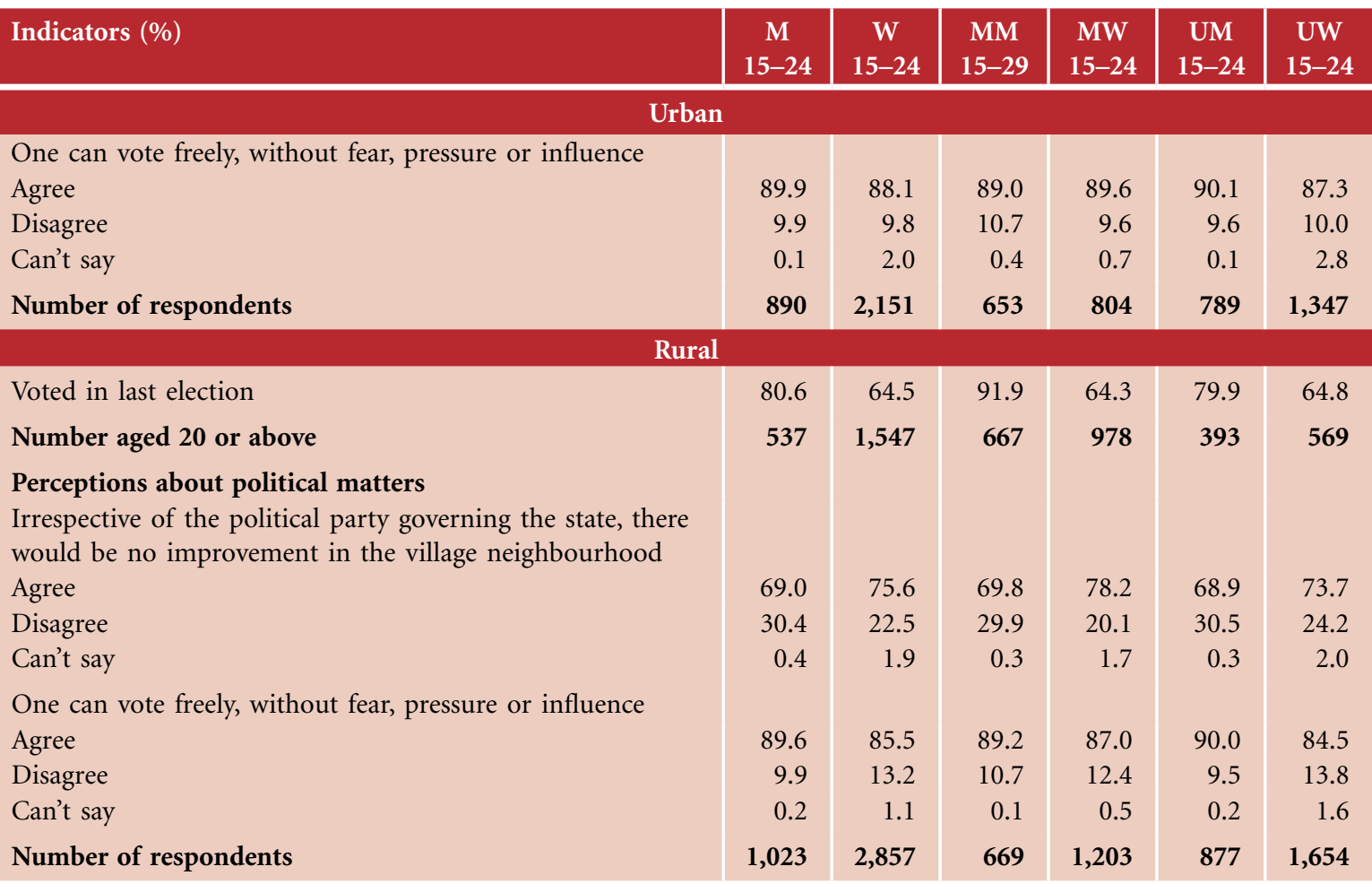

Note: All Ns are unweighted. Column totals may not equal 100\% due to missing cases.

\subsection{Expression of secular attitudes}

In order to gauge attitudes regarding social interaction with individuals of different castes and religions, the Youth Study inquired whether youth mixed freely with those of other castes and religions, whether they would eat together with a person from a different caste or religion, whether they would talk to someone who had an inter-caste marriage and whether they considered it acceptable to punish someone who showed disrespect to their religion.

Findings, presented in Table 12.6, suggest that almost all young men and women (97-98\%) mix freely with individuals of different castes and religions. Somewhat fewer reported that they would eat together with a person from a different caste or religion ( $92 \%$ of young men and $86 \%$ of young women) or talk to someone who had an inter-caste marriage ( $90 \%$ and $89 \%$, respectively). Despite this relatively secular profile, half of young men and $55 \%$ of young women felt that it was acceptable to punish someone who did not show respect to their religion.

Differences in the nature of behaviours and attitudes towards individuals of different castes and religions were narrow, for the most part, by marital status. However, unmarried young women were more likely than their married counterparts to report secular attitudes on such issues as eating together with a person from another caste or religion ( $88 \%$ and $81 \%)$ and tolerating without punishment someone who had shown disrespect to their religion ( $48 \%$ and $40 \%)$. 
Table 12.6: Expression of secular attitudes

Percent distribution of youth by reported behaviours and attitudes towards interaction with people of different castes and religions, according to residence, Tamil Nadu, 2006

\begin{tabular}{|c|c|c|c|c|c|c|}
\hline Behaviours/attitudes (\%) & $\begin{array}{c}\mathrm{M} \\
15-24\end{array}$ & $\begin{array}{c}\text { W } \\
15-24\end{array}$ & $\begin{array}{c}\text { MM } \\
15-29\end{array}$ & $\begin{array}{c}\text { MW } \\
15-24\end{array}$ & $\begin{array}{c}\text { UM } \\
15-24\end{array}$ & $\begin{array}{c}\text { UW } \\
15-24\end{array}$ \\
\hline \multicolumn{7}{|c|}{ Combined } \\
\hline \multicolumn{7}{|c|}{ Mixes freely with people of other castes } \\
\hline Yes & 97.9 & 96.5 & 98.1 & 95.7 & 98.0 & 97.0 \\
\hline No & 1.9 & 3.5 & 1.7 & 4.2 & 1.9 & 3.0 \\
\hline \multicolumn{7}{|c|}{ Mixes freely with people of other religions } \\
\hline Yes & 97.8 & 96.5 & 97.9 & 95.9 & 97.8 & 96.9 \\
\hline No & 2.2 & 3.4 & 2.0 & 4.0 & 2.2 & 3.0 \\
\hline \multicolumn{7}{|c|}{ Would eat together with a person of another caste/religion } \\
\hline Yes & 91.8 & 85.5 & 90.0 & 81.1 & 91.7 & 88.4 \\
\hline No & 8.2 & 14.5 & 9.8 & 18.9 & 8.2 & 11.5 \\
\hline \multicolumn{7}{|c|}{ Would talk to a person who has had an inter-caste marriage } \\
\hline Yes & 89.9 & 89.4 & 90.6 & 88.5 & 89.6 & 89.9 \\
\hline No & 9.9 & 10.4 & 9.3 & 11.4 & 10.1 & 9.7 \\
\hline \multicolumn{7}{|c|}{$\begin{array}{l}\text { Believes it is acceptable to punish someone who shows } \\
\text { disrespect to respondent's religion }\end{array}$} \\
\hline Yes & 50.1 & 54.5 & 52.8 & 59.0 & 50.3 & 51.5 \\
\hline No & 49.2 & 44.7 & 47.0 & 40.4 & 48.9 & 47.6 \\
\hline Number of respondents & 1,913 & 5,008 & 1,322 & 2,007 & 1,666 & 3,001 \\
\hline \multicolumn{7}{|c|}{ Urban } \\
\hline \multicolumn{7}{|c|}{ Mixes freely with people of other castes } \\
\hline Yes & 98.7 & 97.5 & 98.9 & 96.8 & 98.7 & 97.9 \\
\hline No & 1.1 & 2.4 & 0.9 & 3.2 & 1.1 & 2.0 \\
\hline \multicolumn{7}{|c|}{ Mixes freely with people of other religions } \\
\hline Yes & 98.7 & 97.5 & 98.9 & 96.3 & 98.7 & 98.2 \\
\hline No & 1.3 & 2.4 & 0.9 & 3.6 & 1.3 & 1.7 \\
\hline \multicolumn{7}{|c|}{ Would eat together with a person of another caste/religion } \\
\hline Yes & 95.1 & 88.5 & 93.4 & 83.3 & 95.2 & 91.5 \\
\hline No & 4.9 & 11.4 & 6.4 & 16.7 & 4.8 & 8.3 \\
\hline \multicolumn{7}{|c|}{ Would talk to a person who had an inter-caste marriage } \\
\hline Yes & 91.9 & 90.8 & 92.1 & 90.5 & 91.8 & 91.1 \\
\hline No & 7.8 & 8.9 & 7.7 & 9.5 & 7.9 & 8.5 \\
\hline \multicolumn{7}{|c|}{$\begin{array}{l}\text { Believes it is acceptable to punish someone who shows } \\
\text { disrespect to respondent's religion }\end{array}$} \\
\hline Yes & 46.8 & 51.4 & 51.6 & 56.2 & 47.1 & 48.7 \\
\hline No & 52.3 & 47.8 & 48.1 & 43.0 & 51.9 & 50.6 \\
\hline Number of respondents & 890 & 2,151 & 653 & 804 & 789 & 1,347 \\
\hline
\end{tabular}

Cont'd on next page... 
Table 12.6: (Cont'd)

\begin{tabular}{|c|c|c|c|c|c|c|}
\hline Behaviours/attitudes (\%) & $\begin{array}{c}\mathrm{M} \\
15-24\end{array}$ & $\begin{array}{c}\text { W } \\
15-24\end{array}$ & $\begin{array}{c}\text { MM } \\
15-29\end{array}$ & $\begin{array}{c}\text { MW } \\
\text { 15-24 }\end{array}$ & $\begin{array}{c}\text { UM } \\
15-24\end{array}$ & $\begin{array}{c}\text { UW } \\
15-24\end{array}$ \\
\hline \multicolumn{7}{|c|}{ Rural } \\
\hline \multicolumn{7}{|c|}{ Mixes freely with people of other castes } \\
\hline Yes & 97.3 & 95.7 & 97.6 & 95.1 & 97.4 & 96.1 \\
\hline No & 2.6 & 4.3 & 2.3 & 4.8 & 2.5 & 3.8 \\
\hline \multicolumn{7}{|c|}{ Mixes freely with people of other religions } \\
\hline Yes & 97.1 & 95.7 & 97.2 & 95.6 & 97.1 & 95.8 \\
\hline No & 2.9 & 4.2 & 2.7 & 4.3 & 2.8 & 4.1 \\
\hline \multicolumn{7}{|c|}{ Would eat together with a person of another caste/religion } \\
\hline Yes & 89.2 & 83.1 & 87.7 & 79.5 & 88.9 & 85.7 \\
\hline No & 10.7 & 16.9 & 12.2 & 20.5 & 11.0 & 14.3 \\
\hline \multicolumn{7}{|c|}{ Would talk to a person who had an inter-caste marriage } \\
\hline Yes & 88.3 & 88.2 & 89.5 & 87.2 & 87.8 & 88.9 \\
\hline No & 11.5 & 11.5 & 10.4 & 12.7 & 12.0 & 10.7 \\
\hline \multicolumn{7}{|c|}{$\begin{array}{l}\text { Believes it is acceptable to punish someone who shows } \\
\text { disrespect to respondent's religion }\end{array}$} \\
\hline Yes & 52.6 & 56.9 & 53.8 & 60.9 & 52.8 & 53.9 \\
\hline No & 46.9 & 42.3 & 46.1 & 38.6 & 46.5 & 45.0 \\
\hline Number of respondents & 1,023 & 2,857 & 669 & 1,203 & 877 & 1,654 \\
\hline
\end{tabular}

Note: All Ns are unweighted. Column totals may not equal 100\% due to missing cases or "don't know" responses.

In contrast, differences by rural-urban residence were evident, with rural residents expressing more conservative attitudes than urban residents on several issues. For example, with regard to eating with people of other castes or religions, secular attitudes were expressed by $95 \%$ and $89 \%$ of young men and women from urban areas compared to $89 \%$ and $83 \%$, respectively, of those from rural areas. Likewise, rural youth were less likely than their urban counterparts to tolerate without punishment someone who had shown disrespect to their religion (42-47\% versus $48-52 \%)$.

\subsection{Physical fights in the village or urban neighbourhood}

All respondents were asked whether physical fights—-more specifically, youth beating, slapping or pulling the hair of others-were common among young men and women, respectively, in their village or neighbourhood. Findings, presented in Table 12.7, suggest that physical fights were reported to be more common among young men than women. Three-fourths of young men $(77 \%)$ and $60 \%$ of young women reported that young men engaged in physical fights sometimes or often. Fewer youth- $57 \%$ of young men and $47 \%$ of young women-reported that young women engaged in physical fights sometimes or often.

Occasional or frequent physical fighting among young men was more likely to be reported by married than unmarried youth ( $81 \%$ and $76 \%$ of young men, respectively; $64 \%$ and $58 \%$ of young women, respectively), and by those in rural areas compared to those in urban areas $(80 \%$ and $73 \%$ of young men, respectively; $68 \%$ and $51 \%$ of young women, respectively). Young men's perceptions about physical fights among young women did not vary by marital status (56-58\%) or rural-urban residence $(56-57 \%)$. 
Table 12.7: Physical fights in village/neighbourhood

Percentage of youth reporting perceptions of youth involvement in physical fights in their village/ neighbourhood and percentage of youth themselves involved in physical fights in the last 12 months, according to residence, Tamil Nadu, 2006

\begin{tabular}{|c|c|c|c|c|c|c|}
\hline Perceptions/experiences of physical fights (\%) & $\underset{15-24}{M}$ & $\begin{array}{c}W \\
15-24\end{array}$ & $\begin{array}{c}\text { MM } \\
15-29\end{array}$ & $\begin{array}{l}\text { MW } \\
15-24\end{array}$ & $\begin{array}{c}\text { UM } \\
15-24\end{array}$ & $\begin{array}{l}\text { UW } \\
15-24\end{array}$ \\
\hline \multicolumn{7}{|c|}{ Combined } \\
\hline $\begin{array}{l}\text { Respondents' perceptions of the extent to which: } \\
\text { Young men in the area engaged in physical fights }\end{array}$ & & & & & & \\
\hline Never & 23.3 & 40.0 & 19.0 & 36.1 & 24.1 & 42.5 \\
\hline Sometimes & 75.8 & 57.7 & 80.0 & 60.8 & 75.1 & 55.6 \\
\hline Often & 0.9 & 2.3 & 0.9 & 3.1 & 0.8 & 1.9 \\
\hline \multicolumn{7}{|l|}{ Young women in the area engaged in physical fights } \\
\hline Never & 43.3 & 53.3 & 42.2 & 48.8 & 44.1 & 56.3 \\
\hline Sometimes & 56.0 & 44.6 & 56.9 & 49.1 & 55.3 & 41.7 \\
\hline Often & 0.7 & 2.0 & 0.9 & 2.1 & 0.6 & 1.9 \\
\hline $\begin{array}{l}\text { Respondents themselves involved in physical fights in } \\
\text { last } 12 \text { months }\end{array}$ & 9.7 & 2.8 & 9.2 & 3.2 & 9.3 & 2.5 \\
\hline Number of respondents & 1,913 & 5,008 & 1,322 & 2,007 & 1,666 & 3,001 \\
\hline \multicolumn{7}{|c|}{ Urban } \\
\hline $\begin{array}{l}\text { Respondents' perception of the extent to which: } \\
\text { Young men in the area engaged in physical fights }\end{array}$ & & & & & & \\
\hline Never & 27.2 & 49.5 & 22.5 & 45.3 & 27.8 & 52.0 \\
\hline Sometimes & 71.7 & 49.1 & 76.1 & 52.8 & 71.1 & 46.8 \\
\hline Often & 1.1 & 1.4 & 1.3 & 1.9 & 1.1 & 1.1 \\
\hline \multicolumn{7}{|l|}{ Young women in the area engaged in physical fights } \\
\hline Never & 44.2 & 63.0 & 43.8 & 59.0 & 44.8 & 65.4 \\
\hline Sometimes & 55.2 & 35.6 & 54.7 & 39.7 & 54.8 & 33.2 \\
\hline Often & 0.6 & 1.3 & 1.5 & 1.4 & 0.4 & 1.3 \\
\hline $\begin{array}{l}\text { Respondents themselves involved in physical fights in } \\
\text { last } 12 \text { months }\end{array}$ & 8.8 & 1.6 & 9.6 & 1.2 & 8.3 & 1.8 \\
\hline Number of respondents & 890 & 2,151 & 653 & 804 & 789 & 1,347 \\
\hline \multicolumn{7}{|c|}{ Rural } \\
\hline $\begin{array}{l}\text { Respondents' perception of the extent to which: } \\
\text { Young men in the area engaged in physical fights }\end{array}$ & & & & & & \\
\hline Never & 20.3 & 32.4 & 16.7 & 29.9 & 21.0 & 34.1 \\
\hline Sometimes & 78.8 & 64.5 & 82.7 & 66.2 & 78.3 & 63.3 \\
\hline Often & 0.8 & 3.1 & 0.6 & 3.9 & 0.7 & 2.5 \\
\hline Young women in the area engaged in physical fights & & & & & & \\
\hline Never & 42.6 & 45.6 & 41.1 & 42.0 & 43.4 & 48.3 \\
\hline Sometimes & 56.6 & 51.8 & 58.5 & 55.4 & 55.9 & 49.2 \\
\hline Often & 0.7 & 2.5 & 0.4 & 2.6 & 0.8 & 2.4 \\
\hline $\begin{array}{l}\text { Respondents themselves involved in physical fights in } \\
\text { last } 12 \text { months }\end{array}$ & 10.3 & 3.8 & 8.9 & 4.6 & 10.1 & 3.2 \\
\hline Number of respondents & 1,023 & 2,857 & 669 & 1,203 & 877 & 1,654 \\
\hline
\end{tabular}

Note: All Ns are unweighted. Column totals may not equal 100\% due to missing cases or "don't know" responses. 
Young women's reports, in contrast, revealed wider differences by marital status and rural-urban residence. For example, married young women were more likely than the unmarried to perceive that young women in their area engaged in physical fights (51\% versus $44 \%$ ). Likewise, rural young women were more likely than those living in urban areas to perceive that young women in their area engaged in physical fights (54\% versus and $37 \%)$.

Youth were also asked a direct question about their own involvement in physical fights with anyone within the village or urban neighbourhood in the 12 months preceding the interview. The question did not elaborate further and hence we acknowledge that responses may include fights among family members and others. Ten percent of young men and 3\% of young women reported that they had been involved in physical fights. Differences by marital status and rural-urban residence were negligible.

\subsection{Perceptions of the leading problems facing youth}

Youth were asked to give their opinion on the most important problem facing youth in their village or neighbourhood. Table 12.8 clearly shows that the majority of young men and women, irrespective of marital status or rural-urban residence, reported difficulty in finding employment as the single most pressing problem ( $69 \%$ and $49 \%$, respectively), followed by concerns about poverty (10\% and $14 \%$, respectively). Additionally, significant minorities of young men cited, as leading problems, lack of educational opportunities (7\%) and lack of career counselling or vocational training opportunities (5\%). In contrast, other leading problems expressed by young women included lack of amenities and infrastructure, for example, water, toilets, roads and electricity (9\%), and lack of opportunities for education (5\%). Notably, some $9 \%$ of young women (and just $1 \%$ of young men) did not identify a leading problem. Differences by marital status and rural-urban residence were negligible, except that somewhat larger proportions of young women in rural areas than in urban areas reported unemployment or finding a job as a leading problem ( $52 \%$ and $45 \%$, respectively).

Table 12.8: Perceptions about the leading problem facing youth

Percent distribution of youth by their perceptions of the leading problem facing youth, according to residence, Tamil Nadu, 2006

\begin{tabular}{|c|c|c|c|c|c|c|}
\hline Leading problem $(\%)$ & $\begin{array}{c}M \\
15-24\end{array}$ & $\begin{array}{c}\mathrm{W} \\
15-24\end{array}$ & $\begin{array}{c}\text { MM } \\
15-29\end{array}$ & $\begin{array}{c}\text { MW } \\
15-24\end{array}$ & $\begin{array}{c}\text { UM } \\
15-24\end{array}$ & $\begin{array}{c}\text { UW } \\
\text { 15-24 }\end{array}$ \\
\hline \multicolumn{7}{|c|}{ Combined } \\
\hline Finding a job/unemployment & 69.2 & 49.2 & 71.5 & 50.1 & 69.2 & 48.5 \\
\hline Poverty & 10.1 & 14.1 & 10.7 & 13.6 & 10.1 & 14.4 \\
\hline $\begin{array}{l}\text { Lack of amenities/infrastructure (water/toilets/ } \\
\text { roads/electricity) }\end{array}$ & 2.8 & 9.2 & 4.7 & 10.1 & 2.2 & 8.7 \\
\hline Health-/health service-related concerns & 0.8 & 2.6 & 1.1 & 2.5 & 0.8 & 2.8 \\
\hline Security of girls/law and order & 0.9 & 2.9 & 1.0 & 2.0 & 0.8 & 3.4 \\
\hline Finding a good spouse/dowry & 0.3 & 2.0 & 0.4 & 2.8 & 0.2 & 1.4 \\
\hline Lack of educational opportunities & 6.5 & 4.5 & 4.2 & 3.5 & 6.7 & 5.2 \\
\hline Lack of career counselling/vocational training & 4.6 & 2.8 & 3.6 & 1.5 & 4.7 & 3.7 \\
\hline Alcohol/drug abuse & 1.5 & 2.3 & 1.1 & 2.9 & 1.6 & 2.0 \\
\hline Lack of sex education & 0.1 & 0.2 & 0.0 & 0.1 & 0.1 & 0.3 \\
\hline Other $^{1}$ & 2.4 & 1.4 & 1.4 & 1.0 & 2.6 & 1.7 \\
\hline Don't know/can't say & 0.9 & 8.8 & 0.3 & 9.9 & 1.0 & 8.1 \\
\hline Number of respondents & 1,913 & 5,008 & 1,322 & 2,007 & 1,666 & 3,001 \\
\hline
\end{tabular}

Cont'd on next page... 
Table 12.8: (Cont'd)

\begin{tabular}{|c|c|c|c|c|c|c|}
\hline Leading problem (\%) & $\begin{array}{c}M \\
15-24\end{array}$ & $\begin{array}{c}\text { W } \\
15-24\end{array}$ & $\begin{array}{c}\text { MM } \\
15-29\end{array}$ & $\begin{array}{c}\text { MW } \\
15-24\end{array}$ & $\begin{array}{c}\text { UM } \\
15-24\end{array}$ & $\begin{array}{c}\text { UW } \\
15-24\end{array}$ \\
\hline \multicolumn{7}{|c|}{ Urban } \\
\hline Finding a job/unemployment & 67.3 & 45.4 & 68.5 & 45.7 & 67.2 & 45.3 \\
\hline Poverty & 11.4 & 12.6 & 12.5 & 15.2 & 11.6 & 11.2 \\
\hline $\begin{array}{l}\text { Lack of amenities/infrastructure (water/toilets/ } \\
\text { roads/electricity) }\end{array}$ & 1.4 & 8.1 & 3.5 & 9.0 & 1.2 & 7.6 \\
\hline Health-/health service-related concerns & 1.3 & 3.7 & 2.4 & 3.1 & 1.2 & 4.1 \\
\hline Security of girls/law and order & 1.1 & 5.0 & 0.9 & 3.7 & 0.7 & 5.7 \\
\hline Finding a good spouse/dowry & 0.1 & 1.3 & 0.2 & 1.6 & 0.1 & 1.0 \\
\hline Lack of educational opportunities & 4.9 & 4.8 & 3.5 & 3.1 & 5.1 & 5.7 \\
\hline Lack of career counselling/vocational training & 5.2 & 3.9 & 4.2 & 1.9 & 5.2 & 5.1 \\
\hline Alcohol/drug abuse & 2.4 & 2.5 & 1.8 & 3.3 & 2.5 & 2.0 \\
\hline Lack of sex education & 0.0 & 0.3 & 0.0 & 0.2 & 0.0 & 0.2 \\
\hline Other ${ }^{1}$ & 3.0 & 1.9 & 1.7 & 1.5 & 3.2 & 2.1 \\
\hline Don't know/can't say & 1.8 & 10.6 & 0.7 & 11.6 & 1.9 & 10.0 \\
\hline Number of respondents & 890 & 2,151 & 653 & 804 & 789 & 1,347 \\
\hline \multicolumn{7}{|c|}{ Rural } \\
\hline Finding a job/unemployment & 70.6 & 52.1 & 73.8 & 53.0 & 70.9 & 51.4 \\
\hline Poverty & 9.1 & 15.2 & 9.5 & 12.4 & 8.8 & 17.2 \\
\hline $\begin{array}{l}\text { Lack of amenities/infrastructure (water/toilets/ } \\
\text { roads/electricity) }\end{array}$ & 3.8 & 10.1 & 5.5 & 10.8 & 3.1 & 9.6 \\
\hline Health-/health service-related concerns & 0.5 & 1.8 & 0.1 & 2.1 & 0.5 & 1.6 \\
\hline Security of girls/law and order & 0.8 & 1.2 & 1.0 & 0.9 & 0.9 & 1.4 \\
\hline Finding a good spouse/dowry & 0.4 & 2.5 & 0.5 & 3.6 & 0.2 & 1.7 \\
\hline Lack of educational opportunities & 7.6 & 4.3 & 4.6 & 3.8 & 8.1 & 4.8 \\
\hline Lack of career counselling/vocational training & 4.2 & 2.0 & 3.2 & 1.3 & 4.4 & 2.4 \\
\hline Alcohol/drug abuse & 0.7 & 2.3 & 0.6 & 2.7 & 0.8 & 1.9 \\
\hline Lack of sex education & 0.1 & 0.1 & 0.0 & 0.0 & 0.1 & 0.3 \\
\hline Other $^{1}$ & 1.9 & 1.0 & 1.0 & 0.7 & 2.1 & 1.3 \\
\hline Don't know/can't say & 0.2 & 7.4 & 0.0 & 8.7 & 0.2 & 6.5 \\
\hline Number of respondents & 1,023 & 2,857 & 669 & 1,203 & 877 & 1,654 \\
\hline
\end{tabular}

Note: All Ns are unweighted. Column totals may not equal 100\% due to missing cases. ${ }^{1}$ Includes lack of recreational/sports facilities, lack of political participation, gambling, corruption, child marriage, lack of loan services, limited freedom for girls, social conflicts, generation gap, parents not allowing love marriage, caste differences, etc.

\subsection{Summary}

Although a number of programmes are held to build youth skills, relatively few youth (one-fifth of young men and two-fifths of young women) reported familiarity with either government-or NGO-sponsored programmes organised at the community level in which youth could participate. Far fewer youth-14\% of young men and $9 \%$ of young women-reported participating in any such programme. Many more young men $(52 \%)$ and somewhat more young women $(13 \%)$ reported that they had participated in community-led activities such as cleanliness drives and celebration of festivals and national days. Finally, $12 \%$ of young men compared to $16 \%$ of young women reported membership in organised groups.

Findings suggest that voting behaviour was far from universal. Among those eligible to vote, $82 \%$ of young men and $66 \%$ of young women had cast their vote in the most recent election. While $91 \%$ of married 
young men had cast their vote, $82 \%$ of unmarried young men compared to two-thirds of young women, irrespective of marital status, had voted. Also of note is that while most youth perceived that elections were fair and permitted one to vote without fear, the large majority (64-73\%) reported disillusionment with the commitment of political parties to work for change at the community level.

By and large, youth reported secular attitudes; $97 \%$ or more reported that they mixed freely with individuals of different religions and castes. However, just half of young men and somewhat fewer young women agreed that it was best to tolerate rather than punish someone who showed disrespect to their religion. Findings typically suggest that rural youth were more likely than others to report conservative views. Similarly, among young women, the married were more likely than the unmarried to report so.

Considerable proportions of young men and women acknowledged that physical fights among young men and also among young women did occur in their village or neighbourhood. Yet, just $10 \%$ of young men and $3 \%$ of young women reported that they had been involved in a physical fight in the year preceding the interview.

Young people's perceptions of the leading problems facing youth were remarkably similar among young men and women. Both were most likely to report difficulty in finding employment as the most important problem facing youth in the state-expressed by about two-thirds of young men and about half of young women. The second problem reported by significant minorities of young men and women was poverty more generally. Leading problems expressed by smaller numbers of young men and women included lack of educational opportunities, lack of amenities or infrastructure and lack of opportunities for career counselling and vocational training. 
Findings of the Youth Study presented in earlier chapters highlight the situation of young men and women in Tamil Nadu. They underscore the fact that youth are a heterogeneous group with correspondingly diverse needs, and identify numerous challenges youth face in making the transition to adulthood. Findings suggest several key programme areas for action as well as directions for future research, which are highlighted in this chapter.

\subsection{Recommendations for programmes}

Findings suggest a number of key programme areas for intervention at the youth, family and service delivery levels.

Address obstacles to universal secondary school completion

Although young people in Tamil Nadu are spending much of their adolescence pursuing their education, concerted efforts are needed if the state is to meet its goal of achieving universal access to secondary education by the year 2015. Youth Study findings suggesting notable declines in school completion following Class 8 call for efforts to address barriers to secondary school completion. A number of factors have been identified in the Youth Study that inhibit secondary school completion; leading among these were economic reasons; attitudes and perceptions; and school-related reasons. Multiple activities are needed to address these barriers. Efforts must be made, for example, to address the economic pressures that may lead parents to withdraw their children from school in favour of work. While a number of state government programmes are ongoing that aim to reduce the cost of education, additional inputs, by way of conditional grants that encourage school completion among disadvantaged groups, also need to be considered. Moreover, there is a need to ensure that ongoing government programmes do indeed reach the most disadvantaged groups. At the same time, activities are needed that sensitise parents about the importance of a secondary school education in expanding their children's livelihood opportunities.

Activities must also address school-level barriers, notably, poor infrastructure, quality of education and academic failure. There is a need to incorporate livelihoods skills building models within the school setting that will not only raise young people's aspirations regarding their education and careers but also provide them opportunities to gain market-driven job skills. Moreover, investments in improving the quality of the schooling experience are needed that focus on providing better training and ensuring the accountability of teachers.

While the stark gender divide in educational attainment levels seen elsewhere in the country is not observed in Tamil Nadu, findings suggest that married young men and women remain considerably disadvantaged. Interventions are needed that give the married a second chance to continue their education. Likewise, 
evidence that rural youth were more disadvantaged with regard to educational opportunities than their urban counterparts calls for efforts to provide those out of school an opportunity to complete their schooling.

Enable opportunities for youth employment

Findings of the Youth Study that between one in five young men and one in six young women had initiated work in childhood reiterate the recommendation highlighted above regarding the need to provide conditional grants and targeted subsidies to disadvantaged groups, which would encourage parents to opt for schooling over work for their children.

The finding that unemployment rates were particularly high among the educated suggests a possible disconnect between youth skills and market needs. Indeed, few youth were aware of employment generation programmes and even fewer had availed of these or vocational skills training. It is notable that while considerable proportions of urban youth reported exposure to computer skills, English language skills and so on, rural youth tended to opt for relatively traditional vocational skills and may not have had the opportunity to learn about market needs or develop appropriate skills for which a demand exists. Formal mechanisms need to be developed that enable youth-particularly rural youth — to acquire skills for which there is an established market demand, and that link eligible youth to market opportunities.

Build upon youth's growing access to the internet

Findings suggesting that one-quarter of young men and one in seven young women with five or more years of education-and considerably more in urban areas—-had accessed the internet highlight the role that this medium can play in building youth awareness of the world around them and opportunities available to them. The development of youth-friendly websites in Tamil may be a useful way to convey such information to youth.

Promote youth agency and gender equitable norms among youth

Findings highlight that substantial proportions of young men and the majority of young women do not exercise agency in their everyday lives. Almost half of young men and over three-quarters of young women lacked decision-making authority even on such matters as choosing friends, purchasing clothes and spending money. Young women, in addition, lacked freedom of movement and opportunities to build peer networks. These findings call for attention to promote life skills education programmes for youth, especially young women, both unmarried and married, that will enable them to have an informed say in their own lives. Safe spaces should be identified in which young women can build social networks and find support among peers.

Inegalitarian gender role attitudes were expressed by many, notably young men but including young women. Moreover, as many as half of all young men and women justified wife-beating in at least one situation. Egalitarian attitudes must be promoted among young men and women, and programmes should be tailored to meet each group's situation and needs. These programmes should promote new concepts of masculinity and femininity among youth and at the same time, promote messages that build egalitarian relations between women and men.

An increasing number of intervention models to build agency and promote egalitarian gender role attitudes among young people have been tested in India. These models should be reviewed and replicated or scaled up as appropriate. 
Provide opportunities for formal saving, especially for young women

Findings suggest that while young women were more likely than young men to report savings, they were less likely to own a savings account or to operate the account independently. At the same time, few youth owned a bank or post office account; just 13\% of young men and $9 \%$ of young women. Programmes are needed that inculcate a savings orientation among young people, that offer savings products that are attractive and appropriate to the small and erratic savings patterns of young people and that enable young women in particular to overcome obstacles related to owning and controlling savings products.

Promote youth participation in civil society and political processes and reinforce secular attitudes

Findings have noted that large proportions of youth have exercised their right to vote, that the majority hold secular attitudes with regard to mixing with a person from another caste and religion, and few engage in community-level violence. Nevertheless, not all youth expressed secular attitudes; half of young men and somewhat more young women reported that they would endorse violence against someone who showed disrespect to their religion. Relatively few, moreover, had participated in civil society, that is, government- or NGO-sponsored programmes or community-led activities. Programmes are needed-at the school, college and community levels, through national service programmes, sports and other non-formal mechanisms-that encourage civic participation, incorporate value building components and reinforce secular attitudes and values that espouse responsible citizenship.

Provide family life or sex education for those in school and out of school

Youth Study findings provide considerable evidence suggesting that family life or sex education is urgently needed among youth, both those in school and those who have discontinued their education. Findings demonstrate a limited understanding of sexual and reproductive matters among young people, including the married. Misconceptions abound on most topics: sex and pregnancy, contraceptive methods including condoms, STIs and HIV/AIDS, and the conditions under which abortion is legally available or restricted. Where awareness exists, it is typically superficial.

Youth themselves have called for family life or sex education. Findings highlight that large proportions recognised the need for information and education on these issues, and indicated a preference for receiving this education from teachers, health care providers or other experts, and in the case of young women, parents. However, few young people had been exposed to family life or sex education, notwithstanding the School AIDS Education Programme, the Red Ribbon Clubs and the special programme for out-of-school youth. Indeed, substantial proportions of married young women (and some young men) reported entering marriage unaware of what marriage entailed. At the same time, several young people had engaged in sexual risk taking.

As mentioned above, a number of state government programmes are ongoing that aim to impart sexual and reproductive health information to young people. What is needed is a strong commitment to ensuring that these programmes do indeed reach young people, including those in school and out-of-school, married and unmarried, and rural and urban. Moreover, there is a need to expand the content of existing awareness raising programmes to include not just HIV-related information but broader sexual and reproductive topics. These programmes should be designed not only to raise awareness among youth but also to enable young people to correctly understand and assess the risks they face and to adopt appropriate protective actions.

In addition, special attention needs to be paid to the training of trainers. It is important that teachers, health care providers and other experts undergo training that enables them to overcome their reluctance to 
communicate with youth on sensitive sexual and reproductive matters, dispels their misconceptions on these matters and enhances their technical knowledge of these issues.

Ensure that the transition to sexual life is safe and wanted

While for the vast majority of young women sexual activity is initiated within the context of marriage, findings show that small proportions of young men and women had engaged in sex before marriage. As documented in this report, many youth had initiated sexual activities uninformed, reiterating the need to provide family life or sex education to young people. Moreover, the finding that for many youth, premarital sexual experiences were unsafe or unwanted calls for programmes that focus on building sexual and reproductive health awareness among young people, and developing their skills in negotiating safe sex and communicating with their partners on sexual and reproductive health matters. At the same time, programmes must make available appropriate family planning and infection prevention services for both married and unmarried young men and women in a manner acceptable to them.

\section{Address power imbalances within marriage}

Findings confirm that early marriage is relatively rare in Tamil Nadu, and that the majority of youth do play a role in decisions relating to their own marriage and have some pre-marital acquaintance with their spouse. Within marriage, large proportions reported communication and interaction with their spouse; nevertheless, communication on sensitive matters such as contraception was limited for many. Indeed, married life was marked by considerable power imbalances; for example, notable proportions of young women had suffered physical and sexual violence perpetrated by their husband.

Efforts are needed to encourage couple communication on sensitive issues (contraception, for example), negotiation and conflict management skills early in marriage. Efforts are also needed to inform married young women of their rights so that they have the opportunity to exercise control over their own lives; at the same time, efforts must be made to promote new concepts of masculinity and femininity and egalitarian couple relations among young men and women. Intervention models exist in India that have attempted to address these needs; these should be reviewed and up-scaled as appropriate.

\section{Create a supportive family environment}

Findings highlight the limited interaction and social distance between parents and young people while growing up, and the gendered nature of perceptions regarding parental controls on youth behaviours. Efforts must be made to create a supportive environment for young people. While evidence on models that are effective in bridging the distance between parents and children or enabling parents to adopt more gender-egalitarian socialisation practices is not currently available, findings presented in this report call for programmes that address parental inhibitions about discussing sexual matters with their children, encourage greater openness and interaction between parents and children, and enable the adoption of gender-egalitarian child-rearing practices.

Reorient service provision to address the unique needs of unmarried and married young women and men

Although the RCH Programme has advocated special services for youth, including the unmarried, these services had not reached youth in our survey. For example, relatively small percentages of young people had ever practised contraception and the method most likely to be adopted was sterilisation. Few had sought 
care for symptoms of STI or gynaecological problems, and most youth who had sought care for the latter preferred private to public sector facilities. Lack of care seeking and the disconnect between the public health sector and youth underscores the need to sensitise health care providers about the special needs, heterogeneity and vulnerability of unmarried and married young women and men, and to orient them to the need for developing appropriate strategies to reach these diverse groups, including young newly-weds.

Programmes must be inclusive of unmarried as well as married young people, and recognise their need and right to sexual and reproductive health and related information and services. Counselling and contraceptive services must be made available to all young people, including the unmarried, in a non-threatening, nonjudgmental and confidential environment. Indeed, these findings call for the implementation of strategies outlined under the National Rural Health Mission's RCH Programme.

At the same time, mental health issues need to be addressed. While relatively few young men and women reported symptoms suggestive of mental health disorders, these symptoms were somewhat more apparent among the married than the unmarried. Efforts are needed to screen young people-particularly the married-for mental health disorders when they avail of other primary health services, including, for example, sexual and reproductive health services, and to refer youth with such symptoms to appropriate health facilities and providers.

\subsection{Directions for future research}

Findings presented in this report provide a broad picture of youth in Tamil Nadu. At the same time, however, they have raised a number of issues that require further investigation, particularly with regard to the determinants and consequences of youth behaviours and practices during their transition to adulthood. While the Youth Study is indeed a rich source of data that will enable investigators to fill many of the information gaps identified, there are several gaps in knowledge that will require additional research efforts.

A general research recommendation is the urgent need for prospective or panel study designs that follow a cohort of adolescents at regular intervals up to age 24 . Thus far, research has relied on cross-sectional data. While these data are valuable in describing the levels and trends in key markers of transitions to adulthood, they rarely capture the ways in which the situation and experiences of youth influence their life course at later ages. Moreover, drawing causal inferences from cross-sectional surveys has several limitations.

\section{Barriers to secondary school completion}

While evidence presented in this report sheds light on the reasons for school discontinuation prior to completing secondary education, further research is needed that profiles youth at risk of discontinuation, that defines underlying obstacles to school continuation and identifies strategies to mitigate these barriers. Operations research is required that evaluates the reach, effectiveness and feasibility of existing programmes, including those implemented by the Tamil Nadu government, intended to address barriers to school continuation. Moreover, as suggested in the section on recommendations for programmes, a variety of interventions need to be implemented that address school quality issues, enhance parental involvement in children's education, provide the out-of-school, and especially the married, a second chance to continue their education, provide conditional grants to disadvantaged groups and impart livelihoods skills to young people in school; operations research is required to be in-built in these programmes to assess their effectiveness and reach. 


\section{Transitions to work}

Several questions related to transitions to work remain unanswered. For example, the finding that unemployment rates were particularly high among the educated calls for further research to better understand the difficulties experienced by educated youth in finding suitable employment opportunities. Further research is also needed that explores the links between education attained or vocational training acquired and work patterns. With regard to vocational skills building, research is needed that explores the factors underlying the finding that few young people received vocational skills training even though large proportions were in favour of receiving such training, and that despite the availability of a range of vocational skills training opportunities, many young women continued to opt for training in traditional skills. Equally important is the need for operations research that will test models intended to enable youth to acquire skills for which there is an established demand and link eligible youth to market opportunities.

Socialisation experiences, interaction with parents

Youth Study findings are mixed with respect to socialisation experiences and interaction with parents. For example, considerable proportions of young people reported that their parents did not discriminate between sons and daughters in terms of freedom of movement and expectations regarding housework. At the same time, findings suggest that parents were far more controlling of the behaviours of their daughters than of their sons, and that far more young women than young men were not allowed to visit locations within or outside their village or neighbourhood unescorted. Qualitative studies would help shed light on these socialisation experiences, and this observed disconnect.

Findings also suggest that parent-child interaction was limited on sensitive sexual and reproductive matters. Little is known, however, about the ways in which limited interaction may influence young people's lives, for example, their sexual behaviours or their ability to exercise informed choice in their lives. Similarly, there is a dearth of research on parents' perspectives on the socialisation of sons and daughters, the ways in which parents communicate sensitive matters to their adolescent children, and the factors inhibiting parents from adopting gender-egalitarian socialisation practices and communicating with their adolescent children on sexual and reproductive matters. As mentioned earlier, there is a need to design and test interventions intended to involve parents more meaningfully in young people's transitions to adulthood in terms of educational attainment, work, marriage and entry into sexual relations.

Findings also suggest that large proportions of youth had witnessed or observed family violence. Research is needed that assesses whether and how these experiences of violence within the family while growing up affects young people's transitions to adulthood.

\section{Sexual risk behaviours}

Research is needed that explores the correlates of behaviours that undermine healthy development among young people, for example, sexual risk behaviours, substance use and the linkages between them. At the same time, it would be useful to identify the characteristics of youth who make the transition to adulthood in a safe and healthy way, for example, practise consistent condom use and seek appropriate care.

The Youth Study has raised serious methodological concerns that need to be addressed. For example, despite the fact that the Youth Study did employ such methods as gradual sequencing of questions to include progressively more sensitive questions (with regard to romantic and sexual relationships), anonymous third-party reporting 
and anonymous sealed envelope reporting, as in many studies, pre-marital sexual experience was far less likely to be reported among young women than young men. Moreover, sex worker, exchange, forced and same-sex relationships were rarely reported. Such findings emphasise the need to continue the search for appropriate methodologies to measure sensitive behaviours among youth; computer-assisted survey interviews are one such option. Indeed, methodological studies that compare estimates derived using different approaches could provide an insight into efforts to refine measures of reporting of sensitive behaviours among youth.

\section{Partner violence}

Youth Study findings have documented physical and sexual violence perpetrated by young men on their wife, as well as forced sex experienced in romantic and non-romantic situations by a small number of young women prior to marriage. Findings call for research that explores the factors underlying these experiences of violence, documents their health and social consequences for young women and men and their children, and tests interventions that enable youth to prevent such violence, on the one hand, and to overcome obstacles to seeking prompt and appropriate care, on the other.

\section{Family life or sex education}

Findings suggest that in-depth awareness about sexual and reproductive matters was limited, posing an obstacle to their ability to make informed choices. Research is needed that explores the extent to which young people's awareness of sexual and reproductive matters and of sexual and reproductive rights varies according to the sources from which they derive their knowledge. Equally important are studies that examine the sexual and reproductive knowledge and technical competence of those from whom information is sought-including, for example, teachers, health care providers and parents-to communicate sensitive sexual matters to young people.

There has been reticence in several states of the country to impart school-based family life or sex education to youth on the assumption-disproved in some settings-that such education will encourage youth to engage in risky sexual behaviours. Research is needed that explores the extent to which exposure to schoolor community-based family life or sex education does indeed enable youth to make informed decisions and adopt safe behaviours in the area of sexual and reproductive health. Research is also needed that explores whether the transition into married life is safer and healthier among those-particularly young women-who were exposed to such education. In addition, operations research is required that evaluates the reach, quality and effectiveness of existing programmes intended to impart sexual and reproductive health information to young people.

Agency and gender role attitudes

While findings confirm young women's limited agency and gender inegalitarian attitudes held by youth, particularly young men but also young women, several gaps remain in our understanding of the ways in which these affect young people's transitions to adulthood. Further research is needed, for example, that identifies the factors underlying the expression of unequal and equal gender role attitudes by young men and women, particularly the role of parents, teachers, peers and media, and that explores the ways in which inegalitarian gender role attitudes and limited agency compromise sexual and reproductive health among young men and women. 
Methodological issues also arise. There is a need to refine measures of agency as applicable to young men and women. The Youth Study has obtained data on multiple dimensions of agency among young men and women, the married and the unmarried and those from rural and urban areas. These data lend themselves to methodological exercises that measure agency among youth, assess the extent to which key components of agency may differ across different categories of youth and explore whether a single summary measure of agency can be developed among youth.

\section{Mental health disorders}

Findings suggest that one in 10 or more youth experience symptoms suggestive of mental health disorders. Research is needed that explores young people's mental health profile in greater depth and that assesses the linkages between sexual and reproductive health, on the one hand, and mental health, on the other.

Health seeking for sexual and reproductive health symptoms

Findings suggesting that health care seeking, particularly for sexual and reproductive matters, was limited, highlight the need for research that explores the factors inhibiting youth from seeking care. Youth Study data will enable, as a start, exploration of the factors distinguishing those who sought care from those who did not, in terms of both socio-economic factors as well as parental and peer interaction levels and youth inhibitions about seeking services relating to sexual matters. At the same time, further research is needed that explores barriers to care seeking from the perspective of providers.

In brief, the Youth Study has documented, for the first time, the multi-faceted situation of youth in Tamil Nadu. The study highlights several positive aspects of young people's lives but also alerts us to the many challenges confronting youth and their ability to make a successful transition to adulthood. It emphasises the heterogeneity of youth, not only in terms of their situation but also with regard to their stated needs and preferred mechanisms to address these needs. Programmes must recognise the heterogeneity of young people, and interventions and delivery mechanisms should be appropriately tailored to meet their special needs. Evidence presented here provides not only a blue-print for the programming needs of youth in Tamil Nadu but also a base-line by which to measure the impact of programmes intended to address youth needs. 


\section{References}

Abraham, L. 2001. "Redrawing the lakshman rekha: Gender differences and cultural constructions in youth sexuality in urban India," South Asia 24:133-56.

Abraham, L. 2002. "Bhai-behen, true love, time pass: Friendships and sexual partnerships among youth in an Indian metropolis," Culture, Health, and Sexuality 4(3):337-53.

Abraham, L. and K.A. Kumar. 1999. "Sexual experiences and their correlates among college students in Mumbai city, India," International Family Planning Perspectives 25(3):139-46.

Alexander, M., L. Garda, S. Kanade et al. 2003. Formation of partnerships among young women and men in Pune district, Maharashtra, unpublished survey questionnaire. New Delhi: Population Council.

Alexander, M., L. Garda, S. Kanade et al. 2006a. Formation of Partnerships among Young Women and Men in Pune District, Maharashtra. New Delhi: Population Council.

Alexander, M., L. Garda, S. Kanade et al. 2006b. "Romance and sex: Pre-marital partnership formation among young women and men, Pune district, India," Reproductive Health Matters 14(28):144-55.

Andrew, G., V. Patel and J. Ramakrishna. 2003. "Sex, studies or strife? What to integrate in adolescent health services," Reproductive Health Matters 11(21):120-29.

Awasthi, S., M. Nichter and V.K. Pande. 2000. "Developing an interactive STD prevention programme for youth: Lessons from a north Indian slum," Studies in Family Planning 31(2):138-50.

Bashir, K., R. Blizard, R. Jenkins et al. 1996. "Validation of the 12-item General Health Questionnaire in British general practice," Primary Care Psychiatry 2:4-7.

Bhat, P.N.M. and A.J.F. Zavier. 2007. "Factors influencing the use of prenatal diagnostic techniques and sex ratio at birth in India," in Watering the Neighbour's Garden: The Growing Demographic Female Deficit in Asia, eds. I. Attane and C.Z. Guilmoto. Paris: Committee for International Cooperation in National Research in Demography, pp. 131-60.

Bhatia, M.S. and S. Choudhary. 1998. "Dhat symptoms: A culture-bound sex neurosis," Indian Journal of Medical Science 52:30-35.

Bhatia, M.S. and S.C. Malik. 1991. "Dhat syndrome: A useful diagnostic entity in Indian culture," British Journal of Psychiatry 159:691-95.

Bhende, A.A. 1995. "Evolving a model for AIDS prevention education among underprivileged adolescent 
girls in urban India," Women and AIDS Research Program Report, Series No. 5. Washington, DC: International Centre for Research on Women.

Bhuiya, I., U. Rob, M.E. Khan et al. 2003. "Reproductive health services for adolescents: Recent experiences from a pilot project in Bangladesh," in Towards Adulthood: Exploring the Sexual and Reproductive Health of Adolescents in South Asia, eds. S. Bott, S.J. Jejeebhoy, I. Shah et al. Geneva: World Health Organisation, pp. 203-6.

Chandrasekhar, C.P., J. Ghosh and A. Roychowdhury. 2006. "The 'demographic dividend' and young India's economic future," Economic and Political Weekly 41(49): 5055-63.

Cleland, J. 2001. "Illustrative questionnaire for interview-surveys with young people," in Asking Young People about Sexual and Reproductive Behaviours: Illustrative Core Instruments, eds. J. Cleland, R. Ingham and N. Stone. Geneva: World Health Organisation, pp. 5-16.

Cochran, W.G. 1977. Sampling Techniques. New York: John Wiley \& Sons.

Collumbien, M., N. Bohidar, R. Das et al. 2004. "Etic and emic categories in male sexual health: A case study from Orissa," in Categories and Contexts: Anthropological and Historical Studies in Critical Demography, eds. S. Szreter, H. Sholkamy and A. Dharmalingam. New York: Oxford University Press, pp. 199-221.

Dagar, R. 2007. "Rethinking female foeticide: Perspective and issues," in Sex-selective Abortion in India: Gender, Society and New Reproductive Technologies, ed. T. Patel. New Delhi: Sage Publications, pp. 91-134.

Demographic Research and Development Foundation, Inc. (DRDF) and University of the Philippines Population Institute (UPPI). 2002. Young Adult Fertility and Sexuality Study [Married Female] Questionnaire. Quezon City, Philippines: DRDF and UPPI.

Department of Evaluation and Applied Research, Government of Tamil Nadu. n.d. Tamil Nadu - An Economic Appraisal 2005-06, Chennai: Department of Evaluation and Applied Research. Accessed 5 January 2009 at $<$ www.tn.gov.in/dear/index.htm>.

Department of Health and Family Welfare, Government of Tamil Nadu. 2008. Policy Note 2008-09 Demand No.19. Accessed 31 March 2009 at <www.tn.gov.in/policynotes/health_family_welfare.htm>.

Department of Rural Development and Panchayat Raj, Government of Tamil Nadu. 2008. Policy Note 2008-09, Demand No.42. Accessed 31 March 2009 at <www.tn.gov.in/policynotes/ruraldevelopment.pdf $>$.

Department of School Education, Government of Tamil Nadu. 2008. Policy Note on Demand No.43 School Education 2008-09. Accessed 31 March 2009 at <www.tn.gov.in/policynotes/schooleducation_pdf>.

Department of Social Welfare and Nutritious Meal Programme, Government of Tamil Nadu. 2008. Policy Note 2008-09, Demand No.45. Accessed 31 March 2009 at <www.tn.gov.in/policynotes/social_welfare.htm>.

DiClemente, R.J. 1992. "Psychosocial determinants of condom use among adolescents," in Adolescents and AIDS: A Generation in Jeopardy, ed. R.J. DiClemente. Newbury Park, CA: Sage, pp. 34-51.

Donath, S. 2001. "The validity of the 12-item General Health Questionnaire in Australia: A comparison between three scoring methods," Australian and New Zealand Journal of Psychiatry 35(2):231-35. 
Ellickson, P., H. Saner and K.A. McGuigan. 1997. "Profiles of violent youth: Substance use and other concurrent problems," American Journal of Public Health 87:985-91.

Goldberg, D. 1992. General Health Questionnaire (GHQ-12). Windsor: NFER-Nelson.

Government of Tamil Nadu. nd. Districts of Tamil Nadu. Accessed on 21 May 2009 at <http://www.tn.gov. in/districts.htm>.

Gruber, E., R.J. DiClemente, M.M. Anderson et al. 1996. "Early drinking onset and its association with alcohol use and problem behaviour in late adolescence," Preventive Medicine 25(3):293-300.

Guttmacher Institute. 2004a. 2004 Ghana National Survey of Adolescents: Survey Questionnaire, unpublished. New York: Guttmacher Institute.

Guttmacher Institute. 2004b. 2004 Malawi National Survey of Adolescents: Survey Questionnaire, unpublished. New York: Guttmacher Institute.

Guttmacher Institute. 2004c. 2004 Uganda National Survey of Adolescents: Survey Questionnaire, unpublished. New York: Guttmacher Institute.

International Institute for Population Sciences (IIPS) and Macro International. 2007a. National Family Health Survey (NFHS-3), 2005-06: India, Volume 1. Mumbai: IIPS.

International Institute for Population Sciences (IIPS) and Macro International. 2007b. National Family Health Survey (NFHS-3), 2005-06: India, Volume II. Mumbai: IIPS.

International Institute for Population Sciences (IIPS) and Macro International. 2008. National Family Health Survey (NFHS-3), India: 2005-06: Tamil Nadu. Mumbai: IIPS.

International Institute for Population Sciences (IIPS) and Population Council. 2002. First-time Parents project: Baseline survey questionnaire, unpublished.

International Labour Organisation (ILO). 2006. Global Employment Trends for Youth. Geneva: ILO.

Jacob, K.S., D. Bhugra and A.H. Mann. 1997. "The validation of the 12-item General Health Questionnaire among ethnic Indian women living in the United Kingdom," Psychological Medicine 27(5):1215-17.

Jejeebhoy, S.J. and S.S. Halli. 2005. "Marriage patterns in rural India: Influence of sociocultural context," in The Changing Transition to Adulthood in Developing Countries, National Research Council. Washington, DC: National Academies Press, pp. 172-99.

Jejeebhoy, S.J. and M.P. Sebastian. 2003. "Actions that protect: Promoting sexual and reproductive health and choice among young people in India," Regional Working Papers, No. 18. New Delhi: Population Council.

Jejeebhoy, S.J. and M.P. Sebastian. 2004. "Young people's sexual and reproductive health," in Looking Back, Looking Forward: A Profile of Sexual and Reproductive Health in India, ed. S.J. Jejeebhoy. New Delhi: Population Council, pp. 138-68.

Khan, S.I., N. Hudson-Rodd, S. Saggers et al. 2006. "Semen contains vitality and heredity, not germs': Seminal discourse in the AIDS era," Journal of Health, Population and Nutrition 24(4):426-37. 
Kish, L. 1995. "Methods for design effects," Journal of Official Statistics 11:55-77.

Krishnamoorthy, S. and N. Audinarayana. 2001. "Trends in consanguinity in South India," Journal of Biosocial Science, 33(2):185-197.

Laird, R.D., G.S. Pettit, K.A. Dodge et al. 2003. "Change in parents' monitoring knowledge: Links with parenting, relationship quality, adolescent beliefs, and antisocial behaviour," Social Development 12(3):401-19.

Lambert, H. and K. Wood. 2005. "A comparative analysis of communication about sex, health and sexual health in India and South Africa: Implications for HIV prevention," Culture, Health and Sexuality 7(6):527-41.

Lowry, R., D. Holtzman, B.I. Truman et al. 1994. "Substance use and HIV-related sexual behaviours among US high school students: Are they related?” American Journal of Public Health 84:1116-20.

Marta, E. 1997. "Parent-adolescent interactions and psychosocial risk in adolescents: An analysis of communication, support and gender," Journal of Adolescence 20(5):473-87.

Mehra, S., R. Savithri and L. Coutinho. 2002. "Sexual behaviour among unmarried adolescents in Delhi, India: Opportunities despite parental controls," Paper presented at the IUSSP Regional Population Conference, Bangkok, June.

Mensch, B.S., D.N. Anh and W.H. Clark. 2000. Adolescents and Social Change in Vietnam: Preliminary Report. Hanoi: Population Council and Institute of Sociology.

Mensch, B.S., W.H. Clark and D.N. Anh. 2003. "Adolescents in Vietnam: Looking beyond reproductive health," Studies in Family Planning 34 (4): 249-62.

Ministry of Finance. 2008. Economic Survey of India 2007-2008. New Delhi: Ministry of Finance, Government of India.

Ministry of Health and Family Welfare (MOHFW). 2000. National Population Policy 2000. New Delhi: Department of Family Welfare, MOHFW, Government of India.

Ministry of Health and Family Welfare (MOHFW). 2005. National Rural Health Mission: Meeting People's Health Needs, Framework for Implementation 2005-2012. New Delhi: MOHFW, Government of India. PDF file retrieved 1 January 2008 from <www.mohfw.nic.in/NRHM/Documents/NRHM-Framework for Implementation.pdf $>$.

Ministry of Health and Family Welfare (MOHFW). 2006. RCH Phase II: National Programme Implementation Plan. New Delhi: MOHFW, Government of India.

Ministry of Human Resource Development. 2007. Selected Educational Statistics 2004-2005. New Delhi: Ministry of Human Resource Development, Government of India.

Ministry of Statistics and Programme Implementation. 2008. Statement: Gross State Domestic Product at Current Prices as on 28 February. Accessed 31 March 2009 at $<$ http://mospi.nic.in/6_gsdp_cur_9394 ser.htm>.

Ministry of Youth Affairs and Sports. 2003. National Youth Policy 2003. New Delhi: Government of India. 
Mohan, S., P. Sankara Sarma and K.R. Thankappan. 2005. "Access to pocket money and low educational performance predict tobacco use among adolescent boys in Kerala, India," Preventive Medicine 41(2):685-92.

National Institute of Health and Family Welfare (NIHFW) and National AIDS Control Organization (NACO). 2007. Annual HIV Sentinel Surveillance Country Report 2006. New Delhi: NIHFW and NACO.

National Institute of Medical Statistics and National AIDS Control Organisation (NACO). 2008. National Behavioural Surveillance Survey (NBSS), 2006; Youth (15-24 Years). New Delhi: NACO, Ministry of Health and Family Welfare, Government of India. Accessed 5 January 2009 at <http://www.nacoonline.org/Quick_Links/ Publication/ME_and_Research_Surveillance/Reports_and_Surveys/National_BSS_20062/ >.

National Research Council and Institute of Medicine. 2005. Growing Up Global: The Changing Transition to Adulthood in Developing Countries. Washington, DC: National Academies Press.

National Sample Survey Organisation (NSSO). 2006. Employment and Unemployment Situation in India 2004-05, Part 1, NSS 61 ${ }^{\text {st }}$ Round. New Delhi: NSSO, Government of India.

Office of the Registrar General, India. 2003. Sample Registration System, Statistical Report, 2003. New Delhi: Office of the Registrar General, India.

Office of the Registrar General, India. 2008a. SRS Based Abridged Life Tables, 2002-06. New Delhi: Office of the Registrar General, India.

Office of the Registrar General, India. 2008b. Sample Registration System, Statistical Report, 2007, Report No. 2 of 2008. New Delhi: Office of the Registrar General, India.

Office of the Registrar General and Census Commissioner. 2001a. Age Groups. Accessed on 27 November 2008 at $<$ http://www.censusindia.gov.in/Census_Data_2001/Census_Data_Online/Social_and_cultural/Age_Groups. aspx $>$.

Office of the Registrar General and Census Commissioner. 2001b. Primary Census Abstract, Total Population: Table A-5, Series 1. New Delhi: Office of the Registrar General and Census Commissioner.

Office of the Registrar General and Census Commissioner. 2001c. Religious Compositions. Accessed on 27

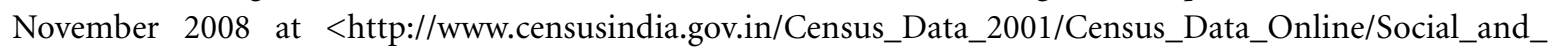
cultural/Religion.aspx $>$.

Office of the Registrar General and Census Commissioner. 2001d. Duration of Residence for Migrants by Last Residence. Accessed on 27 November 2008 at <http://www.censusindia.gov.in/Census_Data_2001/Census_ Data_Online/Social_and_cultural/Literate.aspx $>$.

Office of the Registrar General and Census Commissioner. 2001e. Educational Level by Age and Sex for Population Aged 7 and Above, Table C-8. New Delhi: Office of the Registrar General and Census Commissioner.

Office of the Registrar General and Census Commissioner. 2006. Population Projections for India and States 20012026 (Revised December 2006). New Delhi: Office of the Registrar General and Census Commissioner. 
Patel, V. and G. Andrew. 2001. "Gender, sexual abuse and risk behaviours: A survey of school-based adolescents in Goa," National Medical Journal of India 14:263-67.

Pelto, P.J. 1999. "Sexuality and sexual behaviour: The current discourse," in Implementing a Reproductive Health Agenda in India: The Beginning, ed. S. Pachauri. New Delhi: Population Council, pp. 539-86.

Planning Commission. 2002. Tenth Five Year Plan (2002-2007), Volume II, Sectoral Policies and Programmes. New Delhi: Government of India.

Planning Commission. 2006. Towards Faster and More Inclusive Growth: An Approach to the $11^{\text {th }}$ Five Year Plan (2007-2012). New Delhi: Government of India.

Planning Commission. 2007. Poverty Estimates for 2004-05, Press release, March. New Delhi: Government of India.

Prasad, J.H., S. Abraham, K.M. Kurz et al. 2005. "Reproductive tract infections among young married women in Tamil Nadu, India," International Family Planning Perspectives 31(2): 73-82.

Ram, F., R.K. Sinha, S.K. Mohanty et al. 2006. Marriage and Motherhood: An Exploratory Study of the Social and Reproductive Health Status of Married Young Women in Gujarat and West Bengal, India. New Delhi: Population Council.

Rossier, C. 2003. “Estimating induced abortion rates: A review," Studies in Family Planning 34(2):87-102.

Sachdev, P. 1998. "Sex on campus: A preliminary study of knowledge, attitudes and behaviour of university students in Delhi, India," Journal of Biosocial Science 30:95-105.

Santhya, K.G. and S.J. Jejeebhoy. 2006. "Young women's experience of forced sex within marriage: Evidence from India," in Sex without Consent: Young People in Developing Countries, eds. S.J. Jejeebhoy, I. Shah and S. Thapa. London: Zed Books, pp. 59-73.

Santhya, K.G., S.J. Jejeebhoy and S. Ghosh. 2008. Early Marriage and Sexual and Reproductive Health Risks: Experiences of Young Women and Men in Andhra Pradesh and Madhya Pradesh, India. New Delhi: Population Council.

Santhya, K.G., N. Haberland, A. Das et al. 2008. Empowering Married Girls and Improving their Sexual and Reproductive Health: Effects of the First-time Parents Project. New Delhi: Population Council.

Santhya, K.G., N. Haberland, F. Ram et al. 2007. "Consent and coercion: Examining unwanted sex among married young women in India," International Family Planning Perspectives 33(3):124-32.

Sathar, Z.A., M. Haque, A. Faizunnissa et al. 2003. Adolescents and Youth in Pakistan, 2001-02. Islamabad: Population Council.

Sebastian, M.P., M. Grant and B. Mensch. 2005. Integrating Adolescent Livelihood Activities Within a Reproductive Health Programme for Urban Slum Dwellers in India. New Delhi: Population Council. 
Sebastian, M.P., M. Grant, B. Mensch et al. 2003. Integrating adolescent livelihood activities within a reproductive health programme for urban slum dwellers in India, unpublished survey questionnaire. New Delhi: Population Council.

Singh, S. and S. Saini. 2007. "HIV risk perception in relation to peer pressure and drug abuse behaviour among adolescents," Indian Journal of Sexually Transmitted Diseases 28:53-54.

Sroufe, J.W. 1991. "Assessment of parent-adolescent relationships: Implications for adolescent development," Journal of Family Psychology 5(1):21-45.

Tamil Nadu State AIDS Control Society (TANSACS), Government of Tamil Nadu. 2006. The Tamil Nadu HIV Sentinel Surveillance Report- 2005. Chennai: TANSACS.

Ul Haque, M. and A. Faizunnisa. 2003. "Access to reproductive health information in Punjab and Sindh, Pakistan: The perspectives of adolescents and parents," in Towards Adulthood: Exploring the Sexual and Reproductive Health of Adolescents in South Asia, eds. S. Bott, S.J. Jejeebhoy, I. Shah et al. Geneva: World Health Organisation, pp. 153-55.

United Nations Development Programme (UNDP). 2000. Millennium Development Goals. United Nations website. Accessed 8 January 2008 at <http://www.un.org/millenniumgoals/goals.html>.

Verma, R.K., S. Sharma, R. Singh et al. 2003. "Beliefs concerning sexual health problems and treatment seeking among men in an Indian slum community," Culture, Health and Sexuality 5(3):265-76.

Voluntary Health Services. 1998. Community Prevalence of Sexually Transmitted Diseases in Tamil Nadu: A Report. Chennai: Voluntary Health Services.

Wolter, K.M. 1985. Introduction to Variance Estimation. New York: Springer. 


\section{Appendix A}

\section{Principal investigators and authors}

Usha Ram, Associate Professor, Department of Public Health and Mortality Studies, International Institute for Population Sciences, Mumbai

S.K. Mohanty, Reader, Department of Fertility Studies, International Institute for Population Sciences, Mumbai

Abhishek Singh, Assistant Professor, Department of Public Health and Mortality Studies, International Institute for Population Sciences, Mumbai

F. Ram, Director and Senior Professor, International Institute for Population Sciences, Mumbai

K.G. Santhya, Associate, Population Council, New Delhi

Shireen J. Jejeebhoy, Senior Associate, Population Council, New Delhi

Rajib Acharya, Senior Programme Officer, Population Council, New Delhi 


\section{Appendix A}

\section{Tamil Nadu study staff}

Senior Research Officers

Shreeparna Ghosh

Research Officers

P. Ganesh

S. Jareena

Abhishek Kumar

C. Latha

Finance Staff

Jeba Kumar

Administrative Staff

Pranita H. Dalvi

Namrata Ghadge

Seema Jadhav

M.A. Jose

Editorial Staff

Deepika Ganju

\section{Data Entry Operators}

Sumita D. Choudhari

Sarika D. Dethe

Pragati B. Dilpak

Manisha D. Esave

Shrikant M. Gajbhiye

Sarita S. Mohane
Sangeeta Kumari

\author{
M. Manimaran \\ P. Murugesan \\ Prashant Kumar Singh \\ Lucky Singh
}

Anil Paul

Avadhesh Prajapati

Shyam V. Rathod

Komal Saxena

Usha D. Sonavane

Aparna R. Narvekar

Renuka V. Panchal

Manorama Rautela

Sayali P. Shivalkar

Prasad Surve 
Field Supervisors
S. Manikandan Alagu
K. Mathiyazahan
N. Ganesh
N. Saravanan
S. Arun Kumar
A. Suresh

N. Senthil Kumar

Field Editors

P. Mukesh Babu

A.P. Thamarai Selvi

K. Jayasudha

B. Shanaz

A. Nirmala Josephine

R. Sumathi

K. Kumar

K. Vaitheeswaran

S. Sampath

Office Editors

Ankush Bhamare

Rakesh M. Pawar

Kiran S. Khandarkar

Shantanu G. Sawant

Household Listers and Mappers
A. Anbuvel
S. Lakshmanan
P. Mukesh Babu
A. Manikandan
A. Ramesh Babu
M. Manimaran
P. Baskar
K. Mathiyazhagan
S. M. Chinnaiyan
R. Murali
V. Ilaiyaraja
P. Thiyagarajan

R. Siva Kumar

Field Investigators
M. Arivalagan
S. Meenakshi
G. Arunachalam
T. Nagarathinam
P. Ayyammal
R. Ramesh Pandian
P. Baskar
S. Chanderalekha
A. Ramamoorthy
S. Chanderalekha
C. Ramesh
S. Chandraleka
R. Revathi
K. Elango
S. Sampath
S. Hema
V. Ilaiyaraja
G. Sangeetha
K. Saravanan
K. Jeyanthi
N. Saravanan
K. Jeyasudha
M. Sathyauma
A. Nirmala Josephine
T. Sripriya
K. Kavitha
T. Sumathi
R. Kokilarani
M. Suresh
M. Ramesh Kumar
K. Tamizhselvi
A. Manikandan
N. Mariyammal
J. Thagaru
P. Josephin Mary
P. Thiyagarajan
P. Usharani 


\section{Advisory committees}

\section{Project Advisory Committee}

Additional Secretary

Ministry of Health and Family Welfare

Government of India

Chief Director

Ministry of Health and Family Welfare

Government of India

Deputy Secretary

Information, Education, Communication

Ministry of Health and Family Welfare

Government of India

Director

Directorate of Health Services

Government of Andhra Pradesh

Director

Directorate of Health Services

Government of Bihar

Director

Directorate of Health Services

Government of Jharkhand

Director

Directorate of Health Services

Government of Maharashtra

Director

Directorate of Health Services

Government of Rajasthan

Director

Directorate of Health Services

Government of Tamil Nadu
Director

Nehru Yuvak Kendra Sangatan

Ministry of Sports and Youth Affairs

Government of India

Director

National Institute of Health and Family Welfare,

New Delhi

Country Director (India)

John D. and Catherine T. MacArthur Foundation, New Delhi

Country Programme Advisor (India)

David and Lucile Packard Foundation,

New Delhi

Director

International Institute for Population Sciences,

Mumbai

Regional Director

Population Council, New Delhi

NFHS Coordinator

International Institute for Population Sciences, Mumbai

Shalini Bharat

Professor and Dean

School of Health Systems Studies

Tata Institute of Social Sciences

Mumbai

P.M. Kulkarni

Professor

Centre for the Study of Regional Development

Jawaharlal Nehru University, New Delhi 
Arvind Pandey

Director

Institute for Research in Medical Statistics,

New Delhi

G. Rama Rao

Former Officiating Director

International Institute for Population Sciences

Mumbai

Technical Advisory Committee

Shalini Bharat

Professor and Dean

School of Health Systems Studies

Tata Institute of Social Sciences

Mumbai

Director

International Institute for Population Sciences

Mumbai

P.M. Kulkarni

Professor

Centre for the Study of Regional Development Jawaharlal Nehru University

New Delhi

Arvind Pandey

Director

Institute for Research in Medical Statistics, New Delhi
T.K. Roy

Former Director

International Institute for Population Sciences, Mumbai

Leela Visaria

National Professor

Gujarat Institute of Development Research, Ahmedabad

Pertti J. Pelto

Professor Emeritus

Medical Anthropology

University of Connecticut

USA

T.K. Roy

Former Director

International Institute for Population Sciences, Mumbai

Leela Visaria

National Professor

Gujarat Institute of Development Research

Ahmedabad 


\section{Estimates of sampling errors}

As in the case of any sample survey, estimates from the Youth Study in Tamil Nadu, as presented in Chapters 1-12, are affected by two major sources of errors: non-sampling and sampling errors. Non-sampling errors are generally the result of procedural mistakes made during data collection and data processing, such as the inability to locate and interview the correct household or individual, failure to conform to standard survey procedures laid out by the central office, misunderstanding of questions on the part of either the interviewer or the respondent, and data entry errors. At the same time, because of the inclusion of numerous sensitive issues, the Youth Study faced the risk of other non-sampling errors as well, such as the deliberate skipping of sensitive questions by the interviewer or refusal to answer sensitive questions by the respondent. In order to minimise non-sampling errors, a number of precautions were taken during the implementation of the study, which are described in detail in Chapter 1 . However, we acknowledge that despite these efforts, non-sampling errors are impossible to avoid; they are, moreover, extremely difficult to evaluate statistically.

Sampling errors, on the other hand, can be evaluated statistically. These errors, as the name suggests, result from the choice of the particular sample selected. The sample of respondents selected in the Youth Study is only one of many possible samples that could have been selected from the population of Tamil Nadu using the same design and expected sample size. Each of these samples would have yielded results that differed somewhat from the results of the sample selected. The sampling error is a measure of variability among all possible samples. Although the degree of variability may not be known exactly, it can be estimated from the survey results using standard statistical procedures.

A sampling error, usually measured in terms of the standard error for a particular statistic (mean, percentage, ratio, etc.), is the square root of the variance of that statistic. The standard error can be used to calculate confidence intervals within which the true value for the population can reasonably be assumed to fall. For example, for any given statistic calculated from the survey, the value of that statistic will fall within a range of plus or minus two times the standard error of that statistic in $95 \%$ of all possible samples of identical size and design.

If the sample of respondents had been selected as a simple random sample, it would have been possible to use straightforward formulae for calculating the variance of the statistic and consequently, sampling errors. However, the Youth Study sample is the result of a multi-stage stratified design, and consequently, it was necessary to use more complex formulae. The variance estimators that were used can be found in Cochran (1977) and Wolter (1985). The computer software used to calculate sampling errors for the Youth Study was programmed in STATA SE 8.2. This procedure uses the Taylor linearisation method for variance estimation for survey estimates that are means, proportions or ratios.

The Taylor linearisation method treats any percentage or average as a ratio estimate. Let $r=y / x$ be our sample estimate of the population ratio (mean or percentage) denoted by $\mathrm{R}=\mathrm{Y} / \mathrm{X}$, where $\mathrm{y}$ represents the total sample value for variable $\mathrm{Y}$, and $\mathrm{x}$ represents the total number of sample cases in the group or sub-group 
under consideration. Using first order Taylor expansion, it can be shown that the approximate variance of distribution of $r$ (square root of which is the standard error) is as below:

$$
\operatorname{Var}(r)=\frac{1-f}{x^{2}} \sum_{h=1}^{L}\left[\frac{n_{h}}{n_{h}-1}\left(\sum_{i=1}^{n_{h}} z_{h i}^{2}-\frac{z_{h}^{2}}{n_{h}}\right)\right]
$$

in which $\mathrm{z}_{h i}=\mathrm{y}_{h i}-\mathrm{rx}_{h i}$ and $\mathrm{z}_{h}=\mathrm{y}_{h}-\mathrm{rx}_{h}$

where $h \quad$ represents the sampling stratum which varies from 1 to $\mathrm{L}$,

$n_{h} \quad$ is the number of PSUs selected in the $\mathrm{h}^{\text {th }}$ stratum,

$y_{h i} \quad$ is the sum of the weighted values of variable $\mathrm{Y}$ in the $\mathrm{i}^{\text {th }}$ PSU in the $\mathrm{h}^{\text {th }}$ stratum,

$x_{h i} \quad$ is the sum of the weighted number of cases in the $\mathrm{i}^{\text {th }} \mathrm{PSU}$ in the $\mathrm{h}^{\text {th }}$ stratum,

$f \quad$ is the overall sampling fraction, which is so small that it is ignored.

In addition to the standard error, the design effect (DEFT) for each estimate was also computed, which is defined as the ratio between the standard error using the given sample design and the standard error that would result if a simple random sample had been used (Kish, 1995), represented by the following simple formula:

$$
D E F T=\sqrt{\frac{\operatorname{Var}(r)}{\operatorname{Var} r_{s r s w r}\left(r_{s r s}\right)}}
$$

where $\operatorname{Var}(\mathrm{r})$ is a design-based estimate of variance for the parameter $\mathrm{r}$, $\operatorname{Var}_{\text {srswr }}\left(r_{\text {srs }}\right)$ is an estimate of the variance for an estimator $r_{\text {srs }}$ that would be obtained from a similar hypothetical survey conducted using simple random sampling (srs) with replacement (wr).

A DEFT value of 1.0 indicates that the sample design is as efficient as a simple random sample, while a value greater than 1.0 indicates the increase in the sampling error due to the use of a more complex and less statistically efficient design. Relative standard error (SE/R) and $95 \%$ confidence limits for each estimate were also computed.

Sampling errors for the Youth Study were calculated for selected variables and results are presented in this appendix for each sex and marital status sub-group of respondents for the state as a whole, and for those in urban and rural areas, respectively. For each variable, the type of statistic (mean, proportion or ratio) and the base population are given in Table B.1. Table B.2 presents the value of the statistic (R), its standard error (SE), the number of unweighted $(\mathrm{N})$ and weighted $(\mathrm{WN})$ cases, the design effect (DEFT), the relative standard error (SE/R) and the $95 \%$ confidence limits for each variable. 
Table B.1: List of selected variables for sampling errors, Tamil Nadu, 2006

\begin{tabular}{|c|c|c|}
\hline Variables & Estimates & Base Population \\
\hline Sex ratio (females per 1,000 males) & Ratio & De jure household population, all ages \\
\hline Sex ratio (females per 1,000 males) & Ratio & De jure household population, aged 0-6 \\
\hline $\begin{array}{l}\text { Currently married, including married but not } \\
\text { yet cohabiting }\end{array}$ & Proportion & De jure household population, aged $20-24$ \\
\hline No education & Proportion & $\begin{array}{l}\text { De jure household population, aged } 6 \text { or } \\
\text { above }\end{array}$ \\
\hline No education & Proportion & Young men and women \\
\hline Completed 12 or more years of education & Proportion & Young men and women \\
\hline Ever worked in last 12 months & Proportion & Young men and women \\
\hline Unemployed & Proportion & Young men and women in labour force \\
\hline Discussed friendships with father & Proportion & $\begin{array}{l}\text { Young men and women whose father was } \\
\text { alive at the time of interview }\end{array}$ \\
\hline Discussed friendships with mother & Proportion & $\begin{array}{l}\text { Young men and women whose mother was } \\
\text { alive at the time of interview }\end{array}$ \\
\hline $\begin{array}{l}\text { Independently makes decisions on choice of } \\
\text { friends, spending money and buying clothes for } \\
\text { oneself }\end{array}$ & Proportion & Young men and women \\
\hline $\begin{array}{l}\text { Can visit places outside village or } \\
\text { neighbourhood unescorted }\end{array}$ & Proportion & Young men and women \\
\hline Has savings of any amount & Proportion & Young men and women \\
\hline Justified wife beating in at least one situation & Proportion & Young men and women \\
\hline Awareness of sex- and pregnancy-related matters & Proportion & Young men and women \\
\hline $\begin{array}{l}\text { Correct specific knowledge of at least one } \\
\text { contraceptive method }\end{array}$ & Proportion & Young men and women \\
\hline Correct specific knowledge of condoms & Proportion & Young men and women \\
\hline Ever heard of HIV/AIDS & Proportion & Young men and women \\
\hline Comprehensive knowledge of HIV/AIDS & Proportion & Young men and women \\
\hline Ever heard of STIs other than HIV & Proportion & Young men and women \\
\hline $\begin{array}{l}\text { Correct knowledge of the conditions under } \\
\text { which abortion is legal }\end{array}$ & Proportion & Young men and women \\
\hline Ever received family life or sex education & Proportion & Young men and women \\
\hline Ever had an opposite-sex romantic partner & Proportion & Young men and women \\
\hline $\begin{array}{l}\text { Ever had sex with an opposite-sex romantic } \\
\text { partner }\end{array}$ & Proportion & Young men and women \\
\hline Ever had pre-marital sex & Proportion & Young men and women \\
\hline $\begin{array}{l}\text { Used condom consistently in pre-marital } \\
\text { relations }\end{array}$ & Proportion & $\begin{array}{l}\text { Young men and women who reported } \\
\text { pre-marital sex in face-to-face interview }\end{array}$ \\
\hline $\begin{array}{l}\text { Ever communicated with spouse on } \\
\text { contraception }\end{array}$ & Proportion & $\begin{array}{l}\text { Married young men and women who had } \\
\text { begun cohabiting }\end{array}$ \\
\hline Husband ever forced wife to have sex & Proportion & $\begin{array}{l}\text { Married young men and women who had } \\
\text { begun cohabiting }\end{array}$ \\
\hline $\begin{array}{l}\text { Husband ever perpetrated physical violence } \\
\text { on wife }\end{array}$ & Proportion & $\begin{array}{l}\text { Married young men and women who had } \\
\text { begun cohabiting }\end{array}$ \\
\hline $\begin{array}{l}\text { Husband ever perpetrated physical violence on } \\
\text { wife in last } 12 \text { months }\end{array}$ & Proportion & $\begin{array}{l}\text { Married young men and women who had } \\
\text { begun cohabiting }\end{array}$ \\
\hline
\end{tabular}




Variables
Currently using any modern contraceptive
method
First delivery in a health institution
Mean number of children ever born
Mean number of children surviving
Mean ideal number of children
Experienced 3 or more symptoms or behaviours
suggestive of mental health disorders in the
month preceding the interview
Ever consumed alcohol
Participated in a government-/NGO-sponsored
programme in the 3 years preceding the
interview
Voted in last election

Estimates

Proportion

Base Population

Married young men and women who had begun cohabiting

Proportion

Married young men and women whose

first pregnancy outcome was a live or still birth

Mean

Mean

Mean

Proportion

Married young men and women who had begun cohabiting

Married young men and women who had begun cohabiting

Married young men and women who had begun cohabiting and gave a numeric response

Young men and women

Proportion

Young men and women

Proportion

Young men and women

Proportion 
Table B.2: Sampling errors, Tamil Nadu, 2006

\begin{tabular}{|c|c|c|c|c|c|c|c|c|}
\hline \multirow{2}{*}{$\begin{array}{l}\text { Variable/ } \\
\text { respondent } \\
\text { category }\end{array}$} & \multirow{2}{*}{$\begin{array}{l}\text { Value } \\
(\mathbf{R})\end{array}$} & \multirow{2}{*}{$\begin{array}{c}\text { Standard } \\
\text { error } \\
\text { (SE) }\end{array}$} & \multicolumn{2}{|c|}{ Number of cases } & \multirow{2}{*}{$\begin{array}{c}\text { Design } \\
\text { effect } \\
\text { (DEFT) }\end{array}$} & \multirow{2}{*}{$\begin{array}{c}\text { Relative } \\
\text { standard } \\
\text { error } \\
\text { (SE/R) }\end{array}$} & \multicolumn{2}{|c|}{ 95\% Confidence limits } \\
\hline & & & $\begin{array}{l}\text { Unweighted } \\
(\mathrm{N})\end{array}$ & $\begin{array}{l}\text { Weighted } \\
(\mathrm{WN})\end{array}$ & & & Lower & Upper \\
\hline \multicolumn{9}{|c|}{ Sex ratio } \\
\hline Combined & 0.9991 & 0.0044 & 73,538 & 73,549 & 1.1734 & 0.0044 & 0.9904 & 1.0077 \\
\hline Urban & 1.0000 & 0.0058 & 32,400 & 32,248 & 1.0234 & 0.0058 & 0.9887 & 1.0114 \\
\hline Rural & 0.9983 & 0.0064 & 41,138 & 41,301 & 1.2764 & 0.0064 & 0.9858 & 1.0109 \\
\hline \multicolumn{9}{|c|}{$\begin{array}{l}\text { Sex ratio } \\
\text { (females per 1,000 males, de jure household population, aged 0-6) }\end{array}$} \\
\hline Combined & 0.9251 & 0.0136 & 8,508 & 8,505 & 0.9367 & 0.0147 & 0.8983 & 0.9518 \\
\hline Urban & 0.9136 & 0.0187 & 3,644 & 3,623 & 0.8525 & 0.0205 & 0.8768 & 0.9504 \\
\hline Rural & 0.9336 & 0.0192 & 4,864 & 4,882 & 0.9922 & 0.0205 & 0.8959 & 0.9714 \\
\hline \multicolumn{9}{|c|}{$\begin{array}{l}\text { Currently married, including married but not yet cohabiting } \\
\text { (de jure household population, aged } 20-24)\end{array}$} \\
\hline \multicolumn{9}{|c|}{ Combined } \\
\hline Male & 0.1080 & 0.0054 & 6,654 & 6,638 & 1.4091 & 0.0496 & 0.0974 & 0.1186 \\
\hline Female & 0.5914 & 0.0102 & 6,847 & 6,849 & 1.7115 & 0.0172 & 0.5714 & 0.6114 \\
\hline \multicolumn{9}{|c|}{ Urban } \\
\hline Male & 0.0847 & 0.0067 & 2,930 & 2,917 & 1.3048 & 0.0792 & 0.0715 & 0.0980 \\
\hline Female & 0.5490 & 0.0147 & 3,103 & 3,084 & 1.6401 & 0.0267 & 0.5201 & 0.5778 \\
\hline \multicolumn{9}{|c|}{ Rural } \\
\hline Male & 0.1262 & 0.0081 & 3,724 & 3,721 & 1.4851 & 0.0640 & 0.1103 & 0.1421 \\
\hline Female & 0.6262 & 0.0143 & 3,744 & 3,766 & 1.8141 & 0.0229 & 0.5979 & 0.6544 \\
\hline
\end{tabular}

\begin{tabular}{|c|c|c|c|c|c|c|c|c|}
\hline \multicolumn{9}{|c|}{$\begin{array}{c}\text { No education } \\
\text { (de jure household population, aged } 6 \text { or above) }\end{array}$} \\
\hline \multicolumn{9}{|c|}{ Combined } \\
\hline Male & 0.1524 & 0.0049 & 66,260 & 66,274 & 3.5329 & 0.0324 & 0.1427 & 0.1621 \\
\hline Female & 0.3176 & 0.0065 & 66,753 & 66,793 & 3.5855 & 0.0203 & 0.3049 & 0.3303 \\
\hline \multicolumn{9}{|c|}{ Urban } \\
\hline Male & 0.1021 & 0.0063 & 29,300 & 29,169 & 3.5598 & 0.0617 & 0.0897 & 0.1145 \\
\hline Female & 0.2310 & 0.0097 & 29,586 & 29,444 & 3.9389 & 0.0418 & 0.2120 & 0.2500 \\
\hline \multicolumn{9}{|c|}{ Rural } \\
\hline Male & 0.1920 & 0.0073 & 36,960 & 37,106 & 3.5501 & 0.0379 & 0.1776 & 0.2063 \\
\hline Female & 0.3859 & 0.0087 & 37,167 & 37,352 & 3.4452 & 0.0225 & 0.3688 & 0.4030 \\
\hline
\end{tabular}

Cont'd on next page... 
Table B.2: (Cont'd)

\begin{tabular}{|c|c|c|c|c|c|c|c|c|}
\hline \multirow{2}{*}{$\begin{array}{l}\text { Variable/ } \\
\text { respondent } \\
\text { category }\end{array}$} & \multirow{2}{*}{$\begin{array}{l}\text { Value } \\
\text { (R) }\end{array}$} & \multirow{2}{*}{$\begin{array}{c}\text { Standard } \\
\text { error } \\
\text { (SE) }\end{array}$} & \multicolumn{2}{|c|}{ Number of cases } & \multirow{2}{*}{$\begin{array}{l}\text { Design } \\
\text { effect } \\
\text { (DEFT) }\end{array}$} & \multirow{2}{*}{$\begin{array}{c}\text { Relative } \\
\text { standard } \\
\text { error } \\
\text { (SE/R) }\end{array}$} & \multicolumn{2}{|c|}{ 95\% Confidence limits } \\
\hline & & & $\begin{array}{l}\text { Unweighted } \\
(\mathbf{N})\end{array}$ & $\begin{array}{c}\text { Weighted } \\
(\mathrm{WN})\end{array}$ & & & Lower & Upper \\
\hline \multicolumn{9}{|c|}{ No education (young men and women) } \\
\hline \multicolumn{9}{|c|}{ Combined } \\
\hline M (15-24) & 0.0222 & 0.0045 & 1,913 & 1,917 & 1.3469 & 0.2042 & 0.0133 & 0.0312 \\
\hline $\mathrm{W} \quad(15-24)$ & 0.0495 & 0.0050 & 5,008 & 5,008 & 1.6240 & 0.1006 & 0.0397 & 0.0593 \\
\hline MM (15-29) & 0.0614 & 0.0110 & 1,322 & 1,322 & 1.6608 & 0.1787 & 0.0398 & 0.0830 \\
\hline MW (15-24) & 0.0970 & 0.0091 & 2,007 & 2,007 & 1.3789 & 0.0939 & 0.0791 & 0.1150 \\
\hline UM (15-24) & 0.0149 & 0.0039 & 1,666 & 1,666 & 1.3153 & 0.2617 & 0.0072 & 0.0226 \\
\hline UW (15-24) & 0.0184 & 0.0030 & 3,001 & 3,001 & 1.2089 & 0.1613 & 0.0125 & 0.0242 \\
\hline \multicolumn{9}{|c|}{ Urban } \\
\hline M (15-24) & 0.0116 & 0.0034 & 890 & 832 & 0.9417 & 0.2917 & 0.0049 & 0.0182 \\
\hline $\mathrm{W} \quad(15-24)$ & 0.0322 & 0.0049 & 2,151 & 2,215 & 1.2891 & 0.1524 & 0.0225 & 0.0419 \\
\hline MM (15-29) & 0.0261 & 0.0061 & 653 & 543 & 0.9801 & 0.2346 & 0.0140 & 0.0381 \\
\hline MW (15-24) & 0.0703 & 0.0104 & 804 & 809 & 1.1493 & 0.1475 & 0.0499 & 0.0907 \\
\hline UM (15-24) & 0.0088 & 0.0033 & 789 & 747 & 0.9933 & 0.3764 & 0.0023 & 0.0153 \\
\hline UW (15-24) & 0.0101 & 0.0029 & 1,347 & 1,405 & 1.0547 & 0.2845 & 0.0044 & 0.0158 \\
\hline \multicolumn{9}{|c|}{ Rural } \\
\hline M (15-24) & 0.0304 & 0.0075 & 1,023 & 1,086 & 1.3984 & 0.2471 & 0.0156 & 0.0452 \\
\hline $\mathrm{W} \quad(15-24)$ & 0.0632 & 0.0079 & 2,857 & 2,793 & 1.7349 & 0.1250 & 0.0476 & 0.0787 \\
\hline MM (15-29) & 0.0860 & 0.0176 & 669 & 779 & 1.6251 & 0.2050 & 0.0513 & 0.1207 \\
\hline MW (15-24) & 0.1151 & 0.0133 & 1,203 & 1,198 & 1.4456 & 0.1156 & 0.0889 & 0.1413 \\
\hline UM (15-24) & 0.0200 & 0.0065 & 877 & 919 & 1.3832 & 0.3274 & 0.0071 & 0.0328 \\
\hline UW (15-24) & 0.0257 & 0.0049 & 1,654 & 1,596 & 1.2482 & 0.1892 & 0.0161 & 0.0352 \\
\hline \multicolumn{9}{|c|}{ Completed 12 or more years of education (young men and women) } \\
\hline \multicolumn{9}{|c|}{ Combined } \\
\hline M (15-24) & 0.2622 & 0.0145 & 1,913 & 1,917 & 1.4396 & 0.0552 & 0.2337 & 0.2907 \\
\hline $\mathrm{W} \quad(15-24)$ & 0.2588 & 0.0128 & 5,008 & 5,008 & 2.0702 & 0.0495 & 0.2336 & 0.2840 \\
\hline MM (15-29) & 0.1494 & 0.0141 & 1,322 & 1,322 & 1.4369 & 0.0943 & 0.1217 & 0.1772 \\
\hline MW (15-24) & 0.1616 & 0.0120 & 2,007 & 2,007 & 1.4557 & 0.0740 & 0.1380 & 0.1851 \\
\hline UM (15-24) & 0.2846 & 0.0155 & 1,666 & 1,666 & 1.4012 & 0.0544 & 0.2541 & 0.3151 \\
\hline UW (15-24) & 0.3229 & 0.0150 & 3,001 & 3,001 & 1.7603 & 0.0465 & 0.2934 & 0.3525 \\
\hline \multicolumn{9}{|c|}{ Urban } \\
\hline M $\quad(15-24)$ & 0.3231 & 0.0227 & 890 & 832 & 1.4488 & 0.0703 & 0.2783 & 0.3678 \\
\hline $\mathrm{W} \quad(15-24)$ & 0.3362 & 0.0209 & 2,151 & 2,215 & 2.0499 & 0.0621 & 0.2951 & 0.3773 \\
\hline MM (15-29) & 0.2006 & 0.0254 & 653 & 543 & 1.6216 & 0.1268 & 0.1506 & 0.2507 \\
\hline MW (15-24) & 0.2206 & 0.0223 & 804 & 809 & 1.5217 & 0.1009 & 0.1768 & 0.2644 \\
\hline UM (15-24) & 0.3457 & 0.0245 & 789 & 747 & 1.4472 & 0.0709 & 0.2975 & 0.3940 \\
\hline UW (15-24) & 0.4034 & 0.0222 & 1,347 & 1,405 & 1.6629 & 0.0551 & 0.3596 & 0.4472 \\
\hline \multicolumn{9}{|c|}{ Rural } \\
\hline M (15-24) & 0.2156 & 0.0176 & 1,023 & 1,086 & 1.3691 & 0.0817 & 0.1810 & 0.2503 \\
\hline W $\quad(15-24)$ & 0.1974 & 0.0141 & 2,857 & 2,793 & 1.8898 & 0.0713 & 0.1697 & 0.2251 \\
\hline MM (15-29) & 0.1137 & 0.0148 & 669 & 779 & 1.2045 & 0.1301 & 0.0846 & 0.1429 \\
\hline MW (15-24) & 0.1217 & 0.0123 & 1,203 & 1,198 & 1.3021 & 0.1009 & 0.0976 & 0.1459 \\
\hline UM (15-24) & 0.2348 & 0.0186 & 877 & 919 & 1.2984 & 0.0792 & 0.1982 & 0.2715 \\
\hline UW (15-24) & 0.2521 & 0.0179 & 1,654 & 1,596 & 1.6783 & 0.0711 & 0.2168 & 0.2874 \\
\hline
\end{tabular}


Table B.2: (Cont'd)

\begin{tabular}{|c|c|c|c|c|c|c|c|c|}
\hline \multirow{2}{*}{$\begin{array}{l}\text { Variable/ } \\
\text { respondent } \\
\text { category }\end{array}$} & \multirow{2}{*}{$\begin{array}{l}\text { Value } \\
(\mathbf{R})\end{array}$} & \multirow{2}{*}{$\begin{array}{l}\text { Standard } \\
\text { error } \\
\text { (SE) }\end{array}$} & \multicolumn{2}{|c|}{ Number of cases } & \multirow{2}{*}{$\begin{array}{c}\text { Design } \\
\text { effect } \\
\text { (DEFT) }\end{array}$} & \multirow{2}{*}{$\begin{array}{c}\text { Relative } \\
\text { standard } \\
\text { error } \\
(\mathrm{SE} / \mathrm{R})\end{array}$} & \multicolumn{2}{|c|}{ 95\% Confidence limits } \\
\hline & & & $\begin{array}{c}\text { Unweighted } \\
(\mathbf{N})\end{array}$ & $\begin{array}{c}\text { Weighted } \\
(\mathrm{WN})\end{array}$ & & & Lower & Upper \\
\hline \multicolumn{9}{|c|}{ Ever worked in last 12 months (young men and women) } \\
\hline \multicolumn{9}{|c|}{ Combined } \\
\hline$M \quad(15-24)$ & 0.6248 & 0.0158 & 1,913 & 1,917 & 1.4225 & 0.0252 & 0.5938 & 0.6558 \\
\hline $\mathrm{W} \quad(15-24)$ & 0.3385 & 0.0151 & 5,008 & 5,008 & 2.2615 & 0.0447 & 0.3088 & 0.3683 \\
\hline MM (15-29) & 0.9969 & 0.0014 & 1,322 & 1,322 & 0.9064 & 0.0014 & 0.9941 & 0.9996 \\
\hline MW (15-24) & 0.2851 & 0.0193 & 2,007 & 2,007 & 1.9097 & 0.0675 & 0.2472 & 0.3230 \\
\hline UM (15-24) & 0.5849 & 0.0166 & 1,666 & 1,666 & 1.3762 & 0.0284 & 0.5522 & 0.6176 \\
\hline UW (15-24) & 0.3738 & 0.0160 & 3,001 & 3,001 & 1.8082 & 0.0427 & 0.3424 & 0.4053 \\
\hline \multicolumn{9}{|c|}{ Urban } \\
\hline M (15-24) & 0.5901 & 0.0241 & 890 & 832 & 1.4601 & 0.0408 & 0.5427 & 0.6375 \\
\hline $\mathrm{W} \quad(15-24)$ & 0.2400 & 0.0159 & 2,151 & 2,215 & 1.7278 & 0.0663 & 0.2086 & 0.2713 \\
\hline MM (15-29) & 0.9940 & 0.0029 & 653 & 543 & 0.9726 & 0.0030 & 0.9882 & 0.9998 \\
\hline MW (15-24) & 0.1535 & 0.0202 & 804 & 809 & 1.5885 & 0.1316 & 0.1138 & 0.1933 \\
\hline UM (15-24) & 0.5523 & 0.0254 & 789 & 747 & 1.4339 & 0.0460 & 0.5023 & 0.6023 \\
\hline UW (15-24) & 0.2901 & 0.0191 & 1,347 & 1,405 & 1.5463 & 0.0659 & 0.2525 & 0.3278 \\
\hline \multicolumn{9}{|c|}{ Rural } \\
\hline M (15-24) & 0.6514 & 0.0204 & 1,023 & 1,086 & 1.3710 & 0.0314 & 0.6111 & 0.6916 \\
\hline $\mathrm{W} \quad(15-24)$ & 0.4167 & 0.0213 & 2,857 & 2,793 & 2.3043 & 0.0510 & 0.3749 & 0.4586 \\
\hline MM (15-29) & 0.9988 & 0.0012 & 669 & 779 & 0.8840 & 0.0012 & 0.9965 & 1.0011 \\
\hline MW (15-24) & 0.3741 & 0.0259 & 1,203 & 1,198 & 1.8586 & 0.0693 & 0.3230 & 0.4251 \\
\hline UM (15-24) & 0.6115 & 0.0216 & 877 & 919 & 1.3094 & 0.0353 & 0.5691 & 0.6540 \\
\hline UW (15-24) & 0.4475 & 0.0223 & 1,654 & 1,596 & 1.8246 & 0.0499 & 0.4036 & 0.4914 \\
\hline \multicolumn{9}{|c|}{ Unemployed (young men and women in labour force) } \\
\hline \multicolumn{9}{|c|}{ Combined } \\
\hline M (15-24) & 0.0694 & 0.0091 & 1,153 & 1,118 & 1.2195 & 0.1316 & 0.0514 & 0.0874 \\
\hline $\mathrm{W} \quad(15-24)$ & 0.1455 & 0.0128 & 1,219 & 1,222 & 1.2693 & 0.0881 & 0.1203 & 0.1707 \\
\hline MM (15-29) & 0.0091 & 0.0029 & 1,275 & 1,271 & 1.1065 & 0.3239 & 0.0033 & 0.0149 \\
\hline MW (15-24) & 0.1563 & 0.0214 & 383 & 386 & 1.1537 & 0.1372 & 0.1141 & 0.1985 \\
\hline UM (15-24) & 0.0796 & 0.0105 & 918 & 907 & 1.1745 & 0.1319 & 0.0589 & 0.1002 \\
\hline UW (15-24) & 0.1402 & 0.0145 & 836 & 834 & 1.2086 & 0.1036 & 0.1116 & 0.1688 \\
\hline \multicolumn{9}{|c|}{ Urban } \\
\hline M (15-24) & 0.0655 & 0.0141 & 528 & 478 & 1.3064 & 0.2150 & 0.0378 & 0.0932 \\
\hline $\mathrm{W} \quad(15-24)$ & 0.1493 & 0.0219 & 462 & 480 & 1.3176 & 0.1465 & 0.1062 & 0.1923 \\
\hline MM (15-29) & 0.0071 & 0.0045 & 636 & 529 & 1.3564 & 0.6348 & 0.0000 & 0.0161 \\
\hline MW (15-24) & 0.2265 & 0.0427 & 115 & 117 & 1.0881 & 0.1883 & 0.1425 & 0.3104 \\
\hline UM (15-24) & 0.0742 & 0.0155 & 430 & 402 & 1.2280 & 0.2094 & 0.0436 & 0.1048 \\
\hline UW (15-24) & 0.1242 & 0.0229 & 347 & 364 & 1.2897 & 0.1841 & 0.0792 & 0.1692 \\
\hline \multicolumn{9}{|c|}{ Rural } \\
\hline M (15-24) & 0.0723 & 0.0120 & 625 & 478 & 1.1553 & 0.1656 & 0.0487 & 0.0959 \\
\hline $\mathrm{W} \quad(15-24)$ & 0.1430 & 0.0157 & 757 & 480 & 1.2321 & 0.1097 & 0.1122 & 0.1739 \\
\hline MM (15-29) & 0.0105 & 0.0039 & 639 & 743 & 0.9568 & 0.3685 & 0.0029 & 0.0180 \\
\hline MW (15-24) & 0.1258 & 0.0245 & 268 & 269 & 1.2061 & 0.1946 & 0.0776 & 0.1739 \\
\hline UM (15-24) & 0.0838 & 0.0142 & 488 & 505 & 1.1302 & 0.1693 & 0.0559 & 0.1118 \\
\hline UW (15-24) & 0.1526 & 0.0185 & 489 & 470 & 1.1356 & 0.1212 & 0.1162 & 0.1890 \\
\hline
\end{tabular}


Table B.2: (Cont'd)

\begin{tabular}{|c|c|c|c|c|c|c|c|c|}
\hline \multirow{2}{*}{$\begin{array}{l}\text { Variable/ } \\
\text { respondent } \\
\text { category }\end{array}$} & \multirow{2}{*}{$\begin{array}{l}\text { Value } \\
(\mathbf{R})\end{array}$} & \multirow{2}{*}{$\begin{array}{l}\text { Standard } \\
\text { error } \\
\text { (SE) }\end{array}$} & \multicolumn{2}{|c|}{ Number of cases } & \multirow{2}{*}{$\begin{array}{l}\text { Design } \\
\text { effect } \\
\text { (DEFT) }\end{array}$} & \multirow{2}{*}{$\begin{array}{c}\text { Relative } \\
\text { standard } \\
\text { error } \\
(\mathrm{SE} / \mathrm{R})\end{array}$} & \multicolumn{2}{|c|}{ 95\% Confidence limits } \\
\hline & & & $\begin{array}{l}\text { Unweighted } \\
(\mathbf{N})\end{array}$ & $\begin{array}{c}\text { Weighted } \\
\text { (WN) }\end{array}$ & & & Lower & Upper \\
\hline \multicolumn{9}{|c|}{ Discussed friendships with father (young men and women whose father was alive at the time of interview) } \\
\hline \multicolumn{9}{|c|}{ Combined } \\
\hline M (15-24) & 0.7005 & 0.0167 & 1,660 & 1,676 & 1.4817 & 0.0238 & 0.6678 & 0.7333 \\
\hline $\mathrm{W} \quad(15-24)$ & 0.6052 & 0.0104 & 4,311 & 4,314 & 1.3904 & 0.0171 & 0.5848 & 0.6256 \\
\hline MM (15-29) & 0.5679 & 0.0236 & 998 & 1,006 & 1.5045 & 0.0416 & 0.5215 & 0.6144 \\
\hline MW (15-24) & 0.5201 & 0.0142 & 1,656 & 1,657 & 1.1576 & 0.0273 & 0.4921 & 0.5481 \\
\hline UM (15-24) & 0.7160 & 0.0165 & 1,460 & 1,467 & 1.3990 & 0.0231 & 0.6835 & 0.7485 \\
\hline UW (15-24) & 0.6574 & 0.0120 & 2,655 & 2,656 & 1.3061 & 0.0183 & 0.6338 & 0.6811 \\
\hline \multicolumn{9}{|c|}{ Urban } \\
\hline M (15-24) & 0.7189 & 0.0217 & 769 & 720 & 1.3357 & 0.0301 & 0.6763 & 0.7616 \\
\hline $\mathrm{W} \quad(15-24)$ & 0.6320 & 0.0140 & 1,867 & 1,923 & 1.2550 & 0.0222 & 0.6044 & 0.6596 \\
\hline MM (15-29) & 0.5813 & 0.0304 & 483 & 404 & 1.3528 & 0.0523 & 0.5214 & 0.6411 \\
\hline MW (15-24) & 0.5415 & 0.0198 & 664 & 668 & 1.0208 & 0.0365 & 0.5026 & 0.5804 \\
\hline UM (15-24) & 0.7333 & 0.0218 & 684 & 649 & 1.2901 & 0.0298 & 0.6904 & 0.7763 \\
\hline UW (15-24) & 0.6806 & 0.0162 & 1,203 & 1,255 & 1.2068 & 0.0238 & 0.6486 & 0.7125 \\
\hline \multicolumn{9}{|c|}{ Rural } \\
\hline M (15-24) & 0.6867 & 0.0240 & 891 & 956 & 1.5444 & 0.0350 & 0.6394 & 0.7339 \\
\hline $\mathrm{W} \quad(15-24)$ & 0.5837 & 0.0144 & 2,444 & 2,391 & 1.4455 & 0.0247 & 0.5553 & 0.6121 \\
\hline MM (15-29) & 0.5590 & 0.0336 & 515 & 602 & 1.5329 & 0.0601 & 0.4929 & 0.6251 \\
\hline MW (15-24) & 0.5057 & 0.0196 & 992 & 989 & 1.2334 & 0.0387 & 0.4671 & 0.5442 \\
\hline UM (15-24) & 0.7023 & 0.0238 & 776 & 818 & 1.4496 & 0.0339 & 0.6554 & 0.7492 \\
\hline UW (15-24) & 0.6367 & 0.0171 & 1,452 & 1,400 & 1.3525 & 0.0268 & 0.6031 & 0.6703 \\
\hline \multicolumn{9}{|c|}{ Discussed friendships with mother (young men and women whose mother was alive at the time of interview) } \\
\hline \multicolumn{9}{|c|}{ Combined } \\
\hline M (15-24) & 0.7589 & 0.0175 & 1,852 & 1,860 & 1.7583 & 0.0230 & 0.7245 & 0.7933 \\
\hline $\mathrm{W} \quad(15-24)$ & 0.8254 & 0.0089 & 4,802 & 4,800 & 1.6249 & 0.0108 & 0.8078 & 0.8429 \\
\hline MM (15-29) & 0.6324 & 0.0218 & 1,194 & 1,194 & 1.5631 & 0.0345 & 0.5895 & 0.6754 \\
\hline MW (15-24) & 0.7638 & 0.0115 & 1,882 & 1,881 & 1.1709 & 0.0150 & 0.7412 & 0.7863 \\
\hline UM (15-24) & 0.7713 & 0.0177 & 1,624 & 1,625 & 1.6935 & 0.0229 & 0.7365 & 0.8060 \\
\hline UW (15-24) & 0.8644 & 0.0098 & 2,921 & 2,919 & 1.5416 & 0.0113 & 0.8452 & 0.8837 \\
\hline \multicolumn{9}{|c|}{ Urban } \\
\hline $\mathrm{M} \quad(15-24)$ & 0.7895 & 0.0200 & 870 & 814 & 1.4447 & 0.0253 & 0.7501 & 0.8288 \\
\hline $\mathrm{W} \quad(15-24)$ & 0.8617 & 0.0109 & 2,071 & 2,132 & 1.4371 & 0.0127 & 0.8403 & 0.8832 \\
\hline MM (15-29) & 0.6588 & 0.0269 & 597 & 496 & 1.3859 & 0.0409 & 0.6058 & 0.7118 \\
\hline MW (15-24) & 0.7958 & 0.0145 & 757 & 762 & 0.9861 & 0.0182 & 0.7674 & 0.8243 \\
\hline UM (15-24) & 0.7996 & 0.0206 & 774 & 733 & 1.4320 & 0.0258 & 0.7590 & 0.8401 \\
\hline UW (15-24) & 0.8987 & 0.0113 & 1,314 & 1,370 & 1.3581 & 0.0126 & 0.8764 & 0.9210 \\
\hline \multicolumn{9}{|c|}{ Rural } \\
\hline M (15-24) & 0.7352 & 0.0266 & 982 & 1,047 & 1.8875 & 0.0362 & 0.6828 & 0.7875 \\
\hline $\mathrm{W} \quad(15-24)$ & 0.7963 & 0.0128 & 2,732 & 2,669 & 1.6582 & 0.0160 & 0.7712 & 0.8215 \\
\hline MM (15-29) & 0.6137 & 0.0318 & 597 & 699 & 1.5930 & 0.0518 & 0.5512 & 0.6763 \\
\hline MW (15-24) & 0.7419 & 0.0163 & 1,125 & 1,119 & 1.2499 & 0.0220 & 0.7098 & 0.7740 \\
\hline UM (15-24) & 0.7481 & 0.0271 & 850 & 892 & 1.8174 & 0.0362 & 0.6948 & 0.8014 \\
\hline UW (15-24) & 0.8341 & 0.0146 & 1,607 & 1,549 & 1.5752 & 0.0175 & 0.8053 & 0.8629 \\
\hline
\end{tabular}


Table B.2: (Cont'd)

\begin{tabular}{|c|c|c|c|c|c|c|c|c|}
\hline \multirow{2}{*}{$\begin{array}{l}\text { Variable/ } \\
\text { respondent } \\
\text { category }\end{array}$} & \multirow{2}{*}{$\begin{array}{l}\text { Value } \\
(\mathbf{R})\end{array}$} & \multirow{2}{*}{$\begin{array}{c}\text { Standard } \\
\text { error } \\
\text { (SE) }\end{array}$} & \multicolumn{2}{|c|}{ Number of cases } & \multirow{2}{*}{$\begin{array}{l}\text { Design } \\
\text { effect } \\
\text { (DEFT) }\end{array}$} & \multirow{2}{*}{$\begin{array}{c}\text { Relative } \\
\text { standard } \\
\text { error } \\
\text { (SE/R) }\end{array}$} & \multicolumn{2}{|c|}{ 95\% Confidence limits } \\
\hline & & & $\begin{array}{c}\text { Unweighted } \\
(\mathbf{N})\end{array}$ & $\begin{array}{l}\text { Weighted } \\
(\mathrm{WN})\end{array}$ & & & Lower & Upper \\
\hline \multicolumn{9}{|c|}{ Independently makes decisions about choice of friends, spending money and buying clothes for oneself (young men and women) } \\
\hline \multicolumn{9}{|c|}{ Combined } \\
\hline M (15-24) & 0.5179 & 0.0186 & 1,913 & 1,917 & 1.6278 & 0.0359 & 0.4813 & 0.5545 \\
\hline W (15-24) & 0.2210 & 0.0093 & 5,008 & 5,008 & 1.5915 & 0.0422 & 0.2026 & 0.2393 \\
\hline MM (15-29) & 0.6468 & 0.0217 & 1,322 & 1,322 & 1.6465 & 0.0335 & 0.6042 & 0.6894 \\
\hline MW (15-24) & 0.2396 & 0.0116 & 2,007 & 2,007 & 1.2136 & 0.0483 & 0.2168 & 0.2624 \\
\hline UM (15-24) & 0.5074 & 0.0188 & 1,666 & 1,666 & 1.5331 & 0.0370 & 0.4704 & 0.5444 \\
\hline UW (15-24) & 0.2088 & 0.0119 & 3,001 & 3,001 & 1.6009 & 0.0569 & 0.1854 & 0.2322 \\
\hline \multicolumn{9}{|c|}{ Urban } \\
\hline M (15-24) & 0.5453 & 0.0239 & 890 & 832 & 1.4323 & 0.0439 & 0.4982 & 0.5924 \\
\hline $\mathrm{W} \quad(15-24)$ & 0.2625 & 0.0162 & 2,151 & 2,215 & 1.7098 & 0.0618 & 0.2306 & 0.2945 \\
\hline MM (15-29) & 0.6984 & 0.0273 & 653 & 543 & 1.5196 & 0.0391 & 0.6446 & 0.7521 \\
\hline MW (15-24) & 0.2820 & 0.0187 & 804 & 809 & 1.1746 & 0.0661 & 0.2453 & 0.3187 \\
\hline UM (15-24) & 0.5400 & 0.0248 & 789 & 747 & 1.3982 & 0.0460 & 0.4912 & 0.5889 \\
\hline UW (15-24) & 0.2512 & 0.0203 & 1,347 & 1,405 & 1.7181 & 0.0809 & 0.2112 & 0.2912 \\
\hline \multicolumn{9}{|c|}{ Rural } \\
\hline M (15-24) & 0.4969 & 0.0271 & 1,023 & 1,086 & 1.7319 & 0.0545 & 0.4436 & 0.5502 \\
\hline $\mathrm{W} \quad(15-24)$ & 0.1880 & 0.0105 & 2,857 & 2,793 & 1.4370 & 0.0559 & 0.1673 & 0.2087 \\
\hline MM (15-29) & 0.6109 & 0.0314 & 669 & 779 & 1.6624 & 0.0513 & 0.5491 & 0.6726 \\
\hline MW (15-24) & 0.2109 & 0.0145 & 1,203 & 1,198 & 1.2285 & 0.0685 & 0.1825 & 0.2394 \\
\hline UM (15-24) & 0.4809 & 0.0271 & 877 & 919 & 1.6082 & 0.0565 & 0.4274 & 0.5343 \\
\hline UW (15-24) & 0.1715 & 0.0131 & 1,654 & 1,596 & 1.4080 & 0.0761 & 0.1458 & 0.1972 \\
\hline \multicolumn{9}{|c|}{ Can visit any place outside village or neighbourhood unescorted (young men and women) } \\
\hline \multicolumn{9}{|c|}{ Combined } \\
\hline W $\quad(15-24)$ & 0.3006 & 0.0137 & 5,008 & 5,008 & 2.1217 & 0.0457 & 0.2735 & 0.3276 \\
\hline MW (15-24) & 0.2997 & 0.0172 & 2,007 & 2,007 & 1.6791 & 0.0573 & 0.2659 & 0.3335 \\
\hline UM (15-24) & 0.7090 & 0.0179 & 1,666 & 1,666 & 1.6081 & 0.0252 & 0.6737 & 0.7442 \\
\hline UW (15-24) & 0.3011 & 0.0146 & 3,001 & 3,001 & 1.7454 & 0.0485 & 0.2724 & 0.3299 \\
\hline \multicolumn{9}{|c|}{ Urban } \\
\hline $\mathrm{W} \quad(15-24)$ & 0.3029 & 0.0196 & 2,151 & 2,215 & 1.9819 & 0.0648 & 0.2642 & 0.3415 \\
\hline MW (15-24) & 0.3030 & 0.0266 & 804 & 809 & 1.6433 & 0.0880 & 0.2505 & 0.3555 \\
\hline UM (15-24) & 0.7486 & 0.0236 & 789 & 747 & 1.5287 & 0.0316 & 0.7021 & 0.7951 \\
\hline UW (15-24) & 0.3028 & 0.0201 & 1,347 & 1,405 & 1.6078 & 0.0665 & 0.2632 & 0.3424 \\
\hline \multicolumn{9}{|c|}{ Rural } \\
\hline $\mathrm{W} \quad(15-24)$ & 0.2988 & 0.0191 & 2,857 & 2,793 & 2.2321 & 0.0640 & 0.2611 & 0.3364 \\
\hline MW (15-24) & 0.2975 & 0.0225 & 1,203 & 1,198 & 1.7033 & 0.0755 & 0.2533 & 0.3417 \\
\hline UM (15-24) & 0.6767 & 0.0256 & 877 & 919 & 1.6211 & 0.0379 & 0.6263 & 0.7272 \\
\hline UW (15-24) & 0.2997 & 0.0210 & 1,654 & 1,596 & 1.8654 & 0.0701 & 0.2583 & 0.3411 \\
\hline
\end{tabular}

Cont'd on next page... 
Table B.2: (Cont'd)

\begin{tabular}{|c|c|c|c|c|c|c|c|c|}
\hline \multirow{2}{*}{$\begin{array}{l}\text { Variable/ } \\
\text { respondent } \\
\text { category }\end{array}$} & \multirow{2}{*}{$\begin{array}{l}\text { Value } \\
\text { (R) }\end{array}$} & \multirow{2}{*}{$\begin{array}{l}\text { Standard } \\
\text { error } \\
\text { (SE) }\end{array}$} & \multicolumn{2}{|c|}{ Number of cases } & \multirow{2}{*}{$\begin{array}{c}\text { Design } \\
\text { effect } \\
(\mathrm{DEFT})\end{array}$} & \multirow{2}{*}{$\begin{array}{c}\text { Relative } \\
\text { standard } \\
\text { error } \\
\text { (SE/R) }\end{array}$} & \multicolumn{2}{|c|}{ 95\% Confidence limits } \\
\hline & & & $\begin{array}{l}\text { Unweighted } \\
(\mathrm{N})\end{array}$ & $\begin{array}{c}\text { Weighted } \\
\text { (WN) }\end{array}$ & & & Lower & Upper \\
\hline \multicolumn{9}{|c|}{ Has savings of any amount (young men and women) } \\
\hline \multicolumn{9}{|c|}{ Combined } \\
\hline M (15-24) & 0.1898 & 0.0113 & 1,913 & 1,917 & 1.2594 & 0.0595 & 0.1676 & 0.2121 \\
\hline $\mathrm{W} \quad(15-24)$ & 0.3095 & 0.0121 & 5,008 & 5,008 & 1.8570 & 0.0392 & 0.2856 & 0.3334 \\
\hline MM (15-29) & 0.2719 & 0.0170 & 1,322 & 1,322 & 1.3875 & 0.0625 & 0.2385 & 0.3053 \\
\hline MW (15-24) & 0.3057 & 0.0160 & 2,007 & 2,007 & 1.5566 & 0.0524 & 0.2742 & 0.3373 \\
\hline UM (15-24) & 0.1915 & 0.0120 & 1,666 & 1,666 & 1.2455 & 0.0627 & 0.1678 & 0.2151 \\
\hline UW (15-24) & 0.3124 & 0.0131 & 3,001 & 3,001 & 1.5454 & 0.0419 & 0.2866 & 0.3381 \\
\hline \multicolumn{9}{|c|}{ Urban } \\
\hline M (15-24) & 0.2229 & 0.0146 & 890 & 831 & 1.0463 & 0.0655 & 0.1941 & 0.2516 \\
\hline $\mathrm{W} \quad(15-24)$ & 0.3255 & 0.0164 & 2,151 & 2,214 & 1.6196 & 0.0503 & 0.2933 & 0.3577 \\
\hline MM (15-29) & 0.3513 & 0.0267 & 653 & 543 & 1.4265 & 0.0759 & 0.2988 & 0.4038 \\
\hline MW (15-24) & 0.2936 & 0.0193 & 804 & 809 & 1.2013 & 0.0658 & 0.2556 & 0.3316 \\
\hline UM (15-24) & 0.2214 & 0.0150 & 789 & 747 & 1.0172 & 0.0680 & 0.1918 & 0.2510 \\
\hline UW (15-24) & 0.3440 & 0.0177 & 1,347 & 1,405 & 1.3695 & 0.0515 & 0.3091 & 0.3789 \\
\hline \multicolumn{9}{|c|}{ Rural } \\
\hline M (15-24) & 0.1646 & 0.0163 & 1,023 & 1,086 & 1.4039 & 0.0989 & 0.1325 & 0.1966 \\
\hline $\mathrm{W} \quad(15-24)$ & 0.2969 & 0.0174 & 2,857 & 2,793 & 2.0387 & 0.0587 & 0.2626 & 0.3312 \\
\hline MM (15-29) & 0.2165 & 0.0197 & 669 & 779 & 1.2379 & 0.0911 & 0.1777 & 0.2554 \\
\hline MW (15-24) & 0.3140 & 0.0234 & 1,203 & 1,197 & 1.7478 & 0.0745 & 0.2679 & 0.3600 \\
\hline UM (15-24) & 0.1671 & 0.0179 & 877 & 919 & 1.4174 & 0.1069 & 0.1319 & 0.2023 \\
\hline UW (15-24) & 0.2845 & 0.0187 & 1,654 & 1,596 & 1.6834 & 0.0657 & 0.2477 & 0.3213 \\
\hline \multicolumn{9}{|c|}{ Justified wife beating in at least one situation (young men and women) } \\
\hline \multicolumn{9}{|c|}{ Combined } \\
\hline M (15-24) & 0.5080 & 0.0215 & 1,913 & 1,917 & 1.8833 & 0.0424 & 0.4656 & 0.5503 \\
\hline $\mathrm{W} \quad(15-24)$ & 0.5546 & 0.0166 & 5,008 & 5,008 & 2.3676 & 0.0300 & 0.5218 & 0.5873 \\
\hline MM (15-29) & 0.5046 & 0.0240 & 1,322 & 1,322 & 1.7455 & 0.0476 & 0.4574 & 0.5519 \\
\hline MW (15-24) & 0.6046 & 0.0185 & 2,007 & 2,007 & 1.6939 & 0.0306 & 0.5682 & 0.6410 \\
\hline UM (15-24) & 0.5060 & 0.0224 & 1,666 & 1,666 & 1.8285 & 0.0443 & 0.4619 & 0.5501 \\
\hline UW (15-24) & 0.5216 & 0.0171 & 3,001 & 3,001 & 1.8783 & 0.0328 & 0.4879 & 0.5553 \\
\hline \multicolumn{9}{|c|}{ Urban } \\
\hline M (15-24) & 0.4196 & 0.0301 & 890 & 832 & 1.8164 & 0.0717 & 0.3604 & 0.4787 \\
\hline $\mathrm{W} \quad(15-24)$ & 0.4949 & 0.0206 & 2,151 & 2,215 & 1.9062 & 0.0415 & 0.4545 & 0.5354 \\
\hline MM (15-29) & 0.4461 & 0.0349 & 653 & 543 & 1.7902 & 0.0781 & 0.3775 & 0.5147 \\
\hline MW (15-24) & 0.5523 & 0.0241 & 804 & 809 & 1.3738 & 0.0437 & 0.5048 & 0.5997 \\
\hline UM (15-24) & 0.4224 & 0.0310 & 789 & 747 & 1.7642 & 0.0735 & 0.3613 & 0.4836 \\
\hline UW (15-24) & 0.4616 & 0.0213 & 1,347 & 1,405 & 1.5709 & 0.0462 & 0.4196 & 0.5036 \\
\hline \multicolumn{9}{|c|}{ Rural } \\
\hline M (15-24) & 0.5756 & 0.0294 & 1,023 & 1,086 & 1.9000 & 0.0510 & 0.5178 & 0.6335 \\
\hline $\mathrm{W} \quad(15-24)$ & 0.6019 & 0.0241 & 2,857 & 2,793 & 2.6316 & 0.0400 & 0.5544 & 0.6493 \\
\hline MM (15-29) & 0.5454 & 0.0324 & 669 & 779 & 1.6820 & 0.0594 & 0.4816 & 0.6092 \\
\hline MW (15-24) & 0.6399 & 0.0259 & 1,203 & 1,198 & 1.8711 & 0.0405 & 0.5889 & 0.6909 \\
\hline UM (15-24) & 0.5739 & 0.0308 & 877 & 919 & 1.8431 & 0.0537 & 0.5133 & 0.6345 \\
\hline UW (15-24) & 0.5744 & 0.0250 & 1,654 & 1,596 & 2.0537 & 0.0435 & 0.5252 & 0.6235 \\
\hline
\end{tabular}


Table B.2: (Cont'd)

\begin{tabular}{|c|c|c|c|c|c|c|c|c|}
\hline \multirow{2}{*}{$\begin{array}{l}\text { Variable/ } \\
\text { respondent } \\
\text { category }\end{array}$} & \multirow{2}{*}{$\begin{array}{l}\text { Value } \\
\text { (R) }\end{array}$} & \multirow{2}{*}{$\begin{array}{c}\text { Standard } \\
\text { error } \\
\text { (SE) }\end{array}$} & \multicolumn{2}{|c|}{ Number of cases } & \multirow{2}{*}{$\begin{array}{c}\text { Design } \\
\text { effect } \\
\text { (DEFT) }\end{array}$} & \multirow{2}{*}{$\begin{array}{c}\text { Relative } \\
\text { standard } \\
\text { error } \\
(\mathrm{SE} / \mathrm{R})\end{array}$} & \multicolumn{2}{|c|}{ 95\% Confidence limits } \\
\hline & & & $\begin{array}{l}\text { Unweighted } \\
(\mathrm{N})\end{array}$ & $\begin{array}{c}\text { Weighted } \\
(\mathrm{WN})\end{array}$ & & & Lower & Upper \\
\hline \multicolumn{9}{|c|}{ Awareness of sex- and pregnancy-related matters (young men and women) } \\
\hline \multicolumn{9}{|c|}{ Combined } \\
\hline M (15-24) & 0.0664 & 0.0091 & 1,913 & 1,917 & 1.5937 & 0.1366 & 0.0486 & 0.0843 \\
\hline $\mathrm{W} \quad(15-24)$ & 0.1176 & 0.0065 & 5,008 & 5,008 & 1.4280 & 0.0553 & 0.1048 & 0.1304 \\
\hline MM (15-29) & 0.1484 & 0.0160 & 1,322 & 1,322 & 1.6360 & 0.1078 & 0.1169 & 0.1799 \\
\hline MW (15-24) & 0.2171 & 0.0121 & 2,007 & 2,007 & 1.3118 & 0.0556 & 0.1934 & 0.2409 \\
\hline UM (15-24) & 0.0598 & 0.0089 & 1,666 & 1,666 & 1.5373 & 0.1494 & 0.0422 & 0.0774 \\
\hline UW (15-24) & 0.0521 & 0.0055 & 3,001 & 3,001 & 1.3594 & 0.1059 & 0.0412 & 0.0629 \\
\hline \multicolumn{9}{|c|}{ Urban } \\
\hline M (15-24) & 0.0896 & 0.0153 & 890 & 832 & 1.5976 & 0.1708 & 0.0594 & 0.1197 \\
\hline $\mathrm{W} \quad(15-24)$ & 0.1085 & 0.0080 & 2,151 & 2,215 & 1.1854 & 0.0733 & 0.0929 & 0.1242 \\
\hline MM (15-29) & 0.1700 & 0.0200 & 653 & 543 & 1.3604 & 0.1177 & 0.1306 & 0.2094 \\
\hline MW (15-24) & 0.2203 & 0.0177 & 804 & 809 & 1.2128 & 0.0805 & 0.1854 & 0.2552 \\
\hline UM (15-24) & 0.0834 & 0.0156 & 789 & 747 & 1.5852 & 0.1872 & 0.0527 & 0.1142 \\
\hline UW (15-24) & 0.0436 & 0.0064 & 1,347 & 1,405 & 1.1553 & 0.1474 & 0.0310 & 0.0563 \\
\hline \multicolumn{9}{|c|}{ Rural } \\
\hline M (15-24) & 0.0487 & 0.0106 & 1,023 & 1,086 & 1.5721 & 0.2173 & 0.0279 & 0.0696 \\
\hline $\mathrm{W} \quad(15-24)$ & 0.1247 & 0.0098 & 2,857 & 2,793 & 1.5875 & 0.0787 & 0.1054 & 0.1441 \\
\hline MM (15-29) & 0.1333 & 0.0234 & 669 & 779 & 1.7786 & 0.1754 & 0.0873 & 0.1794 \\
\hline MW (15-24) & 0.2150 & 0.0163 & 1,203 & 1,198 & 1.3758 & 0.0758 & 0.1829 & 0.2471 \\
\hline UM (15-24) & 0.0405 & 0.0095 & 877 & 919 & 1.4329 & 0.2355 & 0.0218 & 0.0593 \\
\hline UW (15-24) & 0.0595 & 0.0087 & 1,654 & 1,596 & 1.4945 & 0.1461 & 0.0424 & 0.0767 \\
\hline \multicolumn{9}{|c|}{ Correct specific knowledge of at least one contraceptive method (young men and women) } \\
\hline \multicolumn{9}{|c|}{ Combined } \\
\hline M (15-24) & 0.7937 & 0.0111 & 1,913 & 1,917 & 1.1988 & 0.0140 & 0.7718 & 0.8155 \\
\hline $\mathrm{W} \quad(15-24)$ & 0.5350 & 0.0140 & 5,008 & 5,008 & 1.9793 & 0.0261 & 0.5075 & 0.5624 \\
\hline MM (15-29) & 0.9521 & 0.0081 & 1,322 & 1,322 & 1.3752 & 0.0085 & 0.9362 & 0.9680 \\
\hline MW (15-24) & 0.7491 & 0.0166 & 2,007 & 2,007 & 1.7190 & 0.0222 & 0.7164 & 0.7819 \\
\hline UM (15-24) & 0.7801 & 0.0119 & 1,666 & 1,666 & 1.1719 & 0.0152 & 0.7567 & 0.8035 \\
\hline UW (15-24) & 0.3940 & 0.0162 & 3,001 & 3,001 & 1.8183 & 0.0412 & 0.3621 & 0.4259 \\
\hline \multicolumn{9}{|c|}{ Urban } \\
\hline M (15-24) & 0.8106 & 0.0167 & 890 & 832 & 1.2708 & 0.0206 & 0.7777 & 0.8435 \\
\hline $\mathrm{W} \quad(15-24)$ & 0.5399 & 0.0187 & 2,151 & 2,215 & 1.7362 & 0.0346 & 0.5032 & 0.5767 \\
\hline MM (15-29) & 0.9437 & 0.0140 & 653 & 543 & 1.5466 & 0.0148 & 0.9162 & 0.9712 \\
\hline MW (15-24) & 0.7946 & 0.0216 & 804 & 809 & 1.5155 & 0.0272 & 0.7521 & 0.8372 \\
\hline UM (15-24) & 0.8012 & 0.0178 & 789 & 747 & 1.2528 & 0.0222 & 0.7662 & 0.8363 \\
\hline UW (15-24) & 0.3920 & 0.0235 & 1,347 & 1,405 & 1.7651 & 0.0599 & 0.3458 & 0.4382 \\
\hline \multicolumn{9}{|c|}{ Rural } \\
\hline M (15-24) & 0.7807 & 0.0147 & 1,023 & 1,086 & 1.1383 & 0.0189 & 0.7517 & 0.8097 \\
\hline $\mathrm{W} \quad(15-24)$ & 0.5310 & 0.0202 & 2,857 & 2,793 & 2.1594 & 0.0380 & 0.4913 & 0.5707 \\
\hline MM (15-29) & 0.9580 & 0.0097 & 669 & 779 & 1.2428 & 0.0101 & 0.9390 & 0.9770 \\
\hline MW (15-24) & 0.7183 & 0.0235 & 1,203 & 1,198 & 1.8122 & 0.0327 & 0.6720 & 0.7646 \\
\hline UM (15-24) & 0.7629 & 0.0158 & 877 & 919 & 1.0976 & 0.0207 & 0.7319 & 0.7940 \\
\hline UW (15-24) & 0.3957 & 0.0224 & 1,654 & 1,596 & 1.8636 & 0.0566 & 0.3516 & 0.4399 \\
\hline
\end{tabular}


Table B.2: (Cont'd)

\begin{tabular}{|c|c|c|c|c|c|c|c|c|}
\hline \multirow{2}{*}{$\begin{array}{l}\text { Variable/ } \\
\text { respondent } \\
\text { category }\end{array}$} & \multirow{2}{*}{$\begin{array}{l}\text { Value } \\
\text { (R) }\end{array}$} & \multirow{2}{*}{$\begin{array}{c}\text { Standard } \\
\text { error } \\
\text { (SE) }\end{array}$} & \multicolumn{2}{|c|}{ Number of cases } & \multirow{2}{*}{$\begin{array}{c}\text { Design } \\
\text { effect } \\
\text { (DEFT) }\end{array}$} & \multirow{2}{*}{$\begin{array}{c}\text { Relative } \\
\text { standard } \\
\text { error } \\
(\mathrm{SE} / \mathrm{R})\end{array}$} & \multicolumn{2}{|c|}{ 95\% Confidence limits } \\
\hline & & & $\begin{array}{l}\text { Unweighted } \\
(\mathrm{N})\end{array}$ & $\begin{array}{c}\text { Weighted } \\
(\mathrm{WN})\end{array}$ & & & Lower & Upper \\
\hline \multicolumn{9}{|c|}{ Correct specific knowledge of condoms (young men and women) } \\
\hline \multicolumn{9}{|c|}{ Combined } \\
\hline M (15-24) & 0.7704 & 0.0124 & 1,913 & 1,917 & 1.2852 & 0.0160 & 0.7461 & 0.7947 \\
\hline $\mathrm{W} \quad(15-24)$ & 0.3862 & 0.0128 & 5,008 & 5,008 & 1.8658 & 0.0332 & 0.3609 & 0.4114 \\
\hline MM (15-29) & 0.8944 & 0.0137 & 1,322 & 1,322 & 1.6198 & 0.0153 & 0.8674 & 0.9213 \\
\hline MW (15-24) & 0.4954 & 0.0185 & 2,007 & 2,007 & 1.6560 & 0.0373 & 0.4590 & 0.5318 \\
\hline UM (15-24) & 0.7606 & 0.0129 & 1,666 & 1,666 & 1.2357 & 0.0170 & 0.7351 & 0.7860 \\
\hline UW (15-24) & 0.3141 & 0.0139 & 3,001 & 3,001 & 1.6345 & 0.0441 & 0.2869 & 0.3414 \\
\hline \multicolumn{9}{|c|}{ Urban } \\
\hline M (15-24) & 0.7918 & 0.0179 & 890 & 832 & 1.3140 & 0.0226 & 0.7566 & 0.8270 \\
\hline $\mathrm{W} \quad(15-24)$ & 0.4002 & 0.0172 & 2,151 & 2,215 & 1.6266 & 0.0429 & 0.3663 & 0.4340 \\
\hline MM (15-29) & 0.9216 & 0.0156 & 653 & 543 & 1.4822 & 0.0169 & 0.8909 & 0.9523 \\
\hline MW (15-24) & 0.5442 & 0.0237 & 804 & 809 & 1.3470 & 0.0435 & 0.4976 & 0.5908 \\
\hline UM (15-24) & 0.7832 & 0.0190 & 789 & 747 & 1.2920 & 0.0242 & 0.7459 & 0.8205 \\
\hline UW (15-24) & 0.3165 & 0.0210 & 1,347 & 1,405 & 1.6579 & 0.0664 & 0.2751 & 0.3579 \\
\hline \multicolumn{9}{|c|}{ Rural } \\
\hline M (15-24) & 0.7540 & 0.0169 & 1,023 & 1,086 & 1.2524 & 0.0224 & 0.7208 & 0.7872 \\
\hline $\mathrm{W} \quad(15-24)$ & 0.3751 & 0.0185 & 2,857 & 2,793 & 2.0421 & 0.0493 & 0.3387 & 0.4115 \\
\hline MM (15-29) & 0.8754 & 0.0203 & 669 & 779 & 1.5915 & 0.0232 & 0.8353 & 0.9154 \\
\hline MW (15-24) & 0.4623 & 0.0264 & 1,203 & 1,198 & 1.8343 & 0.0571 & 0.4104 & 0.5143 \\
\hline UM (15-24) & 0.7422 & 0.0175 & 877 & 919 & 1.1813 & 0.0235 & 0.7078 & 0.7765 \\
\hline UW (15-24) & 0.3120 & 0.0183 & 1,654 & 1,596 & 1.6082 & 0.0587 & 0.2760 & 0.3481 \\
\hline \multicolumn{9}{|c|}{ Ever heard of HIV/AIDS (young men and women) } \\
\hline \multicolumn{9}{|c|}{ Combined } \\
\hline M (15-24) & 0.9889 & 0.0025 & 1,913 & 1,917 & 1.0509 & 0.0025 & 0.9839 & 0.9939 \\
\hline $\mathrm{W} \quad(15-24)$ & 0.9710 & 0.0053 & 5,008 & 5,008 & 2.2468 & 0.0055 & 0.9605 & 0.9815 \\
\hline MM (15-29) & 0.9902 & 0.0038 & 1,322 & 1,322 & 1.4156 & 0.0039 & 0.9827 & 0.9978 \\
\hline MW (15-24) & 0.9680 & 0.0075 & 2,007 & 2,007 & 1.9175 & 0.0078 & 0.9532 & 0.9829 \\
\hline UM (15-24) & 0.9891 & 0.0026 & 1,666 & 1,666 & 1.0229 & 0.0026 & 0.9840 & 0.9942 \\
\hline UW (15-24) & 0.9729 & 0.0051 & 3,001 & 3,001 & 1.7181 & 0.0052 & 0.9629 & 0.9829 \\
\hline \multicolumn{9}{|c|}{ Urban } \\
\hline $\mathrm{M} \quad(15-24)$ & 0.9909 & 0.0037 & 890 & 832 & 1.1730 & 0.0038 & 0.9835 & 0.9982 \\
\hline $\mathrm{W} \quad(15-24)$ & 0.9855 & 0.0033 & 2,151 & 2,215 & 1.2754 & 0.0033 & 0.9790 & 0.9920 \\
\hline MM (15-29) & 0.9913 & 0.0062 & 653 & 543 & 1.7055 & 0.0063 & 0.9791 & 1.0035 \\
\hline MW (15-24) & 0.9828 & 0.0059 & 804 & 809 & 1.2841 & 0.0060 & 0.9712 & 0.9944 \\
\hline UM (15-24) & 0.9912 & 0.0036 & 789 & 747 & 1.0716 & 0.0036 & 0.9842 & 0.9982 \\
\hline UW (15-24) & 0.9871 & 0.0034 & 1,347 & 1,405 & 1.1093 & 0.0035 & 0.9804 & 0.9938 \\
\hline \multicolumn{9}{|c|}{ Rural } \\
\hline M (15-24) & 0.9874 & 0.0034 & 1,023 & 1,086 & 0.9735 & 0.0034 & 0.9807 & 0.9941 \\
\hline $\mathrm{W} \quad(15-24)$ & 0.9594 & 0.0090 & 2,857 & 2,793 & 2.4271 & 0.0093 & 0.9418 & 0.9771 \\
\hline MM (15-29) & 0.9894 & 0.0049 & 669 & 779 & 1.2289 & 0.0049 & 0.9799 & 0.9990 \\
\hline MW (15-24) & 0.9581 & 0.0118 & 1,203 & 1,198 & 2.0338 & 0.0123 & 0.9349 & 0.9812 \\
\hline UM (15-24) & 0.9874 & 0.0037 & 877 & 919 & 0.9893 & 0.0038 & 0.9801 & 0.9948 \\
\hline UW (15-24) & 0.9604 & 0.0088 & 1,654 & 1,596 & 1.8449 & 0.0092 & 0.9430 & 0.9778 \\
\hline
\end{tabular}


Table B.2: (Cont'd)

\begin{tabular}{|c|c|c|c|c|c|c|c|c|}
\hline \multirow{2}{*}{$\begin{array}{l}\text { Variable/ } \\
\text { respondent } \\
\text { category }\end{array}$} & \multirow{2}{*}{$\begin{array}{l}\text { Value } \\
\text { (R) }\end{array}$} & \multirow{2}{*}{$\begin{array}{c}\text { Standard } \\
\text { error } \\
\text { (SE) }\end{array}$} & \multicolumn{2}{|c|}{ Number of cases } & \multirow{2}{*}{$\begin{array}{c}\text { Design } \\
\text { effect } \\
\text { (DEFT) }\end{array}$} & \multirow{2}{*}{$\begin{array}{c}\text { Relative } \\
\text { standard } \\
\text { error } \\
\text { (SE/R) }\end{array}$} & \multicolumn{2}{|c|}{ 95\% Confidence limits } \\
\hline & & & $\begin{array}{l}\text { Unweighted } \\
(\mathbf{N})\end{array}$ & $\begin{array}{c}\text { Weighted } \\
\text { (WN) }\end{array}$ & & & Lower & Upper \\
\hline \multicolumn{9}{|c|}{ Comprehensive knowledge of HIV/AIDS (young men and women) } \\
\hline \multicolumn{9}{|c|}{ Combined } \\
\hline $\mathrm{M} \quad(15-24)$ & 0.4957 & 0.0140 & 1,913 & 1,917 & 1.2283 & 0.0283 & 0.4681 & 0.5234 \\
\hline $\mathrm{W} \quad(15-24)$ & 0.4548 & 0.0165 & 5,008 & 5,008 & 2.3388 & 0.0362 & 0.4224 & 0.4872 \\
\hline MM (15-29) & 0.4833 & 0.0182 & 1,322 & 1,322 & 1.3232 & 0.0376 & 0.4475 & 0.5191 \\
\hline MW (15-24) & 0.4475 & 0.0180 & 2,007 & 2,007 & 1.6239 & 0.0403 & 0.4120 & 0.4830 \\
\hline UM (15-24) & 0.4995 & 0.0145 & 1,666 & 1,666 & 1.1864 & 0.0291 & 0.4709 & 0.5281 \\
\hline UW (15-24) & 0.4597 & 0.0179 & 3,001 & 3,001 & 1.9718 & 0.0390 & 0.4244 & 0.4950 \\
\hline \multicolumn{9}{|c|}{ Urban } \\
\hline M (15-24) & 0.5465 & 0.0226 & 890 & 832 & 1.3557 & 0.0414 & 0.5019 & 0.5910 \\
\hline $\mathrm{W} \quad(15-24)$ & 0.4945 & 0.0232 & 2,151 & 2,215 & 2.1504 & 0.0469 & 0.4489 & 0.5402 \\
\hline MM (15-29) & 0.5599 & 0.0241 & 653 & 543 & 1.2403 & 0.0431 & 0.5125 & 0.6074 \\
\hline MW (15-24) & 0.4825 & 0.0251 & 804 & 809 & 1.4244 & 0.0521 & 0.4331 & 0.5320 \\
\hline UM (15-24) & 0.5528 & 0.0226 & 789 & 747 & 1.2756 & 0.0409 & 0.5084 & 0.5973 \\
\hline UW (15-24) & 0.5015 & 0.0260 & 1,347 & 1,405 & 1.9083 & 0.0519 & 0.4503 & 0.5527 \\
\hline \multicolumn{9}{|c|}{ Rural } \\
\hline M (15-24) & 0.4569 & 0.0169 & 1,023 & 1,086 & 1.0856 & 0.0370 & 0.4236 & 0.4902 \\
\hline $\mathrm{W} \quad(15-24)$ & 0.4233 & 0.0225 & 2,857 & 2,793 & 2.4388 & 0.0533 & 0.3789 & 0.4677 \\
\hline MM (15-29) & 0.4299 & 0.0253 & 669 & 779 & 1.3206 & 0.0588 & 0.3801 & 0.4797 \\
\hline MW (15-24) & 0.4238 & 0.0247 & 1,203 & 1,198 & 1.7314 & 0.0582 & 0.3752 & 0.4724 \\
\hline UM (15-24) & 0.4562 & 0.0179 & 877 & 919 & 1.0620 & 0.0392 & 0.4210 & 0.4913 \\
\hline UW (15-24) & 0.4229 & 0.0243 & 1,654 & 1,596 & 1.9975 & 0.0574 & 0.3751 & 0.4706 \\
\hline \multicolumn{9}{|c|}{ Ever heard of STIs other than HIV (young men and women) } \\
\hline \multicolumn{9}{|c|}{ Combined } \\
\hline$M \quad(15-24)$ & 0.3048 & 0.0174 & 1,913 & 1,917 & 1.6523 & 0.0571 & 0.2705 & 0.3390 \\
\hline $\mathrm{W} \quad(15-24)$ & 0.1169 & 0.0082 & 5,008 & 5,008 & 1.8025 & 0.0700 & 0.1008 & 0.1330 \\
\hline MM (15-29) & 0.3743 & 0.0216 & 1,332 & 1,322 & 1.6213 & 0.0577 & 0.3318 & 0.4168 \\
\hline MW (15-24) & 0.1561 & 0.0127 & 2,007 & 2,007 & 1.5628 & 0.0811 & 0.1312 & 0.1811 \\
\hline UM (15-24) & 0.3021 & 0.0180 & 1,666 & 1,666 & 1.6030 & 0.0597 & 0.2666 & 0.3376 \\
\hline UW (15-24) & 0.9013 & 0.0075 & 3,001 & 3,001 & 1.4344 & 0.0826 & 0.0765 & 0.1062 \\
\hline \multicolumn{9}{|c|}{ Urban } \\
\hline M (15-24) & 0.3140 & 0.0250 & 890 & 832 & 1.6090 & 0.0798 & 0.2647 & 0.3633 \\
\hline $\mathrm{W} \quad(15-24)$ & 0.1197 & 0.0112 & 2,151 & 2,215 & 1.5978 & 0.0934 & 0.0977 & 0.1418 \\
\hline MM (15-29) & 0.4096 & 0.0352 & 653 & 543 & 1.8269 & 0.0859 & 0.3404 & 0.4789 \\
\hline MW (15-24) & 0.1517 & 0.0164 & 804 & 809 & 1.2989 & 0.1084 & 0.1193 & 0.1841 \\
\hline UM (15-24) & 0.3162 & 0.0254 & 789 & 747 & 1.5353 & 0.0804 & 0.2661 & 0.3662 \\
\hline UW (15-24) & 0.1012 & 0.0114 & 1,347 & 1,405 & 1.3883 & 0.1128 & 0.0787 & 0.1236 \\
\hline \multicolumn{9}{|c|}{ Rural } \\
\hline M (15-24) & 0.2977 & 0.0239 & 1,023 & 1,086 & 1.6731 & 0.0804 & 0.2506 & 0.3448 \\
\hline $\mathrm{W} \quad(15-24)$ & 0.1147 & 0.0117 & 2,857 & 2,793 & 1.9617 & 0.1020 & 0.0917 & 0.1377 \\
\hline MM (15-29) & 0.3497 & 0.0268 & 669 & 779 & 1.4549 & 0.0768 & 0.2969 & 0.4026 \\
\hline MW (15-24) & 0.1591 & 0.0181 & 1,203 & 1,198 & 1.7120 & 0.1135 & 0.1236 & 0.1947 \\
\hline UM (15-24) & 0.2906 & 0.0252 & 877 & 919 & 1.6444 & 0.0868 & 0.2409 & 0.3402 \\
\hline UW (15-24) & 0.0826 & 0.0100 & 1,654 & 1,598 & 1.4696 & 0.1205 & 0.0630 & 0.1022 \\
\hline
\end{tabular}


Table B.2: (Cont'd)

\begin{tabular}{|c|c|c|c|c|c|c|c|c|}
\hline \multirow{2}{*}{$\begin{array}{l}\text { Variable/ } \\
\text { respondent } \\
\text { category }\end{array}$} & \multirow{2}{*}{$\begin{array}{l}\text { Value } \\
\text { (R) }\end{array}$} & \multirow{2}{*}{$\begin{array}{c}\text { Standard } \\
\text { error } \\
\text { (SE) }\end{array}$} & \multicolumn{2}{|c|}{ Number of cases } & \multirow{2}{*}{$\begin{array}{c}\text { Design } \\
\text { effect } \\
\text { (DEFT) }\end{array}$} & \multirow{2}{*}{$\begin{array}{c}\text { Relative } \\
\text { standard } \\
\text { error } \\
(\mathrm{SE} / \mathrm{R})\end{array}$} & \multicolumn{2}{|c|}{ 95\% Confidence limits } \\
\hline & & & $\begin{array}{l}\text { Unweighted } \\
(\mathrm{N})\end{array}$ & $\begin{array}{c}\text { Weighted } \\
(\mathrm{WN})\end{array}$ & & & Lower & Upper \\
\hline \multicolumn{9}{|c|}{ Correct knowledge of the conditions under which abortion is legal (young men and women) } \\
\hline \multicolumn{9}{|c|}{ Combined } \\
\hline M (15-24) & 0.0599 & 0.0062 & 1,913 & 1,917 & 1.1406 & 0.1033 & 0.0477 & 0.0721 \\
\hline W $\quad(15-24)$ & 0.0582 & 0.0040 & 5,008 & 5,008 & 1.2102 & 0.0688 & 0.0503 & 0.0661 \\
\hline MM (15-29) & 0.0656 & 0.0080 & 1,322 & 1,322 & 1.1801 & 0.1226 & 0.0497 & 0.0814 \\
\hline MW (15-24) & 0.0695 & 0.0065 & 2,007 & 2,007 & 1.1421 & 0.0933 & 0.0567 & 0.0823 \\
\hline UM (15-24) & 0.0628 & 0.0067 & 1,666 & 1,666 & 1.1320 & 0.1071 & 0.0496 & 0.0761 \\
\hline UW (15-24) & 0.0507 & 0.0044 & 3,001 & 3,001 & 1.1084 & 0.0875 & 0.0420 & 0.0595 \\
\hline \multicolumn{9}{|c|}{ Urban } \\
\hline M (15-24) & 0.0795 & 0.0106 & 890 & 832 & 1.1705 & 0.1336 & 0.0586 & 0.1004 \\
\hline $\mathrm{W} \quad(15-24)$ & 0.0642 & 0.0069 & 2,151 & 2,215 & 1.3046 & 0.1074 & 0.0506 & 0.0778 \\
\hline MM (15-29) & 0.0734 & 0.0132 & 653 & 543 & 1.2887 & 0.1793 & 0.0475 & 0.0993 \\
\hline MW (15-24) & 0.0780 & 0.0123 & 804 & 809 & 1.3006 & 0.1578 & 0.0538 & 0.1023 \\
\hline UM (15-24) & 0.0850 & 0.0113 & 789 & 747 & 1.1341 & 0.1326 & 0.0628 & 0.1072 \\
\hline UW (15-24) & 0.0562 & 0.0069 & 1,347 & 1,405 & 1.0979 & 0.1226 & 0.0426 & 0.0698 \\
\hline \multicolumn{9}{|c|}{ Rural } \\
\hline M (15-24) & 0.0449 & 0.0070 & 1,023 & 1,086 & 1.0745 & 0.1550 & 0.0312 & 0.0586 \\
\hline $\mathrm{W} \quad(15-24)$ & 0.0534 & 0.0046 & 2,857 & 2,793 & 1.0933 & 0.0861 & 0.0443 & 0.0624 \\
\hline MM (15-29) & 0.0601 & 0.0101 & 669 & 779 & 1.0958 & 0.1677 & 0.0403 & 0.0799 \\
\hline MW (15-24) & 0.0637 & 0.0070 & 1,203 & 1,198 & 0.9993 & 0.1105 & 0.0499 & 0.0776 \\
\hline UM (15-24) & 0.0448 & 0.0076 & 877 & 919 & 1.0894 & 0.1699 & 0.0298 & 0.0598 \\
\hline UW (15-24) & 0.0459 & 0.0057 & 1,654 & 1,596 & 1.1107 & 0.1245 & 0.0347 & 0.0572 \\
\hline \multicolumn{9}{|c|}{ Ever received family life or sex education (young men and women) } \\
\hline \multicolumn{9}{|c|}{ Combined } \\
\hline$M \quad(15-24)$ & 0.2137 & 0.0145 & 1,913 & 1,917 & 1.5481 & 0.0679 & 0.1851 & 0.2423 \\
\hline $\mathrm{W} \quad(15-24)$ & 0.1696 & 0.0083 & 5,008 & 5,008 & 1.5700 & 0.0491 & 0.1532 & 0.1860 \\
\hline MM (15-29) & 0.1306 & 0.0117 & 1,322 & 1,322 & 1.2608 & 0.0895 & 0.1076 & 0.1536 \\
\hline MW (15-24) & 0.0863 & 0.0080 & 2,007 & 2,007 & 1.2836 & 0.0933 & 0.0704 & 0.1021 \\
\hline UM (15-24) & 0.2247 & 0.0153 & 1,666 & 1,666 & 1.4918 & 0.0679 & 0.1947 & 0.2548 \\
\hline UW (15-24) & 0.2243 & 0.0113 & 3,001 & 3,001 & 1.4787 & 0.0502 & 0.2021 & 0.2464 \\
\hline \multicolumn{9}{|c|}{ Urban } \\
\hline $\mathrm{M} \quad(15-24)$ & 0.2172 & 0.0199 & 890 & 832 & 1.4415 & 0.0918 & 0.1780 & 0.2565 \\
\hline $\mathrm{W} \quad(15-24)$ & 0.1804 & 0.0133 & 2,151 & 2,215 & 1.6058 & 0.0738 & 0.1542 & 0.2066 \\
\hline MM (15-29) & 0.1394 & 0.0157 & 653 & 543 & 1.1568 & 0.1126 & 0.1085 & 0.1703 \\
\hline MW (15-24) & 0.0979 & 0.0131 & 804 & 809 & 1.2518 & 0.1341 & 0.0720 & 0.1237 \\
\hline UM (15-24) & 0.2262 & 0.0222 & 789 & 747 & 1.4919 & 0.0983 & 0.1825 & 0.2700 \\
\hline UW (15-24) & 0.2284 & 0.0174 & 1,347 & 1,405 & 1.5166 & 0.0760 & 0.1942 & 0.2625 \\
\hline \multicolumn{9}{|c|}{ Rural } \\
\hline M (15-24) & 0.2110 & 0.0206 & 1,023 & 1,086 & 1.6117 & 0.0975 & 0.1705 & 0.2515 \\
\hline $\mathrm{W} \quad(15-24)$ & 0.1610 & 0.0105 & 2,857 & 2,793 & 1.5307 & 0.0654 & 0.1403 & 0.1817 \\
\hline MM (15-29) & 0.1245 & 0.0165 & 669 & 779 & 1.2956 & 0.1329 & 0.0919 & 0.1571 \\
\hline MW (15-24) & 0.0784 & 0.0101 & 1,203 & 1,198 & 1.3073 & 0.1293 & 0.0585 & 0.0984 \\
\hline UM (15-24) & 0.2235 & 0.0209 & 877 & 919 & 1.4877 & 0.0937 & 0.1823 & 0.2647 \\
\hline UW (15-24) & 0.2206 & 0.0146 & 1,654 & 1,596 & 1.4354 & 0.0664 & 0.1918 & 0.2495 \\
\hline
\end{tabular}


Table B.2: (Cont'd)

\begin{tabular}{|c|c|c|c|c|c|c|c|c|}
\hline \multirow{2}{*}{$\begin{array}{l}\text { Variable/ } \\
\text { respondent } \\
\text { category }\end{array}$} & \multirow{2}{*}{$\begin{array}{l}\text { Value } \\
\text { (R) }\end{array}$} & \multirow{2}{*}{$\begin{array}{c}\text { Standard } \\
\text { error } \\
\text { (SE) }\end{array}$} & \multicolumn{2}{|c|}{ Number of cases } & \multirow{2}{*}{$\begin{array}{c}\text { Design } \\
\text { effect } \\
\text { (DEFT) }\end{array}$} & \multirow{2}{*}{$\begin{array}{c}\text { Relative } \\
\text { standard } \\
\text { error } \\
(\mathrm{SE} / \mathrm{R})\end{array}$} & \multicolumn{2}{|c|}{ 95\% Confidence limits } \\
\hline & & & $\begin{array}{l}\text { Unweighted } \\
(\mathrm{N})\end{array}$ & $\begin{array}{c}\text { Weighted } \\
(\mathrm{WN})\end{array}$ & & & Lower & Upper \\
\hline \multicolumn{9}{|c|}{ Ever had an opposite-sex romantic partner (young men and women) } \\
\hline \multicolumn{9}{|c|}{ Combined } \\
\hline M (15-24) & 0.2273 & 0.0146 & 1,913 & 1,917 & 1.5280 & 0.0644 & 0.1984 & 0.2561 \\
\hline $\mathrm{W} \quad(15-24)$ & 0.1541 & 0.0083 & 5,008 & 5,008 & 1.6193 & 0.0536 & 0.1378 & 0.1704 \\
\hline MM (15-29) & 0.3480 & 0.0189 & 1,322 & 1,322 & 1.4407 & 0.0543 & 0.3108 & 0.3852 \\
\hline MW (15-24) & 0.2400 & 0.0126 & 2,007 & 2,007 & 1.3253 & 0.0527 & 0.2151 & 0.2648 \\
\hline UM (15-24) & 0.1993 & 0.0144 & 1,666 & 1,666 & 1.4722 & 0.0723 & 0.1710 & 0.2277 \\
\hline UW (15-24) & 0.0977 & 0.0080 & 3,001 & 3,001 & 1.4815 & 0.0822 & 0.0819 & 0.1135 \\
\hline \multicolumn{9}{|c|}{ Urban } \\
\hline $\mathrm{M} \quad(15-24)$ & 0.1997 & 0.0168 & 890 & 832 & 1.2562 & 0.0843 & 0.1666 & 0.2329 \\
\hline $\mathrm{W} \quad(15-24)$ & 0.1282 & 0.0102 & 2,151 & 2,215 & 1.4136 & 0.0795 & 0.1082 & 0.1483 \\
\hline MM (15-29) & 0.2936 & 0.0250 & 653 & 543 & 1.4039 & 0.0853 & 0.2443 & 0.3429 \\
\hline MW (15-24) & 0.2145 & 0.0212 & 804 & 809 & 1.4648 & 0.0989 & 0.1728 & 0.2563 \\
\hline UM (15-24) & 0.1761 & 0.0170 & 789 & 747 & 1.2511 & 0.0964 & 0.1427 & 0.2095 \\
\hline UW (15-24) & 0.0781 & 0.0079 & 1,347 & 1,405 & 1.0775 & 0.1009 & 0.0626 & 0.0936 \\
\hline \multicolumn{9}{|c|}{ Rural } \\
\hline M (15-24) & 0.2484 & 0.0224 & 1,023 & 1,086 & 1.6600 & 0.0903 & 0.2042 & 0.2925 \\
\hline $\mathrm{W} \quad(15-24)$ & 0.1746 & 0.0121 & 2,857 & 2,793 & 1.6965 & 0.0690 & 0.1509 & 0.1983 \\
\hline MM (15-29) & 0.3859 & 0.0262 & 669 & 779 & 1.3908 & 0.0679 & 0.3344 & 0.4375 \\
\hline MW (15-24) & 0.2571 & 0.0154 & 1,203 & 1,198 & 1.2241 & 0.0600 & 0.2268 & 0.2875 \\
\hline UM (15-24) & 0.2182 & 0.0223 & 877 & 919 & 1.5950 & 0.1020 & 0.1744 & 0.2621 \\
\hline UW (15-24) & 0.1150 & 0.0132 & 1,654 & 1,596 & 1.6761 & 0.1144 & 0.0891 & 0.1409 \\
\hline \multicolumn{9}{|c|}{ Ever had sex with an opposite-sex romantic partner (young men and women) } \\
\hline \multicolumn{9}{|c|}{ Combined } \\
\hline M (15-24) & 0.0582 & 0.0094 & 1,913 & 1,917 & 1.7603 & 0.1619 & 0.0397 & 0.0768 \\
\hline $\mathrm{W} \quad(15-24)$ & 0.0151 & 0.0021 & 5,008 & 5,008 & 1.1883 & 0.1355 & 0.0111 & 0.0192 \\
\hline MM (15-29) & 0.1197 & 0.0145 & 1,322 & 1,322 & 1.6225 & 0.1211 & 0.0911 & 0.1482 \\
\hline MW (15-24) & 0.0255 & 0.0041 & 2,007 & 2,007 & 1.1557 & 0.1595 & 0.0175 & 0.0335 \\
\hline UM (15-24) & 0.0461 & 0.0085 & 1,666 & 1,666 & 1.6611 & 0.1853 & 0.0293 & 0.0628 \\
\hline UW (15-24) & 0.0084 & 0.0018 & 3,001 & 3,001 & 1.1065 & 0.2198 & 0.0048 & 0.0120 \\
\hline \multicolumn{9}{|c|}{ Urban } \\
\hline M (15-24) & 0.0435 & 0.0080 & 890 & 832 & 1.1672 & 0.1835 & 0.0278 & 0.0593 \\
\hline $\mathrm{W} \quad(15-24)$ & 0.0086 & 0.0020 & 2,151 & 2,215 & 1.0067 & 0.2336 & 0.0046 & 0.0125 \\
\hline MM (15-29) & 0.0849 & 0.0191 & 653 & 543 & 1.7539 & 0.2256 & 0.0472 & 0.1225 \\
\hline MW (15-24) & 0.0142 & 0.0040 & 804 & 809 & 0.9592 & 0.2820 & 0.0063 & 0.0221 \\
\hline UM (15-24) & 0.0374 & 0.0074 & 789 & 747 & 1.0957 & 0.1979 & 0.0229 & 0.0520 \\
\hline UW (15-24) & 0.0053 & 0.0022 & 1,347 & 1,405 & 1.1190 & 0.4184 & 0.0009 & 0.0096 \\
\hline \multicolumn{9}{|c|}{ Rural } \\
\hline M (15-24) & 0.0695 & 0.0155 & 1,023 & 1,086 & 1.9447 & 0.2227 & 0.0390 & 0.0999 \\
\hline $\mathrm{W} \quad(15-24)$ & 0.0203 & 0.0032 & 2,857 & 2,793 & 1.2182 & 0.1582 & 0.0140 & 0.0267 \\
\hline MM (15-29) & 0.1439 & 0.0202 & 669 & 779 & 1.4883 & 0.1404 & 0.1042 & 0.1837 \\
\hline MW (15-24) & 0.0332 & 0.0061 & 1,203 & 1,198 & 1.1788 & 0.1836 & 0.0212 & 0.0451 \\
\hline UM (15-24) & 0.0531 & 0.0143 & 877 & 919 & 1.8867 & 0.2693 & 0.0249 & 0.0812 \\
\hline UW (15-24) & 0.0111 & 0.0029 & 1,654 & 1,596 & 1.1079 & 0.2573 & 0.0055 & 0.0167 \\
\hline
\end{tabular}


Table B.2: (Cont'd)

\begin{tabular}{|c|c|c|c|c|c|c|c|c|}
\hline \multirow{2}{*}{$\begin{array}{l}\text { Variable/ } \\
\text { respondent } \\
\text { category }\end{array}$} & \multirow{2}{*}{$\begin{array}{l}\text { Value } \\
(\mathbf{R})\end{array}$} & \multirow{2}{*}{$\begin{array}{l}\text { Standard } \\
\text { error } \\
\text { (SE) }\end{array}$} & \multicolumn{2}{|c|}{ Number of cases } & \multirow{2}{*}{$\begin{array}{c}\text { Design } \\
\text { effect } \\
\text { (DEFT) }\end{array}$} & \multirow{2}{*}{$\begin{array}{c}\text { Relative } \\
\text { standard } \\
\text { error } \\
(\mathrm{SE} / \mathrm{R})\end{array}$} & \multicolumn{2}{|c|}{ 95\% Confidence limits } \\
\hline & & & $\begin{array}{l}\text { Unweighted } \\
\quad(\mathbf{N})\end{array}$ & $\begin{array}{l}\text { Weighted } \\
(\mathrm{WN})\end{array}$ & & & Lower & Upper \\
\hline \multicolumn{9}{|c|}{ Ever had pre-marital sex (young men and women) } \\
\hline \multicolumn{9}{|c|}{ Combined } \\
\hline M (15-24) & 0.0924 & 0.0117 & 1,913 & 1,917 & 1.7742 & 0.1272 & 0.0693 & 0.1155 \\
\hline $\mathrm{W} \quad(15-24)$ & 0.0242 & 0.0030 & 5,008 & 5,008 & 1.3861 & 0.1244 & 0.0183 & 0.0301 \\
\hline MM (15-29) & 0.1818 & 0.0172 & 1,322 & 1,322 & 1.6166 & 0.0944 & 0.1480 & 0.2155 \\
\hline MW (15-24) & 0.0411 & 0.0057 & 2,007 & 2,007 & 1.2939 & 0.1395 & 0.0298 & 0.0524 \\
\hline UM (15-24) & 0.0769 & 0.0103 & 1,666 & 1,666 & 1.5774 & 0.1340 & 0.0566 & 0.0972 \\
\hline UW (15-24) & 0.0132 & 0.0025 & 3,001 & 3,001 & 1.1780 & 0.1862 & 0.0083 & 0.0180 \\
\hline \multicolumn{9}{|c|}{ Urban } \\
\hline M (15-24) & 0.0647 & 0.0103 & 890 & 832 & 1.2445 & 0.1587 & 0.0445 & 0.0849 \\
\hline $\mathrm{W} \quad(15-24)$ & 0.0105 & 0.0021 & 2,151 & 2,215 & 0.9465 & 0.1984 & 0.0064 & 0.0146 \\
\hline MM (15-29) & 0.1426 & 0.0234 & 653 & 543 & 1.7072 & 0.1640 & 0.0965 & 0.1886 \\
\hline MW (15-24) & 0.0182 & 0.0043 & 804 & 809 & 0.9178 & 0.2382 & 0.0096 & 0.0267 \\
\hline UM (15-24) & 0.0544 & 0.0093 & 789 & 747 & 1.1468 & 0.1703 & 0.0362 & 0.0727 \\
\hline UW (15-24) & 0.0060 & 0.0023 & 1,347 & 1,405 & 1.0902 & 0.3823 & 0.0015 & 0.0105 \\
\hline \multicolumn{9}{|c|}{ Rural } \\
\hline$M \quad(15-24)$ & 0.1136 & 0.0189 & 1,023 & 1,086 & 1.9089 & 0.1668 & 0.0763 & 0.1509 \\
\hline $\mathrm{W} \quad(15-24)$ & 0.0351 & 0.0047 & 2,857 & 2,793 & 1.3667 & 0.1342 & 0.0258 & 0.0443 \\
\hline MM (15-29) & 0.2091 & 0.0237 & 669 & 779 & 1.5054 & 0.1133 & 0.1625 & 0.2557 \\
\hline MW (15-24) & 0.0566 & 0.0087 & 1,203 & 1,198 & 1.3122 & 0.1545 & 0.0394 & 0.0739 \\
\hline UM (15-24) & 0.0952 & 0.0171 & 877 & 919 & 1.7250 & 0.1797 & 0.0615 & 0.1288 \\
\hline UW (15-24) & 0.0195 & 0.0041 & 1,654 & 1,596 & 1.2023 & 0.2099 & 0.0114 & 0.0275 \\
\hline \multicolumn{9}{|c|}{$\begin{array}{l}\text { Used condoms consistently in pre-marital relations } \\
\text { and women who reported pre-marital sex in face-to-face interview) }\end{array}$} \\
\hline \multicolumn{9}{|c|}{ Combined } \\
\hline$M \quad(15-24)$ & 0.0528 & 0.0206 & 171 & 156 & 1.2023 & 0.3904 & 0.0120 & 0.0937 \\
\hline $\mathrm{W} \quad(15-24)$ & 0.0000 & 0.0000 & 92 & 91 & 0.0000 & 0.0000 & 0.0000 & 0.0000 \\
\hline MM (15-29) & 0.0500 & 0.0159 & 219 & 212 & 1.0779 & 0.3183 & 0.0185 & 0.0814 \\
\hline UM (15-24) & 0.0491 & 0.0223 & 114 & 110 & 1.0992 & 0.4550 & 0.0049 & 0.0933 \\
\hline \multicolumn{9}{|c|}{$\begin{array}{l}\text { Ever communicated with spouse on contraception } \\
\text { (married young men and women who had begun cohabiting) }\end{array}$} \\
\hline \multicolumn{9}{|c|}{ Combined } \\
\hline MM (15-29) & 0.3708 & 0.0189 & 1,321 & 1,321 & 1.4231 & 0.0511 & 0.3335 & 0.4081 \\
\hline MW (15-24) & 0.5878 & 0.0167 & 2,006 & 2,006 & 1.5228 & 0.0285 & 0.5548 & 0.6208 \\
\hline \multicolumn{9}{|c|}{ Urban } \\
\hline MM (15-29) & 0.4029 & 0.0275 & 652 & 542 & 1.4287 & 0.0683 & 0.3487 & 0.4571 \\
\hline MW (15-24) & 0.6391 & 0.0203 & 803 & 808 & 1.1955 & 0.0317 & 0.5991 & 0.6790 \\
\hline \multicolumn{9}{|c|}{ Rural } \\
\hline MM (15-29) & 0.3485 & 0.0255 & 669 & 778 & 1.3805 & 0.0730 & 0.2984 & 0.3986 \\
\hline MW (15-24) & 0.5532 & 0.0237 & 1,203 & 1,198 & 1.6555 & 0.0430 & 0.5065 & 0.6000 \\
\hline
\end{tabular}

Cont'd on next page... 
Table B.2: (Cont'd)

\begin{tabular}{|c|c|c|c|c|c|c|c|c|}
\hline \multirow{2}{*}{$\begin{array}{l}\text { Variable/ } \\
\text { respondent } \\
\text { category }\end{array}$} & \multirow{2}{*}{$\begin{array}{l}\text { Value } \\
(\mathbf{R})\end{array}$} & \multirow{2}{*}{$\begin{array}{l}\text { Standard } \\
\text { error } \\
\text { (SE) }\end{array}$} & \multicolumn{2}{|c|}{ Number of cases } & \multirow{2}{*}{$\begin{array}{l}\text { Design } \\
\text { effect } \\
\text { (DEFT) }\end{array}$} & \multirow{2}{*}{$\begin{array}{c}\text { Relative } \\
\text { standard } \\
\text { error } \\
(\mathrm{SE} / \mathrm{R})\end{array}$} & \multicolumn{2}{|c|}{ 95\% Confidence limits } \\
\hline & & & $\begin{array}{l}\text { Unweighted } \\
(\mathbf{N})\end{array}$ & $\begin{array}{l}\text { Weighted } \\
\text { (WN) }\end{array}$ & & & Lower & Upper \\
\hline \multicolumn{9}{|c|}{$\begin{array}{l}\text { Husband ever forced wife to have sex } \\
\text { young men and women who had begun cohabiting) }\end{array}$} \\
\hline \multicolumn{9}{|c|}{ Combined } \\
\hline MM (15-29) & 0.1466 & 0.0136 & 1,321 & 1,321 & 1.3957 & 0.0927 & 0.1199 & 0.1734 \\
\hline MW (15-24) & 0.2526 & 0.0163 & 2,006 & 2,006 & 1.6791 & 0.0645 & 0.2205 & 0.2846 \\
\hline \multicolumn{9}{|c|}{ Urban } \\
\hline MM (15-29) & 0.1524 & 0.0191 & 652 & 542 & 1.3533 & 0.1251 & 0.1148 & 0.1899 \\
\hline MW (15-24) & 0.2329 & 0.0192 & 803 & 808 & 1.2862 & 0.0824 & 0.1951 & 0.2706 \\
\hline \multicolumn{9}{|c|}{ Rural } \\
\hline MM (15-29) & 0.1426 & 0.0189 & 669 & 779 & 1.3962 & 0.1324 & 0.1054 & 0.1798 \\
\hline MW (15-24) & 0.2659 & 0.0238 & 1,203 & 1,197 & 1.8676 & 0.0895 & 0.2190 & 0.3127 \\
\hline \multicolumn{9}{|c|}{$\begin{array}{l}\text { Husband ever perpetrated physical violence on wife } \\
\text { (married young men and women who had begun cohabiting) }\end{array}$} \\
\hline \multicolumn{9}{|c|}{ Combined } \\
\hline MM (15-29) & 0.3429 & 0.0176 & 1,321 & 1,321 & 1.3438 & 0.0512 & 0.3083 & 0.3775 \\
\hline MW (15-24) & 0.2698 & 0.0159 & 2,006 & 2,006 & 1.5991 & 0.0587 & 0.2386 & 0.3010 \\
\hline \multicolumn{9}{|c|}{ Urban } \\
\hline MM (15-29) & 0.3182 & 0.0259 & 652 & 542 & 1.4211 & 0.0815 & 0.2672 & 0.3693 \\
\hline MW (15-24) & 0.2204 & 0.0195 & 803 & 808 & 1.3287 & 0.0882 & 0.1821 & 0.2587 \\
\hline \multicolumn{9}{|c|}{ Rural } \\
\hline MM (15-29) & 0.3601 & 0.0237 & 669 & 779 & 1.2755 & 0.0658 & 0.3134 & 0.4067 \\
\hline MW (15-24) & 0.3032 & 0.0223 & 1,203 & 1,197 & 1.6826 & 0.0736 & 0.2593 & 0.3471 \\
\hline \multicolumn{9}{|c|}{$\begin{array}{l}\text { Husband ever perpetrated physical violence on wife in last } 12 \text { months } \\
\text { (married young men and women who had begun cohabiting) }\end{array}$} \\
\hline \multicolumn{9}{|c|}{ Combined } \\
\hline MM (15-29) & 0.3089 & 0.0172 & 1,321 & 1,321 & 1.3551 & 0.0558 & 0.2750 & 0.3428 \\
\hline MW (15-24) & 0.2421 & 0.0143 & 2,006 & 2,006 & 1.4919 & 0.0590 & 0.2140 & 0.2702 \\
\hline \multicolumn{9}{|c|}{ Urban } \\
\hline MM (15-29) & 0.2746 & 0.0242 & 652 & 542 & 1.3824 & 0.0881 & 0.2270 & 0.3222 \\
\hline MW (15-24) & 0.1970 & 0.0173 & 803 & 808 & 1.2304 & 0.0877 & 0.1630 & 0.2310 \\
\hline \multicolumn{9}{|c|}{ Rural } \\
\hline MM (15-29) & 0.3328 & 0.0239 & 669 & 779 & 1.3100 & 0.0718 & 0.2858 & 0.3798 \\
\hline MW (15-24) & 0.2725 & 0.0202 & 1,203 & 1,197 & 1.5744 & 0.0742 & 0.2327 & 0.3123 \\
\hline
\end{tabular}

Cont'd on next page... 
Table B.2: (Cont'd)

\begin{tabular}{|c|c|c|c|c|c|c|c|c|}
\hline \multirow{2}{*}{$\begin{array}{l}\text { Variable/ } \\
\text { respondent } \\
\text { category }\end{array}$} & \multirow{2}{*}{$\begin{array}{l}\text { Value } \\
(\mathbf{R})\end{array}$} & \multirow{2}{*}{$\begin{array}{l}\text { Standard } \\
\text { error } \\
\text { (SE) }\end{array}$} & \multicolumn{2}{|c|}{ Number of cases } & \multirow{2}{*}{$\begin{array}{c}\text { Design } \\
\text { effect } \\
\text { (DEFT) }\end{array}$} & \multirow{2}{*}{$\begin{array}{c}\text { Relative } \\
\text { standard } \\
\text { error } \\
(\mathrm{SE} / \mathrm{R})\end{array}$} & \multicolumn{2}{|c|}{ 95\% Confidence limits } \\
\hline & & & $\begin{array}{l}\text { Unweighted } \\
\quad(\mathbf{N})\end{array}$ & $\begin{array}{l}\text { Weighted } \\
(\text { WN) }\end{array}$ & & & Lower & Upper \\
\hline \multicolumn{9}{|c|}{$\begin{array}{l}\text { Currently using any modern contraceptive method } \\
\text { (married young men and women who had begun cohabiting) }\end{array}$} \\
\hline \multicolumn{9}{|c|}{ Combined } \\
\hline MM (15-29) & 0.1523 & 0.0122 & 1,321 & 1,321 & 1.2374 & 0.0804 & 0.1282 & 0.1763 \\
\hline MW (15-24) & 0.1654 & 0.0105 & 2,006 & 2,006 & 1.2658 & 0.0635 & 0.1447 & 0.1860 \\
\hline \multicolumn{9}{|c|}{ Urban } \\
\hline MM (15-29) & 0.1694 & 0.0188 & 652 & 542 & 1.2801 & 0.1111 & 0.1323 & 0.2064 \\
\hline MW (15-24) & 0.2107 & 0.0188 & 803 & 808 & 1.3023 & 0.0890 & 0.1738 & 0.2477 \\
\hline \multicolumn{9}{|c|}{ Rural } \\
\hline MM (15-29) & 0.1403 & 0.0158 & 669 & 779 & 1.1785 & 0.1128 & 0.1092 & 0.1715 \\
\hline MW (15-24) & 0.1347 & 0.0114 & 1,203 & 1,197 & 1.1582 & 0.0847 & 0.1123 & 0.1572 \\
\hline \multicolumn{9}{|c|}{$\begin{array}{l}\text { First delivery in a health institution } \\
\text { nen and women whose first pregnancy outcome was a live or still birth) }\end{array}$} \\
\hline \multicolumn{9}{|c|}{ Combined } \\
\hline MM (15-29) & 0.8120 & 0.0241 & 816 & 808 & 1.7608 & 0.0297 & 0.7646 & 0.8594 \\
\hline MW (15-24) & 0.8372 & 0.0157 & 1,292 & 1,289 & 1.5324 & 0.0188 & 0.8062 & 0.8682 \\
\hline \multicolumn{9}{|c|}{ Urban } \\
\hline MM (15-29) & 0.8092 & 0.0306 & 411 & 341 & 1.5758 & 0.0378 & 0.7490 & 0.8694 \\
\hline MW (15-24) & 0.8762 & 0.0208 & 527 & 530 & 1.4456 & 0.0237 & 0.8353 & 0.9170 \\
\hline \multicolumn{9}{|c|}{ Rural } \\
\hline MM (15-29) & 0.8140 & 0.0352 & 405 & 467 & 1.8197 & 0.0433 & 0.7447 & 0.8834 \\
\hline MW (15-24) & 0.8100 & 0.0218 & 765 & 759 & 1.5393 & 0.0269 & 0.7671 & 0.8530 \\
\hline \multicolumn{9}{|c|}{$\begin{array}{l}\text { Mean number of children ever born } \\
\text { (married young men and women who had begun cohabiting) }\end{array}$} \\
\hline \multicolumn{9}{|c|}{ Combined } \\
\hline MM (15-29) & 1.0641 & 0.0347 & 1,321 & 1,322 & 1.3343 & 0.0326 & 0.9957 & 1.1325 \\
\hline MW (15-24) & 1.0859 & 0.0248 & 2,006 & 2,007 & 1.2018 & 0.0228 & 1.0371 & 1.1347 \\
\hline \multicolumn{9}{|c|}{ Urban } \\
\hline MM (15-29) & 1.0230 & 0.0538 & 652 & 543 & 1.5133 & 0.0526 & 0.9172 & 1.1289 \\
\hline MW (15-24) & 1.0389 & 0.0371 & 803 & 809 & 1.2041 & 0.0357 & 0.9659 & 1.1118 \\
\hline \multicolumn{9}{|c|}{ Rural } \\
\hline MM (15-29) & 1.0927 & 0.0458 & 669 & 779 & 1.2182 & 0.0419 & 1.0027 & 1.1828 \\
\hline MW (15-24) & 1.1177 & 0.0330 & 1,203 & 1,198 & 1.1980 & 0.0295 & 1.0527 & 1.1827 \\
\hline
\end{tabular}

Cont'd on next page... 
Table B.2: (Cont'd)

\begin{tabular}{|c|c|c|c|c|c|c|c|c|}
\hline \multirow{2}{*}{$\begin{array}{l}\text { Variable/ } \\
\text { respondent } \\
\text { category }\end{array}$} & \multirow{2}{*}{$\begin{array}{l}\text { Value } \\
(\mathbf{R})\end{array}$} & \multirow{2}{*}{$\begin{array}{c}\text { Standard } \\
\text { error } \\
\text { (SE) }\end{array}$} & \multicolumn{2}{|c|}{ Number of cases } & \multirow{2}{*}{$\begin{array}{c}\text { Design } \\
\text { effect } \\
\text { (DEFT) }\end{array}$} & \multirow{2}{*}{$\begin{array}{c}\text { Relative } \\
\text { standard } \\
\text { error } \\
\text { (SE/R) }\end{array}$} & \multicolumn{2}{|c|}{ 95\% Confidence limits } \\
\hline & & & $\begin{array}{l}\text { Unweighted } \\
(\mathbf{N})\end{array}$ & $\begin{array}{l}\text { Weighted } \\
(\mathrm{WN})\end{array}$ & & & Lower & Upper \\
\hline \multicolumn{9}{|c|}{$\begin{array}{l}\text { Mean number of children surviving } \\
\text { young men and women who had begun cohabiting) }\end{array}$} \\
\hline \multicolumn{9}{|c|}{ Combined } \\
\hline MM (15-29) & 1.0301 & 0.0337 & 1,321 & 1,322 & 1.3359 & 0.0327 & 0.9637 & 1.0964 \\
\hline MW (15-24) & 1.0580 & 0.0242 & 2,006 & 2,007 & 1.2008 & 0.0229 & 1.0103 & 1.1056 \\
\hline \multicolumn{9}{|c|}{ Urban } \\
\hline MM (15-29) & 0.9987 & 0.0519 & 652 & 543 & 1.4845 & 0.0520 & 0.8965 & 1.1009 \\
\hline MW (15-24) & 1.0229 & 0.0359 & 803 & 809 & 1.1841 & 0.0351 & 0.9522 & 1.0937 \\
\hline \multicolumn{9}{|c|}{ Rural } \\
\hline MM (15-29) & 1.0519 & 0.0446 & 669 & 779 & 1.2334 & 0.0424 & 0.9642 & 1.1396 \\
\hline MW (15-24) & 1.0817 & 0.0324 & 1,203 & 1,198 & 1.2098 & 0.0300 & 1.0178 & 1.1455 \\
\hline \multicolumn{9}{|c|}{$\begin{array}{l}\text { Mean ideal number of children } \\
\text { omen who had begun cohabiting and gave a numeric response) }\end{array}$} \\
\hline \multicolumn{9}{|c|}{ Combined } \\
\hline MM (15-29) & 2.1110 & 0.0181 & 1,321 & 1,299 & 1.3235 & 0.0086 & 2.0753 & 2.1467 \\
\hline MW (15-24) & 2.0685 & 0.0151 & 2,006 & 1,990 & 1.4727 & 0.0073 & 2.0387 & 2.0982 \\
\hline \multicolumn{9}{|c|}{ Urban } \\
\hline MM (15-29) & 2.0946 & 0.0292 & 652 & 532 & 1.4863 & 0.0140 & 2.0370 & 2.1522 \\
\hline MW (15-24) & 2.0502 & 0.0186 & 803 & 801 & 1.1380 & 0.0091 & 2.0137 & 2.0868 \\
\hline \multicolumn{9}{|c|}{ Rural } \\
\hline MM (15-29) & 2.1223 & 0.0231 & 669 & 768 & 1.2076 & 0.0109 & 2.0768 & 2.1678 \\
\hline MW (15-24) & 2.0808 & 0.0219 & 1,203 & 1,189 & 1.6611 & 0.0105 & 2.0377 & 2.1239 \\
\hline \multicolumn{9}{|c|}{$\begin{array}{c}\text { Experienced } 3 \text { or more symptoms or behaviours suggestive of mental health disorders in the month } \\
\text { preceding the interview (young men and women) }\end{array}$} \\
\hline \multicolumn{9}{|c|}{ Combined } \\
\hline M (15-24) & 0.1259 & 0.0111 & 1,913 & 1,917 & 1.4618 & 0.0881 & 0.1041 & 0.1478 \\
\hline $\mathrm{W} \quad(15-24)$ & 0.1019 & 0.0100 & 5,008 & 5,008 & 2.3392 & 0.0981 & 0.0822 & 0.1216 \\
\hline MM (15-29) & 0.1483 & 0.0141 & 1,322 & 1,322 & 1.4385 & 0.0948 & 0.1206 & 0.1760 \\
\hline MW (15-24) & 0.1352 & 0.0144 & 2,007 & 2,007 & 1.8865 & 0.1065 & 0.1069 & 0.1636 \\
\hline UM (15-24) & 0.1212 & 0.0111 & 1,666 & 1,666 & 1.3835 & 0.0913 & 0.0994 & 0.1430 \\
\hline UW (15-24) & 0.0801 & 0.0089 & 3,001 & 3,001 & 1.7885 & 0.1106 & 0.0627 & 0.0976 \\
\hline \multicolumn{9}{|c|}{ Urban } \\
\hline M (15-24) & 0.0944 & 0.0116 & 890 & 832 & 1.1803 & 0.1226 & 0.0717 & 0.1172 \\
\hline $\mathrm{W} \quad(15-24)$ & 0.0703 & 0.0084 & 2,151 & 2,215 & 1.5266 & 0.1198 & 0.0537 & 0.0868 \\
\hline MM (15-29) & 0.1226 & 0.0170 & 653 & 543 & 1.3265 & 0.1390 & 0.0890 & 0.1561 \\
\hline MW (15-24) & 0.0913 & 0.0137 & 804 & 809 & 1.3442 & 0.1497 & 0.0644 & 0.1182 \\
\hline UM (15-24) & 0.0888 & 0.0117 & 789 & 747 & 1.1512 & 0.1314 & 0.0658 & 0.1117 \\
\hline UW (15-24) & 0.0580 & 0.0082 & 1,347 & 1,405 & 1.2833 & 0.1409 & 0.0419 & 0.0741 \\
\hline \multicolumn{9}{|c|}{ Rural } \\
\hline M (15-24) & 0.1500 & 0.0174 & 1,023 & 1,086 & 1.5553 & 0.1158 & 0.1158 & 0.1842 \\
\hline $\mathrm{W} \quad(15-24)$ & 0.1270 & 0.0161 & 2,857 & 2,793 & 2.5814 & 0.1267 & 0.0953 & 0.1586 \\
\hline MM (15-29) & 0.1663 & 0.0206 & 669 & 779 & 1.4286 & 0.1238 & 0.1258 & 0.2068 \\
\hline MW (15-24) & 0.1649 & 0.0215 & 1,203 & 1,198 & 2.0074 & 0.1303 & 0.1226 & 0.2072 \\
\hline UM (15-24) & 0.1476 & 0.0176 & 877 & 919 & 1.4677 & 0.1192 & 0.1130 & 0.1822 \\
\hline UW (15-24) & 0.0996 & 0.0146 & 1,654 & 1,596 & 1.9764 & 0.1462 & 0.0709 & 0.1282 \\
\hline
\end{tabular}


Table B.2: (Cont'd)

\begin{tabular}{|c|c|c|c|c|c|c|c|c|}
\hline \multirow{2}{*}{$\begin{array}{l}\text { Variable/ } \\
\text { respondent } \\
\text { category }\end{array}$} & \multirow{2}{*}{$\begin{array}{l}\text { Value } \\
(\mathbf{R})\end{array}$} & \multirow{2}{*}{$\begin{array}{l}\text { Standard } \\
\text { error } \\
\text { (SE) }\end{array}$} & \multicolumn{2}{|c|}{ Number of cases } & \multirow{2}{*}{$\begin{array}{c}\text { Design } \\
\text { effect } \\
\text { (DEFT) }\end{array}$} & \multirow{2}{*}{$\begin{array}{c}\text { Relative } \\
\text { standard } \\
\text { error } \\
(\mathrm{SE} / \mathrm{R})\end{array}$} & \multicolumn{2}{|c|}{ 95\% Confidence limits } \\
\hline & & & $\begin{array}{l}\text { Unweighted } \\
\quad(\mathbf{N})\end{array}$ & $\begin{array}{l}\text { Weighted } \\
(\mathrm{WN})\end{array}$ & & & Lower & Upper \\
\hline \multicolumn{9}{|c|}{ Ever consumed alcohol (young men and women) } \\
\hline \multicolumn{9}{|c|}{ Combined } \\
\hline M (15-24) & 0.2574 & 0.0121 & 1,913 & 1,918 & 1.2088 & 0.0470 & 0.2336 & 0.2812 \\
\hline $\mathrm{W} \quad(15-24)$ & 0.0015 & 0.0005 & 5,008 & 5,008 & 0.9693 & 0.3483 & 0.0005 & 0.0026 \\
\hline MM (15-29) & 0.5484 & 0.0156 & 1,322 & 1,322 & 1.1400 & 0.0285 & 0.5177 & 0.5791 \\
\hline MW (15-24) & 0.0029 & 0.0012 & 2,007 & 2,007 & 0.9794 & 0.4075 & 0.0006 & 0.0052 \\
\hline UM (15-24) & 0.2278 & 0.0114 & 1,666 & 1,665 & 1.1065 & 0.0499 & 0.2054 & 0.2502 \\
\hline UW (15-24) & 0.0007 & 0.0005 & 3,001 & 3,001 & 0.9956 & 0.6979 & 0.0000 & 0.0016 \\
\hline \multicolumn{9}{|c|}{ Urban } \\
\hline M (15-24) & 0.2355 & 0.0163 & 890 & 832 & 1.1438 & 0.0691 & 0.2035 & 0.2675 \\
\hline W $\quad(15-24)$ & 0.0013 & 0.0007 & 2,151 & 2,215 & 0.9466 & 0.5637 & 0.0000 & 0.0028 \\
\hline MM (15-29) & 0.5644 & 0.0255 & 653 & 543 & 1.3145 & 0.0452 & 0.5141 & 0.6146 \\
\hline MW (15-24) & 0.0023 & 0.0016 & 804 & 809 & 0.9522 & 0.6988 & 0.0000 & 0.0055 \\
\hline UM (15-24) & 0.2078 & 0.0157 & 789 & 747 & 1.0834 & 0.0753 & 0.1770 & 0.2387 \\
\hline UW (15-24) & 0.0007 & 0.0007 & 1,347 & 1,405 & 0.9818 & 0.9892 & 0.0000 & 0.0022 \\
\hline \multicolumn{9}{|c|}{ Rural } \\
\hline M (15-24) & 0.2742 & 0.0172 & 1,023 & 1,086 & 1.2344 & 0.0628 & 0.2403 & 0.3082 \\
\hline $\mathrm{W} \quad(15-24)$ & 0.0017 & 0.0008 & 2,857 & 2,793 & 0.9867 & 0.4434 & 0.0002 & 0.0032 \\
\hline MM (15-29) & 0.5373 & 0.0195 & 669 & 779 & 1.0083 & 0.0362 & 0.4990 & 0.5756 \\
\hline MW (15-24) & 0.0033 & 0.0016 & 1,203 & 1,198 & 0.9942 & 0.5019 & 0.0000 & 0.0065 \\
\hline UM (15-24) & 0.2441 & 0.0161 & 877 & 919 & 1.1103 & 0.0661 & 0.2123 & 0.2758 \\
\hline UW (15-24) & 0.0006 & 0.0006 & 1,654 & 1,596 & 1.0060 & 0.9846 & 0.0000 & 0.0019 \\
\hline \multicolumn{9}{|c|}{$\begin{array}{l}\text { Participated in a government- /NGO- sponsored programme in the } 3 \text { years preceding the interview } \\
\text { (young men and women) }\end{array}$} \\
\hline \multicolumn{9}{|c|}{ Combined } \\
\hline M (15-24) & 0.1391 & 0.0114 & 1,913 & 1,917 & 1.4444 & 0.0822 & 0.1166 & 0.1616 \\
\hline W (15-24) & 0.0907 & 0.0074 & 5,008 & 5,008 & 1.8169 & 0.0813 & 0.0761 & 0.1052 \\
\hline MM (15-29) & 0.1156 & 0.0122 & 1,322 & 1,322 & 1.3869 & 0.1055 & 0.0916 & 0.1396 \\
\hline MW (15-24) & 0.1595 & 0.0132 & 2,007 & 2,007 & 1.6144 & 0.0827 & 0.1336 & 0.1855 \\
\hline UM (15-24) & 0.1408 & 0.0118 & 1,666 & 1,666 & 1.3847 & 0.0838 & 0.1175 & 0.1640 \\
\hline UW (15-24) & 0.0456 & 0.0053 & 3,001 & 3,001 & 1.3963 & 0.1166 & 0.0352 & 0.0561 \\
\hline \multicolumn{9}{|c|}{ Urban } \\
\hline M (15-24) & 0.1543 & 0.0173 & 890 & 832 & 1.4258 & 0.1120 & 0.1203 & 0.1883 \\
\hline $\mathrm{W} \quad(15-24)$ & 0.0615 & 0.0078 & 2,151 & 2,215 & 1.5072 & 0.1270 & 0.0461 & 0.0769 \\
\hline MM (15-29) & 0.1217 & 0.0164 & 653 & 543 & 1.2782 & 0.1345 & 0.0895 & 0.1539 \\
\hline MW (15-24) & 0.1138 & 0.0141 & 804 & 809 & 1.2548 & 0.1236 & 0.0861 & 0.1415 \\
\hline UM (15-24) & 0.1520 & 0.0170 & 789 & 747 & 1.3258 & 0.1116 & 0.1186 & 0.1853 \\
\hline UW (15-24) & 0.0311 & 0.0067 & 1,347 & 1,405 & 1.4194 & 0.2159 & 0.0179 & 0.0443 \\
\hline \multicolumn{9}{|c|}{ Rural } \\
\hline M (15-24) & 0.1275 & 0.0152 & 1,023 & 1,086 & 1.4586 & 0.1194 & 0.0975 & 0.1575 \\
\hline $\mathrm{W} \quad(15-24)$ & 0.1138 & 0.0113 & 2,857 & 2,793 & 1.9070 & 0.0996 & 0.0915 & 0.1361 \\
\hline MM (15-29) & 0.1114 & 0.0173 & 669 & 779 & 1.4220 & 0.1554 & 0.0773 & 0.1454 \\
\hline MW (15-24) & 0.1905 & 0.0196 & 1,203 & 1,198 & 1.7316 & 0.1030 & 0.1519 & 0.2291 \\
\hline UM (15-24) & 0.1316 & 0.0164 & 877 & 919 & 1.4336 & 0.1244 & 0.0994 & 0.1639 \\
\hline UW (15-24) & 0.0584 & 0.0080 & 1,654 & 1,596 & 1.3801 & 0.1363 & 0.0427 & 0.0741 \\
\hline
\end{tabular}


Table B.2: (Cont'd)

\begin{tabular}{|c|c|c|c|c|c|c|c|c|}
\hline \multirow{2}{*}{$\begin{array}{l}\text { Variable/ } \\
\text { respondent } \\
\text { category }\end{array}$} & \multirow{2}{*}{$\begin{array}{l}\text { Value } \\
\text { (R) }\end{array}$} & \multirow{2}{*}{$\begin{array}{c}\text { Standard } \\
\text { error } \\
\text { (SE) }\end{array}$} & \multicolumn{2}{|c|}{ Number of cases } & \multirow{2}{*}{$\begin{array}{c}\text { Design } \\
\text { effect } \\
\text { (DEFT) }\end{array}$} & \multirow{2}{*}{$\begin{array}{c}\text { Relative } \\
\text { standard } \\
\text { error } \\
\text { (SE/R) }\end{array}$} & \multicolumn{2}{|c|}{ 95\% Confidence limits } \\
\hline & & & $\begin{array}{c}\text { Unweighted } \\
(\mathrm{N})\end{array}$ & $\begin{array}{c}\text { Weighted } \\
(\mathrm{WN})\end{array}$ & & & Lower & Upper \\
\hline \multicolumn{9}{|c|}{ Voted in last election (young men and women, aged 20 and above) } \\
\hline \multicolumn{9}{|c|}{ Combined } \\
\hline M (15-24) & 0.8194 & 0.0135 & 1,014 & 985 & 1.1136 & 0.0164 & 0.7929 & 0.8459 \\
\hline $\mathrm{W} \quad(15-24)$ & 0.6562 & 0.0148 & 2,734 & 2,725 & 1.6251 & 0.0225 & 0.6271 & 0.6852 \\
\hline MM (15-29) & 0.9146 & 0.0087 & 1,319 & 1,320 & 1.1336 & 0.0095 & 0.8974 & 0.9317 \\
\hline MW (15-24) & 0.6503 & 0.0168 & 1,686 & 1,687 & 1.4475 & 0.0259 & 0.6172 & 0.6834 \\
\hline UM (15-24) & 0.8167 & 0.0152 & 770 & 774 & 1.0917 & 0.0187 & 0.7867 & 0.8467 \\
\hline UW (15-24) & 0.6654 & 0.0208 & 1,048 & 1,048 & 1.4266 & 0.0313 & 0.6244 & 0.7063 \\
\hline \multicolumn{9}{|c|}{ Urban } \\
\hline M (15-24) & 0.8363 & 0.0188 & 477 & 437 & 1.1058 & 0.0224 & 0.7994 & 0.8732 \\
\hline $\mathrm{W} \quad(15-24)$ & 0.6702 & 0.0229 & 1,187 & 1,212 & 1.6742 & 0.0341 & 0.6252 & 0.7152 \\
\hline MM (15-29) & 0.9086 & 0.0136 & 652 & 543 & 1.2035 & 0.0150 & 0.8818 & 0.9353 \\
\hline MW (15-24) & 0.6602 & 0.0271 & 708 & 712 & 1.5214 & 0.0410 & 0.6069 & 0.7136 \\
\hline UM (15-24) & 0.8372 & 0.0202 & 377 & 361 & 1.0600 & 0.0241 & 0.7975 & 0.8769 \\
\hline UW (15-24) & 0.6846 & 0.0303 & 479 & 497 & 1.4235 & 0.0442 & 0.6250 & 0.7441 \\
\hline \multicolumn{9}{|c|}{ Rural } \\
\hline M (15-24) & 0.8059 & 0.0189 & 537 & 547 & 1.1075 & 0.0235 & 0.7687 & 0.8432 \\
\hline $\mathrm{W} \quad(15-24)$ & 0.6449 & 0.0193 & 1,547 & 1,514 & 1.5899 & 0.0300 & 0.6069 & 0.6830 \\
\hline MM (15-29) & 0.9188 & 0.0114 & 667 & 777 & 1.0781 & 0.0124 & 0.8963 & 0.9412 \\
\hline MW (15-24) & 0.6431 & 0.0213 & 978 & 974 & 1.3912 & 0.0332 & 0.6011 & 0.6851 \\
\hline UM (15-24) & 0.7988 & 0.0225 & 393 & 412 & 1.1092 & 0.0281 & 0.7545 & 0.8430 \\
\hline UW (15-24) & 0.6481 & 0.0289 & 569 & 551 & 1.4401 & 0.0445 & 0.5913 & 0.7049 \\
\hline
\end{tabular}

Note: M: Men, W: Women, MM: Married men, MW: Married women, UM: Unmarried men, UW: Unmarried women 


\section{Data quality tables}

Table C.1: Household age distribution

Single-year age distribution of the de jure household population by sex (weighted), Tamil Nadu, 2006

\begin{tabular}{|c|c|c|c|c|c|c|c|c|c|}
\hline \multirow{2}{*}{$\begin{array}{l}\text { Age } \\
\text { (year) }\end{array}$} & \multicolumn{2}{|c|}{ Women } & \multicolumn{2}{|c|}{ Men } & \multirow{2}{*}{$\begin{array}{l}\text { Age } \\
\text { (year) }\end{array}$} & \multicolumn{2}{|c|}{ Women } & \multicolumn{2}{|c|}{ Men } \\
\hline & $\begin{array}{l}\text { Unweighted } \\
\text { number }\end{array}$ & Percent & $\begin{array}{l}\text { Unweighted } \\
\text { number }\end{array}$ & Percent & & $\begin{array}{l}\text { Unweighted } \\
\text { number }\end{array}$ & Percent & $\begin{array}{l}\text { Unweighted } \\
\text { number }\end{array}$ & Percent \\
\hline 0 & 955 & 1.3 & 1,071 & 1.5 & 36 & 891 & 1.2 & 907 & 1.2 \\
\hline 1 & 1,045 & 1.4 & 1,143 & 1.6 & 37 & 963 & 1.3 & 932 & 1.3 \\
\hline 2 & 1,155 & 1.6 & 1,204 & 1.6 & 38 & 1,270 & 1.7 & 1,068 & 1.4 \\
\hline 3 & 1,104 & 1.5 & 1,250 & 1.7 & 39 & 767 & 1.0 & 851 & 1.2 \\
\hline 4 & 1,135 & 1.5 & 1,304 & 1.8 & 40 & 2,124 & 2.9 & 2,208 & 3.0 \\
\hline 5 & 1,288 & 1.8 & 1,306 & 1.8 & 41 & 417 & 0.6 & 580 & 0.8 \\
\hline 6 & 1,178 & 1.6 & 1,230 & 1.7 & 42 & 908 & 1.2 & 983 & 1.3 \\
\hline 7 & 1,181 & 1.6 & 1,295 & 1.8 & 43 & 545 & 0.7 & 506 & 0.7 \\
\hline 8 & 1,280 & 1.7 & 1,231 & 1.7 & 44 & 536 & 0.7 & 650 & 0.9 \\
\hline 9 & 1,231 & 1.7 & 1,324 & 1.8 & 45 & 2,014 & 2.7 & 2,006 & 2.7 \\
\hline 10 & 1,274 & 1.7 & 1,355 & 1.8 & 46 & 575 & 0.8 & 564 & 0.8 \\
\hline 11 & 1,135 & 1.5 & 1,215 & 1.7 & 47 & 626 & 0.8 & 644 & 0.9 \\
\hline 12 & 1,434 & 2.0 & 1,510 & 2.0 & 48 & 809 & 1.1 & 733 & 1.0 \\
\hline 13 & 1,332 & 1.8 & 1,387 & 1.9 & 49 & 489 & 0.7 & 556 & 0.8 \\
\hline 14 & 1,161 & 1.6 & 1,265 & 1.7 & 50 & 1,832 & 2.5 & 1,604 & 2.2 \\
\hline 15 & 1,216 & 1.7 & 1,216 & 1.7 & 51 & 325 & 0.4 & 426 & 0.6 \\
\hline 16 & 1,284 & 1.7 & 1,317 & 1.8 & 52 & 567 & 0.8 & 615 & 0.8 \\
\hline 17 & 1,216 & 1.7 & 1,308 & 1.8 & 53 & 295 & 0.4 & 355 & 0.5 \\
\hline 18 & 1,571 & 2.1 & 1,539 & 2.1 & 54 & 514 & 0.7 & 499 & 0.7 \\
\hline 19 & 1,259 & 1.7 & 1,297 & 1.8 & 55 & 1,595 & 2.2 & 1,324 & 1.8 \\
\hline 20 & 1,579 & 2.2 & 1,594 & 2.2 & 56 & 388 & 0.5 & 403 & 0.5 \\
\hline 21 & 1,202 & 1.6 & 1,230 & 1.7 & 57 & 304 & 0.4 & 365 & 0.5 \\
\hline 22 & 1,412 & 1.9 & 1,355 & 1.8 & 58 & 488 & 0.7 & 460 & 0.6 \\
\hline 23 & 1,302 & 1.8 & 1,258 & 1.7 & 59 & 278 & 0.4 & 389 & 0.5 \\
\hline 24 & 1,352 & 1.8 & 1,217 & 1.7 & 60 & 1,916 & 2.6 & 1,497 & 2.0 \\
\hline 25 & 1,361 & 1.9 & 1,477 & 2.0 & 61 & 165 & 0.2 & 194 & 0.3 \\
\hline 26 & 1,400 & 1.9 & 1,270 & 1.7 & 62 & 351 & 0.5 & 366 & 0.5 \\
\hline 27 & 1,506 & 2.0 & 1,321 & 1.8 & 63 & 171 & 0.2 & 212 & 0.3 \\
\hline 28 & 1,682 & 2.3 & 1,221 & 1.7 & 64 & 225 & 0.3 & 296 & 0.4 \\
\hline 29 & 1,210 & 1.6 & 1,037 & 1.4 & 65 & 1,265 & 1.7 & 984 & 1.3 \\
\hline 30 & 2,148 & 2.9 & 1,523 & 2.1 & 66 & 149 & 0.2 & 199 & 0.3 \\
\hline 31 & 784 & 1.1 & 990 & 1.4 & 67 & 169 & 0.2 & 200 & 0.3 \\
\hline 32 & 1,190 & 1.6 & 1,465 & 2.0 & 68 & 212 & 0.3 & 189 & 0.3 \\
\hline 33 & 755 & 1.0 & 957 & 1.3 & 69 & 195 & 0.3 & 212 & 0.3 \\
\hline 34 & 826 & 1.1 & 1,076 & 1.5 & $70+$ & 2,695 & 3.7 & 2,674 & 3.6 \\
\hline 35 & 2,254 & 3.1 & 2,128 & 2.9 & Total & 73,430 & 100.0 & 73,537 & 100.0 \\
\hline
\end{tabular}

Note: The de jure population includes usual residents of the household. 
Table C.2: Single-year age distribution of eligible, selected and interviewed young men

Number and percentage of eligible, selected and interviewed young men and percentage of selected young men who were interviewed by single-year age (unweighted), Tamil Nadu, 2006

\begin{tabular}{|c|c|c|c|c|c|c|c|}
\hline \multirow[t]{2}{*}{ Age (years) } & \multicolumn{2}{|c|}{ Eligible } & \multicolumn{2}{|c|}{ Selected for interview } & \multicolumn{2}{|c|}{ Interviewed } & \multirow{2}{*}{$\begin{array}{c}\% \text { selected } \\
\text { respondents } \\
\text { interviewed }\end{array}$} \\
\hline & No. & $\%$ & No. & $\%$ & No. & $\%$ & \\
\hline \multicolumn{8}{|c|}{ MM (15-29) } \\
\hline 15 & 0 & 0.0 & 0 & 0.0 & 0 & 0.0 & NC \\
\hline 16 & 1 & 0.1 & 0 & 0.0 & 0 & 0.0 & NC \\
\hline 17 & 2 & 0.1 & 0 & 0.0 & 0 & 0.0 & $\mathrm{NC}$ \\
\hline 18 & 0 & 0.0 & 0 & 0.0 & 0 & 0.0 & NC \\
\hline 19 & 7 & 0.4 & 5 & 0.3 & 3 & 0.2 & 60.0 \\
\hline 20 & 30 & 1.7 & 27 & 1.6 & 14 & 1.1 & 51.9 \\
\hline 21 & 34 & 1.9 & 32 & 1.9 & 22 & 1.7 & 68.8 \\
\hline 22 & 64 & 3.6 & 57 & 3.3 & 49 & 3.7 & 86.0 \\
\hline 23 & 77 & 4.3 & 74 & 4.3 & 55 & 4.2 & 74.3 \\
\hline 24 & 136 & 7.6 & 129 & 7.6 & 104 & 7.9 & 80.6 \\
\hline 25 & 228 & 12.7 & 213 & 12.5 & 157 & 11.9 & 73.7 \\
\hline 26 & 271 & 15.1 & 261 & 15.3 & 210 & 15.9 & 80.5 \\
\hline 27 & 307 & 17.2 & 294 & 17.3 & 228 & 17.2 & 77.6 \\
\hline 28 & 314 & 17.6 & 302 & 17.7 & 232 & 17.5 & 76.8 \\
\hline 29 & 318 & 17.8 & 309 & 18.1 & 248 & 18.8 & 80.3 \\
\hline Total & 1,789 & 100.0 & 1,703 & 100.0 & 1,322 & 100.0 & 77.6 \\
\hline \multicolumn{8}{|c|}{ UM (15-24) } \\
\hline 15 & 523 & 9.1 & 183 & 8.3 & 150 & 9.0 & 82.0 \\
\hline 16 & 608 & 10.5 & 252 & 11.4 & 203 & 12.2 & 80.6 \\
\hline 17 & 573 & 9.9 & 224 & 10.2 & 168 & 10.1 & 75.0 \\
\hline 18 & 690 & 12.0 & 267 & 12.1 & 192 & 11.5 & 71.9 \\
\hline 19 & 608 & 10.5 & 230 & 10.4 & 183 & 11.0 & 79.6 \\
\hline 20 & 684 & 11.8 & 242 & 11.0 & 179 & 10.7 & 74.0 \\
\hline 21 & 552 & 9.6 & 201 & 9.1 & 151 & 9.1 & 75.1 \\
\hline 22 & 583 & 10.1 & 225 & 10.2 & 158 & 9.5 & 70.2 \\
\hline 23 & 493 & 8.5 & 197 & 8.9 & 140 & 8.4 & 71.1 \\
\hline 24 & 460 & 8.0 & 184 & 8.3 & 142 & 8.5 & 77.2 \\
\hline Total & 5,774 & 100.0 & 2,205 & 100.0 & 1,666 & 100.0 & 75.6 \\
\hline
\end{tabular}

Note: NC: Not calculated, as there is no case in the denominator.

The difference between the number of respondents eligible for interview and the number who were selected for interview is due to the sampling design adopted in the Youth Study. Please refer to Chapter 1 for details. 
Table C.3: Single-year age distribution of eligible, selected and interviewed young women

Number and percentages of eligible, selected and interviewed female respondents and percentage of selected respondents who were interviewed by single-year age (unweighted), Tamil Nadu, 2006

\begin{tabular}{|c|c|c|c|c|c|c|c|}
\hline \multirow[t]{2}{*}{ Age (Years) } & \multicolumn{2}{|c|}{ Eligible } & \multicolumn{2}{|c|}{ Selected for interview } & \multicolumn{2}{|c|}{ Interviewed } & \multirow{2}{*}{$\begin{array}{l}\% \text { selected } \\
\text { respondent } \\
\text { interviewed }\end{array}$} \\
\hline & No. & $\%$ & No. & $\%$ & No. & $\%$ & \\
\hline \multicolumn{8}{|c|}{ MW(15-24) } \\
\hline 15 & 5 & 0.2 & 5 & 0.2 & 5 & 0.2 & 100.0 \\
\hline 16 & 22 & 0.9 & 22 & 0.9 & 19 & 0.9 & 86.4 \\
\hline 17 & 55 & 2.2 & 53 & 2.2 & 44 & 2.2 & 83.0 \\
\hline 18 & 132 & 5.4 & 121 & 5.1 & 97 & 4.8 & 80.2 \\
\hline 19 & 189 & 7.7 & 180 & 7.6 & 156 & 7.8 & 86.7 \\
\hline 20 & 326 & 13.2 & 315 & 13.3 & 251 & 12.5 & 79.7 \\
\hline 21 & 347 & 14.1 & 339 & 14.3 & 285 & 14.2 & 84.1 \\
\hline 22 & 393 & 15.9 & 374 & 15.7 & 320 & 15.9 & 85.6 \\
\hline 23 & 491 & 19.9 & 473 & 19.9 & 403 & 20.1 & 85.2 \\
\hline 24 & 506 & 20.5 & 495 & 20.8 & 427 & 21.3 & 86.3 \\
\hline Total & 2,466 & 100.0 & 2,377 & 100.0 & 2,007 & 100.0 & 84.4 \\
\hline \multicolumn{8}{|c|}{ UW (15-24) } \\
\hline 15 & 565 & 13.4 & 468 & 13.5 & 406 & 13.5 & 86.8 \\
\hline 16 & 603 & 14.3 & 509 & 14.7 & 441 & 14.7 & 86.6 \\
\hline 17 & 532 & 12.6 & 431 & 12.4 & 378 & 12.6 & 87.7 \\
\hline 18 & 593 & 14.1 & 469 & 13.5 & 399 & 13.3 & 85.1 \\
\hline 19 & 460 & 10.9 & 381 & 11.0 & 329 & 11.0 & 86.4 \\
\hline 20 & 446 & 10.6 & 368 & 10.6 & 310 & 10.3 & 84.2 \\
\hline 21 & 305 & 7.3 & 255 & 7.4 & 223 & 7.4 & 87.5 \\
\hline 22 & 298 & 7.1 & 243 & 7.0 & 213 & 7.1 & 87.7 \\
\hline 23 & 230 & 5.5 & 196 & 5.7 & 169 & 5.6 & 86.2 \\
\hline 24 & 174 & 4.1 & 147 & 4.2 & 133 & 4.4 & 90.5 \\
\hline Total & 4,206 & 100.0 & 3,467 & 100.0 & 3,001 & 100.0 & 86.6 \\
\hline
\end{tabular}

Note: The difference between the number of respondents eligible for interview and the number who were selected for interview is due to the sampling design adopted in the Youth Study. Please refer to Chapter 1 for details. 


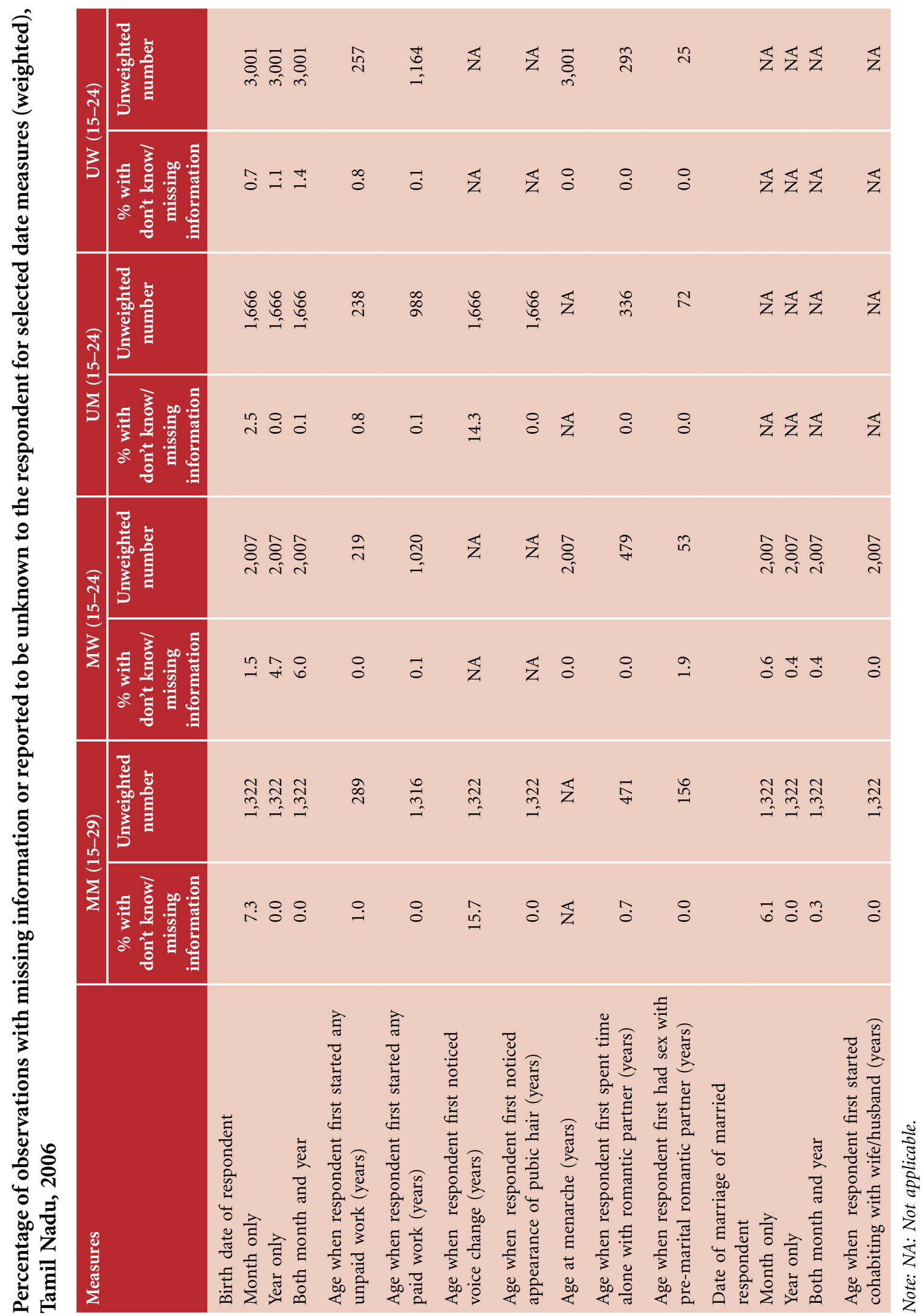




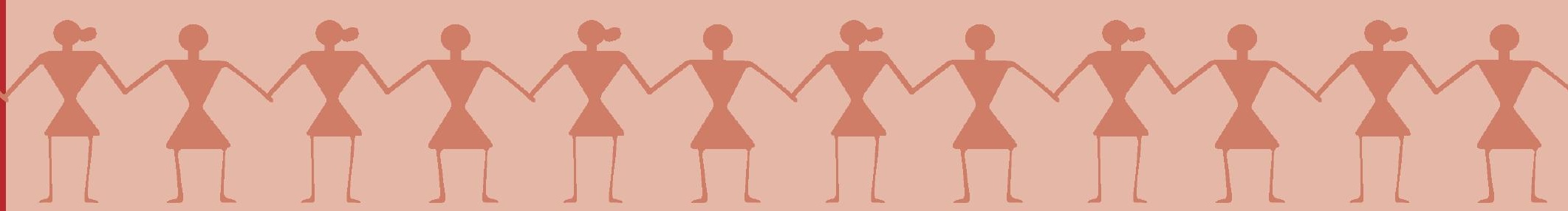




\section{Supported by:}

the David Lucile PaCkard MACARTHUR rolvontor

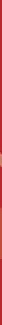

